\title{
Final Technical Report: Hawaii Hydrogen Center for Development and Deployment of Distributed Energy Systems
}

\author{
Prepared for \\ U.S. Department of Energy \\ Office of Energy Efficiency and Renewable Energy \\ Under Award No. DE-FC36-04G014248
}

By

University of Hawaii

Hawaii Natural Energy Institute

School of Ocean and Earth Science and Technology

September 2008 
Acknowledgement: This material is based upon work supported by the United States Department of Energy under Award Number DE-FC36-04GO14248.

Disclaimer: This report was prepared as an account of work sponsored by an agency of the United States Government. Neither the United States Government nor any agency thereof, nor any of their employees, makes any warranty, express or implied, or assumes any legal liability or responsibility for the accuracy, completeness, or usefulness of any information, apparatus, product, or process disclosed, or represents that its use would not infringe privately owned rights. Reference here in to any specific commercial product, process, or service by tradename, trademark, manufacturer, or otherwise does not necessarily constitute or imply its endorsement, recommendation, or favoring by the United States Government or any agency thereof. The views and opinions of authors expressed herein do not necessarily state or reflect those of the United States Government or any agency thereof. 


\section{Table of Contents}

$\underline{\text { Section Number and Title }} \quad \underline{\text { Page }}$

1 Executive Summary 1

2 Task 1 - Hawaii Hydrogen Power Park 7

2.1 Goals and Objectives 7

2.2 Accomplishments and Comparisons with Goals and Objectives 7

2,3 Summary of Project Activities 7

2.4 Hydrogen Power Park - HFCTF Test Program 8

2.4.1 Power Park Components 8

2.4.1.1 $6 \mathrm{Nm} 3 / \mathrm{h}$ Alkaline Electrolyzer System $\quad 8$

2.4.1.2 $5 \mathrm{~kW}$ PEM Fuel Cell System 9

2.4.2 Experiments/Results and Economic Data 9

2.4.2.1 Steady-State Experiments 9

2.4.2.2 Electrolyzer Experimental Results 10

2.4.2.3 Fuel Cell System Experimental Results $\quad 13$

2.4.2.4 Economic Data 14

2.5 Kahua Ranch Integrated Power Park System 14

2.5.1 Kahua Village Power System 15

2.5.2 Renewable Hydrogen $\left(\mathrm{RE}-\mathrm{H}_{2}\right)$ System 16

2.5.2.1 Initial System Modification $\quad 16$

2.5.2.2 Hydrogen Storage System 16

2.5.2.3 Additional Equipment 19

2.5.2.4 System Control 19

2.5.2.5 Economic Data 26

2.5.3 Experimental Results 27

2.5.3.1 One Date of Automatic Mode Operation 27

2.5.3.2 Performance of Each Component 29

2.5.3.3 Performance of Overall Installation $\quad 36$

2.6 Conclusions and Discussion of Results 42

2.6.1 Conclusions on the Kahua Ranch Installation 42

2.6.2 Comparison of the HSS Performance in Steady-State and Stand-Alone Operation 43

2.6.3 Advantages of Hydrogen Storage Systems 44

2.6.4 Hydrogen System Efficiency 45

2.6.5 Renewable Energy Hydrogen Production Systems 45

Final Technical Report, September 2008

Award Number DE-FC36-04GO14248 
2.7 Products Developed and Technology Transfer Activities 46

2.7.1 Publications/Presentations 46

2.7.2 Website 46

2.7.3 Collaboration 46

2.8 Acknowledgements 47

2.9 References 47

3 Task 2 - Hydrogen Fuel Purity Assessment 49

3.1 Goals and Objectives 49

3.2 Accomplishments and Comparisons with Goals and Objectives 49

3.3 Summary of Project Activities 49

3.3.1 Test Plan 49

3.3.2 Hardware and Test Equipment Acquisition 49

3.3.3 Test Results $\quad 50$

3.4 Conclusions 54

3.5 Products Developed and Technology Transfer Activities 55

3.5.1 Publications/Presentations $\quad 55$

3.5.2 Collaborations 55

4 Task 3 - Renewable Hydrogen Production 57

4.1 3A - Electronic Materials for High-Efficiency

Photoelectrochemical Hydrogen Production $\quad 57$

4.1.1 Goals and Objectives $\quad 57$

4.1.2 Accomplishments and Comparisons with Goals and Objectives 57

4.1.3 Summary of Project Activities 57

4.1.3.1 Deposition Process $\quad 57$

4.1.3.2 Modeling Efforts $\quad 58$

4.1.3.3 Test Results $\quad 58$

4.1.3.4 Integration of 4-Terminal Devices into
Hydrogen Production Systems

4.1.4 Conclusions $\quad 60$

4.1.5 Products Developed and Technology Transfer Activities 61

4.1.5.1 Publications/Presentations 61

4.1.5.2 Collaborations $\quad 61$

4.1.5.3 Patents 61

4.1.6 Computer Modeling 61

Final Technical Report, September 2008

Award Number DE-FC36-04GO14248 
4.2 3B - Hydrogen Production from Biomass 63

4.2.1 3B-1 - Hydrogen Via Liquid Biofuels 63

4.2.1.1 Goals and Objectives 63

4.2.1.2 Accomplishments and Comparisons with Goals and Objectives $\quad 63$

4.2.1.3 Summary of Project Activities 63

4.2.1.4 Conclusions $\quad 65$

4.2.1.5 Products Developed and Technology Transfer Activities 65

4.2.2 3B-2 - Feedstock Processing 67

4.2.2.1 Goals and Objectives 67

4.2.2.2 Accomplishments and Comparisons with Goals and Objectives $\quad 67$

4.2.2.3 Summary of Project Activities 67

4.2.2.4 Conclusions 67

4.2.2.5 Products Developed and Technology Transfer Activities $\quad 68$

4.2.3 3B-3 - Microbial Biomass Assessment 69

4.2.3.1 Goals and Objectives 69

4.2.3.2 Accomplishments and Comparison with Goals and Objectives 69

4.2.3.3 Summary of Project Activities $\quad 69$

4.2.3.4 Conclusions and Discussion of Results $\quad 73$

4.2.3.5 Presentations Given 75

4.3 3C - Biohydrogen Analysis $\quad 77$

4.3.1 Goals and Objectives 77

4.3.2 Accomplishments and Comparison with
Goals and Objectives

4.3.3 Summary of Project Activities 77

4.3.4 Conclusions $\quad 77$

4.3.5 Publications/Presentations 77

4.3.6 Invention $\quad 78$

4.3.7 Collaborations $\quad 78$

5 Task 4-Systems Integration $\quad 79$

5.1 Goals and Objectives 79

5.2 Accomplishments and Comparison with Goals and Objectives 79

5.3 Summary of Project Activities 79

5.4 Conclusions $\quad 80$

Final Technical Report, September 2008

Award Number DE-FC36-04GO14248

HNEI 
$\begin{array}{llr}5.5 & \text { Publications/Presentations } & 80\end{array}$

$\begin{array}{lll}5.6 & \text { Collaborations } & 81\end{array}$

Appendix A Analysis Approach of the Electrochemical Components - Steady-State Operation 83

Appendix B Hot Gas Clean Up System Development for the Hawaii Natural Energy Institute Gasifier Facility $\quad 87$

Appendix C Final Report: New Mexico Institute of Mining \& Technology 109

Appendix D Improving Fuel Characteristics of Sugar Cane Trash 137 


\section{Final Technical Report for the \\ Hawaii Hydrogen Center for \\ Development and Deployment of Distributed Energy Systems \\ Award Number DE-FC36-04G014248}

\section{Executive Summary}

This report summarizes work conducted under Award Number DE-FC3604GO14248, the Hawaii Hydrogen Center for Development and Deployment of Distributed Energy Systems, funded through the U.S. Department of Energy Office of Energy Efficiency and Renewable Energy to the Hawaii Natural Energy Institute (HNEI) of the University of Hawaii.

The HNEI Principal Investigator for this project was Richard E. Rocheleau. The project was carried forward with working partners and cost-sharing partners, as delineated below.

Working partners included the State of Hawaii Department of Business, Economic Development \& Tourism; City and County of Honolulu; Hawaiian Electric Company; Hawaii Electric Light Company; The Gas Company; AirGas; Sandia National Laboratory; Hydrogenics/Stuart Energy; MVSystems, Inc.; ClearFuels Technology; New Mexico Institute of Mining and Technology; Hawaiian Commercial \& Sugar Company; Center for a Sustainable Future; Pacific International Center for High Technology Research; Sentech; Kahua Ranch, and Benemann Associates.

Cost-sharing partners included the State of Hawaii Department of Business, Economic Development \& Tourism; City and County of Honolulu; Hawaiian Electric Company; Hawaii Electric Light Company; The Gas Company; AirGas; MVSystems, Inc.; ClearFuels Technology; New Mexico Institute of Mining and Technology; Hawaiian Commercial \& Sugar Company; Center for a Sustainable Future; and Pacific International Center for High Technology Research.

This overall project was divided into separate tasks and these included the following: Task 1 - Hawaii Hydrogen Power Park; Task 2 - Hydrogen Fuel Purity Assessment; Task 3 - Renewable Hydrogen Production; and Task 4 - Systems Integration.

Furthermore, Task 3 was subdivided into individual Subtasks: 3A - Electronic Materials for High-Efficiency Photoelectrochemical Hydrogen Production; 3B Hydrogen Production from Biomass; and 3C - Biohydrogen Analysis.

Finally, Subtask 3B was further broken into these assignments: 3B-1 - Hydrogen via liquid biofuels; 3B-2 - Feedstock processing; and 3B-3 - Microbial biomass assessment.

Summaries for the various tasks of this project are presented in the paragraphs below. Following these summaries, this report continues with detailed sections for the individual tasks and subtasks of the overall project. 


\section{Task 1 - Hawaii Hydrogen Power Park}

The studies realized during the hydrogen power park experiments in Hawaii produced real-world data on the performances of the commercialized electrochemical components and power systems integrating renewable and hydrogen technologies. By analyzing the different losses associated with the various equipment items involved, this work identifies the different improvements necessary to increase the viability of these technologies for commercial deployment. The stand-alone power system installed at Kahua Ranch on the Big Island of Hawaii required the development of the necessary tools to connect, manage and monitor such a system. It also helped the electrolyzer supplier to adapt its unit to the stand-alone power system application.

The Kahua Ranch installation is safe and capable of a stand-alone operation. It is also controllable remotely via the internet. This remote control system would allow the installation of a hydrogen storage system in remote locations and reduce the requirement and associated costs for human intervention on site.

By developing a remotely controllable installation having the capacity to be monitored remotely, thanks to an internet web site, the data is available to the public. It helps the general public to understand the present energy issues and offers a showroom for hydrogen storage technologies. The system could also be used for on-line education and science projects at the secondary school and college levels.

\section{Task 2 - Hydrogen Fuel Purity Assessment}

The efforts under this task yielded additional knowledge regarding fuel cell performance degradation due to exposure to several different fuel contaminants. In addition, a novel fitting strategy was developed to permit accurate separation of the degradation of fuel cell performance due to fuel impurities from other losses. A specific standard MEA and standard flow field were selected for use in future small-scale fuel cell experiments.

The fuel cell testing program carried out in this task gave reproducible results for tests up to 100 hours. Furthermore, the fitting strategy mentioned above was successfully used in data analysis of measurements taken during $\mathrm{CO}$ contamination testing of an MEA.

The test plan developed under this task will provide guidance for future testing efforts. HNEI worked closely with standards-developing organizations to develop impurity test protocols for use by various test laboratories, and help identify operating parameters, materials and hardware for continuing fuel quality work.

\section{Task 3 - Renewable Hydrogen Production}

\section{A - Electronic Materials for High-Efficiency Photoelectrochemical Hydrogen Production}

The activities in this task have explored novel configurations of 'traditional' photovoltaic materials for application in high-efficiency photoelectrolysis for 
solar hydrogen production. The model systems investigated involved combinations of copper-indium-gallium-diselenide (CIGS) and hydrogenated amorphous silicon (a-Si:H). A key result of this work was the establishment of a robust "three-stage" fabrication process at HNEI for high-efficiency CIGS thin film solar cells. The other key accomplishment was the development of models, designs and prototypes of novel 'four-terminal' devices integrating highefficiency CIGS and a-Si:H with operating features compatible with highefficiency photoelectrochemical (PEC) water-splitting. In this study, it was found that the losses associated with device integration negated the expected benefits in performance. As a result, the targeted efficiencies were not met in the "fourterminal" prototypes, though avenues for further optimization in future work were identified. Additionally, alternative configurations for high-efficiency PEC hydrogen production based on modified CIGS materials were identified.

3B - Hydrogen Production from Biomass

3B-1 - Hydrogen via liquid biofuels

The objective of the first activity under Subtask 3B-1 was to conduct parametric testing of the Pearson gasifier and to determine the effects of gasifier operating conditions on the gas yields and quality. The hydrogen yield from the Pearson gasifier was evaluated in a parametric test series over a range of residence times from 0.8 to 2.2 seconds. $\mathrm{H}_{2}$ concentrations as high as $55 \%$ (volume) were measured in the product gas at the longer residence times and this corresponds to a hydrogen yield of $90 \mathrm{~kg}$ per tonne of bagasse without gas upgrading.

The second activity in the ClearFuels Technology subcontract for the engineering design for a biomass gasifier research and development facility was completed. Details of this activity have been identified as proprietary by the subcontractor.

The objective of the third activity in Subtask 3B-1 was to develop hot gas cleanup capabilities for the HNEI gasifier test facility to support hydrogen-frombiomass research. The product gas stream at the outlet of the hot gas filter was characterized for concentrations of permanent gas species $\left(\mathrm{CO}, \mathrm{CO}_{2}, \mathrm{H}_{2}, \mathrm{CH}_{4}, \mathrm{~N}_{2}\right.$ ) and contaminants including tar (principally benzene, naphthalene, and toluene) and sulfur $\left(\mathrm{H}_{2} \mathrm{~S}, \mathrm{COS}\right.$, and $\left.\mathrm{C}_{4} \mathrm{H}_{4} \mathrm{~S}\right)$ species, ammonia, and $\mathrm{NO}_{\mathrm{x}}$. Total tar concentration in the dry product gas was $\sim 10 \mathrm{~g} \mathrm{~m}^{-3}$. Concentrations of $\mathrm{H}_{2} \mathrm{~S}, \mathrm{COS}$, and $\mathrm{C}_{4} \mathrm{H}_{4} \mathrm{~S}$ were 56, 1 , and 1.3 ppmv, respectively. $\mathrm{NO}$ and ammonia concentrations were determined to be 8.2 and 1,626 ppmv respectively.

A clean up strategy was developed to remove contaminant species or convert them to a benign form. Elements included sulfur removal using $\mathrm{ZnO}$ sorbent at $400{ }^{\circ} \mathrm{C}$ and a gas hourly space velocity of $8,000 \mathrm{hr}^{-1}$. Under these conditions, the primary sulfur component, $\mathrm{H}_{2} \mathrm{~S}$, was reduced to $250 \mathrm{ppbv}$ and COS was reduced by a factor of 4 to similar levels. Thiophene concentrations were not affected.

Tar and methane were successfully converted to permanent gas species using nickel catalysts. Temperatures of $850{ }^{\circ} \mathrm{C}$ and GHSV of $\sim 1 \mathrm{~m}^{3} \mathrm{~kg}^{-1} \mathrm{hr}^{-1}$ effectively removed tar compounds below levels of $0.1 \mathrm{~g}$ total tar $\mathrm{m}^{-3}$ dry gas. Acenaphthalene and pyrene were two compounds identified in the gas stream 
exiting the reactor. The Ni catalyst also resulted in reductions of $\mathrm{NH}_{3}$ from values of $\sim 1500 \mathrm{ppmv}$ to as low as $20 \mathrm{ppmv}$ and complete conversion of methane and $\mathrm{NO}_{\mathrm{x}}$. Methane and tar conversion resulted in increased levels of $\mathrm{H}_{2}$ and $\mathrm{CO}$ in the product gas exiting the tar cracking unit.

The fourth activity under Subtask 3B-1 was the development of advanced hydrogen purification systems by NMT that could potentially be used as auxiliary units for the HNEI bench-scale gasifier. Zeolite-based catalysts were prepared and tested for hydrogen production via reforming of hydrocarbons. These showed promise for alcohols but were inapplicable for glucose reforming. Zeolite membrane systems were tested and may have usefulness in driving $\mathrm{CO}_{2}$ from a reforming system, with possible enhancement of $\mathrm{H}_{2}$ production. Some success was observed with micro-reforming of ethylene glycol using a Pt catalyst, but such a catalyst is precluded from use with crop residue feedstocks having organic sulfur.

\section{B-2 - Feedstock processing}

Subtask 3B-2 was a preliminary investigation into methods for processing sugar cane trash at the Puunene Sugar Factory on the island of Maui, Hawaii. The factory is owned and operated by Hawaiian Commercial and Sugar, a subsidiary of Alexander and Baldwin Incorporated. The objective of the investigation was to explore treatment methods that would enable the successful use of cane trash as fuel for the production of hydrogen via gasification. Note that the results are potentially applicable for other thermochemical energy devices as well. Cane trash consists of the leafy plant matter, both living and dead, that accumulates over the course of the growing period. Normally, this material is burned off before harvest in an open-field burn. An alternative is to harvest and process sugar cane trash into a viable fuel. Sugar cane trash is a poor fuel for thermochemical conversion due to its ash composition and the associated tendency to form slag and deposits that foul working surfaces.

Laboratory and pilot-scale tests were carried out using water as a leaching agent to investigate the removal of elements, $\mathrm{K}, \mathrm{Na}$, and $\mathrm{Cl}$, known to be agents for slag and deposit formation. Leach-water temperature, leaching duration, and cane trash particle size were varied in the laboratory. Particle size was found to have a significant effect in the reduction of $\mathrm{K}, \mathrm{Na}$, and $\mathrm{Cl}$ concentrations, and an observed increase in ash fusion temperatures and a decrease in total alkali concentration per energy unit to a level below that empirically found to be the threshold for slagging and fouling. Similar pilot-scale tests were also performed, but particle size reduction was made impossible due to equipment failure. The pilot-scale samples were not reduced below the threshold for slagging and fouling in the leaching treatments.

\section{B-3 - Microbial biomass assessment}

Analyses were completed for the technical and economic feasibility of producing biofuel from photosynthetic marine microbes on a commercial scale. Results included estimates for total costs, energy efficiency, and return on investment. 
For the analyses completed early in 2005 , the estimated production cost for this renewable fuel oil (without carbon credit) was about $\$ 42 / \mathrm{bbl}$, and at that time, crude oil prices ranged from $\$ 42$ to $\$ 57 / \mathrm{bbl}$. The technology described is advanced enough to proliferate rapidly. Renewable biofuels could substantially reduce US dependence on foreign oil supplies.

3C - Biohydrogen Analysis.

The Biohydrogen team undertook a comprehensive review of the field and came to what we think is a realistic conclusion, with details provided in the journal quality paper we have prepared. To summarize, we recommend continued research in the fundamentals of the science related to genetic engineering and specific topics to cover knowledge gaps. In the meantime, we also advocate continued development of related processes which can be linked to pollution control and other real world applications. The extra revenues hydrogen can provide to these multi-product systems can improve profitability. The fact of the matter, though, is that the focused commercialization of hydrogen from biological processes awaits some necessary scientific breakthroughs and much higher conventional energy prices.

\section{Task 4 - Systems Integration.}

During the course of this task, HNEI assembled and organized a renewable hydrogen consortium for the purposes of: 1) conducting the necessary R\&D for validating the technical and economic potential for renewable hydrogen, and 2) encouraging the development of renewable hydrogen and distributed energy resource options for the Big Island of Hawaii.

Efforts were begun towards the establishment of an energy roadmap for the future of the Big Island. These efforts included completion of modeling, calibrating and validation of the Big Island's electrical and transportation fuel infrastructures against current conditions, yielding an energy infrastructure baseline. This baseline is ideal for considering renewable energy technology scenarios and impacts on the Big Island.

These models together with the results of testing at the Power Park on the Big Island provide the necessary tools for development of cost-effective hydrogen pathways. 


\section{This page is intentional blank}




\section{Task 1 - Hawaii Hydrogen Power Park}

\subsection{Goals and Objectives}

- Demonstrate an integrated hydrogen power park comprised of:

0 an electrolyzer powered by a renewable energy (RE) source,

0 hydrogen storage and distribution system,

o PEM fuel cell (FC) connected to the grid and building, and

o optional hydrogen-fueled vehicle dispensing system;

- Demonstrate hydrogen as an energy carrier;

- Investigate interface issues with the grid and buildings;

- Identify codes and standards required to site a power park;

- Identify barriers to a hydrogen infrastructure;

- Educate local authorities on hydrogen technologies;

- Prepare an economic analysis of hydrogen infrastructure development; and

- Generate general public interest and support.

\subsection{Accomplishments and Comparison with Goals and Objectives}

Most of the initial project objectives have been achieved during development of the Hawaii Hydrogen Power Park. The earlier and later phases of development have demonstrated an integrated hydrogen power park testing electrolyzers powered by the grid or RE generators, developing hydrogen $\left(\mathrm{H}_{2}\right)$ infrastructure at Hawaii Natural Energy Institute's Hawaii Fuel Cell Test Facility (HFCTF) on Oahu and at Kahua Ranch on the Big Island, connecting a FC system to a small 48 VDC grid in a stand-alone power system supplying energy to an office/house. Hydrogen has been used as an energy carrier in the $\mathrm{RE}-\mathrm{H}_{2}$ power system. To complete a safe installation, codes and standards have been studied and applied to the installation. The culmination of the installations developed as part of the Power Park required meetings with the local authorities inducing exchange of information on hydrogen safety and handling. Data acquired during the project updated the performances of hydrogen technologies that were shared with Sandia National Laboratory, in support of economic and technical simulation of hydrogen power parks. Finally, the developed installations, especially the Kahua ranch $\mathrm{RE}-\mathrm{H}_{2}$ stand-alone power system, offer the perfect platform to demonstrate a real-world power system using RE and a hydrogen storage system.

\subsection{Summary of Project Activities}

During the initial phase of this project, conducted at the HFCTF, two main electrochemical components have been investigated, and this yielded conclusions regarding performances and losses for the two tested components. The Kahua Ranch installation couples renewable energy generators with a hydrogen storage system. Main tasks included the selection of the components, and the design and installation of the necessary interfaces to allow safe and stand-alone operation of the overall power system. A safety analysis was conducted to aid in the proper design and installation of the power system. Supplying either a load bank or a real load (the office), the installation at Kahua Ranch offers a real-world test facility for remote stand-alone $\mathrm{RE}-\mathrm{H}_{2}$ power systems. The experimental results of 
the first two months of stand-alone operation have contributed to an understanding of the operation of such a system and have allowed us to make conclusions on the performance of the $\mathrm{RE}-\mathrm{H}_{2}$ installation in different weather and load demand conditions. Details for specific activities at the HFCTF and Kahua Ranch are given in the following sections.

\subsection{Hydrogen Power Park - HFCTF Test Program}

Major components of Hydrogen Power Park were tested in steady-state operation at the Hawaii Fuel Cell Test Facility (HFCTF). The alkaline $12 \mathrm{~kg}$ /day electrolyzer was installed at the HFCTF, and used to fill the high pressure gas storage system supplying the different test stations of the laboratory. The $5 \mathrm{kw}$ fuel cell system supplying 48 VDC power was tested and then used in the Kahua Ranch hydrogen system.

\subsubsection{Power Park Components}

The hydrogen power park components installed in 2003 at the HFCTF were commercially available, low-production volume units. While the PEM fuel cell system represents the latest in advances in the industry and was designed as an uninterruptible power supply (UPS) capable of load following, the alkaline electrolyzer system was designed around older technology and was optimized for steady-state operation at peak power.

\subsubsection{1 $6 \mathrm{Nm}^{3} / \mathrm{hr}$ Alkaline Electrolyzer System}

The Stuart [1] TTR225 alkaline electrolyzer produces $6 \mathrm{Nm}^{3} / \mathrm{hr}$. The electrical input specifications are: $80.5 \mathrm{kVA}, 480 \mathrm{~V}, 60 \mathrm{~Hz} / 3$ phase. A rectifier converts incoming AC power to regulated DC power, which is supplied to the electrolyzer cell stack. The system is also supplied potable, municipal water, at a maximum rate of 7.3 liter per hour, which is passed through deionizing beds before entering the electrolyte reservoir.

The electrolyzer system consists of a gas generation unit, a gas/liquid management unit, a cooling unit, and a hydrogen compression and purification unit. The gas generation unit contains a stack of cells connected in series, which use $34 \% \mathrm{w}$. potassium hydroxide electrolyte. The stack is connected to the rectifier and produces nearly atmospheric $(1.07 \mathrm{bar})$ gas/liquid mixtures that are sent to the gas/liquid management unit, which consists of two gas/liquid separators, a water management unit, and $\mathrm{KOH}$ pumps to circulate the electrolyte through the cells. The cooling unit contains a water pump, a heater and an air/liquid heat exchanger, which maintains the stack temperature at $25{ }^{\circ} \mathrm{C}$ when the system is idle and between 60 and $65{ }^{\circ} \mathrm{C}$ during operation. The gas compression and purification unit contains a four-stage, intercooled compressor and a catalytic purifier. The compressor is activated when the hydrogen flow reaches approximately $3 \mathrm{Nm}^{3} / \mathrm{hr}$ and compresses the hydrogen to approximately 140 bar. The product oxygen is vented to the atmosphere.

The electrolyzer system was designed for operation with two stacks, providing twice the hydrogen production rate $\left(12 \mathrm{Nm}^{3} / \mathrm{hr}\right)$ of the single-stack system analyzed in this study. The efficiency of a $12 \mathrm{Nm}^{3} / \mathrm{hr}$ electrolyzer has been estimated and will be discussed in section 2.4.2.2. 


\subsubsection{2 $5 \mathrm{~kW}$ PEM Fuel Cell System}

The Plug Power [2] Gencore $5 \mathrm{~kW}$ fuel cell system requires pure hydrogen (99.95\%, dry), access to ambient air (temperature between -40 to $+46{ }^{\circ} \mathrm{C}$ and noncondensing relative humidity between $0 \%$ to $95 \%$ ), and produces regulated 48 VDC electrical power. The outputs are oxygen-depleted humidified air and liquid water.

The system consists of a stack of cells connected in series, air and hydrogen supply units, a cooling unit, a power converter, a battery pack wired in parallel with the fuel cell system output, and a microprocessor for data acquisition and automatic operation. The hydrogen supply system includes an exhaust gas recirculation system for injecting non-consumed hydrogen and water vapor into the anode inlet stream. There is no active hydrogen flow controller; instead, hydrogen automatically enters the system through a pressure regulator to maintain 0.07 bar (gauge) into the gas line. The air supply unit consists of a filter that removes hydrocarbons and other chemicals, an air blower with speed mapped to fuel cell power demand, and a humidifier. The cooling unit has a single-speed circulation pump and two coolant loops. One loop includes a heater used at startup to heat the stack to the operating temperature of approximately $55{ }^{\circ} \mathrm{C}$. The second loop is used for cooling the stack by passing the coolant through a radiator, which has a fan with speed mapped to fuel cell power demand.

The batteries are used at start-up to supply auxiliary power; however, as soon as the fuel cell is connected to the DC bus, the stack supplies power to the parasitic loads. The power converters use either the stack power or battery power to support the load with regulated voltage settable between 46 and $56 \mathrm{~V}$.

\subsubsection{Experiments/Results and Economic Data}

Fuel cell and electrolyzer system performance depends on several variables, including operating mode, control strategy, component temperature, membrane hydration, lectrolyte concentration, and hours of operation. The first step in characterizing either a fuel cell or electrolyzer system is to assess beginning-oflife, steady-state performance.

\subsubsection{Steady-State Experiments}

Steady-state operation is achieved when operating conditions and output do not appreciably vary with time. For these systems, steady state is usually achieved by setting the current and waiting for the stack to reach constant temperature, pressure, and voltage.

For the electrolyzer, it is possible to set the stack current, and it takes approximately two hours after initial start-up to reach steady state at the desired current.

Similar experiments are difficult to implement with the fuel cell system due to the system control strategy. The stack current cannot be controlled independently. The operating current depends on the load, the battery state of charge, and the auxiliary consumption. In practice, steady-state operation is achieved by adjusting the load and changing the power converter voltage setting until the battery current is zero. Fuel cell system steady-state operation was typically 
achieved after one hour and a half. At low current demand (i.e., at stack current less than $18 \mathrm{~A}$ ), the cooling system works intermittently, creating highly variable auxiliary power demands and variation in the stack operating temperature between 53 and $55^{\circ} \mathrm{C}$.

Although each system was sold with a data acquisition system, additional data was required for the analysis. For the electrolyzer, three additional power sensors were added to measure the energy consumption for the complete system, the auxiliary loads, and the compressor. Hydrogen flow meters were added at the input of the fuel cell system and the output of the electrolyzer system, but were not used inside the systems. As hydrogen flow was only measured at one point, it is not possible to isolate the exact locations of hydrogen loss in each system. The three data acquisition systems (electrolyzer, fuel cell, and additional sensors) were validated by a fourth set of measurements where possible (using a multimeter and a current clamp-on meter) and synchronized for analysis.

The analysis approach is detailed in Appendix A. The enthalpy of liquid water formation based on the higher heating value (HHV) has been chosen as the basis of performance analysis. This choice allows for consistent comparisons between technologies, and presents the most appropriate basis for analysis of thermal losses given low-temperature operation of the electrochemical components.

\subsubsection{Electrolyzer Experimental Results}

The electrolyzer system performance is presented as Figure 2.1, which includes system efficiency (the black bottom line) and losses in the system as a function of the input $\mathrm{AC}$ power. The stand-by power of the unit is $4 \mathrm{~kW}$, which is consumed by the auxiliaries. For input power less than $21 \mathrm{~kW}$, the electrolyzer does not produce useable hydrogen because the compressor does not operate below that power point. After this point, the system efficiency (HHV) increases from 44 to $51 \%$ as the hydrogen production rate increases, see the black curve in Figure 2.1. At maximum input power, $42 \mathrm{~kW}$, the losses break down as follows: $24.5 \%$ is heat loss in the stack, $13.7 \%$ is auxiliary loads loss, excluding the compressor, $7.5 \%$ is loss due to hydrogen compression, and $3.3 \%$ is gas loss. As can be seen in Figure 2.2, the electrolyzer system design and control has been optimized for operation at peak power, where the electrolyzer stack consumes $5.45 \mathrm{kWh} / \mathrm{Nm}^{3}$ and the complete system consumes $7 \mathrm{kWh} / \mathrm{Nm}^{3}$. 


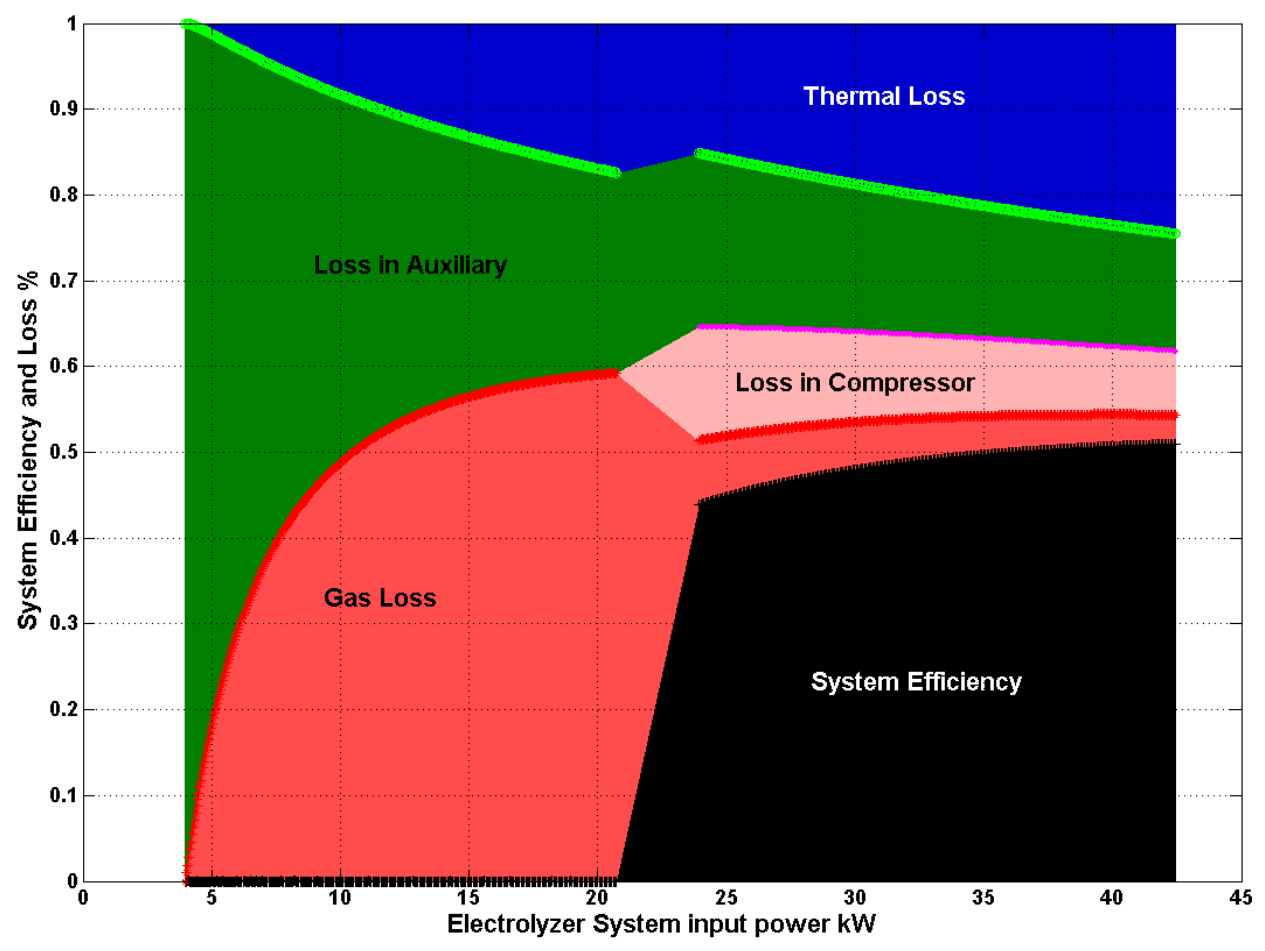

Figure 2.1: Electrolyzer steady-state efficiency (HHV) and details of the major sources of energy loss as a function of the input power.

The electrolyzer stack performance versus current is presented in detail in Figure 2.2, and the different efficiency terms (HHV basis) are defined in Appendix A. The voltage efficiency varies from 87 to $68 \%$ as the current is increased from 100 to $600 \mathrm{~A}$. The system gas efficiency, which includes gas loss in the stack and in the process, increases from 85 to $94 \%$ as current is increased from 320 to $600 \mathrm{~A}$. Finally, the stack efficiency, which is system hydrogen production divided by stack power consumption, is almost constant at 65 to $67 \%$ from 320 to $600 \mathrm{~A}$. The increase of system efficiency with increased stack current is due to the reduction in relative auxiliary loss.

As mentioned earlier, the electrolyzer system was designed to host two stacks. Considering the same stack performance and the same behavior of the auxiliary consumption, the $12 \mathrm{Nm}^{3} / \mathrm{hr}$ unit performance has been estimated (Figure 2.3). The following assumptions were made to support this analysis: the auxiliary consumption is linear with the electrical input power; and the compressor consumption is considered independent of the flow as it is operated at a single speed, and was designed for $12 \mathrm{Nm}^{3} / \mathrm{hr}$ of hydrogen flow. The full unit should reach an efficiency of $56 \%$ at maximum power, $78 \mathrm{~kW}$, with $27 \%$ lost as heat, $10 \%$ for supplying auxiliaries (including $4 \%$ for compression), and $4 \%$ lost as gas. Although this unit operates as efficiently as other similar products in the market (e.g., a $6.2 \mathrm{kWh} / \mathrm{Nm}^{3}$ unit), the stacks do show room for performance improvement and the auxiliary losses could be substantially reduced. Finally, the gas losses are significant at all operating points, and could be reduced. 


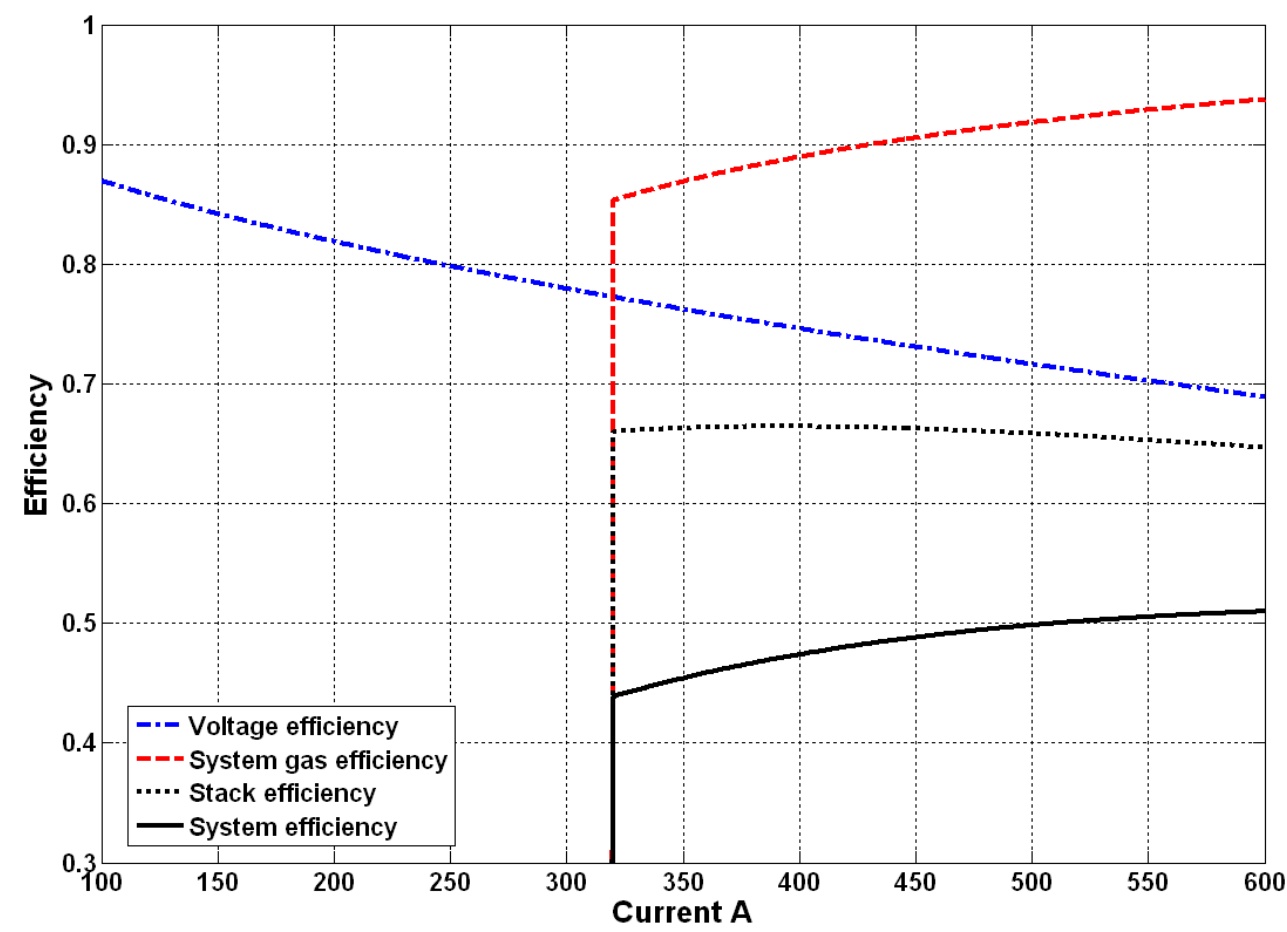

Figure 2.2: Voltage efficiency, system gas efficiency, stack efficiency and system efficiency versus stack current for the electrolyzer (all on HHV basis).

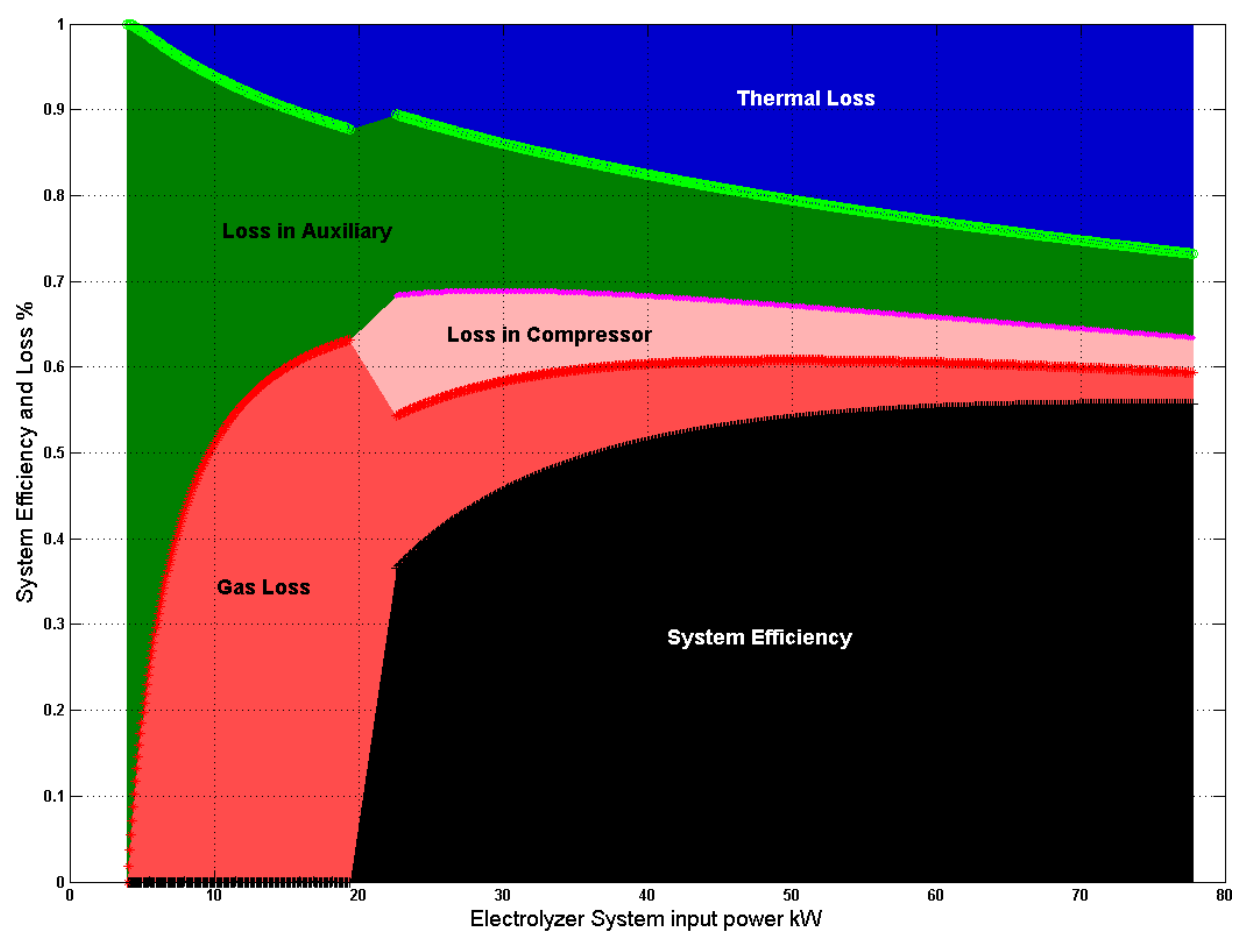

Figure 2.3: Electrolyzer steady-state efficiency (HHV) and details of the major sources of energy loss as a function of the input power - results extended for $12 \mathrm{Nm}^{3} / \mathrm{hr}$ unit. 


\subsubsection{Fuel Cell System Experimental Results}

The fuel cell system performance is presented as Figure 2.4, which includes system efficiency (black line above the lowest grey area) and losses in the system as a function of the output DC power. At low power, the fuel cell system efficiency (HHV basis) increases as output power increases; however, the efficiency peaks at 40 to $42 \%$ over the range of 20 to $70 \%$ of peak power. At higher power demands, the fuel cell system efficiency slightly decreases. The main energetic loss is the thermal loss, which increases as stack current increases. The importance of the gas and auxiliary losses is high at low output power (45\% for gas loss, $30 \%$ for auxiliary) but reduces to very low relative values at high power demand ( $6 \%$ for gas loss and $4 \%$ for auxiliary loss).

The fuel cell stack and system performance (HHV basis) is presented in detail in Figure 2.5, which includes the voltage efficiency, gas system efficiency, stack efficiency and system efficiency as functions of stack current. The hydrogen supply management is excellent, producing $94 \%$ gas efficiency over most of the current range. The voltage efficiency varies from 57 to $43 \%$ as the current increases, and the stack performance is higher than $40 \%$ for most of the operating points. The stack achieves peak efficiency at $25 \mathrm{~A}$, whereas the system efficiency peaks at a stack current of $40 \mathrm{~A}$; this significant difference can be attributed to the diminishing contribution of the auxiliary power subsystem.

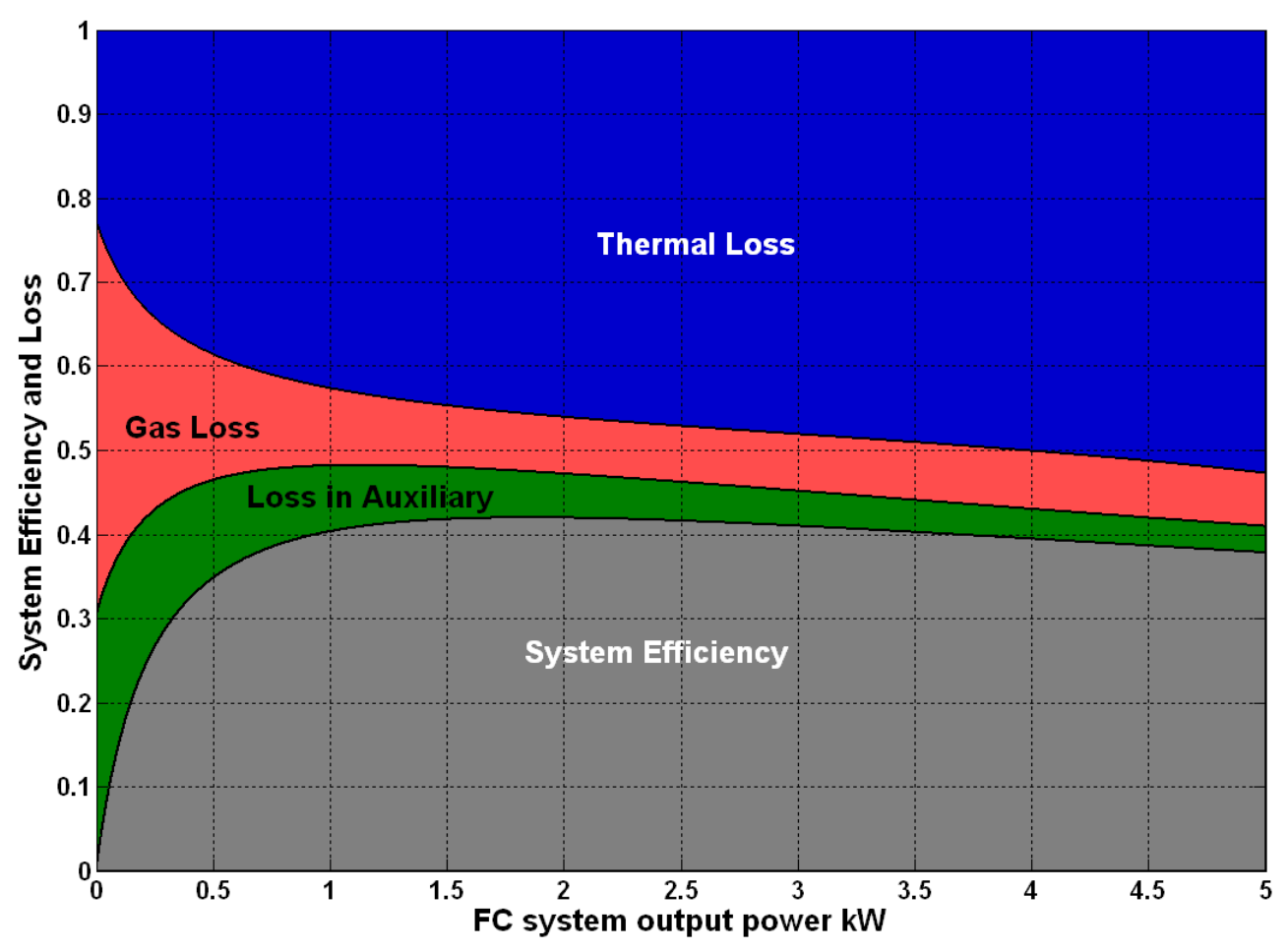

Figure 2.4: Fuel cell system steady-state efficiency (HHV) and details of the major sources of energy loss as a function of the output power. 


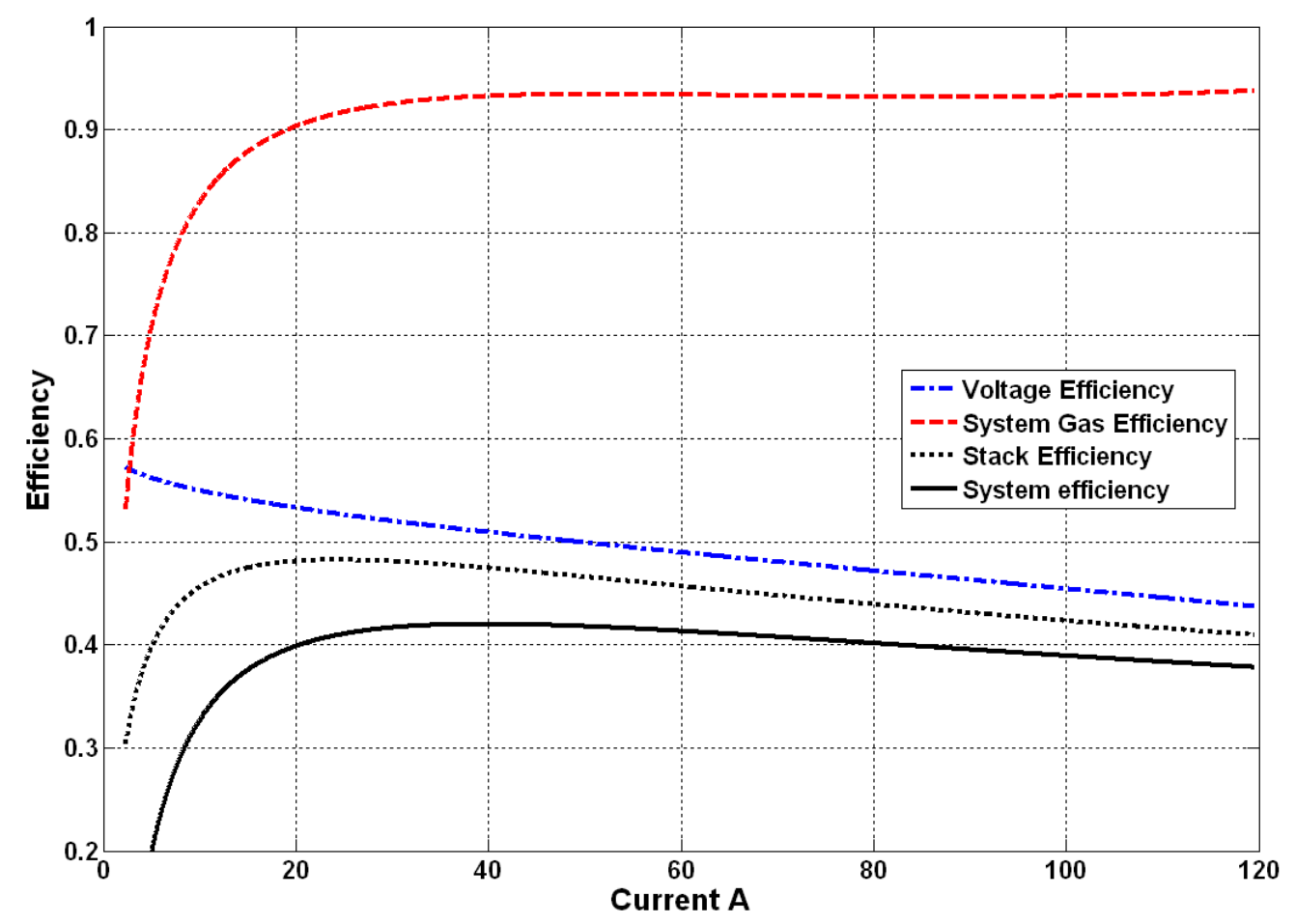

Figure 2.5: Cell voltage, system gas efficiency, stack efficiency and system efficiency versus stack current (all on HHV basis).

\subsubsection{Economic Data}

The electrolyzer and fuel cell systems were not mass-produced, so capital costs are high. The capital and installation costs for both the electrolyzer and the fuel cell systems are presented as Table 2.1 .

Table 2.1: Electrolyzer and fuel cell system cost breakdown.

\begin{tabular}{|c|c|c|}
\hline System & $\begin{array}{c}\text { Capital Cost } \\
\text { (\$) }\end{array}$ & $\begin{array}{c}\text { Shipping \& Installation } \\
\text { Cost (\$) }\end{array}$ \\
\hline Electrolyzer & 320,000 & 24,000 \\
\hline Fuel Cell & 16,000 & 1,600 \\
\hline
\end{tabular}

\subsection{Kahua Ranch Integrated Power Park System}

Kahua Ranch [3] has a long history of involvement in the development of renewable energy on the Big Island. In 1985, it hosted the first Big Island wind farm supplying the grid with 2.3 MW. In 1996, Kahua Ranch was supplied by a wind-solar-battery-diesel system developed by our partner, Pacific International Center for High Technology Research (PICHTR) [4]. This village power system has been modified under this project to include a hydrogen storage system (HSS). 


\subsubsection{Kahua Village Power System}

Completed in 1996, PICHTR has developed a Renewable-Hybrid-Village-Power demonstration plant including three $7.5 \mathrm{~kW}$ wind turbines (WT), a $10 \mathrm{~kW}$ photovoltaic (PV) array, and a $30 \mathrm{~kW}$ diesel generator in conjunction with a battery bank and pumped hydro system to supply power to a greenhouse, 11 homes and shops on the ranch [5]. The $360 \mathrm{kWh} /$ day system was a prototype for a larger version built in Fiji in 1998.

Figure 2.6.a shows a schematic of the Kahua village power system. The three Bergey WT generators produced an unregulated AC electricity that was transmitted to the electrical room through a 500-m long buried power cable. Each unit had a rectifier/controller such that wind energy was made available as DC current at the battery voltage. The PV array consisted of 40 ASE Americas GP-8 modules rated at $245 \mathrm{~W}_{\text {peak }}$ at standard conditions. The DC electricity from the $\mathrm{PV}$ was also transmitted via $60 \mathrm{~m}$ of buried cable to the electrical room. The RE generators (PV and WT) were connected to a 240 VDC flooded-lead-acid Trojan battery system with a storage capacity of $428 \mathrm{kWh}$. A single-point watering system by Watermaster was used to water the battery system with distilled water. In addition, the system had a diesel generator and a rectifier/inverter/ controller from Advanced Energy System, supplying the village load using renewable resources, battery or diesel generator.

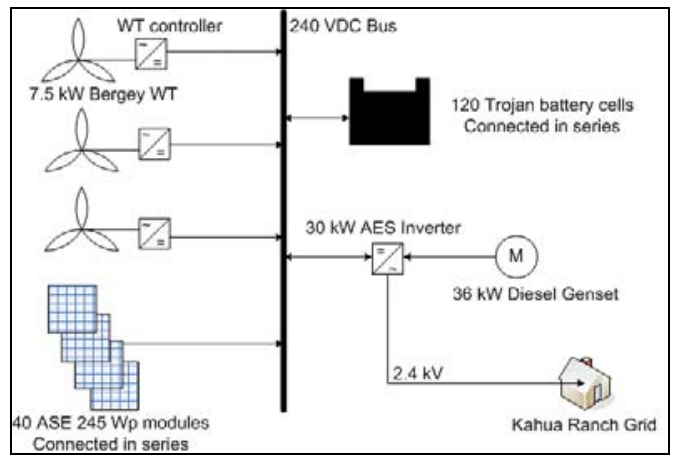

(2.6.a)

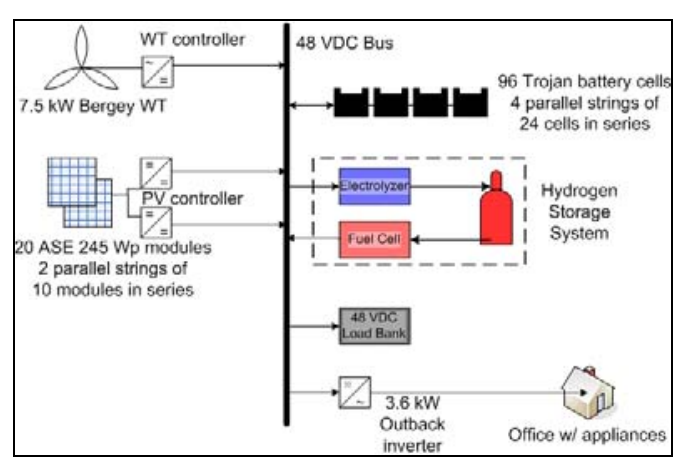

(2.6.b)

Figure 2.6: Design of the installations at Kahua Ranch - (2.6.a): village power system; (2.6.b): present RE-hydrogen power system.

From 1996 to 2006, the Kahua Ranch village was supplied by the village power system allowing renewable energy to account for $80 \%$ of annual electricity production. Essential information on these systems, including operation and maintenance cost, was recorded [6].

In March 2006 during the design of the new Hawaii Natural Energy Institute (HNEI) installation, two of the three WT units malfunctioned, requiring expensive repairs. Kahua Ranch decided to switch to Hawaii Electricity Light Company (HELCO) services. The remainder of the original power system was then converted into 48 VDC output for exclusive use in the HNEI power park project. 


\subsubsection{Renewable Hydrogen $\left(\mathrm{RE}-\mathrm{H}_{2}\right)$ System}

Figure 2.6.b shows a schematic of the HNEI power system. In this new system, the diesel generator is not used. Instead, a hydrogen-based energy storage system (HSS) was added, consisting of an electrolyzer, hydrogen gas storage cylinders, and a fuel cell. Although less efficient than the battery storage, the HSS has other advantages such as a long-term energy storage capacity, an independent energy/power relationship, a possibility for cogeneration of electricity and heat, and a capability to supply hydrogen to other uses such as transportation applications. A 48-VDC configuration was selected because this voltage is widely used in renewable energy and hydrogen technologies. The decision was largely influenced by the possibility to use the 48 VDC Plug Power fuel cell system.

The main tasks of HNEI were the selection of the components available for this application and the development of the interface between all components allowing fail-safe and stand-alone operation of the overall installation. The selection of the components was based on availability of equipment capable of being integrated into a 48 VDC electrical bus, efficiency, and the investment cost. The interface was designed to be expandable, easily movable, and visible/controllable from anywhere in the world via the internet.

\subsubsection{Initial System Modification}

The wind turbine system was modified by installing an additional transformer to step wild $300 \mathrm{VAC}$ voltage down to $48 \mathrm{VAC}$. A Bergey controller VCS-10 was also added to convert the 48 VAC into controlled 48 VDC. The VCS-10 controller can also be used to disconnect the source to avoid overcharging the batteries. Part of the PV array was rewired into two arrays of ten modules in series. Each of the resulting $2.45-\mathrm{kW}$ arrays were connected in parallel with two 3 kW Outback Power Systems MX60 PV Maximum-Power-Point-Tracker (MPPT) controllers, allowing maximum use of solar energy and customized battery recharging, including absorbing charge, and floating control based on battery voltage. The two MPPT controllers have difficulty running in parallel (see section 2.5.3.1), reducing the available PV power. The battery bank was rewired into a 48-VDC configuration, using the best 96 cells. The overall battery storage is therefore a 10 -year-old battery bank of $343-\mathrm{kWh}$ capacity.

\subsubsection{Hydrogen Storage System (HSS)}

The HSS is now in place at Kahua Ranch. Figure 2.7 shows the hydrogen room where most of the equipment is installed. Figure 2.8 shows the equipment, including safety elements placed outside, in the gas storage area. The HSS includes an electrolyzer (EL) splitting deionized water into hydrogen and oxygen, a hydrogen tank, a fuel cell (FC) system, and a deionized water supply tank. The HSS was built and tested at the HFCTF in Honolulu (Figure 2.9), and then shipped to the Big Island by barge. 


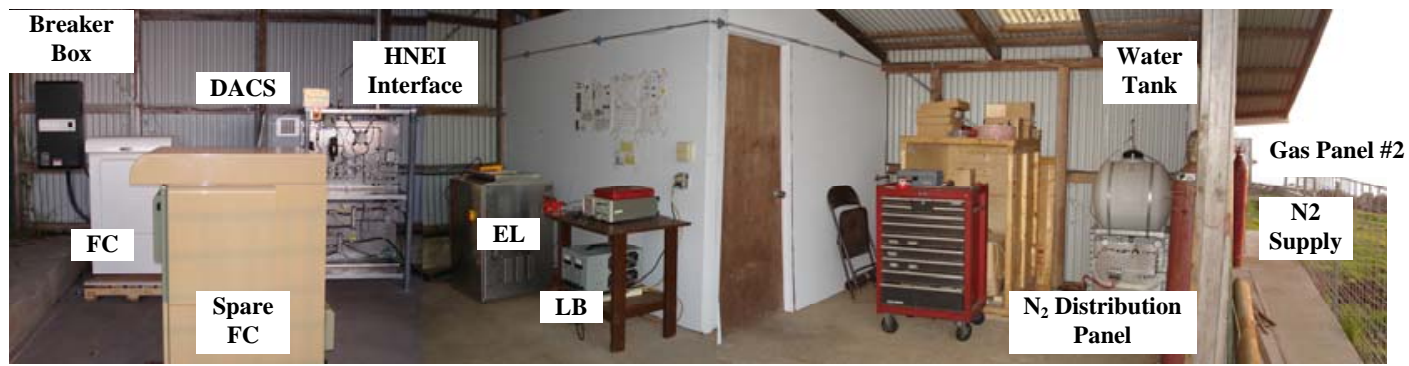

Figure 2.7: Hydrogen room at Kahua Ranch.

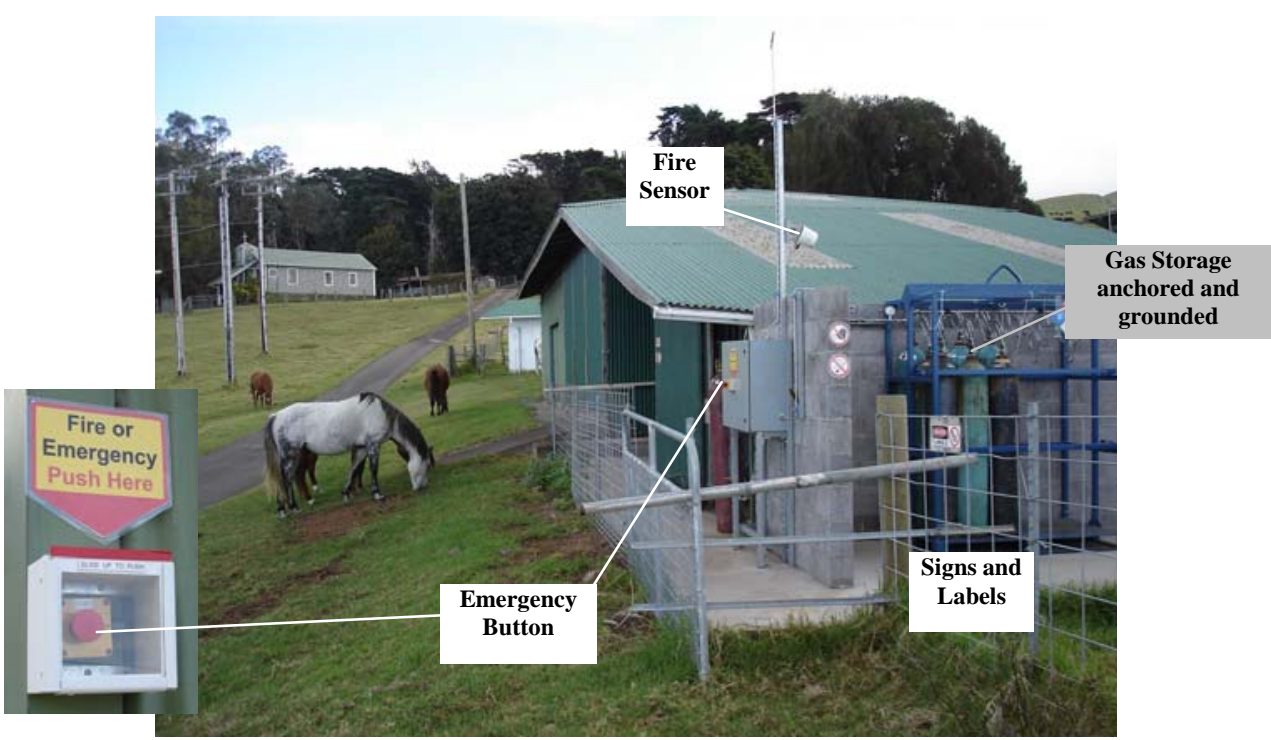

Figure 2.8: Kahua Ranch gas storage and safety equipment.

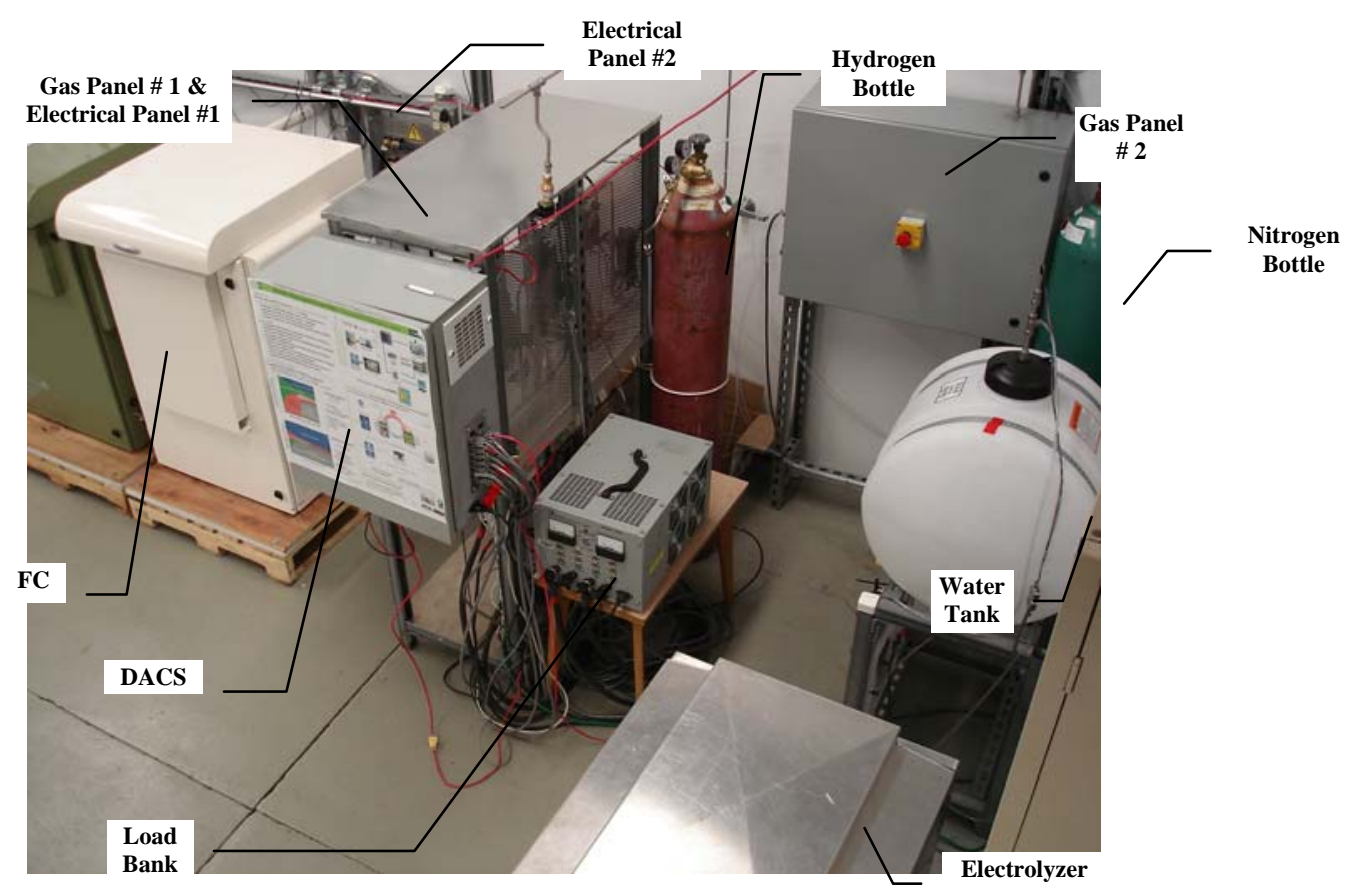

Figure 2.9: View of the installation in test at the HFCTF in Honolulu. 
The Proton Exchange Membrane (PEM) electrolyzer supplier is Electric Hydrogen, Eh! [7], a new Canadian company that was selected due to having a good background in PEM electrolyzers and proposing a 48-VDC unit with high efficiency that would be designed for our application. Also, the small size of the unit is rare on the market and was available at a relatively low price. The electrolyzer (EL) specifications are a hydrogen production rate of $0.2 \mathrm{Nm}^{3} / \mathrm{hr}(7$ $\mathrm{scf} / \mathrm{hr}$ ) at 12 bar gage (175 psig). The electrical input specifications are: $25 \mathrm{~A}$ at $48 \mathrm{VDC}$, with an allowable range from $46 \mathrm{~V}$ to $58 \mathrm{~V}$. The hydrogen generator consumes deionized water (ASTM Type I) supplied at a pressure between 3 and 20 psig. The maximum efficiency was specified to be $74 \%$ based on the higher heating value (HHV) $-63 \%$ based on lower heating value (LHV). The analysis approach used for the electrochemical components is the same as the one used for the initial phase of hydrogen power park (HPP), detailed in Appendix A.

The EL system consists of a gas generation unit, a gas/liquid management unit, and a cooling unit. The gas generation unit contains a stack of ten PEM cells connected in series. The stack is mechanically connected on the cathode side to the gas/liquid separator and a pressure regulator, allowing hydrogen production upon reaching 12 bars. The anode side of the stack is connected to a gas/liquid tank for oxygen drying and for managing the water level in the stack. The product oxygen is vented to the atmosphere. A solenoid valve allows water to fill up the tank when it reaches a preset low-water level. The cooling unit, part of the anode side, contains a water pump and an air/liquid heat exchanger to regulate the stack temperature. Finally, the unit is protected by an outdoor cabinet that is vented in order to cool the unit and to avoid hydrogen accumulation. An integrated hydrogen sensor in the cabinet shuts down the unit, if necessary.

The first prototype unit was commissioned in August 2007. With a design adapted to be integrated into a stand-alone power system, the unit started up as soon as it was connected to the DC bus bar and it reached its maximum performances in 5 minutes: $0.1 \mathrm{Nm}^{3} / \mathrm{hr}$ at $8.6 \mathrm{bar}$, consuming $20 \mathrm{~A}$ at $53.5 \mathrm{~V}$, on the commissioning day. The 10-cell stack operated at $28 \mathrm{~A}$ and $33.1 \mathrm{~V}$. The unit demonstrated an overall efficiency of only 37\% (HHV), but exhibited a good gas efficiency, losing only $2 \%$ of the theoretical gas production. Loss in auxiliaries was $14 \%$. The main problem in the unit was the stack showing $49 \%$ of the unit loss in heat. In addition, the stack experienced rapid degradation, lowering the maximum operating point. A new stack was built by Eh! and integrated into the unit in December 2007. The unit met the specifications, producing $0.2 \mathrm{Nm}^{3} / \mathrm{hr}$ at 12 bars. The efficiency has been evaluated at $50.2 \%$.

The 5-kW Plug Power Gencore FC system has already been described in section 2.4.1.2. In addition, the $\mathrm{FC}$ unit has an operation mode called Low Bus Operation. When this is selected, the internal controller starts the unit, to maintain the output voltage in a settable range. This operation mode is appropriate for operation in the Kahua Ranch installation because the FC unit can automatically start up when the battery voltage is low, avoiding over-discharge of the batteries. In that way, the battery storage is used as the primary storage system and the HSS as the secondary storage system. 
During the initial HFCTF testing period, in consultation with Plug Power, the inlet pressure specified at $5.5 \mathrm{bar}(80 \mathrm{psig})$ was reduced to 2 bar (30 psig) without operational degradation. This test was conducted to increase the usability of the low-pressure hydrogen gas storage system in the final stationary application.

Several options were studied for the hydrogen gas storage during the design process. Compression was quickly abandoned as it is a big energy consumer and the ranch has the real estate for a large low-pressure storage system. In the final design, the maximum storage pressure is then the maximum pressure of the electrolyzer (12 bars). The hydrogen gas storage was intended to be a $7.6-\mathrm{m}^{3}$ (2,000 gallons) low- pressure propane tank. For safety reasons, the supplier decided to supply a tank specially designed for hydrogen. This would have caused a significant delay in the project and it was decided to use nine hydrogen cylinders of 50 liters each connected into an 18-cylinder bottle rack. The full storage is then equivalent to $5.4 \mathrm{Nm}^{3}$ or $452 \mathrm{~g}(17.8 \mathrm{kWh}, \mathrm{HHV})$. It is acknowledged that this storage capacity is too small for optimal operation, but it can be easily expandable later. The project goal was to demonstrate the potential to use pre-commercial components, to evaluate present technologies, to complete an expandable test bench, to develop the data acquisition and control system, and to improve knowledge on such applications.

The water storage system consists of a 113-liter (30 gallons) applicator tank from American Tank Company. The tank is made of a linear, high-density polyethylene resin. The lid has been modified as shown in Figure 2.7, in order to add four water-level switches and to pressurize the water to 0.5 bar (6 psig), as required by the electrolyzer. The pressure is supplied by pressure-regulated nitrogen supplied from a high-pressure nitrogen cylinder.

\subsubsection{Additional Equipment}

One high-pressure nitrogen cylinder is connected to the gas lines for purging before hydrogen use, and for supplying pressure to the pneumatic system and the water tank. In operation, the nitrogen consumption should be virtually zero. Nitrogen is used only for start-up/shut-down periods or if hydrogen tanks need to be purged. An Avtron K492 7.8-kW resistive DC load bank is used to simulate resistive load profiles. The load bank is connected to the $48 \mathrm{VDC}$ bus.

In December 2007, an additional Outback Power Systems GVFX 36483.6 kW inverter was installed in the electrical room, on the 48 VDC bus, supplying electricity to the office which is equipped with small home appliances. This inverter could be used to supply the grid for grid-connected experimental purposes.

\subsubsection{System Control}

All of the components described above require an interface to operate together. The interface developed by HNEI connects all components electrically, electronically, and mechanically into an integrated system. It includes sensors, valves, and relays connected to the Data Acquisition and Control System (DACS) for system control and data recording. A safety analysis in the design process resulted in the development of a fail-safe system. Because the main components 
have their own controllers to run safely and automatically, the HNEI DACS controls the overall system and especially the shut-down procedures in case of an emergency such as fire, earthquake or instrumentation failure. It also optimizes the energy management of the system. In addition, it has been designed to be expandable, easily movable, and visible/controllable utilizing the internet.

Guaranteeing safety in a demonstration hydrogen project is essential for its sustainability and public acceptance. Therefore, the overall design criteria for the installation design was based on the safety requirements listed in the following codes and standards publications:

$\checkmark$ NFPA 55: Standard for Storage, Use, and Handling of Compressed Gases and Cryogenic Fluids in Portable and Stationary Containers, Cylinders and Tanks;

$\checkmark$ NFPA 583: Installation of Stationary Fuel Cell Power Systems;

$\checkmark$ ASME B31.3: Process Piping;

$\checkmark$ CGA G-5.4: Standard for Hydrogen Piping; and

$\checkmark$ CGA-5.5: Hydrogen Vent Systems.

Safety control components were integral parts of the installation, including a hydrogen fire sensor, a hydrogen sensor, and an oxygen concentration sensor for controlling hydrogen purity. Three (3) emergency-stop buttons identified by large signs are situated at different locations on the site. Many essential measurement sensors were duplicated in order to insure that gas leaks or component failure would be detected. A brick firewall was built surrounding the hydrogen storage area. Warning signs identify restricted areas including the hydrogen storage area and the hydrogen room. Some of these safety measures and equipment are shown in Figure 2.8.

Other essential safety features included are intended to address unattended events such as losing system control due to DACS power shortage or a depressurization of the pneumatic line. In order to avoid hazardous situations, the interface was designed as a fail-safe system, meaning that in such unattended events, the system stops safely: 1) all components are disconnected, 2) the gas storage is isolated, and 3) the gas lines are depressurized. The design was subjected to a safety analysis based on Fault Tree Analysis methodology. Up to now, the system has been operating as planned. Long-term operations are essential to validate and improve system safety design for unattended autonomous operations.

Figure 2.10 shows the Process Instrumentation Diagram (PID) of the installation, showing all sensors for pressure, flow, current and voltage measurements as well as the valves and the contactors. All elements are connected to the DACS. The interface is split into four main assemblies to allow easy transport of the system:

1. The main assembly is in the hydrogen room (Figure 2.7), including gas panel \# 1, electrical panel \# 1, and the DACS box;

2. A cabinet with gas panel \# 2 is in the gas storage area (Figure 2.8);

3. The structure under the water tank holds gas panel \# 4 (Figure 2.7); and.

4. Finally, electrical panel \#2 is situated adjacent to the batteries. 


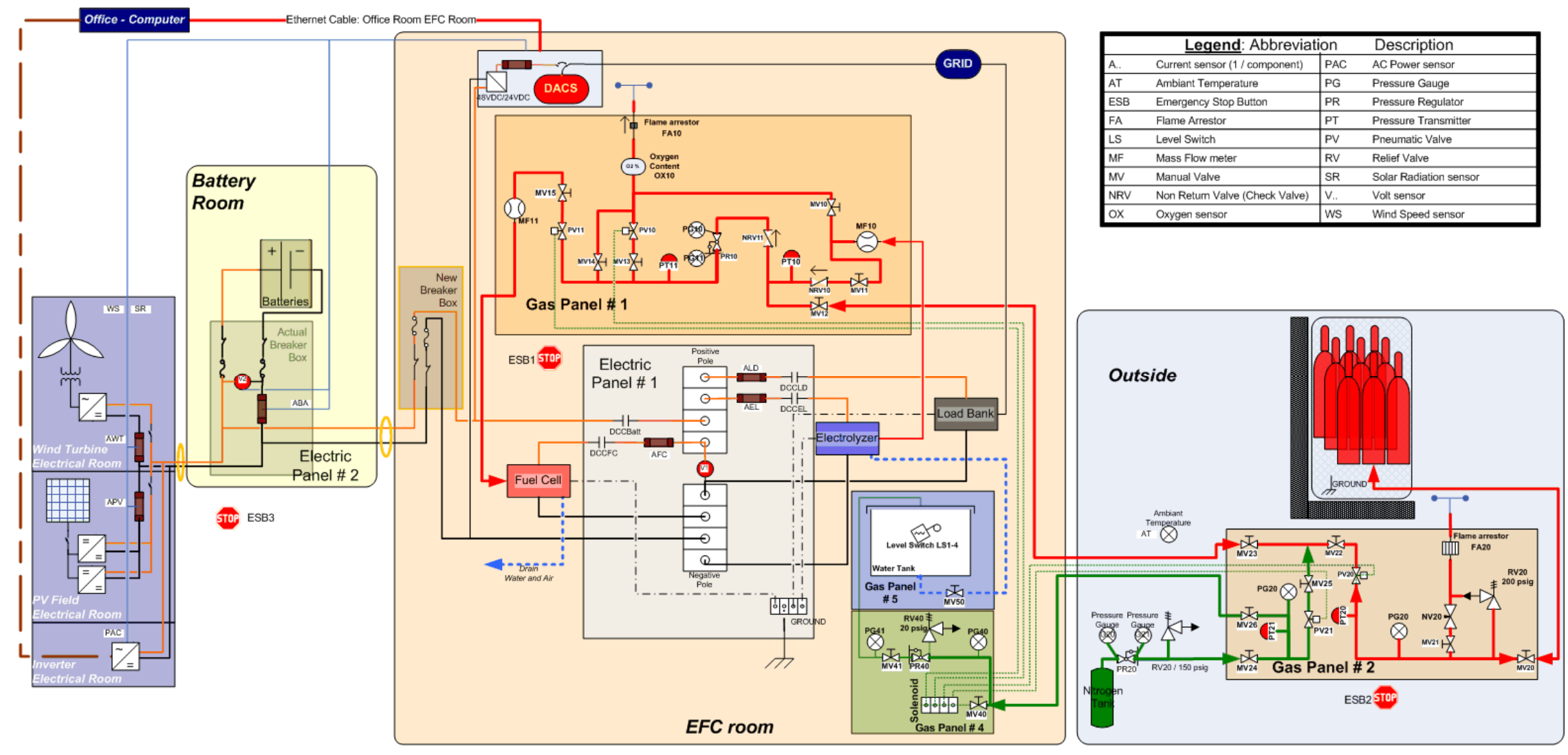

Figure 2.10: Process Instrumentation Diagram. 
The Data Acquisition and Control System (DACS) located in a vented cabinet includes:

$\checkmark$ A Fieldpoint (FP-2000) microprocessor controller from National Instruments, programmed using LabVIEW software.

$\checkmark$ Analog/digital input/output modules. The input data is listed in Table 2.2 and the output data is in Table 2.3.

$\checkmark$ Power supply hardware to supply the control unit using either the 48-VDC power system itself or the grid.

$\checkmark$ A communication unit allowing data transfer between the host computer and the DACS, the electrolyzer, and the FC via service interfaces.

Table 2.2: List of inputs at the Kahua Ranch hydrogen installation.

\begin{tabular}{|c|c|c|c|}
\hline Name & Name & Description & Unit \\
\hline H2 Pressure (FC Side) & PT11 & Pressure on the FC side line after Pressure Regulator PR 10 (30 psig) & psig \\
\hline H2 Flow FC & MF11 & Flow of hydrogen produced by electrolyzer & $\operatorname{slm}$ \\
\hline H2 Flow EL & MF10 & Flow of hydrogen consumed by Fuel Cell & $\operatorname{sim}$ \\
\hline O2 content in Vent & OX10 & Oxygen content into vent & $\%$ \\
\hline Wind Speed & WS & wind speed sensor located on the roof of the office & $\mathrm{mph}$ \\
\hline H2 Pressure GP1 & PT10 & Pressure of gas storage located on gas panel \# 1 & psig \\
\hline Amb Temp & AT & Ambient temperature & Celsius \\
\hline Solar Radiation & SR & Solar radiation sensor located on the roof of the office & Wpm2 \\
\hline PV Current & APV & Shunt measurement & A \\
\hline WT Current & AWT & Shunt measurement & A \\
\hline DC Bus Volt (Batt) & $\mathrm{V} 2$ & Voltage measurement on DC Bus in Electric panel \# 2 & $\mathrm{~V}$ \\
\hline DC Bus Volt (EFC) & $\mathrm{V} 1$ & Voltage measurement on DC Bus in Electric panel \# 1 & $\mathrm{~V}$ \\
\hline Shunt EL & AEL & Shunt measurement & A \\
\hline Shunt LD (load) & ALD & Shunt measurement & A \\
\hline Shunt Batt & ABA & Shunt measurement & A \\
\hline Shunt FC & $\mathrm{AFC}$ & Shunt measurement & $\mathrm{A}$ \\
\hline N2 Pressure & PT21 & Pressure on nitrogen line (75 psig) & psig \\
\hline H2 ST Pressure & PT20 & Pressure of gas storage located on gas panel \# 2 & psig \\
\hline FC Alarm & FCES & Send Boolean signal to stop the FC system & 0 or 1 \\
\hline ESB3 & ESB4 & Emergency Stop Button \# 3 - Outside the battery room & 0 or 1 \\
\hline Batt Signal DCC & DCCBatt & Contactor signal between initial system and HSS & 0 or 1 \\
\hline EL Signal DCC & DCCEL & Contactor signal for electrolyzer & 0 or 1 \\
\hline FC Signal DCC & DCCFC & Contactor signal for FC system & 0 or 1 \\
\hline LD Signal DCC & DCCLD & Contactor signal for load bank & 0 or 1 \\
\hline WLS High & LS51 & Water tank level switch \# 1 & 0 or 1 \\
\hline WLS MidHigh & LS52 & Water tank level switch \# 2 & 0 or 1 \\
\hline WLS MidLow & LS53 & Water tank level switch \# 3 & 0 or 1 \\
\hline WLS Low & LS54 & Water tank level switch \# 4 & 0 or 1 \\
\hline ESB1 & ESB1 & Emergency stop button \# 1 - On the main interface unit & 0 or 1 \\
\hline ESB2 & ESB2 & Emergency Stop button \# 2 - On the gas panel & 0 or 1 \\
\hline Fire Sens & FS & Fire sensor & 0 or 1 \\
\hline H2 Sens & HS & Hydrogen sensor on the ceiling of the hydrogen room & 0 or 1 \\
\hline Earthquake Sens & EQS & Vibration sensor located in the DACS box & 0 or 1 \\
\hline AC Supply & Auto & Signal if DACS is supplied with grid or power system & 0 or 1 \\
\hline
\end{tabular}


Table 2.3: Digital outputs of the Kahua Ranch installation.

\begin{tabular}{|l|l|l|l|}
\hline FC Estop & ESFC & Send boolean signal to emergency stop the FC system & 0 or 1 \\
\hline Batt DCC & DCCBatt & Contactor between the initial system and the HSS & 0 or 1 \\
\hline EL DCC & DCCEL & Contactor for the electrolyzer & 0 or 1 \\
\hline FC DCC & DCCFC & Contactor for the FC system & 0 or 1 \\
\hline LD DCC & DCCLD & Contactor for the load bank & 0 or 1 \\
\hline EV_Vent & PV10 & Electrovalve allowing Pneumatic Valve de/pressurisation - Vent & 0 or 1 \\
\hline EV_ST & PV20 & Electrovalve allowing Pneumatic Valve de/pressurisation - Storage & 0 or 1 \\
\hline EV_FC & PV11 & Electrovalve allowing Pneumatic Valve de/pressurisation - FC supply & 0 or 1 \\
\hline EV_PV & PV21 & Electrovalve allowing Pneumatic Valve de/pressurisation $-\mathrm{N}_{2}$ supply & 0 or 1 \\
\hline Grid Supply & Relay & Contactor for either grid or 48 VDC supply & 0 or 1 \\
\hline
\end{tabular}

The program in the microprocessor assures safe stand-alone operation, taking into account the requirement for operation via the HNEI service interface or via the emergency-stop buttons. Figure 2.11 shows a simple diagram of the repeating sequence running every $250 \mathrm{~ms}$ in the controller. This frequency has been considered high enough to assure quick emergency responses, if necessary. Based on the data and control configuration files, sensor measurements are analyzed and sent to the host computer for data acquisition and visualization. Analyzed data is used by the program to determine the present state of the system as well as the next state, according to the external control from the host computer or the automatic operation. The updated system state induces new values for the output modules. The configuration files allow changing the scaling of analog data and the parameters of the control, without stopping the system.

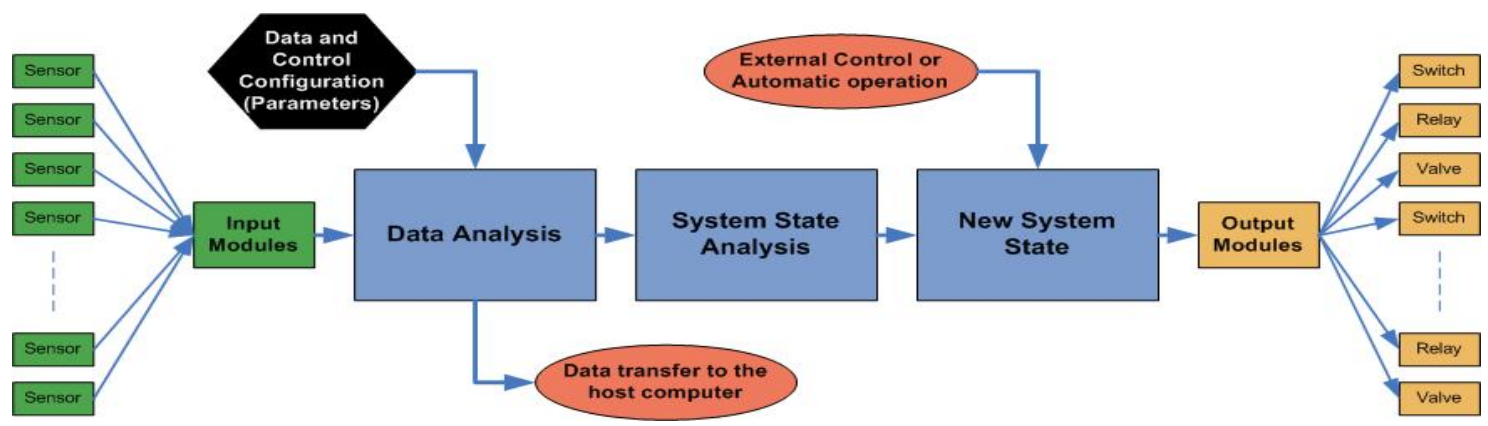

Figure 2.11: Repeating sequence in the control program (every $250 \mathrm{~ms}$ ).

The microprocessor is completely stand-alone, meaning that if the host computer or internet connection has a problem, the power system is still controlled and, in case of any hazardous situation, may be stopped automatically or through on-site activation of emergency-stop buttons.

The control of the overall installation is implemented into the DACS controller using a LabVIEW software program. Different operational modes have been programmed, as delineated below:

In "Manual Mode," each component can be connected individually, the gas lines can be purged, and the complete installation can be stopped. The operation called "Automatic Mode" is used for the power system to run stand-alone. It induces a purge of the gas lines before use of hydrogen and connection of all components. In this operation mode, the components are 
automatically connected/disconnected for safe operation and optimized energy management. The automatic mode control has been designed to harvest the maximum amount of available renewable resources, using the battery storage as primary storage due to its high efficiency compared to the HSS. It utilizes bus voltage and hydrogen storage pressure as its primary system sensors. It controls by connecting and disconnecting the load bank and the electrolyzer, because the generators of the installation (WT, PV and FC) have their own regulators. The implemented automatic control has been designed to be as simple as possible. A more sophisticated control could also be tested by reprogramming the controller program.

Main Control: In all operation modes, the controller always checks to see if there are any warnings or alarms. Warnings or alarms can be generated by analog sensors that show signals out of their allowable ranges. Ranges are defined in the configuration files. Alarms may also be linked to the safety equipment, such as the fire, hydrogen or earthquake sensors, or the emergency-stop buttons. Alarms or long warnings (occurring for five seconds) automatically trigger a complete shut-down of the installation: 1) all components are disconnected from the bus, 2) the gas storage is isolated, and 3) the gas lines are purged and depressurized. Once such emergency stops occur, an operator is required to restart the installation.

Voltage Control: Battery voltage has been selected to control the system. Although the state-ofcharge (SOC) is more accurate to evaluate the available energy stored into the battery, it is also very difficult to measure. Moreover, the regulators integrated into the generators of the installation already use the battery voltage to operate. Indeed, the PV and wind generators reduce the available renewable power to avoid overcharge of the batteries. Regulation starts when the battery voltage reaches $56.8 \mathrm{~V}$ for the WT and $58 \mathrm{~V}$ for the PV system. Figure 2.12 illustrates the voltage control of the whole installation showing the operating voltage range of each component. The FC system has been set in order to operate to avoid battery deep discharge. It starts up when the battery voltage reaches $47 \mathrm{~V}$ and maintains it between 47 and $47.7 \mathrm{~V}$. It automatically stops when the voltage gets higher than $47.7 \mathrm{~V}$. The load bank, priority load, is always connected when the battery voltage is between 46.8 and $60 \mathrm{~V}$. It may be disconnected when the FC runs and the hydrogen storage is empty. In such a case, both of the storage systems are considered empty and the load is reduced to allow recharge of the storage systems. The electrolyzer supply is allowed when there are the following: 1) an excess of renewable resources, 2) charged batteries, and 3) a hydrogen storage system that is not full. Therefore, the electrolyzer voltage range has been set between 49 and $60 \mathrm{~V}$. The EL unit starts up when the battery voltage reaches $54 \mathrm{~V}$ and the battery current is above $20 \mathrm{~A}$. It is disconnected when the battery current is less than $0 \mathrm{~A}$. A two-minute average value of the battery current is used in order to avoid short-term operation of the electrolyzer. When the lowvoltage limit is reached $(49 \mathrm{~V})$, the electrolyzer is turned on again only if the batteries are recharged and their voltage is $54 \mathrm{~V}$ or above. 


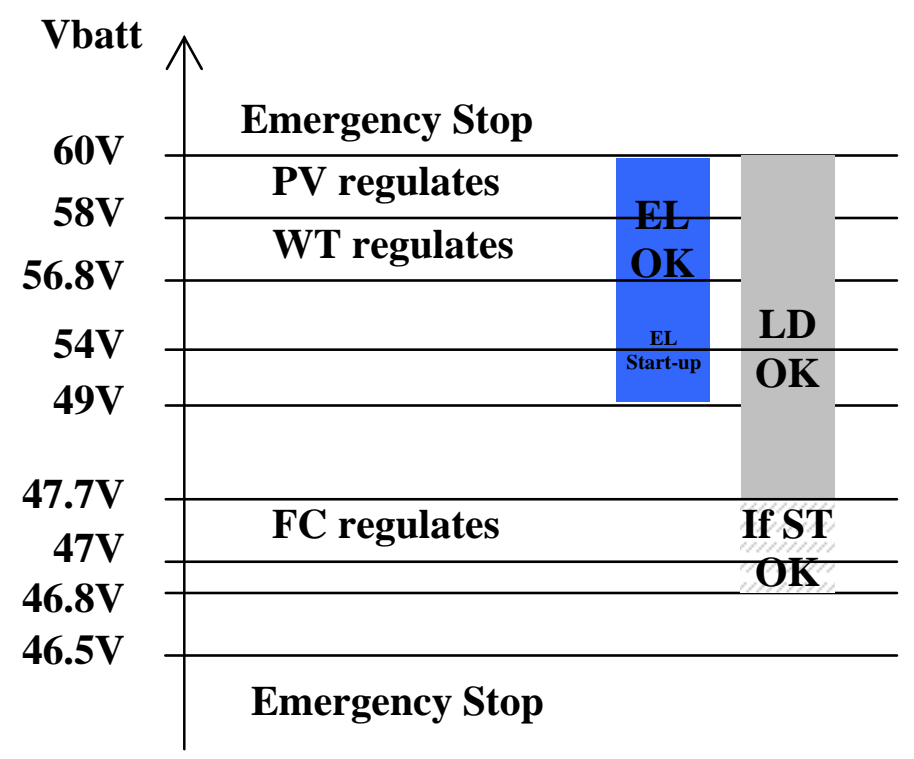

Figure 2.12: Voltage control in the overall installation - operating voltage range of the components (LD = load; ST = storage).

Pressure Control: Control based on the hydrogen storage pressure avoids starting the electrolyzer when the gas storage is full, in order to avoid idle consumption by the unit. As mentioned earlier, when the gas storage is empty, the end-user load is disconnected because the FC system cannot help in matching the demand without a risk of running out of gas.

All the voltage and pressure set points can be modified simply, by using the service interfaces or the configuration files. For most of these set points, hysteresis effects are used in order to avoid short-term operation of the components.

A LabVIEW program runs in the host computer for data visualization and remote control. Data sent via Ethernet by the DACS are recorded directly or after averaging. They are also displayed in a graphic service interface. Data recorded every $250 \mathrm{~ms}$ is used for trouble-shooting the installation. Figure 2.13 shows the program used on the host computer for this purpose. Fast measurements are also helpful to evaluate the transient behavior of the whole installation. Averaged data is more convenient when evaluating the overall energy flow in the power system during a one day or longer period of time.

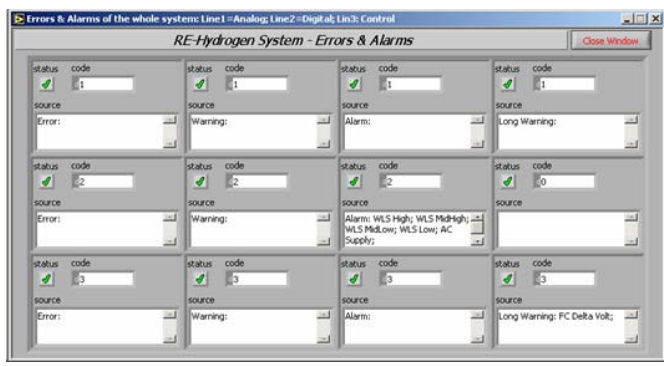

Figure 2.13: Trouble-shooting Windows. 
Figure 2.14 shows the service interface allowing data visualization and system control. Data shown on the visualization screen consists of all the measurements or controls detailed in Tables 2.2 and 2.3. A graph allows visualizing the time evolution of the recorded data. Finally, the interface displays information on the system state (mode of operation, gas line status) and on the status of the control program itself. The picture on the right of Figure 2.14 is the control service interface which allows connecting and disconnecting components, and changes in the operation mode and control parameters. Although the visualization screen is available to anyone on the project web site, the control program is only accessible to authorized users.

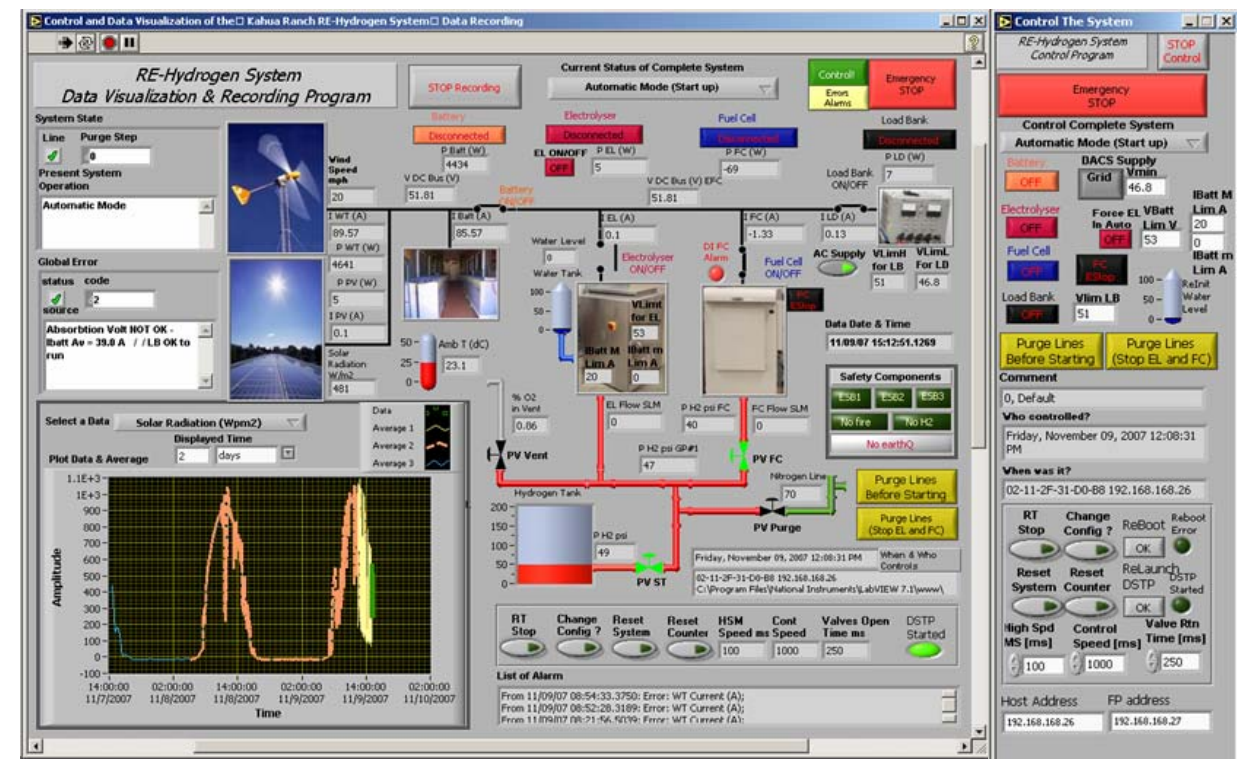

Figure 2.14: Data visualization of the Kahua Ranch installation: (left) available on a web site, and (right) control interface, only accessible to authorized users.

\subsubsection{Economic Data}

Figure 2.15 summarizes the budget analysis for the Kahua Ranch Hydrogen Storage System, including the interface and all HSS components. It only takes into account the material cost. The overall cost was $\$ 80 \mathrm{k}$, with $60 \%$ allocated to the electrochemical components. The next two important costs were the gas connection materials and DACS. Other expenses included the shipping cost $(\$ 1.2 \mathrm{k}$ for inter-island freight) and the cost for the initial system modification $(\$ 20 \mathrm{k})$. 


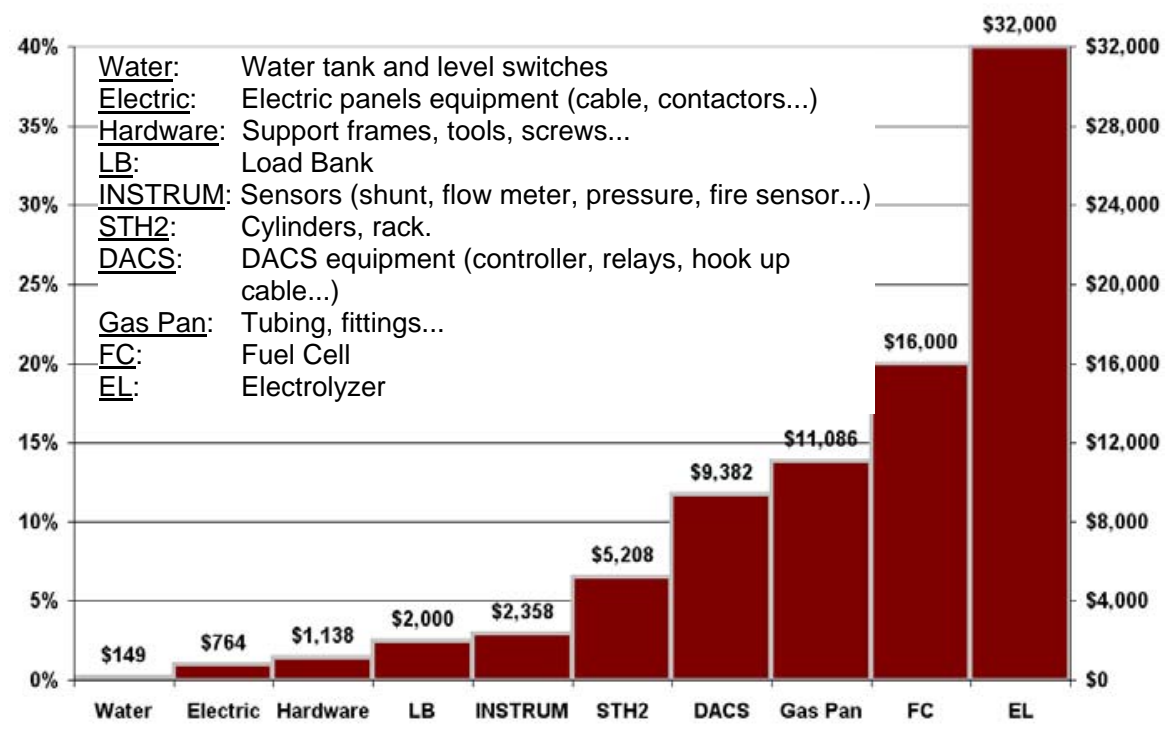

Figure 2.15: Budget analysis for the Kahua Ranch installation.

\subsubsection{Experimental Results}

After installing the hardware, each component was connected individually. During the first operating phase, the scaling of all analog electrical data was checked using a digital multimeter and a current clamp-on meter. Then, the emergency procedures were verified. When the electrolyzer was connected, the oxygen sensor showed that the product hydrogen did not contain oxygen. However, a peak level of oxygen was observed after a long stand-by period of the electrolyzer. This issue was resolved by replacing the PFA (Perfluoroalkoxy) tubing with stainless steel tubing. A special procedure might be necessary in order to regularly test the hydrogen purity, particularly after a long standby period of the electrolyzer. Finally, the general control of the installation was improved and the control parameters were tuned in order to reach a reliable, safe and stand-alone operation of the overall installation.

\subsubsection{One Day of Automatic Mode Operation}

The initial experiments were conducted with the PV as the only renewable generator. The wind turbine was connected on November $9^{\text {th }} 2007$. Figures 2.16 and 2.17 show the system performance recorded on October $5^{\text {th }}, 2007$. In Figure 2.16, the sun started rising at 7 am and reached a peak power output of $1,200 \mathrm{~W} / \mathrm{m}^{2}$. The solar radiation reached zero at $6 \mathrm{pm}$. After sunrise, the PV array supplied current to charge the batteries whose voltage (Figure 2.17) reached $54 \mathrm{~V}$ just after 8:30 am. This signaled the electrolyzer to start. The current of the electrolyzer unit (prototype \# 1) reached an average current of $7.2 \mathrm{~A}$ in five minutes (min) and the hydrogen production started three min later. The current increased to $10 \mathrm{~A}$ after 2.5 hours of operation. Similarly, as shown in Figure 2.17, the hydrogen flow meter measured an average flow of 0.63 and 0.97 SLM during these intervals. The EL efficiency is evaluated at 35 and $36 \%$ (HHV) for these two operating points. The hydrogen storage pressure increased continuously during the electrolyzer operation, reaching 125 psi just after $2 \mathrm{pm}$, causing the electrolyzer to be disconnected by HNEI's controller, because it reached the maximum storage pressure set at 125 psi. The storage volume during this day was 130 Liters. 


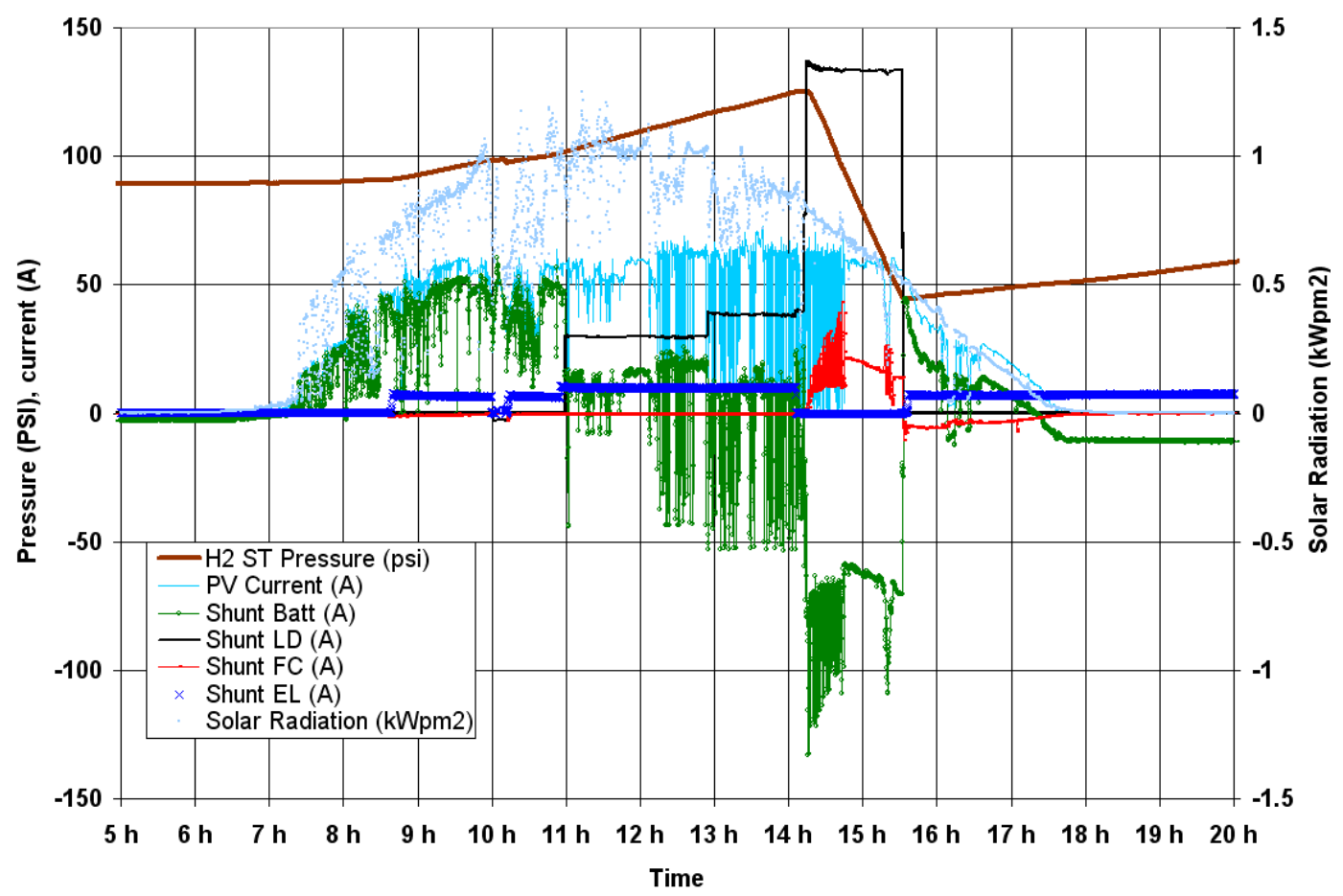

Figure 2.16: Evolution of main data during a day of operation - October $5^{\text {th }}, 2007$.

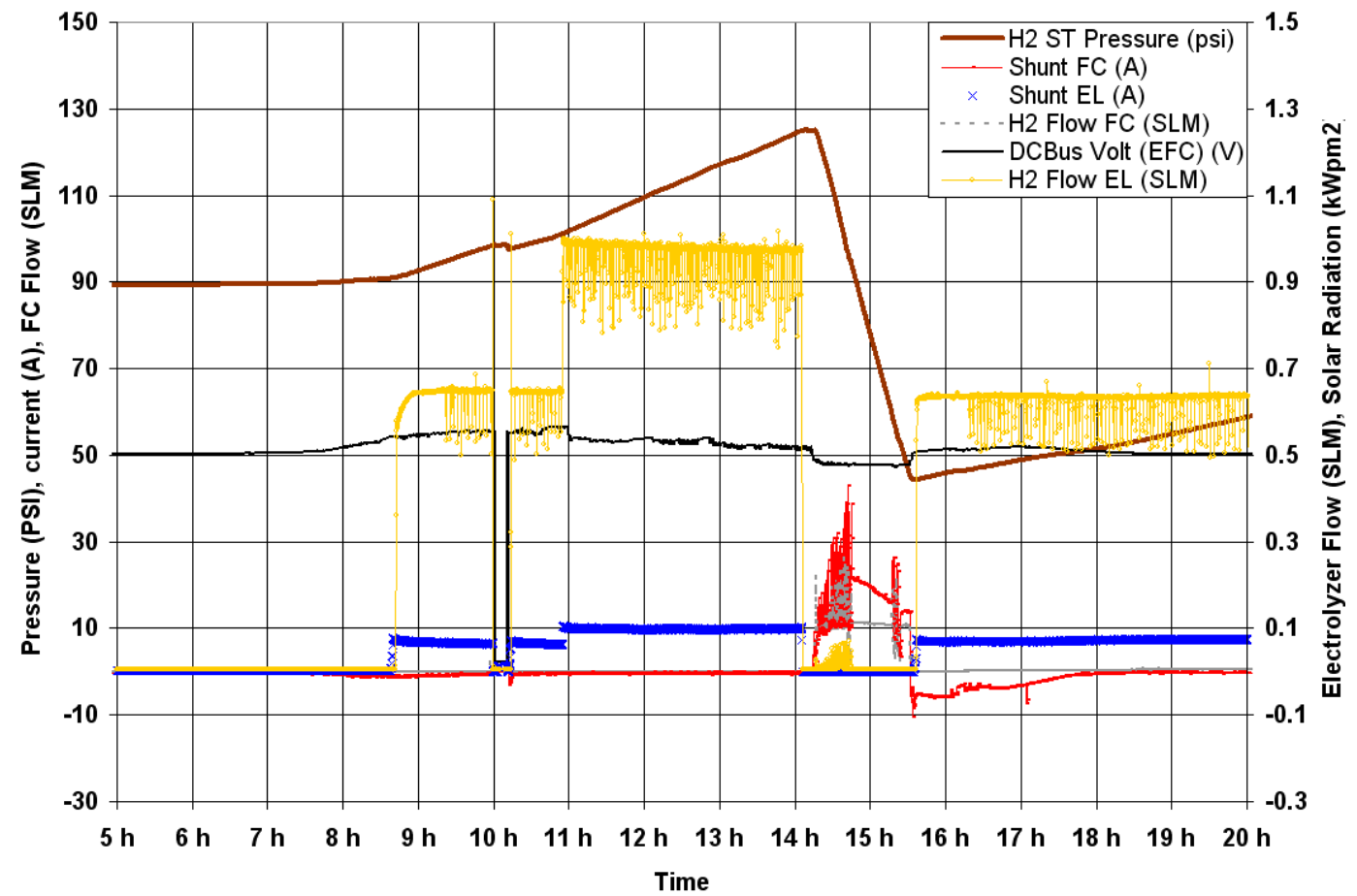

Figure 2.17: Evolution of the Hydrogen Storage System data during operation on October $5^{\text {th }}, 2007$.

After 10 am, the PV/battery bank also supplied power to the load bank. Although the load bank is priority, the electrolyzer was not shut down because the average battery current remained 
higher than -20 A (battery discharge of $20 \mathrm{~A}$ ), one of the electrolyzer's control parameters. This parameter was set at this low value to increase the use of the electrolyzer. It is now set at $0 \mathrm{~A}$ to avoid discharge of the batteries to produce hydrogen.

At 2:15 pm, the required load bank current increased to $130 \mathrm{~A}$, inducing a drop of bus voltage below $47 \mathrm{~V}$. The FC system started up automatically, maintaining the voltage between 47 and 47.7 V. The FC current followed the large variation of the PV current. This variation was actually due to a conflict between the two MPPT controllers operating in parallel. One of the controllers was shut down at $2: 35 \mathrm{pm}$, removing the conflict (see the figures). The average efficiency of the FC unit during this operation was calculated at $34.3 \%$. The maximum FC current demand was $43 \mathrm{~A}, 40 \%$ of its maximum power output. The FC unit might be oversized for the selected system configuration. Further experiments will be focused on this issue.

At 3:30 pm, the load bank was shut down by the main controller because the hydrogen storage was considered empty (low-pressure set point is $40 \mathrm{psi}$ ). It induced an automatic stop of the FC unit, since the battery voltage increased without the load demand. Then, the load bank demand was reduced to $0 \mathrm{~A}$ and the available excess energy allowed the electrolyzer to run again.

\subsubsection{Performances of Each Component}

Two months of stand-alone operation were recorded. Each component performance was analyzed for operating the system in automatic mode. The performances of the electrochemical components in the complete installation and steady-state operation are compared.

\subsection{Photovoltaic Array}

The PV array consists of two parallel strings of ten modules in series, but only one MPPT controller is used because of operating conflict of the two controllers in parallel (see section 2.5.3.1). Each $245-\mathrm{W}_{\text {peak }}$ module has an area of $2 \mathrm{~m}^{2}$. Figure 2.18 shows $\mathrm{PV}$ performance (PV current or power supplied to the bus bar) as a function of the solar radiation. The PV electric production is mainly linear with the solar radiation as long as the PV current does not exceed 60 A. This limitation is due to the MPPT controller being undersized due to the unavailability of the correct power range at the time of selection. The linear behavior is due to the PV controller which is always operating in MPPT operation mode. Indeed, if the batteries were fully charged, the controller would reduce the PV power in order to avoid battery overcharging. Finally, looking at this linear performance, the PV array shows an efficiency of around $11 \%$, calculated by dividing the PV power by the solar radiation received by the $40 \mathrm{~m}^{2}$ wide $\mathrm{PV}$ array.

\subsection{Wind Turbine}

The $7.5 \mathrm{~kW}$ Bergey Excel wind turbine, after stator replacement, has been in operation since November 9, 2007. Figure 2.19 shows wind turbine current and power recorded at Kahua Ranch as a function of wind speed. The high dispersion of the data is due to the distance between blades and the wind speed sensor. The start-up/cut-in wind speed is around $8 \mathrm{mph}$. The WT power is quite linear with wind speed up to $25 \mathrm{mph}$. For faster wind speed, the available power drops down. Indeed, the Bergey wind turbine has two furling mechanisms: the blade flexibility and a tail folding at high wind speed (see photograph on Figure 2.19). Figure 2.19 also draws the trend line of the power produced by the WT. Based on this tendency curve, the efficiency of the unit has been calculated by dividing the WT power by the wind power. 


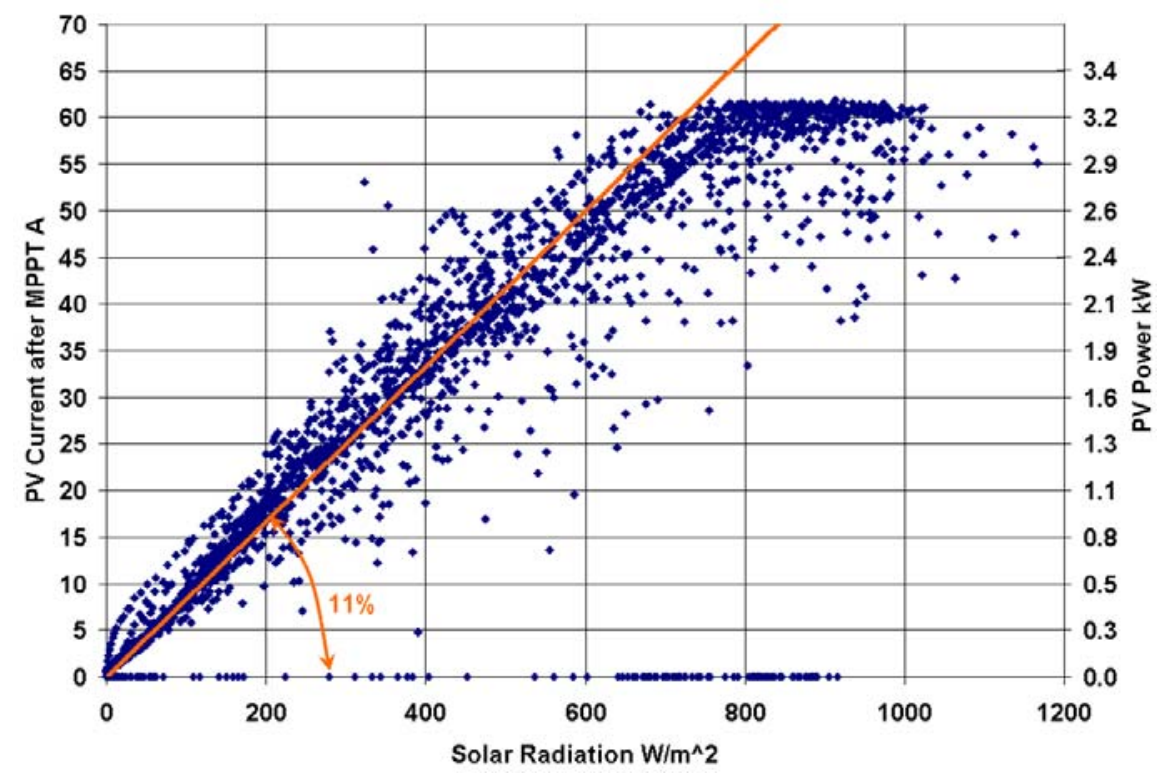

Figure 2.18: PV performance - PV current or PV power as a function of solar radiation.
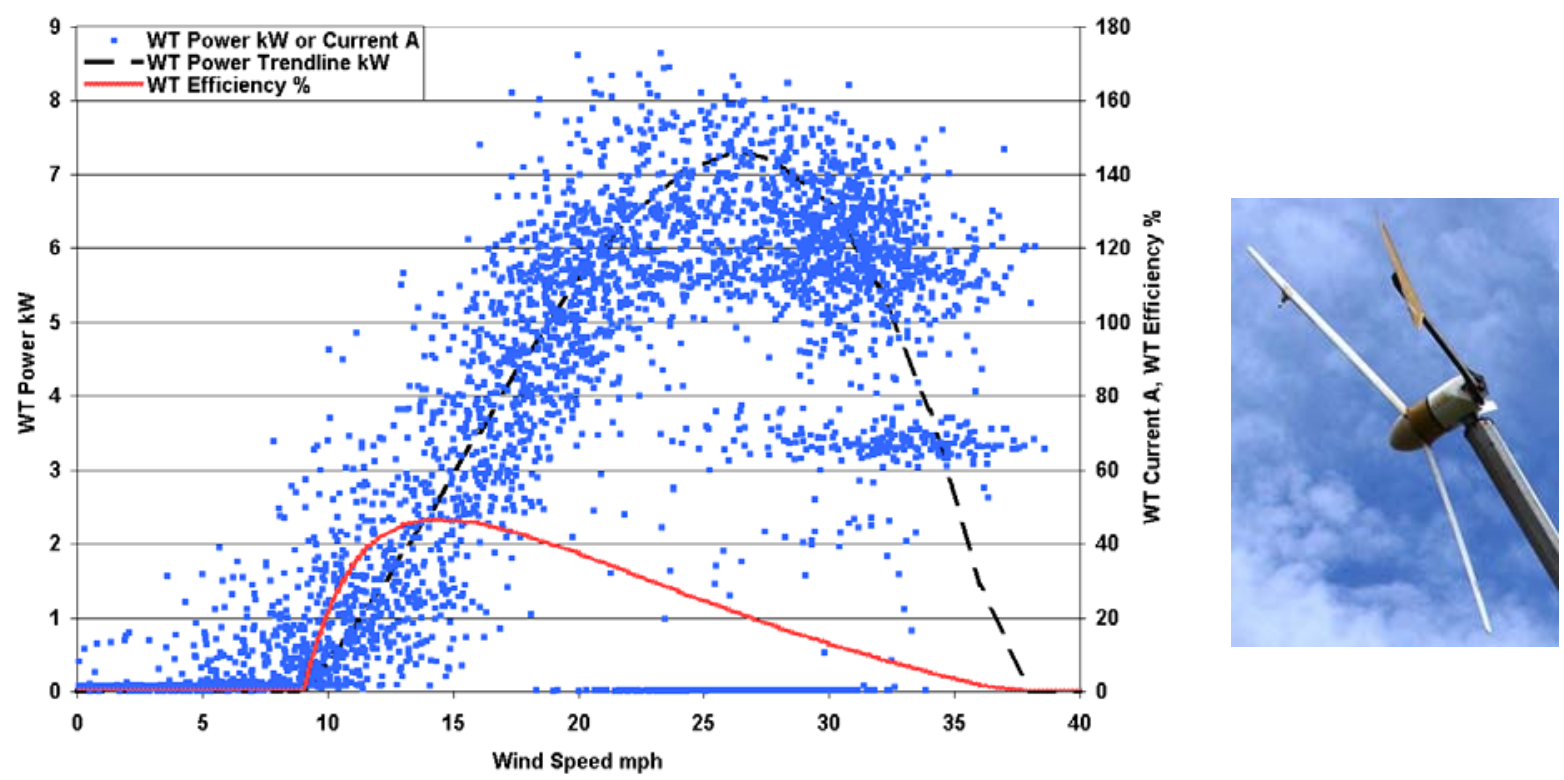

Figure 2.19: Wind turbine power, current and efficiency as a function of the wind speed - photograph of the WT, showing the furling protection at high wind speed. 
Equation 1 describes the calculation of the wind power received by the WT. Just after the startup/cut-in wind speed, the efficiency quickly increases, reaching $45 \%$ when the wind speed is between 8 and $15 \mathrm{mph}$. The efficiency then decreases slowly with increasing wind speed.

$$
P_{\text {wind }}=\frac{1}{2} \times \rho_{\text {air }} \times A_{\text {blades }} \times V_{\text {wind }}^{3} \quad \text { Equation } 1
$$

where:

$P_{\text {wind }} \quad$ Power in W;

$\rho_{\text {air }} \quad$ Air density in kg.m $\mathrm{m}^{-3}\left(1.07 \mathrm{~kg} \cdot \mathrm{m}^{-3}\right.$ at Kahua Ranch elevation $\left.\sim 1,000 \mathrm{~m}\right)$;

$A_{\text {blades }}$ Rotor swept area, exposed to the wind in $\mathrm{m}^{2}$ (Bergey area: $35.3 \mathrm{~m}^{2}$ ); and

$V_{\text {wind }} \quad$ Wind speed in $\mathrm{m} \cdot \mathrm{s}^{-1}\left(20 \mathrm{mph}=9 \mathrm{~m} \cdot \mathrm{s}^{-1}\right)$.

\subsection{Batteries}

The battery storage system was not tested since the main focus of the experiments was on the integration of the HSS.

\subsection{Electrolyzer}

The electrolyzer unit was commissioned at different times throughout the project as the supplier improved the design of the unit during the project duration. The following analysis corresponds to the final unit in place at Kahua Ranch.

\section{Steady-state operation}

Figure 2.20 shows the time evolution of the main electrolyzer data on December $21^{\text {st }}$, when the unit was commissioned: unit current and voltage, hydrogen flow, and calculated electrolyzer efficiency, based on the High Heating Value of hydrogen (HHV). The unit started at 8:40 am and the unit current increased up to $35 \mathrm{~A}$ in 18 minutes. This high current helped in reaching optimal operating conditions. Following this warm-up period, the current dropped down to 25 A, reaching its optimal operating point at $10 \mathrm{am}$. Only 2.5 minutes were necessary for the unit to deliver hydrogen after supplying electricity to the electrolyzer stack. Hydrogen flow was then proportional to the current. The unit efficiency (HHV) was around $40 \%$ during the warm up period. At the optimal operating point, the average flow was $3.5 \mathrm{SLM}(0.2 \mathrm{Nm} / \mathrm{hr})$. The unit current averaged $25 \mathrm{~A}$ at $55 \mathrm{~V}$. The efficiency of the electrolyzer at the optimal operating point was then $50.2 \%$ (HHV), equivalent to an energy consumption of $7 \mathrm{kWh} / \mathrm{Nm}^{3}$. Although the electrolyzer current varied a little over time, this performance was assimilated into steady-state performance, since the unit ran almost steady for more than two hours. Further experiments are required to investigate real steady-state performance of the unit.

According to the oxygen sensor, the hydrogen produced by the electrolyzer did not contain any oxygen but its water content was high. The unit should include a hydrogen drying unit. This feedback has been communicated to the manufacturer, Eh!. 


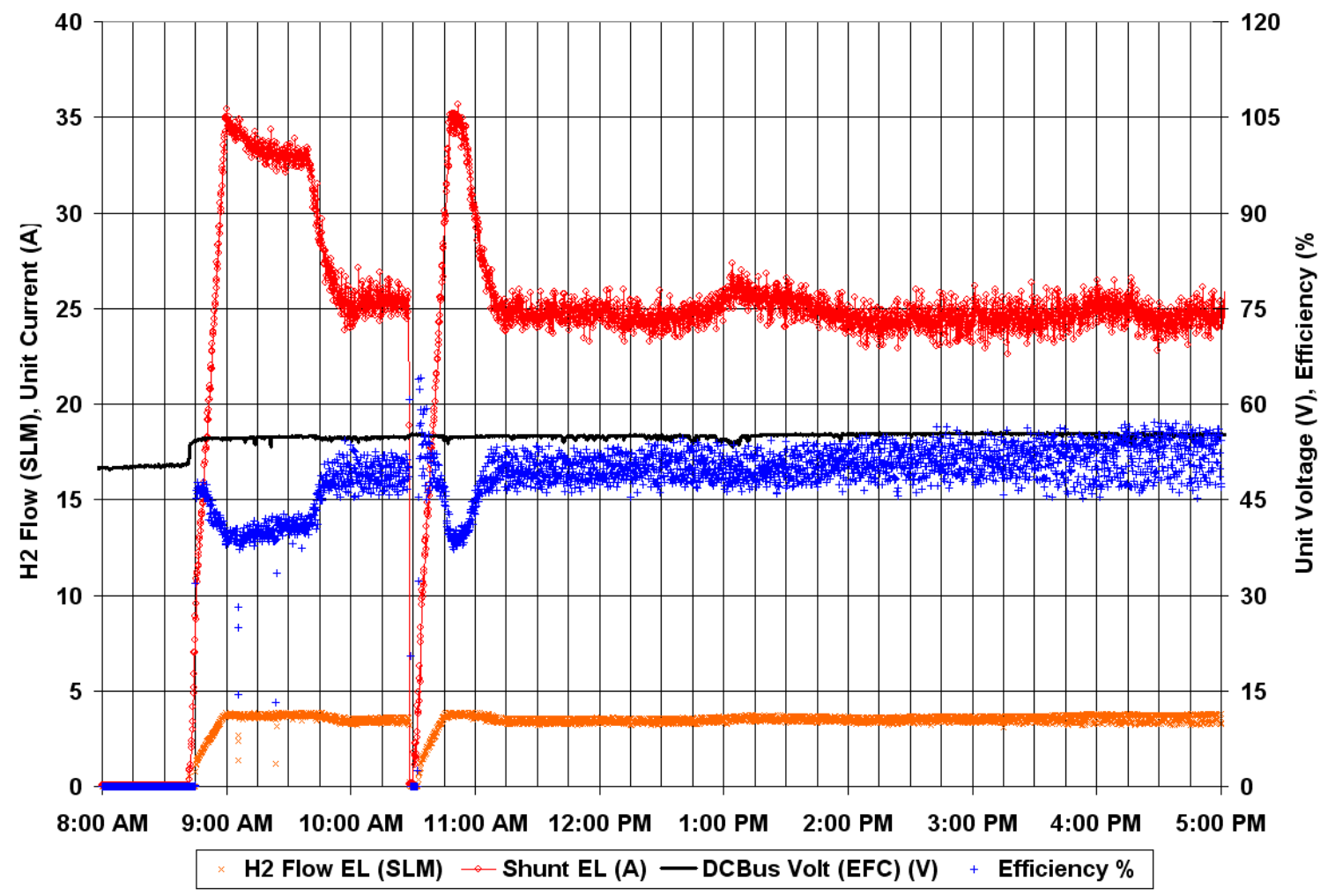

Figure 2.20: Electrolyzer data evolution versus time: current and voltage of the unit, hydrogen production flow and efficiency (HHV) - December $21^{\text {st }}$, 2007.

\section{Electrolyzer performance at Kahua Ranch}

The similarly steady-state operation mode described above does not always occur when the electrolyzer is integrated into the complete Kahua Ranch installation. Figure 2.21 shows the main data of the electrolyzer operating in automatic mode in the complete power system. The electrolyzer operates for either short or long periods of time depending on the renewable resource availability. The shortest period was ten minutes (on December $22^{\text {nd }}$ at 6 am), where the current did not reach its optimal operating point. The longest period is five hours. The brown line on Figure 2.21 is the pressure in the hydrogen storage (320 liters). When the pressure reached its maximum pressure set at 165 psi, the electrolyzer was disconnected by the HNEIdeveloped controller, on December $22^{\text {nd }}$, just before 11:00 am. The overall energy needed to fill up the storage equivalent to $2.8 \mathrm{Nm}^{3}$ of hydrogen (HHV) was calculated at $21.4 \mathrm{kWh}$. The efficiency of the electrolyzer in operation in the complete installation was therefore equal to 7.6 $\mathrm{kWh} / \mathrm{Nm}^{3}$ or $46.5 \%$ (HHV). 


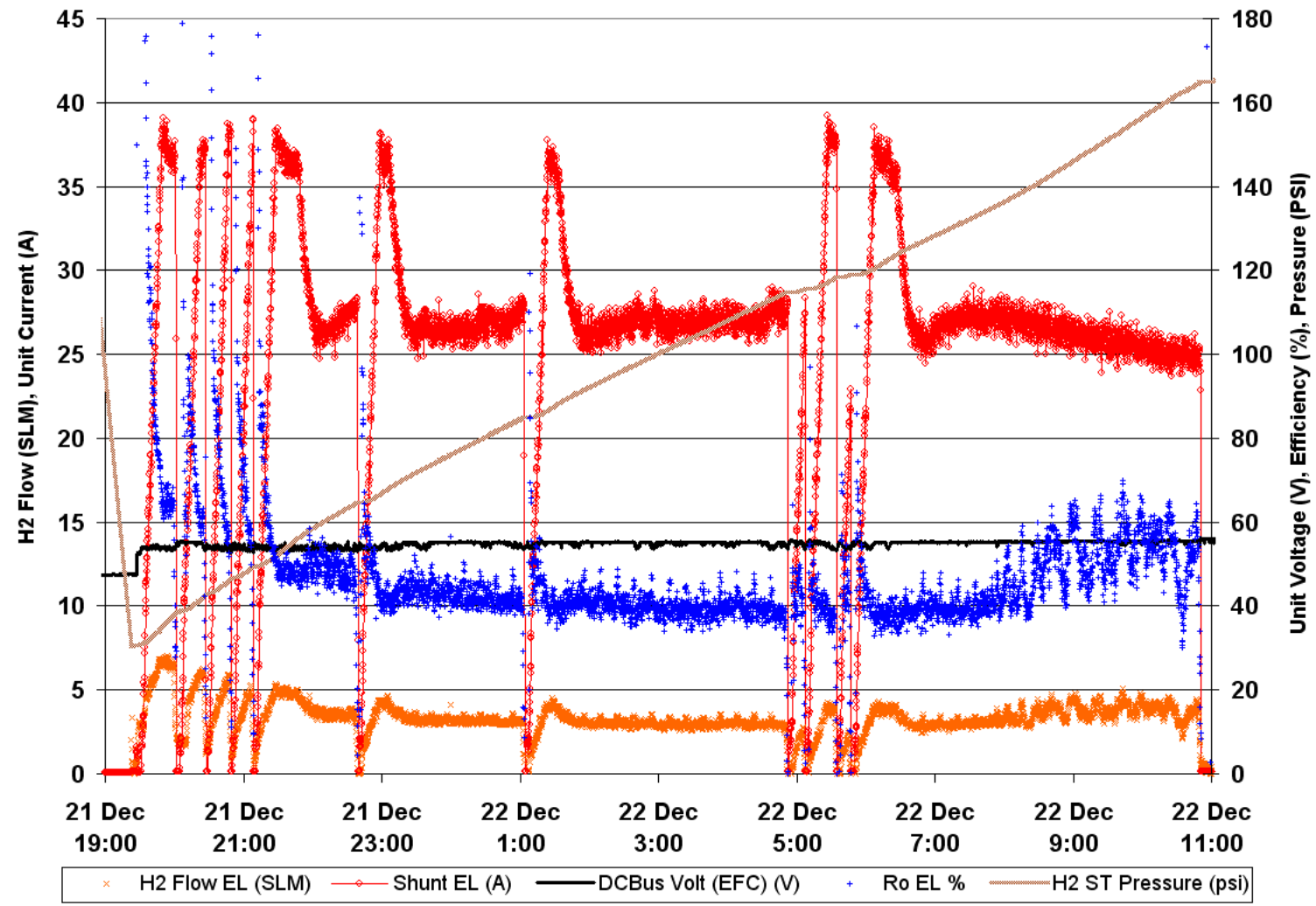

Figure 2.21: Electrolyzer data in stand-alone operation mode of the complete installation.

\section{Electrolyzer performance conclusions}

The performance of the PEM electrolyzer was evaluated at $7 \mathrm{kWh} / \mathrm{Nm}^{3}$ or $50.2 \%$ (HHV), equivalent to the $6 \mathrm{Nm}^{3} / \mathrm{hr}$ alkaline electrolyzer tested during the initial phase of the HPP. In automatic operation in the power system, the PEM unit was only $4 \%$ less efficient, 7.6 $\mathrm{kWh} / \mathrm{Nm}^{3}$ or $46.5 \%$ (HHV), compared to its similarly steady-state performance. This advantage is due to the small size and design of the PEM electrolyzer, allowing a quick warm-up period. It is also due to the control strategy of the overall installation in avoiding short-time operation of the electrolyzer.

\subsection{Fuel Cell}

The fuel cell unit was analyzed in steady-state operation mode during the initial phase of the HPP. It was then used in automatic operation of the stand-alone power system, using the lowvoltage operation mode of the FC unit.

Fuel cell performance - steady-state operation

The fuel cell system performance in steady-state operation has been presented in section 2.4.2.3. The unit efficiency was higher than $38 \%$ (HHV), during operation at from 14 to $100 \%$ of the peak power.

\section{Fuel cell performance at Kahua Ranch}

The FC system is used to supply the load when the RE availability is low and the battery storage is empty. The FC unit has a low-bus voltage operation mode. It has been set to start operation 
when the bus voltage reaches its low value $(47 \mathrm{~V})$. It automatically shuts down when the bus voltage is higher than $47.7 \mathrm{~V}$ (see section 2.5.2.4).

Figure 2.22 shows the FC operation on November $17^{\text {th }}, 2007$, when only the photovoltaic array was connected to the bus bar and the load demand was constant and equal to $133 \mathrm{~A}$. The light blue stars correspond to the PV current varying from 2 to $42 \mathrm{~A}$, as a function of the solar radiation. The black circles are the bus voltage data. Just before 1:40 pm, the voltage reached $47 \mathrm{~V}$ and the FC started. The FC current was negative for a short period at the start-up, allowing the auxiliaries to be supplied. The stack was in operation shortly after and the FC unit current was positive. The hydrogen flow increased drastically at the start-up and was then proportional to the unit current. Until time 1:55 pm, the FC heater was on, in order to quickly reach the optimal temperature. During this start-up period, the FC unit efficiency, calculated using the power produced by the $\mathrm{FC}$ system divided by the power equivalent to the hydrogen consumption (HHV), was between 12 and 27\%. After this warm up period, the FC unit efficiency was between 28 and 35\%. Out-of range efficiencies were due to the transient behavior of the FC unit using its batteries to soften the necessary variation of the stack production to supply the load demand. During the entire operation, the FC unit current varied from 0 to $42 \mathrm{~A}$, to match the load, which was also being supplied by the PV and the batteries, with the battery current varying between 50 and 100 A. Just after 3:00 pm, the hydrogen storage reached the low-pressure level and the load was disconnected from the bus-bar by the main controller, to keep the FC unit from running out of hydrogen. The load disconnection was followed by a drastic increase of the busbar voltage up to $49 \mathrm{~V}$, signaling the FC unit to stop. During this period, the overall hydrogen consumption was 57.5 moles or $4.57 \mathrm{kWh}$ (HHV). The FC unit electrical production was calculated at $1.32 \mathrm{kWh}$. The FC system showed then an average efficiency equal to $29 \%$ (HHV).

Figure 2.23 shows the efficiency of the FC unit in operation in the complete installation as a function of the electrical output power. The crosses are the points recorded on November $17^{\text {th }}$, 2007. The diamond points were recorded when the FC unit was directly supplying the load, in order to reach higher power demand. FC system efficiency primarily ranged between 28 and $40 \%$. The low efficiency points below $30 \%$ correspond mainly to the warm-up period performance. Compared to the steady-state operation mode presented earlier, the real-time efficiency was disparate and lower. This is due to the transient behavior of the unit using its included batteries to match the load demand. Moreover, the short operation time and the variable load demands in the complete power system did not allow the FC unit to reach optimal operating conditions.

In addition, although it is convenient to have a $5 \mathrm{~kW} \mathrm{FC}$ unit to help supply the load demand, the operation in parallel with a large battery storage capacity would require a less powerful FC unit. This would allow higher system efficiency.

\section{Fuel cell performance conclusions}

The FC unit showed an efficiency above $38 \%$ when producing more than $700 \mathrm{~W}$ in steady-state operation. When integrated into the complete power system, however, the FC unit, which was used as a complement to the battery storage to match the load, appeared to be oversized as well as having long and low efficiency warm-up periods. This induced a low operating efficiency of the FC unit in the complete installation of almost $10 \%$ less than in steady-state operation and about $15 \%$ less during the warm-up period. This point will require more experiments to reach a conclusion on the importance of the unit design size. 


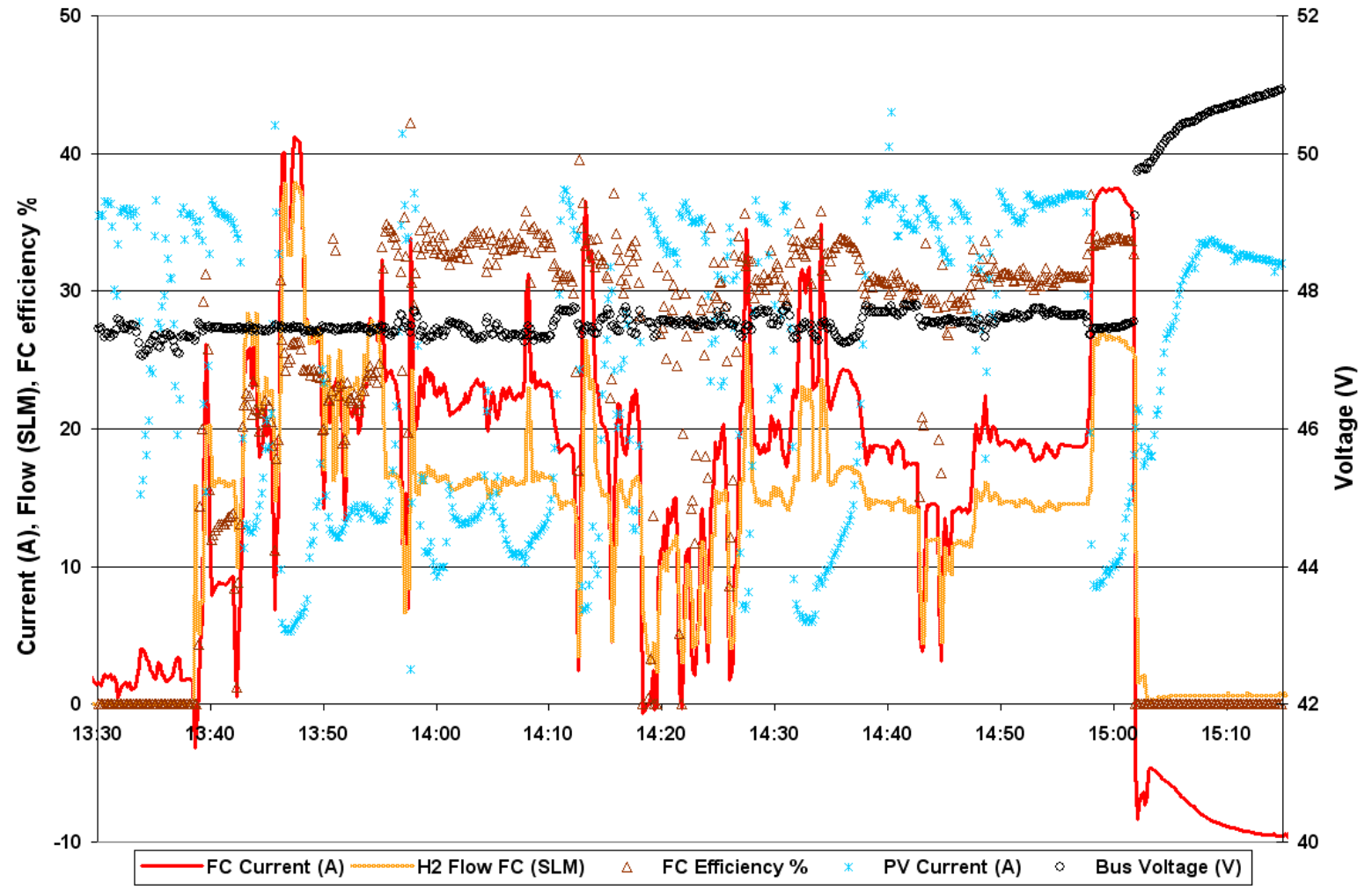

Figure 2.22: FC unit operation in the complete installation - November $17^{\text {th }} 2007$.

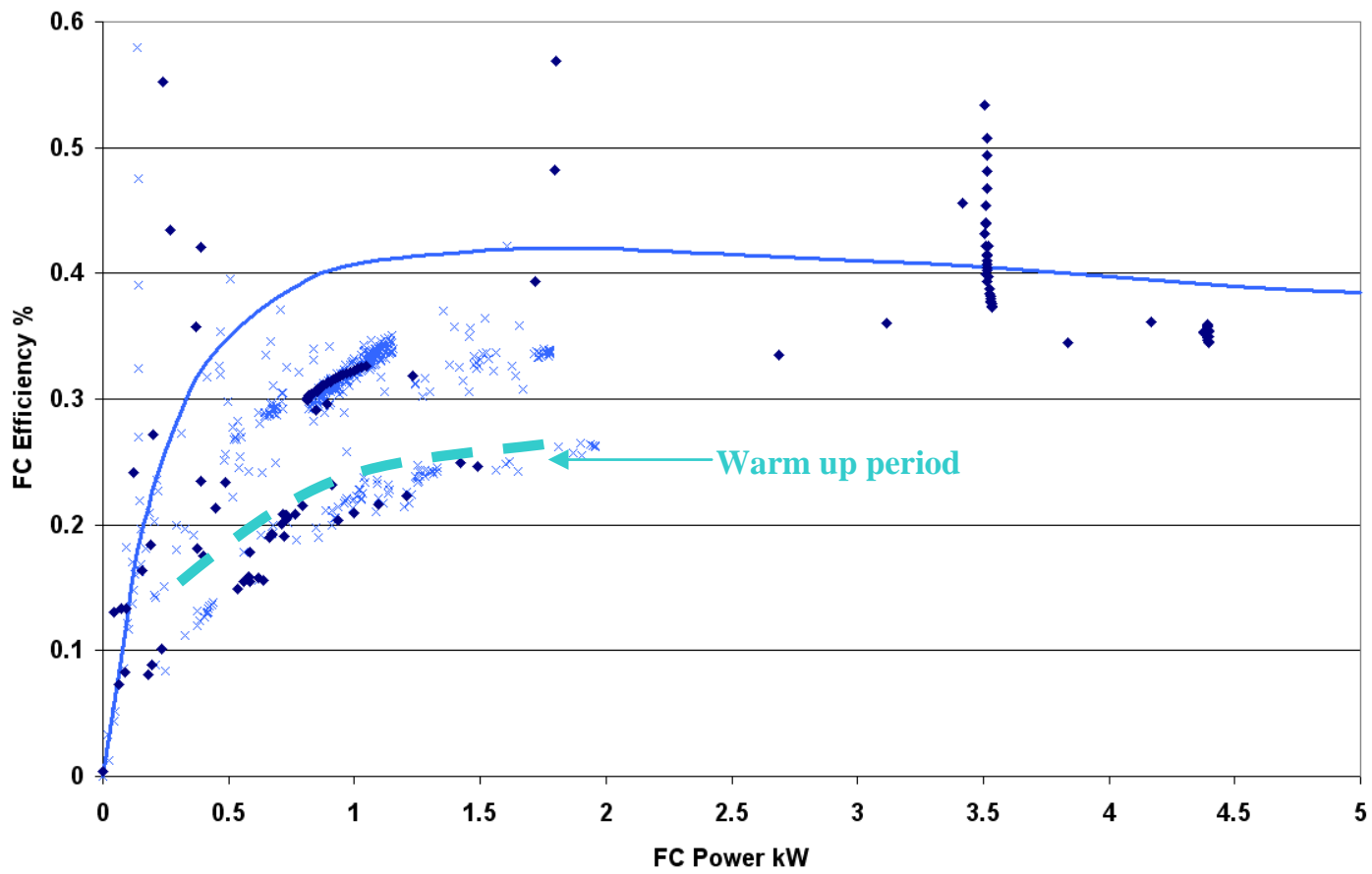

Figure 2.23: FC efficiency (HHV) as a function of electrical output power - FC system with new stack. 


\subsection{Load}

Since December $14^{\text {th }}, 2007$, an Outback VFX3648 inverter has been converting DC power into AC power to supply the office equipped with house-hold appliances (fridge, micro oven, coffee maker, lights, heater, etc). The AC load demand was recorded as shown in Figure 2.24. The basis of the load was the power required by the fridge and the computers. The different load steps are the lights, the micro oven and the coffee maker. Finally, the peaks are required by the fridge and the coffee maker.

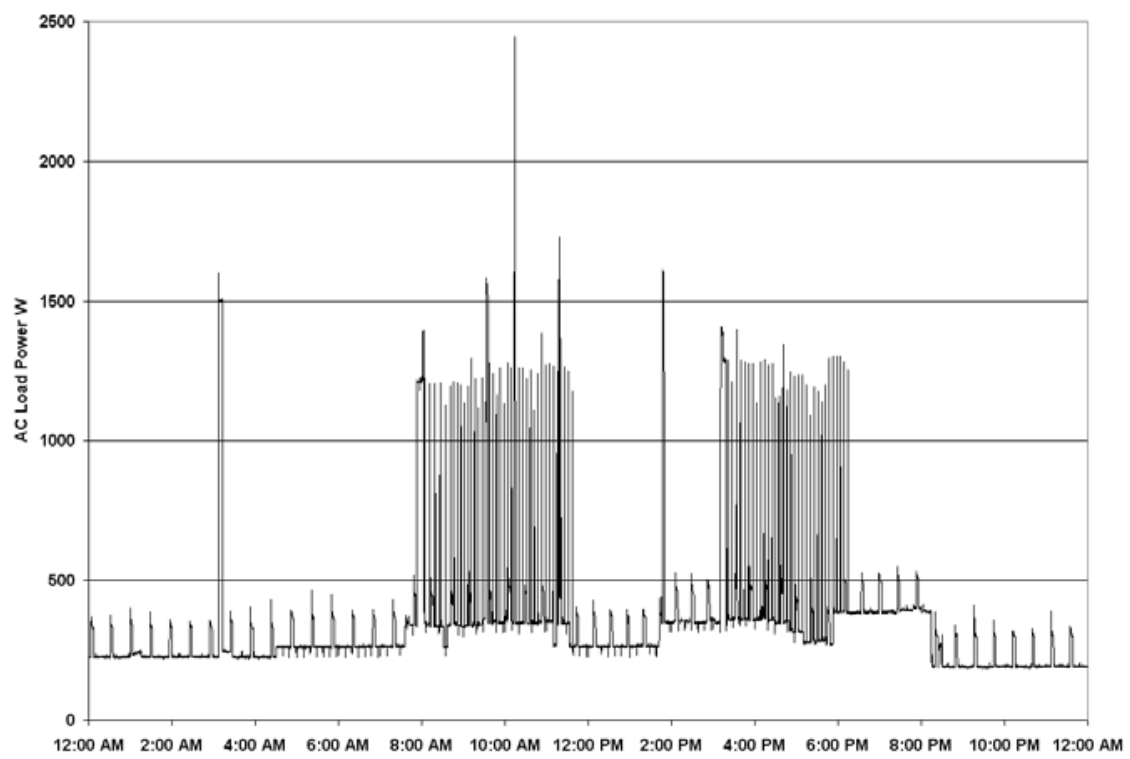

Figure 2.24: AC Load demand during one day.

\subsubsection{Performance of Overall Installation in Automatic Mode}

The complete or partial power system has operated in stand-alone mode since October $17^{\text {th }}$, 2007. Figure 2.25 shows the overall results of the system from October $17^{\text {th }}$ until December $24^{\text {th }}$, 2007. Details of these results are also shown in Figures 2.26 (11/15-11/17) and 2.27 (12/1912/24). These data are hourly averages of the power of each component, so it may also be read as kWh of energy for each hour. 

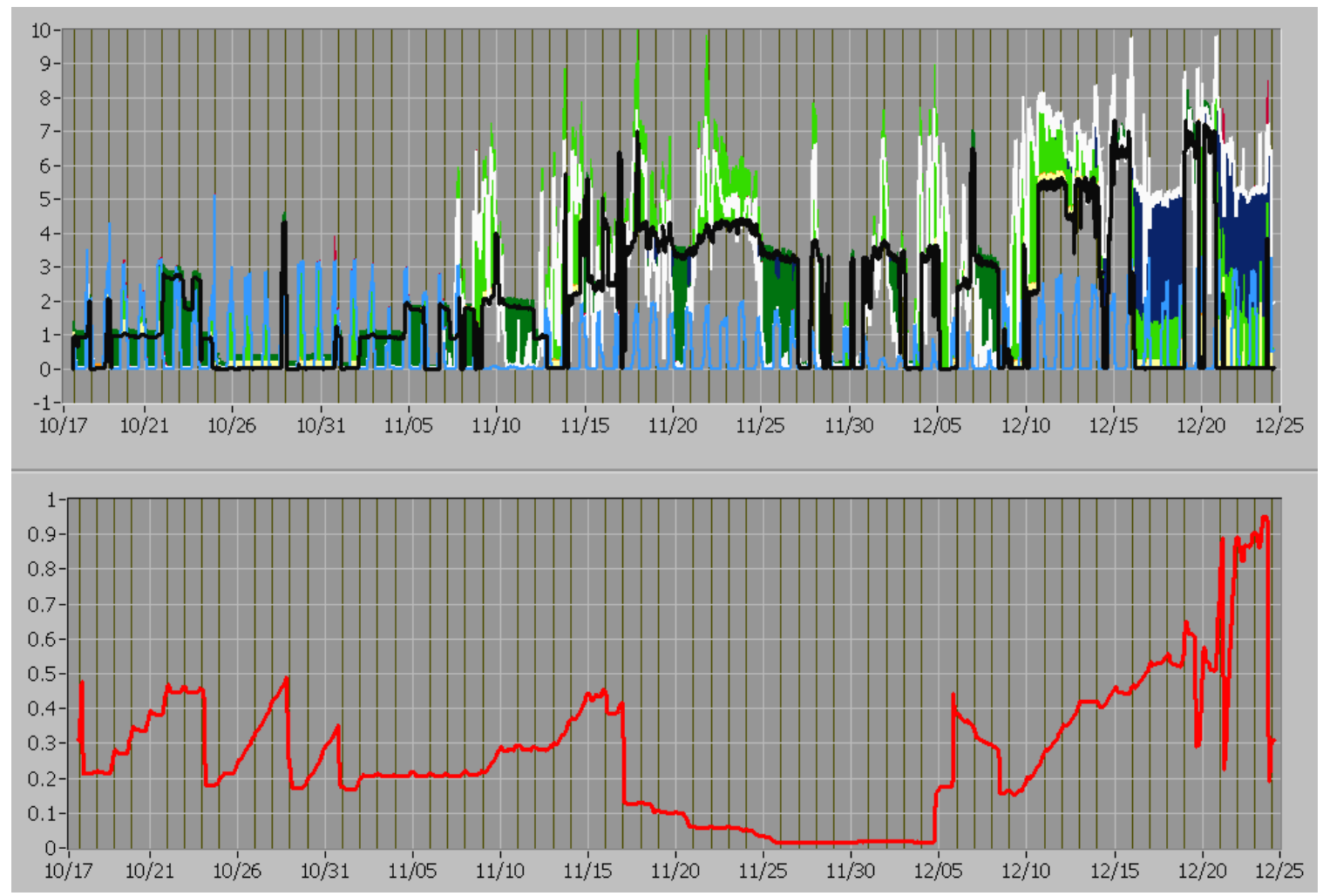

Figure 2.25: Hourly average power of all components and evolution of the state of charge of the hydrogen storage at the Kahua Ranch from October $17^{\text {th }}$ to December $24^{\text {th }}, 2007$.

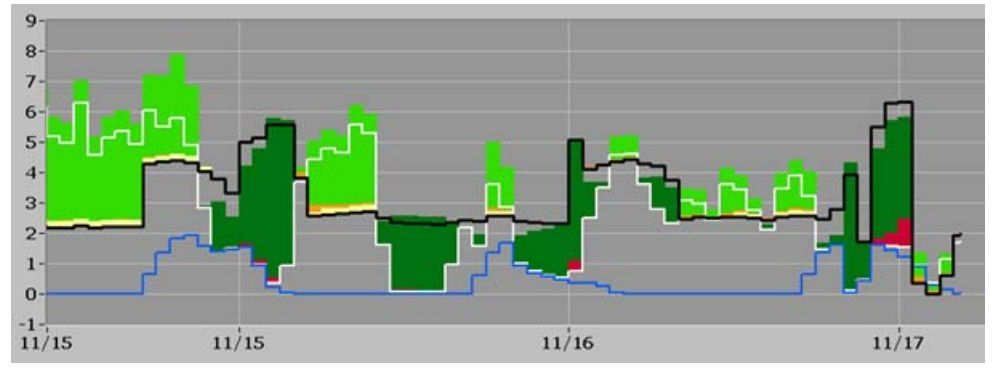

\begin{tabular}{|l|l|}
\hline & Load consumption \\
\hline & PV prod \\
\hline & WT Production (Added to PV prod) \\
\hline & Battery Discharge \\
\hline & Battery Charge \\
\hline & Electrolyzer consumption \\
\hline & FC Production \\
\hline & FC Battery Charge \\
\hline & AC Load consumption \\
\hline
\end{tabular}

Figure 2.26: Hourly average power of all components of the Kahua Ranch installation - detail from 11/15 to 11/17 - legend for graphs. 


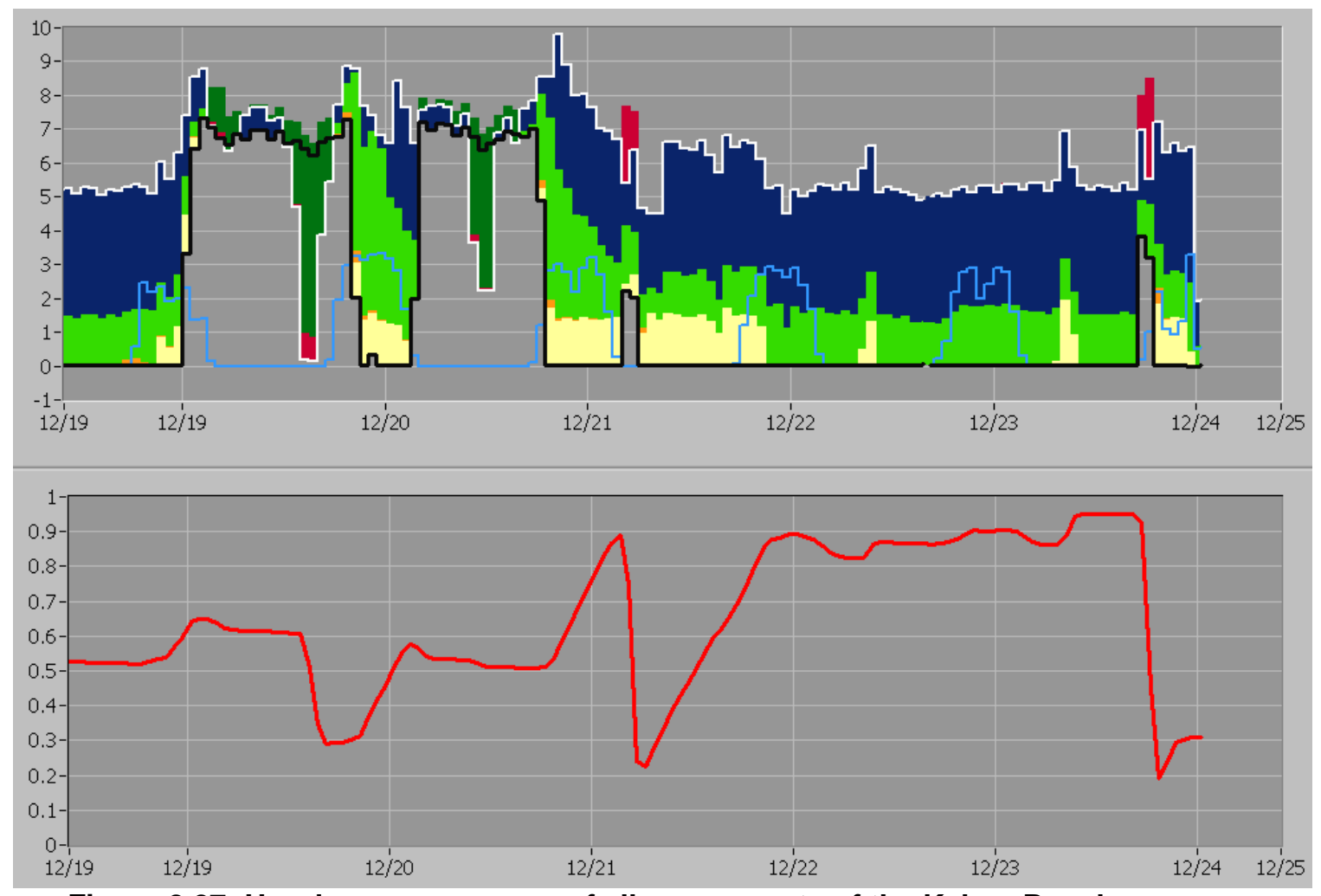

Figure 2.27: Hourly average power of all components of the Kahua Ranch installation and evolution of the state of charge of the hydrogen storage from December $19^{\text {th }}$ to December $24^{\text {th }}, 2007$.

During the first phase, the only renewable energy generator was the PV array (blue line). After November $9^{\text {th }}$ (white line), the wind turbine power was added to the PV power and this combination corresponded to the total primary (renewable) power of the installation. When the renewable power was higher than the load demand (black line), the excess of energy was sent to the battery for recharge (light green area) or to the electrolyzer (light yellow area). The electrolyzer power was almost invisible on Figure 2.26 because of the low stack performance of prototype \# 1, but it averaged 1 to $1.5 \mathrm{~kW}$ in Figure 2.27, with the new stack (prototype \# 2). The orange area corresponds to the power consumed by the FC system batteries. The last load appearing on December $14^{\text {th }}$ (dark blue area) was the DC power converted by the inverter to supply the AC load. In the case where the load demand was higher than the primary power, both the batteries (dark green area) and, if necessary, the FC system (dark red area) matched the load power.

When the electrolyzer (or FC system) runs, the energy content in the hydrogen storage increases (or decreases), as shown on the bottom part of Figures 2.25 and 2.27. The energy content or state of charge (SOC) of the hydrogen storage is a percentage of the maximum storable energy, i.e., 320 liters (volume used for this experiment) at 12 bars or $3.86 \mathrm{Nm}^{3}$, equivalent to $13.7 \mathrm{kWh}$ of hydrogen (HHV). The hydrogen storage usability range is between $15 \%$ and $100 \%$ of its maximum capacity, since the FC needs a minimum pressure of 30 psi to operate. During the first set of experiments, the SOC peaked at only $50 \%$ because of the electrolyzer maximum pressure (125 psi) and since only a portion of the storage cylinders was connected. 
Table 2.3 summarizes the energy production and consumption of each component for the 68 days of stand-alone operation. These results come from the hourly average data. Table 2.4 includes system efficiency calculated using the results of Table 2.1.

Table 2.3: Complete system operation results (68 days) - energy production and consumption of each component.

\begin{tabular}{|l|r|}
\hline Solar Energy $\mathrm{kWh} / \mathrm{m}^{2}$ & 298 \\
\hline Average Wind Speed mph & 16 \\
\hline $\begin{array}{l}\text { Wind energy received by WT kWh }\left(35 \mathrm{~m}^{2},\right. \\
\left.\text { air density } 1.07 \mathrm{~kg} / \mathrm{m}^{3}\right)\end{array}$ & 14,729 \\
\hline Total RE kWh & $\mathbf{2 6 , 6 4 9}$ \\
\hline PV production $\mathrm{kWh}$ & 915 \\
\hline WT production kWh (45 days) & 3,444 \\
\hline Total RE Generator Production $\mathbf{k W h}$ & $\mathbf{4 , 3 5 9}$ \\
\hline DC Load $\mathrm{kWh}$ & 3,210 \\
\hline AC Load $\mathrm{kWh}(11$ days) & 463 \\
\hline Total Load kWh & $\mathbf{3 , 6 7 3}$ \\
\hline EL Consumption $\mathrm{kWh}$ & 155 \\
\hline FC Production $\mathrm{kWh}$ & 18 \\
\hline Battery Charge $\mathrm{kWh}$ (including FC batteries) & 1,526 \\
\hline Battery Discharge $\mathrm{kWh}$ (including FC batteries) & 977 \\
\hline
\end{tabular}

Table 2.4: Efficiency of each component

(column 1: 68 days; column 2: last 6 days with new electrolyzer stack).

\begin{tabular}{|l|r|r|}
\hline Efficiency & $\begin{array}{c}\text { \% 68 } \\
\text { days }\end{array}$ & $\begin{array}{r}\text { \% Last } \\
\mathbf{6} \text { days }\end{array}$ \\
\hline PV $\left(40 \mathrm{~m}^{2}\right)$ & $8 \%$ & $11 \%$ \\
\hline WT $\left(35 \mathrm{~m}^{2}\right)$ & $23 \%$ & $23 \%$ \\
\hline Battery Dis/Charge & $63 \%$ & $22 \%$ \\
\hline Hydrogen Storage System & $12 \%$ & $17 \%$ \\
\hline System / RE & $\mathbf{8 5 \%}$ & $\mathbf{7 6 \%}$ \\
\hline System / Nat. Sources & $14 \%$ & $15 \%$ \\
\hline Energy directly to load & $61 \%$ & $70 \%$ \\
\hline Energy through batteries & $35 \%$ & $23 \%$ \\
\hline Energy through HSS & $4 \%$ & $7 \%$ \\
\hline
\end{tabular}


The $298 \mathrm{kWh} / \mathrm{m}^{2}$ solar radiation corresponded to $4.4 \mathrm{kWh} / \mathrm{m}^{2} /$ day. The average wind speed was $16 \mathrm{mph}(26 \mathrm{~km} / \mathrm{hr})$. The wind energy received by the $35 \mathrm{~m}^{2}$ wide wind turbine at 1000 meter elevation was calculated at $14,729 \mathrm{kWh}$ for the 45 days of the wind turbine operation. During this period, the WT electricity production was $3,444 \mathrm{kWh}$, corresponding to $23 \%$ efficiency. The PV array efficiency has been evaluated at $8 \%$. These average efficiencies are lower than the efficiency described before for each component. Indeed, the two-month average values took into account periods where the components were on the edge of their performances. For the PV, the low efficiency periods were when the MPPT controller limits the PV production to $60 \mathrm{~A}$, and when the two MPPT controllers were used in parallel. For the WT, when calculating the potential efficiency taking into account the average wind speed (16 mph), the WT should reach $45 \%$, which proves the highly unsteady wind speed at this location, with high-wind-speed periods and no-wind periods.

The load consisted of DC and AC loads, for a total load consumption of 3,673 kWh over 68 days. This demonstrated an overall system efficiency of $85 \%$ by dividing the total load (Table 2.3 , row 10 ) by the renewable energy generation production (Table 2.3 , row 7 ). When the total load was divided by the renewable resources (Table 2.3, row 4), including the solar radiation received by the PV area and the wind energy hitting the blades of the WT, the complete installation was $14 \%$ efficient, as this calculation took into account the efficiency of the renewable energy generators.

The two storage systems (the HSS and the battery system) have also been evaluated in operation in the complete installation. We evaluated the percentage of discharge/charge by dividing the output energy (discharge) by the input energy (charge). For the HSS, the discharge was the electricity produced by the FC unit and the charge was the electricity consumed by the electrolyzer. This percentage becomes the storage efficiency for the case where the state of charge (SOC) of the storage is the same at the beginning and the end of the time period. For the 10 -year-old battery system, including the FC batteries, the percentage discharge/charge was $64 \%$ for the overall experimentation period. Unfortunately, the SOC of the batteries was not available. For the HSS, this percentage was the efficiency of the storage, since the SOC of the hydrogen storage was the same at the beginning and the end of the experiment (see Figure 2.25). The HSS was $12 \%$ efficient for the overall period.

Although this is relatively low storage efficiency, the overall system efficiency is as high as $85 \%$ because all of the renewable production can be consumed or stored, thanks to the two types of storage. Moreover, $61 \%$ of the input power was directly consumed by the load, 35\% passed through the battery storage and only $4 \%$ was stored into hydrogen. As for the stored energy, $90 \%$ was stored by the batteries and $10 \%$ by the HSS. Figure 2.28 shows a graphic representation of the energy flows during the 68 days of stand-alone operation, using results from Table 2.4.

When taking into account only the last six days of operation (electrolyzer unit with final stack), the results for the power system were significantly different (see column 2 in Table 2.4). The RE generators had about the same efficiency, but the battery storage percentage of discharge/charge was $22 \%$, explained by the fact that the storage was mainly charged during this period, as shown on Figure 2.25 (light green area). During this period, the HSS was $17 \%$ efficient, thanks to better efficiency of the hydrogen generator. This efficiency has been evaluated for periods where the initial and final SOC of the hydrogen storage were the same. This efficiency of the HSS was in concordance with component efficiency described earlier: around $46 \%$ for the 
electrolyzer and between 35 and $40 \%$ for the FC system. Finally, the overall installation showed an efficiency of $76 \%$, with $70 \%$ of the renewable energy supplied directly to the load, $23 \%$ passing through the battery storage and 7\% converted into hydrogen before the FC supplies the load (Figure 2.29). During this period of the experiment, the batteries stored $76 \%$ of the total stored energy and $24 \%$ was stored in hydrogen.

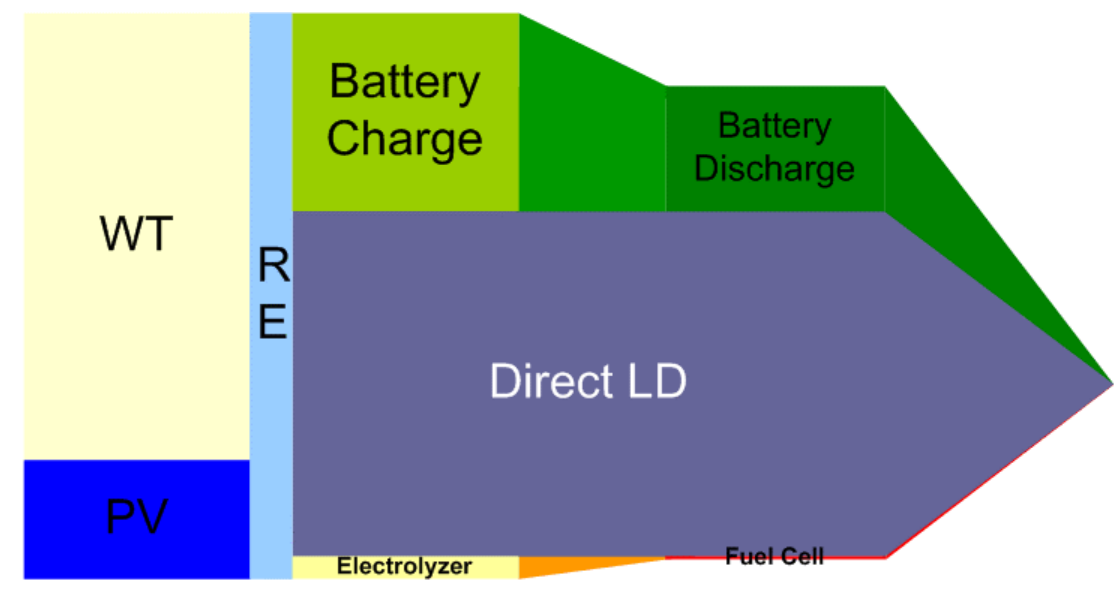

Figure 2.28: Energy flow representation during the 68 days of stand-alone operation.

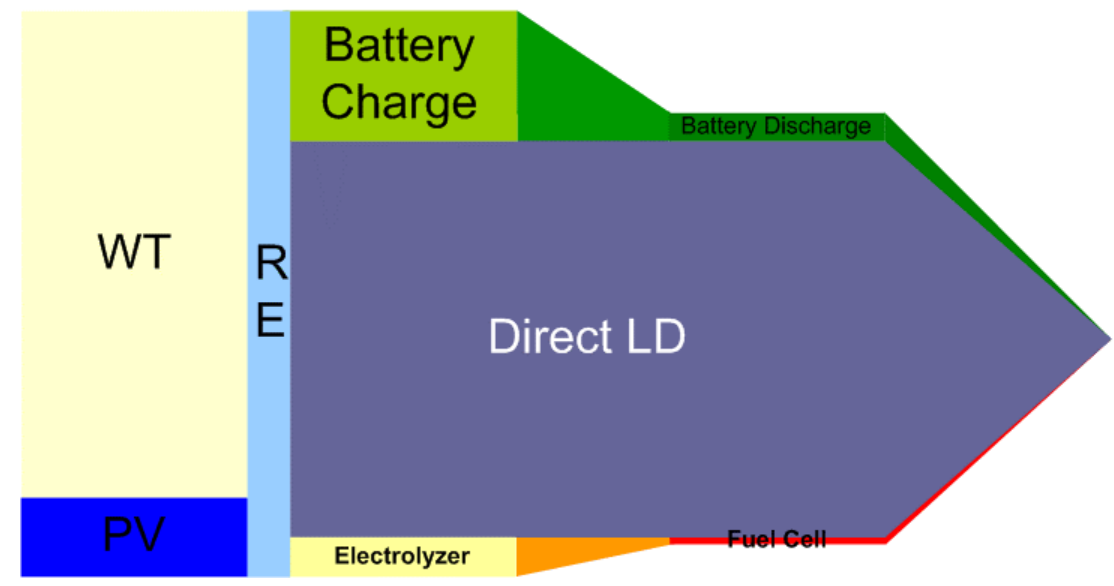

Figure 2.29: Energy flow representation during the last six days of stand-alone operation.

The performance of the overall installation is strongly dependant on the component efficiency, but also on the proportion directly sent to the load and the energy going through the different storage systems, as well as the initial and final state of charge of the storage systems. The experimental results are therefore not fully representative of a properly designed $\mathrm{RE}-\mathrm{H}_{2}$ power system, since the HSS was only partially used, and because of the large battery storage plus small hydrogen storage. 


\subsection{Conclusions and Discussion of Results}

\subsubsection{Conclusions on the Kahua Ranch Installation}

The Kahua Ranch $\mathrm{RE}-\mathrm{H}_{2}$ system has been successfully designed, installed and tested. It demonstrates the potential for the integration and operation of renewable energy sources and hydrogen technologies presently available commercially.

The necessary interface to control the overall system has been carefully designed to reach a safe and stand-alone operation. Experiments show that the interface is reliable and easy to use, allows remote control, and can be easily modified. It also proves that a simple control program is possible. Long-term operation would allow better tuning of the actual control parameters and could also prove the necessity for a more complex control program. This interface has been designed in order to be able to expand the installation for higher current, higher pressure and/or higher flow rates.

Experimental results allow the following evaluation of component performance in operation in the stand-alone power system.

$\checkmark$ The PV array was about 10\% efficient, thanks to the PV controller tracking for the maximum available power and the ability to store all excess RE and thus avoiding overcharging the batteries. Two MPPT controllers were planned for use with the $4.9 \mathrm{~kW}$ connected modules, but their conflicting parallel operation introduced harshly variable PV power. It is planned to solve this problem in further experiments under new funding.

$\checkmark$ The WT had an efficiency peak of $45 \%$, but over a very small range of operation. Its average efficiency was $23 \%$ over 45 days of operation. The regulator connected to the WT never has to reduce the available WT power, since the battery storage was never overcharged, thanks to the second energy storage system.

$\checkmark$ The batteries represent an important storage capacity. Operating in the complete installation, the batteries stored from $76 \%$ to $90 \%$ of the overall stored energy.

$\checkmark$ The electrolyzer reached $50.2 \%$ in efficiency in quasi steady-state operation. Integrated into the overall system, it was $4 \%$ less efficient due to the warm-up period and short time operation. This proved to be a good integration into the complete power system, thanks to its size and the HNEI-developed control strategy. The unit will require a better drying unit to reduce water content of the hydrogen.

$\checkmark$ The FC unit demonstrated an efficiency of over 38\% when producing more than $700 \mathrm{~W}$ in steady-state operation. When integrated into the complete power system, however, the FC unit, which is used as a complement to the battery storage to match the load, appeared to be oversized as well as having long and low-efficiency warm-up periods. This induced a lower operating efficiency of the FC unit in the complete installation of around $10 \%$ less than in steady state. This point will require more experiments to be more precise on the importance of the size and/or unit design.

$\checkmark$ The present performance of the hydrogen storage system in the stand-alone power system reached $17 \%$. A wide range of improvements exists, from the reduction of the parasitic auxiliary load consumption to an increase in stack performance. Further research should lead to better optimization of the electrochemical components in the overall system. In particular 
the recovery of the wasted heat produced by the two units (about $50 \%$ of unit loss is heat produced by the stack) would lead to a higher efficiency storage system.

The overall installation shows good performance thanks to the direct use of the RE power to supply the load as well as the possibility of using all excess output from the available RE sources. This efficiency is strongly dependent on the proportion of energy sent to the two types of storage.

The Kahua Ranch test facility offers the potential as a test bed for a wide range of experiments, as there are two types of load (DC \& AC) and the battery storage could be easily reduced to analyze the relationship between its size and system efficiency. Moreover, its expansion capacity would allow increasing the HSS energy and/or power, as well as testing other hydrogen technologies such as hydrogen compressors and internal combustion engines.

Finally, the recorded data can be used to develop or validate simulation of each component or of the whole power system. Using the recording data every $250 \mathrm{~ms}$, the transient behavior can be studied and simulated for each component and for the complete power system.

\subsubsection{Comparison of the HSS Performance in Steady-State and Stand-Alone Operation}

Although the two hydrogen storage systems studied in the early and later phases of the Hydrogen Power Park (HPP) are very different in terms of power, technology and type of operation, the experimental results are comparable.

By compiling the performance of the electrochemical components in steady-state operation and assuming a 100\% efficient gas storage, the performance of the HSS studied in the initial phase of the HPP can be evaluated. Supplied by the grid, the electrolyzer was always used at maximum power in order to recharge the hydrogen storage when empty. The gas storage actually supplies the different test stands of the HFCTF as well as the FC unit. The overall HSS efficiency was calculated using $51 \%$ for the efficiency of the $6 \mathrm{Nm}^{3} / \mathrm{hr}$ electrolyzer $\left(56 \%\right.$ for the $12 \mathrm{Nm}^{3} / \mathrm{hr}$ unit). That induced an overall HSS efficiency of between 19.4 and 21.4\% (21.3 and 23.5\%) for the $6 \mathrm{Nm}^{3} / \mathrm{hr}\left(12 \mathrm{Nm}^{3} / \mathrm{hr}\right)$ electrolyzer. These efficiencies depend on the FC power being between 14 and 100\% of its maximum power. Moreover, it is emphasized that these values are steady-state operation mode efficiency, meaning that these optimal efficiencies will be reached after two hours of operation. This kind of operating mode could be the case of grid connected or geothermal-plant connection, allowing long-term operation.

Results on overall system operation, recorded over 68 days of stand-alone operation, demonstrated an average efficiency of the Kahua Ranch HSS of $17 \%$.

The tested electrolyzers showed a consumption of about $7 \mathrm{kWh} / \mathrm{Nm}^{3}$ in steady-state operation, corresponding to the present state-of-the-art of these components, especially for the alkaline electrolyzer producing 200 bar hydrogen. The alkaline unit could reach higher efficiency in many ways: (1) higher stack performance, (2) lower auxiliary consumption, and (3) better gas efficiency. The PEM prototype electrolyzer requires more experimentation to localize potential improvement areas. A major advantage of the small PEM unit was the very short warm-up period, allowing good performance even when integrated into a power system. Indeed, the unit was only 4\% less efficient when operating in the Kahua Ranch installation.

The tests made on the $5 \mathrm{~kW} \mathrm{FC}$ unit showed that the unit had a fair efficiency (above $38 \% \mathrm{HHV}$ ) over most of its power range. Improvements on the stack performance and on auxiliary parasitic 
consumption are the main keys for higher unit efficiency. In operation in an intermittent RE power system, the unit was $10 \%$ to $15 \%$ less efficient.

These results prove that electrochemical components have to be carefully designed in order to reach higher efficiency. Steady-state performance should be optimized by reducing any loss in the stack and in the auxiliaries. High-efficiency auxiliaries as well as waste heat recovery could lead to much higher performances. In addition, warm-up periods should be shortened as much as possible when integrated into an RE power system.

\subsubsection{Advantages of Hydrogen Storage Systems}

Looking at the reported experimental results, there are significant technical and economic challenges for the production of hydrogen to store energy. Important improvements are necessary to reach better efficiency and lower costs; however, there are important and unique value-added advantages of the HSS that should be considered and evaluated:

$>$ Hydrogen is an environmentally friendly energy carrier:

When using hydrogen produced by an electrolyzer that is powered by a renewable energy source, the only by-product of a fuel cell or an internal combustion engine (ICE) is water, although a hydrogen ICE might produce low levels of NOx under some operating conditions. The water then returns to nature's cycle and can be split again into hydrogen.

$>$ Long-term seasonal storage:

Storing hydrogen gas allows long-term storage with almost no loss over time. The first experiments on renewable energy hydrogen systems in the nineties demonstrated the potential of using hydrogen for seasonal storage, to store from summer to winter, advantages only available when using pumped hydro or compressed air storage technologies.

$>$ Large-scale energy storage anywhere:

Hydrogen allows large-scale energy storage. There are few other options: batteries are not practical and too costly; pumped water systems and compressed air energy storage systems are only implementable in limited geographical areas.

$>$ Utilization of hydrogen for transportation:

This experiment demonstrated the use of hydrogen to support the use of intermittent renewable energy sources for firm power electrical applications. The hydrogen can also be used to supply other applications such as transportation.

$>$ Combined heat and power:

As identified earlier in this document, electrolyzers and fuel cells should have a design allowing for the capture and use of waste heat. In addition to much higher system efficiency, heat is an important by-product in some market niches, especially when supplying homes in remote areas, even in Hawaii.

$>$ Decoupling power production from energy storage:

Hydrogen storage allows for the independent sizing of energy and power contrary to battery storage (except for flow batteries). Each part of the HSS is independent of the others. Therefore, the electrolyzer is sized to match the available excess of energy or the required flow. The FC power is selected to match the load or the maximum required power demand. In addition, electrolyzers and fuel cells have a very wide range of power. Finally, the gas volume depends on the needs of the stored energy and on the efficiency 
of the FC unit, the ICE, or any other components converting hydrogen to the end-user energy requirement.

\section{$>$ High potential storage}

In addition to these advantages, the HSS has potentially other essential characteristics such as long lifetime (already proven for alkaline technologies), low maintenance requirement, and low disposal and recycling charges. Contrary to the older and more mature storage technologies, the HSS technology has a high potential for improvements in these fields.

\subsubsection{Hydrogen System Efficiency}

Previous studies have given results or predictions on efficiencies. The Finnish project NEMO in 1989 , reached an HSS efficiency of $28 \%$ in operation in a $1.3 \mathrm{~kW}$ stand-alone operation [8]. The German Oldenburg project in 1990 discussed reaching a 50\% efficient HSS in a $4.2 \mathrm{~kW}$ power system [9]. Both of these studies addressed alkaline technologies and the main technical paths were focused on reducing auxiliary system parasitic consumption. PEM technologies require simpler peripherals and eliminate the use of highly corrosive electrolyte, thus reducing auxiliary electrolyte management system power consumption. On the other hand, the PEM systems need to reach higher efficiency, longer lifetime, and lower cost. Our experimental efficiency results presented earlier are lower than the alkaline technologies, especially due to lower stack efficiency. Moreover, the tested components are pre-commercial units, a step further towards commercialized components compared to the laboratory components of the older projects.

\subsubsection{Renewable Energy Hydrogen Production Systems}

Although the hydrogen storage systems have demonstrated relatively low potential efficiency ( $28 \%$ to be compared to the 75 to $85 \%$ round-trip efficiency of batteries or pumped hydro storage solutions), the HSS advantages demonstrate good potential performance when integrated into RE power systems. Indeed, the long-term storage capacity makes possible a perfect sizing of the installation. By using most of the RE generator production, the performance of the $\mathrm{RE}-\mathrm{H}_{2}$ power systems reached an efficiency of $44 \%$ (Fraunhofer, [10]) or 54\% (PHOEBUS, [11]) with a potential efficiency of $65 \%$. Moreover, these results did not consider the possibility of utilizing heat generation. These performances are in the range of the RE-battery systems, being generally $30-40 \%$ efficient, due to the need of oversized RE generators [12].

Although it is necessary to resolve numerous technical challenges, hydrogen is definitely a very good storage solution for RE generators, especially in applications requiring long-term energy storage and heat generation. Development of hydrogen-fueled vehicles will increase the advantages of the HSS. Developers of hydrogen technology components are presently focusing on cost reduction and reliability improvement. The results presented in this report demonstrate that component efficiency is crucial, especially when an HSS is integrated into RE systems. 


\subsection{Products Developed and Technology Transfer Activities}

\subsubsection{Publications/Presentations}

1. S. Busquet, C.J, Mas, "Experimental Results and Analysis of an Alkaline Electrolyzer and Fuel Cell System," in preparation for the Journal of Power Sources.

2. The two-month operation results presented in sections 2.5.3.2 and 2.5.3.3 will be also published.

3. R. Rocheleau, M. Ewan, S.Q. Turn," Renewable Hydrogen: The Hawaii Hydrogen Power Park," $235^{\text {th }}$ American Chemical Society National Meeting \& Exposition, New Orleans, LA, April 6-10, 2008.

4. S. Busquet, M. Ewan, "Description and First Results of a Wind-PV Hydrogen System at Kahua Ranch on the Big Island of Hawaii," National Hydrogen Association Annual Conference, Sacramento, CA, March 30 - April 3, 2008.

5. M. Ewan, R. Rocheleau, "Hawaii Hydrogen Power Park - Keystone to Developing a Hydrogen Economy in Hawaii," National Hydrogen Association Annual Conference, Sacramento, CA, March 30 - April 3, 2008.

6. M. Ewan, "The Hawaii Hydrogen Power Park," two training workshops for the Friends of NELHA (FON) to support the FON daily public outreach program for Hawaii residents and tourists, Kailua-Kona, HI, December 21, 2006 and February 24, 2007.

7. M. Ewan. L. Duwall, "Alternative Transportation Options at Volcanoes National Park," Presentation to the Climate Friendly Parks Workshop, Volcanoes National Park, HI, 21 February, 2007.

8. M. Ewan, "Hydrogen Power Park - Hydrogen Technology Validation - Separating Fact from Fiction," HNEI Seminar Series, Honolulu, HI, December 5, 2006.

9. R. Rocheleau, M. Ewan, J. Huizingh, "Hawaii Fuel Cell Test Facility Design, Construction, Safety," NHA Fuel Cell Seminar Workshop, Honolulu, HI, November 13, 2006.

10. R. Rocheleau, Renewable Hydrogen in Hawaii, NHA "Renewables to Hydrogen" Forum, Albuquerque, NM, October 4, 2006.

11. R. Rocheleau, Renewable Energy Programs at the Hawaii Natural Energy Institute, ASCE Hawaii, Honolulu, HI, August 17, 2006.

12. R. Rocheleau, "Hawaii Hydrogen Center for Development and Deployment of Distributed Energy Systems," DOE Review Meeting, Washington, DC, May 2005.

13. R. Rocheleau and P. Takahashi, "The Story of Hydrogen and Fuel Cells in Hawaii," HNEI Seminar Series, Honolulu, HI, January 2005.

\subsubsection{Website}

A website displaying the state of the power system and the real-time experimental data was developed during the last phase of the Hydrogen Power Park, but this was an internal feature to permit remote control operation.

\subsubsection{Collaboration}

All the technical and economical data collected during the initial phase of the Hydrogen Power Park were shared with Sandia National Laboratories, which conducted modeling on Hydrogen 
Power Parks. This collaboration was materialized with an article written with Carl Mas from Sandia, in preparation for publication (see item 1. in Publications/Presentations above).

\subsection{Acknowledgements}

The Power Park has been funded by the US DOE and the State of Hawaii. Many people contributed to the realization of the Kahua Ranch power system: Luis Vega from PICHTR, Peter and Rolland Shackelford from Renewable Energy Services [13] for the initial system modification, and all the HNEI colleagues at the HFCTF. Finally, we wish to acknowledge the generous support of Monty Richards and all the Kahua Ranch staff for their involvement in the renewable energy development and aloha spirit.

\subsection{References}

[1] www.hydrogenics.com

[2] http://www.plugpower.com

[3] http://www.kahuaranch.com

[4] Www.pichtr.org

[5] Design and Construction of the PICHTR Renewable Hybrid Village Power Demonstration and Training Facility, J. B. Clarkson, P. R. Shackelford, L. A. Vega, Solar Engineering, Vol. G01050, pp. 421-431, 1997

[6] Operation of a $360 \mathrm{kWh} /$ day Hybrid Village Power System, J. B. Clarkson, P. R. Shackelford, L. A. Vega, Solar 98: Renewable Energy For The Americas, Albuquerque, New Mexico, June 1998

[7] http://www.electrichydrogen.com

[8] J.P. Vanhanen, "Operating experiences on a self-sufficient solar- $\mathrm{H}_{2}-\mathrm{FC}$ system," Proceedings of the $2^{\text {nd }}$ Nordic Symposium on Hydrogen and Fuel cells for Energy Storage, pp. 46-54, Helsinki, Finland,1995.

[9] A. Haas \& al., "Hydrogen energy storage for an autonomous renewable energy system Analysis of experimental results," Proceedings of the ISES 1991 Solar World Congress, pp. 723-728, Denver, Colorado, 1991.

[10] A. Goetzberger \& al., "The PV/Hydrogen/Oxygen - system of the self-sufficient solar house Freiburg," IEEE, pp. 1152-1158, 1993.

[11] C. Meurer \& al., "PHOEBUS - An autonomous supply system with renewable energy: six years of operational experience and advanced concepts," Solar Energy, Vol.67, N 1-3, pp. 131-138, 1999.

[12] D. Mayer, M. Heidenreich, "Performance analysis of stand alone PV systems from a rational use of energy point of view," Proceeding of the $16^{\text {th }}$ European Photovoltaic Solar Energy Conference, Glasgow, UK, May 2000, Poster VD2.28.

[13] http://www.renewablenergy.com 
This page is intentional blank 


\section{Task 2 - Hydrogen Fuel Purity Assessment}

\subsection{Goals and Objectives}

- Evaluate the effects of trace level hydrogen fuel contaminants on the performance of PEM fuel cells.

- Develop a test plan including fuel cell and component diagnostics, with input from standards-developing organizations (SDOs) and industry, to characterize effects of contaminants on fuel cell performance and to provide guidance for future efforts.

- Collect and disseminate non-proprietary pre-commercial data for use by SDOs.

\subsection{Accomplishments and Comparison with Goals and Objectives}

The Hawaii Fuel Cell Test Facility (HFCTF), developed by the Hawaii Natural Energy Institute (HNEI) in partnership with the Hawaiian Electric Company (HECO) and UTC Fuel Cells, and with funding from the Office of Naval Research (ONR), opened for operation in April 2003. Since that time, the facility has been augmented and modified to permit fuel cell testing and analysis, using trace levels of contaminants in the hydrogen fuel. A test program was completed and the resultant data was used to evaluate the effects of these contaminants on PEM fuel cell performance. HNEI also developed a fitting strategy whereby fuel cell performance decay resulting from fuel impurities can be accurately calculated.

HNEI developed a test plan with inputs from the DOE Hydrogen Quality Working Group and with assistance from the US Fuel Cell Council (USFCC), Ballard Power Systems (BPS), General Motors (GM), and UTC Fuel Cell Systems. This plan was used to guide the HNEI test program mentioned above, and will serve as a guide for future efforts.

Since December 2003, HNEI personnel have been participating in the SAE Hydrogen Fuel Purity Working Group, with the DOE Hydrogen Codes and Standards Coordinating Committee on Fuels Purity Specifications, and more recently with the North America Fuel Quality Team. Under this program, HNEI is collecting pre-commercial, nonproprietary data on the effect of trace contaminants on fuel cell performance and durability. In addition, we worked closely with the North America Fuel Quality Team to finalize impurity test protocols for use by various test laboratories.

\subsection{Summary of Project Activities}

\subsubsection{Test Plan}

HNEI gathered suggestions from the various fuel cell industry organizations (USFCC, BPS, GM, and UTC Fuel Cell Systems) in preparing a draft test plan, including fuel cell and component diagnostics, aimed at characterizing effects of fuel contaminants on fuel cell performance. This draft was then further refined with inputs from SDOs, and the final draft test plan was submitted for review to the DOE Hydrogen Quality Working Group. Based on final comments received, the plan was finalized and then used as the basis for the HNEI testing program.

\subsubsection{Hardware and Test Equipment Acquisition}

Fuel Cell Test Stations

Initial test work was accomplished using one of the existing full-scale test stations at the HFCTF, modified for use with small-scale fuel cells. To achieve the accuracy required in this test program, 
we acquired two Greenlight Power Technologies (GLP) FCATS G50 test stations, specifically designed for testing small-scale fuel cells. After operation of the stations for some time, modifications were made to the gas sampling lines for each. The modifications gave multiplexing capability, allowing gas analysis at the inlet and outlet of both electrodes. Performance of these new GLP test stations was verified by testing calibrated membrane electrode assemblies (MEAs) supplied by original equipment manufacturers (OEMs). The resultant measurements were in agreement with the OEM measured values. These test units operated quite well, except for measurement of impedance and effects of refilling the anode humidifier.

To solve the impedance measurement difficulty, the GLP impedance system was replaced with a milli-ohmmeter, capable of $1 \mathrm{kHz}$ resistance measurement. A frequency response analyzer (FRA, Solartron 1260) and two Low-Noise-Amplifiers were employed to verify the ability of these - test stands to perform AC impedance spectroscopy. The experiments were performed by controlling the cell current and its perturbation using the external input of the electrical load via FRA signal. The determined high-frequency resistance values agreed with the $1 \mathrm{kHz}$ milli-ohmmeter resistance measurement of the test station within the expected level. We found that AC impedance spectroscopy performed during life test experiments requires the ability to superimpose the perturbation signal onto the controlled cell current. Solutions for this problem were obtained after discussions with the suppliers of the test station and the electrical load.

Early tests showed that voltage spikes were noted immediately following the refilling of the anode humidifier. Evidently, this filling operation introduced oxygen into the system and this problem was solved by installing oxygen filters. Since the humidifiers in the GLP test stations were generally much better than those in the HFCTF full-scale stations, this fact needed to be taken into account in interpreting test results.

Gas Analysis

We purchased a Varian gas analyzer with specifications including the ability to measure $\mathrm{CO}$ and $\mathrm{CO}_{2}$ concentrations down to $0.1 \mathrm{ppm}$. Initial testing of this equipment indicated a failure to meet the $\mathrm{CO}$ measurement specification. With subsequent modification, the analyzer was able to meet the required $100 \mathrm{ppb}$ detection limit for $\mathrm{CO}$. As the test program progressed, we began to optimize the gas sampling rate with respect to impact on fuel cell performance. This involved using specific purge timing, purge flow rates, and flow rates for filling the sample loops. We also purchased a new set of calibration standards to yield the highest possible accuracy during analysis of $\mathrm{CO}$ and $\mathrm{CO}_{2}$ impurity testing.

Fuel Cell Test Units

Small-scale fuel cells $\left(50 \mathrm{~cm}^{2}\right)$ were supplied by GM for testing in our program. In addition, we purchased MEAs for testing from Gore Fuel Cell Technologies (Gore), Johnson Matthey Inc., and Ion Power.

\subsubsection{Test Results}

Benzene and Toluene Tests

Independent tests with $20 \mathrm{ppm}$ of benzene and toluene in the hydrogen were conducted for 100hour periods. For the benzene tests, no detectable decay in the fuel cell performance was noted. For the toluene tests, there was also no detectable decay, but methylcyclohexane was measured in the outlet stream. Evidently, there is up to $90 \%$ conversion of the toluene to methylcyclohexane as 
it flows through the fuel cell. The possible impact of this methylcyclohexane on fuel cell performance will have to be explored in longer-term testing to be conducted in the future.

It should be noted that the $20 \mathrm{ppm}$ level of benzene used in these tests is 60 times the level proposed for total hydrocarbons in hydrogen fuel for commercial PEM fuel cell vehicles ${ }^{1}$. The test results reported here suggest that the threshold specifications for benzene and toluene could be increased.

\section{Tests with the GM Hardware}

Whereas the preliminary test with a GM unit showed unexpected degradation, subsequent tests yielded an acceptable baseline. These were 100-hour tests with $7 \mathrm{ppm} \mathrm{CO}$ in the hydrogen and the result was $>200 \mathrm{mV}$ decay. These results yielded probable causes of the performance decay and the magnitude of the decay rate. This information formed the beginning of an HNEI-developed fitting strategy for permitting accurate calculation of performance decay caused by fuel impurity exposure.

One feature that was noted during these tests was the high level of $\mathrm{CO}_{2}$ measured in the exhaust stream. A possible interpretation put forward at that time was that perhaps $35 \%$ of the $\mathrm{CO}$ was being converted into $\mathrm{CO}_{2}$. This issue of unexpectedly high levels of $\mathrm{CO}_{2}$ in the exhaust stream shows up again in other test result sections.

\section{Tests with Gore MEAs}

During preliminary tests with these units, we noted that $\mathrm{CO}_{2}$ seemed to diffuse from the cathode to the anode (giving misleading gas analysis measurements) and we suspected that the $\mathrm{CO}_{2}$ level in the incoming air needed to be reduced. For this reason, we modified the air supply system to decrease the $\mathrm{CO}_{2}$ concentration in the air delivered to the fuel cell. Further infrastructure modifications, along with gas analysis improvements, appeared to allow full closure of the carbon balance.

Subsequent testing involved 100-hour tests with low-level CO contamination (1 ppm) in the hydrogen feed to the anode at 60,70 , and $80^{\circ} \mathrm{C}$. When using neat hydrogen, cell temperature had little effect on cell performance or daily decay; higher cell operating temperature resulted in less degradation (overpotential) at all current densities; and, for a given test condition, overpotential increased with current density. It should also be noted that all cells achieved their new steady-state (decayed) performance with less than 30 hours exposure to CO. Steady-state cell performance after introduction of a contaminant was achieved most quickly at low operating temperatures and high $\mathrm{CO}$ concentrations.

Potential changes (i.e., changes in operating current) after reaching steady-state under contaminated conditions resulted in significant but temporary increases in the concentration of $\mathrm{CO}_{2}$ in the outlet fuel stream. While we believe that $\mathrm{O}_{2}$ crossover is a significant contributor to the conversion of $\mathrm{CO}$ to $\mathrm{CO}_{2}$ under steady-state conditions, the amount of $\mathrm{CO}_{2}$ released during this transient is consistent with release and subsequent oxidation of $\mathrm{CO}$ from the catalyst. Additional experiments were conducted to further explore this issue (see the Specialized Tests section below.

Tests with Johnson Matthey Inc. (JMI) and Ion Power MEAs

Both brands of MEAs contain electrodes with $50 \% \mathrm{Pt} / \mathrm{C}$ catalyst and $0.4 / 0.4 \mathrm{mg} \mathrm{Pt} / \mathrm{cm}^{2}$ standard loadings. The JMI MEA was a five-layer MEA, i.e., one bonded unit with gas diffusion layers

${ }^{1}$ SAE J2719 Draft, Surface Vehicle Information Report 06/2005 
(GDLs), catalyst layers, and an electrolyte membrane. The Ion Power MEA consisted of two half-cells bonded together to complete a single MEA. Each half-cell was made of a catalyst layer bonded to a $12.5 \mu \mathrm{m}$ thick Nafion membrane. The gas diffusion media were pressed on the MEA during fuel cell assembly. Interfacial contacts rely on compression only.

When operated at standard humidification conditions of $100 / 50 \% \mathrm{RH}$ on the anode/cathode, the JMI MEA showed strong performance fluctuations at a current density of $0.2 \mathrm{~A} / \mathrm{cm}^{2}$. These fluctuations were attributed to water management of the JMI five-layer MEA. In contrast, the performance of the Ion Power MEA, which was operated using Sigracet 25BC GDL material, showed no indication of performance fluctuations at current densities of $0.2,0.6$, and $1.0 \mathrm{~A} / \mathrm{cm}^{2}$. In addition, the recorded high fuel-cell performance was comparable to the previously tested Gore MEA. Due to the performance, the short production lead times, the low cost and the high responsiveness of the company, the Ion Power MEAs were selected as standard MEAs for fuels impurity testing from the point forward.

Testing with the Ion Power MEAs included operation with two different flow-field designs. The two designs compared were: (i) a $50 \mathrm{~cm}^{2}$ single serpentine flow-field designed and built at HNEI, and (ii) a $50 \mathrm{~cm}^{2}$ double/triple serpentine flow-field as received from GM. The double/triple serpentine flow-field outperformed the in-house design at our challenging standard operating conditions of anode/cathode: stoich $2 / 2$, pressure $7 / 7 \mathrm{psig}$, gas $\mathrm{H}_{2} /$ Air, relative humidity $100 / 50 \%$, cell temperature $80{ }^{\circ} \mathrm{C}$. Consequently, the double/triple serpentine flow-field was confirmed as the standard flow-field for future small-scale fuel cell experiments.

Baseline impurity and polarization experiments were conducted at standard conditions (see above), at $60{ }^{\circ} \mathrm{C}$, and at decreased anode-side relative humidity of $80 / 50 \%$. Initial polarization experiments at $60{ }^{\circ} \mathrm{C}$ showed slightly decreased activation losses over the entire current range and a strong increase of concentration and mass transport losses with increasing current density. No significant performance variation was observed with initial polarization experiments at lower anode humidification.

At standard operating conditions, 200-hour baselines showed a range of performance degradations of $50-240 \mu \mathrm{V} / \mathrm{hr}$. At $60{ }^{\circ} \mathrm{C}$, cell degradation of a baseline experiment was at $125 \mathrm{~V} / \mathrm{hr}$, or within the standard degradation range, while at lower anode humidification stronger cell degradation of up to $644 . \mu \mathrm{V} / \mathrm{hr}$ was observed during the baseline experiment. Impurity experiments were performed at the same three operating conditions, exposing the cell to 1,2 , and $10 \mathrm{ppm} \mathrm{CO}$. Performance decay was shown to be more severe and faster at the decreased temperature, while at lower anode humidification performance decay appeared almost unchanged with respect to standard conditions. The method to extrapolate baseline performance employed, which allows us to selectively compute the overpotential change caused by exposure to fuel impurities, is described in the following section. The testing phase of this method was successfully completed and the method found valuable for analysis of the produced impurity data. The testing and analysis of the selected matrix elements under this subtask is now completed.

\section{Specialized Tests and Development of the HNEI Fitting Strategy}

Further tests were conducted using Gore MEAs to explore the in-situ production of $\mathrm{CO}_{2}$. Included in these tests were hydrogen pump experiments designed to separate chemical and electrochemical reactions contributing to the $\mathrm{CO}_{2}$ generation. 
Hydrogen pump and CO contaminant experiments were performed using Gore MEAs, exposing the fuel cell to 2 and $20 \mathrm{ppm} \mathrm{CO}$ (see Figures 2.1 and 2.2 for results). At $20 \mathrm{ppm}$ the increase in anode overpotential during constant current operation was identical for air or oxygen on the cathode, but was observed to be higher during the hydrogen pump experiments. At $2 \mathrm{ppm} \mathrm{CO}$, the greatest increase in potential was again seen during the hydrogen pump experiments. This was followed by air on the anode with the least increase in anode overpotential measured when pure oxygen was used on the cathode. We attribute this effect to oxygen permeating the membrane. We postulate that increasing the oxygen concentration at the cathode increases the oxygen permeation from cathode to anode. The resulting elevated $\mathrm{O}_{2}$ concentration at the anodecatalyst layer enhanced the anode performance by supporting electro-oxidation of $\mathrm{CO}$ to $\mathrm{CO}_{2}$ at poisoned catalyst sites. At higher $\mathrm{CO}$ levels, i.e., $20 \mathrm{ppm} \mathrm{CO}$, re-adsorption of $\mathrm{CO}$ on the $\mathrm{Pt}$ catalyst occurred too fast for the effect to be identified.

While the measurements yielded insights into the processes that dominate the steady-state poisoning conditions of a fuel cell, further analysis and experiments will be needed to fully understand the mechanisms involved.

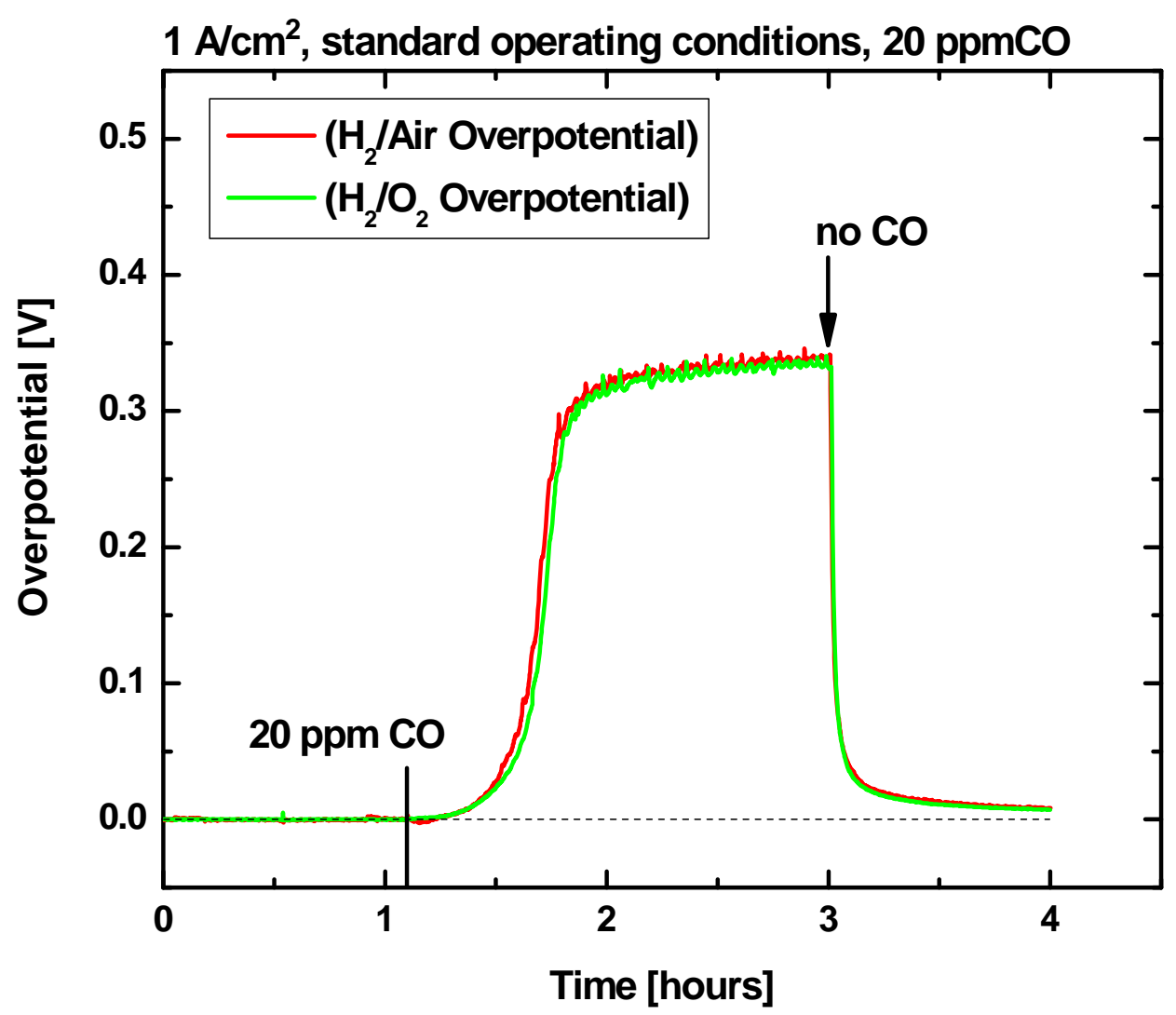

Figure 2.1: Test results with Gore MEA at $20 \mathrm{ppm} \mathrm{CO}$ 


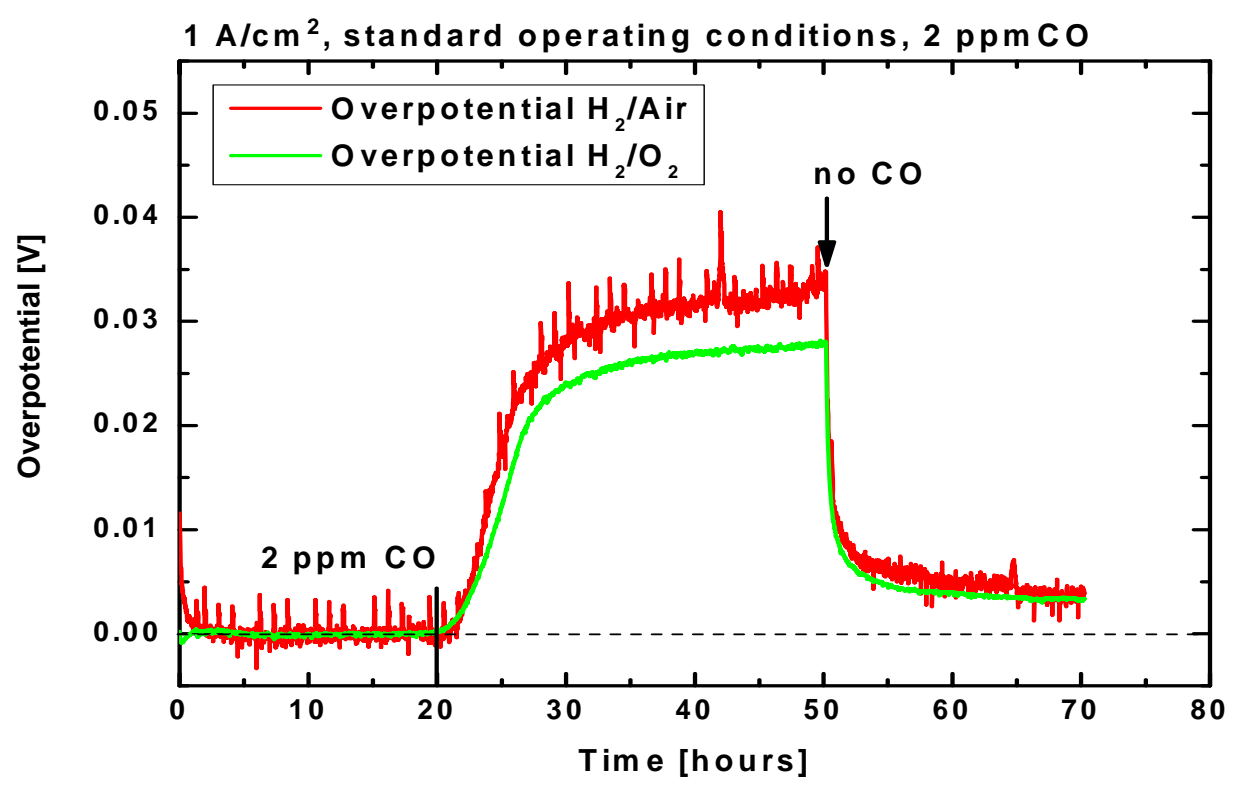

Figure 2.2: Test results with Gore MEA at 2 ppm CO

The analysis of the measurements described above, were based on a novel method developed during this period. This method employs a fitting strategy to either (i) an entire baseline or (ii) the fuel cell response prior to exposure to the impurity. Fits are performed either in linear or non-linear fashion, using criteria that follow a strict and reproducible procedure. Utilization of this fitting strategy allows accurate prediction of cell performance for test times approximately three times the fitting period. This permits accurate calculation of the overpotential increase caused by exposure to fuel impurities.

\subsection{Conclusions}

A test plan was developed for characterizing the effects of contaminants on fuel cell performance and as a guide for future testing research efforts. The plan included fuel cell and component diagnostics. Development of this plan was assisted by inputs from SDOs, industry representatives, and the DOE Hydrogen Quality Working Group.

A detailed testing program based on the above test plan was successfully carried out at the Hawaii Fuel Cell Test Facility. The effects of benzene and toluene contamination were characterized. Based on test results, Ion Power MEAs were selected as the standard MEAs to use for future fuels purity testing. Also based on test results, the double/triple serpentine flow field, as received from GM, was selected as the standard flow field for future small-scale fuel cell experiments.

Based on the accumulation of test results throughout the entire test program, HNEI developed a novel method for the accurate calculation of fuel cell overpotential increase resulting from fuel impurity exposure. This method was successfully used in data analysis of the measurements taken during $\mathrm{CO}$ contamination testing of Gore MEAs.

Our testing program placed heavy emphasis on short-term testing, since this was an area of interest in DOE and the fuel cell industry. Due to the interest and demand for short-term testing of fuel 
cells and the limited funding under this program, longer-term testing that had been planned was postponed and will be implemented under future testing.

\subsection{Products Developed and Technology Transfer Activities}

\subsubsection{Publications/Presentations}

1. G. Bender, K. Bethune, D. Wheeler, R. Rocheleau, "Impurity Test Protocol," 8th meeting of ISO/TC 197/ WG 12 in Honolulu, HI, November 9, 2006.

2. T. Thampan, R. Rocheleau, K. Bethune, D. Wheeler, "Effect of Trace Contaminants on PEM Fuel Cell Performance," Fall Meeting of the Materials Research Society Boston, MA, November-December 2005.

3. T. Thampan, R. Rocheleau, K. Bethune, D. Wheeler, "Effect of Trace Contaminants on PEM Fuel Cell Performance,” 2005 Fuel Cell Seminar Palm Springs, CA, November 2005.

4. T. Thampan, R. Rocheleau, K. Bethune, and D. Wheeler, Proceedings - MRS 2005 Fall Meeting, Boston MA, Generation, Storage and Fuel Cells, Mater. Res. Soc. Symp. Proc. \#0885A01-05.

5. R. Rocheleau, Hydrogen Fuel Contaminant Tests: Status Report. Presented to the DOE Hydrogen Fuel Quality Working Group, Washington, DC, March 2005.

\subsubsection{Collaborations}

HNEI worked closely with the North America Fuel Quality Team to finalize impurity test protocols for use by various test laboratories. We also collaborated with this Team to identify operating parameters, materials and hardware for continuing the fuel quality work.

HNEI hosted the $8^{\text {th }}$ meeting of ISO/TC 197/WG 12 (hydrogen fuel quality) on November $9 \& 10$, 2006 in Honolulu, HI. This meeting was arranged by the National Hydrogen and Fuel Cells Codes and Standards Coordinating Committee. During this meeting we presented the finalized and distributed version of a fuel impurity testing protocol using the previously reported $1.75 \mathrm{ppm} \mathrm{CO}$ data set as an example. We also provided tours of our HFCTF for attendees of this meeting and the meeting of the Fuel Cell Seminar held during the following week, on November 13-17, 2006.

HNEI is continuing fuel impurity testing work at the Hawaii Fuel Cell Test Facility in collaboration with the Naval Research Laboratory through funding from the Office of Naval Research. 


\section{This page is intentional blank}




\section{Task 3 - Renewable Hydrogen Production}

\subsection{Subtask 3A - Electronic Materials for High-Efficiency Photoelectro- chemical Hydrogen Production}

\subsubsection{Goals and Objectives}

- Develop a robust multisource evaporation process for deposition of high-efficiency CIGS onto photoelectrochemical (PEC)-compatible substrates.

- Characterize the optical, electronic and PEC properties of the high-efficiency copperindium-gallium-diselenide (CIGS) materials. Design 4-terminal devices incorporating CIGS and hydrogenated-amorphous-silicon (a-Si:H) materials for high solar conversion efficiency.

- Demonstrate an operational 4-terminal device with solar efficiency greater than $15 \%$.

- Develop preliminary designs for integrating 4-terminal devices into high-efficiency PEC hydrogen production systems.

\subsubsection{Accomplishments and Comparison with Goals and Objectives}

The desired robust CIGS evaporation process called for was successfully developed within HNEI's Thin Films Laboratory. The process was used in production of a number of high-efficiency CIGS devices suitable for PEC hydrogen production, which were appropriately characterized under simulated solar illumination. Using these CIGS devices, a series of 4-terminal tandem devices were designed, based on optical modeling results, for high solar conversion efficiency. Testing of such devices, produced within the time and expenditure limits of this task, resulted in efficiency values slightly lower than the greater-than-15\% target value established as an objective for this study. There remain, however, untested improvements that have been identified that appear to have potential for yielding higher efficiency values.

Three individual preliminary designs for the integration of 4-terminal devices into PEC hydrogen production systems were presented. From these designs, the most appropriate mechanism for integration of prototype devices was selected.

\subsubsection{Summary of Project Activities}

\subsubsection{Deposition Process}

In our HNEI Thin Films Laboratory, we originally had three operating systems with application for PEC hydrogen production work. These included the: 1) CIGS Evaporation System (five independently-controlled sources for producing uniform films over a 10 x $10 \mathrm{~cm}$ substrate area), 2) Sputtering Deposition System (3-gun co-sputtering), and 3) Metal Thermal Evaporation System (4-source thermal evaporator). During the course of this task, equipment and procedural modifications were made to yield a more robust multisource evaporation process for deposition of CIGS films onto substrates for use in PEC devices.

Overall modifications included acquisition of equipment (new sputter system, pyrometer and thermocouples), process control changes, and an upgrade in the data acquisition system. The new sputter system has capability for large-area deposition of $\mathrm{Mo}, \mathrm{ZnO}$, and indium tin oxide (TIO). The pyrometer, along with infrared thermocouples and modified thermocouple placement, was instrumental in obtaining better end-point detection during the deposition process. Data 
acquisition was upgraded in order to be able to deal with the shorter time scale necessary for the upgrading from the 2-stage to the 3-stage CIGS co-evaporation process. The data acquisition upgrade, together with the thermocouple improvements, made it possible to successfully establish the 3-stage CIGS co-evaporation process. Specialized processing controls were developed as needed for production of a-Si/CIGS devices.

\subsubsection{Modeling Efforts}

We established a subcontract with MVSystems Inc.and, as one of the subcontracted tasks, they provided an optical model for our use in developing the a-Si/CIGS 4-terminal device. This model was useful in calculating photocurrents and efficiencies of devices in the 4-terminal configuration. It also helped in indicating the potential efficiency gains of an a-Si/CIGS device over a stand-alone CIGS one. After this model was refined, it indicated a possible $1.4 \%$ efficiency improvement for the a-Si/CIGS over the stand-alone CIGS.

\subsubsection{Test Results}

Improved 2-Stage CIGS Deposition Process

With the higher quality of thermocouple readings achieved with equipment modifications, we saw refined end-point detection and better copper effusion. After the improvements for this process were completed, we produced several runs of high-performance solar cell devices on glass and $\mathrm{Ti}$ foil. Test results showed efficiencies ranging up to 13.3 and $13.8 \%$. Some of the produced CIGS devices were sent to NREL for testing and certification. One of these gave a certified value of $14.1 \%$ efficiency which was the highest value obtained to that point for a CIGS device from the HNEI Thin Films Laboratory.

The New 3-Stage CIGS Deposition Process

To improve the robustness of the CIGS evaporation procedure, we adopted an industry standard "3-stage" process, which was adapted for the HNEI co-evaporation system. The specific recipe for this deposition process was developed and improved over the course of the project. Ultimately, we achieved repeatable performance results for CIGS devices produced by the 3-stage process, and the initial results were comparable to those from 2-stage deposition devices (about 12\% efficiency).

Further refinement of the 3-stage CIGS solar cell processing developed under this project has resulted in the fabrication of CIGS photovoltaic devices with $15.3 \%$ conversion efficiency (glass/Mo substrates supplied by the University of Toledo). This value is now the highest efficiency for any solar cell produced at HNEI's Thin Films Laboratory.

\section{Development of Elements of the a-Si/CIGS Device}

One element in the design for production of the a-Si/CIGS device is deposition of silicon nitride (SiNx). One concern was the possible effect of this deposition on performance. Fortunately, tests conducted on deposited $\mathrm{SiNx}$ revealed that there was no degradation of performance.

Another element is the a-Si top cell for the overall device. Efforts were carried out to achieve improvements in this cell and a run of improved a-Si cells showed higher open-circuit voltage ( $0.96 \mathrm{~V}$ compared to $0.90 \mathrm{~V}$ earlier). The basis for the increased $\mathrm{V}_{\mathrm{OC}}$ is the modified intrinsic amorphous silicon layer with higher bandgap (up to $1.98 \mathrm{eV}$ ) due to the higher hydrogen dilution during vapor-deposition growth of the material. 


\section{Complete a-Si/CIGS Device}

Development of the fully integrated device was carried out in stages, with testing of initial devices yielding information useful for possible modifications needed to improve performance. Unfortunately, whereas several modification schemes resulted in improved performance for the 4terminal a-Si/CIGS device, the last tests conducted still yielded efficiency results lower than for the stand-alone CIGS device (up to $8.2 \%$ versus up to $10.7 \%$ ). Further improvements were thought possible, but efforts at this point were addressed to issues of integration of an s-Si/CIGS device with an electrolysis cell, and other approaches to direct water splitting.

Following the last series of tests of these devices, the most promising method for performance improvement is seen as the handling/masking steps during fabrication, aimed at reducing shunting problems. With favorable reduction of shunting, a possible 0.8 percentage point increase in conversion efficiency for the a-Si/CIGS cell, compared to the stand-alone CIGS cell, is projected.

Alternative Approaches to Water Splitting - $\mathrm{CuGaSe}_{2}$

Exploration of direct water-splitting with $\mathrm{CuGaSe}_{2}$ (CGS) photocathodes has resulted in high photocurrents of $26 \mathrm{~mA} / \mathrm{cm}^{2}$ for 2-micron thick $\mathrm{CuGaSe}_{2}$ films. The films showed good stability over the duration of the electrochemical testing. However, a large voltage bias is necessary, pointing to an unfavorable band-edge position with respect to the water splitting redox potentials. Alloying with sulfur to yield $\mathrm{CuGa}(\mathrm{S}, \mathrm{Se})_{2}$ could result in a lowering of the valence band, thus reducing the need for external voltage bias. The larger bandgap $(\sim 2 \mathrm{eV})$ compound could also be used as top-junction in a tandem $\mathrm{PEC} / \mathrm{PV}$ device with the potential for unassisted photoelectrolysis.

The initially tested CGS films were about 2 microns thick, which is thicker than necessary and detrimental in a multi-junction configuration where light needs to be passed through to the second photovoltaic absorber. New films were fabricated with a thickness of 0.9 microns. In line with the projections from Tauc optical parameters, 1-sun (Air Mass $1.5 \mathrm{G}, 100 \mathrm{~mW} / \mathrm{cm}^{2}$ ) photocurrents greater than $20 \mathrm{~mA} / \mathrm{cm}^{2}$ were observed in a CGS $/ 0.5 \mathrm{M} \mathrm{H}_{2} \mathrm{SO}_{4} / \mathrm{Pt}$ cell. The shorter exposure to the high-CGS-deposition temperature $\left(>500{ }^{\circ} \mathrm{C}\right)$ also left the $\mathrm{SnO}_{2}: \mathrm{F}$ substrate at its nominal performance $(15 \mathrm{ohms} / \mathrm{sq}$. sheet resistance), whereas the previous longer depositions had degraded the resistivity. The bias voltage required to reach saturation photocurrents was reduced compared to previous CGS photoelectrodes because of the lower back-contact resistance in the new devices.

\subsubsection{Integration of 4-Terminal Devices into Hydrogen Production Systems}

Provided such 4-terminal tandem devices can be successfully fabricated on larger areas, they could be utilized for electrolytic hydrogen production with proper integration of the electrolysis cell. Ideally, the electrolysis cells and photovoltaic modules would be integrated to occupy the same footprint, resulting in a low electrolysis current density favorable to low-voltage operation. The main design options are: (a) DC-AC conversion of the a-Si and CIGS sub-module photovoltaic output, followed by AC-DC conversion to the desired electrolysis cell voltage, (b) DC-DC conversion of the photovoltaic output to the desired electrolysis voltage, and (c) series connection of current-matched (possibly area-mismatched) segments of the photovoltaic modules and electrolysis cells (see Figure 4.1.1).

The first option would be readily implemented with off-the-shelf inverters and electrolyzers, but is likely to suffer from excessive losses due to the multiple conversion steps. The second option 
appears more attractive because of the single-voltage conversion step. However, it also involves the appropriate matching of the current, which may result in different effective areas for the photovoltaic modules and the electrolysis cells. This is also true for the last option. That option is the simplest since it forgoes any auxiliary device, but by the same token will not offer the benefits of power conditioning circuitry such as maximum-power-point tracking. For prototype devices, the series connection of current-matched segments is an appropriate mechanism.

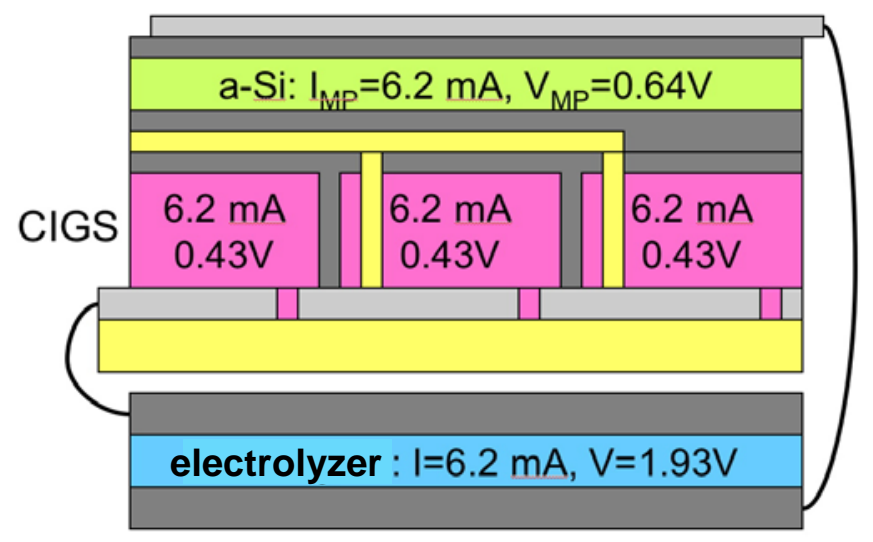

Figure 4.1.1: Integration of a-Si/CIGS device with electrolysis cell by series connection of currentmatched segments (not a 4-terminal device).

\subsection{4 $\underline{\text { Conclusions }}$}

The improved multisource evaporation system developed by HNEI has proved to be effective in producing a variety of devices. In particular, it has demonstrated the ability to deposit highefficiency CIGS material onto PEC-compatible materials, and resultant devices have shown reproducibility in subsequent testing.

Through the use of optical modeling analyses, electronic measurements, and tests for conversion efficiencies of the CIGS devices for producing hydrogen from water, the required properties of the CIGS materials of these devices have been adequately characterized.

An evolving design for 4-terminal devices combining CIGS and a-Si materials has been developed during the course of this task. The design process has included improvement phases following the results of a series of test programs. Initial test results provided the basis for improvements made to the design at each step of this development. Owing to the limitations of time and expenditures, it was not possible to meet the goal of demonstrating a 4-termainal device with solar efficiency greater than 15\%. Based on the last tests conducted, however, there are still untested improvements that could be made to improve performance of the 4-terminal device.

An alternative to the CIGS-based method of water splitting, we have also done preliminary work in exploring the possible use of $\mathrm{CuGaSe}_{2}$ (CGS) materials. This approach was pursued through one level of improvement and the material shows some promise for use in direct hydrogen production from water.

A set of preliminary designs was presented for integrating 4-terminal tandem devices into hydrogen productions systems. From the three design approaches explored, there was one approach that appeared to be the most appropriate mechanism for integration of prototype devices. 


\subsubsection{Products Developed and Technology Transfer Activities}

\subsubsection{Publications/Presentations}

1. B. Marsen, B. Cole, E.L. Miller, Photoelectrolysis of Water using Semitransparent Copper Gallium Diselenide Electrodes, Solar Energy Materials and Solar Cells, Volume 92, Issue 9, Pages 1054-1058, September 2008.

2. B. Marsen, B. Cole, S. Dorn, R.E. Rocheleau, E.L. Miller, Copper Gallium Diselenide Photocathodes for Solar Photoelectrolysis, Proc. SPIE 6650-3, 2007.

3. B. Marsen, S. Dorn, B. Cole, R. E. Rocheleau, E. L. Miller, Copper Chalcopyrite Film Photocathodes for Direct Solar-Powered Water Splitting, in Solar Energy Conversion, edited by Matt Beard (Mater. Res. Soc. Symp. Proc. 974E, Warrendale, PA, 2007), 0974-CC09-05.

4. B. Marsen, S. Dorn, R. Rocheleau, E. Miller, S. Morrison, R. Martin, S. Marsillac, "Cu(In,Ga)Se ${ }^{2}$-based Solar Cells on Flexible Insulating Substrates," Proceedings of the $3^{\text {rd }}$ International Energy Conversion Engineering Conference, San Francisco, CA, August 2005.

5. B. Marsen, S. Marsillac, S. Dorn, R. Rocheleau, "Effect of Selenium Effusion Rate on CIGS Thin Films Deposited at Low Substrate Temperature," 31st IEEE PVSC, Orlando, FL, January 2005.

\subsubsection{Collaborations}

MVSystems Incorporated and the University of Toledo.

\subsubsection{Patents}

US Pat. 6887728, E. Miller, R. Rocheleau, "Hybrid Solid State/Electrochemical Photoelectrode for Hydrogen Production", issued 05/03/05.

US Pat. 7122873, E. Miller, R. Rocheleau, "Hybrid Solid State/Electrochemical Photoelectrode for Hydrogen Production", issued 10/17/06.

\subsubsection{Computer Modeling}

MVSystems, Inc., under subcontract, provided an optical model for our use in developing the a$\mathrm{Si} / \mathrm{CIGS}$ 4-terminal device. This model was useful in calculating photocurrents and efficiencies of devices in the 4-terminal configuration. It also helped in indicating the potential efficiency gains of an a-Si/CIGS device over a stand-alone CIGS one. 


\section{This page is intentional blank}




\subsection{Subtask 3B - $\underline{\text { Hydrogen Production from Biomass }}$}

\subsubsection{Subtask 3B-1 - Hydrogen via liquid biofuels}

\subsubsection{Goals and Objectives}

This subtask had four main goals and objectives. Two were subcontracted to ClearFuels Technology, as delineated below.

- Conduct parametric testing of the Pearson Technologies' gasification system to understand effects of gasifier operating conditions on gas yields and quality.

- Conduct a detailed engineering design for a biomass gasifier research and development facility.

The third goal was to develop a hot gas clean-up train for the HNEI bench-scale gasifier unit located at the University of Hawaii. A final goal was to investigate advanced hydrogen purification systems as auxiliary units for the HNEI bench-scale gasifier. This fourth and final goal/activity was subcontracted to New Mexico Institute of Mining and Technology (NMT).

\subsubsection{Accomplishments and Comparison with Goals and Objectives}

ClearFuels Technology was subcontracted to conduct the parametric testing of the Pearson Technologies' gasification system and determine the effects of gasifier operating conditions on the gas yields and quality. ClearFuels Technology successfully conducted gasification tests over a range of residence times using the Pearson Technologies five ton-per-day pilot plant. The results were summarized in a series of reports. ClearFuels Technology second goal was to conduct an engineering design for a biomass gasifier research and development facility was also completed and a final report was prepared and submitted.

The third goal of Subtask 3B-1 was the development of a hot gas clean-up unit for the HNEI gasifier test facility. This unit included components for removing particulates, hydrogen sulfide, and hydrogen chloride, and a catalytic tar cracking unit for the conversion of tar and methane to lower molecular weight permanent gas species. A water-gas-shift reactor and compressor system were also installed to enable testing of pressure swing adsorption and other advanced hydrogen purification technologies.

NMT completed an investigation of advanced hydrogen purification systems that could potentially be used as auxiliary units for the HNEI bench scale gasifier and a summarized their activities in a final report.

\subsubsection{Summary of Project Activities}

Two activities in Subtask 3B-1 were subcontracted to ClearFuels Technology. The first activity was to conduct parametric testing of the Pearson gasification technology to determine the effects of gasifier operating conditions on the gas yields and quality. The hydrogen yield from the Pearson gasifier was evaluated in a parametric test series over a range of residence times from 0.8 to 2.2 seconds as shown in Figure 4.2.1. $\mathrm{H}_{2}$ concentrations as high as $55 \%$ (volume) were measured in the product gas at the longer residence times and this corresponds to a hydrogen yield of $90 \mathrm{~kg}$ per tonne of bagasse without gas upgrading. The $\mathrm{CO}$ and $\mathrm{CH}_{4}$ in the product gas have the potential to yield additional hydrogen through the use of reforming and water gas shift reactors. Increasing residence time from 0.8 to 1.4 seconds and 1.8 to 2.2 seconds increased hydrogen concentration by less than $1 \%$ (absolute) in the product gas. Lengthening residence 
time from 1.4 to 1.8 seconds produced the greatest single increase from 49.8 to $54.4 \%$ (absolute). Although more extensive testing should be performed to further validate these results, these preliminary findings indicate that the greatest gains in hydrogen concentration can be realized by maintaining residence time above 1.8 seconds. This information is useful in designing biomass reforming systems as it allows the increased capital costs associated with longer residence times to be weighed against increases in hydrogen content of the product gas. This information may also impact downstream systems where greater concentration of hydrogen in the product gas could lead to decreased purification requirements and costs. Note that extended details of the final report have been identified as proprietary by the subcontractor.

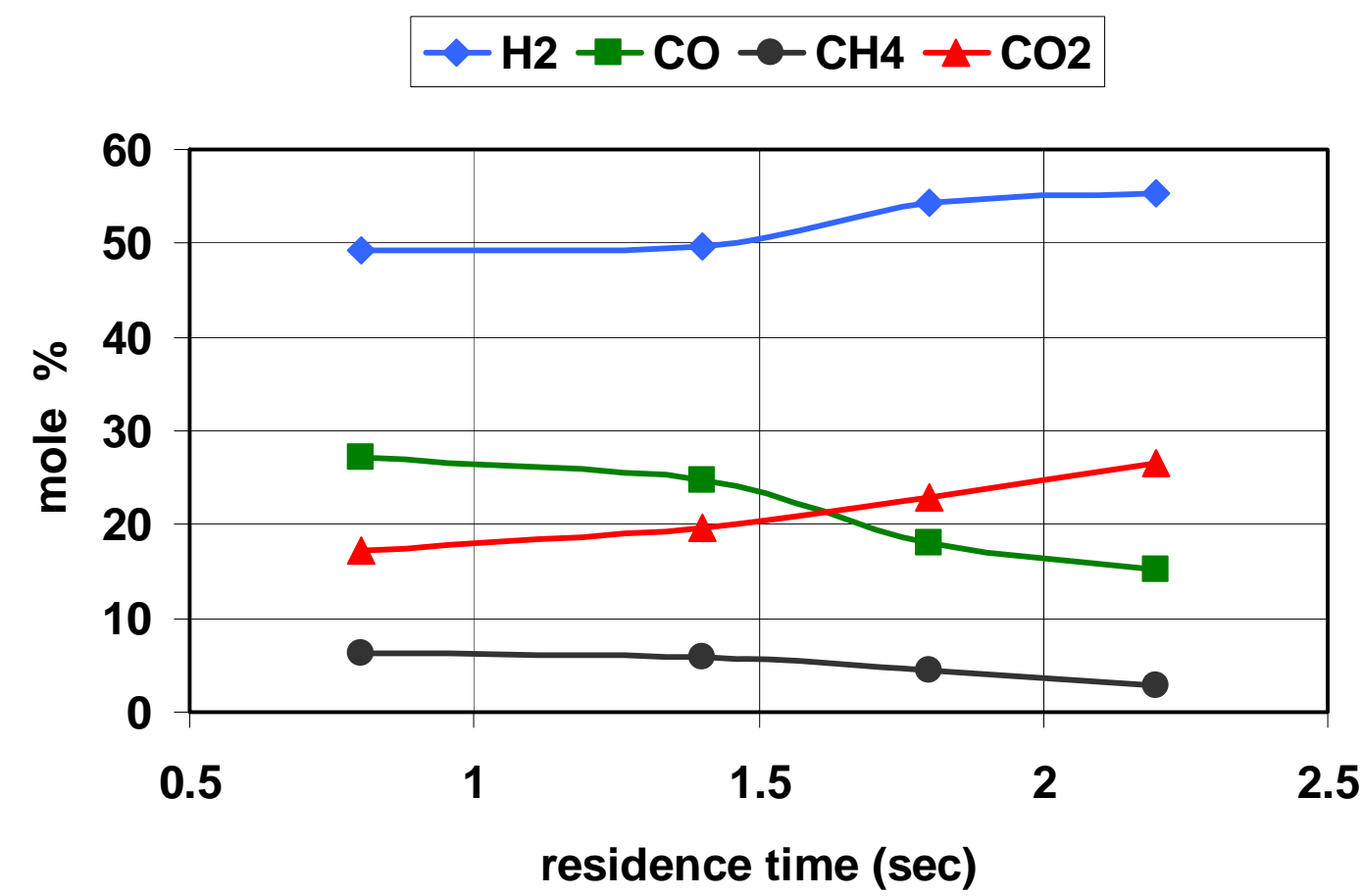

Figure 4.2.1: Hydrogen concentration in the product gas as a function of residence time for the Pearson gasifier.

The second activity in the ClearFuels Technology subcontract, for the engineering design for a biomass gasifier research and development facility, was completed. Details of this report have been identified as proprietary by the subcontractor.

The third activity under the Subtask 3B-1 was the development of the hot gas clean-up unit for the HNEI gasifier facility. Projects activities are summarized in a final report that is attached in Appendix B.

The fourth activity under the Subtask 3B-1 was the development advanced hydrogen purification systems that could potentially be used as auxiliary units for the HNEI bench-scale gasifier by NMT. Project activities are summarized in a final report that is attached in Appendix C. 


\subsubsection{Conclusions}

The objective of the first activity under Subtask 3B-1 was to conduct parametric testing of the Pearson gasifier and to determine the effects of gasifier operating conditions on the gas yields and quality The hydrogen yield from the Pearson gasifier was evaluated in a parametric test series over a range of residence times from 0.8 to 2.2 seconds. $\mathrm{H}_{2}$ concentrations as high as $55 \%$ (volume) were measured in the product gas at the longer residence times and this corresponds to a hydrogen yield of $90 \mathrm{~kg}$ per tonne of bagasse without gas upgrading.

The second activity in the ClearFuels Technology subcontract, for the engineering design for a biomass gasifier research and development facility, was completed. Details of this report have been identified as proprietary by the subcontractor.

The objective of the third activity under Subtask 3B-1 was to develop hot gas clean-up capabilities for the HNEI gasifier test facility to support hydrogen from biomass research. The product gas stream at the outlet of the hot gas filter was characterized for concentrations of permanent gas species $\left(\mathrm{CO}, \mathrm{CO}_{2}, \mathrm{H}_{2}, \mathrm{CH}_{4}, \mathrm{~N}_{2}\right)$ and contaminants including tar (principally benzene, naphthalene, and toluene) and sulfur $\left(\mathrm{H}_{2} \mathrm{~S}, \mathrm{COS}\right.$, and $\left.\mathrm{C}_{4} \mathrm{H}_{4} \mathrm{~S}\right)$ species, ammonia, and $\mathrm{NO}_{\mathrm{x}}$. Total tar concentration in the dry product gas was $\sim 10 \mathrm{~g} \mathrm{~m}^{-3}$. Concentrations of $\mathrm{H}_{2} \mathrm{~S}, \mathrm{COS}$, and $\mathrm{C}_{4} \mathrm{H}_{4} \mathrm{~S}$ were 56, 1, and $1.3 \mathrm{ppmv}$, respectively. $\mathrm{NO}$ and ammonia concentrations were determined to be 8.2 and 1,626 ppmv respectively.

A clean-up strategy was developed to remove contaminant species or convert them to a benign form. Elements included sulfur removal using $\mathrm{ZnO}$ sorbent at $400{ }^{\circ} \mathrm{C}$ and a gas hourly-spacevelocity (GHSV) of $8,000 \mathrm{hr}^{-1}$. Under these conditions, the primary sulfur component, $\mathrm{H}_{2} \mathrm{~S}$, was reduced $250 \mathrm{ppbv}$ and $\operatorname{COS}$ was reduced by a factor of 4 to similar levels. Thiophene concentrations were not affected.

Tar and methane were successfully converted to permanent gas species using nickel catalysts. Temperatures of $850^{\circ} \mathrm{C}$ and GHSV of $\sim 1 \mathrm{~m}^{3} \mathrm{~kg}^{-1} \mathrm{hr}^{-1}$ effectively removed tar compounds below levels of $0.1 \mathrm{~g}$ total $\operatorname{tar~}^{-3}$ dry gas. Acenaphthalene and pyrene were two compounds identified in the gas stream exiting the reactor. The $\mathrm{Ni}$ catalyst also resulted in reductions of $\mathrm{NH}_{3}$ from values of $\sim 1500$ ppmv to as low as 20 ppmv, and complete conversion of methane and $\mathrm{NO}_{\mathrm{x}}$. Methane and tar conversion resulted in increased levels of $\mathrm{H}_{2}$ and $\mathrm{CO}$ in the product gas exiting the tar cracking unit.

The fourth activity under Subtask 3B-1 was the development of advanced hydrogen purification systems that could potentially be used as auxiliary units for the HNEI bench-scale gasifier by NMT. Zeolite-based catalysts were prepared and tested for hydrogen production via reforming of hydrocarbons. These showed promise for alcohols but were inapplicable for glucose reforming. Zeolite membrane systems were tested and may have usefulness in driving $\mathrm{CO}_{2}$ from a reforming system, with possible enhancement of $\mathrm{H}_{2}$ production. Some success was observed with micro-reforming of ethylene glycol using a Pt catalyst, but such a catalyst is precluded from use with crop residue feedstocks having organic sulfur.

\subsubsection{Products Developed and Technology Transfer Activities}

1. S.Q. Turn, Bioenergy Products from Fiber, Hawaii Bioenergy Workshop, Honolulu, HI, October 27, 2006. 
2. S.Q. Turn, Biomass Gasification Research in Support of Biorefinery Development, $232^{\text {nd }}$ American Chemical Society National Meeting, San Francisco, CA, September 10-14, 2006.

3. S.Q. Turn, Terrestrial Biomass Resources in Hawaii, Ethanol Workshop, Hawaii Department of Business, Economic Development \& Tourism, Honolulu, HI, February 9, 2006.

In addition, a manuscript is being prepared for submission to a peer-reviewed technical journal. 


\subsubsection{Subtask 3B-2 - Feedstock processing}

\subsubsection{Goals and Objectives}

Develop and assess novel feedstock preparation methods to improve gasification characteristics of sugar cane leaf and top material normally open-burned for disposal.

\subsubsection{Accomplishments and Comparison with Goals and Objectives}

The work product from Subtask 3B-2 summarizes a preliminary investigation into methods for processing sugar cane trash at the Puunene Sugar Factory on the island of Maui, Hawaii. The factory is owned and operated by Hawaiian Commercial and Sugar (HC\&S), a subsidiary of Alexander and Baldwin Inc.. The objective of the investigation was to explore treatment methods that would enable the successful use of cane trash as fuel for the production of hydrogen via gasification. Note that the results are potentially applicable for other thermochemical energy devices as well. Cane trash consists of the leafy plant matter, both living and dead, that accumulates over the course of the growing period. Normally, this material is burned off before harvest in an open field burn. An alternative is to harvest and process sugar cane trash into a viable fuel. Sugar cane trash is a poor fuel for thermochemical conversion due to its ash composition and the associated tendency to form slag and deposits and foul working surfaces.

Laboratory and pilot scale tests were carried out using water as a leaching agent to investigate the removal of elements, $\mathrm{K}, \mathrm{Na}$, and $\mathrm{Cl}$, known to be agents for slag and deposit formation. Leach water temperature, leaching duration, and cane trash particle size were varied in the laboratory. Particle size was found to have a significant effect in the reduction of $\mathrm{K}, \mathrm{Na}$, and $\mathrm{Cl}$ concentrations and an observed increase in ash fusion temperatures and a decrease in total alkali concentration per energy unit to a level below that empirically found to be the threshold for slagging and fouling. Similar pilot-scale tests were also performed, but particle size reduction was made impossible due to equipment failure. The pilot-scale samples were not reduced below the threshold for slagging and fouling in the leaching treatments.

\subsubsection{Summary of Project Activities}

A comprehensive report for this project is attached as Appendix D.

\subsubsection{Conclusions}

Particle size reduction of cane trash was found to improve the removal of potassium and chlorine by leaching compared to the other two variables, leaching duration and temperature. Hand harvested, leached cane trash with small particle size was found to have qualities very similar to bagasse and would likely make a suitable boiler fuel based on small-scale testing.

The first set of laboratory-scale tests conducted for leaching durations of 5 and 60 minutes showed no effect. Temperature was also shown to have little bearing on the successful leaching of alkali materials at the two test temperatures of 25 and $55^{\circ} \mathrm{C}$ with only chlorine concentration showing an effect. These results are not encouraging for the proposed commercial treatment procedures which have limited capacity to reduce particle size.

The parameters in the second set of experiments were selected, where possible, to mimic fullscale conditions with short residence times and high temperature leach water. Proposed particle treatments for the commercial scale include no reduction (i.e., full-size cane trash) to chopping to 
obtain 1 to 2 foot pieces. Laboratory-scale equipment precluded handling material in these size classes.

Results from the second set of laboratory tests conducted for durations of 1 and 2.5 minutes show multiple interaction effects for almost all measures of successful fuel treatment. These results indicate that further work at the laboratory scale is needed to identify the ideal treatment conditions for the range that will be available at the commercial scale.

Comparing the results of the two laboratory-scale tests, particle size reduction is clearly the most important factor in successful leaching. However, at shorter time durations $(<5 \mathrm{~min})$, interaction effects between temperature, duration and particle size arise. This would indicate that the commercial-scale cleaning plant would need to operate with residence times greater than the preliminary 1-minute time period indicated by HC\&S personnel.

At the pilot scale, mechanical harvesting and poor field conditions can lead to soil contamination which will be a major issue surrounding cane trash processing. The simple leaching treatments at high temperature and long duration were not effective at removing soil contaminants and did not appreciably improve alkali leaching at the pilot scale.

\subsubsection{Products Developed and Technology Transfer Activities}

This project was done in collaboration with Hawaiian Commercial \& Sugar Co., the largest sugar producer in the State of Hawaii. It is anticipated that results from this work will be used as a resource in the design of cane trash handling and processing systems going forward.

A manuscript is being prepared for submission to a peer-reviewed technical journal. 


\subsubsection{Subtask 3B-3 - Microbial Biomass Assessment}

\subsubsection{Goals and Objectives}

Assess the potential for using direct microbial production of biofuel (renewable fuel oil) as an alternative hydrogen carrier.

\section{2.3.2 Accomplishments and Comparison with Goals and Objectives}

Efforts were focused on the technical and economic feasibility of commercial-scale production of renewable fuel oil from photosynthetic marine microbes. We analyzed the production process and the principal elements of capital and operating costs. The overall assessment yielded estimates for the cost of goods (including a listing of the most significant capital and operating costs) for the produced biofuel, energy efficiency, and return on investment.

\subsubsection{Summary of Project Activities}

\subsection{Approach and Methods}

\section{Performance and Review}

The engineering and economic analyses were performed jointly by scientists from the Hawaii Natural Energy Institute, University of Hawaii; civil and mechanical engineers from Engineering Dynamics Corporation, Honolulu; and Kokua Construction and Project Management, KailuaKona. Hawaiian Electric Industries provided engineering services related to flue gas and power requirements. The overall analysis was independently reviewed by the Rocky Mountain Institute, Diversa Corporation, and Drs. B. G. Mitchell (Scripps Institution of Oceanography), J. J. Cullen (Dalhousie University) and P. J. LeB. Williams (University of Wales).

\section{Production Process - General Description}

Photosynthetic marine microbes are cultivated using the proprietary process of HR BioPetroleum, LLC, which incorporates a two-phase system of controlled, closed-system "photobioreactors" coupled with large-scale open ponds. The photobioreactors provide a constant source of high-quality cell culture to the open ponds, which are inoculated and harvested daily. Process piping is sterilizedaily by a sodium-hypochlorite (bleach) based "cleanin-place" system that is automated. Key raw materials for the process are seawater, sunlight, nitrogen, phosphorus, and carbon dioxide. Flue gas from an adjacent fuel-burning power plant provides carbon dioxide. When cultivation is complete, the cell culture is dewatered, homogenized, and separated into oil and aqueous phases. The aqueous phase is disposed. The oil phase, equivalent to crude oil, is stored for subsequent refining.

\section{Scale of Operation}

This analysis assumes a production scale of 1,000 bbl/day of biodiesel feedstock, comprised of plant oil extract. Biodiesel feedstock is approximately equivalent to a high-quality, "sweet" crude oil. At this scale, the system consists of individual modules that are already at maximum size, so production at larger scales only requires additional modules. The $1,000 \mathrm{bbl} /$ day facility requires an area of 1,863 acres (754 ha), of which 1,620 acres (655 ha) are devoted to production equipment, and 13\% of which (243 acres; $98 \mathrm{ha}$ ) is provided for access.

\section{Site Characteristics and Preparation}

The site has an average native slope of less than $1 \%$, graded level to within $0.05 \%$. Soil is clay/loam ash with minor rock content. The site is stripped of vegetation and treated for weed 
control prior to mass grading and compaction. Average elevation of the site is 20 feet above sealevel (or, for the use of saline aquifers, $20 \mathrm{ft}$ above the water table).

\section{Microbe Characteristics}

The species has an oil content of $35 \%$ of dry weight when grown under nutrient-sufficient conditions, and a photosynthetic efficiency of $20 \%$ in cultures exposed to full sunlight. Temperature tolerance is $40{ }^{\circ} \mathrm{C}$. Nitrogen requirements are supplied entirely by fixation of atmospheric nitrogen. The cell is at least $20 \mu \mathrm{m}$ in diameter and negatively buoyant, with a sinking rate of $\approx 1 \mathrm{~m} / \mathrm{h}$. Oil occurs primarily in the form of droplets dispersed in the protoplasm. All of these features are known to occur among photosynthetic microbes.

\section{Construction Cost Estimates}

The main elements of construction are grading and compaction, trenching, well-digging, and the construction of berms to create shallow open ponds. Open pond surfaces are entirely covered by geotextile, latex impregnated, fiber-reinforced liner with a guaranteed 20-year life. Water supply wells are 5 feet in diameter and 40 feet deep. Injection wells for process water disposal are 12" in diameter, steel-lined and 250 feet deep. Trenching is minimal; pipes are buried only under access roads, but otherwise are above-ground. Electrical distribution is all above ground.

All cost estimates for construction are based on an industry standard estimating reference (R. S. Means, Construction Publishers, Kingston MA), for which we use the national values with no adjustments made for any particular state. Suppliers were directly contacted to quote cost if no Means estimate was available.

\section{Capital Equipment Cost Estimates}

Most items of capital equipment are plumbing related: pumps, pipe, pipe fittings, valves and storage tanks. Plumbing elements were selected for maximum tolerance to saltwater. Flow rates were calculated for each process, with pump, valve and pipe sizes chosen accordingly. Pipe run lengths, friction, and head losses were taken into account in determining power requirements for each pump type. Where feasible, HDPE pipe was selected over PVC, due to ease of installation and better tolerance to sunlight. Flow-through ultraviolet sterilizing equipment is used for treating makeup water. Paddlewheels are used to drive recirculation of the open ponds. Air blowers are used to provide a low pressure, high-flow-rate supply of flue gas. All valves are automated, and powered by compressed air. The cost of the primary electrical distribution system will be borne by the electric power provider; this assumption was confirmed by HECO, justified on the basis that the biofuel plant will be a significant customer. The secondary electrical distribution system is included in our cost estimate.

All cost estimates for mechanical and electrical equipment are based on an industry standard estimating reference (R. S. Means, Construction Publishers, Kingston MA). Suppliers were directly contacted to quote cost if no Means estimate was available. Photobioreactor costs were estimated by one of our contributors who has direct experience in construction of photobioreactors of the specified scale.

\section{Depreciation Schedule}

Each element of capital equipment or construction cost was assigned an average lifetime (Table 4.2.3.1). Straight-line depreciation was used to estimate amortized cost. 
Table 4.2.3.1: Depreciation Schedules

(Principal equipment and construction items)

\begin{tabular}{lr} 
Equipment & $\begin{array}{c}\text { Life } \\
\text { (yrs) }\end{array}$ \\
\hline Tubing, polyethylene & 1 \\
Air blower & 5 \\
Pumps & 10 \\
Airlift end assembly, PBR & 10 \\
Compressors & 10 \\
Laboratory equipment & 10 \\
UV Sterilization system & 15 \\
Buildings & 20 \\
Paddlewheels & 20 \\
Geotextile liner & 20 \\
Pipe and fittings & 20 \\
Valves, motorized & 20 \\
Well, injection, 250' deep, 12"diam & 30 \\
Tank, steel, storage & 40 \\
Site preparation & 50 \\
Well, supply, 40' deep, 5 ft diam & 50 \\
& \\
\hline
\end{tabular}

\section{Energy Consumption}

Energy consumption was estimated for each piece of equipment based on its power requirement and its daily duty cycle. All components were then summed to determine total energy consumption, provided entirely by the adjacent electrical plant that also provides $\mathrm{CO}_{2}$-rich stack gas.

\section{Operating Cost Estimates}

Operating costs fall into only three categories: (1) electricity, (2) inorganic phosphorus, and (3) manpower. Electricity costs are assumed to be $\$ 0.07$ per $\mathrm{kWh}$. Phosphorus cost for commercial fertilizer (as potassium phosphate) is estimated at $\$ 0.45$ per $\mathrm{kg}$. Manpower requirements are based on a workflow analysis that takes into account all routine daily tasks, including plant maintenance. This analysis yields a manpower requirement of 0.1 persons per production hectare of facility (i.e., 655 hectares). Manpower costs assume a benefit rate of $35 \%$, and a fullyburdened per capita cost of $\$ 40,000$ per person per annum. Operating costs are normalized on an areal basis, i.e., $\$$ per hectare per year.

\section{Annualized Capital Cost Estimates}

Annually amortized capital costs were calculated for each cost element by determining the total cost for the 1,000 bbl/day facility, dividing by the total area of the facility, and then assuming 
straight-line depreciation (Table 4.2.3.1). This yields a cost estimate expressed in \$USD per hectare per year.

\subsection{Results}

\section{Cost of Goods}

The cost of production for this renewable fuel oil is estimated to be $\$ 37.93 / \mathrm{bbl}$ (Table 4.2.3.2), which includes a carbon credit of $\$ 10$ per MT. Without the carbon credit, net production cost rises to $\$ 43.72 / \mathrm{bbl}$. These results were based on analyses completed early in 2005 .

\section{Energy Efficiency}

The biofuels production facility uses 59,275 MWh annually to produce 365,000 bbl of biofuels. This requires bio-assimilation of 211,518 MT/year of carbon dioxide. The oil-fired power plant produces this amount of carbon dioxide by consuming 391,064 bbl/year which, in turn, yields $229,194 \mathrm{MWh} /$ year of power production. Conversion ratios used were based on historical values for the State of Hawaii.

In summary, the energy input of the facility is 59,275 MWh, or 213,390 GJ (based on energy conversion of $277.8 \mathrm{kWh}$ per GJ). Assuming an energy density of biofuel at $5.05 \mathrm{GJ}$ per bbl, the resulting oil production (365,000 bbl/year) yields an energy output of 1,861,500 GJ. The ratio of energy output to energy input, or energy efficiency, is therefore 8.72.

\section{Most Significant Capital Costs}

The five most significant capital costs on an annualized basis are, in descending order of cost:

- Geotextile fabric:

$\$ 4,172 / \mathrm{ha} / \mathrm{yr}:(34.4 \%)$

- Transfer pumps, photobioreactor to pond: $\$ 984 / \mathrm{ha} / \mathrm{yr} \quad(8.1 \%)$

- Pipe for stack gas delivery: $\quad \$ 763 / \mathrm{ha} / \mathrm{yr} \quad(6.3 \%)$

- Photobioreactor polyethylene tubing: $\$ 743 / \mathrm{ha} / \mathrm{yr} \quad(6.1 \%)$

- Pond paddlewheels: \$605/ha/yr (5.0\%)

Together, these items account for $60 \%$ of the total for capital costs.

Most Significant Operating Costs

The most significant operating costs are electricity $(\$ 5,503 / \mathrm{ha} / \mathrm{yr})$ and manpower $(\$ 3,475 / \mathrm{ha} / \mathrm{yr})$. Among the electrical costs, the greatest are:

- Pumps for fluid transfers:

$\$ 2,510 / \mathrm{ha} / \mathrm{yr}(45.6 \%)$

- Blowers for stack gas and fluid transfer:

$\$ 1,789 / \mathrm{ha} / \mathrm{yr}(32.5 \%)$

- Paddlewheels for pond recirculation:

$\$ 807 / \mathrm{ha} / \mathrm{yr}(14.7 \%)$

\section{Return on Investment}

At sales prices of $\$ 50, \$ 75$ and $\$ 100 / \mathrm{bbl}$, capital costs would be recouped in $5.6,7.5$, or 11.2 years, respectively. The weighted-average depreciation period is 22.3 years. 
Table 4.2.3.2: Cost Summary

\begin{tabular}{lcccc} 
& & Areal & Annualized & Annual \\
ITEM & Total & Cost & Areal Cost & Expense/ \\
& Cost & $(\$ / \mathrm{ha})$ & $(\$ / \mathrm{ha} / \mathrm{yr})$ & Revenue \\
\hline
\end{tabular}

\section{EXPENSES}

\section{Capital Costs}

Makeup water to ponds

Makeup water to PBRs

Culture Laboratory

Lab-PBR Inoculation

PBR-Pond Inoculation

Pond supernatant

Pond harvest to Extraction Tank

Extraction system

Pond, $11,500 \mathrm{~m} 2$

PBR, (3,773 sq ft)

$\mathrm{CO} 2 /$ Stack gas delivery system

Nutrient Media system

Electrical

Site preparation

\begin{tabular}{|c|c|c|c|c|c|c|}
\hline & $\$ 10,380,270$ & $\$ 13,767$ & $\$$ & 647 & $\$$ & 487,664 \\
\hline & $\$ 1,712,200$ & $\$ 2,271$ & $\$$ & 126 & $\$$ & 95,060 \\
\hline & $\$ 1,580,000$ & $\$ 2,095$ & $\$$ & 190 & $\$$ & 143,000 \\
\hline & $\$ 61,500$ & $\$ 82$ & $\$$ & 16 & $\$$ & 12,300 \\
\hline & $\$ 5,529,800$ & $\$ 7,334$ & $\$$ & 1,105 & $\$$ & 832,990 \\
\hline & $\$ 11,496,680$ & $\$ 15,248$ & $\$$ & 1,002 & $\$$ & 755,334 \\
\hline & $\$ 2,446,500$ & $\$ 3,245$ & $\$$ & 235 & $\$$ & 177,045 \\
\hline & $\$ 3,127,200$ & $\$ 4,147$ & $\$$ & 107 & $\$$ & 81,053 \\
\hline & $\$ 95,123,500$ & $\$ 126,158$ & $\$$ & 4,608 & $\$$ & $3,474,783$ \\
\hline & $\$ 26,814,770$ & $\$ 35,563$ & $\$$ & 2,220 & $\$$ & $1,674,130$ \\
\hline & $\$ 14,066,800$ & $\$ 18,656$ & $\$$ & 933 & $\$$ & 703,340 \\
\hline & $\$ 128,750$ & $\$ 171$ & $\$$ & 9 & $\$$ & 6,988 \\
\hline & $\$ 2,957,700$ & $\$ 3,923$ & $\$$ & 196 & $\$$ & 147,885 \\
\hline & $\$ 28,683,758$ & $\$ 38,042$ & $\$$ & 761 & $\$$ & 573,675 \\
\hline Total Capital Costs: & $\$ 204,109,428$ & $\$ 270,702$ & $\$$ & 12,155 & $\$$ & $9,165,247$ \\
\hline
\end{tabular}

Operating Costs

Electricity @0.07/kWh

Manpower@ 0.087/ha \& \$40K/yr

Phosphorus@ @ $0.45 / \mathrm{kg}$

Total Operating Costs:

Credits

Carbon credit: 211,518 MT @ \$10/MT

Total expenses

COGS $(365,000 \mathrm{bbl} / \mathrm{yr}: \$ / \mathrm{bbl})$

INCOME

Sweet crude, @ \$50/bbl, 1000 bbl/day

PROFIT (LOSS)

$$
\begin{array}{lrrr}
\$ & 5,503 & \$ & 4,149,281 \\
\$ & 3,475 & \$ & 2,620,000 \\
\$ & 32 & \$ & 24,309 \\
& & & \\
\$ & 9,010 & \$ & 6,793,590
\end{array}
$$

$\$ \quad(2,805) \$(2,115,180)$

$\$ \quad 21,166 \quad \$ \quad 13,843,657$

$\$ \quad 37.93$

$\$ 24,204 \quad \$ \quad 18,250,000$

$\$ \quad 3,039 \quad \$ \quad 4,406,343$

\section{2.3.4 Conclusions and Discussion of Results}

\section{2.3.4.1 Overall Conclusions}

The cost of goods estimate (completed early in 2005) of $\$ 37.93 / \mathrm{bbl}$ for this renewable fuel compares favorably with the range of spot crude oil prices during the period of late 2004 to early 
2005 , when prices were $\$ 42-\$ 57 / \mathrm{bbl}$. Furthermore, we conclude that the technology described in this section is advanced enough to proliferate rapidly. Renewable biofuels could substantially reduce US dependence on foreign oil supplies.

\subsection{Scope for Cost Increase}

Nitrogen

The single most important potential for cost increase is in the provision of nitrogen. Our primary R\&D goal is to use a microbe that fixes atmospheric nitrogen to supply all its $\mathrm{N}$ requirements. Such microbes exist, particularly among the cyanobacteria, but their known growth rates are substantially lower than many other microbes. We believe that discovery of a rapidly-growing, nitrogen-fixing microbe is possible, and we have a plan to do so. Alternatives are feasible, but all will increase cost, as described in the following subsections:

\section{Commercial fertilizer - no recycling}

Use of commercial nitrogen fertilizer, without any attempt to recover the nitrogen, will add a cost of approximately $\$ 16 / \mathrm{bbl}$ at current world prices, increasing production cost to a total of $\$ 54 / \mathrm{bbl}$. The cost of synthetic nitrogen fertilizer varies directly with the cost of natural gas, which is used to produce anhydrous ammonia.

\section{Commercial fertilizer - with recycling}

It is technically feasible to recover nitrogen from the production process. This would require remineralization of dissolved organic nitrogen in the concentrated waste stream. We did not estimate the cost of such a system, but believe it could be substantial.

\section{Electricity}

A doubling of electricity cost, from $\$ 0.07$ to $\$ 0.14 / \mathrm{kWh}$, would increase production cost by more than $\$ 11 / \mathrm{bbl}$, to a total of $\$ 49.30 / \mathrm{bbl}$.

\subsection{Scope for Cost Decrease}

\section{Enhanced Oil Content}

Our current model assumes oil content of 35\% (on a dry-weight basis), which has already been achieved in cultures growing in nutrient-sufficient conditions at high growth rates. An increase to $50 \%$ oil content would decrease production costs by $30 \%$, to $\$ 26.71 / \mathrm{bbl}$.

\section{Enhanced Photosynthetic Efficiency (PE)}

Our current model assumes 20\% PE, which has already been achieved in large-scale outdoor cultures. Laboratory experiments have demonstrated a PE of more than $45 \%$. Even if $30 \% \mathrm{PE}$ is attainable, this would significantly reduce production costs. The capital and operating costs of transmitting stack gas would remain approximately the same, but offset by carbon credits. Manpower and phosphorous costs would increase, but their total impact is small. Overall, production costs would fall by $33 \%$, to $\$ 25.30 / \mathrm{bbl}$.

\section{Enhanced Oil Content and PE}

If we achieve both $50 \%$ oil content and $30 \% \mathrm{PE}$, overall production cost would fall to $\$ 17.82 / \mathrm{bbl}$. 


\subsubsection{Presentations Given}

1. C.B. Raleigh, "Wind, Sun, Palm Trees and Green Slime," HNEI Seminar Series, University of Hawaii, Honolulu, HI, October 3, 2006.

2. C.B. Raleigh and M.E. Huntley, "Renewable Oil from Photosynthetic Microbes: Engineering and Economic Analysis," HNEI Seminar Series, University of Hawaii, Honolulu, HI, March 2005. 
$\underline{\text { This page is intentional blank }}$ 


\subsection{Subtask 3C - Biohydrogen Analysis}

\section{3.1 Goals and Objectives}

- Conduct a technical evaluation of a full range of photobiological hydrogen production processes.

- Prepare a journal quality paper summarizing the results for publication by an appropriate biotechnology/bioenergy journal.

\section{3.2 Accomplishments and Comparison with Goals and Objectives}

Subtask $3 \mathrm{C}$ accomplished all the goals and objectives originally indicated. The journal quality paper is in the final draft form and will be submitted for publication before termination of the project.

\section{3.3 Summary of Project Activities}

The partners working under this subtask produced a requested paper entitled "Blue Hydrogen" for the 2004 World Hydrogen Energy Conference held in Yokohama, Japan. This publication provides the history and background for this subtask. A copy is available upon request.

A series of papers were prepared and submitted on various aspects of photobiological hydrogen production processes. See the section on Publications/Presentations for a complete list of these.

\section{3.4 Conclusions}

The state of biohydrogen production remains in the fundamental R\&D stage. Developments in genetic engineering plus eventual price of oil and niche linkages of this process with pollution control and other applications will serve as the bridge to wider-scale utilization someday.

\subsubsection{Publications/Presentations}

J. Yu and P. Takahashi, Biophotolysis-based Hydrogen Production by Cyanobacteria and Green Microalgae, Microbiology Book Series, Communicating Current Research and Educational Topics and Trends in Applied Microbiology (to be published - book now being printed).

M.J. Cooney, N. Maynard, J. Benemann, and C. Cannizzaro, Two-phase Anaerobic Digester for Simultaneous Biological Hydrogen and Methane Production, Bioresource Technology 98 (14), 2007.

M.J. Cooney, N. Maynard, C. Cannizzaro, and D. Harris, On-line Measurement of Gas Production Rates, Biotechnology Progress, V 22 (5), 1456-1460, October 2006.

M.J. Cooney, "Two-phase Production of H2/CH4 Mixtures," HNEI Seminar Series, Honolulu, HI, October 24, 2006.

M.J. Cooney, N. Maynard, J. Benemann, and C. Cannizzaro, Two-phase Anaerobic Digester for Simultaneous Biological Hydrogen and Methane Production. Pacific Rim Summit on Industrial Biotechnology and Bioenergy, Honolulu, HI, January 11-13, 2006.

G. Wang, "Hydrogen and hydrogen biocatalyst production in synthetic E. coli strains," Annual Meeting of the Society for Industrial Microbiology, Chicago, IL, August 2005. 
J. Benemann, "Energy and Wastewater Treatment by Microalgae," Presented at the International Society of Applied Phycology, $10^{\text {th }}$ Congress of Applied Phycology, Kunming, China, July 2005.

J. Yu, "Physiology of Carbohydrate Accumulation and H2 Production by Algal Cultures," at the $1^{\text {st }}$ Biohydrogen Project meeting, Clemson University, Clemson, SC, February 2005.

J. Benemann, "How-to and Not-to Guide on Biohydrogen R\&D (with Case Studies)," HNEI Seminar Series, Honolulu, HI, February 2005.

J. Yu and G. Wang, "Integrated Approaches toward Biohydrogen Production," HNEI Seminar Series, Honolulu, HI, January 2005.

P. Takahashi, M. Cooney, J. Yu, and J. Benemann, "Blue Hydrogen," Presented at 15th World Hydrogen Energy Conference, Yokohama, Japan, June 27-July 2, 2004.

\subsubsection{Inventions}

Michael Cooney, a member of the team involved in this task, invented an on-line gas measurement device for measurement of gases from anaerobic digestion. An invention disclosure was prepared and submitted to the University of Hawaii Office of Technology Transfer and Economic Development.

A second physical prototype of this device was assembled and delivered to Dr. Cooney's laboratory. This device represents a computer-automated form of the original prototype and works on the same principle as the prototype. but is now mostly automated in terms of data accumulation and processing.

\subsubsection{Collaborations}

Jian $\mathrm{Yu}$, another member of the team for this task, was involved as a co-PI in developing a proposal titled "Novel Two-stage Process for Photobiological Hydrogen Production." The project PI was Dr. David Kyle, CEO of Advanced BioNutrition Corp. Other co-PIs included Dr. Juergen Polle of Brooklyn College of the City University of New York, Dr. David Rune of Clemson University, Dr. Ragaiy Zidan of Savannah River Technology Center (A DOE laboratory) and Dr. Joseph Weissman of SeaAg, Inc. The proposal was awarded by DOE, but was not funded because of budget.

During the course of his research efforts, one other team member, Guangyi Wang, collaborated with Prof. Debabrata Das from the Indian Institute of Technology. 


\section{Task 4 - Systems Integration}

\subsection{Goals and Objectives}

Form a renewable hydrogen consortium that will conduct research and development to validate the technical and economic potential for renewable hydrogen and encourage the investment in the development of renewable hydrogen and DER options on the Big Island of Hawaii. Develop plans for implementation of the most cost-effective renewable hydrogen pathways.

\subsection{Accomplishments and Comparison with Goals and Objectives}

Original plans called for a partnership with 1) the Pacific International Center for High Technology Research (PICHTR), a Hawaii-based organization with strong outreach capabilities and ties to Asia, and 2) Sentech, Inc., a Washington, DC-based engineering consulting firm with broad capabilities in the hydrogen and renewable energy fields to work with HNEI in promoting and creating the consortium.

The program was restructured (as approved by DOE October 2005) and PICHTR was made a subcontractor under Task 1, Hawaii Hydrogen Power Park. GE Global Research was added as a partner for development of the consortium. Task 4 involved two primary activities. The first was the analysis of electric and transportation energy pathways on the Big Island. The results of this analysis were used to develop project plans to demonstrate the viability of these technologies in Hawaii. The second activity was education and outreach to disseminate the results of that analysis to potential partners in order to develop a consortium of public and private sector entities interested in developing renewable hydrogen projects on the Big Island.

The Hydrogen Power Park was established at Kahua Ranch, the location of PICHTR's Village Power System, consisting of PV panels, wind turbines, and a battery storage facility. Operation of the Power Park included integration of PV and wind turbine energy with an electrolyzer (see section 2 Task 1 of this report). The results of these efforts have shown the possibility of an economical source of hydrogen by interaction of wind with cost-effective electrolysis. The analysis also indicated candidate electrolyzer technologies for integration is such systems and the possibilities for greater penetration of wind energy onto the grid. Furthermore, the results of the Hydrogen Power Park work provided suggestions for improvements in the various elements of systems for renewable hydrogen production. These suggestions are important for planning efforts aimed at achieving more cost-effective renewable hydrogen pathways.

HNEI worked with Big Island energy stakeholder groups to discuss scenario analysis, testing, evaluation, demonstration and deployment of DER technologies. These discussion ultimately led to solicitation of inputs from the various stakeholders involved and a Stakeholder Summit meeting, all of which were carried out under a different DOE award.

\subsection{Summary of Project Activities}

On 22 October 2004, participated in the Hawaii Gateway Energy Center (HGEC) Business Partnering Meeting to look at the types of projects and partners that could support the development of sustainable energy technologies in Hawaii. Participants included US DOE, NREL, Hawaii State House of Representatives elected representatives, Hawaiian Electric Company, Hawaii Electric Light Company, The Gas Company, Puna Geothermal Ventures, and Hydrogenics. 
Participated in a tour of Big Island renewable energy sites with the US DOE Hydrogen Technology Validation Manager. The tour included a site visit of the Puna Geothermal Ventures plant, a visit to the PICHTR Village Power System at Kahua Ranch, and a tour of the HELCO grid control room, where we were briefed on issues concerning the integration of wind and other renewable resources into the grid. Using other funds, follow-on meetings were conducted with Hydrogenics and GE to address their interest in participating in DER projects at HGEC.

Attended the APEC (Asia-Pacific Economic Cooperation) PATH (Partnership for Advancing the Transition to Hydrogen) Hydrogen Workshop for APEC Economies held in Honolulu on May 16, 2005. Continued discussions with potential partners.

A contract was executed early in 2007 with GE for work on Phase 1 of the Hawaii Energy Roadmap - Assessment of Electric and Transportation Infrastructure on the Big Island. This effort is aimed at describing energy flow on the Big Island. It involved a strategic energy roadmap effort from a technology-neutral vantage point. The Big Island's electrical and transportation fuel infrastructures were modeled, calibrated, and validated against current conditions. The result was the establishment of an energy infrastructure baseline. It is the intention to use this baseline in the future for developing renewable energy scenarios useful for evolution of this infrastructure baseline and analysis of impacts on the Big Island. Such efforts will be part of Phase 2 work to be conducted under another award.

The Phase 2 contract with GE for carry-on work with the Big Island energy infrastructure analysis was executed and the contract was funded under a different DOE award.

HNEI efforts also included education and outreach activities to support renewable hydrogen production projects on the Big Island. In December 2006 and February 2007, training workshops on "The Hawaii Hydrogen Power Park" were given for the Big Island organization, Friends of NELHA (FON), in support of the FON daily public outreach program for Hawaii residents and tourists.

\section{$5.4 \underline{\text { Conclusions }}$}

HNEI successfully assembled and organized a fully effective renewable hydrogen consortium. This consortium was educated and prepared for contributing to the important decisions relating to encouraging the development of renewable hydrogen and DER options for the Big Island.

Initial efforts were completed in establishing an energy infrastructure baseline for the Big Island, forming an energy roadmap for the future. This baseline sets the stage for developing alternative renewable energy scenarios and analyzing impacts on the Big Island.

Through the installation and operation of the Hawaii Hydrogen Power Park at Kahua Ranch on the Big Island, HNEI achieved test results and analyses with direct relevance for future implementation of the most cost-effective renewable hydrogen pathways.

\subsection{Publications/Presentations}

R. Rocheleau, M. Ewan, S.Q. Turn," Renewable Hydrogen: The Hawaii Hydrogen Power Park," $235^{\text {th }}$ American Chemical Society National Meeting \& Exposition, New Orleans, LA, April 6-10, 2008 . 
S. Busquet, M. Ewan, "Description and First Results of a Wind-PV Hydrogen System at Kahua Ranch on the Big Island of Hawaii," National Hydrogen Association Annual Conference, Sacramento, CA, March 30 - April 3, 2008.

M. Ewan, R. Rocheleau, "Hawaii Hydrogen Power Park - Keystone to Developing a Hydrogen Economy in Hawaii," National Hydrogen Association Annual Conference, Sacramento, CA, March 30 - April 3, 2008.

M. Ewan, "The Hawaii Hydrogen Power Park," two training workshops for the Friends of NELHA (FON) to support the FON daily public outreach program for Hawaii residents and tourists, Kailua-Kona, HI, December 21, 2006 and February 24, 2007.

M. Ewan. L. Duwall, "Alternative Transportation Options at Volcanoes National Park," Presentation to the Climate Friendly Parks Workshop, Volcanoes National Park, HI, 21 February, 2007.

R. Rocheleau, Renewable Hydrogen in Hawaii, NHA "Renewables to Hydrogen" Forum, Albuquerque, NM, October 4, 2006.

R. Rocheleau, Renewable Energy Programs at the Hawaii Natural Energy Institute, ASCE Hawaii, Honolulu, HI, August 17, 2006.

\section{6 $\underline{\text { Collaborations }}$}

During the course of this task, HNEI assembled a consortium group for focusing on issues of renewable energy implementation on the Big Island. This group included a wide-ranging collection of representatives from organizations including Hawaii State and County Governments, DBEDT, Hawaii utilities (electricity and gas), Big Island industry, tourism, and non-profit organizations, and the media, as well as mainland industrial organizations.

HNEI contracted with GE Global Research for assistance in the Big Island energy roadmap efforts, leading to an energy infrastructure baseline. Future work under a different grant with GE will deal with analysis of mixes of renewable energy technologies and impacts on the Big Island. 
$\underline{\text { This page is intentional blank }}$ 


\section{APPENDIX A}

\section{Analysis Approach of the Electrochemical Components - Steady-State Operation}

The enthalpy of liquid water formation (HHV) has been chosen as the basis of performance analysis. This choice allows for consistent comparisons between technologies, and presents the most appropriate basis for analysis of thermal losses given low-temperature operation of the electrochemical components.

The steady-state energy balance of the electrolyzer system is presented as Figure A.1. The electrolyzer system is supplied with $A C$ power, $P_{\text {elec, }}$, which is used to power the auxiliaries, is consumed in the rectifier, and is converted into hydrogen and oxygen by the stack. The power consumed by the stack, $P_{\text {stack, }}$ is calculated by measuring the stack current and voltage. Based on these two measurements and the output hydrogen flow measurement, two other losses are calculated: the gas loss $\left(\mathrm{P}_{\mathrm{GL}}\right)$ and the thermal loss $\left(P_{T L}\right)$. Figure A.2.a gives a graphical representation of how to evaluate these two power losses and Table A.1 defines the efficiency terms used in this report. The thermal loss (top rectangle on Figure A.2.a) of the stack can be calculated by multiplying the stack current by the difference between the measured stack voltage and the voltage corresponding to the higher heating value $(\mathrm{HHV})$ of the reaction. Below this rectangle, the area corresponds to hydrogen power that, theoretically, could be produced by the stack. Knowing the actual hydrogen production rate, the real available hydrogen power is calculated as described by equation (1). Furthermore, the current equivalent to the real hydrogen flow, $l_{e q}$, is defined in equation (2). The difference between the actual current, $I_{\text {Stack }}$, and the current equivalent gives the amount of current that was consumed to produce the gas that was lost. Figure A.1.a schematically shows the areas corresponding to the real hydrogen output power available for the end-user $\left(\mathrm{P}_{\mathrm{H} 2}\right)$ and the gas loss power $\left(\mathrm{P}_{\mathrm{GL}}\right)$, which includes gas recombination in the stack as well as gas loss in the process (e.g., leaks and venting to atmosphere for process pressure control).

$$
\begin{aligned}
& P_{\mathrm{H}_{2}}=\dot{n}_{\mathrm{H}_{2}} \times H H V \\
& I_{\text {eq }}=\frac{2 \times F}{N_{\text {cell }}} \times \dot{n}_{\mathrm{H}_{2}}
\end{aligned}
$$

where: $P_{H_{2}} \quad$ Hydrogen power (W);

$$
\begin{array}{ll}
\dot{n}_{H_{2}} & \text { Hydrogen molar flow }\left(\mathrm{mol} . \mathrm{s}^{-1}\right) ; \\
\mathrm{HHV} & \text { High heating value }\left(285,830 \mathrm{~J} . \mathrm{mol}^{-1}\right) ; \\
I_{e q} & \text { Current equivalent to the real hydrogen flow (A); } \\
\mathrm{F} & \text { Faraday number }\left(96,485 \mathrm{C} \cdot \mathrm{mol}^{-1}\right) ; \text { and } \\
N_{\text {cell }} & \text { Number of cells. }
\end{array}
$$




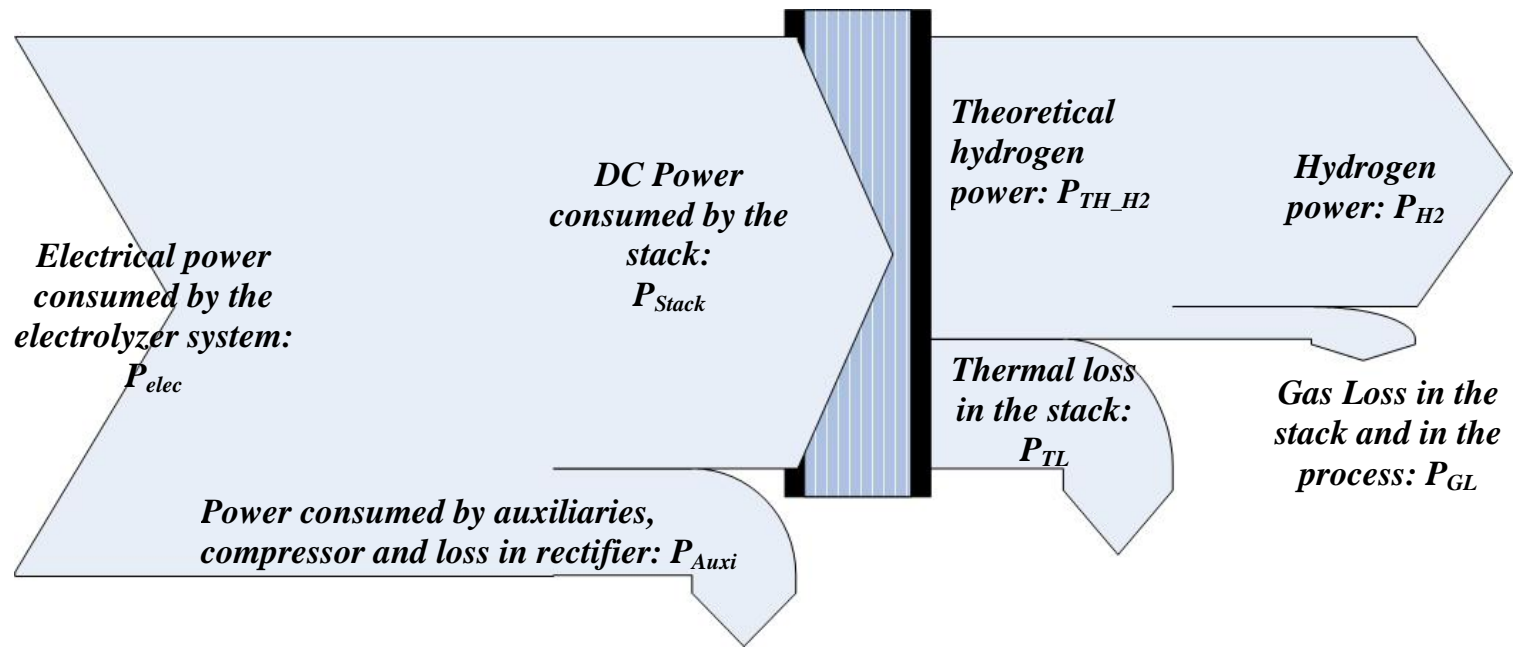

Figure A.1: Electrolyzer energy balance scheme.

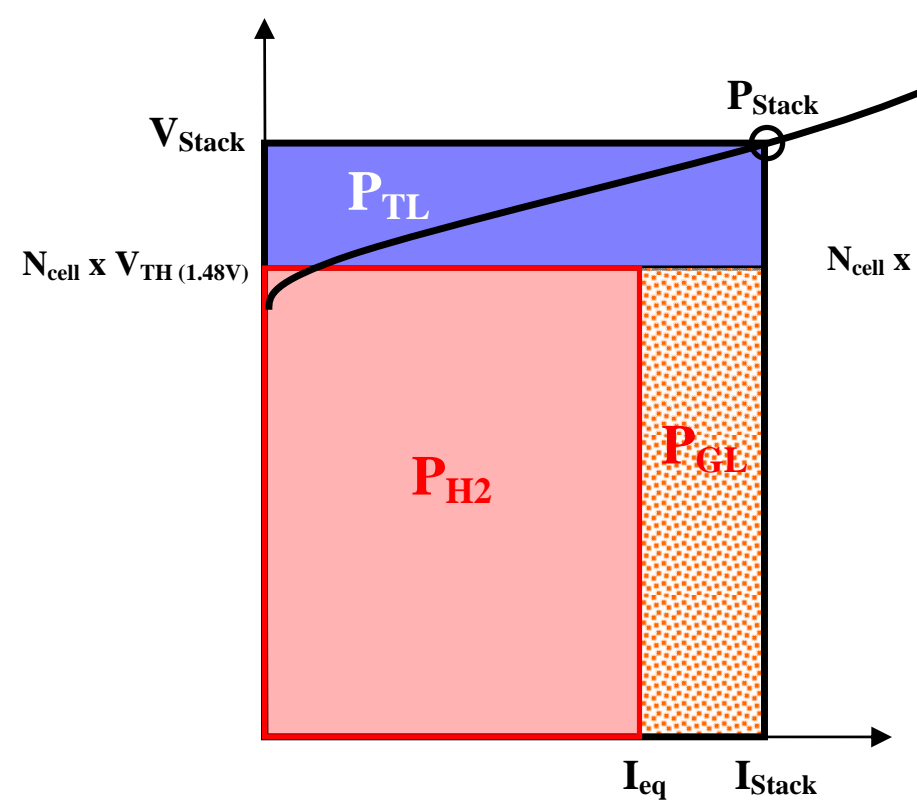

a) Electrolyzer

Figure A.2: Schematic showing gas loss power $\left(\mathrm{P}_{\mathrm{GL}}\right)$ and thermal loss power $\left(\mathrm{P}_{\mathrm{TL}}\right)$, given the stack current and voltage and the hydrogen flow for a) the electrolyzer and b) the FC.

A similar energy accounting approach is used when analyzing the fuel cell system (Figure A.3). The fuel cell system consumes hydrogen sent to the stack and produces electricity to supply its auxiliary loads $\left(P_{\text {Aux }}\right)$ and the load demand of the end-user $\left(P_{\text {elec }}\right)$. Even if there is hydrogen recirculation in the anode side, the gas efficiency is not $100 \%$. To evaluate the gas loss power, we use equation (2) to calculate the current equivalent, $\mathrm{I}_{\mathrm{eq}}$, to the flow consumed by the system. The right rectangle on Figure A.2b, represents the gas loss power $\left(\mathrm{P}_{\mathrm{GL}}\right)$ in the fuel cell system including gas recombination in the stack and gas loss in the system. The two other rectangles correspond to the usable electrical power $\left(P_{\text {Stack }}\right)$ and the thermal loss $\left(P_{T L}\right)$ in the stack. 


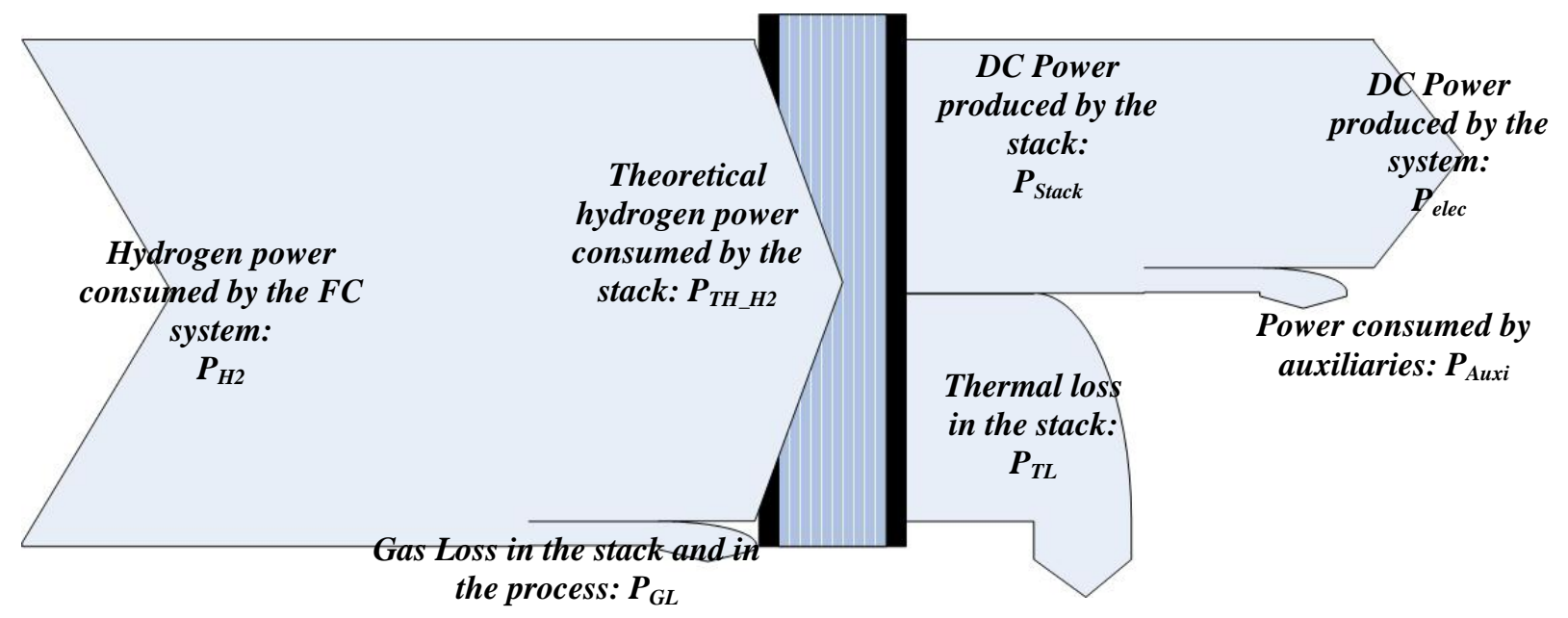

Figure A.3: Steady-state fuel cell energy balance scheme (without battery).

All the results presented in this study are expressed as efficiencies (higher heating value basis) and percentage losses. For the electrolyzer, the percentage losses are calculated by dividing the power loss by the AC power supplied to the complete system, where as the fuel cell percentage losses are calculated by dividing the power loss by the thermal power of hydrogen supplied to the system. All of these terms are defined in Table A.1 below.

Table A.1: Definitions of efficiency and loss terms used in the report.

\begin{tabular}{|c|c|c|}
\hline & Electrolyzer & Fuel Cell \\
\hline $\begin{array}{c}\text { Global } \\
\text { equation }\end{array}$ & $P_{\text {elec }}=P_{H_{2}}+P_{G L}+P_{T L}+P_{\text {Auxi }}$ & $P_{H_{2}}=P_{\text {elec }}+P_{G L}+P_{T L}+P_{\text {Auxi }}$ \\
\hline $\begin{array}{l}\text { System } \\
\text { efficiency }\end{array}$ & $P_{\mathrm{H}_{2}} / P_{\text {elec }}$ & $P_{\text {elec }} / P_{H_{2}}$ \\
\hline Gas Loss & $\begin{array}{c}P_{G L} / P_{\text {elec }}= \\
H H V \times\left[N_{\text {cell }} \times I_{\text {Stack }} /(2 \times F)-\dot{n}_{H_{2}}\right] / P_{\text {elec }}\end{array}$ & $\begin{array}{c}P_{G L} / P_{H_{2}}= \\
H H V \times\left\lfloor\dot{n}_{H_{2}}-N_{\text {cell }} \times I_{\text {Stack }} /(2 \times F)\right] / P_{H_{2}}\end{array}$ \\
\hline Thermal Loss & $\begin{array}{c}P_{T L} / P_{\text {elec }}= \\
{\left[P_{\text {Stack }}-H H V \times N_{\text {cell }} \times I_{\text {Stack }} /(2 \times F)\right] / P_{\text {elec }}}\end{array}$ & $\begin{array}{c}P_{T L} / P_{\mathrm{H}_{2}}= \\
{\left[H H V \times N_{\text {cell }} \times I_{\text {Stack }} /(2 \times F)-P_{\text {Stack }}\right] / P_{H_{2}}}\end{array}$ \\
\hline $\begin{array}{l}\text { Loss in } \\
\text { Auxiliary }\end{array}$ & $\left(P_{\text {Auxi }}-P_{\text {Compressor }}\right) / P_{\text {elec }}$ & $P_{\text {Auxi }} / P_{H_{2}}$ \\
\hline $\begin{array}{l}\text { Loss in the } \\
\text { Compressor }\end{array}$ & $P_{\text {Compressor }} / P_{\text {elec }}$ & - \\
\hline $\begin{array}{c}\text { Voltage } \\
\text { efficiency } \eta_{v}\end{array}$ & $\left(N_{\text {Cell }} \times 1.48\right) / V_{\text {Stack }}$ & $V_{\text {Stack }} /\left(N_{\text {Cell }} \times 1.48\right)$ \\
\hline $\begin{array}{c}\text { Gas efficiency* } \\
\eta_{F} \\
\end{array}$ & $\dot{n}_{\mathrm{H}_{2}} /\left[N_{\text {Cell }} \times I_{\text {Stack }} /(2 \times F)\right]$ & {$\left[N_{\text {Cell }} \times I_{\text {Stack }} /(2 \times F)\right] / \dot{n}_{H_{2}}$} \\
\hline $\begin{array}{c}\text { Stack } \\
\text { efficiency* }\end{array}$ & $P_{\mathrm{H}_{2}} / P_{\text {Stack }}=\eta_{v} \times \eta_{F}$ & $P_{\text {Stack }} / P_{H_{2}}=\eta_{v} \times \eta_{F}$ \\
\hline
\end{tabular}

* includes gas loss in the process 


\section{This page is intentional blank}




\section{APPENDIX B}

Hot Gas Clean Up System Development for the

Hawaii Natural Energy Institute Gasifier Facility

A final HNEI report previously completed is presented on the following pages. This report contains its own internal section numbering system. 
This page is intentional blank 


\title{
Hot Gas Clean Up System Development for the \\ Hawaii Natural Energy Institute Gasifier Facility
}

\author{
University of Hawaii \\ Scott Turn \\ Hong Cui \\ Vheissu Keffer \\ Donald Evans \\ Thai Tran \\ Michael Foley \\ Hawaii Natural Energy Institute \\ School of Ocean and Earth Sciences and Technology
}

June 2008 


\title{
Hot Gas Clean Up System Development for the Hawaii Natural Energy Institute Gasifier Facility
}

\begin{abstract}
The objective of this project was to develop hot gas clean up capabilities for the HNEI gasifier test facility to support hydrogen from biomass research. The product gas stream at the outlet of the hot gas filter was characterized for concentrations of permanent gas species $\left(\mathrm{CO}, \mathrm{CO}_{2}, \mathrm{H}_{2}\right.$, $\mathrm{CH}_{4}, \mathrm{~N}_{2}$ ) and contaminants including tar (principally benzene, naphthalene, and toluene) and sulfur $\left(\mathrm{H}_{2} \mathrm{~S}, \mathrm{COS}\right.$, and $\left.\mathrm{C}_{4} \mathrm{H}_{4} \mathrm{~S}\right)$ species, ammonia, and $\mathrm{NO}_{\mathrm{x}}$. Total tar concentration was in the dry product gas was $\sim 10 \mathrm{~g} \mathrm{~m}^{-3}$. Concentrations of $\mathrm{H}_{2} \mathrm{~S}, \mathrm{COS}$, and $\mathrm{C}_{4} \mathrm{H}_{4} \mathrm{~S}$ were 56,1 , and 1.3 ppmv, respectively. $\mathrm{NO}_{\mathrm{x}}$ and ammonia concentrations were determined to be 8.2 and 1,626 ppmv respectively.
\end{abstract}

A clean up strategy was developed to remove contaminant species or convert them to a benign form. Elements included sulfur removal using $\mathrm{ZnO}$ sorbent at $400^{\circ} \mathrm{C}$ and a gas hourly space velocity of $8,000 \mathrm{hr}^{-1}$. Under these conditions, the primary sulfur component, $\mathrm{H}_{2} \mathrm{~S}$, was reduced to $250 \mathrm{ppbv}$ and COS was reduced by a factor of 4 to similar levels. Thiophene concentrations were not affected.

Tar and methane were successfully converted to permanent gas species using nickel catalysts. Temperatures of $850^{\circ} \mathrm{C}$ and GHSV of $\sim 1 \mathrm{~m}^{3} \mathrm{~kg}^{-1} \mathrm{hr}^{-1}$ effectively removed tar compounds below levels of $0.1 \mathrm{~g}$ total tar $\mathrm{m}^{-3}$ dry gas. Acenaphthalene and pyrene were two compounds identified in the gas stream exiting the reactor. The Ni catalyst also resulted in reductions of $\mathrm{NH}_{3}$ from values of $\sim 1500$ ppmv to as low as 20 ppmv and complete conversion of methane and $\mathrm{NO}_{\mathrm{x}}$. Methane and tar conversion resulted in increased levels of $\mathrm{H}_{2}$ and $\mathrm{CO}$ in the product gas exiting the tar cracking unit. 


\subsection{Introduction}

Steam reforming is a method to convert biomass to synthesis gas (syngas) for the production of renewable liquid transportation fuels. In addition to the principal elements of $\mathrm{C}, \mathrm{H}$, and $\mathrm{O}$, biomass also contains minor and trace elements including $\mathrm{N}$ and $\mathrm{S}$. The main components of syngas exiting a reformer are $\mathrm{H}_{2}, \mathrm{CO}, \mathrm{CH}_{4}$, and $\mathrm{CO}_{2}$. Nitrogen and sulfur are also converted in the reformer and are present as contaminants in the syngas at concentrations typically less than $1 \%$ by volume. Identifying the contaminant species and knowing their concentrations in the raw syngas is important information for the design of systems that will use syngas to produce liquid fuels. The objective of this project to identify and quantify contaminant species present in the product gas and develop unit operations for the Hawaii Natural Energy Institute's fluidized bed gasifier facility to remove contaminants from the product gas stream or convert them to benign forms. Target compounds included those containing $\mathrm{N}$ and $\mathrm{S}$ and hydrocarbon species, $\mathrm{C}_{6}$ and higher. This report summarizes the results of this effort.

\subsection{Materials and Methods}

\subsection{Experimental}

A schematic of the HNEI bench scale fluidized bed reactor is shown in Figure B.1. The reactor is constructed of 310 stainless steel pipe, with a bed diameter of $89 \mathrm{~mm}$ and a freeboard diameter of $152 \mathrm{~mm}$. The reactor is externally heated by four, $4 \mathrm{~kW}$ heaters (Model 274A, Thermcraft, Inc., Winston-Salem, NC). Pressure taps, thermocouples and probe access ports are located along the height of the reactor. Fuel was fed to the reactor from a sealed fuel hopper via a variable speed metering screw. Nitrogen and steam were used as fluidizing agents for the tests. Nitrogen was added to the windbox below the distributor by individual mass flow controllers (Model 5851E, Brooks Instruments, Hatfield, PA). Steam was metered to the windbox from a steam generator via a calibrated control valve. Nitrogen was used as an inert trace gas to permit calculation of gas yields and to control fluidization. The bed material consisted of alumina beads with diameters in the range of 0.21 to $0.42 \mathrm{~mm}$ (Norton-Alcoa, Fort Smith, AR). Flow exits the reactor, passes through a heated, ceramic filter (Pall Process Filtration Corporation, Cortland, $\mathrm{NY}$ ), $6 \mathrm{~cm}$ in diameter and $0.49 \mathrm{~m}$ in length with a pore size of $3 \mu \mathrm{m}$. Filter elements have been operated at temperatures ranging from 600 to $850^{\circ} \mathrm{C}$. At the exit of the filter, the product gas can be directed through the series of downstream vessels for contaminant removal or destruction. Provision is also made to direct a fraction or the entire product gas stream to disposal by first passing it through a heat exchanger to remove condensate and then flaring it in a swirl combustor. This allows the gas flow rate through the down stream vessels to be varied. A sampling point is also located at the exit of the filter vessel to provide a slip stream of the product gas for characterization. All electronic signals are processed using two, 32 channel multiplexer amplifiers (Model SCXI-1100, National Instruments, Austin, TX) and a 12 bit, analog to digital converter board (National Instruments, Austin, TX) controlled by a personal computer. 


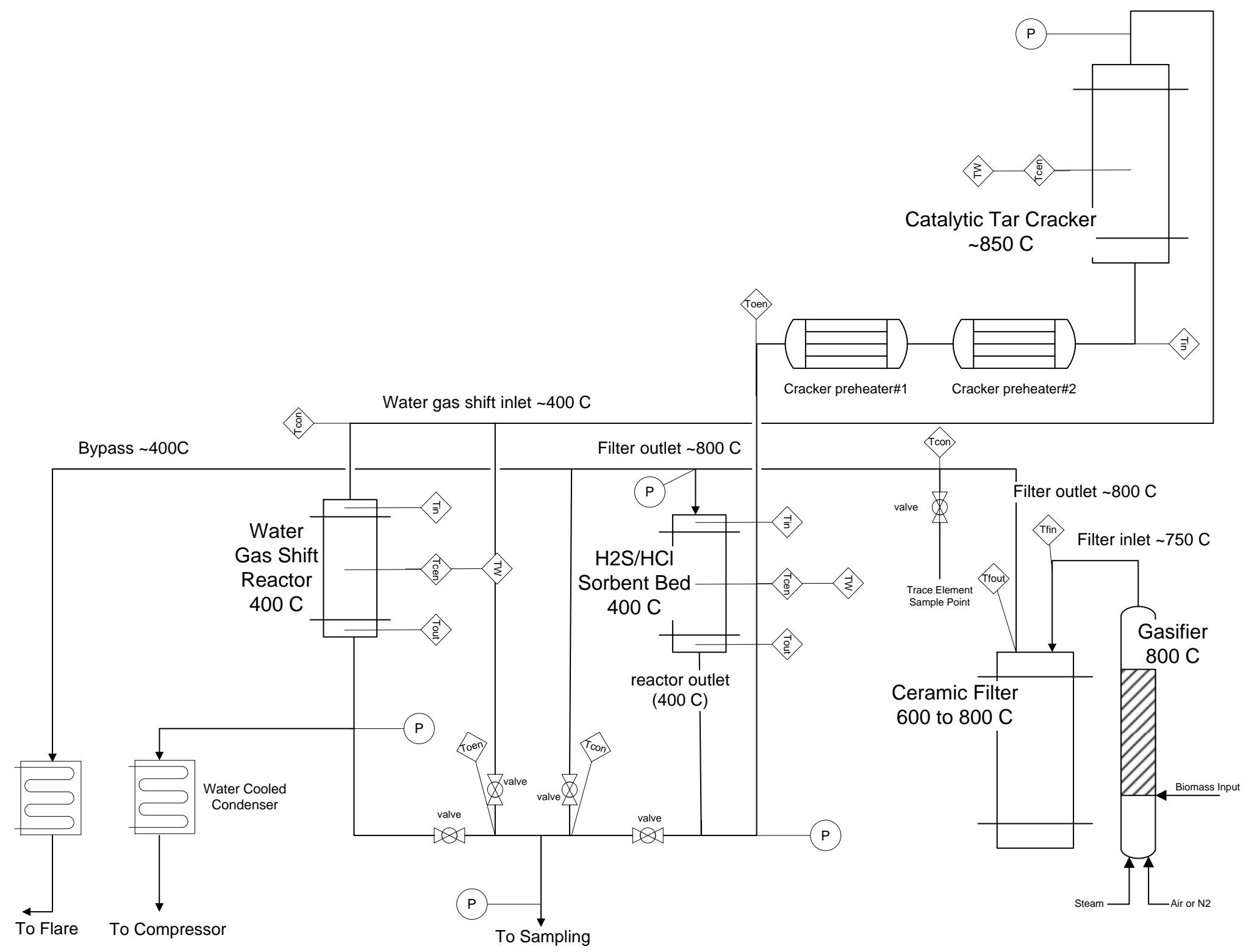

Figure B.1. Schematic diagram of the Hawaii Natural Energy Institute fluidized bed reactor system. 
The gas clean up system downstream of the heated filter consists of three vessels in series. Provision has been made to have all three in line during a test or to bypass individual units, with the method of operation depending on the test objectives. The first vessel downstream of the filter is a $76 \mathrm{~mm}$ inner diameter, fixed bed of solid sorbent that can be operated at temperatures up to $600^{\circ} \mathrm{C}$. A practical lower temperature limit of $300^{\circ} \mathrm{C}$ is mandated by the condensation point of tar compounds. At the exit of the first vessel, provision is made to direct a slip stream of the gas to a sampling system for characterization. The first vessel has been used to test removal of sulfur compounds and would be suitable for sorbent testing of $\mathrm{HCl}$ removal. Both sulfur and $\mathrm{HCl}$ are poisons for catalysts commonly used for tar and methane destruction, thus the location of the bed prior to the secondary tar cracking vessel.

After exiting the sorbent bed, the product gas stream passes through two preheaters to raise the gas temperature to $\sim 800^{\circ} \mathrm{C}$ prior to entering the catalytic tar cracker unit. The tar cracker unit is a $76 \mathrm{~mm}$ inner diameter, fixed bed equipped with heating elements that allow control of the bed temperature up to $850^{\circ} \mathrm{C}$. At the exit of the tar cracking unit, provision is made to direct a slip stream of the gas to a sampling system for characterization.

The product gas stream exiting the catalytic tar cracking unit is directed to the water gas shift reactor. This is a $76 \mathrm{~mm}$ inner diameter, fixed bed of shift catalyst equipped with heating elements that allow control of the bed temperature up to $600^{\circ} \mathrm{C}$. This provides the capability to upgrade the hydrogen content of the product gas by converting carbon monoxide present in the gas stream according to the water gas shift reaction, $\mathrm{CO}+\mathrm{H}_{2} \mathrm{O} \leftrightarrow \mathrm{H}_{2}+\mathrm{CO}_{2}$. At the exit of the tar cracking unit, provision is made to direct a slip stream of the gas to a sampling system for characterization.

Gas exiting the third vessel passes through a heat exchanger to remove condensate and can then be directed to the flare for disposal or to a compressor (Model A1-35, Fluitron, Inc., Ivyland, PA) capable of providing storage pressure to $3,447 \mathrm{kPa}$. Stored gas can be used for hydrogen purification studies using pressure swing adsorption or other appropriate technologies.

In preparation for a test, bed material and fuel were weighed and placed in the reactor and the fuel hopper, respectively. The fuel feed rate was also calibrated over a range of screw speeds prior to each test. The gasifier bed was preheated to the desired temperature using the external heaters with air flowing through the reactor until a stable temperature profile was obtained. Gas flow was then switched from air to the desired mixture of steam and nitrogen. After the reactor was once again stabilized, the feeder was turned on and the test begun. Flow was directed through the bypass line to the flare during the initial period of feeding until the gasifier had attained a steady operating condition, normally about two hours. When steady conditions were attained, flow was directed to down stream vessels as desired. Quantitative sampling, as described below, was performed when the system had attained a steady temperature and product gas distribution. At the conclusion of the test, fuel, fluidizing gases, and system heaters were shut down simultaneously. After the system had cooled, remaining fuel was removed from the feed hopper, char was recovered from the ceramic filter, and bed material was removed from the reactor. Each was sampled and weighed. 


\subsection{Sampling and Analytical Methods}

The fuels used in the gasifiation test were sampled and subjected to ultimate $(\mathrm{C}, \mathrm{H}, \mathrm{O}, \mathrm{N}, \mathrm{S}$ and $\mathrm{Cl}$ ), proximate (volatile, fixed carbon and ash), heating value, and elemental ash ( $\mathrm{Si}, \mathrm{Al}, \mathrm{Ti}, \mathrm{Fe}$, $\mathrm{Ca}, \mathrm{Mg}, \mathrm{Na}, \mathrm{K}, \mathrm{P}, \mathrm{S}, \mathrm{Cl}$, and $\mathrm{CO}_{2}$ ) analyses (Hazen Research, Inc., Golden, $\mathrm{CO}$ ). The process stream from the outlets of the gasifier or any of the three downstream vessels could be quantitatively sampled to determine the permanent gas species and concentrations, condensable light oil and tar species and concentrations, or concentrations of ammonia, oxides of nitrogen, and cyanide. The sampling program for a particular test depended on the test objective. A description of the sampling and analytical methods for each component follows.

The bulk gas stream that was directed through the bypass line to the flare first passed through a water-cooled heat exchanger followed by an ice-cooled condensate separator and a coalescing filter. The cool, dry, gas stream was directed through a gas meter that indicated gas flow rate and provided a record of the total gas volume over the duration of the test.

A sample of the product gas exiting the hot gas filter or any of the three downstream vessels could be directed to two on-line gas chromatographs (GC) equipped with automatic sampling valves. The first GC (AutoSystem, Perkin-Elmer, Norwalk, CT) injected a sample from the process at 20 minute intervals and was equipped with a $1.5 \mathrm{~m}$ by $3 \mathrm{~mm}$ packed column (Carboxen 1000, Supelco, Bellefonte, PA) and thermal conductivity detector that quantified the permanent gases $\mathrm{H}_{2}, \mathrm{~N}_{2}, \mathrm{CO}, \mathrm{CH}_{4}, \mathrm{CO}_{2}$, and $\mathrm{C}_{2} \mathrm{H}_{\mathrm{m}}$. The second $\mathrm{GC}$ (Model 2014, Shimadzu, Kyoto, Japan) injected a sample from the process at 10 minute intervals and was equipped with a capillary column (Rtx-1, 60m-0.53-7um, Restek Corporation) and sulfur chemiluminescence detector (SCD) (Sievers Model 355, GE Analytical Instruments, Boulder, CO) that quantified sulfur containing species. Both GC's were calibrated using certified standard gases prior to each test.

A sample gas stream could also be directed to a three channel, on-line, nondispersive infrared gas analyzer (Model URAS 10E, Applied Automation/Hartmann \& Braun, Bartlesville, OK) equipped to analyze $\mathrm{CO}, \mathrm{CO}_{2}$ and $\mathrm{CH}_{4}$, and a continuous-flow, thermal-conductivity detector (Model CALDOS 5G, Applied Automation/Hartmann \& Braun, Bartlesville, OK) which measured the product gas $\mathrm{H}_{2}$ concentration. An additional gas stream was directed to a chemiluminescent analyzer for the detection of oxides of nitrogen as NO (Model 10-AR, Thermo Environmental Instruments, Franklin, MA). The on-line analyzers were calibrated prior to each test using certified zero and span gases.

A sample stream could be extracted from the exit of the high temperature filter or any of the three downstream vessels for the analysis of tar and light oil $\left(\geq \mathrm{C}_{6}\right)$ species, ammonia, and cyanide. Each required a different sampling technique and only one sample was acquired at any given time. All of the analytes were separated from the gas stream using impingers filled with liquid trapping solution designed to extract the target analyte from the gas stream and hold it in solution. The dry gas exiting the impingers passed through a vacuum pump, a coalescing filter, and a gas meter that indicated gas flow rate and provided a record of the total gas volume drawn through the impinger set during the sampling period. 
Tar species were sampled using series of six impingers that employed 2-propanol as a trapping solution in the first five impingers. Impingers 1, 2, and 4 were placed in a water bath maintained at 35 to $40^{\circ} \mathrm{C}$ and impingers 3,5 , and 6 were placed in an ice/rock salt bath maintained at $-12^{\circ} \mathrm{C}$. The sample flow through the impinger set was maintained at $\sim 5$ liter per minute using a vacuum pump and a total of 120 liters of dry gas was extracted for each sample. The trapping solution recovered from each of the three impinger sets was analyzed after the test was completed using a GC (AutoSystem, Perkin-Elmer, Norwalk, CT) equipped with a capillary column (Rtx-1, 60m0.53-7um, Restek Corporation) and a flame ionization detector (FID). A $200 \mu \mathrm{g}$ per ml primary standard (AccuStandard, New Haven, CT) was used to produce a six point $(1,5,25,50,100$, and $200 \mu \mathrm{g}$ per $\mathrm{ml}$ ) calibration curve for each of the following individual tar components; benzene $\left(\mathrm{C}_{6} \mathrm{H}_{6}\right)$, pyridine $\left(\mathrm{C}_{5} \mathrm{H}_{5} \mathrm{~N}\right)$, toluene $\left(\mathrm{C}_{6} \mathrm{H}_{5} \mathrm{CH}_{3}\right)$, guaiacol $\left(\mathrm{C}_{7} \mathrm{H}_{8} \mathrm{O}_{2}\right)$, phenol $\left(\mathrm{C}_{6} \mathrm{H}_{5} \mathrm{OH}\right)$, indene $\left(\mathrm{C}_{9} \mathrm{H}_{8}\right)$, 4-methyl guaiacol $\left(\mathrm{C}_{8} \mathrm{H}_{10} \mathrm{O}_{2}\right)$, naphthalene $\left(\mathrm{C}_{10} \mathrm{H}_{8}\right)$, acenaphthalene $\left(\mathrm{C}_{12} \mathrm{H}_{8}\right)$, fluorene $\left(\mathrm{C}_{13} \mathrm{H}_{10}\right)$, phenanthrene $\left(\mathrm{C}_{14} \mathrm{H}_{10}\right)$, anthracene $\left(\mathrm{C}_{14} \mathrm{H}_{10}\right)$, fluoranthene $\left(\mathrm{C}_{16} \mathrm{H}_{10}\right)$, and pyrene $\left(\mathrm{C}_{16} \mathrm{H}_{10}\right)$. A 5000 ppmv solution of decane in acetone was prepared as an internal standard and $10 \mu \mathrm{l}$ was added to each sample as an internal standard ( $37 \mu \mathrm{g}$ decane per $\mathrm{ml}$ analyzed sample). The internal standard was used for evaluating results and to compute a response factor for estimating concentrations of unidentified peaks in sample chromatograms. Each sample was analyzed twice; once as undiluted sample and again diluted to $10 \%$ strength using acetone. This technique was used to ensure that all analytes were evaluated at concentrations that fell within the calibration range of 1 to $200 \mu \mathrm{g}$ per $\mathrm{ml}$. The tar trapping solutions were also used to determine the water content of the product gas. Samples of the trapping solution recovered from the three impinger set were analyzed for water using Karl Fischer titration (Model DL31 Karl Fischer titrator, Mettler-Toledo, Inc., Columbus, OH). Water content of the impinger trapping solution was related to the gas volume drawn through the impingers to calculate the partial pressure of water in the product gas.

Ammonia was sampled using a single impinger that employed dilute sulfuric acid as a trapping solution. The impinger was placed in an ice bath. The sample flow through the impinger was maintained at $\sim 2$ liter per minute using a vacuum pump and a total of 40 liters of dry gas was extracted for each sample. The trapping solution recovered from each of the three impinger sets was analyzed after the test was completed using an ion selective electrode (ISE) (Part No. EW27502-00, Cole Parmer Instrument Co., Vernon Hills, IL). A primary calibration standard was prepared by dissolving reagent grade $\mathrm{NH}_{4} \mathrm{Cl}$ in $0.1 \mathrm{~N} \mathrm{H}_{2} \mathrm{SO}_{4}$ solution. Lower concentration calibration standards were produce by serially diluting the primary standard.

Cyanide was sampled using a set of four impingers. The first impinger contained a solution of $10 \%$ lead acetate for the removal of acid gases, the second impinger was empty, and the third and fourth impingers contained a $0.1 \mathrm{~N}$ solution of sodium hydroxide. The sample flow through the impinger set was maintained at $\sim 2$ liter per minute using a vacuum pump and a total of 40 liters of dry gas was extracted for each sample. The trapping solution recovered from the impinger set was analyzed after the test was completed using an ion selective electrode (Part No. 13642264, Fisher Scientific, Houston, TX). A primary calibration standard was prepared by dissolving reagent grade $\mathrm{NaCN}$ in $0.1 \mathrm{~N} \mathrm{NaOH}$ solution. Lower concentration calibration standards were produce by serially diluting the primary standard. 
Trace element analysis was performed by extracting a sample stream from an isolation valve located at the exit of the hot gas filter as indicated in Figure B.1. For trace element analysis it is important that sample contamination is avoided. Immediately upon exiting the isolation valve, all surfaces that the sample flow contacts are composed of either quartz or teflon. The $\sim 600^{\circ} \mathrm{C}$ sample flow exiting the isolation valve was directed into $9.5 \mathrm{~mm}$ quartz tube encased in a stainless steel cooling water jacket that reduced the temperature of the gas to $\sim 150^{\circ} \mathrm{C}$. A 9.5 $\mathrm{mm}$ compression fitting made from teflon was used to connect the quartz tube to flexible teflon tubing of the same diameter and the direct the flow to a set of four impingers made of borosilicate glass. The first impinger in the set had a volume of $1,500 \mathrm{ml}$ and the volume of the three remaining impingers was $500 \mathrm{ml}$. The second and third impingers contained $100 \mathrm{ml}$ of trapping solution containing $5 \% \mathrm{HNO}_{3}$ and $10 \% \mathrm{H}_{2} \mathrm{O}_{2}$ with the balance made up of Type II deionized water. The sample flow through the impinger set was maintained at $\sim 12$ liter per minute using a vacuum pump and a total of $\sim 1000$ liters of dry gas was extracted for each sample. The trapping solution recovered from the impinger set was subjected to microwave digestion in concentrated nitric acid and was subsequently analyzed using an inductively coupled plasma (ICP) unit equipped with an optical emission spectrophotometer (OES). The system was calibrated using a primary calibration standard that was used to produce a curve by serial dilution. Analysis was performed for the elements $\mathrm{Fe}, \mathrm{K}, \mathrm{Mg}, \mathrm{Mn}, \mathrm{Mo}, \mathrm{Na}, \mathrm{Ni}, \mathrm{P}, \mathrm{Pb}, \mathrm{Si}, \mathrm{Sr}, \mathrm{Ti}$, $\mathrm{V}$, and $\mathrm{Zn}$.

\subsection{Results}

\subsection{Fuel Analysis}

A single fuel lot was used during the tests of the hot gas clean up components in the Hawaii Natural Energy Institute gasifier facility. Leucaena leucocephala was harvested from experimental plots at the Waimanalo Experiment Station of the Unversity of Hawaii. The fuel lot was dried in a forced ambient air drying bed until it had reached equilibrium moisture content, about $10 \%$ dry basis. The fuel lot was sampled and sent to Hazen Research for analysis. Results of the analyses are shown in Table B.1. Material loaded into the fuel feed hopper prior to the gasification tests was subjected to moisture analysis. A typical result is also shown in Table B.1. 
Table B.1. Results of analyses on Leucaena leucocephala sample obtained from the fuel lot harvested at the University of Hawaii Waimanalo Experiment Station.

\begin{tabular}{lrlr}
\hline Moisture Content, as Fired (\% dry basis) & 7.5 & & \\
Proximate Analysis (\% dry basis) & & \multicolumn{1}{c}{ Ash Analysis (\% dry basis) } & \\
Ash & 0.86 & $\mathrm{SiO}_{2}$ & 2.92 \\
Volatiles & 81.81 & $\mathrm{Al}_{2} \mathrm{O}_{3}$ & 0.48 \\
Fixed Carbon & 15.78 & $\mathrm{TiO}_{2}$ & 0.09 \\
& & $\mathrm{Fe}_{2} \mathrm{O}_{3}$ & 0.73 \\
HHV (MJ/kg) & 19.5 & $\mathrm{CaO}$ & 31.70 \\
HHV (BTU/lb) & 8,390 & $\mathrm{MgO}$ & 11.00 \\
& & $\mathrm{Na}_{2} \mathrm{O}$ & 2.72 \\
Ultimate Analysis (\% dry basis) & & $\mathrm{K}_{2} \mathrm{O}$ & 20.60 \\
C & 53.08 & $\mathrm{P}_{2} \mathrm{O}_{5}$ & 7.20 \\
$\mathrm{H}$ & 6.13 & $\mathrm{SO}_{3}$ & 1.39 \\
O (by difference) & 39.43 & $\mathrm{Cl}_{2}$ & 4.05 \\
N & 0.31 & $\mathrm{CO}_{2}$ & 17.16 \\
S & 0.05 & $\mathrm{Undetermined}$ & -0.34 \\
Cl & 0.13 & & \\
Ash & 0.87 & & \\
\hline
\end{tabular}

\subsection{Characterization of Gasifier Product Stream}

A summary of typical gasifier and ceramic filter operating conditions is provided in Table B.2 based on a test conducted on April 11, 2008. As described in Figure B.1, the reactor is equipped with electric heaters to maintain temperature. An average of four thermocouples inserted in the bed above the fuel feeding point was calculated to be $800{ }^{\circ} \mathrm{C}$. Average feed rates of bagasse and steam were 0.97 and $1.93 \mathrm{~kg}$ per hour, respectively, providing an average steam to bagasse ratio of 1.98. Nitrogen flowed to the reactor at a rate of $12 \mathrm{slpm}$ to aid in fluidization. Note that quantities may be reported on the basis of three gas volumes throughout this report; (1) dry product gas volume, this includes gas that is derived from the fuel and the $\mathrm{N}_{2}$ injected into the reactor, (2) dry, $\mathrm{N}_{2}$ free, product gas, this is the gas that is derived from the fuel, and (3) wet, $\mathrm{N}_{2}$ free, product gas, this includes moisture removed by trapping, analyzed by Karl Fischer titration, and then added back to the volume of dry, $\mathrm{N}_{2}$ free, gas produced from the fuel. Unless noted otherwise, all values are reported at standard temperature and pressure (STP) which is defined as 1 atm and $0{ }^{\circ} \mathrm{C}$.

The high temperature ceramic filter was operated at an average temperature of $800{ }^{\circ} \mathrm{C}$ during the test. The mass of char recovered from the filter after the test totaled $206 \mathrm{~g}$. Concentration of char in the dry product gas was calculated to be $15.3 \mathrm{~g} \mathrm{per}^{3}$ of dry gas at STP. Note that the average partial pressure of water in the product gas was calculated to be $0.45 \mathrm{~atm}$. Results of the permanent gas species analysis by GC are also presented in Table B.2. The average composition of the gas exiting the hot filter unit was $32.2 \% \mathrm{H}_{2}, 39.0 \% \mathrm{~N}_{2}, 7.5 \% \mathrm{CO}, 4.1 \% \mathrm{CH}_{4}, 16.6 \% \mathrm{CO}_{2}$, 
$0.6 \% \mathrm{C}_{2} \mathrm{H}_{4}$, and $0.1 \% \mathrm{C}_{2} \mathrm{H}_{6}$. Gas yield under this set of reactor conditions was $2.15 \mathrm{~m}^{3}$ (STP) $\mathrm{kg}^{-1}$ of biomass.

Table B.2. Summary of gasifier operating conditions and primary process data from test conducted April 11, 2008.

\begin{tabular}{|c|c|}
\hline Average reactor temperature $\left({ }^{\circ} \mathrm{C}\right)$ & 800 \\
\hline Total fuel fed to reactor (wet kg) & 6.75 \\
\hline Duration of fuel feeding (hr) & 6.45 \\
\hline Wet feed rate $\left(\mathrm{kg} \mathrm{hr}^{-1}\right)$ & 1.05 \\
\hline Fuel moisture content ( $\%$ wet basis) & 7.1 \\
\hline Dry feed rate $\left(\mathrm{kg} \mathrm{hr}^{-1}\right)$ & 0.972 \\
\hline Steam feed rate $\left(\mathrm{kg} \mathrm{hr}^{-1}\right)$ & 1.93 \\
\hline $\mathrm{N}_{2}$ flow to gasifier (slpm) & 12.0 \\
\hline Steam to dry biomass ratio (-) & 1.98 \\
\hline Ceramic filter temperature $\left({ }^{\circ} \mathrm{C}\right)$ & 800 \\
\hline Char collected from ceramic filter $(\mathrm{g})$ & 206 \\
\hline Average char concentration in dry, product gas at STP $\left(\mathrm{g} \mathrm{m}^{-3}\right)$ & 15. \\
\hline Dry gas yield at STP, measured (m dry gas $\mathrm{kg}^{-1}$ dry fuel) & 2.15 \\
\hline Average $\mathrm{H}_{2} \mathrm{O}$ partial pressure of wet gas at STP $(\mathrm{atm})$ & 0.4 \\
\hline
\end{tabular}

Dry Gas Composition (average \pm standard deviation)

$\begin{array}{lr}\mathrm{H}_{2}(\% \text { from GC) } & 32.2 \pm 2.3 \\ \mathrm{~N}_{2}(\% \text { from GC) } & 39.0 \pm 3.6 \\ \mathrm{CO}(\% \text { from GC) } & 7.5 \pm 0.6 \\ \mathrm{CH}_{4}(\% \text { from GC) } & 4.1 \pm 0.2 \\ \mathrm{CO}_{2}(\% \text { from GC) } & 16.6 \pm 1.2 \\ \mathrm{C}_{2} \mathrm{H}_{2}(\% \text { from GC) } & 0.0 \pm 0.0 \\ \mathrm{C}_{2} \mathrm{H}_{4}(\% \text { from GC) } & 0.6 \pm 0.2 \\ \mathrm{C}_{2} \mathrm{H}_{6}(\% \text { from GC) } & 0.1 \pm 0.01 \\ \mathrm{H}_{2} \mathrm{~S}(\text { ppmv }) & \\ \mathrm{COS}(\text { ppmv }) & 56.0 \pm 8.1 \\ \mathrm{C}_{4} \mathrm{H}_{4} \mathrm{~S} & 1.0 \pm 0.1 \\ & 1.3 \pm 0.3 \\ \mathrm{NO}(\text { ppmv }) & \\ \text { Ammonia (ppmv) } & 8.3 \\ \end{array}$

Gas composition measurements made with the continuous, on-line gas analyzers are presented in Figure B.2 and compared against the GC measurements in Figures B.3 and B.4. The continuous gas measurements are presented from the commencement of fuel feeding until the end of the test and include periods when the flow from the gasifier was diverted through a catalytic tar cracking unit from 11:30 to 14:30. Agreement between the two measurement methods is generally good. 
Data on the concentration of sulfur species measured at the exit of the hot filter during the Leucaena gasification test are presented in Table B.2. Three sulfur species, hydrogen sulfide $\left(\mathrm{H}_{2} \mathrm{~S}\right)$, carbonyl sulfide $(\mathrm{COS})$, and thiophene $\left(\mathrm{C}_{4} \mathrm{H}_{4} \mathrm{~S}\right)$, were identified and their average concentrations in the dry product gas were 56.0, 1.0, and $1.3 \mathrm{ppmv}$, respectively.

Two ammonia measurements were made at the outlet to the hot filter. The average of the two values was 1,626 ppmv $\mathrm{NH}_{3}$ in the dry product gas. Oxides of nitrogen $\left(\mathrm{NO}_{\mathrm{x}}\right)$ were also measured in the product gas stream using a continuous gas analyzer as shown in Figure B.2. $\mathrm{NO}_{\mathrm{x}}$ emissions are characterized by an initial, two-hour, transient period after startup followed by relatively constant values that averaged 8.3 ppmv. Recall that the sampling point in Figure B.2 was located at the hot gas filter exit from 09:00 to 11:30 and 14:30 to 15:06, and at the exit of the tar cracking unit from 11:30 to 14:30.

Table B.3 presents data on tar species identified in six individual samples taken at the exit of the hot gas filter over the course of four test days. With consistency, the data show that benzene, naphthalene, and toluene, are the species present in greatest abundance with concentrations of $5.5,1.4$, and $0.6 \mathrm{~g} \mathrm{~m}^{-3}$, respectively. On average, the total of individual species and unidentified compound quantified by response factor methodology was $9.6 \mathrm{~g} \mathrm{~m}^{-3}$ and identified compounds accounted for $>85 \%$ of the total, with only one exception.
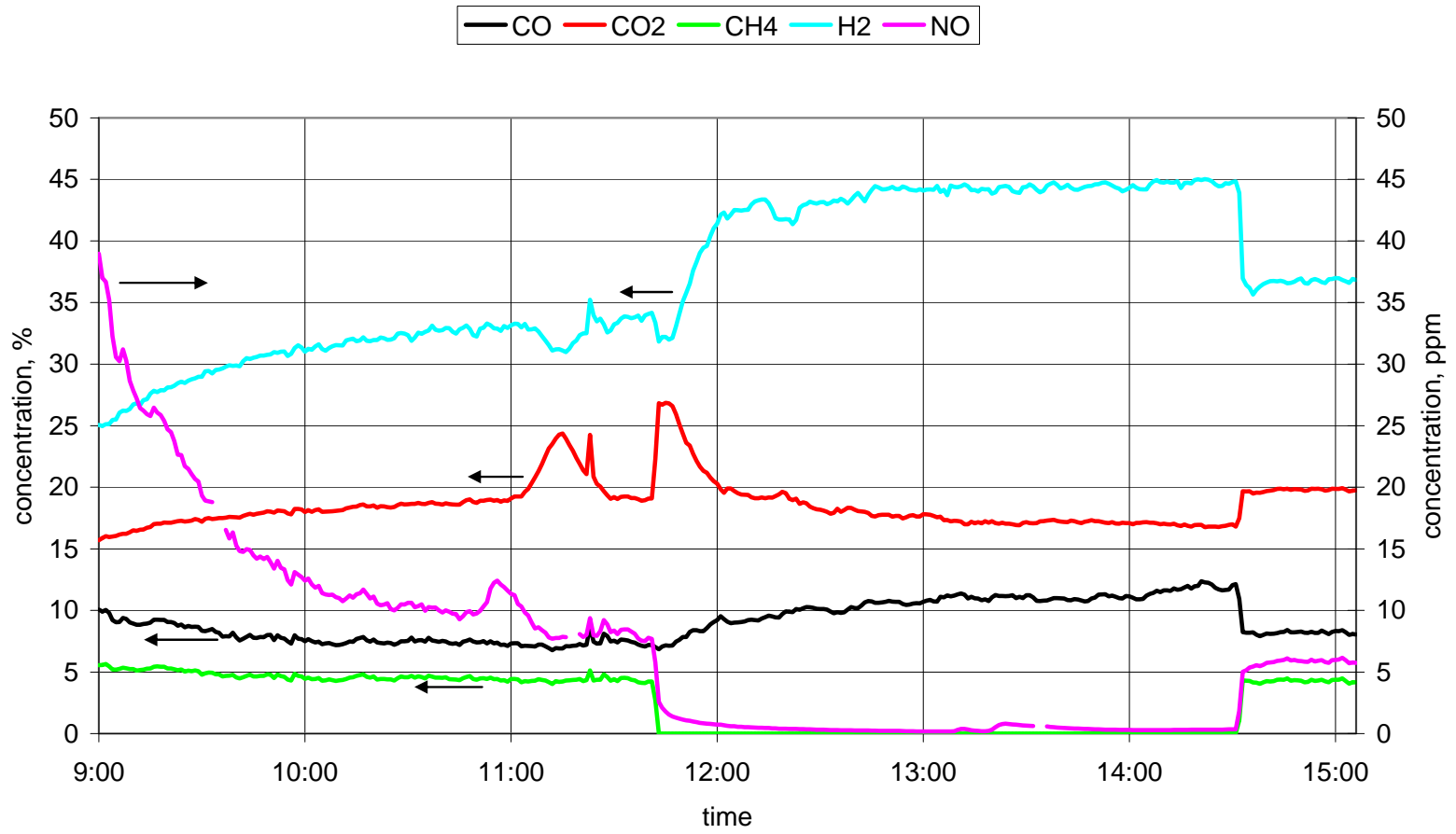

Figure B.2. Gas composition of the product gas measured by continuous gas analyzers. Sample points are (1) at the exit of the hot gas filter from 09:00 to 11:30 and 14:30 to 15:06, and (2) at the exit of the tar cracking unit from 11:30 to 14:30. 


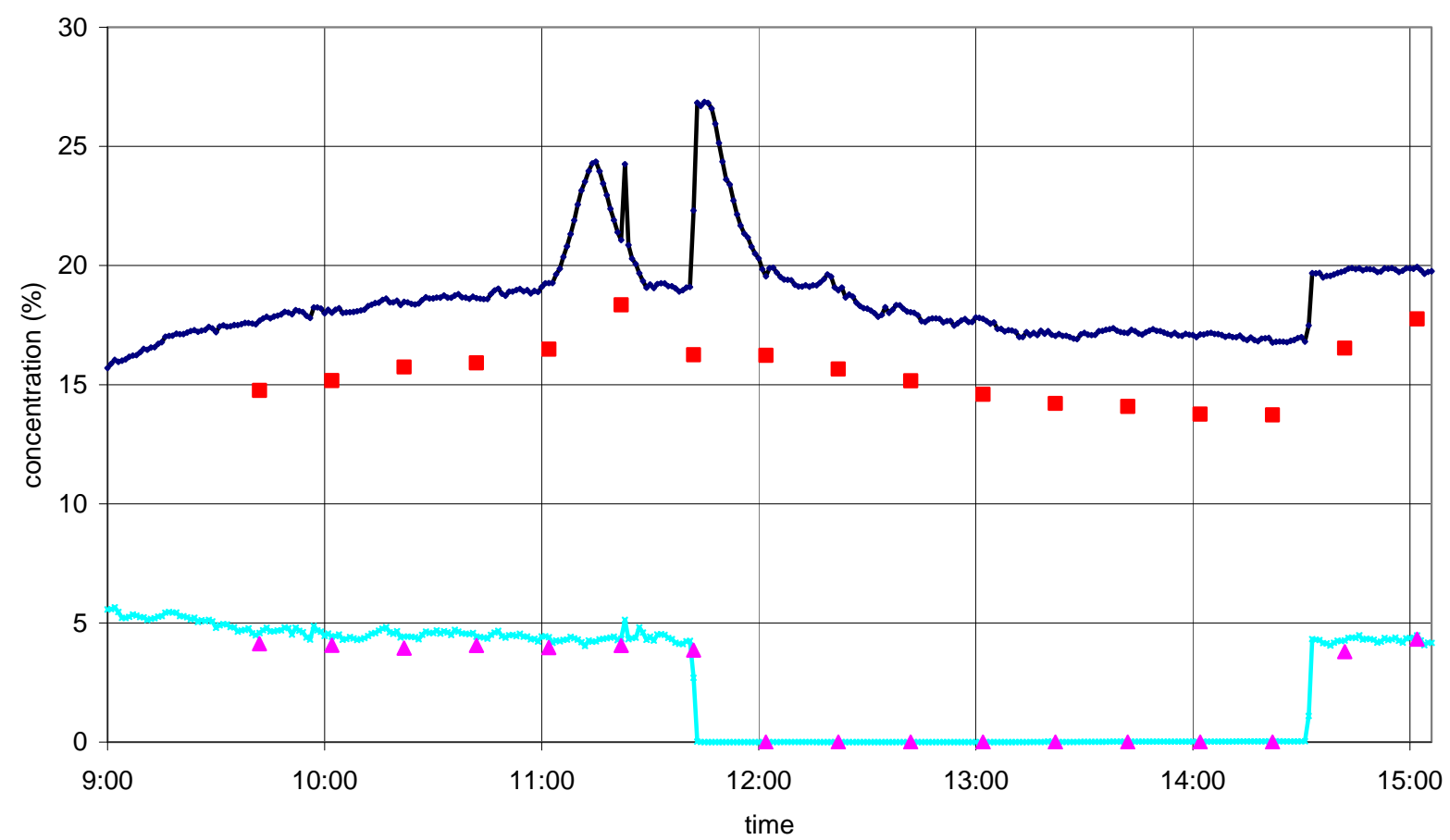

Figure B.3. Comparison of the product gas $\mathrm{CO}_{2}$ and $\mathrm{CH}_{4}$ measurements by continuous gas analyzers and GC. Sample points are (1) at the exit of the hot gas filter from 09:00 to 11:30 and 14:30 to $15: 06$, and (2) at the exit of the tar cracking unit from 11:30 to 14:30. 


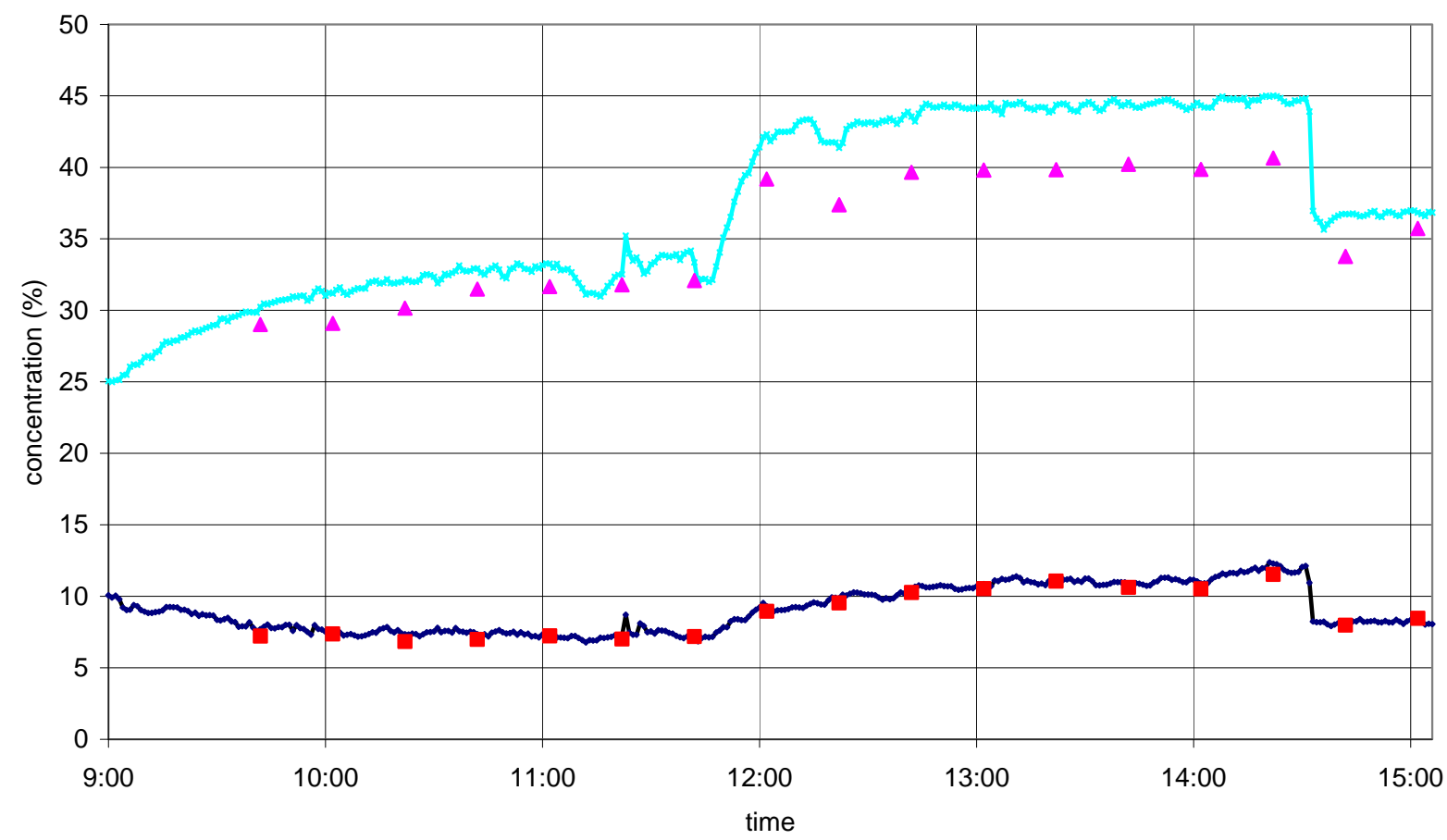

Figure B.4. Comparison of the product gas $\mathrm{CO}$ and $\mathrm{H}_{2}$ measurements by continuous gas analyzers and GC. Sample points are (1) at the exit of the hot gas filter from 09:00 to 11:30 and 14:30 to $15: 06$, and (2) at the exit of the tar cracking unit from 11:30 to 14:30. 
Table B.3. Summary of tar species in raw product gas exiting the hot gas filter.

\begin{tabular}{|lr|r|r|r|r|r|r|r|r|}
\hline & \multicolumn{7}{|c|}{080129} & \multicolumn{7}{c|}{080228} & 080403 & 080411 & Average & St. Dev. \\
\hline Test Date & \multicolumn{9}{|c|}{ Concentration, $\mathrm{g} \mathrm{m}^{-3}$} \\
\hline Benzene & 5.45 & 5.01 & 4.28 & 6.80 & 6.69 & 5.01 & 5.54 & 1.01 \\
\hline Pyridine & 0.11 & 0.08 & 0.05 & 0.15 & 0.12 & 0.06 & 0.10 & 0.04 \\
\hline Toluene & 0.79 & 0.55 & 0.42 & 1.26 & 0.54 & 0.21 & 0.63 & 0.36 \\
\hline Guaiacol & 0.25 & 0.84 & 0.30 & bdl & 0.04 & 0.04 & 0.24 & 0.32 \\
\hline Phenol & 0.05 & 0.07 & bdl & 0.18 & 0.06 & bdl & 0.06 & 0.07 \\
\hline Indene & 0.05 & 0.07 & 0.07 & 0.04 & 0.02 & 0.02 & 0.04 & 0.02 \\
\hline 4-methyl- guaiacol & bdl & bdl & bdl & bdl & bdl & bdl & bdl & bdl \\
\hline Naphthalene & 1.20 & 0.88 & 0.57 & 3.36 & 1.57 & 1.13 & 1.45 & 0.99 \\
\hline Acenaphthalene & 0.07 & 0.01 & 0.18 & 0.21 & 0.07 & bdl & 0.09 & 0.09 \\
\hline Fluorine & 0.01 & bdl & 0.12 & 0.05 & 0.02 & bdl & 0.03 & 0.05 \\
\hline Phenanthrene & 0.10 & 0.04 & 0.45 & 0.22 & 0.11 & bdl & 0.15 & 0.16 \\
\hline Anthracene & bdl & bdl & 0.77 & 0.04 & 0.01 & bdl & 0.14 & 0.31 \\
\hline Fluoranthene & 0.01 & bdl & 0.14 & 0.05 & 0.02 & bdl & 0.03 & 0.05 \\
\hline Pyrene & 0.02 & bdl & bdl & 0.06 & 0.02 & bdl & 0.02 & 0.02 \\
\hline Unidentified Total & 1.04 & 1.23 & 1.74 & 1.09 & 0.91 & 0.52 & 1.09 & 0.40 \\
\hline Total Tar & 9.15 & 8.76 & 9.09 & 13.51 & 10.20 & 6.98 & 9.61 & 2.18 \\
\hline $\begin{array}{l}\text { Identified } \\
\text { compounds as } \\
\text { fraction of Total }\end{array}$ & 0.89 & 0.86 & 0.81 & 0.92 & 0.91 & 0.93 & & \\
\hline
\end{tabular}




\subsection{Hot Gas Clean Up Activities}

Results of efforts to remove or convert contaminants identified in Tables B2 and B.3 (S, $\mathrm{N}$, and tar) are described below.

The removal of $\mathrm{H}_{2} \mathrm{~S}$ using $\mathrm{ZnO}$ is a common practice in the petrochemical industry and occurs according to the reaction:

$$
\mathrm{ZnO}+\mathrm{H}_{2} \mathrm{~S} \longrightarrow \mathrm{ZnS}+\mathrm{H}_{2} \mathrm{O}
$$

A sample of commercial sorbent was acquired and used in a series of tests in the gasifier facility. A $200 \mathrm{~cm}^{3}$ sample was placed in the sulfur sorbent bed and tests were conducted to determine the effects of gas hourly space velocity and sorbent temperature. Gas hourly space velocity (GHSV) is calculated by dividing the wet gas volumetric flow rate at STP by the volume of sorbent and has units of $\mathrm{hr}^{-1}$, i.e. this represents the number of times the sorbent bed gas volume is changed in an hour. The inverse of GHSV is residence time, the time it takes gas to pass through the sorbent bed at the prescribed flow rate. An alternative definition divides the wet gas flow rate at STP by the mass of sorbent or catalyst and has units of $\mathrm{m}^{3} \mathrm{~kg}^{-1} \mathrm{hr}^{-1}$. The inverse of this quantity is also used in the literature.

Figure B.5 presents the results of tests conducted at a GHSV of $8,036 \mathrm{hr}^{-1}$ and over a range of temperatures. The data indicate that at temperatures of 350 and $400^{\circ} \mathrm{C}$, the $\sim 50$ ppmv $\mathrm{H}_{2} \mathrm{~S}$ in the inlet stream to the reactor is nearly complete, reduced to levels of $\sim 100$ ppbv. The data also show that the concentration of COS is also reduced under these conditions, decreasing roughly one order of magnitude from 1 to $0.1 \mathrm{ppmv}$. Sorbent temperatures of $450^{\circ} \mathrm{C}$ and higher, result in greater concentrations of $\mathrm{H}_{2} \mathrm{~S}$ and COS in the outlet stream. Thiophene present in the inlet gas stream is largely unaffected by exposure to the sorbent. 


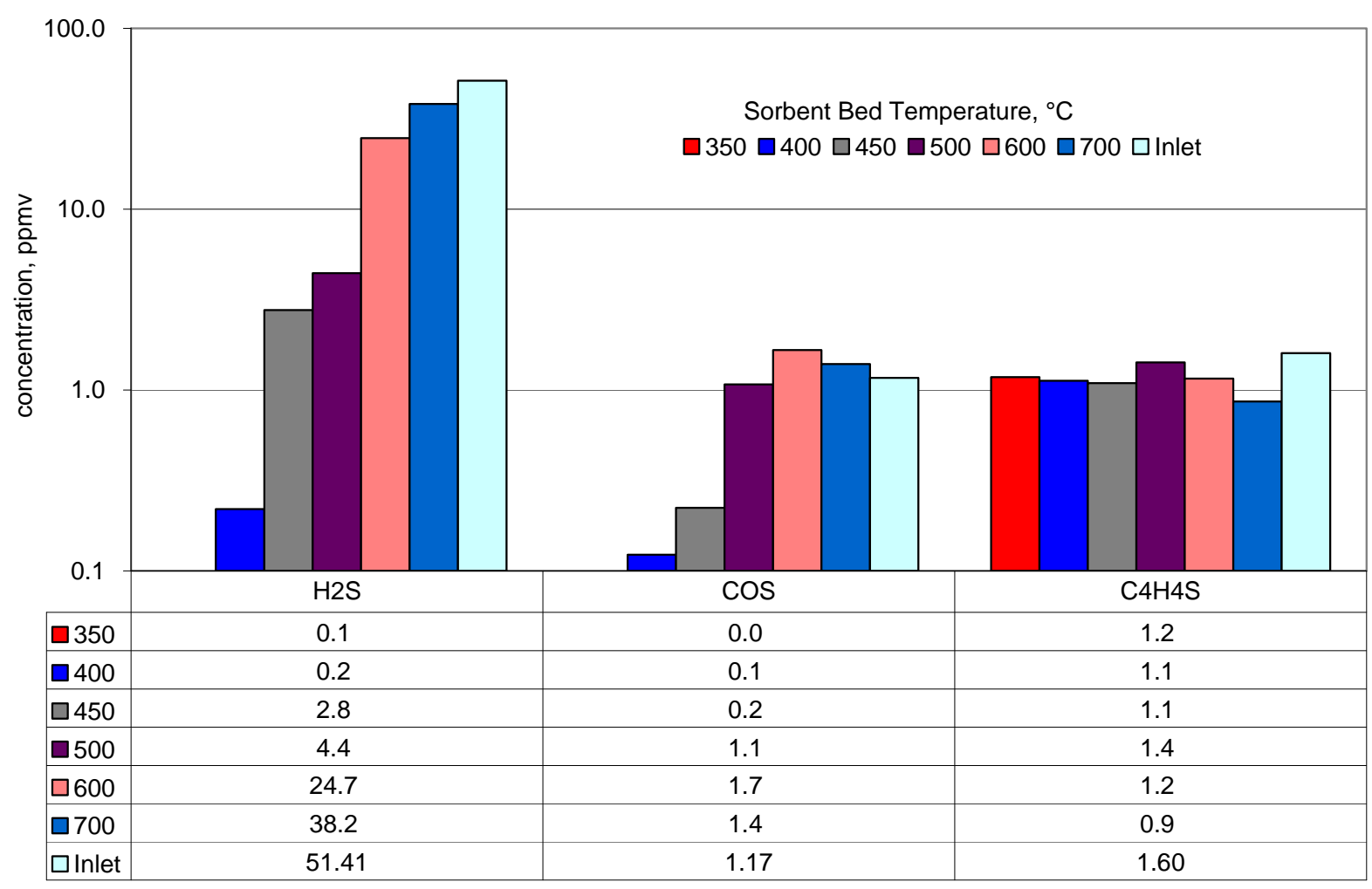

Figure B.5. Efficiency of sulfur compound removal using a $\mathrm{ZnO}$ sorbent bed as a function of temperature at GHSV $=8,036 \mathrm{hr}^{-1}$.

The effects of GHSV on $\mathrm{H}_{2} \mathrm{~S}$ are summarized in Figure B.6 for a series of tests conducted at a sorbent temperature of $400^{\circ} \mathrm{C}$. Flow rate through the reactor was varied while maintaining the sorbent bed temperature. $\mathrm{H}_{2} \mathrm{~S}$ removal is most clearly affected by changes in GHSV, with decreasing removal resulting with increased flow rate. COS shows little effect, with all flow rates resulting in the 1 ppmv COS inlet concentration being reduced to $\sim 200 \mathrm{ppb}$. Thiophene concentrations are largely unaffected. 


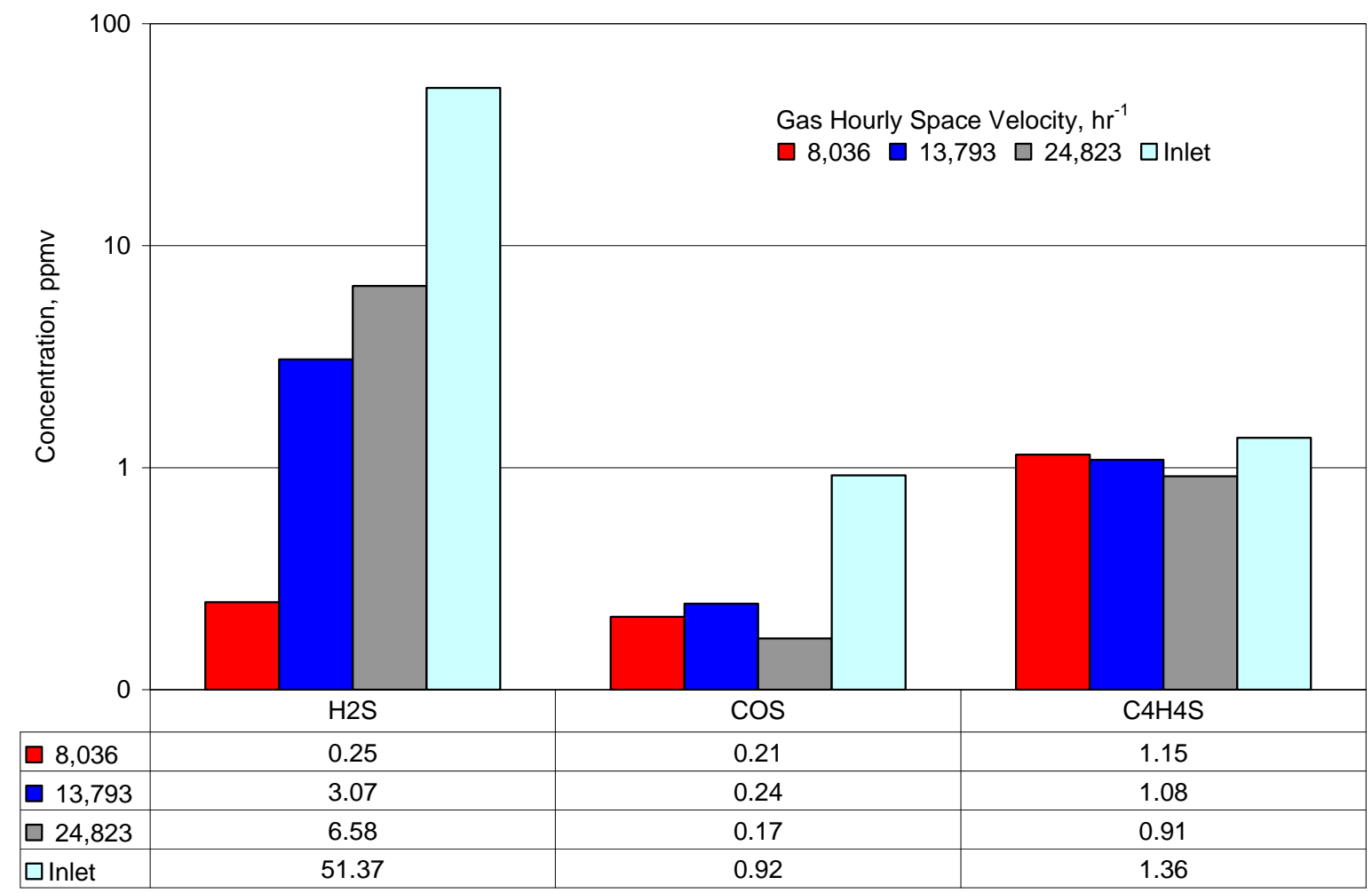

Figure B.6. Efficiency of sulfur compound removal using a $\mathrm{ZnO}$ sorbent bed at $400^{\circ} \mathrm{C}$ as a function of wet gas hourly space velocity.

Figure B.7 summarizes test results of tar destruction tests using a fixed bed reactor containing inert alumina silicate, $12 \mathrm{~mm}$ spheres and two nickel based catalysts, G91 and $\mathrm{C} 11 \mathrm{NK}$ from Sud Chemie. All tests were conducted at a catalyst temperature of $850^{\circ} \mathrm{C}$ and at two reactor flow rates. Inlet concentrations of 8 to $10 \mathrm{~g}$ total tar $\mathrm{m}^{-3}$ of dry gas were converted by the C11-NK catalyst to levels less than $0.1 \mathrm{~g}$ total tar $\mathrm{m}^{-3}$ of dry gas. The catalyst G91 did not convert the tar as effectively and the outlet gas from the reactor contained tar in the range of 0.6 to $1.6 \mathrm{~g}$ total tar $\mathrm{m}^{-3}$ of dry gas. The differences in conversion may be due in part to differences between the catalysts, but GHSV (m3 kg-1 $\mathrm{hr}^{-1}$ ) also contributes. GHSV values for each catalyst condition is indicated on the figure and the values for C11-NK are nearly twice those of G91. The low levels of tar measured in the outlet from the C11-NK tests contained acenaphthalene, pyrene, and unidentified compounds. The species there in greatest concentration at the inlet, benzene, naphthalene, and toluene were not detected at the outlet. The concentration of methane present in the dry fuel gas under steady gasifier operating conditions was $\sim 4 \%$ as shown in Figure B.2 and Table B.1. Recall that the sampling point in Figure B.2 was located at the hot gas filter exit from 09:00 to $11: 30$ and 14:30 to 15:06, and at the exit of the tar cracking unit from 11:30 to 14:30. Figure B.2 shows that methane was completely converted in the product gas and that the conversion of methane and tar species resulted in an increase in permanent gas species, $\mathrm{CO}$ and $\mathrm{H}_{2}$. 


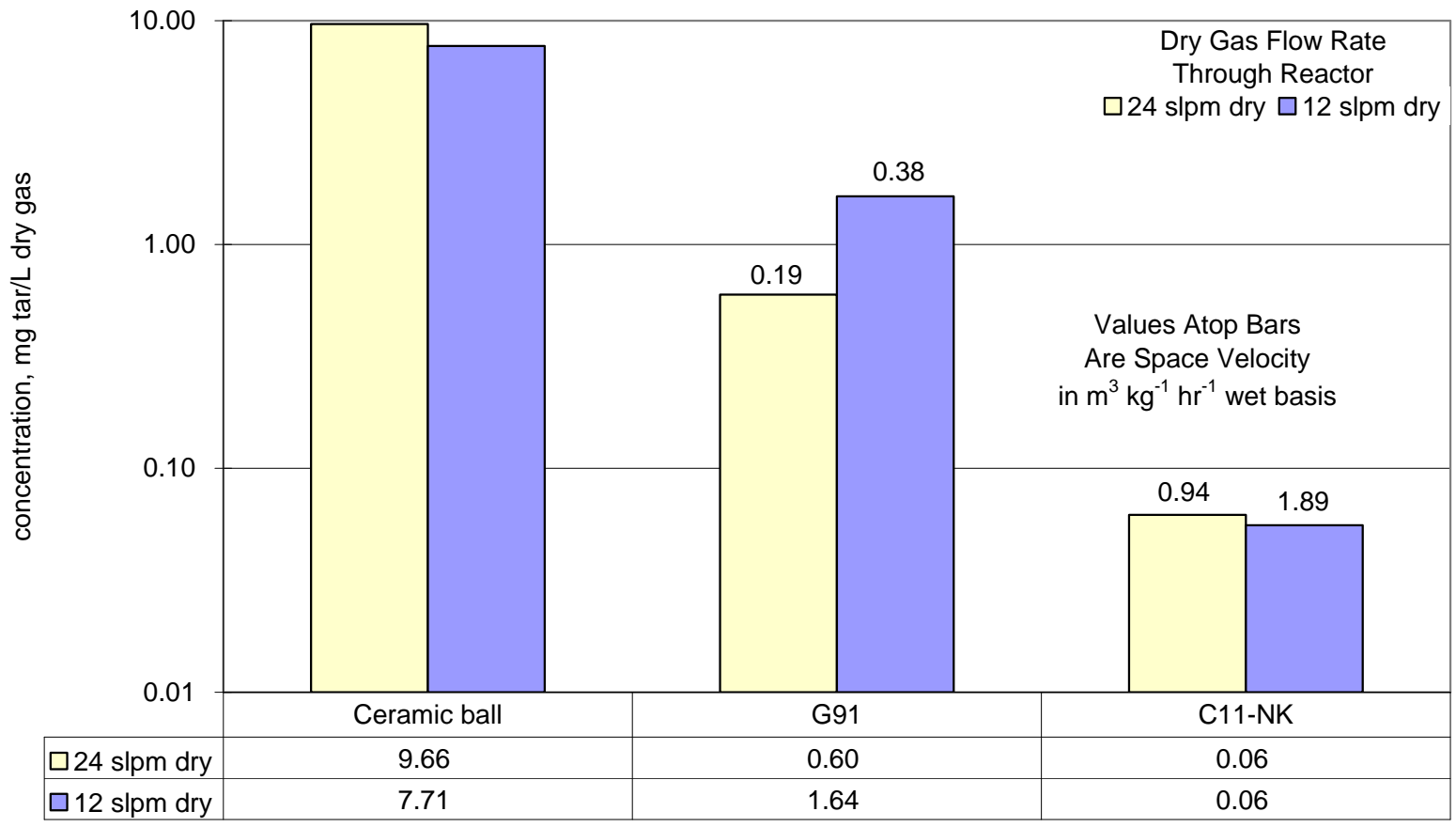

Figure B.7. Summary of tar destruction results using a fixed bed of inert ceramic balls, catalyst G91, and catalyst C11-NK, at varied space velocities.

Results of the destruction of ammonia by exposure to the Ni based tar cracking catalysts are summarized in Figure B.8. Ammonia concentrations measured at the inlet of the tar cracking bed were a range of 1,400 to $1,600 \mathrm{ppmv}$. Ammonia concentrations were not affected by the use of inert ceramic balls in the $850^{\circ} \mathrm{C}$ bed, but were reduced by the $\mathrm{Ni}$ catalysts to values ranging from 21 to $650 \mathrm{ppmv}$. Catalyst type and GHSV (m3 kg-1 $\mathrm{hr}^{-1}$ ) contributed to this reduction with lower concentrations corresponding to lower values of GHSV and catalyst C11-NK providing better performance. 


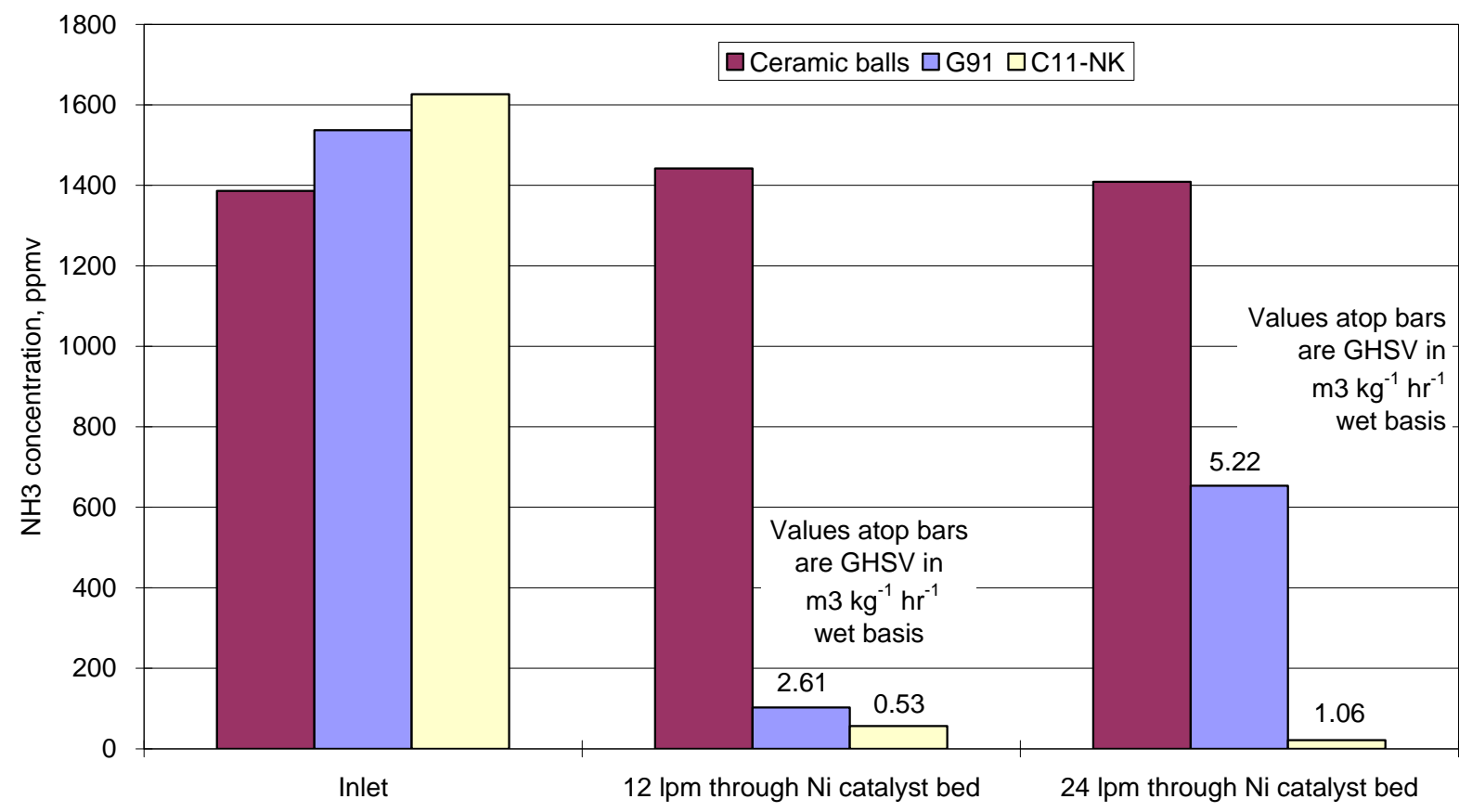

Figure B.8. Efficiency of $\mathrm{NH}_{3}$ destruction by nickel catalysts $\mathrm{G} 91$ and $\mathrm{C} 11-\mathrm{NK}$ compared to inert ceramic balls at $850^{\circ} \mathrm{C}$.

The concentration of oxides of nitrogen present in the dry fuel gas (reported as NO) under steady gasifier operating conditions was $\sim 8$ ppmv as shown in Figure B.2 and Table B.1. Recall that the sampling point in Figure B.2 was located at the hot gas filter exit from 09:00 to 11:30 and 14:30 to 15:06, and at the exit of the tar cracking unit from 11:30 to 14:30. The effect of directing the flow through the tar cracking unit on the NO concentration in the gas is readily apparent from Figure B.2, dropping to less than 1 ppmv.

\subsection{Conclusions}

The objective of this project was to develop hot gas clean up capabilities for the HNEI gasifier test facility to support hydrogen from biomass research. The product gas stream at the outlet of the hot gas filter was characterized for concentrations of permanent gas species $\left(\mathrm{CO}, \mathrm{CO}_{2}, \mathrm{H}_{2}, \mathrm{CH}_{4}, \mathrm{~N}_{2}\right)$ and contaminants including tar (principally benzene, naphthalene, and toluene) and sulfur $\left(\mathrm{H}_{2} \mathrm{~S}, \mathrm{COS}\right.$, and $\left.\mathrm{C}_{4} \mathrm{H}_{4} \mathrm{~S}\right)$ species, ammonia, and $\mathrm{NO}_{\mathrm{x}}$. Total tar concentration was in the dry product gas was $\sim 10 \mathrm{~g} \mathrm{~m}^{-3}$. Concentrations of $\mathrm{H}_{2} \mathrm{~S}$, $\mathrm{COS}$, and $\mathrm{C}_{4} \mathrm{H}_{4} \mathrm{~S}$ were 56,1 , and 1.3 ppmv, respectively. NO and ammonia concentrations were determined to be 8.2 and 1,626 ppmv respectively. 
A clean up strategy was developed to remove contaminant species or convert them to a benign form. Elements included sulfur removal using $\mathrm{ZnO}$ sorbent at $400^{\circ} \mathrm{C}$ and a gas hourly space velocity of $8,000 \mathrm{hr}^{-1}$. Under these conditions, the primary sulfur component, $\mathrm{H}_{2} \mathrm{~S}$, was reduced to $250 \mathrm{ppbv}$ and $\mathrm{COS}$ was reduced by a factor of 4 to similar levels. Thiophene concentrations were not affected.

Tar and methane were successfully converted to permanent gas species using nickel catalysts. Temperatures of $850^{\circ} \mathrm{C}$ and GHSV of $\sim 1 \mathrm{~m}^{3} \mathrm{~kg}^{-1} \mathrm{hr}^{-1}$ effectively removed tar compounds below levels of $0.1 \mathrm{~g}$ total tar $\mathrm{m}^{-3}$ dry gas. Acenaphthalene and pyrene were two compounds identified in the gas stream exiting the reactor. The Ni catalyst also resulted in reductions of $\mathrm{NH}_{3}$ from values of $\sim 1500 \mathrm{ppmv}$ to as low as $20 \mathrm{ppmv}$ and complete conversion of methane and $\mathrm{NO}_{\mathrm{x}}$. Methane and tar conversion resulted in increased levels of $\mathrm{H}_{2}$ and $\mathrm{CO}$ in the product gas exiting the tar cracking unit. 


\section{APPENDIX C}

New Mexico Tech report

Appendix $C$ is presented on the following pages. It represents a final report submitted by the New Mexico Institute of Mining and Technology and has its own task, figure and table numbering system. 
$\underline{\text { This page is intentional blank }}$ 
Final Report- December 15, 2006

New Mexico Institute of Mining and Technology

D. H. Weinkauf-Chemical Engineering

J.H. Dong - Chemical Engineering

D. Hirschfeld - Materials Engineering

\title{
Task 1. Development of Novel Catalytic Membranes for Efficient Conversion of Biomass-Derived Hydrocarbons to Hydrogen
}

\author{
P.I.(s): \\ J.H. Dong and D.H. Weinkauf - jhdong@nmt.edu , \\ weinkauf@nmt.edu ) \\ Participants: Justin Monroe (MS Materials Engineering - NMT) \\ Zhong Tang (Post Doc Research Associate - NMT) \\ Xuehong Gu ((Post Doc Research Associate - NMT)
}

\subsection{Task 1 Goals:}

1) Develop transition metal-loaded zeolite catalytic membranes for conversion of biomass-derived hydrocarbons (e.g. methanol and glucose etc.) to hydrogen through liquid-phase reaction.

2) Examine the effects of improved dispersion of metal species in the zeolitic channels on yield.

3) Design membranes to reduce residence time of produced hydrogen on the catalyst surface thereby minimizing hydrogen-consuming side reactions.

\subsection{Task 1 Final Report}

$\mathrm{Pt} / \mathrm{NaY}$ zeolite catalysts and $\mathrm{Pt} / \gamma-\mathrm{Al}_{2} \mathrm{O}_{3}$ catalysts were prepared and tested for APR (aqueous phase reforming) of biomass-derived carbohydrates to produce $\mathrm{H}_{2}$. The catalysts were characterized by BET, (CO) chemisorption, microprobe, XRD, SEM and TEM. The $0.5 \mathrm{wt} \% \mathrm{Pt} / \mathrm{NaY}$ catalyst exhibited catalytic performance comparable to or better than the $2.9 \mathrm{wt} \% \mathrm{Pt} / \gamma-\mathrm{Al}_{2} \mathrm{O}_{3}$ in APR of methanol and ethanol solutions at 493 538 $\mathrm{K}$. The results demonstrate that zeolite is an excellent support/promoter for metal catalysts for APR of alcohols. However, the zeolite-based catalysts were found to be inapplicable for glucose reforming most likely because the pore openings of Y-zeolite $(0.74 \mathrm{~nm}$ before Pt loading) are inaccessible to the ringed glucose molecules. 


\subsubsection{Catalytic reaction system}

The reactor system, as schematically shown in Fig.1.1, has been established/modified and tested to be fully functional. The system can be used for both membrane reactor and packed-bed reactor tests.

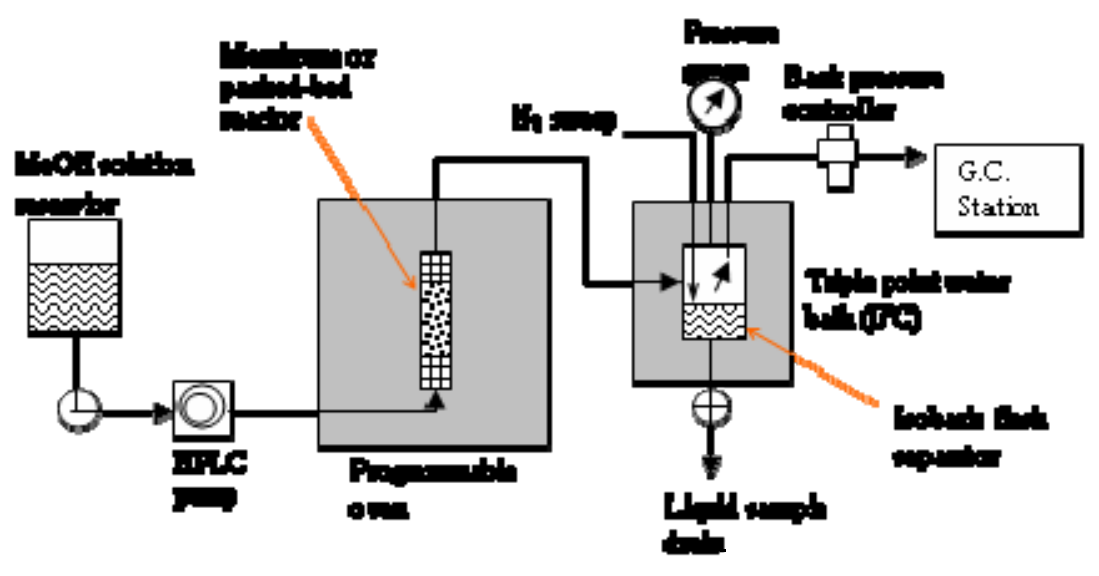

Figure. 1.1 Schematic diagram of the reactor system.

\subsubsection{Catalyst synthesis and characterization}

In this project, catalysts were synthesized following the procedures previously developed in our labs (Gu et al., 2004, Catal. Lett.; Monroe, 2006, MS thesis). The synthesized $\mathrm{Pt} / \mathrm{NaY}$ and $\mathrm{Pt} / \gamma-\mathrm{Al}_{2} \mathrm{O}_{3}$ catalysts were characterized by XRD, SEM, TEM, microprobe, and physical (N2) and chemisorption (CO).

$\boldsymbol{P t} / \boldsymbol{\gamma}-\boldsymbol{A l}_{2} \mathrm{O}_{3}$ catalysts: The $\gamma-\mathrm{Al}_{2} \mathrm{O}_{3}$ gel particles were synthesized by the sol-gel process. The $\mathrm{Pt} / \gamma-\mathrm{Al}_{2} \mathrm{O}_{3}$ catalyst was prepared by incipient wetness impregnation method, followed by thermal treatments and reduction in $\mathrm{H}_{2}$ at $533 \mathrm{~K}$. The catalysts have been characterized with XRD, TEM, and BET-(CO)chemisorption. Pt particles with size of $\sim 2$ $\mathrm{nm}$ were dispersed uniformly on the surface of $\gamma-\mathrm{Al}_{2} \mathrm{O}_{3}$ nanopowders (see Fig. 2) for all three Pt loading levels (i.e. $0.5 \mathrm{wt} \%, 1.0 \mathrm{wt} \%$, and $3.0 \mathrm{wt} \%$ ). 


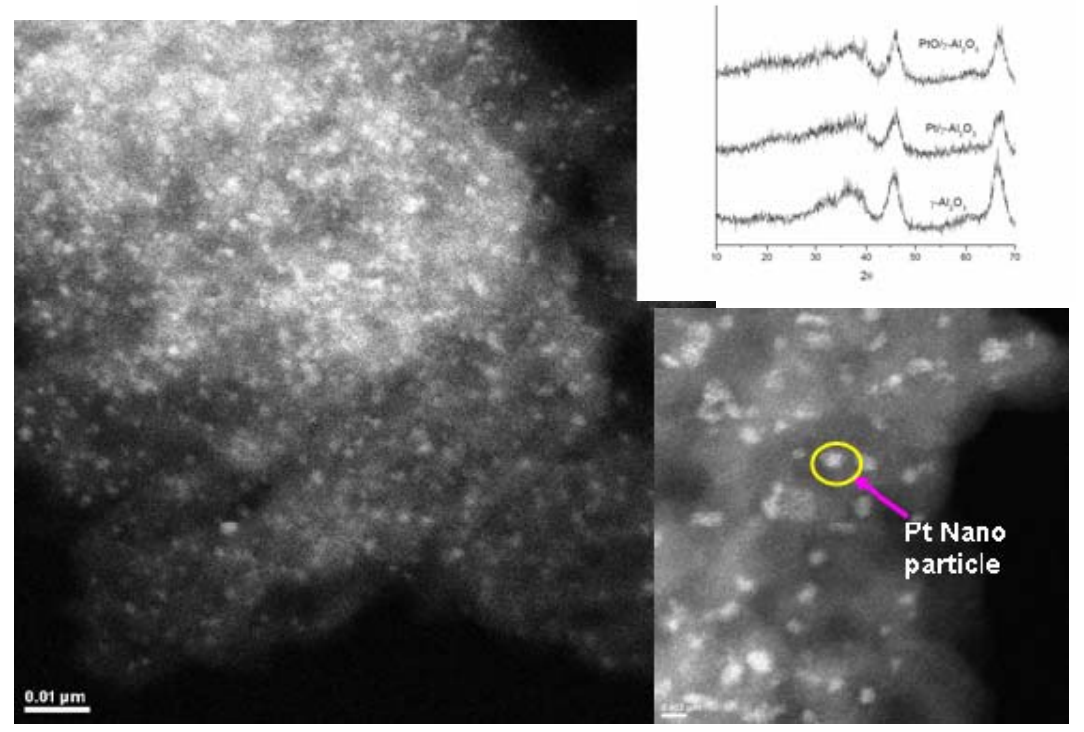

Figure 1.2 STEM image of $\mathrm{Pt} / \gamma-\mathrm{Al}_{2} \mathrm{O}_{3}$ (Pt load 3.0wt.\%) (Insert: XRD)

Pt/NaY catalysts: The NaY zeolite particles were synthesized by hydrothermal crystallization method. The $\mathrm{Pt} / \mathrm{NaY}$ catalyst was prepared by ion exchange followed by thermal treatments and reduction in $\mathrm{H}_{2}$ flow. The catalysts were examined by XRD, microprobe, CO-chemisorption, SEM and TEM (Fig. 3). According to the STEM examination, the size of Pt clusters in the zeolite cages was $\sim 1 \mathrm{~nm}$. Due to the small size and extremely high dispersion of the Pt particles, Pt metal was not detectable by XRD measurement. However, the Pt composition in the catalysts was measured by microprobe with excellent reproducibility. The $\mathrm{CO}$-uptake values determined by $\mathrm{CO}$-chemisorption were used to calculate the metal dispersion and catalyst turnover frequency (TOC).

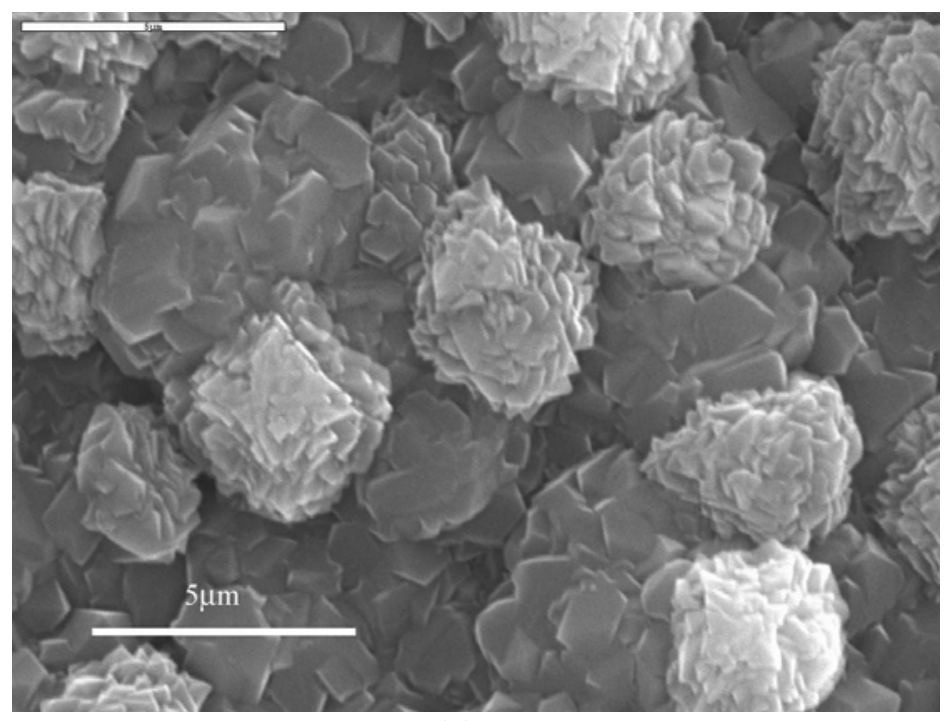

(a) SEM 


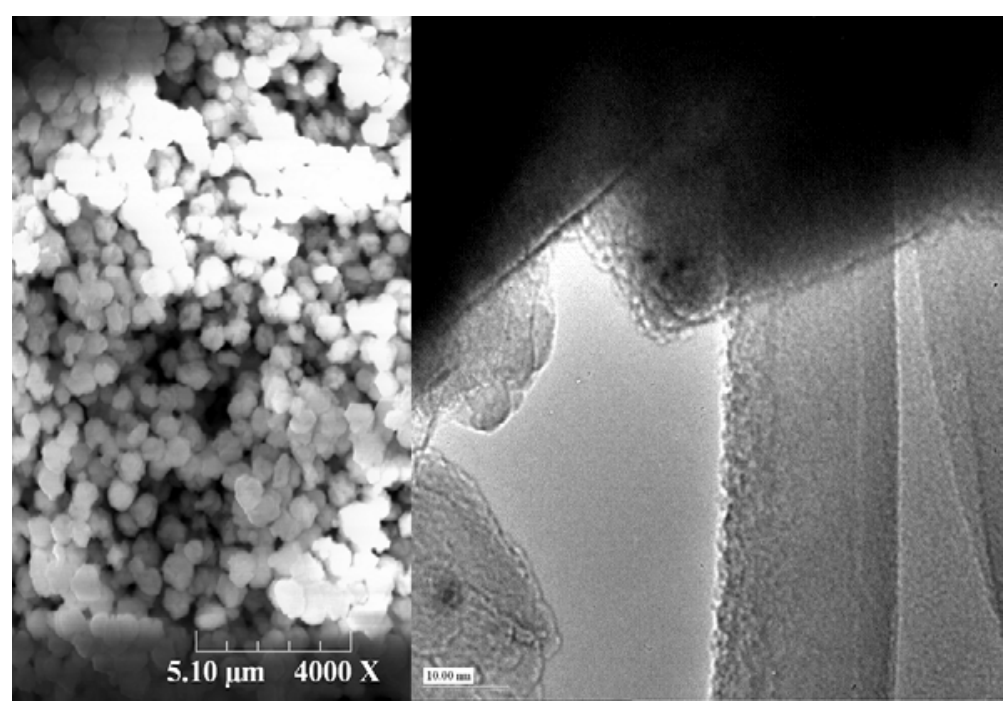

(b) SEM (left) and TEM (right)

Figure. 1.3 Microscopic images of the $\mathrm{Pt} / \mathrm{NaY}$ catalyst.

\subsubsection{Liquid phase reforming of biomass-derived carbohydrates}

Experiments were first conducted on aqueous phase reforming of methanol to hydrogen and compared with our previous results (Monroe, 2006, MS thesis New Mexico Tech). The catalysts were then tested for liquid phase ethanol and glucose reforming for production of $\mathrm{H}_{2}$.

\section{Reforming of Methanol}

Experiments were carried out in a fixed-bed reactor system. The catalytic performance of the $\mathrm{Pt} / \mathrm{NaY}$ was evaluated and compared with the state-of-the-art $\mathrm{Pt} / \gamma-\mathrm{Al}_{2} \mathrm{O}_{3}$ catalysts. The $\mathrm{Pt} / \mathrm{NaY}$ catalyst with a $\mathrm{Pt}$ loading of $0.5 \mathrm{wt} \%$ exhibited catalytic performance comparable to or better than the $\mathrm{Pt} / \gamma-\mathrm{Al}_{2} \mathrm{O}_{3}$ with a Pt loading of $2.9 \mathrm{wt} \%$ in liquid phase reforming of methanol solutions at $493 \sim 538 \mathrm{~K}$ (Table 1.1). The TOC number of the $\mathrm{Pt} / \mathrm{NaY}$ catalyst was much greater than that of the $\mathrm{Pt} / \gamma-\mathrm{Al}_{2} \mathrm{O}_{3}$ catalyst, indicating that the zeolite supported catalyst possessed much higher catalytic activity compare to the $\mathrm{Pt} / \gamma$ $\mathrm{Al}_{2} \mathrm{O}_{3}$ catalyst. 
Table 1.1. Comparison of data between $3 \% \mathrm{Pt} / \mathrm{Al}_{2} \mathrm{O}_{3}$ and $0.5 \mathrm{wt} \% \mathrm{PtNaY}$ catalysts

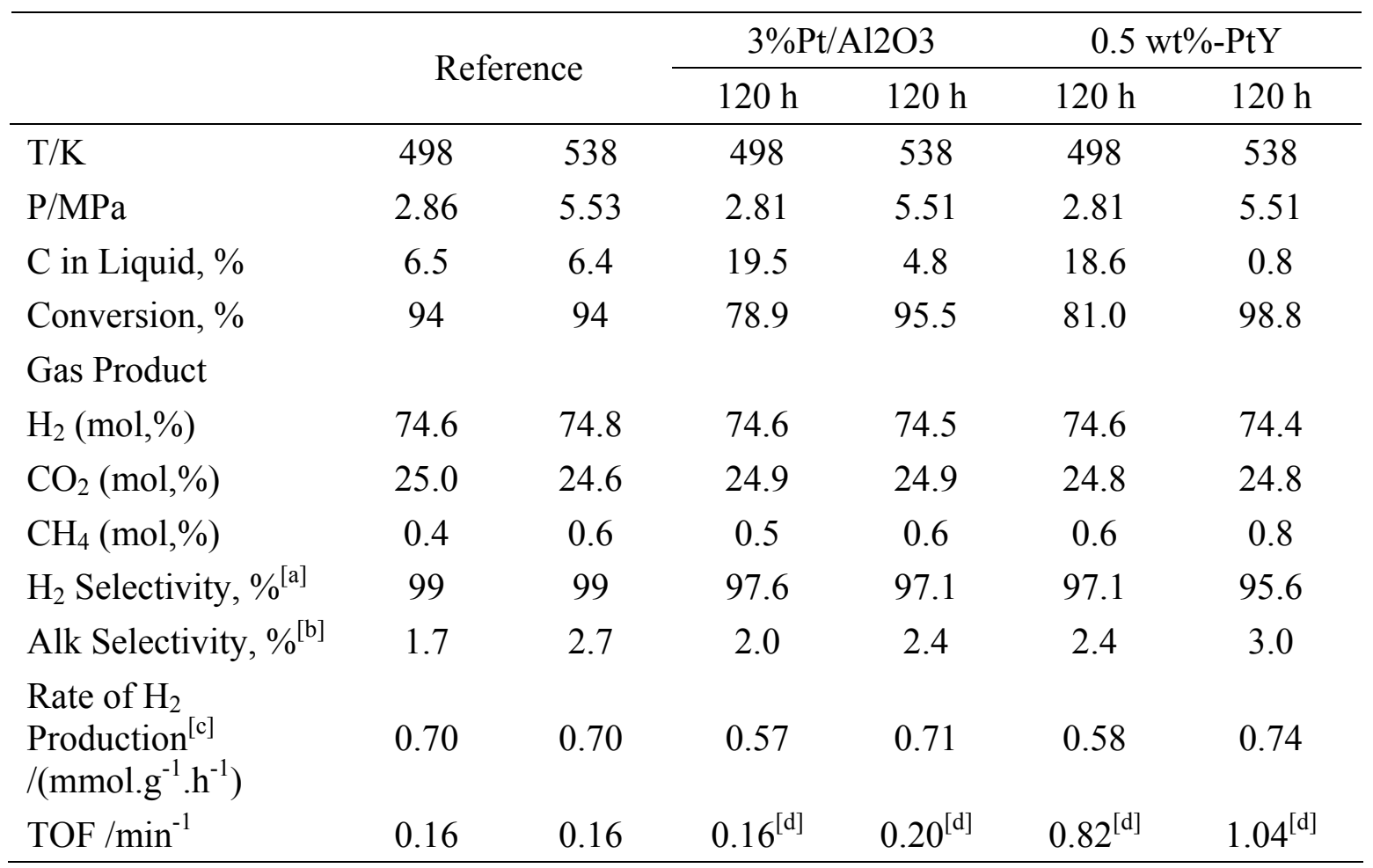

[a] Based on H-balance, selectivity of hydrogen $=\mathrm{H}_{2} /\left(\mathrm{H}_{2}+4 \times \mathrm{CH}_{4}\right)$.

[b] Based on C-balance, selectivity of alkane $=\mathrm{CH}_{4} /\left(\mathrm{CH}_{4}+\mathrm{CO}_{2}\right)$.

[c] WHSV $=0.008 \mathrm{~g}$ of methanol ( $1 \mathrm{wt} \%$ aqueous solution) per gram of catalyst per hour.

[d] Normalized by the number of surface metal atoms as determined from irreversible uptake of $\mathrm{CO}$ at $308 \mathrm{~K}$.

We conducted the reforming test with various methanol solution feed rates (from $0.8 \mathrm{ml} / \mathrm{hr}$ to $3.7 \mathrm{ml} / \mathrm{hr}$ ). The experimental results have shown that the conversion of methanol remains high when the feed rate increases. The selectivity and conversion were $96.6 \%$ and $91.6 \%$, respectively, at a feed flow rate of $3.7 \mathrm{ml} / \mathrm{hr}$ and solution concentration of $1 \mathrm{wt} \%$ in the feed.

\section{Reforming of Ethanol \& Glucose}

Liquid-phase reforming of bio-ethanol was carried out under the conditions of $538 \mathrm{~K}$, $5.51 \mathrm{Mpa}$ over PtY catalysts and $\mathrm{Pt} / \gamma-\mathrm{Al}_{2} \mathrm{O}_{3}$ catalysts. The results also showed that catalytic performance of $\mathrm{Pt} / \mathrm{NaY}(0.5 \mathrm{wt} \% \mathrm{Pt})$ was better than $\mathrm{Pt} / \gamma-\mathrm{Al}_{2} \mathrm{O}_{3}(2.9 \mathrm{wt} \% \mathrm{Pt})$ at low temperatures and higher pressures (Table 1.2). 
Table 1.2. Results of APR for ethanol over $\mathrm{Pt} / \mathrm{NaY}$ and $\mathrm{Pt} / \gamma-\mathrm{Al}_{2} \mathrm{O}_{3}$

\begin{tabular}{lcccc}
\hline Catalyst & \multicolumn{3}{c}{$0.5 \mathrm{wt} \% \mathrm{PtNaY}$} & $2.9 \mathrm{wt} \% \mathrm{Pt} / \gamma-$ \\
$\mathrm{Al}_{2} \mathrm{O}_{3}$ \\
$\mathrm{~T} / \mathrm{K}$ & 498 & 518 & 538 & 538 \\
$\mathrm{P} / \mathrm{MPa}$ & 2.81 & 3.88 & 5.53 & 5.53 \\
\hline $\mathrm{C}$ in Liquid, \% & 12.0 & 2.1 & 2.2 & 2.4 \\
Conversion, \% & 89.8 & 97.4 & 97.1 & 97.2 \\
Gas Product & & & & \\
$\mathrm{H}_{2}$ (mol,\%) & 78.5 & 74.2 & 75.4 & 72.5 \\
$\mathrm{CO}_{2}$ (mol,\%) & 11.0 & 15.5 & 14.8 & 14.5 \\
$\mathrm{CH}_{4}$ (mol,\%) & 10.9 & 10.1 & 9.7 & 9.4 \\
$\mathrm{C}_{2} \mathrm{H}_{6}$ (mol,\%) & 0.3 & 0.2 & 0.2 & 3.6 \\
$\mathrm{H}_{2}$ Selectivity, \% ${ }^{[\mathrm{a}]}$ & 60.9 & 64.6 & 65.8 & 63.8 \\
Alk Selectivity, \% $^{[\mathrm{b}]}$ & 51.1 & 39.6 & 39.8 & 50.2 \\
$\mathrm{H}_{2}$ Production \\
(mmol.g $^{-1} \cdot \mathrm{h}^{-1}$ )
\end{tabular}

[a] Based on H-balance, Selectivity of hydrogen $=\mathrm{H}_{2} /\left(\mathrm{H}_{2}+4 \times \mathrm{CH}_{4}+\mathrm{C}_{2} \mathrm{H}_{6}\right)$.

[b] Based on C-balance, selectivity of alkane $=\left(\mathrm{CH}_{4}+2 \times \mathrm{C}_{2} \mathrm{H}_{6}\right) /\left(\mathrm{CH}_{4}+2 \times \mathrm{C}_{2} \mathrm{H}_{6}+\mathrm{CO}_{2}+\mathrm{CO}\right)$.

[c] WHSV $=0.008 \mathrm{~g}$ of ethanol ( $1 \mathrm{wt} \%$ aqueous solution) per gram of catalyst per hour.

Liquid phase reforming of glucose over $0.5 \mathrm{wt} \% \mathrm{PtY}$ catalyst was also performed at the same reaction conditions. It was found that very little hydrogen was detected by the gas chromatography during the reaction, most likely because the $\mathrm{NaY}$ zeolite pores are not accessible to the ringed glucose molecules in liquid phase.

\subsubsection{Stability testing}

Long-term tests ( $>200 \mathrm{hr}$ continuous operation) have shown that both the PtY and Pt/ $\gamma$ $\mathrm{Al}_{2} \mathrm{O}_{3}$ catalysts have excellent stability when used in aqueous-phase reforming reaction (no appreciable decreases in selectivity and conversion rate). Figure 1.4 shows the results of catalyst stability test for $120 \mathrm{hr}$. 


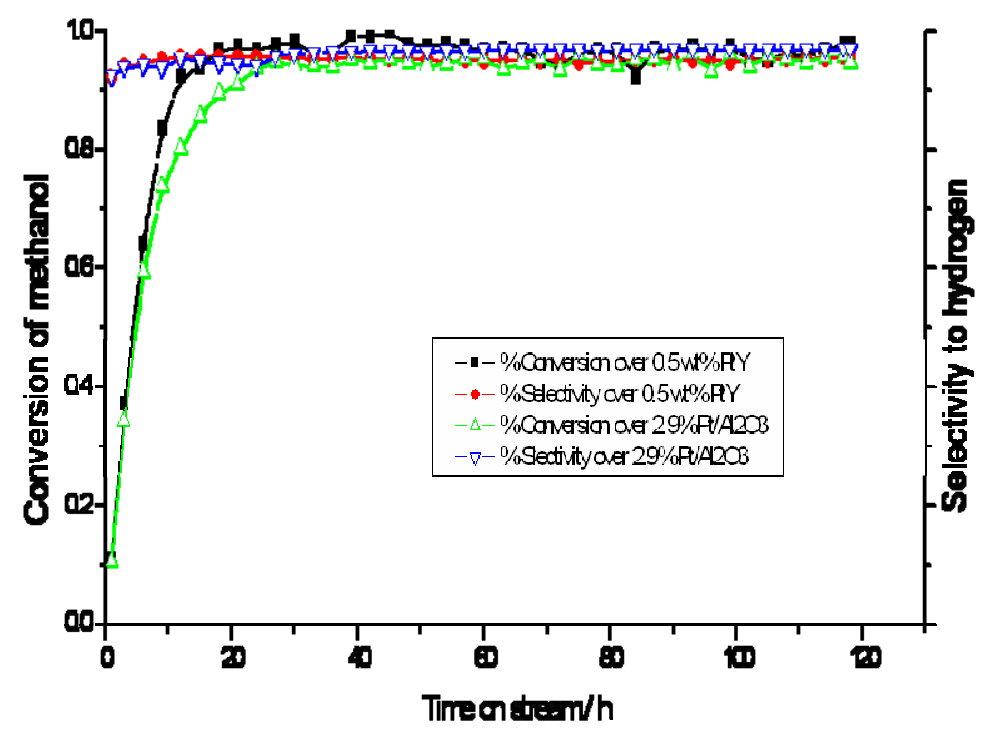

Figure 1.4. Stability test (120hr) for $0.5 \mathrm{wt} \% \mathrm{Pt} / \mathrm{NaY}$ and $2.9 \% \mathrm{Pt} / \mathrm{g}-\mathrm{Al} 2 \mathrm{O} 3$. (538 K, $5.51 \mathrm{Mpa}$, WHSV=0.008 h-1, with $1 \mathrm{wt} \% \mathrm{MeOH}$ feed)

\subsection{Project Conclusions and Future Work}

$\mathrm{Pt} / \mathrm{NaY}$ zeolite catalysts and $\mathrm{Pt} / \gamma-\mathrm{Al}_{2} \mathrm{O}_{3}$ catalysts were prepared and tested for $\mathrm{APR}$ (aqueous phase reforming) of biomass-derived carbohydrates to produce $\mathrm{H}_{2}$. The catalysts were characterized by BET, (CO) chemisorption, microprobe, XRD, SEM and TEM. The $0.5 \mathrm{wt} \% \mathrm{Pt} / \mathrm{NaY}$ catalyst exhibited catalytic performance comparable to or better than the $2.9 \mathrm{wt} \% \mathrm{Pt} / \gamma-\mathrm{Al}_{2} \mathrm{O}_{3}$ in APR of methanol and ethanol solutions at 493 538 $\mathrm{K}$. The results demonstrate that zeolite is an excellent support/promoter for metal catalysts for APR of alcohols. However, the zeolite-based catalysts were found to be inapplicable for glucose reforming most likely because the pore openings of Y-zeolite $(0.74 \mathrm{~nm}$ before Pt loading) are inaccessible to the ringed glucose molecules.

\subsection{Products and Publications}

[1] J. Monroe, Z. Tang, X. Gu, J. Dong, D. Weinkauf, T. M. Nenoff, Investigation on the platinum-loaded $\mathrm{NaY}$ zeolite catalysts for liquid phase reforming of carbohydrates to hydrogen, AIChE Annual Meeting, Nov. 2006, San Francisco, USA

[2] A paper is currently under preparation for journal publication. 


\title{
Task 2. Carbon Dioxide / Hydrogen Separations under Biomass Reforming Conditions
}

\author{
P.I.: $\quad$ D.H. Weinkauf - weinkauf@nmt.edu \\ Participants: $\quad$ Nicole Brown (MS Materials Engineering - NMT) \\ Richard Nelson (BS Chemical Engineering - NMT)
}

\section{$2.1 \quad$ Task 2 Goals}

1. Develop a broad understanding of the structure property relationships which govern RF plasma-polymerized organic/inorganic thin film composite materials as well as metallic support composite membranes.

2. Determine the durability of these novel membrane structures in high temperature and mixed feed scenarios expected in the reforming/water gas shift product streams.

\subsection{Task 2 Final Report}

A general problem with the hydrogen production of biomass is the effective separation of $\mathrm{H} 2$ from $\mathrm{CO} 2$ and other hydrocarbons formed in the reforming reaction. The catalytic membranes and nanoscale emerging as effective methods for hydrogen production operate under a high temperature - pressure feed (>20 atm at $230 \mathrm{C}$ ).

\subsubsection{High Temperature Permeation Apparatus}

The work has involved the construction of a high temperature gas permeation apparatus for the measurement of gas pair selectivities in the range of 25 to $300 \mathrm{C}$. The device has been calibrated for examination of the high temperature membranes.

Figure 2.1. High temperature pure gas permeation cell.

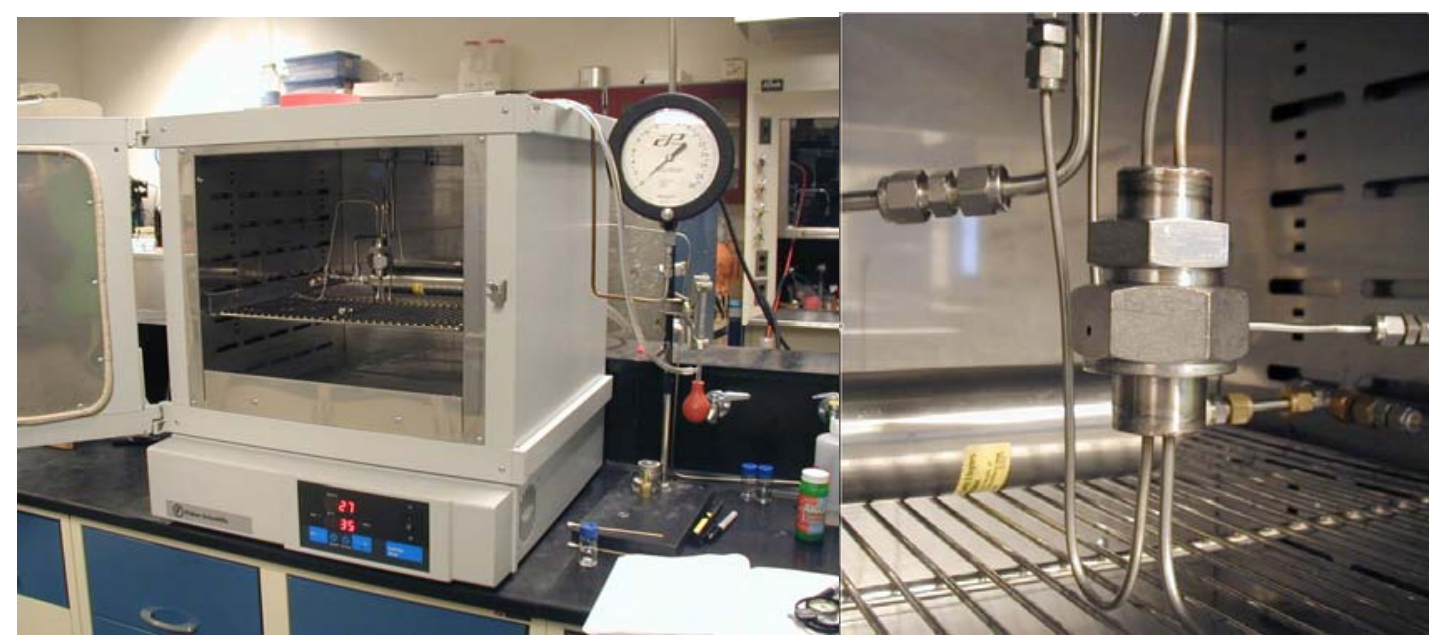




\subsubsection{Plasma SiOx Type Membranes}

Thin plasma SiOx composite membranes have been synthesized from hexamethyl disiloxane (HMDSO) and preliminary testing of selectivities at $25 \mathrm{C}$ has been initiated. A picture of the membrane is shown in Figure 2.1. The membranes are characterized by high flux and Knudsen type diffusion characteristics. Previous work has shown that the standard PDMS spin-coating caulking technique builds selectivity in these same membrane structures by healing the nanoscale defects.

The $\mathrm{CO} 2$ permeability of the plasma polymerized HMDSO (ppHMDSO) membranes are plotted as a function of the $\mathrm{He} / \mathrm{CO} 2$ selectivity in Figure 2.3. Here, helium is used as a

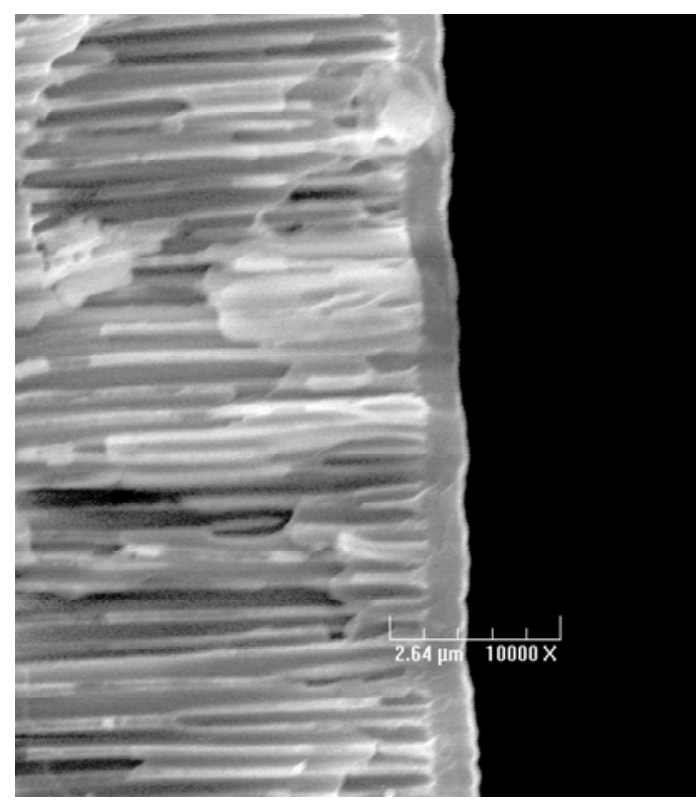

Figure 2.2. Plasma deposited 0.5 micron thick SiOx supported composite membrane structure for $\mathrm{H} 2 / \mathrm{CO} 2$ separation hydrogen analog. The data show an interesting trend regarding gas pair selectivities. At high fluxes, the membranes are $\mathrm{CO} 2$ selective $(\mathrm{He} / \mathrm{CO} 2<1)$. As the membrane flux decreases, the membranes are helium selective. At the lowest flux conditions, the membranes appear to reach a $\mathrm{He} / \mathrm{CO} 2$ selectivity ceiling of around 3.3. This value (3.3) is the theoretical Knudsen selectivity. The results suggest that the low flux membranes operate in a Knudesen mode, where as the high flux membranes exhibit $\mathrm{He} / \mathrm{CO} 2$ selectivities similar to that of rubbery materials such as poly(dimethyl siloxane). Generally, the high flux membranes are synthesized with lower plasma power conditions and retain much of the functionality of the HMDSO monomer.

The PDMS spin-coating (caulking) of the plasma polymerized HMDSO SiOx-type membranes has been carried out. Selectivies of the membranes increase substantially over the Knudsen selectivity limit observed in the pre-caulked systems. $\mathrm{He} / \mathrm{CO} 2$ selectivities as high as 56 have been observed. The results suggest that the predominant mode of transport is through the $\mathrm{SiOx}$ structure, thus enhancing selectivity.

The $\mathrm{CO} 2$ sorption isotherms of the ppHMDSO thin films have also been measured as part of this work. The $35 \mathrm{C}$ isotherms are shown in Figure 2.4. Following synthesis, the ppHMDSO materials have an extraordinarily high sorption capacity for $\mathrm{CO} 2$. With time, the sorption capacity diminishes significantly. The results suggest that the synthesis of 
high temperature $\mathrm{H} 2$ selective membranes should involve an aging process to minimize $\mathrm{CO} 2$ sorption capacity.

In summary, the ppHMDSO caulked membrane systems exhibit relatively high $\mathrm{H} 2 / \mathrm{CO} 2$ selectivities, but somewhat lower than conventional polymeric systems on the market today. The high-temperature characteristics of the SiOx membrane structure may have some advantages, but selectivity performance is not near that expected for $\mathrm{SiO} 2$ membrane systems.

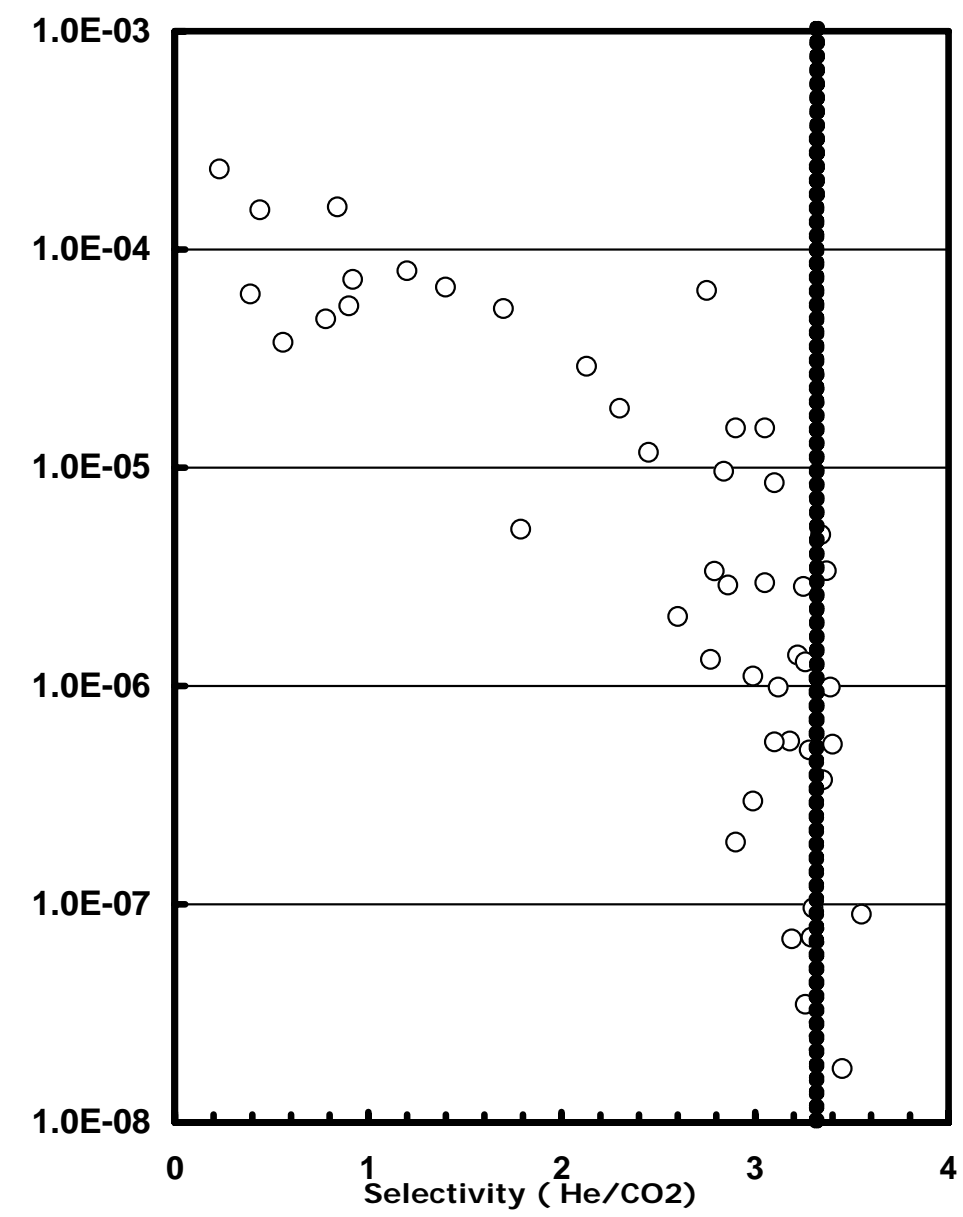

Figure 2.3. CO2 permeability at $25 \mathrm{C}$ of 45 plasma polymerized-HMDSO thin film materials versus $\mathrm{He} / \mathrm{CO} 2$ gas pair selectivity. The dashed line represents the ideal Knudsen diffusion selectivity for $\mathrm{He} / \mathrm{CO} 2$ ( 3.3) 


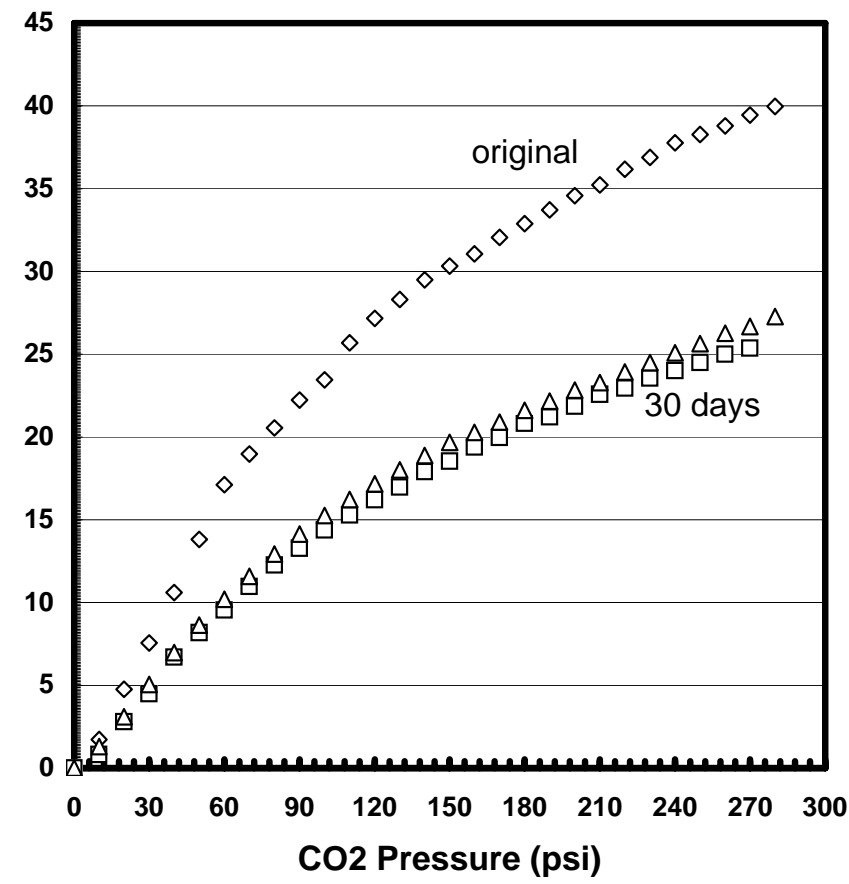

Figure 2.4. CO2 sorption isotherms of the plasma polymerized HMDSO SiOx-type thin films showing rapid aging phenomena and sorption capacity loss following synthesis.

\subsubsection{PDMS-Zeolite Mixed Matrix Membranes}

Mixed-matrix PDMS-Y-type zeolite systems have been explored as a means of developing high temperature $\mathrm{CO} 2$ selective membranes. Mixed-matrix membranes are being explored for a broad array of difficult separations, enough to command separate Technical Sessions at the 2005 and 2006 AIChE National Meetings.

In this work, Y-type zeolite and PDMS (polydimethylsiloxane) mixed-matrix membranes were prepared on Anopore filter via spin-coating. A series of membranes with different weight fractions of zeolite were tested for permeability as a function of temperature in the range of 30 to $150 \mathrm{C}$. As shown in Table 2.1, the incorporation of the Y-type zeolite greatly enhances the $\mathrm{CO} 2 / \mathrm{H} 2$ selectivity at low temperature conditions $(35 \mathrm{C})$. At $30 \%$ weight fraction, the $\mathrm{CO} 2 / \mathrm{H} 2$ selectivity is 1.5 times higher than that of the neat PDMS membrane material. At high temperature, the selectivity drops as would be expected; however, the zeolite filled systems demonstrate significantly higher selectivities at these conditions. Clearly, the enhanced sorption capacity of $\mathrm{CO} 2$ with the zeolite systems is driving the permeation selectivity. Analsysis of permeation over a braod range of temperatures indicate that there is little change in the activation energy as shown in Figure 2.5. Overall the work represents a promising direction for the design of $\mathrm{CO} 2$ selective membranes which could operate near reforming temperatures. 
Table 2.1 CO2/H2 Gas Pair Selectivity of PDMS Mixed Matrix Membranes at 35 and $150 \mathrm{C}$ as a function of weight \% zeolite loading.

\begin{tabular}{cccc}
\hline Selectivity & PDMS 0\% & PDMS 20\% & PDMS 30\% \\
\hline CO2/H2@35 C & 4.8 & 5.4 & 7.5 \\
CO2/H2@150 C & 1.4 & 1.6 & 1.9 \\
\hline
\end{tabular}

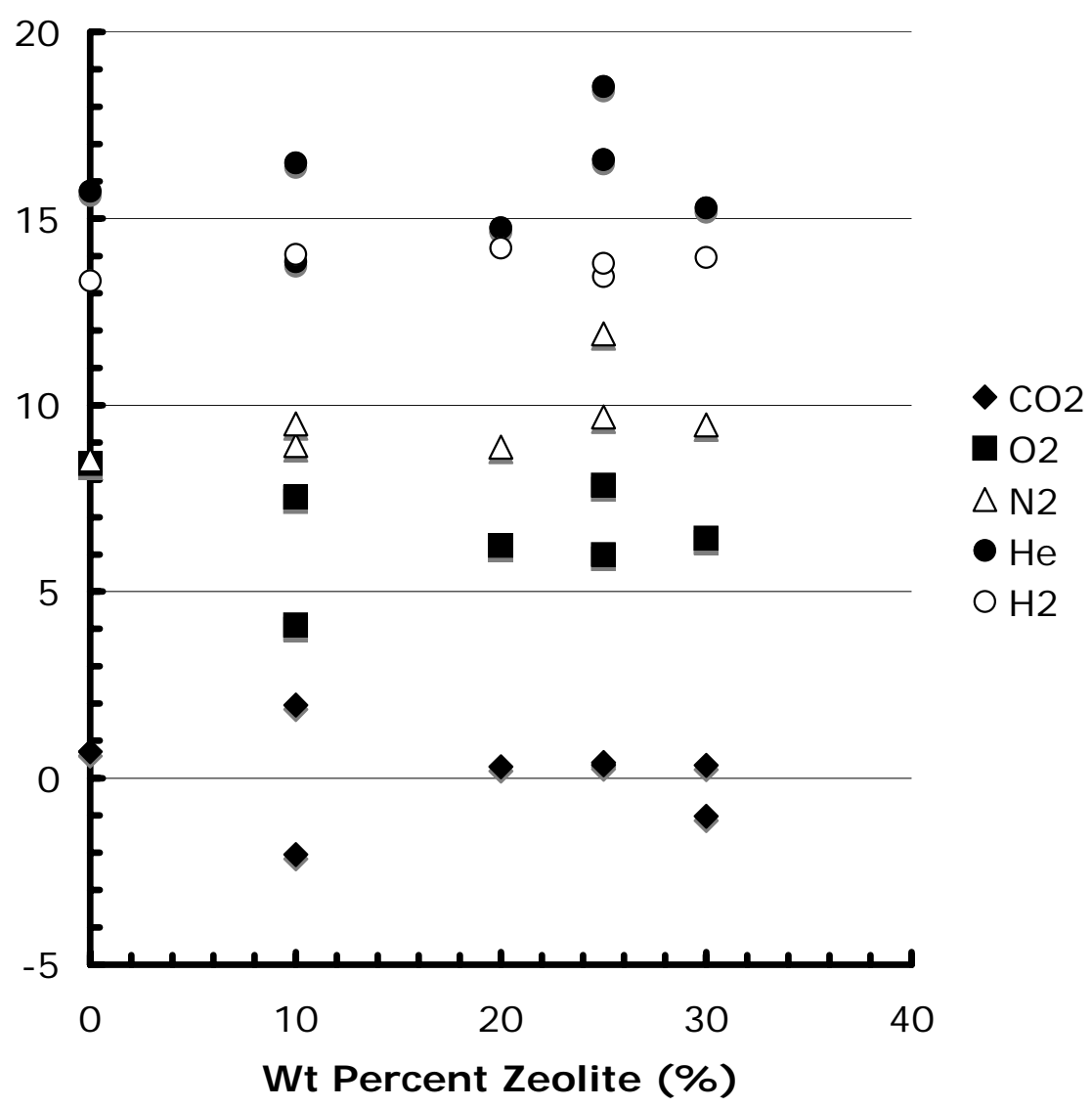

Figure 2.5. Activation energy of permeation for several gases as a function of Y-type zeolite weight fraction. Results are derived from permeation measurements in the range of 30 to $150 \mathrm{C}$. 


\subsection{Project Conclusions and Future Work}

The work as explored to novel membrane systems which may have potential application in high temperature $\mathrm{CO} 2 / \mathrm{H} 2$ separations involved with biomass production of hydrogen. The plasma SiOx membranes synthesized and characterized for this project are $\mathrm{H} 2$ selective, but appear at best to function as ideal Knudsen diffusion mode. Additionally, the plasma $\mathrm{SiOx}$ membranes appear to have a significant aging problem which results in a loss of sorption capacity. The second system explored in this work consisted of a mixed matrix membrane of PDMS and y-type zeolite. The systems showed significant enhancement of $\mathrm{CO} 2$ selectivity over $\mathrm{H} 2$ which was maintained into the high temperature regime.

The results indicate that PDMS/zeolite membrane systems may provide an avenue to $\mathrm{CO} 2$ selective systems which can operate near reforming conditions. The ability to selectively drive $\mathrm{CO} 2$ from the reforming system is expected to enhance $\mathrm{H} 2$ production. Future work will continue to explore other zeolite systems as well as modified zeolites to increase $\mathrm{CO} 2$ sorption capacity as has been described in the literature.

\subsection{Products and Education Impact}

The project has financially supported the Master's work of one female Materials Engineering student as well as the undergraduate research experience of an undergraduate, native American, Chemical Engineering student.

Presentations and Publications Covering this Effort:

1. "Mixed Matrix Zeolite Membranes for Hydrogen Separations," R. Nelson, N. Brown, D. H. Weinkauf, Society for the Advancement of Chicanos and Native Americans in Science (SACNAS), National Conference, Tampa, Florida (October 2006).

2. "Mixed Matrix Zeolite Membranes for Carbon Dioxide Selective Separations," N. Brown, Thesis Proposal, New Mexico Institute of Mining and Technology. 


\section{Task 3 Microscale glucose reforming for renewable hydrogen}

PI:

Participants:
Deidre Hirschfeld ( hirsch@nmt.edu )

Vince McIntire (Materials Engineering - NMT)

Kirsten Norman (Materials Engineering - NMT)

Benjamin Simkin (Post Doc Research Associate )

\subsection{Task 3 Goals}

1) Examine novel catalysts for micro reforming of glucose to hydrogen. Current micro reactor utilizes platinum catalyst. At least one additional catalyst will be developed and performance evaluated.

2) Examine effect of different glucose sources on micro-reactor performance.

3) Further understanding/optimization of novel catalysts and incorporation of those catalysts into the micro-reformer.

\subsection{Task 3 Final Report}

Alternative energy has been given much attention lately due to concerns about depletion of fossil fuel reserves and atmospheric pollutants resulting from increased energy consumption. An attractive option is polymer electrolyte membrane (PEM) fuel cells, which efficiently convert chemical energy directly to electrical. PEM fuel cells use oxygen and either hydrogen gas or a hydrogen-containing compound like methanol and produce water and heat. The potential for hydrogen use as an energy carrier is limited by the ability to produce and store hydrogen. Microscale steam reforming of glucose, a biomass derived carbohydrate, is proposed as a novel method of hydrogen production and is the focus of this research.

Current technologies for hydrogen production involve the breakdown of either $\mathrm{H}_{2} \mathrm{O}$ or hydrocarbon fuel stocks. The available avenues of water splitting, including electrolytic, photolytic, photobiological and photoelectrochemical based systems, are inefficient and cost prohibitive compared with thermochemical breakdown of hydrocarbons. The problematic production of $\mathrm{CO}_{2}$ during thermochemical hydrocarbon processing is of major concern given the atmospheric complications of $\mathrm{CO}_{2}$ emissions and the disruption of the carbon cycle. The utilization of biomass as a hydrocarbon fuel source mitigates this concern as the carbon dioxide produced is consumed for biomass growth leading to a closed carbon loop. 
Aqueous phase reforming of biomass-derived hydrocarbons is a promising method of hydrogen production. Of current hydrocarbon reforming methods including partial and preferential oxidation, and autothermal reforming, steam reforming has the highest theoretical efficiency and potential $\mathrm{H}_{2}$ selectivity. ${ }^{1,2}$ It has been demonstrated that biomass related sugars and alcohols can be converted to hydrogen via steam reforming in bench scale packed bed reactors. ${ }^{3,4,5}$ Micro-scale aqueous steam reforming of glucose is suggested as a novel alternative method of $\mathrm{H}_{2}$ production for micro fuel cells. Compact fuel cell systems are a viable alternative to batteries as a portable electrical power source. Compared with conventional lithium batteries, hydrocarbon powered fuel cells are more compact and boast a higher energy density. ${ }^{6}$ Micro reactor advantages over bench top scale counter parts include decreased surface: volume ratios and increased thermal conduction and mass transfer rates. While direct biomass pyrolysis or gasification measures are being pursued on the manufacturing scale, aqueous steam reforming is best suited for micro scale reforming due to simplicity of the design and minimal waste handling issues. In addition, hydrocarbons steam reforming has the highest theoretical efficiency and $\mathrm{H}_{2}$ selectivity.

An attractive $\mathrm{H}_{2}$ source is biomass because it is renewable and carbon cycle neutral. Although numerous hydrocarbons are potentially useful as fuel, glucose and ethanol have been demonstrated to be excellent candidates for biomass derived hydrogen. Glucose is a major component of biomass; ${ }^{7}$ the fermentation of sugars such as glucose produces ethanol which can then be easily reformed. A fuel cost analysis indicates that glucose is a more cost effective fuel from any source. Unprocessed sugars are considered even more cost effective. The process and economics of hydrogen production from glucose is being reviewed. It is not known how miniaturization of steam reforming will affect $\mathrm{H}_{2}$ selectivity. While many bench scale reactor systems are based on a tubular reactor, the design at New Mexico Tech utilizes a micro reactor with $100 \mu \mathrm{m}$ channels. The microreactor system was designed based on that of Cortright, et al. ${ }^{4}$ The reactor system consists of: an HPLC pump (Hitachi L-6000, Arcade, NY) which feeds the reactants into the reactor (IMM ${ }^{\circledR}$ GPMR-MIX micro plate reactor, Mainz, Germany), pressure and temperature sensors upstream and downstream of the reactor, a back pressure regulator valves and a collection cylinder.

1

J. D. Holladay, E. O. Jones, M. Phelps, and J. Hu, "Microfuel processor for use in a miniature power supply," Journal of Power Sources, vol. 108, pp. 21-27, 2002.

2 L. J. M. J. Blomen and M. N. Mugerwa, Fuel Cell Systems. New York, NY: Plenum Press, 1993.

3 R. R. Davda and J. A. Dumesic, "Renewable hydrogen by aqueous-phase reforming of glucose," Chem. Commun., pp. 36-37, 2004.

$4 \quad$ R. D. Cortright, R. R. Davda, and J. A. Dumesic, "Hydrogen from catalytic reforming of biomassderived hydrocarbons in liquid water," Nature, vol. 418, pp. 964 - 967, 2002.

5 A. N. Fatsikostas, D. I. Kondarides, and X. E. Verykios, "Steam reforming of biomass-derived ethanol for the production of hydrogen for fuel cell applications," Chem. Commun., pp. 851-852, 2001.

$6 \quad$ E. A. Daymo, D. P. VanderWiel, S. P. Fitzgerald, Y. Wang, R. T. Rozmiarek, M. J. LaMont, A.

Y. Tonkovich, Microchannel Fuel Processing for Man Portable Power, AlChE 2000 Spring National Meeting, Altanta, GA, 2000.

7 L. A. Underkofler, Cellulases and Their Applications. Washington, D. C.: American Chemical Society, 1969. 


\subsubsection{Microreactor System}

Significant modifications to the experimental setup have been accomplished. Modifications to the pressurized reactor system were done to reduce the system throughput; the large system volume of previous system designs combined with the slow flow rates necessary for sugar processing led to a significant delay in product detection. A mass spectrometer with atmospheric pressure inlet was acquired to simplify the gas detection process.

The pressurized reactor system consists of an HPLC pump (Hitachi L-6000, Arcade, NY) a microreactor (IMM $\mathbb{R}$ GPMR-MIX micro nlate reactor Mainz. Germanv) and a

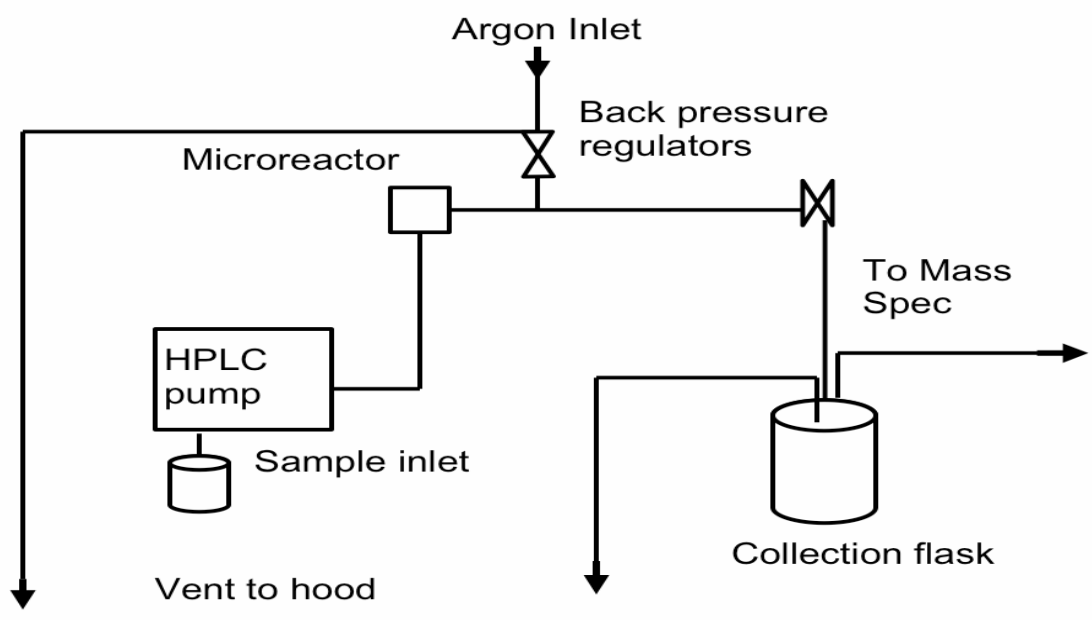

Figure 1 Schematic representation of rector setup.

Figure 3.1. Schematic representation of reactor set up. 
The mass spectrometer used is a SRS QMS 200 Gas Analyzer (Stanford Research Systems, Sunnyvale, CA, USA) with an analytical range up to $200 \mathrm{amu}$ and $<1 \mathrm{amu}$ resolution. The gas analyzer has a high-pressure inlet that accommodates an inlet stream from 10 mbar up to atmospheric pressure. Continuous sampling and data acquisition provides for real-time information on the gas effluent from the reactor system. The system has an integrated hybrid turbomolecular/drag pump and diaphram pump; the vacuum chamber's operating pressure is $5 \times 10^{-6} \mathrm{mbar}$. The compact design allows for easy transport. Figure 3.2 shows an image of the QMS 200.

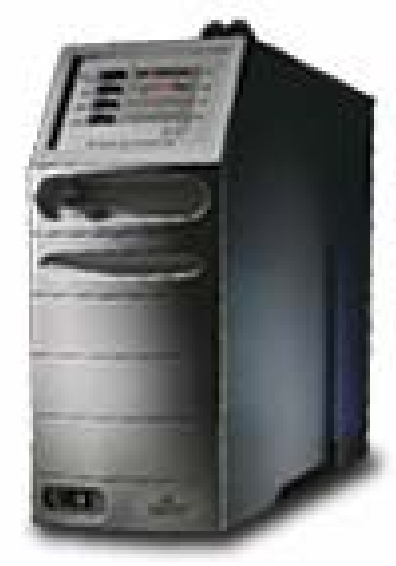

Figure 3.2 SRS QMS 200 Gas Analyzer

\subsubsection{Catalysis}

Catalysis in the IMM micro-reactor occurs in stacks of microchannel plates. Each of the ten 316 stainless steel microchannel plates in the reactor (Fig. 3.3) contain nine parallel $500 \mu \mathrm{m} \times 100 \mu \mathrm{m}$ channels within which the catalyst resides and all reaction occurs.

A variety of catalyst materials are under consideration, including platinum, palladium, rhodium, and ruthenium. Because the catalyst deposition method and morphology are expected to play a role in both the overall activity as well as the specific activity of the catalyst, a variety of methods for presenting the catalyst to the reactants are also under consideration. These include aluminum oxide-supported catalysts with sparse distributions of large-scale catalyst which is several microns in diameter as shown in Fig. 3.4, plasma-deposited catalysts with dense distributions of small nanometer-scaled catalyst, and vacuum-evaporated catalyst with large-scale, dense catalyst distributions.

Initial catalyst preparation protocols utilized aqueous suspensions of alumina-supported Pt catalyst. These were prepared as suspensions using ammonium polyacrylate and hydroxypropyl methylcellulose as dispersant and binding agents. Deposition from the 
solution was preformed via evaporation, dipping, and electrophoretic deposition, followed by heating to a variety of temperatures. In general, most attempts to coat stainless steel surfaces under these conditions were unsuccessful. The most successful of these coating attempts are shown in Figures 3.5 and 3.6, however none of the catalyst samples treated in this way had sufficient strength to survive handling. Equally problematic, the coatings with the best adhesion also tended to be very thick $(\sim 500 \mu \mathrm{m})$ and to have little open porosity for reactant access to the catalyst e.g., Fig. 3.5. Although this coating preparation method might result in a successful coating at sufficiently high heat-treatment temperatures, the 316 stainless steel is effectively limited by oxidation to a maximum processing temperature of around $800^{\circ} \mathrm{C}$. This precludes a high temperature sinter for alumina-supported catalyst mounting.

As an alternative to the alumina-supported Pt catalyst, initial experiments with the microreactor were conducted using reactor plates coated with a nominal 30nm thick plasmasputtered Pt film. Platinum deposited in this way characteristically forms a near-uniform film, with a grain size on the order of a few nanometers; good coverage of the reactor plate channel walls is also expected, due to the scattering of the Pt that occurs within the Ar plasma of the sputtering system. ${ }^{8}$

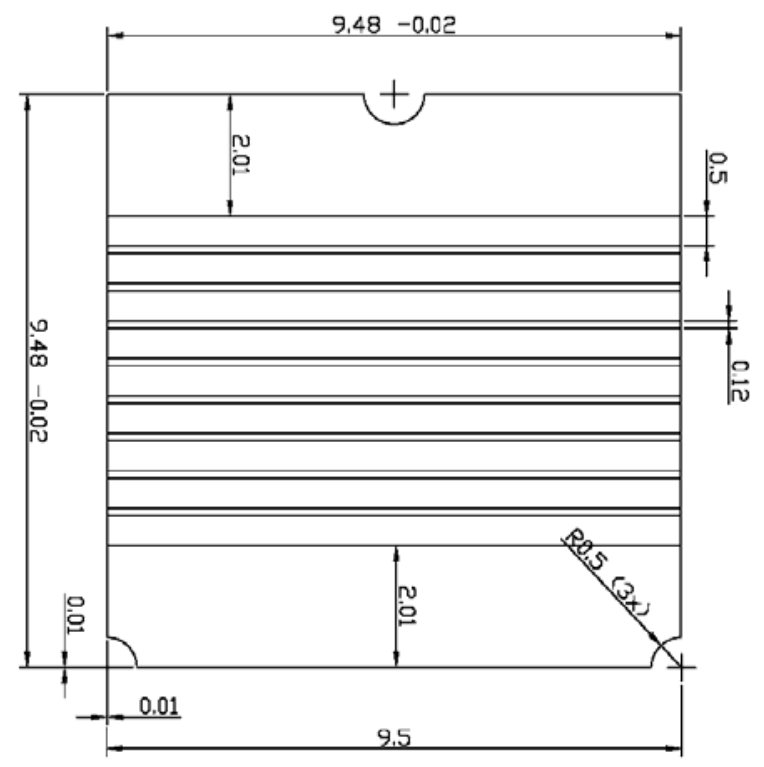

Figure 3.3 Schematic of microchannel plate for the IMM micro-reactor. All dimensions are in millimeters. The nominal plate thickness is $0.25 \mathrm{~mm}$, and the nominal channel depth is $0.1 \mathrm{~mm}$. (Image courtesy of Institut für Mikroechnik Mainz GmbH.)

8 J. Goldstein, et al, Scanning Electron Microscopy and X-Ray Microanalysis, 3rd edition, pp.662664 (Springer, 2003) 


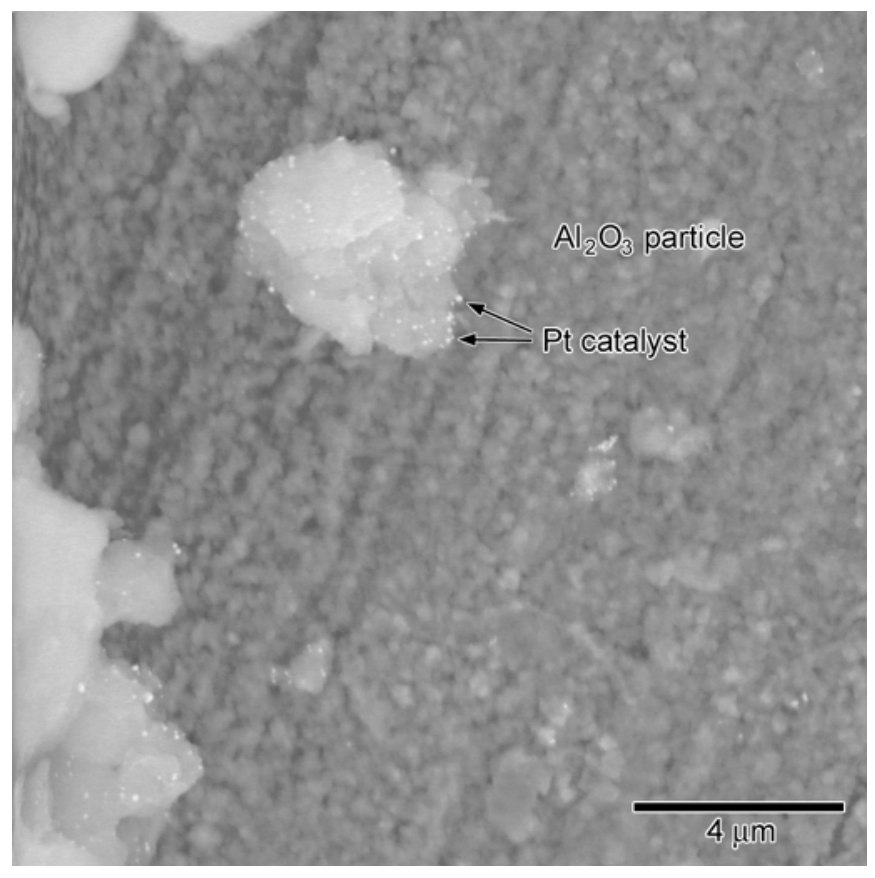

Figure 3.4 Platinum catalyst islands (white specks) supported by alumina on oxidized 316 stainless steel.

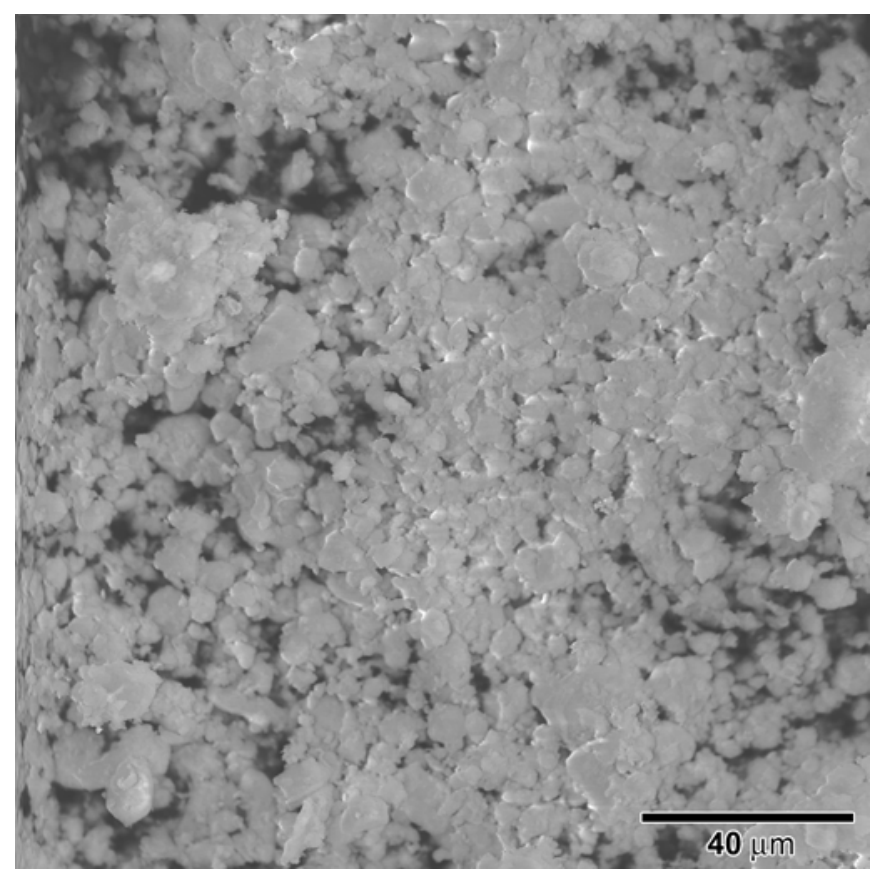

Figure 3.5 Surface layer of a Pt-decorated alumina deposited on 316 stainless steel via aqueous processing. Low amounts of open porosity and mechanical fragility make this a poor choice for coating of catalyst plates. 


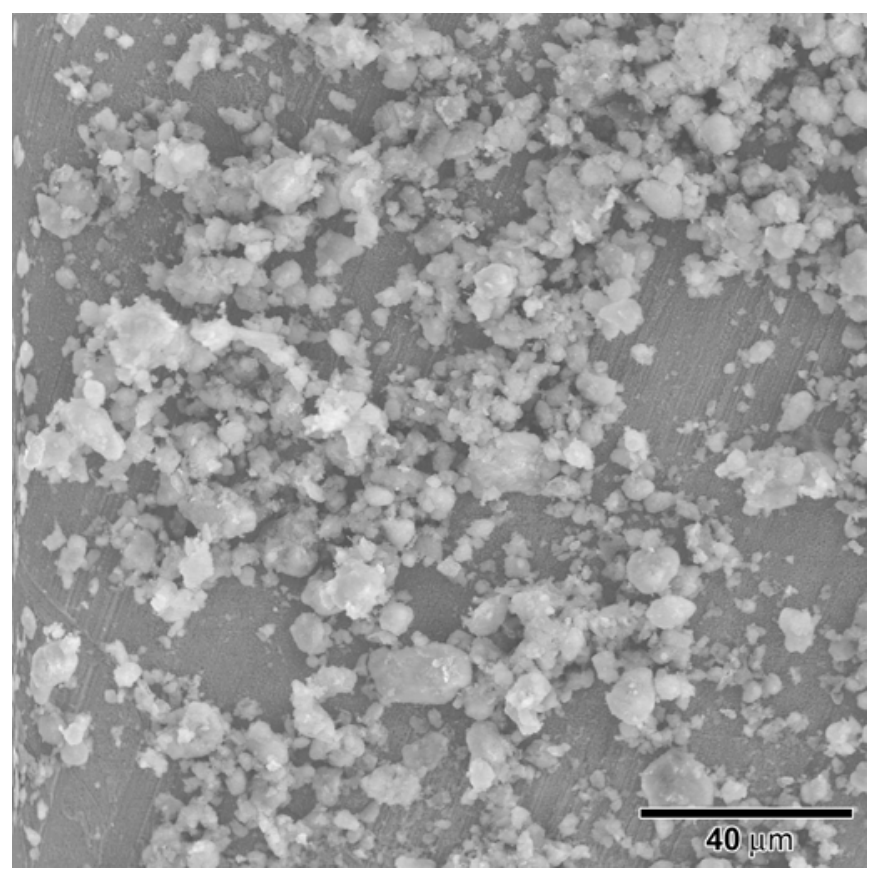

Figure 3.6 Thin coating of Pt-decorated alumina deposited on 316 stainless steel via aqueous processing. More open structure of the coating is compromised by poorer coating adhesion.

In order to overcome the catalyst adhesion problems noted for the alumina-supported metal catalysts, we have developed a new method for adhering the alumina/catalyst particles to the reactor microchannel plate substrates. A protocol to coat catalyst plates for future experiments has been developed, which gives adequate bonding between the alumina-supported catalyst and the stainless steel backing, while not exposing the catalyst plates to temperatures greater than $800^{\circ} \mathrm{C}$.

Cementing of the alumina powder was accomplished by forming a borosilicate glass insitu at the particle-particle and particle-substrate contact points. This was achieved by first dissolving borosilicate glass precursor compounds (tetraethylorthosilicate (TEOS, $\left.\left(\mathrm{C}_{2} \mathrm{H}_{3}\right)_{4} \mathrm{SiO}_{4}\right)$, boric acid $\left(\mathrm{H}_{3} \mathrm{BO}_{3}\right)$, sodium nitrate $\left(\mathrm{NaNO}_{3}\right)$ in an ethanol solution in a 81:26:8 molar ratio, adding alumina powder to form a suspension, and then dropping the suspension on stainless steel coupons. The wetted coupons were then allowed to dry in room air, simultaneously concentrating the glass precursors and absorbing water from the air into the remaining solution. Once most of the solution evaporates, the glass precursors have simultaneously been drawn to the inter-particle interfaces by capillary action then begin to precipitate out of solution into those interfacial regions: $\mathrm{NaNO}_{3}$ and $\mathrm{H}_{3} \mathrm{BO}_{3}$ because of their increasing concentration in the solution, and $\mathrm{SiO}_{2}$ as a reaction product between TEOS and the absorbed water in the solution.

After drying of the powder+precursor mixture (typically $\sim 30$ minutes), the assembly is slowly heated to $800^{\circ} \mathrm{C}$ and allowed to furnace cool. This finishes the decomposition of 
any residual TEOS, dehydrates the $\mathrm{H}_{3} \mathrm{BO}_{3}$ to $\mathrm{B}_{2} \mathrm{O}_{3}$, and decomposes the $\mathrm{NaNO}_{3}$ to $\mathrm{Na}_{2} \mathrm{O}$, leaving a $81 \cdot \mathrm{SiO}_{2}: 13 \cdot \mathrm{B}_{2} \mathrm{O}_{3}: 4 \cdot \mathrm{Na}_{2} \mathrm{O}$ molar ratio oxide mixture in a borosilicate glass composition similar to that used in laboratory glassware.

The typical as-fired morphology of the borosilicate-bonded alumina is shown in Figures 3.7 and 3.8. The open porosity between alumina particles is typical, allowing easy access to the interior of the structure. The loss of solvent at the surface of the evaporating slurry tends to concentrate the glass precursors at the surface of the bonded alumina, occasionally leading to free-standing whiskers of oxide, shown in Fig. 3.8. Due to the relative glass enrichment of the surface layer, the top of thick glass-bonded alumina deposit is the strongest so it is possible to fracture off (and dispose of) the top glassenriched layer, leaving the bottom few particles of glass-alumina as shown in Figures 3.9 and 3.10. This remaining layer has equivalent porosity to the surface layer, is thinner than the original as-fired layer, has greater mechanical stability due to the proximity of the substrate, and in general makes an ideal candidate as a catalyst support.

In addition to the already-prepared plasma-deposited Pt catalyst plates and the upcoming $\mathrm{Pt} / \mathrm{AlO}_{3}, \mathrm{Pd} / \mathrm{Al}_{2} \mathrm{O}_{3}, \mathrm{Rh} / \mathrm{Al}_{2} \mathrm{O}_{3}$ catalyst plates prepared by borosilicate-glass bonding, work is also underway to prepare Pd-rich nanoparticle-coated reactor plates in collaboration with Sandia National Laboratory, Albuquerque, NM, as well as vacuum-evaporated Pt and $\mathrm{Pd}$ reactor plates, which are expected to be more robust than the alumina-supported plates and possess a larger catalyst grain size than the plasma-deposited or nanoparticlecoated reactor plates.

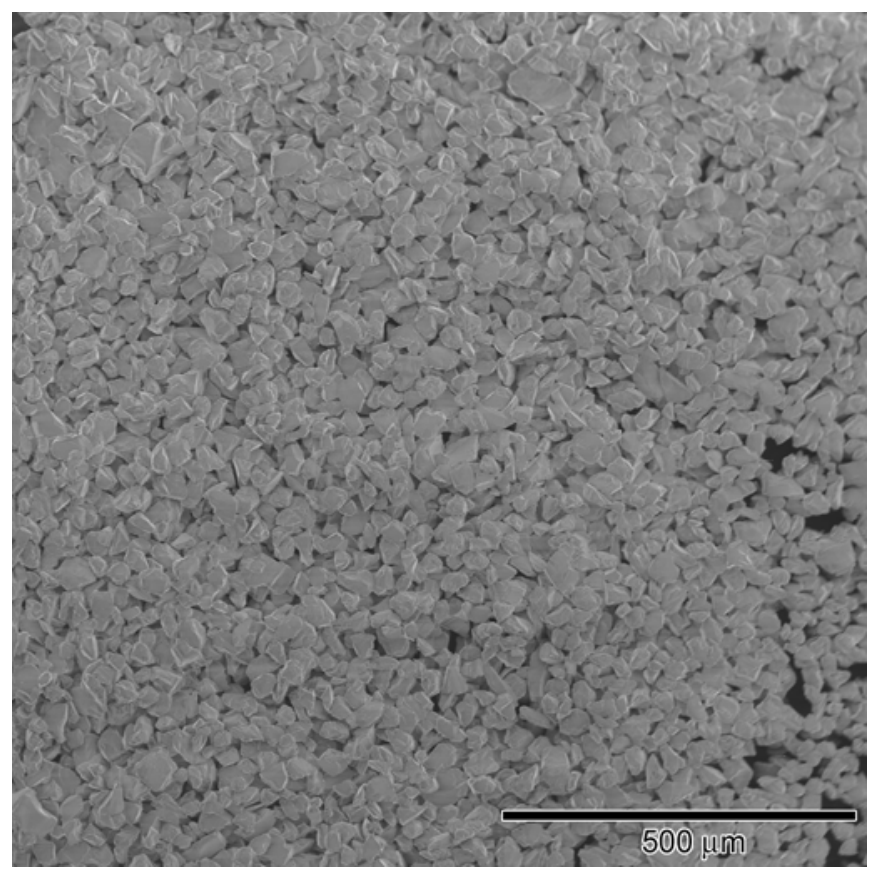

Figure 3.7 Borosilicate-bonded alumina, as-deposited and fired exhibiting an open intergrainular structure. 


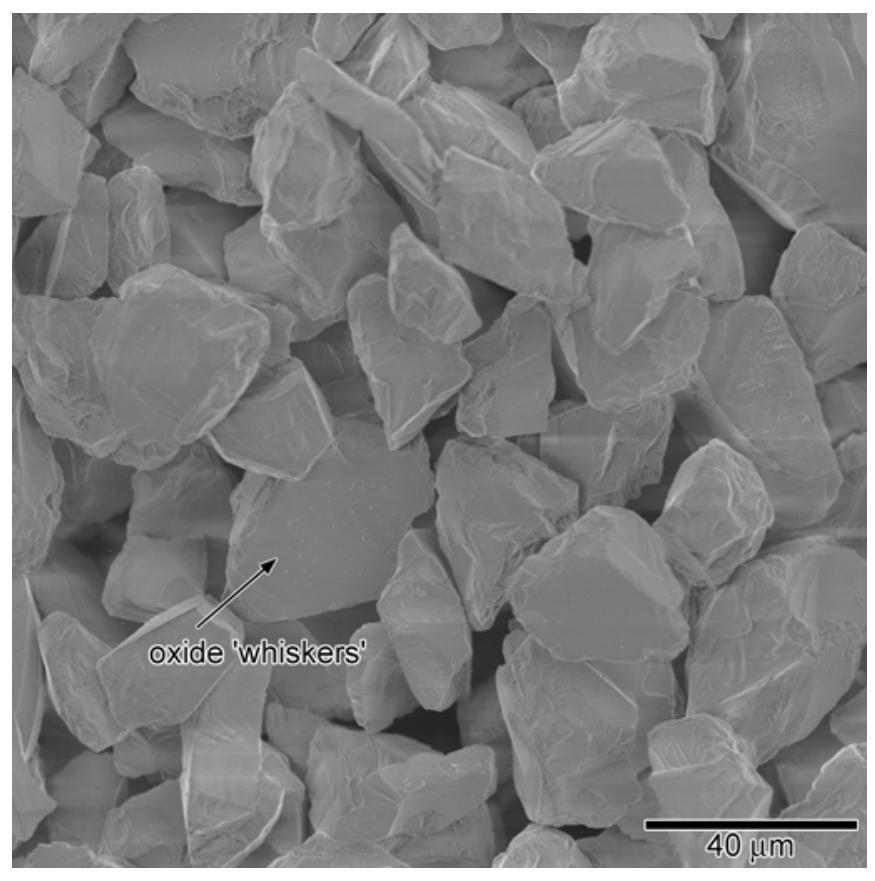

Figure 3.8 Detail of borosilicate-bonded alumina, as-deposited and fired from Figure 3.5 of the open network of intergranular pores.

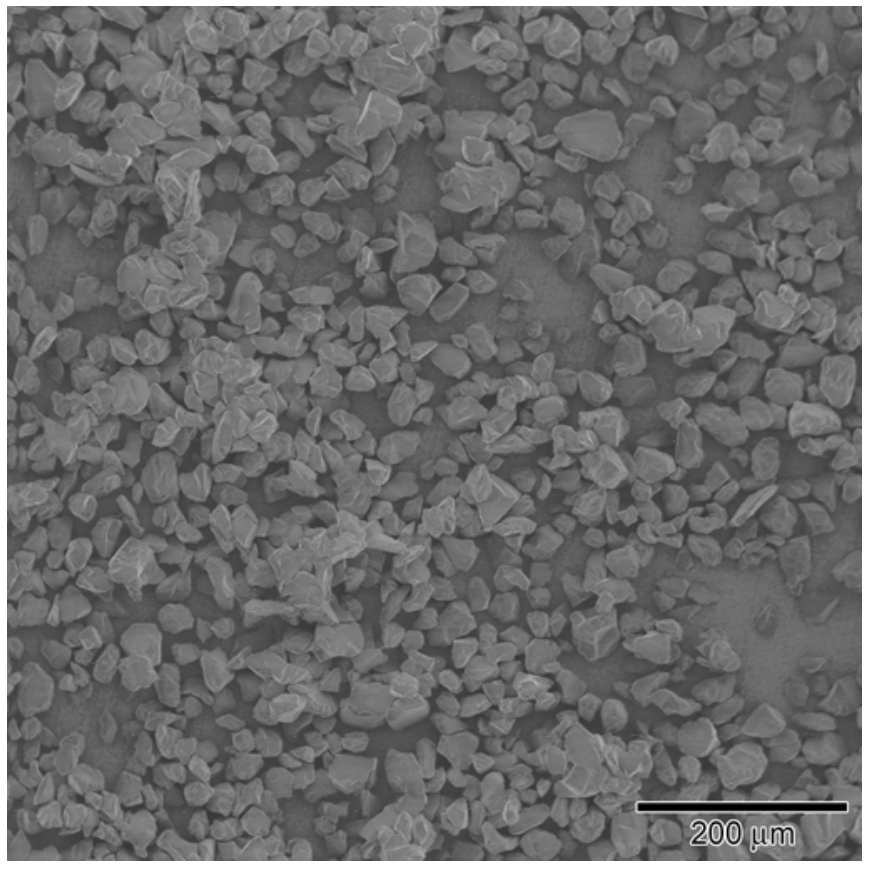

Figure 3.9 Borosilicate-bonded alumina, deposited, fired, then fractured to show that the open inter-grain structure is retained down to the substrate, and the resulting durable coating is no more than a few particle diameters thick. 


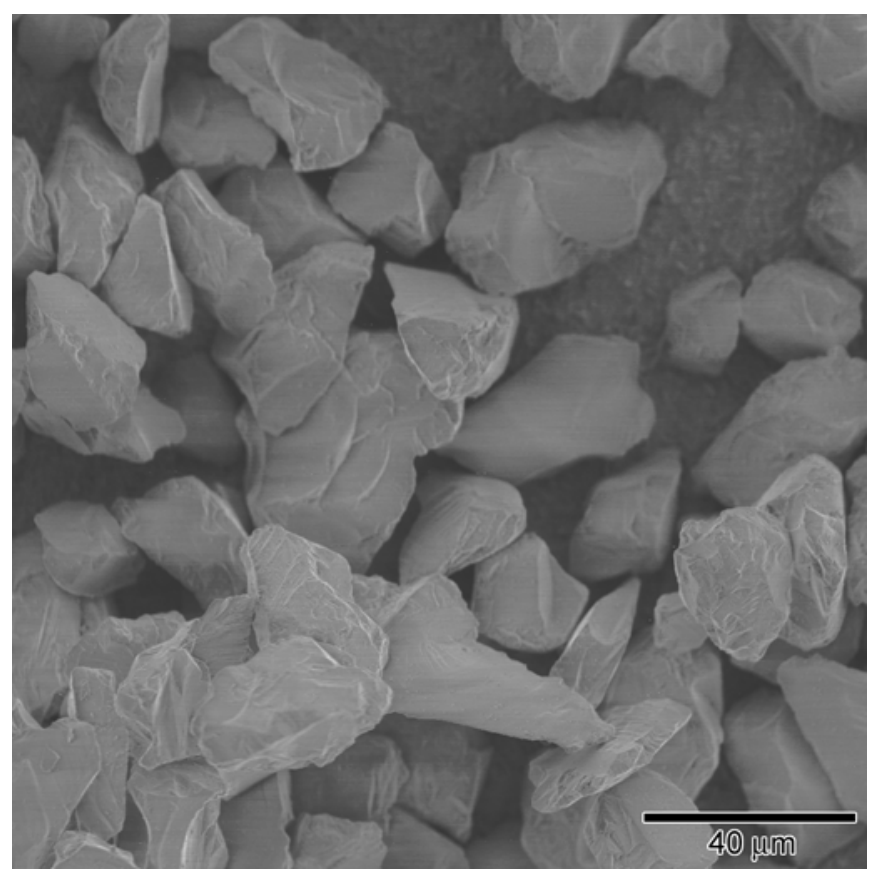

Figure 3.10 Borosilicate-bonded alumina, deposited, fired, then fractured. Detail from figure 3.9 showing the excellent exposure of the remaining alumina particles to the environment.

\subsubsection{Reforming}

Ethylene glycol $\left(\mathrm{HOCH}_{2} \mathrm{CH}_{2} \mathrm{OH}\right)$ is a molecule relevant to glucose aqueous-phase reforming because it contains the same functional groups as all larger polyols, including $\mathrm{C}-\mathrm{C}, \mathrm{C}-\mathrm{O}, \mathrm{C}-\mathrm{H}, \mathrm{O}-\mathrm{H}$ and $\mathrm{OH}$ groups on adjacent carbon atoms. All the reactions involved in sugar processing are present in ethylene glycol as well. Therefore, ethylene glycol aqueous phase reforming can be used to model the reactions that occur for direct production of $\mathrm{H}_{2}$ from biomass-derived polyols like glucose.

Figure 3.11 shows the gas evolved from $10 \mathrm{wt} \%$ ethylene glycol processed at $3 \mathrm{ml} / \mathrm{min}$, $225^{\circ} \mathrm{C}$ and 30 bar. The catalyst used was plasma deposited Pt. Mass spectra were taken after one hour of processing at the times listed above. The presence of peaks at mass 28 , 32 and 44 are indicative of $\mathrm{N}_{2}, \mathrm{O}_{2}$, and $\mathrm{CO}_{2}$ found in air. The peak for Ar at mass 40 is higher than what is typically found in atmospheric pressure; the system was initially pressurized with Ar so it is likely. The largest characteristic peak for ethylene glycol is 31 ; here the mass 31 peak appears at a pressure of $\sim 2 \times 10^{-8}$ at both sampling times. This indicates the presence of unprocessed ethylene glycol in the effluent stream. A hydrogen peak (mass 2) of $1.4 \times 10^{-7}$ is also present. This hydrogen quantity cannot be attributed to $\mathrm{H}_{2}$ alone as both water and ethylene glycol break down upon ionization in a mass spectrometer and produce $\mathrm{H}_{2}$. A background scan with water and ethylene glycol present showed peak ratios of 0.18 and 0.9 for $2 / 18$ and $2 / 31$ respectively (18 is the signature peak for water and 31 is the signature peak for ethylene glycol). The mass spectra presented above had peak ratios at both sampling times of 0.32 for $2 / 18$ and $\sim 6$ for $2 / 31$. The larger ratios (small in the case of water and large in the case of ethylene glycol) 
indicate a small but measurable amount of hydrogen gas was detected. Calibration of the SRS QMS 200 is necessary to determine the specific quantity of hydrogen produced. While a small about of hydrogen gas was detected, complete conversion of ethylene glycol should result in much greater amounts. The presence of the signature ethylene glycol peak at 31 also indicates incomplete conversion of ethylene glycol. With a total reactor platelet volume of $25 \mathrm{~mm}^{2}$ a flow rate of $3 \mathrm{ml} / \mathrm{min}$ produces a total reactor volume turnover rate of 120 times per minute. Slower flow rates may yield more complete conversion of ethylene glycol.

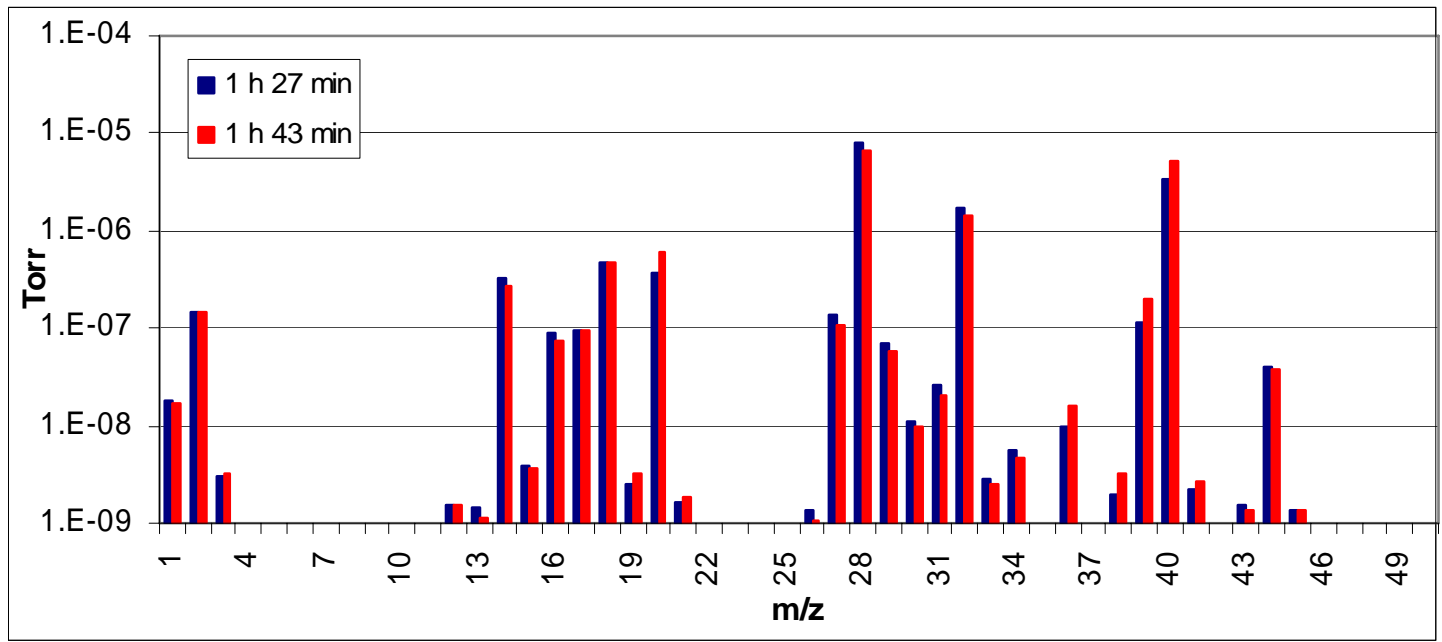

Figure 3.11 Mass spectra of $10 \mathrm{wt} \%$ ethylene glycol processed at $3 \mathrm{ml} / \mathrm{min}, 225^{\circ} \mathrm{C}$, and 30 bar.

Glucose, a sugar found in cellulosic biomass, corn starch and sugar cane, was processed using plasma deposited Pt catalyst. Figure 3.12 shows the evolved gas from $1 \mathrm{wt} \%$ glucose in an aqueous solution processed at $30 \mathrm{bar}, 225^{\circ} \mathrm{C}$ at flow rates of $0.5,1$ and 3 $\mathrm{ml} / \mathrm{min}$. No Ar backpressure was used for these experiments. The partial pressures of the ions detected are shown in Torr. Peaks at 28, 32, 40 and 44 are representative of $\mathrm{N}_{2}$, $\mathrm{O}_{2}$, Ar and $\mathrm{CO}_{2}$ in air. The collection cylinder is periodically drained and exposed to atmosphere; this adds air to the analyzed gas stream. The ratios of $\mathrm{O}_{2}$ and $\mathrm{Ar}$ to $\mathrm{N}_{2}$ are similar to those found in air. The $\mathrm{CO}_{2} / \mathrm{N}_{2}$ ratio for air is 0.0005 ; the $\mathrm{CO}_{2} / \mathrm{N}_{2}$ ratio detected ranges from 0.003-0.004 for the various flow rates. This indicates a small production of $\mathrm{CO}_{2}$, which may indicate a partial breakdown of glucose. Peaks at 17, 18 and $2\left(\mathrm{OH}, \mathrm{H}_{2} \mathrm{O}\right.$ and $\left.\mathrm{H}_{2}\right)$ are indicative of water vapor present in the analyzed gas. The ratio of the hydrogen gas to water peaks is $\sim 0.3$ for each of the flow rates used. Water analyzed independently of glucose has a $\mathrm{H}_{2} / \mathrm{H}_{2} \mathrm{O}$ peak ratio of 0.25 . As these ratios are very close, it is unlikely that any hydrogen gas from the breakdown of glucose was present in the effluent gas stream. These data indicate a partial breakdown of glucose but with no measurable hydrogen production. It is also possible that the large $\mathrm{H}_{2}$ peak from water may make it difficult to separate $\mathrm{H}_{2}$ ions detected from hydrogen gas. The flow rates used may also be fast for the complete breakdown of glucose. The total reactor platelet volume is $25 \mathrm{~mm}^{2}$. Even at the slowest flow rate of $0.5 \mathrm{ml} / \mathrm{min}$ the volume in the reactor platelets is replaced 20 times every minute. Flow rates on the order of $\mathrm{ml} / \mathrm{h}$ are 
reported for bench scale reforming of glucose; ${ }^{4}$ slower flow rates may be necessary for successful hydrogen production from glucose in a microscale system.

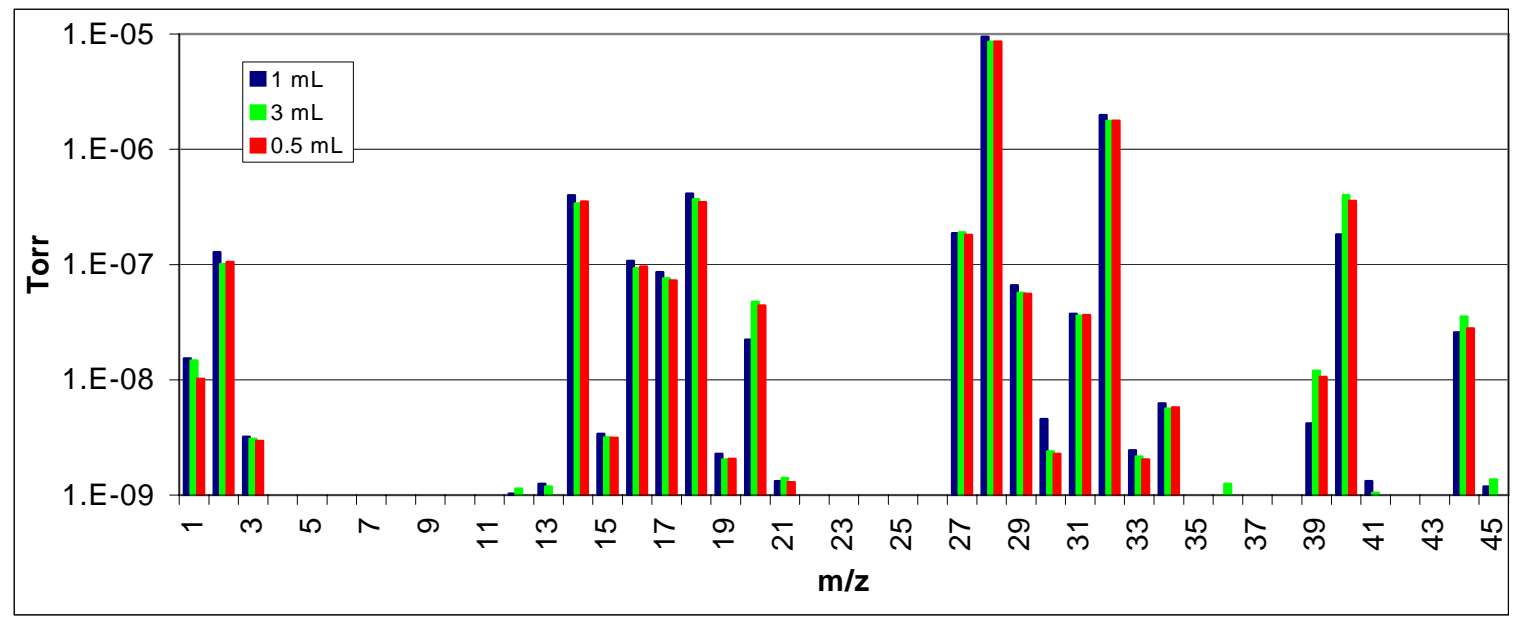

Figure 3.12 Mass spectra of 1 wt\% glucose processing at $225^{\circ} \mathrm{C}$ and 30 bar.

Some examples of cellulosic biomass are the sugar-rich crop residues remaining after the processing of cane, beet, citrus and other plant matter, commonly known as molasses. These are potentially an attractive source for hydrogen production because they are frequently considered a low-value byproduct of the initial production process, and sometimes discarded as waste material. In order to examine the feasibility of using crop residue as a hydrogen production feedstock, a sample of molasses from Hawaii was obtained from Dr. Scott Turn, Hawaii Natural Energy Institute.

One potential difficulty with hydrogen production using a feedstock of raw crop residue (molasses) is the large variety of compounds that exist in these crop residues, and which can be expected to vary depending on the source crop. While a lower overall hydrogen production efficiency (due to the differing ideal conditions required for $\mathrm{H}_{2}$ production) may be cost-effective once the costs of refining are considered, the presence of sulfur may be expected to halt hydrogen production completely in Pt-based reactors due to poisoning of the Pt catalyst with sulfur compounds created during the reaction process. Molasses usually contain $\sim 0.5 \%$ sulfur by dry weight ${ }^{9}$, prompting a search for the presence or absence of sulfur in the HI molasses sample. Fourier transform infrared spectroscopy (FTIR) of the HI sample (Fig. 3.13) is inconclusive as to the presence or absence of organic sulfur-bearing compounds, while a test for sulfur by the method of Carius $^{10}$ was consistent with a small sulfur content. Therefore, Pt-based hydrogen production experiments have been avoided for this feedstock. Crop residue feedstock

9 T.L Stanton, S. Levalley, Colorado State University Cooperative Extension Publication No. 1.615, February 2006

10 J.B. Cohen, Practical Organic Chemistry, MacMillan and Co., London (1910), p. 28. 
experiments involving other catalyst materials will be conducted as a component of the continuing research.

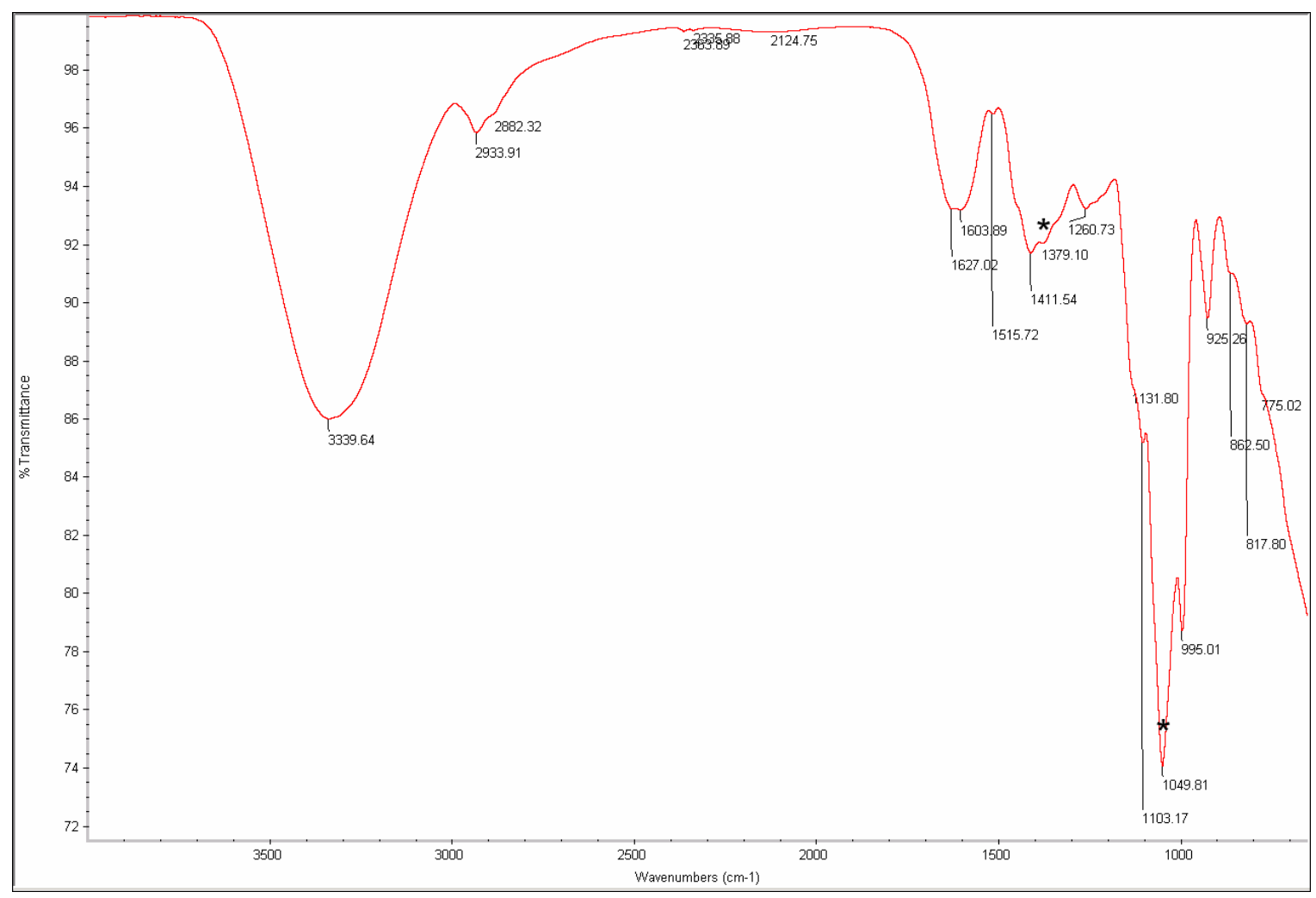

Figure 3.13 Infrared transmittance spectrum from $\mathrm{HI}$ crop residue showing features consistent with the presence of $S=O$ bonding within one or more compounds.

\subsection{Project Conclusions and Future Work}

Glucose and ethylene glycol results indicate slow flow rates are necessary for conversion to gaseous products. A small but measurable amount of $\mathrm{H}_{2}$ was detected in ethylene glycol processing implies successful function of the microreactor with Pt catalyst. Organic sulfur in crop residue precludes its use as a feedstock for $\mathrm{H}_{2}$ production with $\mathrm{Pt}$ catalyst. Alternative catalysts which are not poisoned by sulfur and/or do not contain Pt are still under investigation. 


\section{APPENDIX D}

Improving Fuel Characteristics of Sugar Cane Trash

An HNEI final report (previously completed) is presented on the following pages.

This report contains its own internal section, figure, table, and subappendix numbering system. 
This page is intentional blank 


\title{
Improving Fuel Characteristics of Sugar Cane Trash
}

\author{
University of Hawaii \\ Scott Turn \\ Kurt Woytiuk \\ Vheissu Keffer \\ Donald Evans \\ Hawaii Natural Energy Institute \\ School of Ocean and Earth Sciences and Technology
}

June 2008 


\begin{abstract}
This paper summarizes a preliminary investigation into methods for processing sugar cane trash at the Puunene Sugar Factory on the island of Maui, Hawaii. The factory is owned and operated by Hawaiian Commercial and Sugar, a subsidiary of Alexander and Baldwin Incorporated. The objective of the investigation was to explore treatment methods that would enable the successful use of cane trash as fuel for the production of hydrogen via gasification. Note that the results are potentially applicable for other thermochemical energy devices as well. Cane trash consists of the leafy plant matter, both living and dead, that accumulates over the course of the growing period. Normally this material is burned off before harvest in an open field burn. An alternative is to harvest and process sugar cane trash into a viable fuel. Sugar cane trash is a poor fuel for thermochemical conversion due to its ash composition and the associated tendency to form slag and deposits and foul working surfaces.

Laboratory and pilot scale tests were carried out using water as a leaching agent to investigate the removal of elements, $\mathrm{K}, \mathrm{Na}$, and $\mathrm{Cl}$, known to be agents for slag and deposit formation. Leach water temperature, leaching duration, and cane trash particle size were varied in the laboratory. Particle size was found to have a significant effect in the reduction of $\mathrm{K}, \mathrm{Na}$, and $\mathrm{Cl}$ concentrations and an observed increase in ash fusion temperatures and a decrease in total alkali concentration per energy unit to a level below that empirically found to be the threshold for slagging and fouling. Similar pilot scale tests were also performed, but particle size reduction was made impossible due to equipment failure. The pilot scale samples were not reduced below the threshold for slagging and fouling in the leaching treatments.
\end{abstract}




\section{Table of Contents}

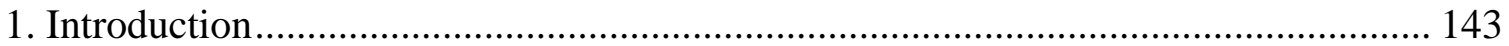

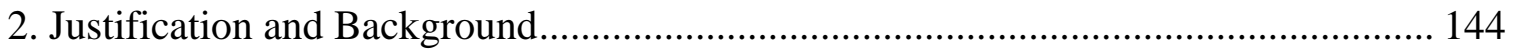

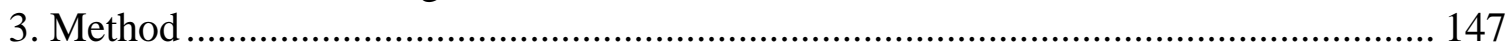

$\begin{array}{ll}\text { 3.1 Laboratory Scale Experiment I } & 147\end{array}$

3.1.1 Laboratory Scale Experiment II 148

3.2 Sample Collection I.................................................................................. 149

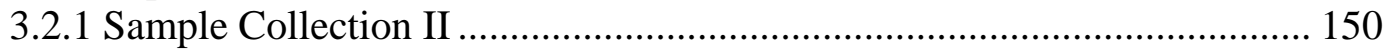

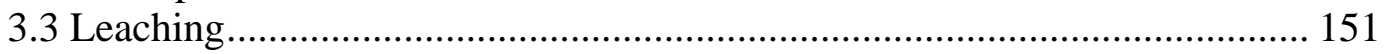

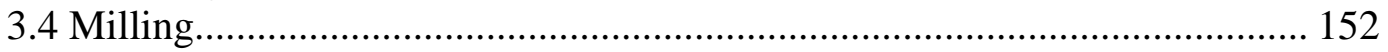

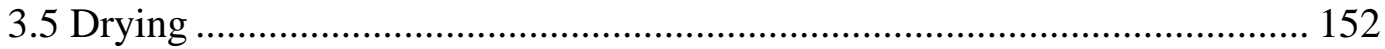

3.6 Data Collection and Analysis...................................................................... 152

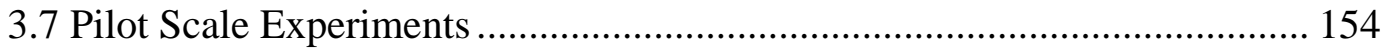

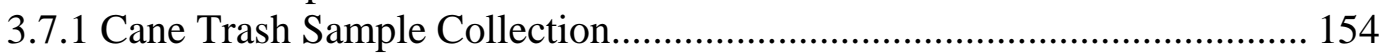

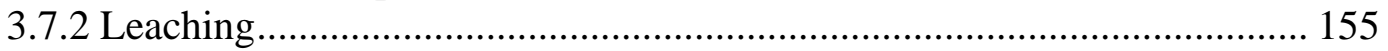

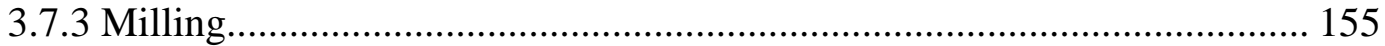

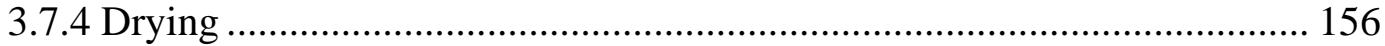

3.7.5 Data Collection and Analysis.................................................................... 156

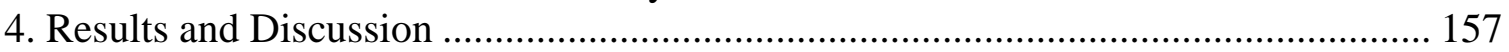

4.1 Validation of Laboratory Scale Experimental Practices ................................ 157

4.1.1 Mass Balances for Laboratory Experiments I............................................. 158

4.1.2 Mass Balances for Laboratory Experiments II .......................................... 159

4.2.1 Moisture Analyses for Laboratory Experiments I ....................................... 160

4.2.2 Moisture Analyses for Laboratory Experiments II ....................................... 161

4.3.1 Electrical Conductivity for Laboratory Experiments I ................................ 162

4.3.2 Electrical Conductivity for Laboratory Experiments II ............................... 164

4.4.1 Total Suspended Solids Laboratory Experiments I ...................................... 165

4.4.2 Total Suspended Solids Laboratory Experiments II .................................... 166

4.5.1 Fuel Characterization Laboratory Experiments I......................................... 167

4.5.2 Fuel Characterization Laboratory Experiments II ....................................... 169

4.6.1 Element Removal by Leaching for Laboratory Experiments I.................... 171

4.6.2 Element Removal for Leaching Laboratory Experiments II....................... 176

4.7.1 Slagging and Fouling Probability for Laboratory Experiments I ............... 185

4.7.2 Slagging and Fouling Probability for Laboratory Experiments II .............. 187

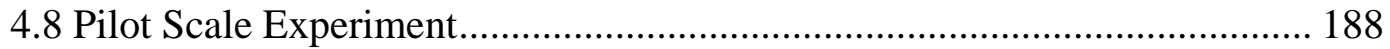

4.8.1 Validation of Experimental Practices ......................................................... 189

4.8.2 Element Removal by Leaching in the Pilot Scale Experiment .................... 193

4.8.3 Moisture Analyses of the Fuels from the Pilot Scale Experiment .............. 195

4.8.4 Electrical Conductivity ............................................................................. 196

4.8.5 Total Suspended Solids in the Pilot Scale Experiment ................................ 197

4.8.6 Wastewater Analysis in the Pilot Scale Experiment.................................... 197

4.8.7 Fermentable Sugars Content of Leachate and Expressed Liquids from the

Pilot Scale Experiment..................................................................................... 198

4.8.8 Characterization of Fuel Samples from the Pilot Scale Experiment........... 199

4.8.9 Slagging and Fouling Probability .............................................................. 200 


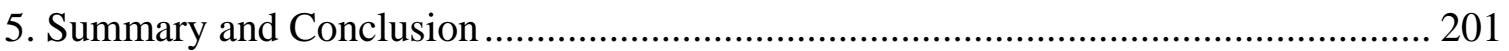

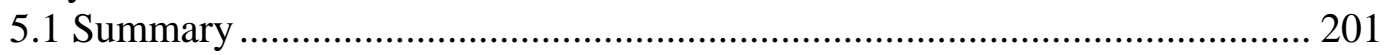

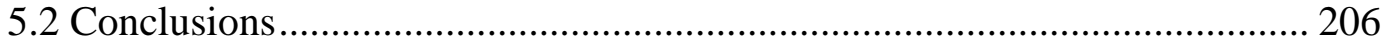

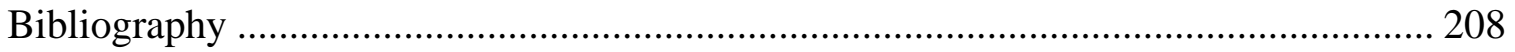

Subappendix A: Laboratory Scale Experiments I.................................................... 210

Experimental Data and Calculations for Sugar Cane Trash Processing Investigation 210

Subappendix B: Laboratory Scale Experiments II.................................................. 220

Experimental Data and Calculations for Sugar Cane Trash Processing Investigation 220

Subappendix C: Pilot Scale Experimental Data and Calculations for Sugar Cane Trash

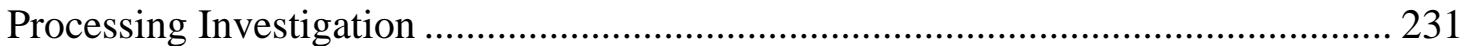

Leachate and Milling Water Balance .............................................................. 232

Fuel Ash Balance ......................................................................................... 239 


\section{Introduction}

The sugar industry is one of the earliest and most successful users of biomass for commercial energy production. The primary producer of sugar in Hawaii is Hawaiian Commercial \& Sugar (HC\&S), a subsidiary of Alexander \& Baldwin Inc. HC\&S irrigates 37,000 acres on a two-year growth cycle, harvesting approximately half of the acreage annually. The cane is processed at the Puunene Sugar Factory, producing roughly 200,000 tons of sugar, 80,000 tons of molasses, and 550,000 tons of bagasse each year. The Puunene mill uses the bagasse to attain energy self-sufficiency and meet part of a $12 \mathrm{MW}$ firm power contract with Maui Electric Co., the local utility. Boilers are also fired with supplemental coal and oil when bagasse is not available.

For several reasons, including an increasing demand for electricity, HC\&S seeks to incorporate the non-sugar bearing component of sugar cane, called sugar cane trash, in their existing energy scheme. Along with reducing dependency on coal, utilizing cane trash as a fuel source could eliminate the need for open field burning prior to cane harvesting.

Sugar cane trash is high in potassium, silica, chlorine and calcium. Potassium and chlorine naturally occurring in biomass are known to reduce heat transfer by causing slagging and fouling in boilers. Sugar cane fiber undergoes a number of milling and leaching steps during sugar processing before becoming bagasse, the commonly used boiler fuel. Leaching and dewatering have been shown to significantly reduce the inorganic constituents found in herbaceous crops that cause slagging and fouling in biomass boilers and gasifiers.

In order to minimize capital expenses, HC\&S hopes to minimize modifications to harvesting and processing methods in order to accommodate the increased fiber volume brought to the Puunene mill site under an unburned or green cane harvesting scenario. One of the primary modifications for green cane harvesting will be the separation, preparation, and treatment of cane trash for use as a fuel. Successful green cane harvesting will allow HC\&S to expand the sale of fiber-based energy products and reduce the consumption of coal and fuel oil. The proposed method to treat cane trash at HC\&S would use high temperature condensate water produced from evaporators in the sugar 
milling process. The condensate would be used in a sink-float tank to wash and leach inorganic matter from the cane trash with the intent of improving fuel properties.

This paper summarizes the results of an investigation aimed at developing a method to improve the fuel properties of sugar cane trash using leaching methods. Two lab scale experiments were designed to investigate the effects of time, temperature, and particle size on leaching potassium and chlorine from unburned, hand-harvested cane trash. A pilot scale test was also carried out to investigate the use of these methods on a larger scale. The pilot scale experiment evaluated temperature and time as variables using unburned, machine-harvested cane trash and shorts (1-2 foot sections of sugar cane) at the HC\&S mill site. The laboratory experiments were carried out using sugar cane trash hand harvested from the Hawaii Agricultural Research Center's (HARC) Kunia Research Station on the Island of Oahu.

\section{Justification and Background}

After two years of growth, cane is harvested using a push rake method unique to Hawaii. The cane is first burned to remove leaves and other non-essential fiber and then pushed into long windrows using Caterpillar D-8s. The collected cane and any adhering soil are grapple loaded into cane haul trailers and transported to the mill site for processing.

The Puunene mill operates for approximately 270 days a year and has a four to six week, year-end maintenance shutdown. Three bagasse fired spreader stoker boilers provide heat and power for plantation operations and for export to Maui Electric. Steam from the boilers feeds $\sim 40 \mathrm{MW}$ of turbogenerator capacity and have the potential to produce $~ 100$ GWh of electricity per year. During the annual maintenance shutdown bagasse is not available and the boilers are fired with coal to meet a $12 \mathrm{MW}$ firm power contract with Maui Electric.

Cane burning has been a routine part of HC\&S's harvest operation. The estimated dry trash to cane stalk ratio is approximately 14\% [2]. For every tonne of sugar cane stalk produced, $140 \mathrm{~kg}$ of dry or $350 \mathrm{~kg}$ at $60 \%$ moisture cane trash is also produced.

To be successfully used, cane trash must meet certain fuel quality benchmarks, chief among them ash quantity and quality. The ash constituents in biomass fuels (those that 
remain following complete combustion of the fuel) may create significant negative impacts when fired in conventional boilers or next generation gasifiers. Wood has been burned successfully in conventional boilers for generations. Wood ash, consisting mainly of calcium, potassium, magnesium, manganese, sodium oxides, iron, and aluminum, can be as low as $0.1 \%$ by weight [5]. Ash content of herbaceous crops, on the other hand, can be as much as two orders of magnitude higher.

Depending on ash chemistry, proportionately large quantities of ash may result in slag formation and fouling of heat transfer surfaces, thus quickly reducing boiler or gasifier effectiveness and potentially rendering them inoperable. In particular, the use of untreated herbaceous fuels has been found to lead to large deposits on superheaters and cross-flow screen tubes in boilers [6] and agglomeration in fluidized bed gasifiers. The resulting deposits have low thermal conductivity and are highly reflective, reducing the effectiveness of heat transfer surfaces. Several decades of research have shown that the inorganic constituents, mainly the alkali and alkaline earth elements in conjunction with other inorganic components such as silica, sulfur, and chlorine in herbaceous fuels, are primarily responsible for slagging and fouling in thermochemical energy conversion devices. Investigations have concluded outright that certain untreated annual herbaceous fuels are unsuitable for use in existing boilers [7]. However, the use of bagasse to surpass the sugar factory heat and power requirements is an indication that, with sufficient processing, herbaceous annual fuels can be used effectively.

Silicon, potassium, sodium, calcium, iron, and aluminum are considered the primary inorganic constituents of concern [8]. Silicon is the most abundant of these elements and is absorbed by the plant for structural purposes as silicic acid from soil. Potassium occurs in ionic form and is thus highly mobile. It is crucial to plant metabolism and is thereby most concentrated in regions where active growth occurs, such as the leaves and plant tops that make up cane trash. Sodium and calcium are found in small concentrations in plants and are important for metabolism and structural integrity, respectively. Aluminum is toxic to plants, but is common in many soils. High aluminum concentration in plantderived ash may therefore indicate soil contamination of the fuel. Finally, iron is critical to photosynthesis and found primarily in the chloroplasts of the leaf material that makes up a large fraction of cane trash. 
According to Baxter et al., not only is the quantity of the aforementioned elements in plant material of importance, but also the chemical form in which they occur (i.e. as hydroxides, silicates, or chlorides). For example, potassium in the form of clay material does not play a major role in boiler degradation. However, condensation of atomically dispersed potassium is a major component in alkali deposits in biomass boilers.

Chlorine is another element of considerable importance when examining biomass boiler deposits. Most plants are capable of readily absorbing $\mathrm{Cl}^{-}$passively into their roots and through their leaves from aerial sources [9]. Plants use chlorine for photosynthesis, phosphorlysis processes, cytochromoxidase activities, and to a small degree for metabolism. $\mathrm{Cl}$ ions are concentrated in chloroplasts found in the growing portion of the plant.

Once released into a thermochemical conversion device, chlorine acts to enhance the transport of alkalis from the fuel to the working surfaces. Potassium chloride is among the most stable gas-phase, alkali containing species [7]. Miles et al. concluded that chlorine concentration has stronger correlation to the amount of alkali vaporized during combustion than the alkali ( $\mathrm{K}$ and $\mathrm{Na}$ ) concentration of the fuel. It is important therefore, to consider chlorine concentration when assessing the suitability of a particular biomass fuel such as cane trash. In combination with the surface fouling facilitated by the chlorine ions, potassium chloride deposits on boiler surfaces have been found to react with sulfur oxides to form potassium sulfate. Potassium sulfate at high temperatures creates a sticky coating which enhances surface bonds of alkalis to boiler surfaces and may cause adherence of particulate matter.

Given the success of bagasse fired spreader-stoker boilers and the chemical fractionation tests used in biomass fuel characterization, much research has gone into removing inorganic material from biomass by leaching. Simple water baths, spraysoaking, and in-field rainwater leaching have all been used to successfully reduce total ash in various grasses and straws [6]. The success of each method was heavily dependent upon both the material and the conditions. For example, hand spraying a bed of whole straw for one minute was found to be an ineffective means of reducing ash content due to limited surface exposure to the leach water. The fuel quality improved with increased 
treatment severity. Soaking straw for a twenty-four hour period was found to reduce total ash by $2 \%$.

Although a reduction in ash indicates a reduction of inorganic material in the fuel, it does not give concrete evidence of an improvement in fuel properties. By considering the trace constituents of the ash, Jenkins et al. found leaching reduced potassium, chlorine, and sulfur concentrations in the fuel even during a one minute spray wash. Furthermore, delayed ash sintering or fusion with increasing temperature may indicate improved refractory characteristics and indirectly imply reduced boiler fouling. For rice and wheat straw, Jenkins et al. found that only one minute of hand spraying improved the ash properties. Ash from untreated material became completely fluid after four minutes at $1500^{\circ} \mathrm{C}$ but the ash from the treated material never reaching a fluid state at the same temperature. Leaching has been shown to be an effective means of enhancing the properties of biomass fuels for conventional boiler and gasifier use.

Another important indicator of fuel quality is the weight of alkali oxides $\left(\mathrm{K}_{2} \mathrm{O}+\right.$ $\mathrm{Na}_{2} \mathrm{O}$ ) per unit energy [7]. Originally developed by the coal industry, the index threshold limits, established from field testing and experience, indicate that slagging is probable for fuels in the range of $0.17 \mathrm{~kg} / \mathrm{GJ}$ to $0.34 \mathrm{~kg} / \mathrm{GJ}$ and certain for fuels above $0.34 \mathrm{~kg} / \mathrm{GJ}$. The index has also been used to measure the probability of slagging and fouling by $\mathrm{SO}_{3}$ and $\mathrm{Cl}[10]$.

This previous body of research has been considered and applied in development of the experimental methods for the processing sugar cane trash in Hawaii.

\section{Method}

\subsection{Laboratory Scale Experiment I}

Experiments were organized using a factorial design with each variable evaluated at two levels [11]. The class of investigation was selected to provide a framework for future investigation. Factorial methods are particularly useful in early investigations for examining a wide range of variables on a superficial level to determine their importance on the process. 
The variables investigated were leach water temperature, leaching time, and cane trash particle size. Broad ranges were selected for each of the three variables. Leaching time was varied between five minutes and sixty minutes with frequent agitation to further improve water-fiber contact. Selected leachate temperatures were ambient $\left(25^{\circ} \mathrm{C}\right)$ and $55^{\circ} \mathrm{C}$. The two particle sizes used were $5 \mathrm{~cm}$ (2 inch) lengths, produced using a standard paper cutter, and smaller particles, nominally $1 \mathrm{~mm}$, produced by a Jeffco Food and Fodder Cutter with a $12 \mathrm{~mm}$ screen.

In accordance with the findings of other leaching investigations [3, 9], the samples of cane trash were treated using a water to dry matter ratio greater than 10 to ensure uniform treatment of the material. The processing schedule was randomized to prevent biasing the experiments towards any of the selected variables. Table 3.1.1 describes the eight treatments that were performed. Both the acronym and run number will be used to identify the treatment throughout this report.

Table 3.1.1: Description of the eight cane trash treatments performed during the first test sequence.

\begin{tabular}{|c|c|c|c|c|c|}
\hline Run & Acronym & Description & Temperature & Duration & $\begin{array}{c}\text { Approx. } \\
\text { Particle } \\
\text { Size }\end{array}$ \\
\hline 1 & $\mathrm{H}-\mathrm{JC}-60$ & Hot soak, long duration, pulverized cane trash & $55^{\circ} \mathrm{C}$ & $60 \min$ & $1 \mathrm{~mm}$ \\
\hline 2 & $\mathrm{H}-\mathrm{JC}-5$ & Hot soak, short duration, pulverized cane trash & $55^{\circ} \mathrm{C}$ & $5 \min$ & $1 \mathrm{~mm}$ \\
\hline 3 & H-2"-60 & Hot soak, long duration, chopped cane trash & $55^{\circ} \mathrm{C}$ & $60 \mathrm{~min}$ & $50 \mathrm{~mm}$ \\
\hline 4 & H-2"-5 & Hot soak, short duration, chopped cane trash & $55^{\circ} \mathrm{C}$ & $5 \min$ & $50 \mathrm{~mm}$ \\
\hline 5 & C-JC-60 & Cold soak, long duration, pulverized cane trash & $25^{\circ} \mathrm{C}$ & $60 \mathrm{~min}$ & $1 \mathrm{~mm}$ \\
\hline 6 & C-JC-5 & Cold soak, short duration, pulverized cane trash & $25^{\circ} \mathrm{C}$ & $5 \min$ & $1 \mathrm{~mm}$ \\
\hline 7 & $C-2 "-60$ & Cold soak, long duration, chopped cane trash & $25^{\circ} \mathrm{C}$ & $60 \mathrm{~min}$ & $50 \mathrm{~mm}$ \\
\hline 8 & C-2"-5 & Cold soak, short duration, chopped cane trash & $25^{\circ} \mathrm{C}$ & $5 \min$ & $50 \mathrm{~mm}$ \\
\hline
\end{tabular}

\subsubsection{Laboratory Scale Experiment II}

A second set of laboratory scale experiments was designed and conducted to provide more information on the effects of higher temperature and shorter duration on leaching efficiency. Results and test parameters from the first experiment were considered during the design of the second set of tests. 
The experiment was organized using a factorial design with each variable evaluated at two levels [11]. The variables investigated were leach water temperature, leaching time and cane trash particle size. Leaching time was varied between one minute and 2.5 minutes with constant agitation to further improve water-fiber contact. Leach water temperatures of $40^{\circ} \mathrm{C}$ and $75^{\circ} \mathrm{C}$ were selected, the higher temperature being close to that which might be available from the condensers at the sugar factory. Cane trash lots were reduced to $10 \mathrm{~cm}$ (4 inch) lengths, produced by using scissors, and smaller particles produced by a Jeffco Food and Fodder Cutter with a 12 mm screen.

A leach water to dry matter ratio of 10 was also applied to this set of experiments. Table 3.1.2 summarizes the eight treatment conditions that were performed. Both the acronym and run number will be used to identify the treatment throughout the investigation.

Table 3.1.2: Description of the eight cane trash treatments performed during the second test sequence.

\begin{tabular}{c|ccccc} 
& & & & & $\begin{array}{c}\text { Approx. } \\
\text { Particle } \\
\text { Size }\end{array}$ \\
\hline $\mathbf{R u n}$ & Acronym & Description & Temperature & Duration & $1 \mathrm{~mm}$ \\
10 & $+\mathrm{H}-\mathrm{JC}-2.5$ & Hot soak, long duration, pulverized cane trash & $75^{\circ} \mathrm{C}$ & $2.5 \mathrm{~min}$ & $1 \mathrm{~mm}$ \\
$\mathbf{1 1}$ & $+\mathrm{H}-\mathrm{JC}-1.0$ & Hot soak, short duration, pulverized cane trash & $75^{\circ} \mathrm{C}$ & $1 \mathrm{~min}$ & $1 \mathrm{~mm}$ \\
12 & $+\mathrm{H}-4 "-2.5$ & Hot soak, long duration, chopped cane trash & $75^{\circ} \mathrm{C}$ & $2.5 \mathrm{~min}$ & $100 \mathrm{~mm}$ \\
13 & C-JC-2.5 & Hot soak, short duration, chopped cane trash & $75^{\circ} \mathrm{C}$ & $1 \mathrm{~min}$ & $100 \mathrm{~mm}$ \\
14 & C-JC-1.0 & Cold soak, long duration, pulverized cane trash & $45^{\circ} \mathrm{C}$ & $2.5 \mathrm{~min}$ & $1 \mathrm{~mm}$ \\
15 & C-4"-2.5 & Cold soak, long duration, chopped cane trash & $45^{\circ} \mathrm{C}$ & $1 \mathrm{~min}$ & $1 \mathrm{~mm}$ \\
16 & C-4"-1.0 & Cold soak, short duration, chopped cane trash & $45^{\circ} \mathrm{C}$ & $2.5 \mathrm{~min}$ & $100 \mathrm{~mm}$
\end{tabular}

\subsection{Sample Collection I}

Cane trash was collected from the Hawaii Agriculture Research Center (HARC) Kunia research station on the island of Oahu. Cane that was 1.5 years old was selected. A single stool (all stalks grown from a single seed piece) was selected and the tops, attached leaves, ground trash and stalks were separated and weighed. The portion of the growing point that could be separated from the stalk by hand at the last internode was considered the top. Attached leaves were those leaves, living and dead that remained 
attached to the stalk. Ground trash included detached dead leaves surrounding the harvested stand. Tops, attached leaves, and ground trash, accounted for 33.9\%, 28.4\%, and $37.7 \%$ of the composite trash dry matter, respectively.

Half of the tops and attached leaves and ground trash were reduced to $5 \mathrm{~cm}$ lengths using a conventional paper cutter. Using the same proportions that the three cane trash components were collected from the field, the lengths were recombined in a large drum and thoroughly mixed.

Similarly, half of the weight was processed in a Jeffco Food and Fodder Cutter Grinder (Jeffress Bros. Ltd, Queensland, Australia). The 7.5 kW, 3 phase machine consists of a double armed rotating cutter head that passes over a large holed screen (9.5 $\mathrm{mm}$ in diameter). Four stationary knives are fixed to the head cover. Material is fed into the top of the machine and is expelled by rotating paddles beneath the screen. The cutting head and paddles rotate at approximately $3000 \mathrm{rpm}$ and their weight ensure wet material does not overload the machine. The resulting pulverized cane trash was assumed to be approximately $1 \mathrm{~mm}$ in diameter with a geometric standard deviation of $2.2 \mathrm{~mm}$. This size distribution was determined for banagrass using the Jeffco cutter in a previous investigation [14]. The Jeffco cut materials were also recombined proportionately and mixed thoroughly in a large drum.

\subsubsection{Sample Collection II}

Cane trash was collected from the HARC Kunia research station on the island of Oahu. The oldest cane available, at approximately 1.0 years, was selected from the farm. This cane was present in a single row and serving as a windbreak. Differences in age and composition from the first set were noted but given the available stock the selected cane was the best match.

Several stools (all stalks grown from a single seed piece) were selected and the tops, attached leaves, ground trash and stalks were separated and weighed. The portion of the growing point that could be separated from the stalk by hand at the last internode was considered the top. Attached leaves were those leaves, living and dead that remained attached to the stalk. Ground trash comprised detached dead leaves surrounding the 
harvested stand. Tops, green leaves and dry leaves accounted for 57.3\%, 28.8\% and $13.9 \%$ of the composite trash material respectively.

Half of the tops, attached leaves and ground trash were reduced to $10 \mathrm{~cm}$ length by hand using large shears. The lengths of the different plant parts were then recombined, in the proportions they were collected and thoroughly mixed in a large drum.

Similarly, half of the weight was processed in the Jeffco Food and Fodder Cutter Grinder. The Jeffco cut materials were also recombined proportionately and mixed thoroughly in a large drum.

\subsection{Leaching}

Approximately $400 \mathrm{~g}$ of the $50 \mathrm{~mm}$ and $1 \mathrm{~mm}$ trash samples were weighed in clean plastic fine mesh bags before being submersed completely in 3 liter of tap water with an electrical conductivity of $0.39-0.50 \mathrm{mS} / \mathrm{cm}$. Previous investigations have shown leaching water to dry fiber ratios of around eight to one to be effective in removing inorganic elements from herbaceous fuels [10]. A minimum ratio of ten was targeted for these experiments and this was exceeded in all eight tests.

The material was agitated for the first and last minute of the leaching duration. For the 60 minute tests, the samples were agitated for 1 minute at 10 minute intervals. Agitation was used to ensure complete exposure of the fiber to the leaching water as well as to mimic the activity expected in the sink-float tank proposed for the industrial scale cane trash treatments.

For the heated water treatments, the bath was heated to $55^{\circ} \mathrm{C}$. Water temperature was maintained by placing the leaching container in a heated water bath. The water in the bath was pumped, using a $12 \mathrm{lpm}$ diaphragm pump (JABSCO Industrial Model 31801-0115, Foothill Ranch, CA), through a 120 W, 9.5 liter water heater (General Electric, Smartwater ${ }^{\mathrm{TM}}$ Model GE2P6A, Montgomery, AL). Three liters of hot water was pumped into the leaching container, which was weighed and finally submersed in the hot bath to maintain a $55^{\circ} \mathrm{C}$ temperature without contaminating the leachate. The sample in the plastic mesh bag was added to the 3 liter container for treatment. Following treatment, the mesh bag of leached cane trash was hung above a pail for 5 minutes to 
allow the surface water to drain from the sample. This surface water was added back into the leachate and the resulting quantity weighed. A $500 \mathrm{ml}$ sample of well mixed leachate was removed in a Nalgene bottle for analysis.

The second treatment test battery was conducted in the same manner as the first with the modifications noted in the experimental design section. A different pump was selected to withstand the higher temperatures of the leaching water.

\subsection{Milling}

The wet samples were loaded into a slotted cylinder on a deep grooved base for dewatering under pressure. This technique was used to simulate the milling process that occurs in a sugar factory. A large solid-iron piston was placed into the cylinder and loaded using a 10 ton hydraulic ram (Enerpac, Model C1010K9) powered by a hydraulic pump (SPX Corporation, Model F, Rockford, IL). The fluid pressure was raised to 632 bar and left for $30 \mathrm{~s}$. Fluid pressure in the cylinder was reduced by 70 to 140 bar over the $30 \mathrm{~s}$ due to air leakage from the air-hydraulic pump. Liquid expressed from the sample through from the slots and grooves in the cylinder and base drained into a pan beneath the press and was directed into a $500 \mathrm{ml}$ bottle beneath. Weights of expressed water and pressed cane trash were measured and recorded.

\subsection{Drying}

Following the milling of the cane trash samples, the material was placed in a drying oven and left for 72 to 96 hours until a constant weight had been reached. Dry weight of each sample was approximately 200 grams.

\subsection{Data Collection and Analysis}

Moisture content of the individual raw cane trash portions; tops, attached leaves, and ground trash, as well as the mixed lots, were measured prior to beginning the treatments. Dry fiber weights determined using the moisture content results were used to establish the leach water to dry fiber ratios. Water and material weights were recorded before leaching. Leachate mass was also recorded following the soaking procedure to determine the absorption of water by the samples. Pressed fiber and expressed water masses were measured and recorded following the milling treatment. A hand-held 
electrical conductivity probe (VWR Model 21800-012, Brisbane, CA) was used to measure the electrical conductivity of the cold leachate before and after exposure to the sample. The electrical conductivity of the expressed water was also recorded. Clean water, leachate, and expressed water from the hot water tests were cooled to ambient conditions $\left(25 \pm 2^{\circ} \mathrm{C}\right)$ before electrical conductivity was measured.

Leachate and expressed liquid samples were centrifuged and filtered to remove all particulate matter. Ion suspension in the resulting filtered liquids was maintained by adding $2 \mathrm{ml}$ of $1 \%$ of concentrated nitric acid. The filtered liquid samples were analyzed for a suite of elements listed in Table 3.6.1 using inductively-coupled plasma optical emission (ICP-OE) spectroscopy.

Table 3.6.1: Major and minor elements included in the analysis of liquid samples.

\begin{tabular}{|c|c|c|c|}
\hline \multicolumn{2}{|c|}{ Major Elements } & \multicolumn{2}{|c|}{ Minor (Trace) Elements } \\
\hline Symbol & Name & Symbol & Name \\
\hline Al & Aluminum & B & Boron \\
\hline $\mathrm{Ca}$ & Calcium & $\mathbf{B a}$ & Barium \\
\hline $\mathrm{Fe}$ & Iron & $\mathrm{Be}$ & Beryllium \\
\hline $\mathbf{K}$ & Potassium & Cd & Cadmium \\
\hline Mg & Magnesium & Co & Cobalt \\
\hline $\mathrm{Na}$ & Sodium & $\mathrm{Cr}$ & Chromium \\
\hline $\mathbf{P}$ & Phosphorus & $\mathrm{Cu}$ & Copper \\
\hline Si & Silicon & Mn & Manganese \\
\hline $\mathrm{Ti}$ & Titanium & Mo & Molybdenum \\
\hline & & $\mathrm{Ni}$ & Nickel \\
\hline & & $\mathrm{Pb}$ & Lead \\
\hline & & Sn & Tin \\
\hline & & $\mathrm{Sr}$ & Strontium \\
\hline & & $\mathbf{V}$ & Vanadium \\
\hline & & Zn & Zinc \\
\hline
\end{tabular}

A color based titrimetric method was used to determine the concentration of chloride ion $\left(\mathrm{Cl}^{-}\right)$. Chloride is too volatile to be accurately measured using ICP.

Samples of freshly harvested and experimentally treated trash samples were sent to Hazen Research Inc. in Golden, Colorado, where they were subjected to proximate, ultimate, and $\mathrm{Cl}$ analyses. The energy content of the samples was also determined. Ash was analyzed for $\mathrm{Si}, \mathrm{Al}, \mathrm{Ti}, \mathrm{Fe}, \mathrm{Ca}, \mathrm{Mg}, \mathrm{Na}, \mathrm{K}, \mathrm{P}, \mathrm{S}, \mathrm{Cl}$, and C. Ash fusion temperatures of the fiber samples were also determined. 


\subsection{Pilot Scale Experiments}

HC\&S staff estimated that the normal leaching time for large scale processing would be approximately one minute and this was chosen as the low value of the time variable. The high value was set at ten minutes to bracket a wide data spread. Temperature was constrained by the heat source available in the investigation. The maximum temperature available was approximately $60^{\circ} \mathrm{C}$ and the lowest value was the ambient water temperature of around $25^{\circ} \mathrm{C}$. During the pilot scale experiments, particle size was omitted as a variable due to unavailability of appropriate size reduction equipment, reducing the experiment to a two variable, two level factorial design.

When the parameter values were determined, the experimental schedule was established by selecting each of the four runs at random and assigning it to the corresponding time slot. The randomization prevented any biasing given the biologically active nature of the samples. Table 3.7.1 summarizes the tests that were conducted.

Table 3.7.1: Cane Trash Treatment Schedule

\begin{tabular}{c|cc} 
Run & Acronym & Description \\
\hline $\mathbf{1}$ & H-S & 1 minute leach in hot water \\
$\mathbf{2}$ & H-L & 10 minute leach in hot water \\
$\mathbf{3}$ & C-S & 1 minute leach in cold water \\
$\mathbf{4}$ & C-L & 10 minute leach in cold water
\end{tabular}

\subsubsection{Cane Trash Sample Collection}

HC\&S was harvesting unburned cane to supply the Puunene sugar factory on November 30, 2005. Cane trash is mechanically separated from green cane in the cane cleaning plant at the factory. This method is indiscriminate and contains "shorts", pieces of broken cane typically 0.15 to $0.3 \mathrm{~m}$ in length, in addition to the trash component. Conveyor 144 in the factory transports separated cane trash and shorts extracted from the cleaning plant. An access door mounted in the bottom carrier of the chain conveyor was opened and allowing the unburned cane trash to fall into 4'x4'x8' expanded metal boxes positioned beneath. Four boxes of trash were collected from the conveyor and stored over the four days of experiments. A new bucket was used in each run and the untreated material was sampled and analyzed to account for temporal variation in the untreated samples due to degradation over the testing period. 


\subsubsection{Leaching}

Cane trash was grapple loaded from the buckets into $1 \mathrm{~m}^{3}$ cages that were constructed out of expanded metal and then lined with 100 mesh stainless steel screen. A cane trash sample was taken from the cages analysis. The cages were weighed using an load cell (Interface Inc., Model SM1000, Scottsdale, AZ) suspended from the hoist used for placing the cages into the leaching bath. A data logger (Campbell Scientific, Model CR23X, Logan, UT) was used to record weight and water temperature measured by six, type K thermocouples (Omega, Stanford, CA) placed around the tank. The bulk density of the untreated material was estimated by measuring the depth of material in the cages. The tank water was heated using a gas fired heater. Once the tank was filled and heated, the cages were lowered into the tank for the specified time period. Upon removal, the cages were suspended above the tank and allowed to drain for ten minutes. The cages were re-weighed and the water level in the tank was recorded to account for water absorbed by the material. Leachate was sampled from the tanks after the cages were removed.

\subsubsection{Milling}

The treated cane trash was milled in a three-roll Cuba Mill shown schematically in Figure 3.1. The rolls are uniform with size and width of $30.5 \mathrm{~cm}$. Each roll has circumferential grooves measuring $3.2 \mathrm{~mm}$ deep and $6.3 \mathrm{~mm}$ wide. The separation between rolls on the feed side is greater than that on the delivery side and thus the delivery rolls are primarily responsible for expressing the liquid from the matt. The top roll floats in the vertical plane and is held in place by two compression springs on either end of the shaft. As shown in the figure the material is fed as a uniform matt into the mill and is pulled through the rolls which rotate in opposite directions. The top roll rotates clockwise and the bottom rolls counterclockwise. The expressed liquid is filtered using a large mesh screen beneath the mill and piped to a collection bucket. Collected liquids were weighed and sampled before being discarded. 


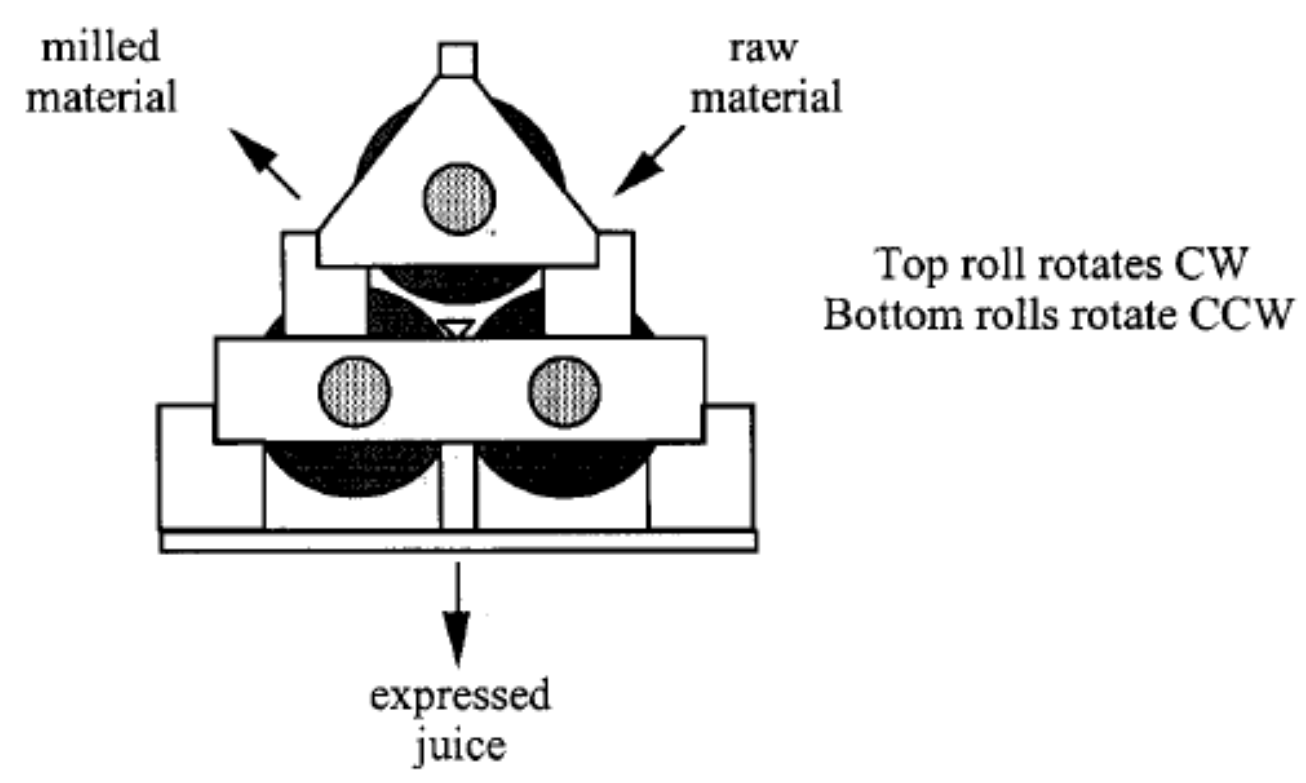

Figure 3.7.1: Cuba Mill used to reduce moisture content of cane trash [10]

In a previous investigation, Turn et al. determined a single milling yields approximately 4-6\% reduction in moisture content [10]. At full scale, bagasse burns efficiently with a moisture content of approximately 50\% [13]. Thus, it was assumed three millings of the treated cane trash in the pilot scale Cuba Mill would produce a 15\% reduction in moisture content equivalent to a single pass through an industrial scale mill. After three millings, the cane trash was again weighed and sampled before being dried.

\subsubsection{Drying}

The treated fiber was transported to a sheltered location where it was spread in separated windrows and allowed to dry for two weeks. The windrows were raked and turned on a daily basis to ensure uniform drying.

\subsubsection{Data Collection and Analysis}

The primary objective of the data collection was to perform mass balances of potassium and chlorine throughout the treatment process, thus producing in a record of the change in fuel properties resulting from the various treatments. During the experiment, online measurements of wet and dry fiber weight before and after the leaching process as well as leaching water temperature were recorded on a CR23X data logger. 
Fiber samples were taken from the cages prior to leaching. Bulk density of the raw material was estimated by measuring the depth of material in the $1 \mathrm{~m}^{3}$ cages used for leaching. Moisture content of the treated and untreated fiber samples were measured according to ASTM Standard Method E-871. Once dried to a constant weight, the fiber samples were sent to Hazen Research Inc. (Golden CO) where they were subjected to proximate, ultimate, and $\mathrm{Cl}$ analyses. The energy content of the samples was also determined. Ash was analyzed for $\mathrm{Si}, \mathrm{Al}, \mathrm{Ti}, \mathrm{Fe}, \mathrm{Ca}, \mathrm{Mg}, \mathrm{Na}, \mathrm{K}, \mathrm{P}, \mathrm{S}, \mathrm{Cl}$, and C. Ash fusion temperatures of the fiber samples were also determined. Finally, ash fusion temperatures in reducing and oxidizing environments were determined. For all postprocessing fuels, ash content measurements were repeated using ASTM standard method D-1102-84 to verify the results found by Hazen.

Liquid samples were analyzed for $\mathrm{K}^{+}, \mathrm{Cl}^{-}, \mathrm{pH}$, electrical conductivity, chemical oxygen demand (COD), and 5-day biochemical oxygen demand $\left(\mathrm{BOD}_{5}\right)$. Elemental analysis of liquid samples was done using ICP-OE at the University of Hawaii at Manoa. The suite of elements included in the analysis is shown in Table 3.2. Electrical conductivity (EC) and $\mathrm{pH}$ were measured using handheld probes connected to a digital voltmeter. Both EC and $\mathrm{pH}$ probes were calibrated with standards prior to measurements. Total dissolved solids in liquid samples were determined by centrifugation and filtration in preparation for ICP-OE analysis. Wastewater analysis $\left(\mathrm{BOD}_{5}, \mathrm{COD}\right)$ was carried out to characterize the byproducts of the treatment process. Samples for COD analysis were acidified immediately after collection with $0.25 \mathrm{ml}$ of concentrated hydrochloric acid. All samples were frozen to suspend degradation until analysis could be performed. The wastewater analysis was carried out at the University of Hawaii at Manoa's Civil and Environmental Engineering Department. Finally, fermentable sugars of the liquid samples were determined using high performance liquid chromatography (HPLC).

\section{Results and Discussion}

\subsection{Validation of Laboratory Scale Experimental Practices}

The validity of the experiments require that masses of fiber, water, ash and elements be accounted for in the input and output streams of the treatment process. 
Without accurate overall mass balances, small differences in concentrations of elements in the samples are magnified into large errors by discrepancy in the overall masses.

Figure 4.1.1 is a schematic of the experimental system and shows the inputs and outputs as they were considered in the mass balance. The excess leachate and expressed liquids were separated into suspended solid and liquid fractions for analysis. The solid fraction was not characterized and, by visual inspection, consisted of a large fraction of organic matter for the pulverized samples as opposed to the largely inorganic constituents observed in the chopped samples.

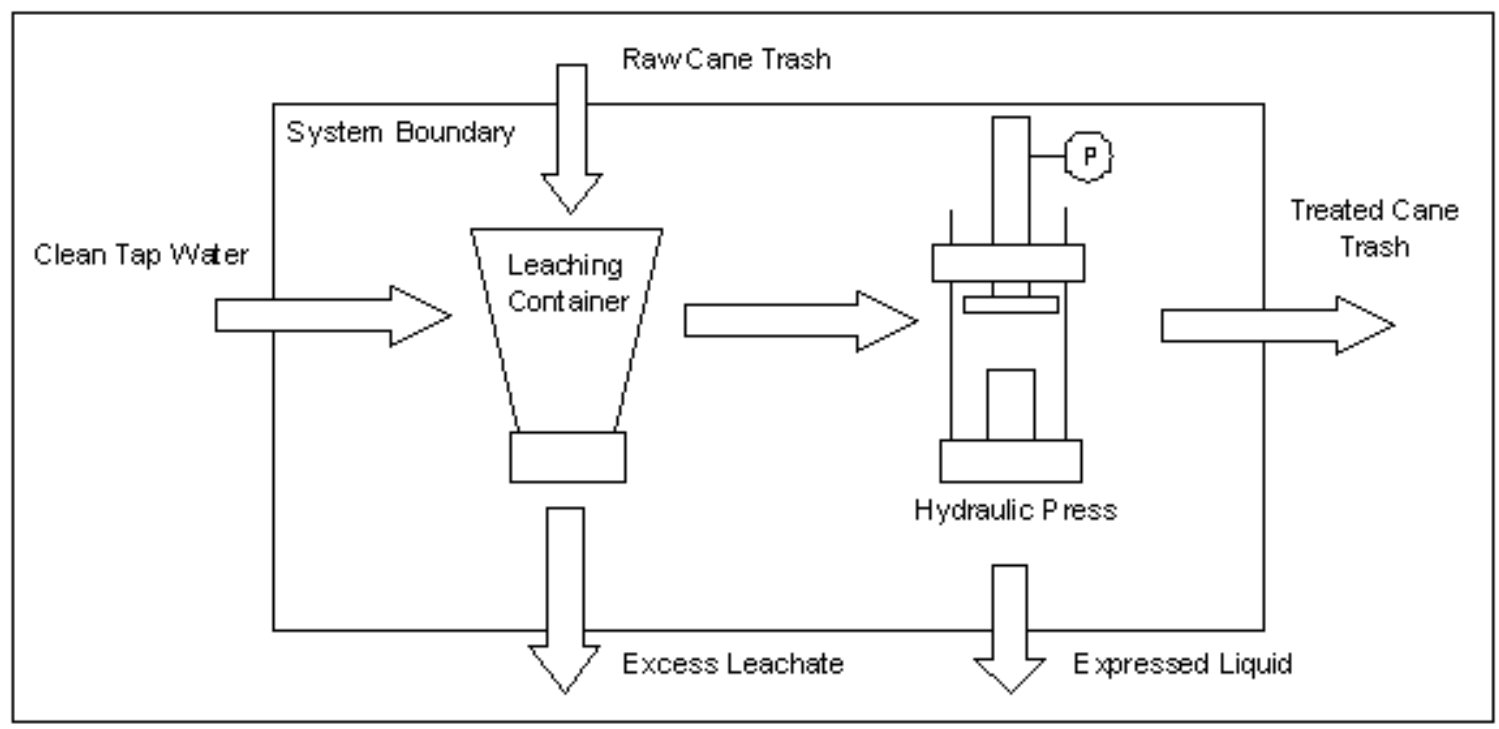

Figure 4.1.1: Schematic of solid and liquid inputs and outputs from the experimental system for the laboratory scale experiments.

\subsubsection{Mass Balances for Laboratory Experiments I}

As shown in Figure 4.1.2, the overall mass of the system for the eight treatments was determined to be closed to within $3.1 \%$ on average with a standard deviation of $2.0 \%$. The range of inconsistency between the input and output streams was $1.1 \%$ to 7.2\%. For the dry fiber samples clear differences were observed between the chopped and pulverized particles sizes. The pulverized (Jeffco Cut) material was closed within $19.6 \%$ with a standard deviation of $2.0 \%$. The 2" chopped material on the other hand was closed to within $-2.8 \%$ with a standard deviation of $7.2 \%$. Although suspended solids in the liquid samples were accounted for in the fiber balance, the soluble material 
that was leached from the sample was not and contributes to the large discrepancy in the pulverized test closure. All loses were considered to be within the limits of experimental error. The complete data set for these calculations is included as Table A.1 in Subappendix A.

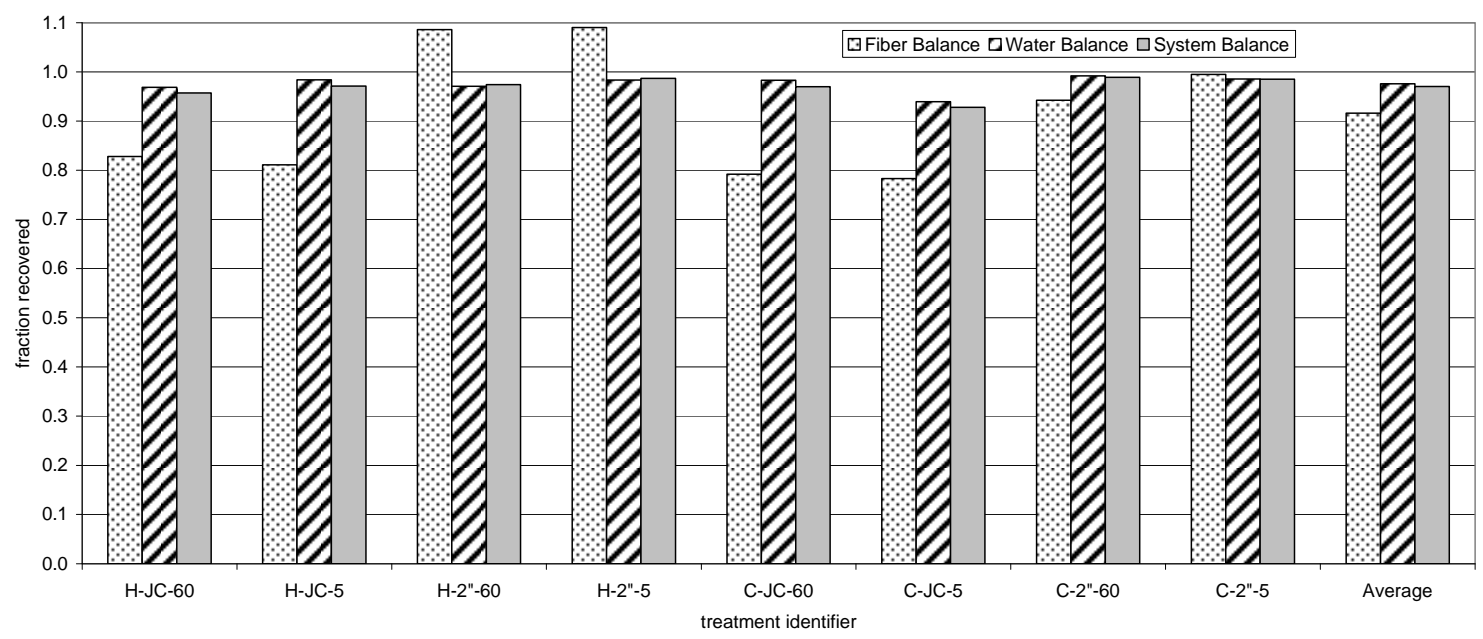

Figure 4.1.2: Dry fiber, water, and overall system mass balances for laboratory scale experiments I.

\subsubsection{Mass Balances for Laboratory Experiments II}

As shown in Figure 4.1.3, the average mass balance of the overall system for the eight treatments was determined to be closed to within $1.4 \%$ on average with a standard deviation of $.08 \%$. The range of inconsistency between the input and output streams was $-2.9 \%$ to $+.05 \%$. For the dry fiber balance, the pulverized (Jeffco Cut) material was closed within $14.3 \%$ with a standard deviation of $1.3 \%$. The 4 ” chopped material on the other hand was closed to within $12.1 \%$ with a standard deviation of $10.8 \%$. The large deviation in the 4" material is likely a function of moisture content disparity between the untreated sample and the treated samples. Suspended solids in the liquid samples were accounted for in the dry mass balance. The soluble material that was leached from the sample was not and this likely contributes to the discrepancy in the pulverized test closure. All loses were considered to be within the limits of experimental error. The complete data set for these calculations is included as Table B.1 in Subappendix B. 


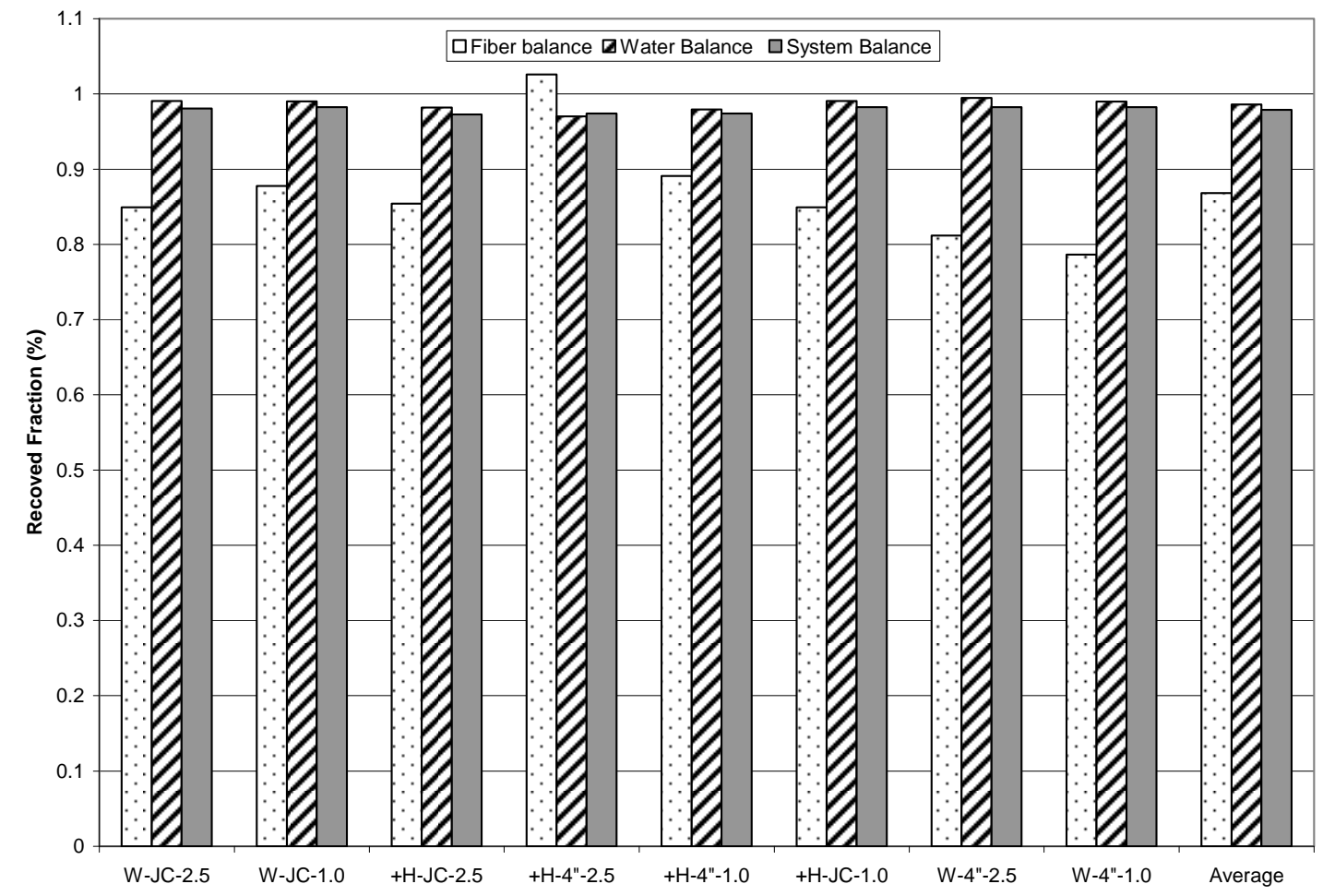

Figure 4.1.3: Fiber, water, and overall mass balance for laboratory scale experiments II.

\subsubsection{Moisture Analyses for Laboratory Experiments I}

The hydraulic press used in the laboratory investigation does not dewater as effectively as a full-scale sugar mill and moisture content of the milled samples were not expected to be as low as required by the HC\&S boilers ( $50 \%$ moisture) or for gasification applications. However, Figure 4.2.1 shows that the pulverized samples, in most cases, were reduced to near or below $50 \%$ after a single pressing to 9000 psi. On average, the four pulverized samples were reduced by $8.29 \%$ compared to $5.49 \%$ for the chopped samples. Although the greater reduction in moisture content under the identical milling conditions indicates greater moisture removal efficiency for the smaller particle size, particle size reduction requires power as well and would offset these gains. Both unit operations should be evaluated within the context of the larger energy conversion system which is beyond the scope of this investigation. Neither leaching time nor water temperature had an appreciable effect on the ability to remove moisture by milling. 


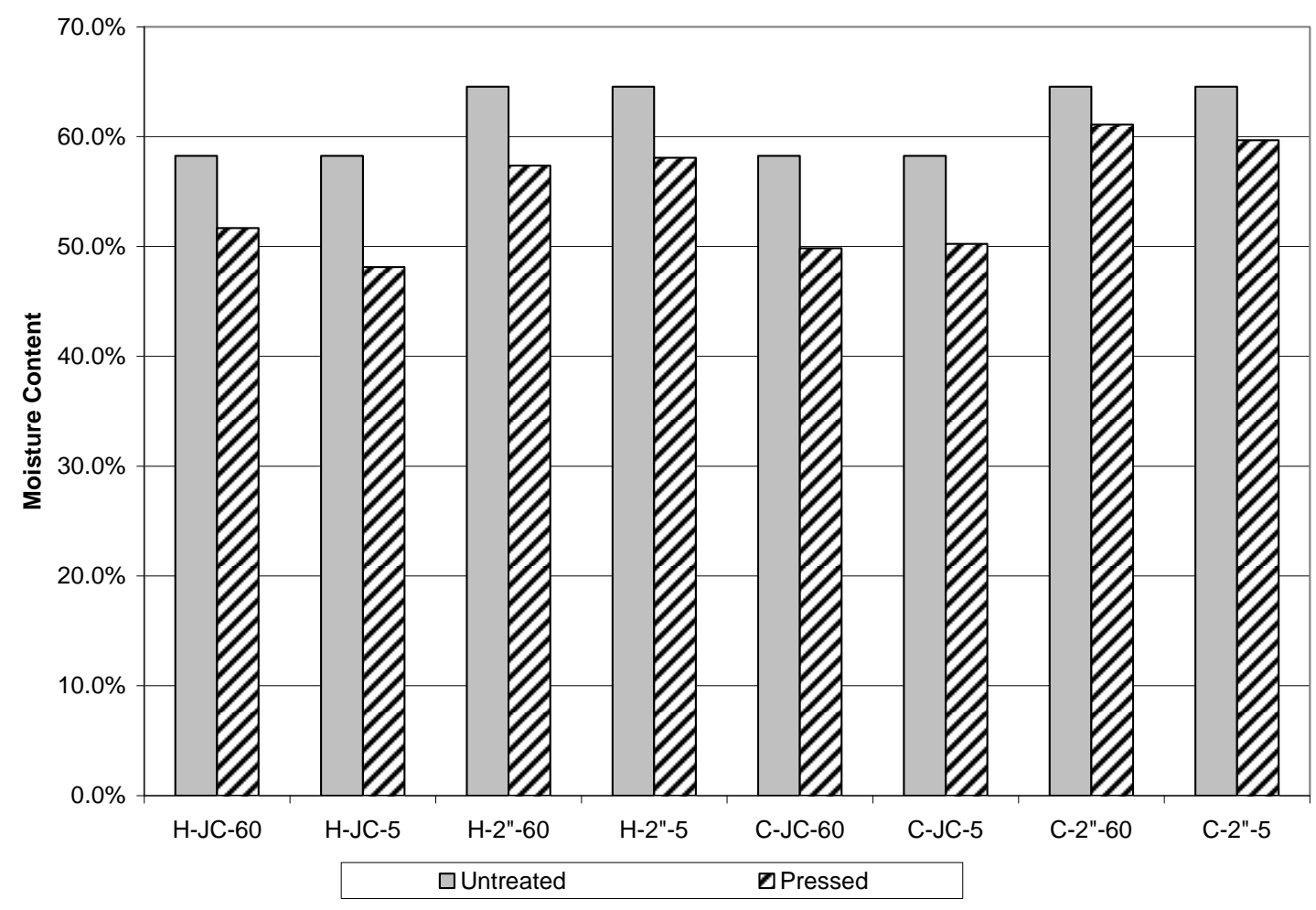

Figure 4.2.1: Change in moisture content resulting from pressing the cane trash samples in the laboratory scale experiments I.

\subsubsection{Moisture Analyses for Laboratory Experiments II}

The cane trash used for this set of experiments had very low initial moisture content of $\sim 40 \%$, much lower than the first experiment where moisture contents were $\sim 60 \%$. The low initial moisture content resulted in increases in moisture content in the pressed fiber for all treatments. Figure 4.3.2 shows that all samples attained a moisture content of $45-50 \%$ after soaking and a single pressing at 9000 psi.

The four pulverized samples showed an average increase of 5.94\% compared to 8.48\% for the chopped samples. While it might appear from this data the pulverized material absorbed less water it is more likely that whatever water was absorbed in the leaching phase was more readily removed from the pulverized material during the pressing stage. Similar data for the hot vs cold treatments was observed, with moisture content increases of $5.62 \%$ for hot treatments and $8.80 \%$ for cold treatments. The high temperature treatment likely caused cell rupture which could account for the apparent 
increase in moisture removal effectiveness for the hot treatments. Duration did not show any appreciable effect on the ability to remove moisture by milling.

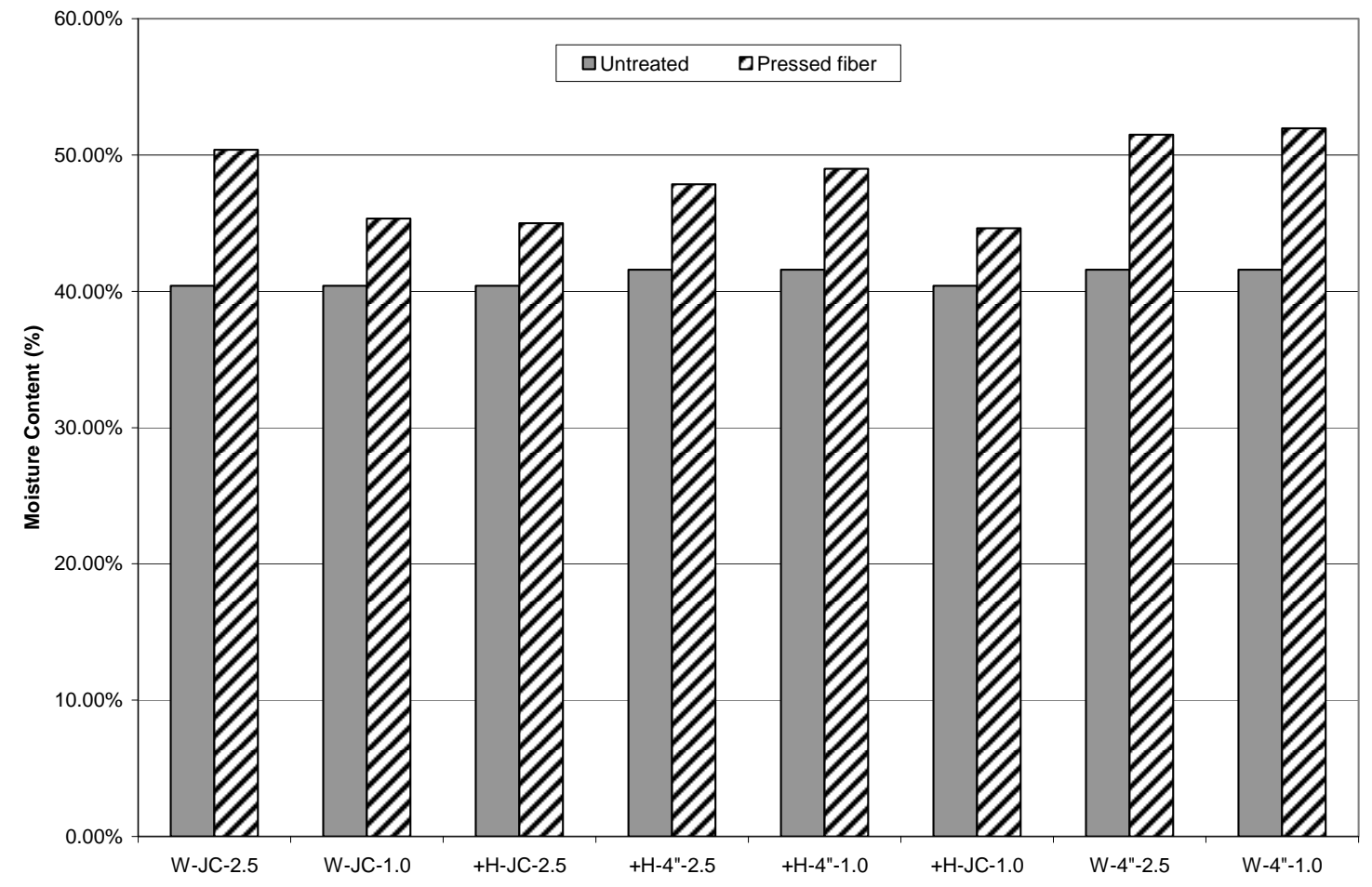

Figure 4.2.2: Change in moisture content resulting from pressing the cane trash samples in the laboratory scale experiments II.

\subsubsection{Electrical Conductivity for Laboratory Experiments I}

Electrical conductivity (EC) provides an indication of the ion concentration in liquid samples. Transfer of alkali and other inorganic constituents from the cane trash is indicated by an increase in electrical conductivity of the leachate and expressed liquid.

Table 4.3.1 shows ions concentrations in the leachate from the pulverized (JC) samples are higher compared to the chopped samples. However, the opposite can be said for the liquids expressed during the milling process. The expressed liquids from the chopped samples have an average EC of $4.98 \mathrm{mS} / \mathrm{cm}$ compared to $3.24 \mathrm{mS} / \mathrm{cm}$ for the pulverized samples. 
Table 4.3.1: Electrical conductivity of the A: clean water, B: excess leachate and C: expressed liquids from cane trash during laboratory experiments I.

\begin{tabular}{|c|c|c|c|c|}
\hline \multirow{2}{*}{ ID } & & \multicolumn{3}{|c|}{ Electrical Conductivity $(\mathrm{mS} / \mathrm{cm})$} \\
\cline { 3 - 5 } & Acronym & $\begin{array}{c}\text { Clean } \\
\text { Water }\end{array}$ & $\begin{array}{c}\text { Excess } \\
\text { Leachate }\end{array}$ & $\begin{array}{c}\text { Expressed } \\
\text { Liquids }\end{array}$ \\
\hline $\mathbf{1}$ & H-JC-60 & 0.45 & 3.26 & 3.31 \\
\hline $\mathbf{2}$ & H-JC-5 & 0.48 & 3.16 & 3.26 \\
\hline $\mathbf{3}$ & H-2"-60 & 0.49 & 1.09 & 4.30 \\
\hline $\mathbf{4}$ & H-2"-5 & 0.50 & 0.78 & 5.20 \\
\hline $\mathbf{5}$ & C-JC-60 & 0.39 & 2.81 & 3.08 \\
\hline $\mathbf{6}$ & C-JC-5 & 0.40 & 2.73 & 3.29 \\
\hline $\mathbf{7}$ & C-2"-60 & 0.45 & 0.80 & 5.03 \\
\hline $\mathbf{8}$ & C-2"-5 & 0.44 & 0.63 & 5.38 \\
\hline
\end{tabular}

A complete listing of all the effects for EC is included as Table 4.3.2. The effects of temperature and duration, including individual and two- and three-factor interactive effects were attributed to experimental error (noise). Error reported in the EC effects was calculated by assuming the three-factor interactions were negligible and attributed solely to experimental error. According to Box et al., the three-factor interactions thus provide a reasonable approximation of variance and the error for an experiment with only a single degree of freedom and no replicate treatments. Significant effects are those in bold type in the table. Based on the factorial design calculations, the main effect of particle size on the excess leachate and expressed liquids was $2.17 \pm 0.030 \mathrm{mS} / \mathrm{cm}$ and $-1.74 \pm 0.203$ $\mathrm{mS} / \mathrm{cm}$ respectively. The negative sign indicates that the smaller particle size (more severe treatment) was less effective than the larger particle size at producing a high EC reading in the expressed liquid. During the leaching process, the more severe treatment (small particle size, hot water and long duration) mobilized a greater fraction of the total water soluble ions from the material into the leach water. Thus, during milling, the concentration of water soluble ions in the cane trash is lower compared to the less severely treated samples (large particle size, cold water, short duration) and thus the EC of the expressed liquids from the more severely treated samples is lower. 
Table 4.3.2: Individual, two- and three-factor interaction effects resulting from the variables on the electrical conductivity of the laboratory scale experiments I.

\begin{tabular}{|c|c|c|c|c|}
\hline & \multicolumn{2}{|c|}{ Excess Leachate } & \multicolumn{2}{|c|}{ Expressed Liquids } \\
\hline & $\mathrm{mS} / \mathrm{cm}$ & Error & $\mathrm{mS} / \mathrm{cm}$ & Error \\
\hline \multicolumn{5}{|l|}{ Main, Individual Effects } \\
\hline Temperature $(\mathrm{T})$ & 0.329 & \pm 0.030 & -0.178 & \pm 0.203 \\
\hline Leaching Duration (D) & 0.167 & \pm 0.030 & -0.353 & \pm 0.203 \\
\hline Particle Size (PS) & 2.166 & \pm 0.030 & -1.743 & \pm 0.203 \\
\hline \multicolumn{5}{|c|}{ Two-Factor Interaction Effects } \\
\hline TxPS & 0.111 & \pm 0.030 & 0.278 & \pm 0.203 \\
\hline TxD & 0.039 & \pm 0.030 & -0.073 & \pm 0.203 \\
\hline PSxD & -0.077 & \pm 0.030 & 0.273 & \pm 0.203 \\
\hline \multicolumn{5}{|c|}{ Three-Factor Interaction Effects } \\
\hline TxPSxD & \multicolumn{2}{|c|}{-0.030} & \multicolumn{2}{|c|}{0.203} \\
\hline
\end{tabular}

\subsubsection{Electrical Conductivity for Laboratory Experiments II}

Table 4.3.3 shows that the ions in the pulverized samples are more readily leached compared to the chopped samples. The leach water from the pulverized samples has an average EC of $2.90 \mathrm{mS} / \mathrm{cm}$ compared to an average of $1.58 \mathrm{mS} / \mathrm{cm}$ for the chopped samples. However, the opposite can be said for the milling process. The expressed liquids from the chopped samples have an average EC of $7.45 \mathrm{mS} / \mathrm{cm}$ compared to 4.36 $\mathrm{mS} / \mathrm{cm}$ for the pulverized samples. Reasons for this have been discussed in the previous section.

Table 4.3.3: Electrical conductivity of the A: clean water, B: excess leachate and C: expressed liquids from cane trash laboratory experiments II.

\begin{tabular}{|c|c|c|c|c|}
\hline \multirow{2}{*}{ ID } & & \multicolumn{3}{|c|}{ Electrical Conductivity $(\mathrm{mS} / \mathrm{cm})$} \\
\cline { 3 - 5 } & Acronym & $\begin{array}{c}\text { Clean } \\
\text { Water }\end{array}$ & $\begin{array}{c}\text { Excess } \\
\text { Leachate }\end{array}$ & $\begin{array}{c}\text { Expressed } \\
\text { Liquids }\end{array}$ \\
\hline $\mathbf{9}$ & W-JC-2.5 & 0.385 & 2.930 & 3.970 \\
\hline $\mathbf{1 0}$ & W-JC-1.0 & 0.391 & 2.460 & 4.560 \\
\hline $\mathbf{1 1}$ & $+\mathrm{H}-\mathrm{JC}-2.5$ & 0.494 & 3.300 & 3.940 \\
\hline $\mathbf{1 2}$ & $+\mathrm{H}-4 "-2.5$ & 0.495 & 1.382 & 8.050 \\
\hline $\mathbf{1 3}$ & $+\mathrm{H}-4 "-1.0$ & 0.492 & 1.000 & 10.020 \\
\hline $\mathbf{1 4}$ & $+\mathrm{H}-\mathrm{JC}-1.0$ & 0.471 & 2.900 & 4.970 \\
\hline $\mathbf{1 5}$ & W-4"-2.5 & 0.467 & 0.869 & 7.460 \\
\hline $\mathbf{1 6}$ & W-4"-1.0 & 0.458 & 0.774 & 10.360 \\
\hline
\end{tabular}


A complete listing of all the effects for EC is included as Table 4.3.4. The relevant effects are those highlighted in the table. As discussed earlier, error reported in the EC effects was calculated by assuming the three-factor interactions were negligible and attributed solely to experimental error.

The main effect of particle size on the excess leachate was $1.89 \pm 0.089 \mathrm{mS} / \mathrm{cm}$. The main effect for the expressed liquids cannot be determined because of the two factor interaction effects between duration and particle size for these samples. From Table 4.3.4 the main effect for duration is measured as $-1.62 \mathrm{mS} / \mathrm{cm}$ for the expressed liquids, however no associated main effect in the leachate is observed. The source of this discrepancy is not clear.

Table 4.3.4: Individual, two- and three-factor interaction effects resulting from the variables on the electrical conductivity of the laboratory scale treatments II.

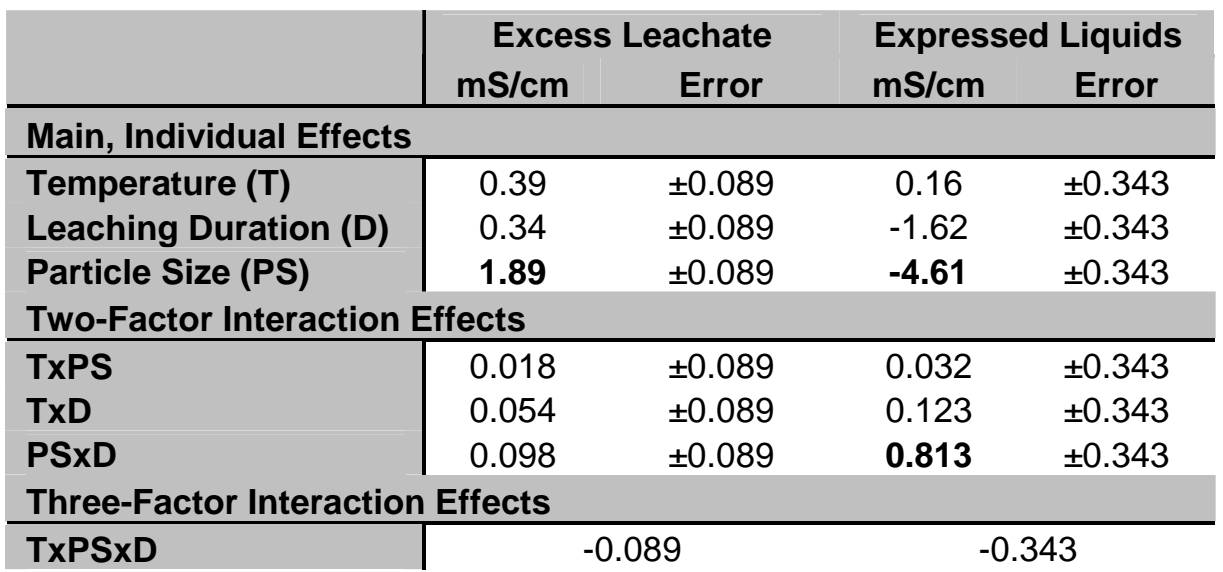

\subsubsection{Total Suspended Solids Laboratory Experiments I}

Suspended solids in the laboratory investigation were considerably lower than those found during the pilot scale experiments discussed later. The difference is a result of the hand-harvesting method used in the laboratory scale experiments. However, due to the small particle size of the pulverized samples, some of the organic matter in the sample passed through the mesh bag into the excess leachate. Table 4.3 shows that the suspended solids found in the excess leachate (B) of the pulverized samples (1, 2, 5 and 6) are considerably higher than for the chopped material (3, 4, 7 and 8). No such pattern appears for the expressed liquids where values range from $0.06 \%$ to $0.47 \%$ solid material. 
Table 4.4.1: Total suspended solids of the excess leachate (B) and expressed liquids (C) from the laboratory scale experiments I.

\begin{tabular}{c|ccc} 
& Total Suspended Solids \\
ID & Acronym & $\begin{array}{c}\text { (mg/L) } \\
\text { Excess } \\
\text { Expressed } \\
\text { Liquids }\end{array}$ \\
\hline $\mathbf{1}$ & H-JC-60 & 5,944 & 813 \\
$\mathbf{2}$ & H-JC-5 & 5,236 & 1,834 \\
$\mathbf{3}$ & H-2"-60 & 1,116 & 4,711 \\
$\mathbf{4}$ & H-2"-5 & 638 & 3,729 \\
$\mathbf{5}$ & C-JC-60 & 6,063 & 2,035 \\
$\mathbf{6}$ & C-JC-5 & 4,591 & 1,170 \\
$\mathbf{7}$ & C-2"-60 & 746 & 640 \\
$\mathbf{8}$ & C-2"-5 & 461 & 3,191
\end{tabular}

\subsubsection{Total Suspended Solids Laboratory Experiments II}

For the second set of laboratory experiments similar results to the first test were observed. Table 4.4.2 shows that the suspended solids found in the excess leachate (B) of the pulverized samples $(9,10,11$ and 14$)$ are considerably higher than for the chopped material (12, 13, 15 and 16). The pattern reverses for the expressed liquids where higher values are measured for the chopped material. The high concentrations of suspended solids found in the expressed liquids of the chopped material are a function of the low liquid recovery for these samples. Expressed liquid volumes for the chopped material averaged $160 \mathrm{ml}$ while volumes for the pulverized material averaged $618 \mathrm{ml}$.

Table 4.3: Total suspended solids of the excess leachate (B) and expressed liquids (C) from the laboratory scale experiments.

\begin{tabular}{c|ccc} 
ID & Acronym & $\begin{array}{c}\text { Total Suspended Solids (mg/L) } \\
\text { Excess } \\
\text { Leachate }\end{array}$ & $\begin{array}{c}\text { Expressed } \\
\text { Liquids }\end{array}$ \\
\hline $\mathbf{9}$ & W-JC-2.5 & 2920 & 1598 \\
10 & W-JC-1.0 & 2440 & 1557 \\
$\mathbf{1 1}$ & $+\mathrm{H}-\mathrm{JC}-2.5$ & 3437 & 1311 \\
$\mathbf{1 2}$ & $+\mathrm{H}-4 "-2.5$ & 406 & 3193 \\
$\mathbf{1 3}$ & $+\mathrm{H}-4 "-1.0$ & 66 & 3666 \\
$\mathbf{1 4}$ & $+\mathrm{H}-\mathrm{JC}-1.0$ & 2383 & 1189 \\
$\mathbf{1 5}$ & W-4"-2.5 & 0 & 3187 \\
$\mathbf{1 6}$ & W-4"-1.0 & 0 & 4548
\end{tabular}




\subsubsection{Fuel Characterization Laboratory Experiments I}

The characterization of the treated and untreated fiber samples is shown in Table 4.5.1. Although total ash percent of the untreated versus treated samples does not show large reductions, the elemental ash composition indicates a substantial fraction of $\mathrm{Ca}$, $\mathrm{Mg}, \mathrm{K}, \mathrm{Cl}$, and $\mathrm{P}$ have been removed from the treated samples. This suggests the soluble alkalis were successfully leached over the course of the treatments.

Higher heating value is another commonly measured fuel characteristic. Bagasse normally has a higher heating value of approximately $18 \mathrm{MJ} / \mathrm{kg}$. In this investigation, the treated cane trash samples were found to have higher heating values ranging from 17.07 $\mathrm{MJ} / \mathrm{kg}$ to $18.32 \mathrm{MJ} / \mathrm{kg}$.

Ash fusion data are often analyzed as an indicator of alkali slagging potential. The results reported in the table are a promising indicator of the nature of the treated cane trash fuel. Fuels that do not reach a fluid state until $>1500^{\circ} \mathrm{C}$ are less likely to cause operating problems in commercial boilers or gasifiers from slag formation or bed agglomeration in the case of fluidized bed reactors. Only two of the treated samples were found to become completely fluid at temperatures below $1482^{\circ} \mathrm{C}$, the highest temperature of the deformation tests.

Water soluble alkalis are also of importance to ash slagging and fouling. $\mathrm{K}_{2} \mathrm{O}$ was reduced by nearly an order of magnitude, from $0.789 \%$ to $0.12 \%$ (on average) for the pulverized samples and from $1.50 \%$ to $1.08 \%$ (on average) for the chopped samples. $\mathrm{Na}_{2} \mathrm{O}$ was not reduced as consistently. In several treatments, the percentage of water soluble $\mathrm{Na}_{2} \mathrm{O}$ increased as a result of the treatments. The parent cane trash is relatively low in sodium and this increase may be due to absorption of $\mathrm{Na}$ from the leach water during treatment. 
Table 4.6: Complete fuel characterization for untreated and treated cane trash samples provided by Hazen Research Inc. (Golden, CO). Laboratory scale experiments.

\begin{tabular}{|c|c|c|c|c|c|c|c|c|c|c|}
\hline $\begin{array}{l}\text { Treatment } \\
\text { ID\# }\end{array}$ & $\begin{array}{l}\text { Pulverized } \\
\text { JC-blank }\end{array}$ & $\begin{array}{l}\text { Chopped } \\
\text { 2"-blank }\end{array}$ & $\begin{array}{c}\text { H-JC-60 } \\
1\end{array}$ & $\begin{array}{c}\text { H-JC-5 } \\
2 \\
\end{array}$ & $\begin{array}{c}H-2 "-60 \\
3\end{array}$ & $\begin{array}{c}H-2 "-5 \\
4\end{array}$ & $\begin{array}{c}\text { C-JC-60 } \\
5\end{array}$ & $\begin{array}{c}\text { C-JC-5 } \\
6\end{array}$ & $\begin{array}{c}C-2 "-60 \\
7\end{array}$ & $\begin{array}{c}C-2 "-5 \\
8\end{array}$ \\
\hline $\begin{array}{l}\text { Moisture Content } \\
\text { (Fraction) }\end{array}$ & 0.583 & 0.645 & 0.517 & 0.481 & 0.574 & 0.581 & 0.498 & 0.502 & 0.611 & 0.597 \\
\hline \multicolumn{11}{|c|}{ Proximate Analysis (\% dry basis) } \\
\hline Ash & 10.67 & 11.92 & 11.09 & 9.55 & 10.68 & 10.68 & 9.19 & 10.47 & 9.11 & 8.93 \\
\hline Volatile & 72.47 & 73.23 & 77.31 & 78.1 & 74.11 & 74.29 & 76.93 & 77.63 & 75.63 & 74.47 \\
\hline Fixed C & 16.86 & 14.85 & 11.6 & 12.35 & 15.21 & 15.03 & 13.88 & 11.9 & 15.26 & 16.6 \\
\hline HHV (BTU/lb) & 7557 & 7359 & 7326 & 7586 & 7648 & 7539 & 7856 & 7863 & 7663 & 7711 \\
\hline HHV MJ/kg & 17.61 & 17.15 & 17.07 & 17.68 & 17.82 & 17.57 & 18.30 & 18.32 & 17.85 & 17.97 \\
\hline \multicolumn{11}{|c|}{ Ultimate Analysis (\% dry basis) } \\
\hline C & 44.97 & 44.79 & 45.32 & 45.83 & 45.23 & 45.48 & 46.13 & 46.13 & 45.98 & 45.92 \\
\hline H & 5.84 & 6.2 & 6.18 & 6.26 & 6.19 & 6.14 & 6.31 & 6.27 & 6.28 & 6.37 \\
\hline $\mathbf{N}$ & 0.74 & 0.75 & 0.54 & 0.59 & 0.67 & 0.67 & 0.56 & 0.60 & 0.75 & 0.78 \\
\hline S & 0.20 & 0.19 & 0.06 & 0.12 & 0.14 & 0.08 & 0.08 & 0.13 & 0.14 & 0.24 \\
\hline Ash & 10.67 & 11.92 & 11.09 & 9.55 & 10.68 & 10.68 & 9.19 & 10.47 & 9.11 & 8.93 \\
\hline O (by diff) & 37.6 & 36.15 & 36.81 & 37.65 & 37.09 & 36.95 & 37.73 & 36.40 & 37.74 & 37.76 \\
\hline $\mathrm{Cl}$ & 0.431 & 0.369 & 0.03 & 0.02 & 0.03 & 0.03 & 0.03 & 0.04 & 0.29 & 0.28 \\
\hline \multicolumn{11}{|c|}{ Water Soluble Alkalis } \\
\hline $\mathrm{Na2O}$ & 0.0335 & 0.024 & 0.09 & 0.009 & 0.021 & 0.034 & 0.012 & 0.012 & 0.02 & 0.02 \\
\hline K2O & 0.789 & 1.502 & 0.101 & 0.106 & 0.888 & 0.784 & 0.133 & 0.132 & 1.382 & 1.276 \\
\hline \multicolumn{11}{|c|}{ Elemental Analysis of Ash (\% dry basis) } \\
\hline $\mathrm{SiO2}$ & 65.54 & 67.12 & 77.47 & 80.99 & 74.91 & 73.93 & 81.19 & 80.58 & 73.36 & 72.03 \\
\hline $\mathrm{Al} 2 \mathrm{O} 3$ & 2.5 & 2.05 & 5.61 & 3.02 & 1.45 & 1.11 & 2.56 & 2.22 & 0.73 & 1.38 \\
\hline TiO2 & 0.28 & 0.29 & 0.43 & 0.30 & 0.15 & 0.13 & 0.30 & 0.28 & 0.13 & 0.17 \\
\hline $\mathrm{Fe} 2 \mathrm{O} 3$ & 2.05 & 1.83 & 2.97 & 2.43 & 1.05 & 0.89 & 2.32 & 2.37 & 0.85 & 1.08 \\
\hline $\mathrm{CaO}$ & 7.56 & 6.50 & 5.58 & 5.58 & 5.83 & 6.21 & 5.44 & 5.98 & 5.97 & 6.11 \\
\hline $\mathrm{MgO}$ & 3.33 & 2.91 & 1.21 & 1.14 & 2.40 & 2.68 & 1.10 & 1.23 & 2.33 & 2.45 \\
\hline $\mathrm{Na2O}$ & 0.61 & 0.50 & 0.82 & 0.27 & 0.40 & 0.56 & 0.27 & 0.19 & 0.47 & 0.75 \\
\hline K2O & 8.9 & 9.48 & 1.63 & 1.36 & 6.80 & 7.53 & 1.72 & 1.67 & 8.84 & 8.72 \\
\hline P2O5 & 1.945 & 1.91 & 0.52 & 0.62 & 1.48 & 1.85 & 0.74 & 0.77 & 2.47 & 2.00 \\
\hline SO3 & 2.94 & 2.11 & 0.69 & 0.85 & 1.33 & 1.80 & 0.79 & 0.96 & 1.89 & 1.79 \\
\hline Cl & 2.56 & 2.66 & 0.09 & 0.04 & 1.23 & 1.11 & 0.04 & 0.05 & 1.14 & 1.79 \\
\hline $\mathrm{CO} 2$ & 1.13 & 0.42 & 0.86 & 0.45 & 0.44 & 0.46 & 0.34 & 0.30 & 0.41 & 0.12 \\
\hline Undetermined & 0.68 & 2.22 & 2.12 & 2.95 & 2.53 & 1.74 & 3.19 & 3.40 & 1.41 & 1.61 \\
\hline Total & 99.32 & 97.78 & 97.88 & 97.05 & 97.47 & 98.26 & 96.81 & 96.60 & 98.59 & 98.39 \\
\hline \multicolumn{11}{|c|}{ Ash Fusion Temperature (C) } \\
\hline \multicolumn{11}{|c|}{ Oxidizing Atmosphere } \\
\hline Initial & 1166 & 1474 & 1398 & $1482+$ & 1286 & 1294 & $1482+$ & $1482+$ & 1231 & 1274 \\
\hline Softening & 1281 & 1301 & 1445 & & 1438 & 1387 & & & 1366 & 1411 \\
\hline Hemispherical & 1340 & 1331 & 1467 & & $1482+$ & 1394 & & & 1428 & $1482+$ \\
\hline Fluid & 1422 & 1389 & $1482+$ & & & 1403 & & & 1462 & \\
\hline \multicolumn{11}{|c|}{ Reducing Atmosphere } \\
\hline Initial & 1165 & 1141 & 1371 & $1482+$ & 1228 & 1201 & $1482+$ & $1482+$ & 1207 & 1227 \\
\hline Softening & 1263 & 1243 & 1445 & & 1397 & 1398 & & & 1375 & 1425 \\
\hline Hemispherical & 1348 & 1334 & 1466 & & 1431 & 1427 & & & 1428 & 1442 \\
\hline Fluid & 1408 & 1406 & $1482+$ & & $1482+$ & 1473 & & & $1482+$ & 1480 \\
\hline
\end{tabular}




\subsubsection{Fuel Characterization Laboratory Experiments II}

The fuel characterization of the treated and untreated fiber samples for the second set of treatments is shown in Table 4.6.1. Total ash percent is consistently reduced for the pulverized treatments but exhibits mixed results for the chopped treatments. This behavior is likely due to the more homogeneous nature of the pulverized samples. Inspection of the elemental ash composition indicates $\mathrm{Ca}, \mathrm{Mg}, \mathrm{K}, \mathrm{Cl}$, and $\mathrm{P}$ (shown as oxides) have been reduced relative to the treated samples in all but the least severe treatments.

Higher heating value is another commonly measured fuel characteristic. Bagasse normally has a higher heating value of approximately $18 \mathrm{MJ} / \mathrm{kg}$. In the second set of treatments, the treated cane trash samples were found to have a higher heating value slightly lower than bagasse. The values shown in the table for the treated cane trash, range from $17.22 \mathrm{MJ} / \mathrm{kg}$ to $17.63 \mathrm{MJ} / \mathrm{kg}$. The lower heating value is likely a function of the less mature cane used for the second set of experiments.

Ash fusion data are often analyzed as an indicator of alkali slagging potential. Fuels that do not reach a fluid state until $>1500^{\circ} \mathrm{C}$ are less likely to cause fouling in commercial boilers. All of the pulverized treatments were found to melt above $1482^{\circ} \mathrm{C}$ (the highest measurable temperature), while only the most severely treated chopped sample $\left(2.5 \mathrm{~min}\right.$ at $\left.75{ }^{\circ} \mathrm{C}\right)$ met this benchmark. There also appears to be some inconsistency in the untreated chopped sample as results indicate that it has more favorable ash fusion characteristics than the treated samples.

Water soluble alkalis are also important indicators of boiler slagging and fouling potential. $\mathrm{K}_{2} \mathrm{O}$ was reduced by an order of magnitude from $1.06 \%$ to $0.19 \%$ (on average) for the pulverized samples and from $1.13 \%$ to $0.82 \%$ (on average) for the chopped samples. Chopped samples treated with the high temperature $\left(75^{\circ} \mathrm{C}\right)$ water showed an average reduction to $.67 \%$. Reductions of the other water soluble alkali measured, $\mathrm{Na}_{2} \mathrm{O}$, were from $0.138 \%$ to $0.03 \%$ for pulverized samples and $0.137 \%$ to $0.08 \%$ for chopped samples. 
Table 4.6.1: Complete fuel characterization for untreated and treated cane trash samples provided by Hazen Research Inc. (Golden, CO). Laboratory scale experiments.

\begin{tabular}{|c|c|c|c|c|c|c|c|c|c|c|}
\hline $\begin{array}{l}\text { Treatment } \\
\text { ID\# }\end{array}$ & $\begin{array}{l}\text { Pulverized } \\
\text { JC-blank }\end{array}$ & $\begin{array}{l}\text { Chopped } \\
\text { 4"-blank }\end{array}$ & $\begin{array}{c}\text { W-JC-2.5 } \\
1\end{array}$ & $\begin{array}{c}\text { W-JC-1.0 } \\
2\end{array}$ & $\begin{array}{c}+\mathrm{H}-\mathrm{JC}-2.5 \\
3\end{array}$ & $\begin{array}{c}+\mathrm{H}-4 "-2.5 \\
4\end{array}$ & $\begin{array}{c}+\mathrm{H}-4 "-1.0 \\
5\end{array}$ & $\begin{array}{c}+\mathrm{H}-\mathrm{JC}-1.0 \\
6\end{array}$ & $\begin{array}{c}W-4 "-2.5 \\
7\end{array}$ & $\begin{array}{c}W-4 "-1.0 \\
8\end{array}$ \\
\hline $\begin{array}{l}\text { Moisture Content } \\
\text { (Fraction) }\end{array}$ & 0.40 & 0.42 & 0.50 & 0.45 & 0.45 & 0.48 & 0.49 & 0.45 & 0.51 & 0.52 \\
\hline \multicolumn{11}{|c|}{ Proximate Analysis (\% dry basis) } \\
\hline Ash & 9.41 & 9.75 & 8.14 & 8.59 & 7.44 & 10.3 & 9.99 & 7.96 & 9.39 & 9.22 \\
\hline Volatile & 74.12 & 74.19 & 78.91 & 77.08 & 78.43 & 73.33 & 73.98 & 78.03 & 74.8 & 75.76 \\
\hline Fixed C & 16.48 & 16.06 & 12.95 & 14.33 & 14.13 & 16.37 & 16.03 & 14.01 & 15.81 & 15.02 \\
\hline HHV(BTU/lb) & 7476 & 7514 & 7578 & 7578 & 7530 & 7403 & 7434 & 7649 & 7459 & 7491 \\
\hline $\mathrm{MJ} / \mathrm{kg}$ & 17.4 & 17.5 & 17.6 & 17.6 & 17.5 & 17.2 & 17.3 & 17.8 & 17.4 & 17.4 \\
\hline \multicolumn{11}{|c|}{ Ultimate Analysis (\% dry basis) } \\
\hline C & 44.08 & 43.93 & 44.81 & 44.79 & 44.55 & 44.27 & 44.13 & 46.39 & 44.51 & 44.46 \\
\hline H & 5.74 & 5.64 & 5.85 & 5.81 & 5.74 & 5.66 & 5.71 & 5.51 & 5.71 & 5.73 \\
\hline $\mathbf{N}$ & 0.26 & 0.31 & 0.21 & 0.21 & 0.23 & 0.26 & 0.46 & 0.25 & 0.37 & 0.32 \\
\hline $\mathbf{S}$ & 0.11 & 0.10 & 0.06 & 0.07 & 0.05 & 0.08 & 0.11 & 0.07 & 0.13 & 0.09 \\
\hline Ash & 9.41 & 9.75 & 8.14 & 8.59 & 7.44 & 10.30 & 9.99 & 7.96 & 9.39 & 9.22 \\
\hline O (by diff) & 40.24 & 39.81 & 40.91 & 40.51 & 41.98 & 39.31 & 39.45 & 39.81 & 39.82 & 40.09 \\
\hline $\mathrm{Cl}$ & 0.53 & 0.55 & 0.06 & 0.07 & 0.04 & 0.21 & 0.28 & 0.05 & 0.43 & 0.40 \\
\hline \multicolumn{11}{|c|}{ Water Soluble Alkalis } \\
\hline $\mathrm{Na2O}$ & 0.138 & 0.137 & 0.034 & 0.034 & 0.03 & 0.072 & 0.078 & 0.03 & 0.085 & 0.087 \\
\hline K2O & 1.055 & 1.130 & 0.216 & 0.22 & 0.156 & 0.564 & 0.769 & 0.177 & 1.039 & 0.896 \\
\hline \multicolumn{11}{|c|}{ Elemental Analysis of Ash (\% dry basis) } \\
\hline $\mathrm{SiO2}$ & 71.06 & 73.59 & 85.96 & 84.07 & 88.30 & 84.33 & 76.58 & 81.63 & 73.63 & 72.58 \\
\hline $\mathrm{Al} 2 \mathrm{O} 3$ & 0.97 & 0.46 & 1.47 & 0.60 & 1.25 & 0.31 & 1.71 & 2.04 & 0.38 & 0.99 \\
\hline TiO2 & 0.22 & 0.09 & 0.18 & 0.17 & 0.18 & 0.09 & 0.17 & 0.18 & 0.09 & 0.09 \\
\hline $\mathrm{Fe} 2 \mathrm{O} 3$ & 1.63 & 0.90 & 2.31 & 1.85 & 1.82 & 0.93 & 1.43 & 7.57 & 0.91 & 0.97 \\
\hline $\mathrm{CaO}$ & 4.54 & 4.42 & 3.93 & 3.82 & 3.74 & 4.41 & 5.25 & 3.76 & 4.47 & 4.63 \\
\hline MgO & 2.96 & 2.58 & 1.56 & 1.51 & 1.43 & 2.08 & 2.46 & 1.54 & 2.53 & 2.80 \\
\hline $\mathrm{Na2O}$ & 1.59 & 1.30 & 0.47 & 0.43 & 0.40 & 0.86 & 1.06 & 0.39 & 0.99 & 1.18 \\
\hline K2O & 9.51 & 10.00 & 2.61 & 2.56 & 1.98 & 4.63 & 6.64 & 2.02 & 10.30 & 10.30 \\
\hline P2O5 & 1.66 & 1.96 & 0.77 & 0.68 & 0.65 & 1.12 & 2.05 & 0.72 & 2.06 & 2.20 \\
\hline SO3 & 1.82 & 1.60 & 0.59 & 0.54 & 0.42 & 1.14 & 1.26 & 0.61 & 1.52 & 1.91 \\
\hline $\mathrm{Cl}$ & 2.95 & 3.08 & 0.10 & 0.11 & 0.06 & 0.36 & 0.76 & 0.08 & 3.05 & 2.57 \\
\hline $\mathrm{CO} 2$ & 0.35 & 0.30 & 0.76 & 0.77 & 0.37 & 0.32 & 0.21 & 0.79 & 0.56 & 0.28 \\
\hline Undetermined & 0.77 & -0.28 & -0.71 & 2.89 & -0.60 & -0.58 & 0.42 & -1.33 & -0.49 & -0.50 \\
\hline Total & 99.24 & 100.28 & 100.71 & 97.11 & 100.60 & 100.58 & 99.58 & 101.33 & 100.49 & 100.50 \\
\hline \multicolumn{11}{|c|}{ Ash Fusion Temperature (C) } \\
\hline \multicolumn{11}{|c|}{ Oxidizing Atmosphere } \\
\hline Initial & 1151 & 1187 & $1482+$ & 1438 & 1456 & 1329 & 1196 & 1441 & 1136 & 1340 \\
\hline Softening & 1245 & 1342 & & $1482+$ & $1482+$ & $1482+$ & 1344 & $1482+$ & 1294 & 1387 \\
\hline Hemispherical & 1357 & 1460 & & & & & 1350 & & 1326 & 1413 \\
\hline Fluid & 1441 & $1482+$ & & & & & 1364 & & 1346 & 1465 \\
\hline \multicolumn{11}{|c|}{ Reducing Atmosphere } \\
\hline Initial & 1059 & 1101 & $1482+$ & $1482+$ & $1482+$ & 1475 & 1168 & $1482+$ & 1075 & 992 \\
\hline Softening & 1243 & 1347 & & & & $1482+$ & 1331 & & 1285 & 1092 \\
\hline Hemispherical & 1371 & $1482+$ & & & & & 1381 & & 1341 & 1331 \\
\hline Fluid & 1405 & & & & & & 1402 & & 1369 & 1397 \\
\hline
\end{tabular}




\subsubsection{Element Removal by Leaching for Laboratory Experiments I}

The laboratory experiments showed varying degrees of removal of $\mathrm{Mg}, \mathrm{Ca}, \mathrm{Na}$, $\mathrm{K}, \mathrm{P}, \mathrm{S}$ and $\mathrm{Cl}$ by the leaching methods employed. Distribution of the elements across the experimental components is shown in Figures 4.6.1 and 4.6.2 for the most severe $(\mathrm{H}$ JC-60) and least severe (C-2"-5) treatments. The remaining distributions are shown as Figures A.1-A.6 in Subappendix A. The unexpectedly high recovery (>1) of all elements in Figure 4.6.1 is anomalous and cannot be readily explained. Most treatments showed distributions similar to Figure 4.6.2. In general the $\mathrm{Si}, \mathrm{Al}, \mathrm{Ti}$ and $\mathrm{Fe}$ fractions were considerably lower in the liquid components than the other elements that are more readily soluble. These constituents, found mainly in soil, were likely washed from the surface of the cane trash into the excess leachate or expressed liquids and removed as suspended solids. Although the fraction of suspended solids was measured, no characterization of this material was done. The highly inconsistent closure of sulfur content occurred because sulfur was not accurately measured in the liquid samples. By comparing the least to most severe treatments shown in Figures 4.6.2 and 4.6.2, respectively, it is readily apparent that $\mathrm{Ca}, \mathrm{Mg}, \mathrm{K}, \mathrm{P}$ and $\mathrm{Cl}$ move from the fiber to the liquid component as treatment severity increases. 


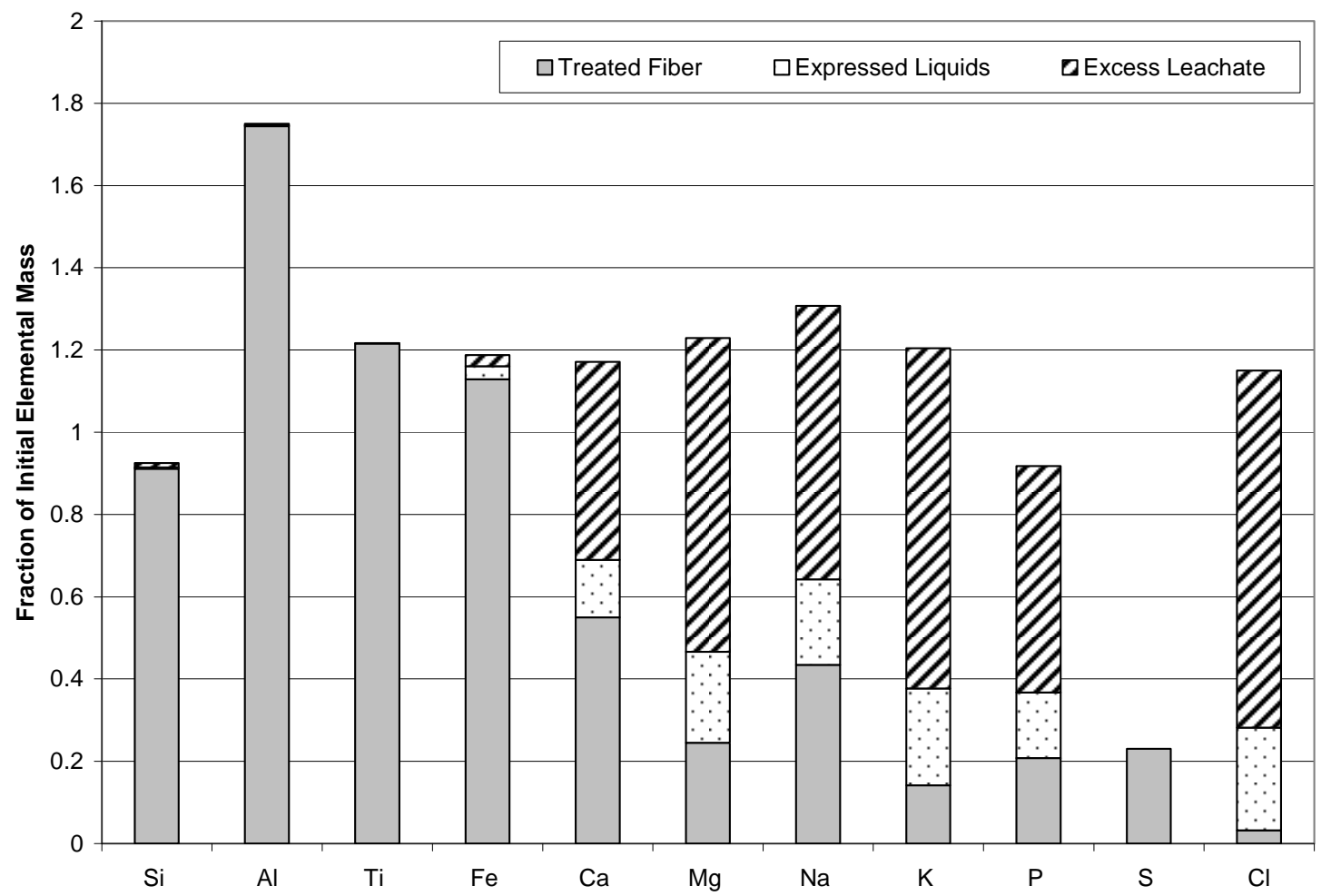

Figure 4.6.1: Distribution of elements as a fraction of the initial mass for treatment H-JC-60, the most severe treatment in laboratory scale experiment I. 


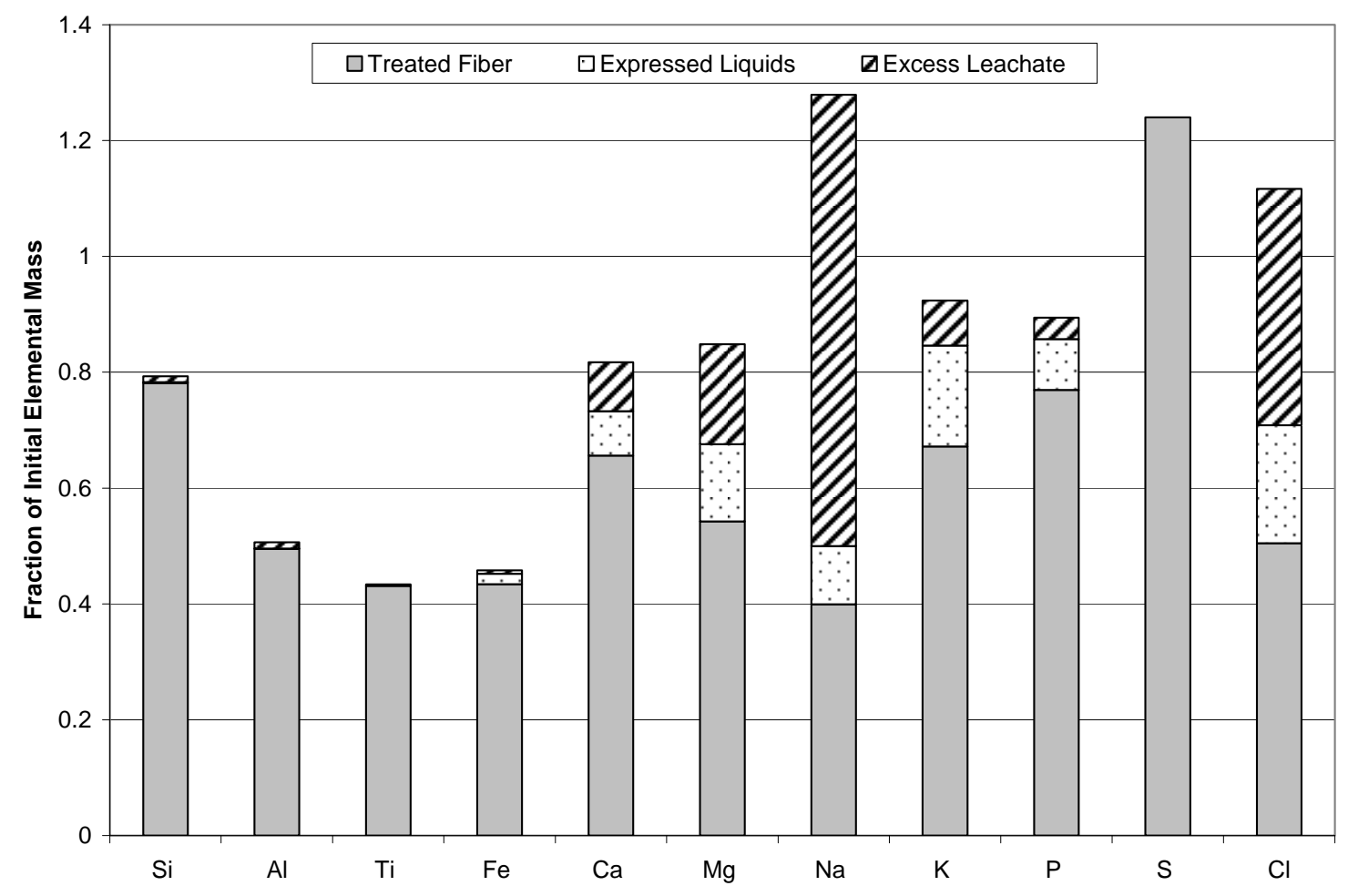

Figure 4.6.2: Distribution of elements as a fraction of the initial mass for treatment C-2"-5, the least severe treatment in laboratory scale experiment I.

Figures 4.6.3 and 4.6.4 show the fraction of the elements removed from the dry fiber. The figures reiterate the difficulties experienced in removing the soil contaminants. However, in some cases, over $90 \%$ of the water soluble elements were removed. In particular, potassium and chlorine show consistent results and were used to investigate the effects of leaching temperature, leaching duration and particle size on their removal from sugar cane trash. 


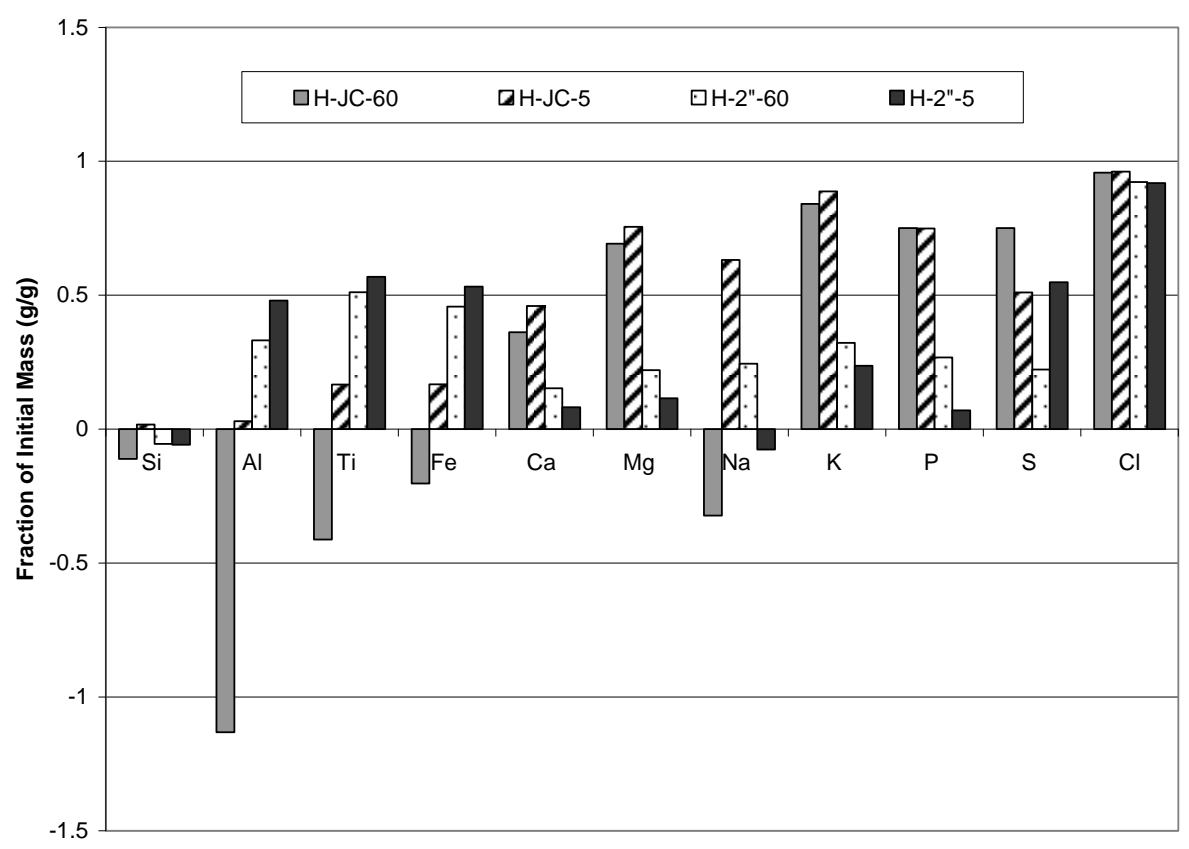

Figure 4.6.3: Constituents removed from dry fiber by high temperature leaching treatments H-JC-60, HJC-5, H-2"-60 and H-2"-5 as a fraction of the initial dry sample mass for laboratory experiment I.

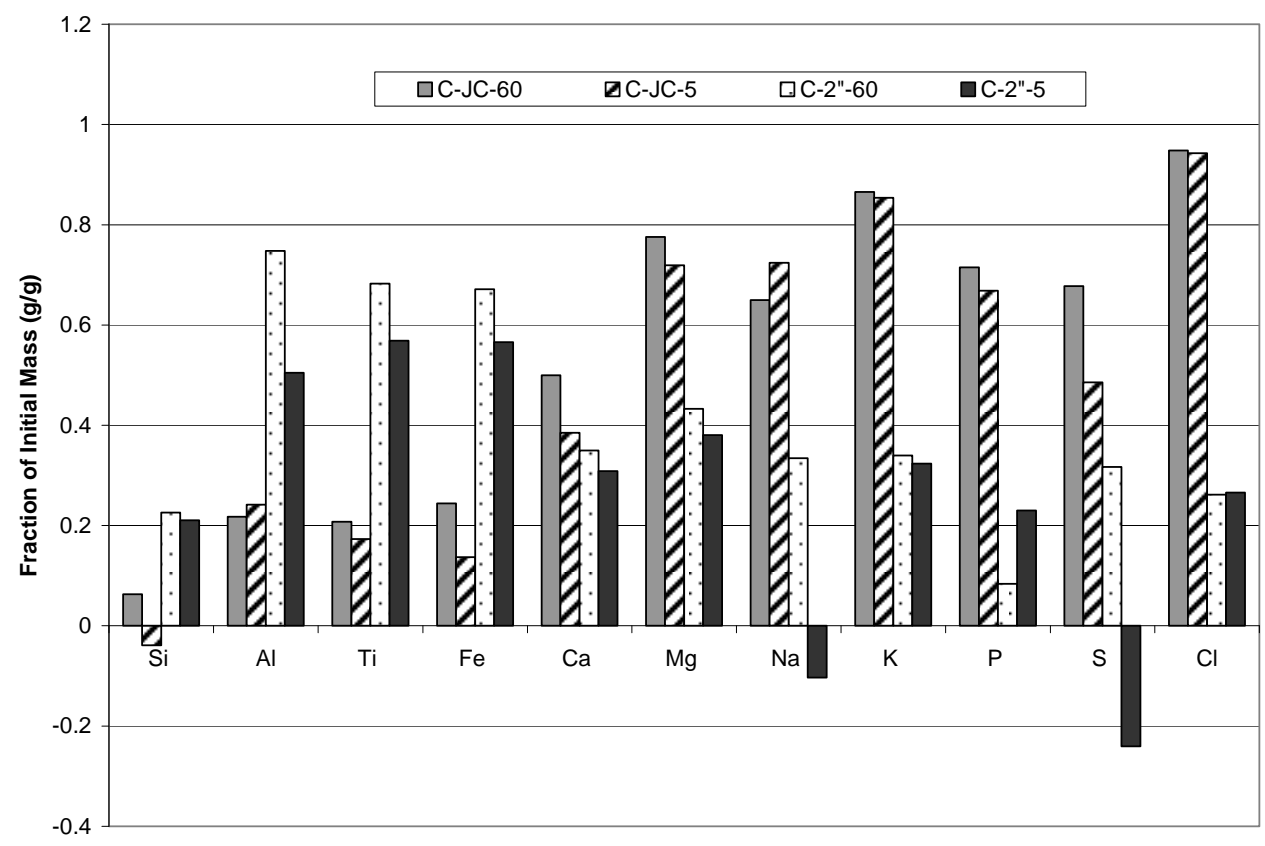

Figure 4.6.4: Constituents removed from dry fiber by low temperature leaching treatments C-JC-60, C-JC5, C-2"-60 and C-2"-5 as a fraction of initial dry sample mass for laboratory experiment I 
The potassium results from the pulverized (JC) tests showed an average removal of $86.2 \%$ with a standard deviation of $2.0 \%$. The chopped tests were found to have an average removal of $30.5 \%$ with a standard deviation of $4.6 \%$. For $\mathrm{Cl}$, similar results for the pulverized samples were obtained at an average removal of $95.3 \%$ with standard deviation of $0.8 \%$. However, for the chopped samples the average removal was $59.2 \%$ with a standard deviation of 37.9\%. The large standard deviation indicates interactive effects between variables of temperature and particle size.

Table 4.6.1 shows the individual effects and two- and three-factor interactive effects. By assuming three-factor effects are negligible, the value observed from the three-factor interaction is attributable to experimental error only and, since no replicate treatments were carried out, is used as an approximation of variance or, for a single degree of freedom, experimental error [11].

From the table, only four of the effects can be distinguished from experimental error. Those four are the individual effect of particle size on $\mathrm{K}$ and $\mathrm{Cl}$ removal, the individual temperature effect on $\mathrm{Cl}$ removal and the two-factor interaction between temperature and particle size on $\mathrm{Cl}$ removal, all of which are highlighted in Table 4.5. Since the effect of particle size on K removal does not interact with any other variables, it can be concluded that potassium removal increases $55.66 \pm 3.18 \%$ when particle size is reduction from $5 \mathrm{~cm}$ nominal length to $0.1 \mathrm{~cm}$ nominal length. The same cannot be concluded, however about the effect of particle size on $\mathrm{Cl}$ removal. Interaction of particle size with temperature precludes any direct conclusions. However, by considering the schematic shown as Figure 4.8, it is apparent that with a small particle size, $\mathrm{Cl}$ approaches $100 \%$ removal from the cane trash irrespective of temperature. However, chlorine removal's sensitivity to temperature increases greatly when larger particle size material is leached, resulting in a much higher apparent effect of temperature on leaching for large particle size material. The detailed calculation, results of the element mass, and recovery percentage is shown in Table A.3-A.7 of Subappendix A. 
Table 4.6.1: Individual, two- and three-factor interaction effects of temperature, leaching duration and particle size on alkali removal in laboratory scale experiments I.

\begin{tabular}{l|cccc} 
& K & Error & Cl & Error \\
\hline \multicolumn{2}{l|}{ Main, Individual Effects } & & & \\
\hline Temperature (T) & $-2.35 \%$ & \pm 3.18 & $\mathbf{3 3 . 5 3} \%$ & \pm 0.45 \\
Leaching Duration (D) & $1.65 \%$ & \pm 3.18 & $0.04 \%$ & \pm 0.45 \\
Particle Size (PS) & $\mathbf{5 5 . 6 6 \%}$ & \pm 3.18 & $\mathbf{3 6 . 0 4 \%}$ & \pm 0.45 \\
Two-Factor Interaction Effects & & & \\
\hline TxPS & $2.86 \%$ & \pm 3.18 & $-\mathbf{3 2 . 1 8} \%$ & \pm 0.45 \\
TxD & $0.27 \%$ & \pm 3.18 & $-0.04 \%$ & \pm 0.45 \\
PSxD & $-3.42 \%$ & \pm 3.18 & $0.03 \%$ & \pm 0.45 \\
Three-Factor Interaction Effects & & & \\
\hline TxPSxD & $-3.18 \%$ & $-0.45 \%$
\end{tabular}

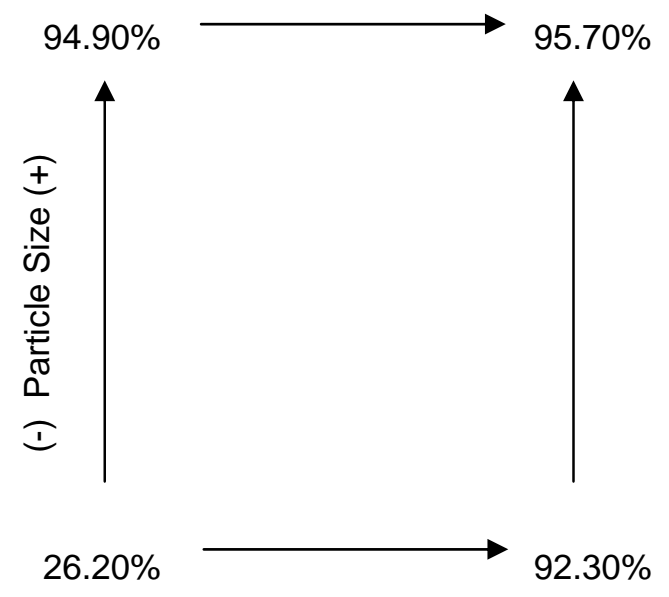

(-) Temperature (+)

Figure 4.6.5: Two-way schematic showing interaction between temperature and particle size for chlorine removal from sugar cane trash for laboratory experiments I.

\subsubsection{Element Removal for Leaching Laboratory Experiments II}

The second set of laboratory experiments showed varying degrees of removal of $\mathrm{Mg}, \mathrm{Ca}, \mathrm{Na}, \mathrm{K}, \mathrm{P}, \mathrm{S}$ and $\mathrm{Cl}$ by the leaching methods employed. Distribution of the elements across the experimental components is shown in Figures 4.6.6 and 4.6.7, respectively, for the most severe (+H-JC-2.5) and least severe (W-4"-1.0) treatments. The remaining distributions are shown as Figures B.1-B.6 in Subappendix B. Greater 
than $100 \%$ recovery of sodium was recorded for all treatments. The source of the sodium anomaly is undetermined, but high levels of sodium measured in the clean water used for leaching ( $70 \%$ of that found in the raw fuel) may be a contributing factor.

Sulfur and iron were not measured in the liquid samples so recoveries can not be accurately calculated for these two elements. Most treatments showed distributions similar to Figure 4.6.1, although titanium, iron, and aluminum exhibited poor recoveries. In general the $\mathrm{Si}, \mathrm{Al}, \mathrm{Ti}$ and $\mathrm{Fe}$ fractions were considerably lower in the liquid components than the other elements that are more readily soluble. These constituents, found mainly in the soil material were likely washed from the surface of the cane trash into the excess leachate or expressed liquids and removed as suspended solids. Although the fraction of suspended solids was measured, no characterization of this material was done. By comparing the least to most severe treatments shown in Figures 4.6.6 and 4.6.7, respectively, it is apparent that the elements $\mathrm{Ca}, \mathrm{Mg}, \mathrm{K}, \mathrm{P}$ and $\mathrm{Cl}$ move from the fiber to the liquid component as treatment severity increases. 


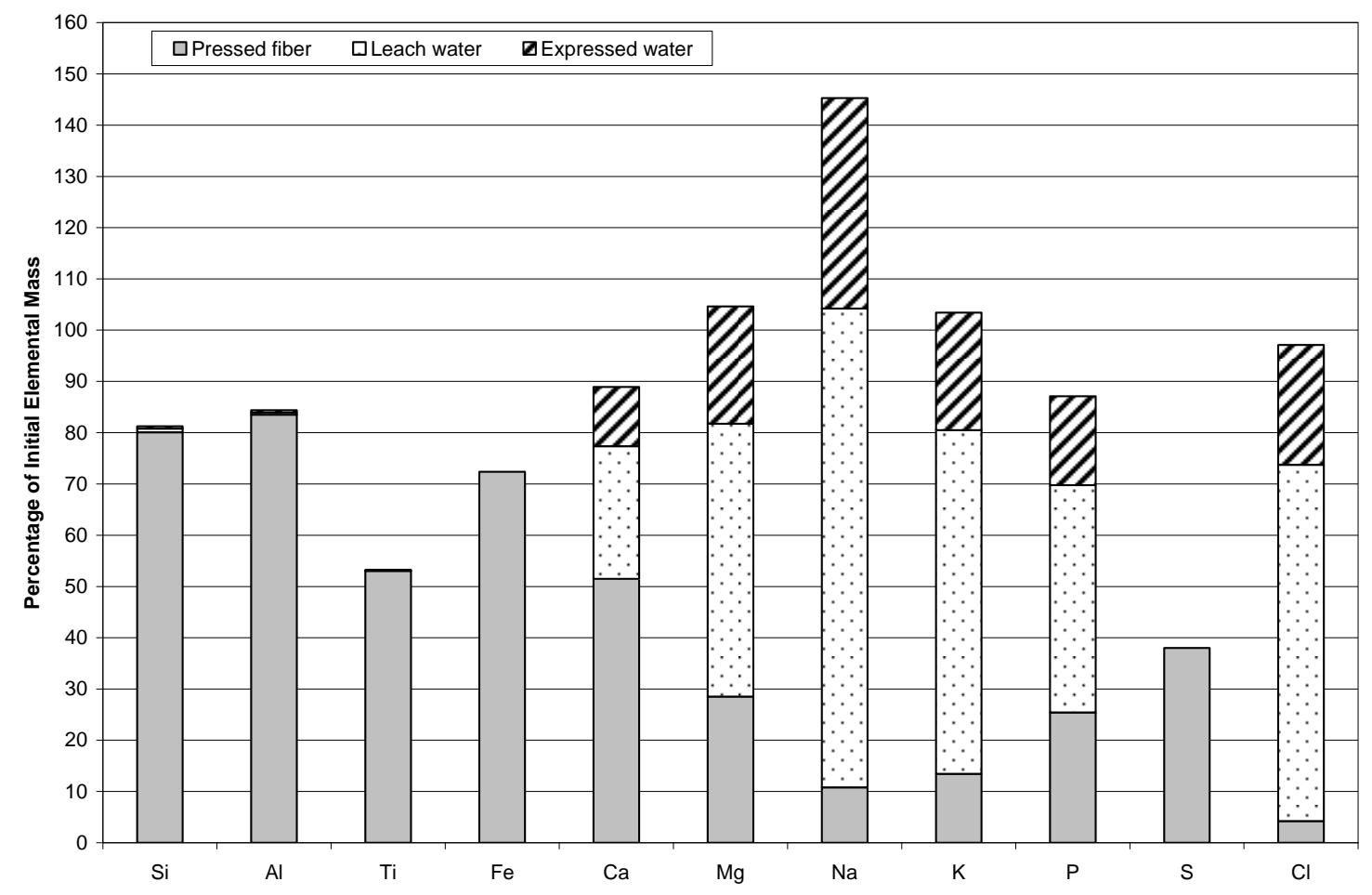

Figure 4.6.6: Distribution of elements as a percentage of the initial mass for treatment $+\mathrm{H}-\mathrm{JC}-2.5$, the most severe treatment in the laboratory scale experiment II. (Note: liquid samples were not analyzed for $\mathrm{S}$ and $\mathrm{Fe})$ 


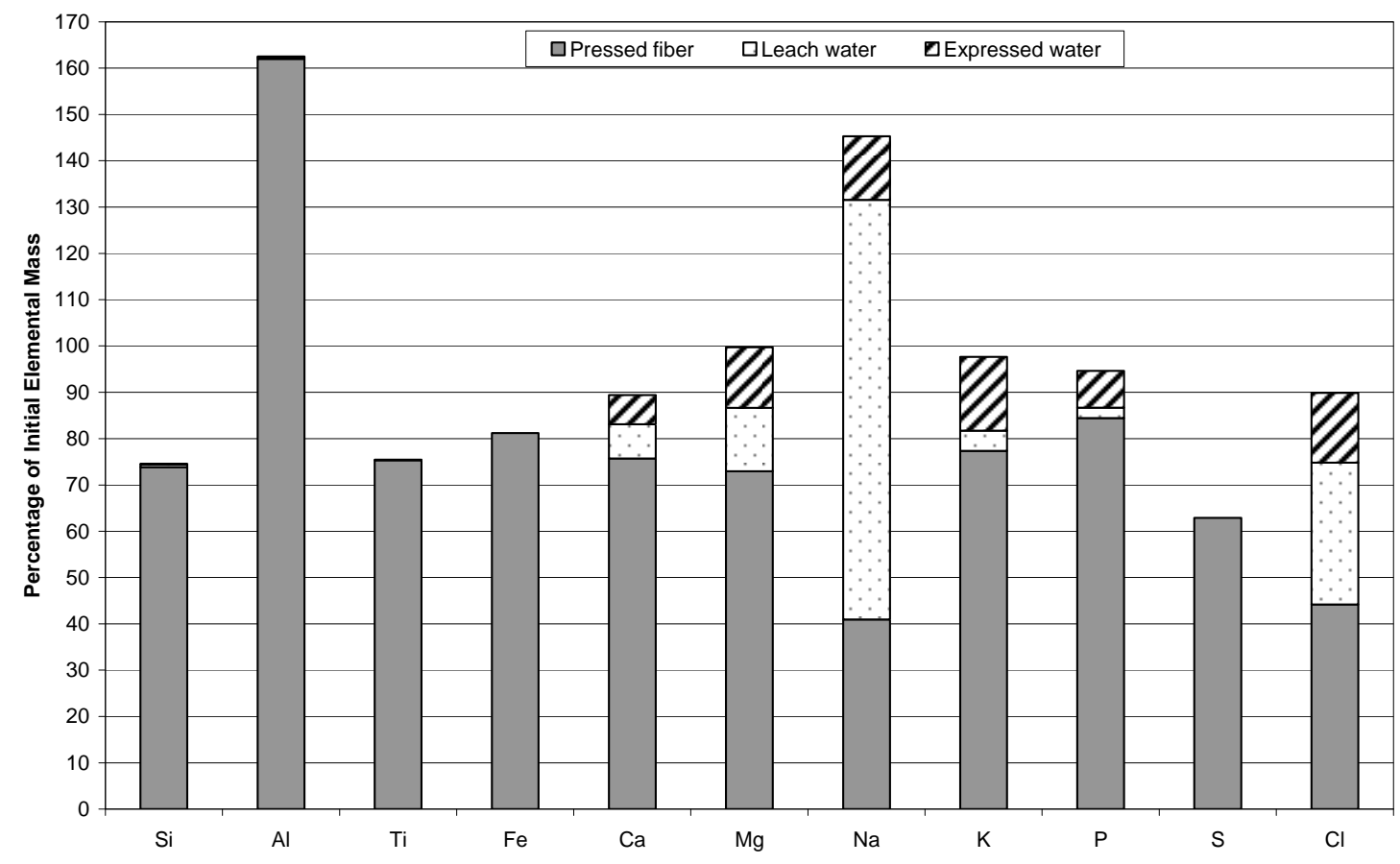

Figure 4.6.7: Distribution of elements as a percentage of the initial mass for treatment W-4"-1.0, the least severe treatment in the laboratory scale experiment II. (Note: liquid samples were not analyzed for $\mathrm{S}$ and $\mathrm{Fe})$

Figures 4.6.8 and 4.6.9 show the fraction of the elements removed from the dry fiber. The figures illustrate the difficulties experienced in removing the soil contaminants. However, in some cases, nearly $90 \%$ of the water soluble elements were removed. In particular, potassium and chlorine show consistent results. 


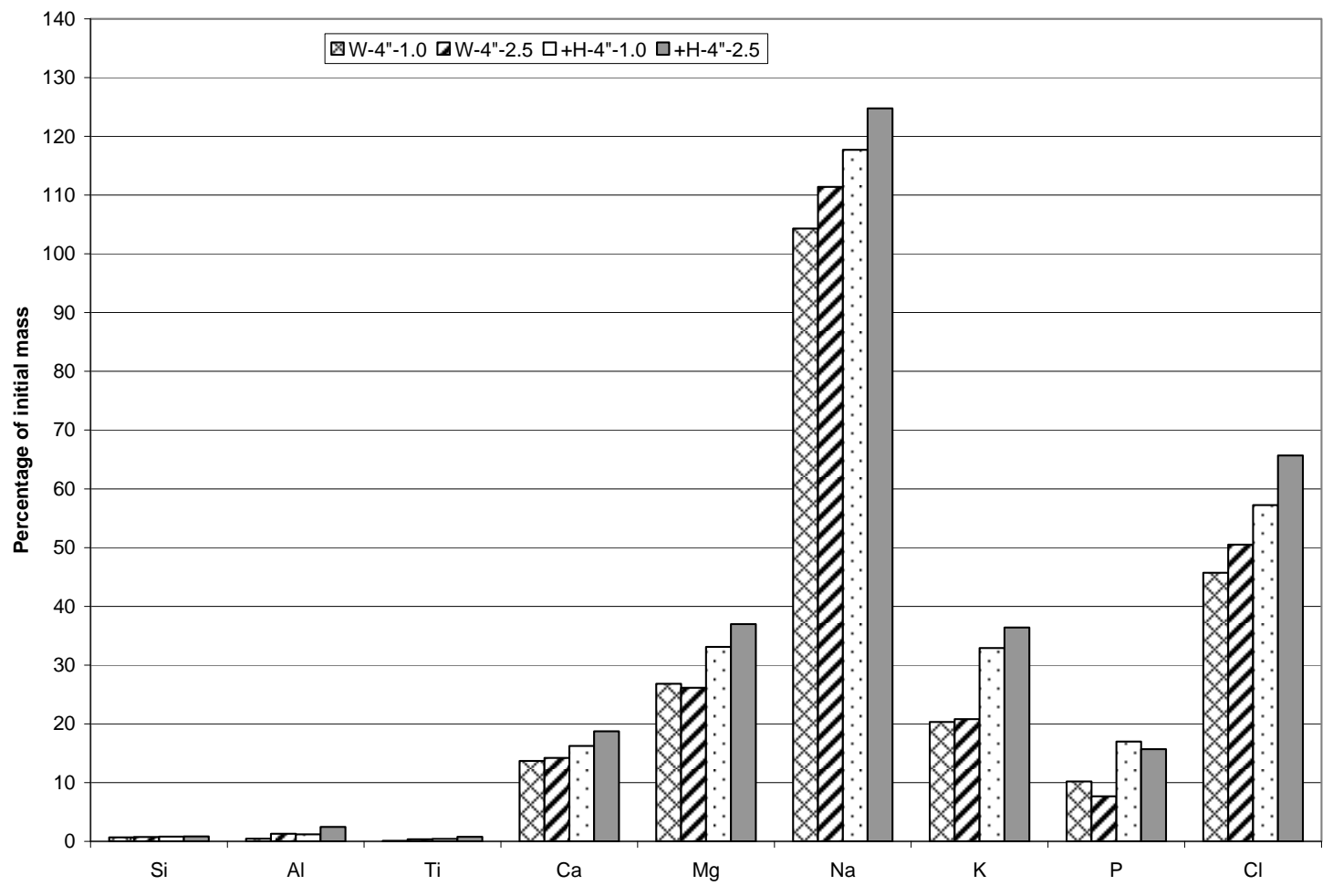

Figure 4.6.8: Constituents removed from dry fiber by leaching treatments W-4"-1.0, W-4"-2.5, +H-4"-1.0 and $+\mathrm{H}-4 "-2.5$, as a percentage of the initial dry sample mass from the laboratory experiments $\mathrm{I}$. 


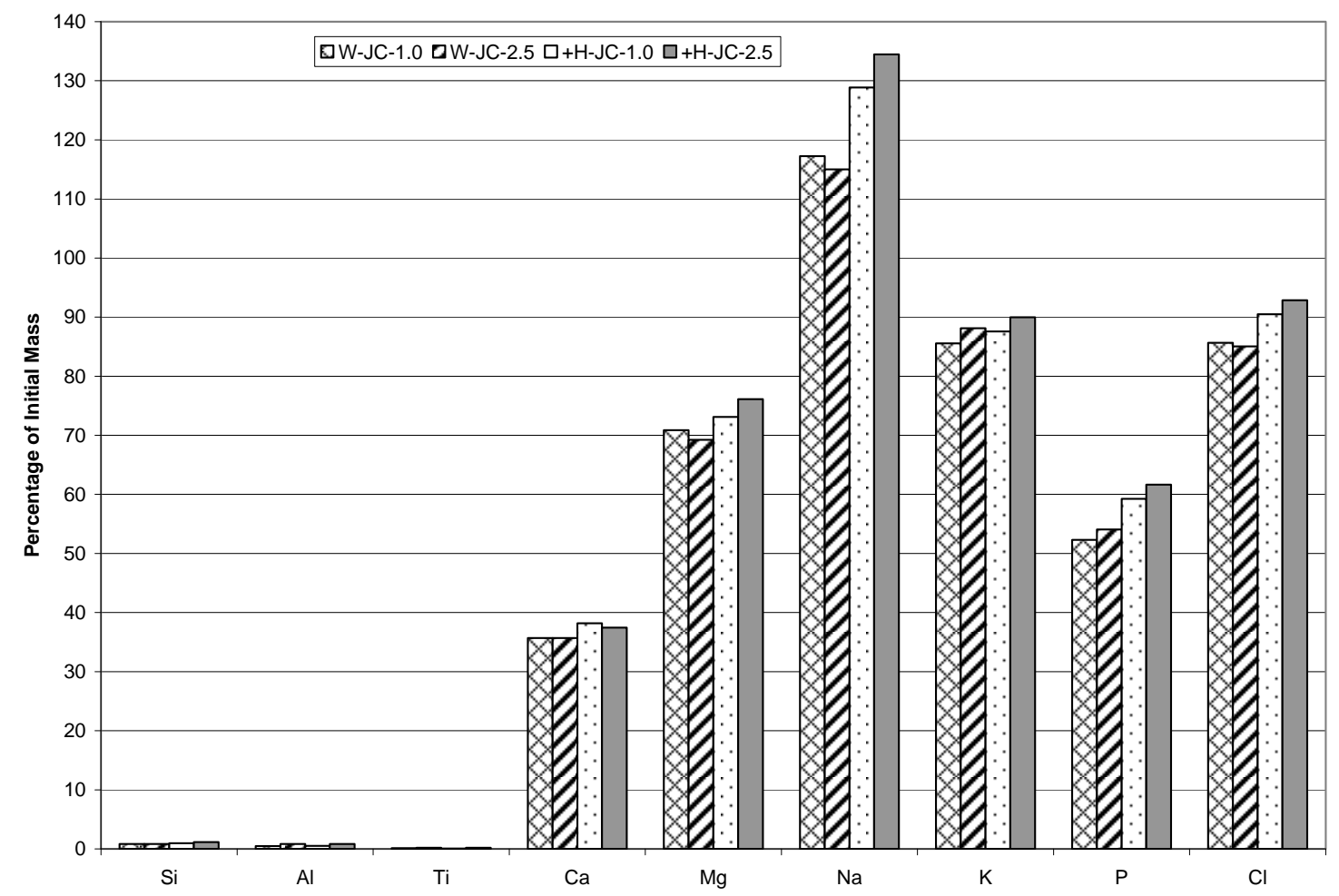

Figure 4.6.9: Constituents removed from dry fiber by leaching treatments W-JC-1.0, W-JC-2.5, +H-JC-1.0 and $+\mathrm{H}-\mathrm{JC}-2.5$ as a percentage of initial dry sample mass for laboratory experiments II.

For potassium, the pulverized tests showed an average removal of $88.5 \%$ with a standard deviation of $1.8 \%$. The chopped tests, on the other hand, were found to have an average removal of $27.6 \%$ with a standard deviation of $8.3 \%$. For $\mathrm{Cl}$, similar results for the pulverized samples were obtained at an average removal of $88.5 \%$ with standard deviation of 3.5\%. For the chopped samples the average $\mathrm{Cl}$ removal was $54.8 \%$ with a standard deviation of $8.7 \%$. The larger standard deviations seen for the chopped samples indicate interactive effects between the temperature and duration variables.

Table 4.6.2 shows the individual effects and two- and three-factor interactive effects. By assuming three-factor effects are negligible, the value observed from the three-factor interaction is attributable to experimental error only and, since no replicate treatments were carried out, is used as an approximate variance or, for a single degree of freedom, experimental error [11]. From the table, nine different effects can be distinguished from experimental error.

For potassium there appear to be statistically valid individual effects for two of the three variables. Particle size clearly has the greatest impact followed by temperature 
with duration showing an effect just slightly greater than the experimental noise. For potassium the only two factor interaction effect is that of temperature and particle size. Chlorine removal shows statically valid individual effects for all three variables. For chlorine, as with potassium, the individual effect of particle size appears to dominate followed by temperature and then duration.

Interaction effects for both potassium and chlorine preclude any direct conclusions about individual variable effects. However, by considering the schematic shown as Figure 4.8.1, it is apparent that with a small particle size, $\mathrm{Cl}$ approaches $80 \%$ removal from the cane trash irrespective of temperature or duration. Chlorine sensitivity to temperature shows moderate increases for both pulverized and chopped materials.

Table 4.6.2: Individual, two- and three-factor interaction effects of temperature, leaching duration and particle size on alkali removal in laboratory scale experiments II.

\begin{tabular}{|c|c|c|c|c|}
\hline & K & Error & $\mathrm{Cl}$ & Error \\
\hline \multicolumn{5}{|l|}{ Main, Individual Effects } \\
\hline Temperature $(T)$ & 7.93 & \pm 1.48 & 12.97 & \pm 0.39 \\
\hline Leaching Duration (D) & 2.23 & \pm 1.48 & 4.93 & \pm 0.39 \\
\hline Particle Size (PS) & 60.82 & \pm 1.48 & 43.65 & \pm 0.39 \\
\hline \multicolumn{5}{|c|}{ Two-Factor Interaction Effects } \\
\hline TxPS & -5.98 & \pm 1.48 & -4.72 & \pm 0.39 \\
\hline TxD & 0.70 & \pm 1.48 & 2.25 & \pm 0.39 \\
\hline PSxD & 0.26 & \pm 1.48 & -3.60 & \pm 0.39 \\
\hline \multicolumn{5}{|c|}{ Three-Factor Interaction Effects } \\
\hline TxPSxD & & & & \\
\hline
\end{tabular}

Similar to chlorine, potassium removal is most effected by particle size with removal in the range $80-90 \%$ for pulverized material and $30-50 \%$ for chopped. Potassium exhibits no temperature effect for the pulverized material but shows strong effects at the chopped particle size. Figures 4.6.10 and 4.6.11 detail the particle size, temperature interactions.

Figures 4.6.12 and 4.6.13 show the temperature duration interactions for chlorine and potassium removal respectively. The detailed calculation results of the element mass and recovery percentage is shown in Table B.3-B.7 of Subappendix B. 


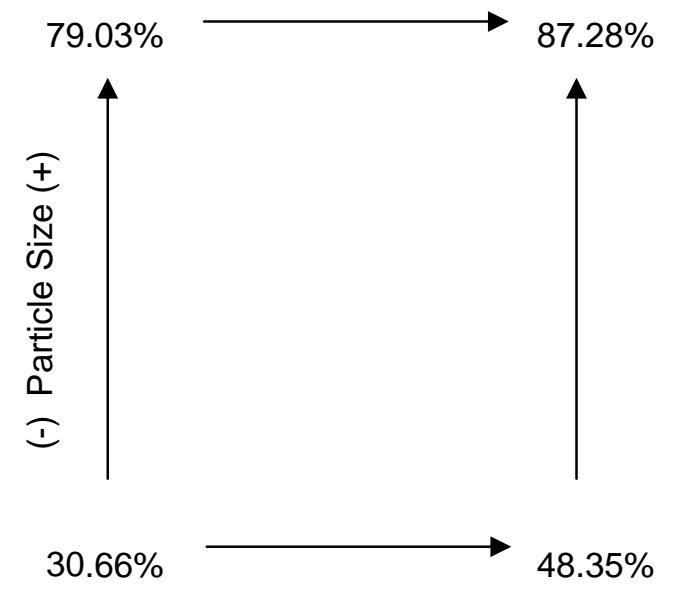

(-) Temperature (+)

Figure 4.6.10: Two-way schematic showing interaction between temperature and particle size for chlorine removal from sugar cane trash for laboratory experiments II.

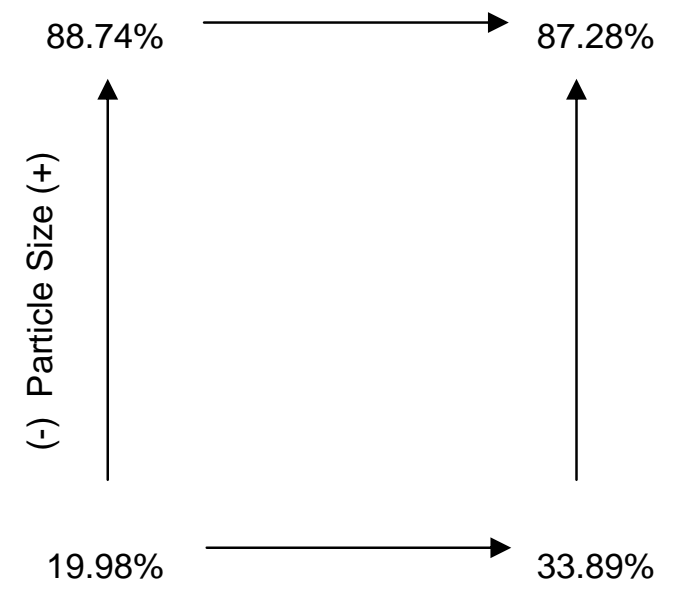

(-) Temperature (+)

Figure 4.6.11: Two-way schematic showing interaction between temperature and particle size for potassium removal from sugar cane trash for laboratory experiments II. 


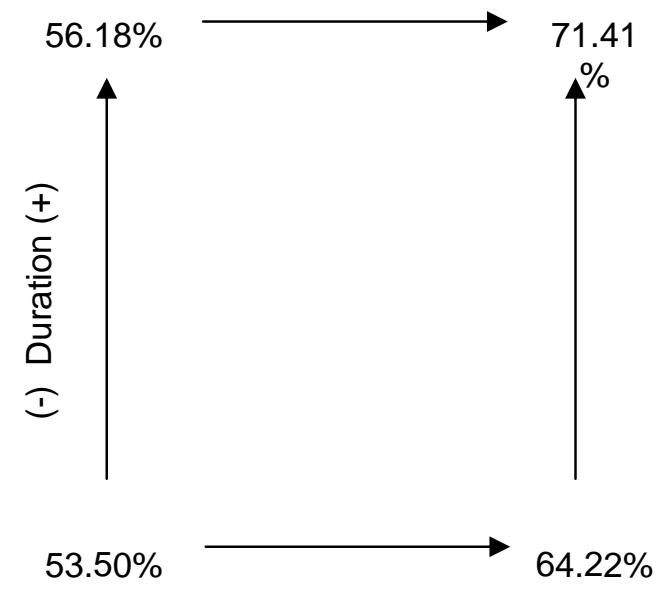

(-) Temperature (+)

Figure 4.6.12: Two-way schematic showing interaction between temperature and duration for chlorine removal from sugar cane trash for laboratory experiments II.

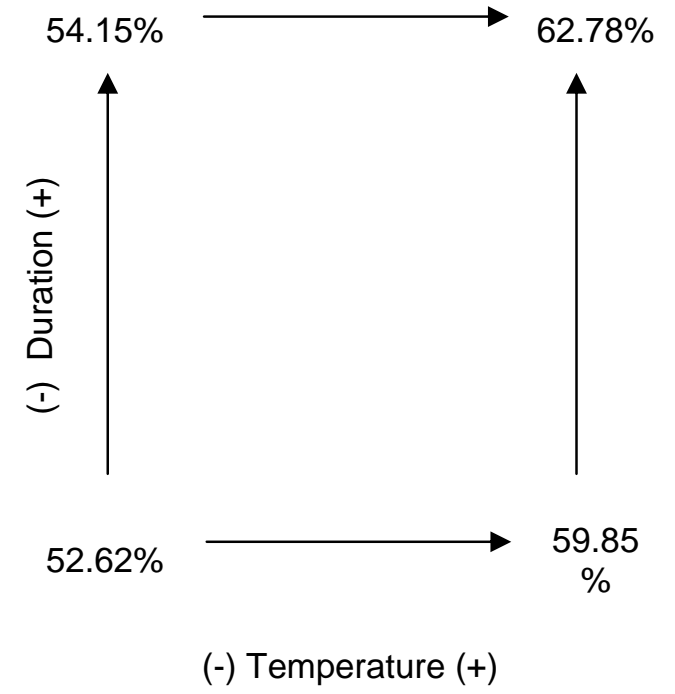

Figure 4.6.13: Two-way schematic showing interaction between temperature and duration for potassium removal from sugar cane trash for laboratory experiments II. 


\subsubsection{Slagging and Fouling Probability for Laboratory Experiments I}

The concentrations of total alkali and sulfur, as oxides, and chlorine on a unit energy basis are shown in Figure 4.7.1. The indices were calculated using data in Table 4.6.1. Slagging and fouling are probable when the index of the fuel is between 0.17 $\mathrm{kg} / \mathrm{GJ}$ and $0.34 \mathrm{~kg} / \mathrm{GJ}$ and certain above $0.34 \mathrm{~kg} / \mathrm{GJ}$.

The untreated samples, JC-blank and 2"-blank, lie in excess of $0.34 \mathrm{~kg} / \mathrm{GJ}$ and, therefore total alkali $\left(\mathrm{K}_{2} \mathrm{O}+\mathrm{Na}_{2} \mathrm{O}\right)$ are certain to disrupt boiler or gasifier operation. However, the treated samples for the pulverized cane trash have an average index of $0.080 \mathrm{~kg} / \mathrm{GJ}$ with a standard deviation of $0.038 \mathrm{~kg} / \mathrm{GJ}$, well below the probable range. Treated chopped material has a value of $0.467 \mathrm{~kg} / \mathrm{GJ}$ with a standard deviation of 0.026 $\mathrm{kg} / \mathrm{GJ}$ and lies well above the $0.34 \mathrm{~kg} / \mathrm{GJ}$ limit.

Although particle size appears to be the most prominent variable, interactions effects must be considered. Table 4.7.1 shows the individual, main effects and the two and three-factor interaction effects. The three-factor interactions were assumed negligible, attributed to and representative of the error in determination of the slagging and fouling index. Only the highlighted values can be differentiated from the noise in the experiment. The particle size is the only variable having an appreciable effect in reducing the concentration of alkali per energy unit. Therefore, reducing particle size from $5 \mathrm{~cm}$ nominal length to $0.1 \mathrm{~cm}$ nominal length reduces the concentration of total alkali $\left(\mathrm{K}_{2} \mathrm{O}+\mathrm{Na}_{2} \mathrm{O}\right)$ per energy unit by $0.387 \pm 0.002 \mathrm{~kg} / \mathrm{GJ}$, the concentration of $\mathrm{SO}_{3}$ per energy unit by $0.057 \pm 0.003 \mathrm{~kg} / \mathrm{GJ}$ and the concentration of $\mathrm{Cl}$ per energy unit by $0.070 \pm 0.009 \mathrm{~kg} / \mathrm{GJ}$. 


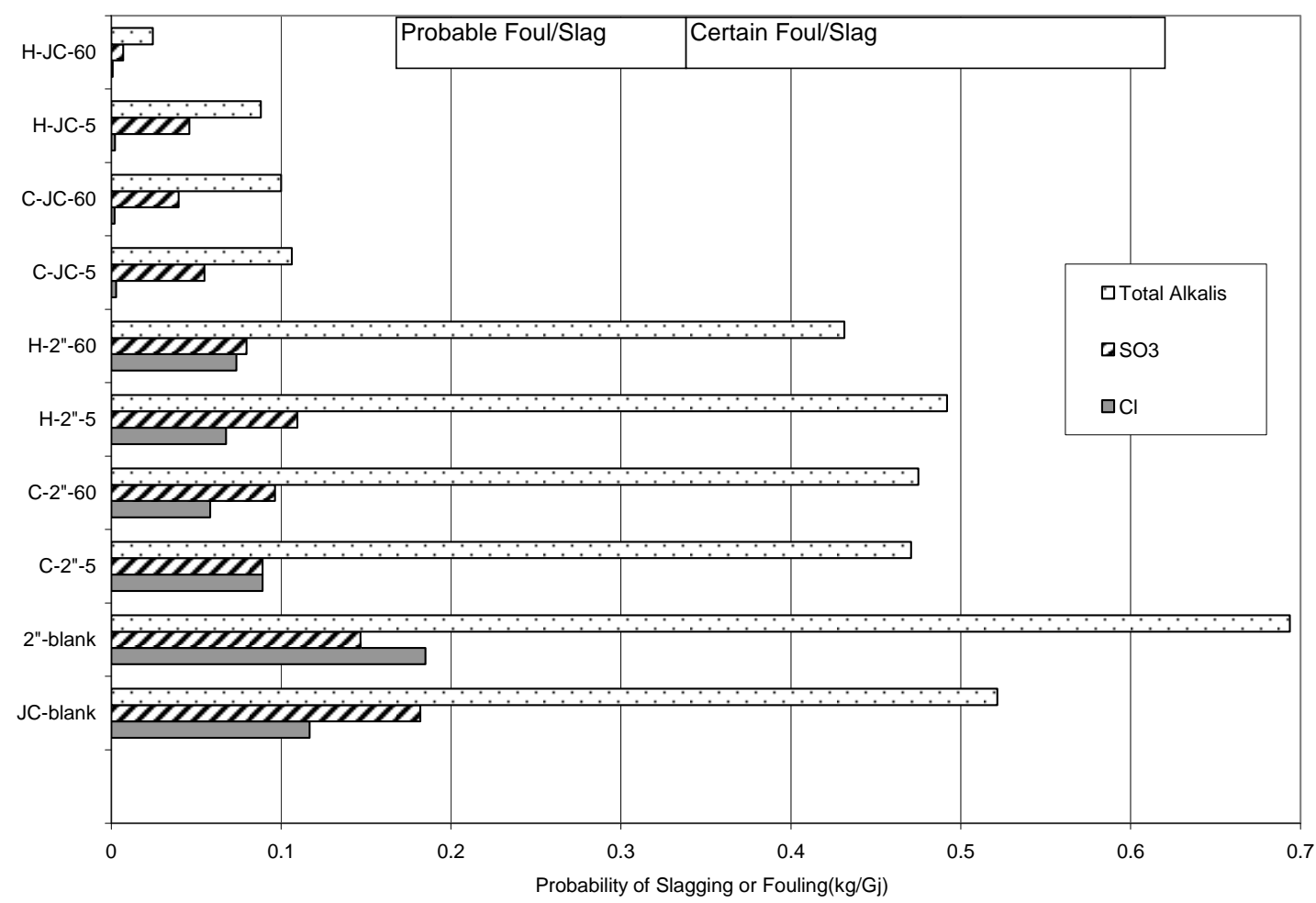

Figure 4.7.1: Total alkalis $\left(\mathrm{K}_{2} \mathrm{O}+\mathrm{Na}_{2} \mathrm{O}\right), \mathrm{SO}_{3}$ and $\mathrm{Cl}$ concentrations on a unit energy basis for sugar cane trash in the laboratory scale experiments I.

Table 4.7.1: Individual and two- and three-factor effects for the slagging/fouling index of the laboratory scale experiments I.

\begin{tabular}{|c|c|c|c|c|c|c|}
\hline & \multicolumn{2}{|c|}{ Total Alkali } & \multicolumn{2}{|c|}{ SO3 } & \multicolumn{2}{|c|}{$\mathrm{Cl}$} \\
\hline & kg/GJ & Error & kg/GJ & Error & kg/GJ & Error \\
\hline \multicolumn{7}{|c|}{ Main, Individual Effects } \\
\hline Temperature (T) & -0.0290 & \pm 0.0019 & -0.0095 & \pm 0.0033 & -0.0019 & \pm 0.0094 \\
\hline Leaching Duration (D) & -0.0315 & \pm 0.0019 & -0.0191 & \pm 0.0033 & -0.0067 & \pm 0.0094 \\
\hline Particle Size (PS) & -0.3876 & \pm 0.0019 & -0.0568 & \pm 0.0033 & -0.0701 & \pm 0.0094 \\
\hline \multicolumn{7}{|c|}{ Two-Factor Interaction Effects } \\
\hline TxPS & -0.0178 & \pm 0.0019 & -0.0114 & \pm 0.0033 & 0.0010 & \pm 0.0094 \\
\hline TxD & -0.0305 & \pm 0.0019 & -0.0153 & \pm 0.0033 & 0.0092 & \pm 0.0094 \\
\hline PSxD & -0.0035 & \pm 0.0019 & -0.0080 & \pm 0.0033 & 0.0056 & \pm 0.0094 \\
\hline \multicolumn{7}{|c|}{ Three-Factor Interaction Effects } \\
\hline TxPSxD & \multicolumn{2}{|c|}{0.0019} & \multicolumn{2}{|c|}{0.0033} & \multicolumn{2}{|c|}{-0.0094} \\
\hline
\end{tabular}




\subsubsection{Slagging and Fouling Probability for Laboratory Experiments II}

The concentrations of total alkali and sulfur, as oxides, and on a unit energy basis for chlorine for the second set of treatments are shown in Figure 4.7.2. The indices were calculated using data in Table 4.6.1. Slagging and fouling are probable when the index of the fuel is between $0.17 \mathrm{~kg} / \mathrm{GJ}$ and $0.34 \mathrm{~kg} / \mathrm{GJ}$ and certain above $0.34 \mathrm{~kg} / \mathrm{GJ}$.

The untreated samples, JC-blank and 4"-blank, lie in excess of $0.34 \mathrm{~kg} / \mathrm{GJ}$ and, therefore total alkali $\left(\mathrm{K}_{2} \mathrm{O}+\mathrm{Na}_{2} \mathrm{O}\right)$ are certain to disrupt boiler or gasifier operation. However, the treated samples for the pulverized cane trash have an average index of $0.124 \mathrm{~kg} / \mathrm{GJ}$ with a standard deviation of $0.023 \mathrm{~kg} / \mathrm{GJ}$, below the probable range. Treated chopped material has a value of $0.498 \mathrm{~kg} / \mathrm{GJ}$ with a standard deviation of $0.137 \mathrm{~kg} / \mathrm{GJ}$ and lies well above the $0.34 \mathrm{~kg} / \mathrm{GJ}$ limit. Although particle size appears to be the most prominent variable once again, interactions effects must be considered.

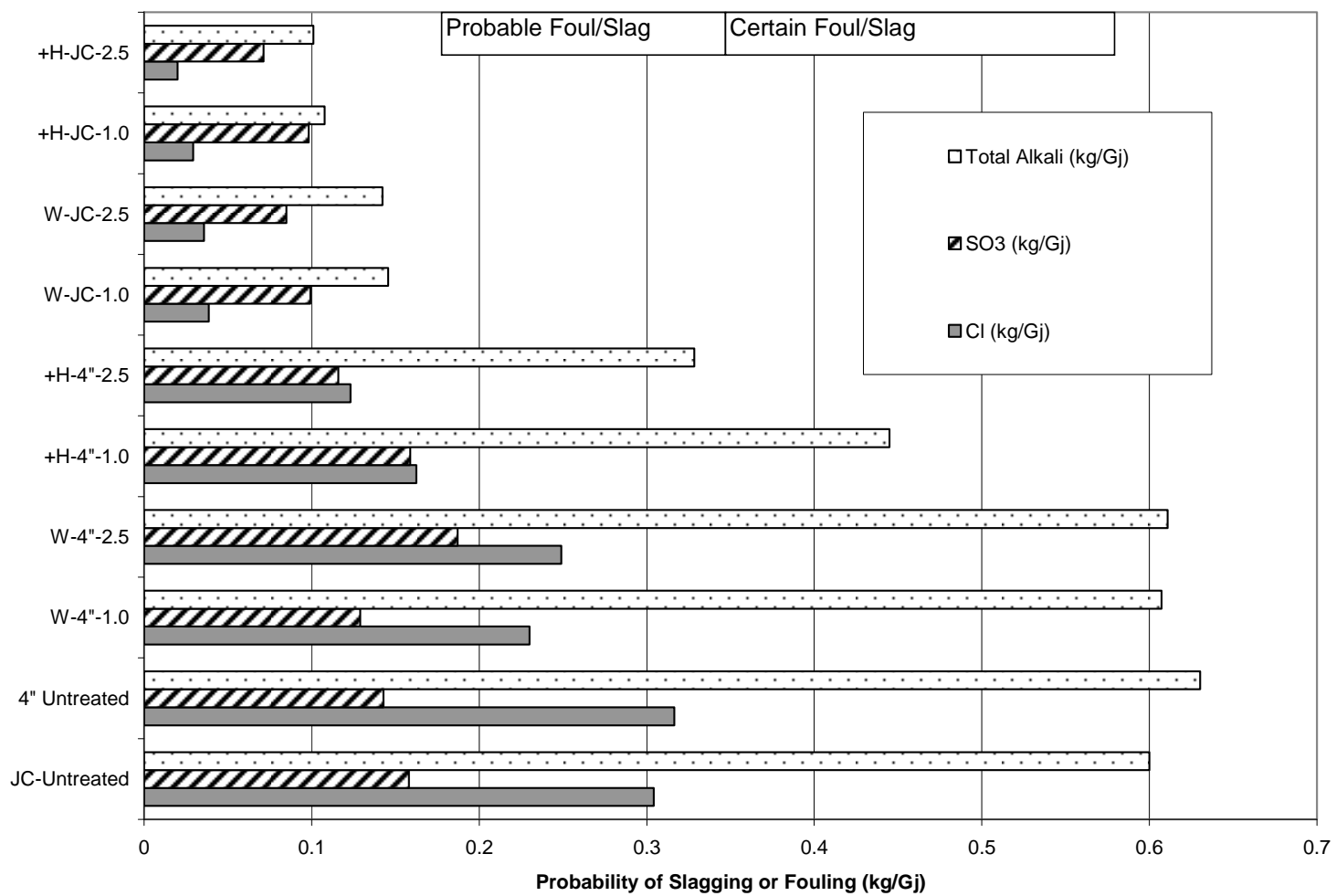

Figure 4.9: Total alkalis $\left(\mathrm{K}_{2} \mathrm{O}+\mathrm{Na}_{2} \mathrm{O}\right), \mathrm{SO}_{3}$ and $\mathrm{Cl}$ concentrations on a unit energy basis for sugar cane trash in the laboratory scale experiments I. 
Table 4.7.2 shows the individual, main effects and the two and three-factor interaction effects. The three-factor interactions were assumed negligible, attributed to and representative of the error in determination of the slagging and fouling index. Only the highlighted values can be differentiated from the noise in the experiment. The temperature, particle size interaction identified in element removal analysis is also present in the alkali, and chlorine per energy unit measurements. Interaction effects preclude any direct conclusions about individual variable effects. $\mathrm{SO}_{3}$ per unit energy does not show these interaction effects. Reducing particle size from $10 \mathrm{~cm}$ nominal length to $0.1 \mathrm{~cm}$ nominal length reduces the concentration of $\mathrm{SO}_{3}$ per energy unit by $0.0593+/-0.013 \mathrm{~kg} / \mathrm{GJ}$.

Table 4.7.2: Individual and two- and three-factor effects for the slagging/fouling index of the laboratory scale experiments II.

\begin{tabular}{|c|c|c|c|c|c|c|}
\hline & \multicolumn{2}{|c|}{ Total Alkali } & \multicolumn{2}{|c|}{ SO3 } & \multicolumn{2}{|c|}{$\mathrm{Cl}$} \\
\hline & kg/GJ & Error & kg/GJ & Error & kg/GJ & Error \\
\hline \multicolumn{7}{|c|}{ Main, Individual Effects } \\
\hline Temperature (T) & -0.1310 & \pm 0.029 & -0.0140 & \pm 0.022 & -0.055 & \pm 0.013 \\
\hline Leaching Duration (D) & -0.0308 & \pm 0.029 & -0.0065 & \pm 0.022 & -0.008 & \pm 0.013 \\
\hline Particle Size (PS) & -0.3737 & \pm 0.029 & -0.0593 & \pm 0.022 & -0.160 & \pm 0.013 \\
\hline \multicolumn{7}{|c|}{ Two-Factor Interaction Effects } \\
\hline TxPS & 0.0915 & \pm 0.029 & 0.0066 & \pm 0.022 & 0.0421 & \pm 0.013 \\
\hline TxD & -0.0308 & \pm 0.029 & -0.0284 & \pm 0.022 & -0.0162 & \pm 0.013 \\
\hline PSxD & 0.0257 & \pm 0.029 & -0.0141 & \pm 0.022 & 0.0021 & \pm 0.013 \\
\hline \multicolumn{7}{|c|}{ Three-Factor Interaction Effects } \\
\hline TxPSxD & \multicolumn{2}{|c|}{0.029} & \multicolumn{2}{|c|}{0.022} & \multicolumn{2}{|c|}{-0.013} \\
\hline
\end{tabular}

\subsection{Pilot Scale Experiment}

The pilot scale experiments were carried out in early December of 2005 following a period of heavy rain that made fields impassable, ceased harvest activities, and forced a brief shutdown of the Puunene Sugar Mill. When HC\&S resumed operation, the sugar fields were so wet that cane burning was impossible. Although the period of green cane harvest lent itself well to the objectives of the cane trash processing experiment, more adventitious soil than normal was present in the harvested cane due to the wet conditions. 


\subsubsection{Validation of Experimental Practices}

Figure 4.8.1 shows a schematic of the system indicating the inputs and outputs used in the balance calculations. The overall mass balance of the input to output water and cane trash indicate the system to be closed to within $1.2 \%$ on average with a standard deviation of $0.8 \%$ across all four of the treatments. Similarly, dry fiber mass was balanced to within $8.7 \%$ on average with a standard deviation of $18.6 \%$ for the four treatments. The second, and most severe treatment $\left(60^{\circ} \mathrm{C}\right.$ leaching for 10 minutes), showed a considerable loss of dry fiber between the input and output (approximately 34\%) resulting in the high standard deviation. A potential source for the discrepancy was removal of rock material before milling of the sample. Weight of rocks and debris removed before milling was not accounted for during the experiments. Although in most cases the quantity was relatively small, the relative weight of the rocks and debris to that of the cane trash may have caused larger than anticipated losses.

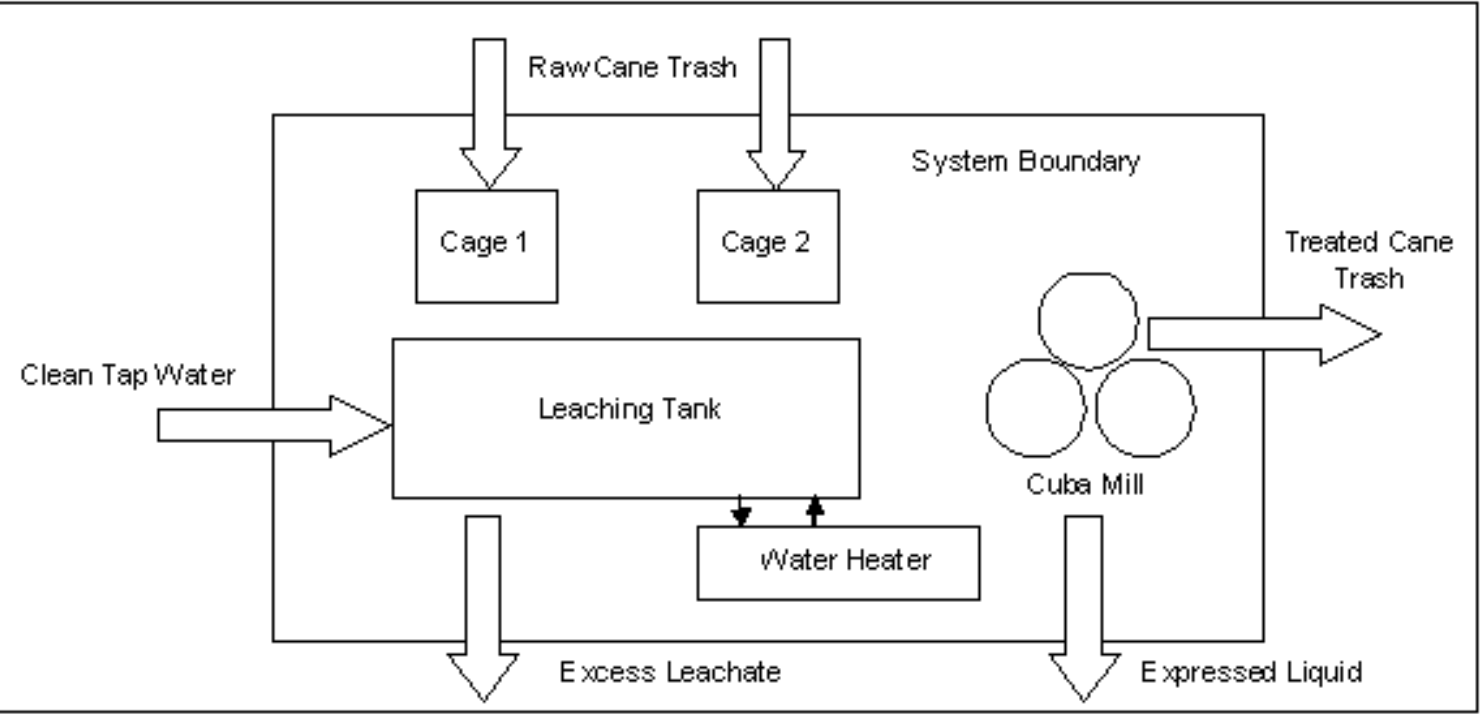

Figure 4.8.1: Schematic diagram of experimental system used for mass balance calculations for the pilot scale experiment.

Despite the minimal loss of cane trash and water across the experimental system, the balance of ash percentage in the dry matter before and after the treatments showed considerable and unexpected discrepancies. Figure 4.8.2 shows the considerable increase 
in ash, measured in the fiber samples and suspended solids measured in the excess leachate and expressed liquids. The figure shows $>50 \%$ discrepancy between the input and output streams for all but the second of the four treatments. The mass of ash input for the second treatment was found to be $65 \%$ of the mass of the ash output.

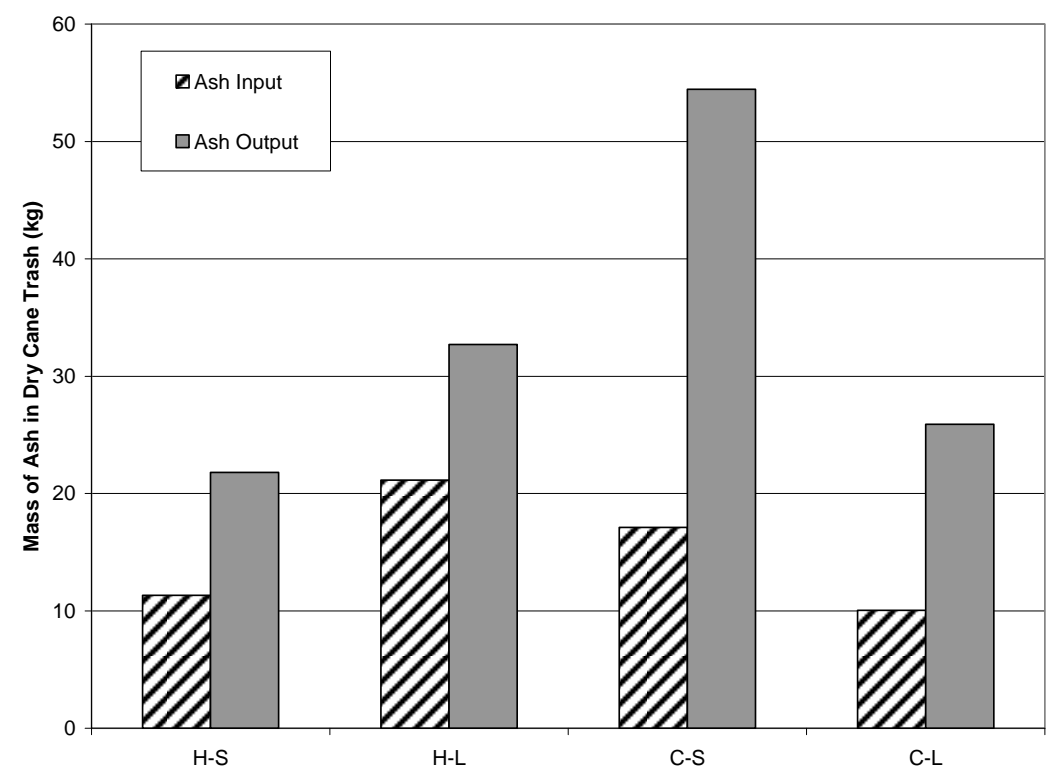

Figure 4.8.2: Ash and suspended solids balanced across the experimental system for the pilot scale experiment.

The complete fuel analysis shown in Table 4.8 .1 shows the data used in the calculations. Reductions in element concentrations as a result of leaching use the concentration in the untreated samples as the basis of comparison. Low concentrations are often difficult to accurately measure and subject to experimental error. A plausible explanation for the excess ash and suspended solids in the treated cane trash is that the samples of untreated cane trash taken from cages 1 and 2 were not representative of the untreated material. Based on visual inspection, the cages consisted of an inhomogeneous mixture of cane trash, shorts, soil/mud, rocks and possibly other debris. Although $1 \mathrm{~kg}$ samples of the cane trash were taken before the treatments, soil and other debris that constitutes a significant fraction of the ash material were not representatively included in the samples. During the treatments, despite leaching and cleaning some of the rocks and debris from the samples, much of the soil/mud was dispersed throughout the fuel lot, increasing its 
homogeneity. This mixture was sampled in a similar manner as the untreated material and analyzed. Therefore, the discrepancy in ash content before and after the treatment is likely caused by the relatively small sample size used to represent the untreated cane trash. Although this precludes the balance of alkali elements across the system, the potential fuel resulting from the treatments can be analyzed. 
Table 4.8.1: Fuel characterization of samples of cane trash before and after the pilot scale experiment (results from Hazen Research Inc. Laboratories in Golden, Colorado)

\begin{tabular}{|c|c|c|c|c|c|c|c|c|}
\hline \multirow{2}{*}{$\begin{array}{l}\text { Description: } \\
\text { ID \#: }\end{array}$} & \multicolumn{2}{|c|}{ Hot/Short } & \multicolumn{2}{|c|}{ Hot/Long } & \multicolumn{2}{|c|}{ Cold/Short } & \multicolumn{2}{|c|}{ Cold/Long } \\
\hline & $1-U$ & 1-HS & 2-U & 2-HL & $3-U$ & 3-CS & 4-U & 4-CL \\
\hline $\begin{array}{l}\text { Moisture } \\
\text { Content }\end{array}$ & 70.72 & 61.59 & 63.29 & 54.19 & 71.97 & 52.97 & 70.95 & 55.98 \\
\hline \multicolumn{9}{|c|}{ Proximate Analysis (\% dry basis) } \\
\hline $\begin{array}{l}\text { Ash } \\
\text { Volatile } \\
\text { Fixed C }\end{array}$ & $\begin{array}{l}15.93 \\
72.11 \\
11.96\end{array}$ & $\begin{array}{l}24.88 \\
64.19 \\
10.93\end{array}$ & $\begin{array}{l}18.34 \\
67.98 \\
13.68\end{array}$ & $\begin{array}{c}27.51 \\
64.04 \\
8.45\end{array}$ & $\begin{array}{l}18.28 \\
70.14 \\
11.58\end{array}$ & $\begin{array}{c}39 \\
58.29 \\
2.71\end{array}$ & $\begin{array}{l}13.52 \\
73.95 \\
12.53\end{array}$ & $\begin{array}{c}29.63 \\
61.02 \\
9.35\end{array}$ \\
\hline \multicolumn{9}{|l|}{ HHV } \\
\hline$(\mathbf{M J} / \mathbf{k g})$ & 16.03 & 14.23 & 15.56 & 13.67 & 15.66 & 11.12 & 16.7 & 13.42 \\
\hline \multicolumn{9}{|c|}{ Ultimate Analysis (\% dry basis) } \\
\hline C & 46.34 & 40.42 & 43.79 & 39.85 & 44.69 & 33.17 & 45.75 & 38.29 \\
\hline $\mathrm{H}$ & 4.67 & 5.13 & 5.46 & 3.97 & 4.39 & 3.33 & 4.61 & 3.77 \\
\hline $\mathrm{N}$ & 0.35 & 0.24 & 0.31 & 0.26 & 0.29 & 0.2 & 0.32 & 0.23 \\
\hline $\mathrm{S}$ & 0.1 & 0.09 & 0.1 & 0.08 & 0.09 & 0.06 & 0.09 & 0.07 \\
\hline Ash & 15.93 & 24.88 & 18.34 & 27.51 & 18.28 & 39 & 13.52 & 29.63 \\
\hline O (by diff) & 32.61 & 29.24 & 32 & 28.33 & 32.26 & 24.24 & 35.71 & 28.01 \\
\hline $\mathrm{Cl}$ & 0.176 & 0.105 & 0.192 & 0.071 & 0.285 & 0.081 & 0.233 & 0.092 \\
\hline \multicolumn{9}{|c|}{ Water Soluble Alkalis } \\
\hline $\mathrm{Na} 2 \mathrm{O}$ & 0.1 & 0.054 & 0.094 & 0.044 & 0.09 & 0.065 & 0.088 & 0.052 \\
\hline $\mathrm{K} 2 \mathrm{O}$ & 0.32 & 0.248 & 0.349 & 0.15 & 0.581 & 0.187 & 0.45 & 0.206 \\
\hline \multicolumn{9}{|c|}{ Elemental Analysis of Ash (\% dry basis) } \\
\hline $\mathrm{SiO} 2$ & 61.22 & 49.69 & 56.78 & 45.2 & 46.26 & 43.39 & 56.16 & 45.43 \\
\hline $\mathrm{Al} 2 \mathrm{O} 3$ & 12.8 & 16.74 & 14.64 & 19.38 & 19.53 & 20.89 & 14.59 & 19.19 \\
\hline TiO2 & 2.52 & 3.8 & 3.14 & 4.45 & 4.07 & 4.18 & 2.78 & 4.79 \\
\hline $\mathrm{Fe} 2 \mathrm{O} 3$ & 9.69 & 15.07 & 11.82 & 16.61 & 16.62 & 17.64 & 11.19 & 17.92 \\
\hline $\mathrm{CaO}$ & 4.02 & 4.79 & 5.26 & 2.63 & 4.64 & 5.34 & 3.88 & 4.72 \\
\hline $\mathrm{MgO}$ & 1.55 & 2.62 & 2.62 & 1.68 & 2.95 & 3.51 & 1.7 & 2.87 \\
\hline $\mathrm{Na2O}$ & 0.87 & 0.97 & 1.08 & 0.71 & 1.06 & 1.16 & 1.02 & 1.06 \\
\hline $\mathrm{K} 2 \mathrm{O}$ & 2.38 & 1.81 & 1 & 3.15 & 1.04 & 1.01 & 4.61 & 1.34 \\
\hline P2O5 & 0.56 & 0.44 & 0.48 & 0.42 & 0.54 & 0.4 & 0.63 & 0.42 \\
\hline SO3 & 0.93 & 0.53 & 1.01 & 0.29 & 0.69 & 0.22 & 1.25 & 0.3 \\
\hline $\mathrm{Cl}$ & 0.05 & 0.02 & 0.1 & 0.31 & 0.31 & 0.02 & 0.3 & 0.03 \\
\hline $\mathrm{CO} 2$ & 0.18 & 0.09 & 0.12 & 0.71 & 0.09 & 0.09 & 0.16 & 0.08 \\
\hline Und. & 3.23 & 3.43 & 1.95 & 4.46 & 2.2 & 2.15 & 1.73 & 1.85 \\
\hline Total & 96.77 & 96.57 & 98.05 & 95.54 & 97.8 & 97.85 & 98.27 & 98.15 \\
\hline \multicolumn{9}{|c|}{ Ash Fusion Temperature (C) } \\
\hline \multicolumn{9}{|c|}{ Oxidizing Atmosphere } \\
\hline Initial & 1262.78 & 1216.67 & 1265.56 & 1239.44 & 1272.22 & 1251.11 & 1206.11 & 1244.11 \\
\hline Softening & 1277.78 & 1249.44 & 1288.89 & 1247.78 & 1312.78 & 1266.11 & 1273.89 & 1260.56 \\
\hline Hemispherical & 1295 & 1260 & 1306.67 & 1271.67 & 1327.78 & 1297.78 & 1281.11 & 1277.22 \\
\hline Fluid & 1328.33 & 1277.22 & 1326.11 & 1278.89 & 1340.56 & 1311.67 & 1287.22 & 1303.33 \\
\hline \multicolumn{9}{|c|}{ Reducing Atmosphere } \\
\hline Initial & 1260 & 1234.44 & 1260 & 1239.44 & 1275.56 & 1231.11 & 1221.11 & 1257.22 \\
\hline Softening & 1288.89 & 1243.89 & 1295.56 & 1247.22 & 1284.44 & 1243.33 & 1261.11 & 1265 \\
\hline Hemispherical & 1302.78 & 1250.56 & 1301.11 & 1263.89 & 1312.78 & 1249.44 & 1298.89 & 1278.89 \\
\hline Fluid & 1327.22 & 1260 & 1318.89 & 1272.22 & 1318.89 & 1266.11 & 1307.78 & 1307.78 \\
\hline
\end{tabular}




\subsubsection{Element Removal by Leaching in the Pilot Scale Experiment}

The distributions of elemental masses in the treated cane trash are shown in Figure 4.8.3. The majority of the potassium in the system was retained within the treated fuel. Chlorine and sodium, however, were much more easily leached from the fuel. The figure shows that the soil elements $\mathrm{Al}, \mathrm{Ti}$, and Fe remain in abundance in the treated fuel. This indicates, as discussed earlier, a high degree of soil contamination in the cane trash sample obtained from the sugar factory conveyor. The water soluble elements appear to be leached excessively over the course of the treatments. However, the figure is misleading in that the elements in the clean water of the leaching tank must also be considered. Furthermore, sample size must be taken into account to accurately compare the treatments. Figure 4.8.4 shows the mass of elements removed from the cane trash sample per kg of dry matter in the original sample. Although no comparison to the untreated cane trash can be made in this investigation, the elements that are most readily leached from the cane trash are apparent. The figure does not, however, give a clear indication of the impacts of variable treatment severity. The main effect of increasing the temperature and duration of the treatments on the elements are shown in Table 4.8.2. 

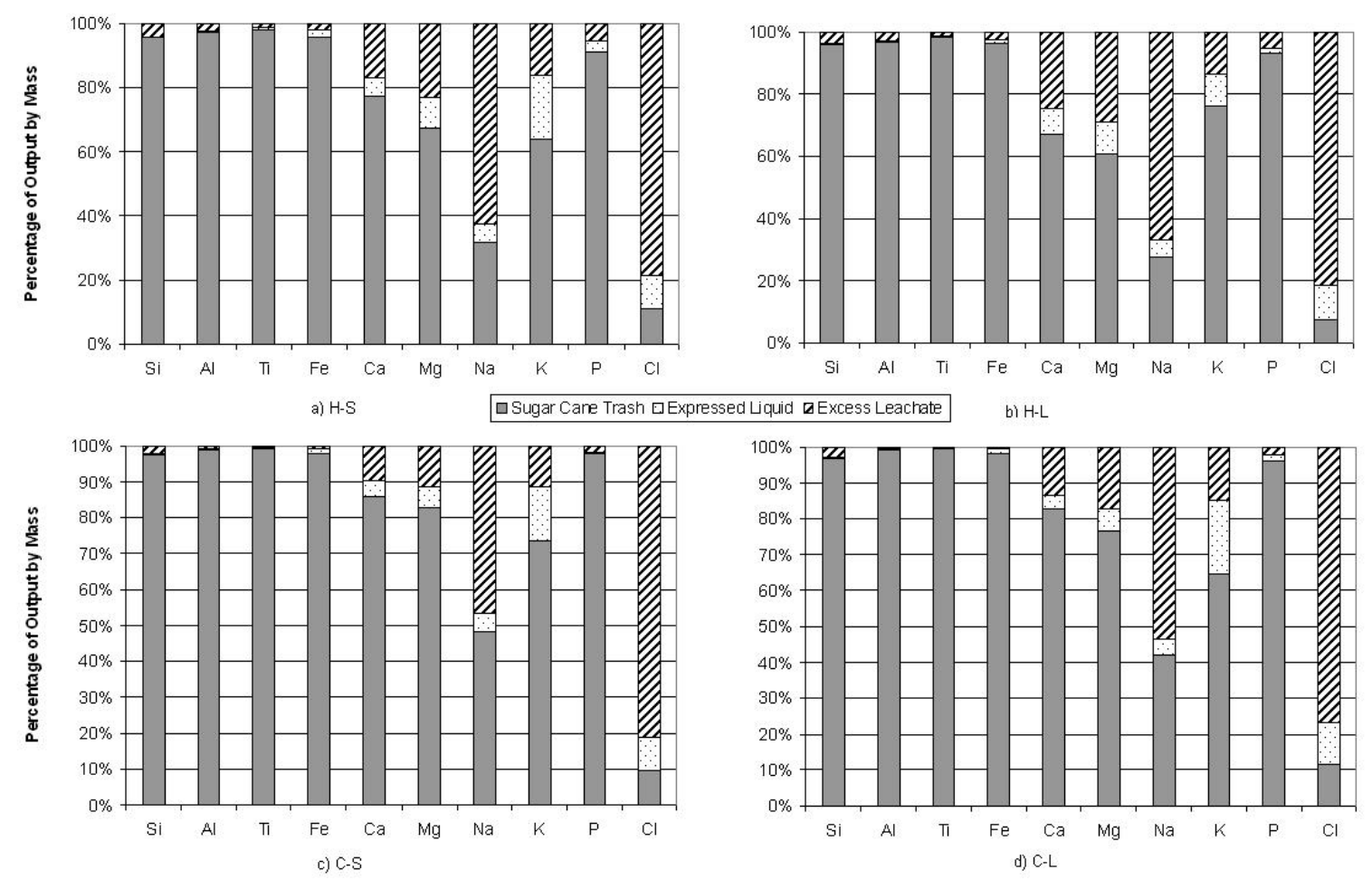

Figure 4.8.3: Breakdown of the element percentages in the output streams of each of the four treatments of the pilot scale experiment.

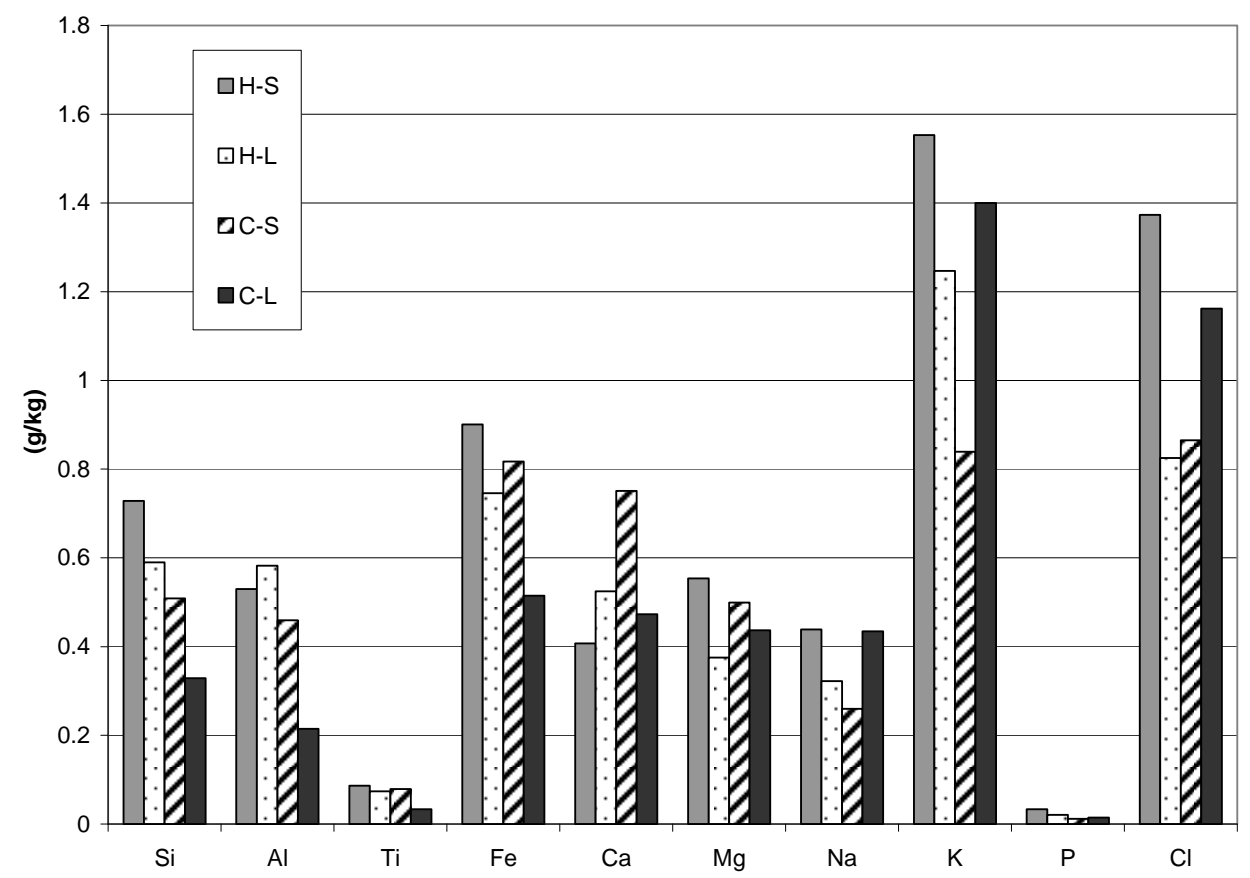

Figure 4.8.4: Mass of elements removed from cane trash per kg of dry matter in the untreated sample from the pilot scale experiment. 
Table 4.8.2: Main, individual effects of increasing the variables on the removal of elements from the cane trash sample per $\mathrm{kg}$ of dry matter treated.

\begin{tabular}{c|cc} 
Element & $\begin{array}{c}\text { Individual Effect of } \\
\text { Increasing Temperature* } \\
\text { (g/kg of dry matter) }\end{array}$ & $\begin{array}{c}\text { Individual Effect of } \\
\text { Increasing Duration* } \\
\text { (g/kg of dry matter) }\end{array}$ \\
\hline $\mathbf{S i}$ & 0.241 & -0.159 \\
$\mathbf{A l}$ & 0.219 & -0.096 \\
$\mathrm{Ti}$ & 0.024 & -0.029 \\
$\mathbf{F e}$ & 0.157 & -0.229 \\
$\mathbf{C a}$ & -0.146 & -0.080 \\
$\mathbf{M g}$ & -0.003 & -0.121 \\
$\mathbf{N a}$ & 0.033 & 0.029 \\
$\mathbf{K}$ & 0.280 & 0.127 \\
$\mathbf{P}$ & 0.014 & -0.005 \\
$\mathbf{C l}$ & 0.086 & -0.126
\end{tabular}

*Negative values indicate the less severe (lower/shorter) treatment removed a greater mass of the element than the more severe treatment.

The data show a consistent reduction in inorganic elements with increasing temperature and decreasing leaching duration. However, the numbers can vary to a large extent due to the soil contamination of a particular sample. Similar inconsistency was found in literature whereby soil contaminants (mainly $\mathrm{Al}, \mathrm{Ti}$ and $\mathrm{Fe}$ ) were found to increase as a result of leaching treatments [14]. The details of the balance calculations as well as a breakdown of the ions traced through the levels of treatment (clean, leached and expressed liquids) are shown in Subappendix C.

\subsubsection{Moisture Analyses of the Fuels from the Pilot Scale Experiment}

Once again, although it is unclear if the untreated measurements are representative of the sample, the results of moisture content analysis, shown in Figure 4.8.5, are consistent with the results of Turn et al [10]. Although some of the samples clearly are not reduced below 50\% (typical bagasse as-fired moisture content), it is assumed that in processing cane trash, milling can be done with much higher precision in order to better control the fuel moisture content. The figure also implies consistency amongst the untreated and treated samples. Furthermore, despite the variation in leaching time and temperature, no patterns in the moisture content after milling are visible. 


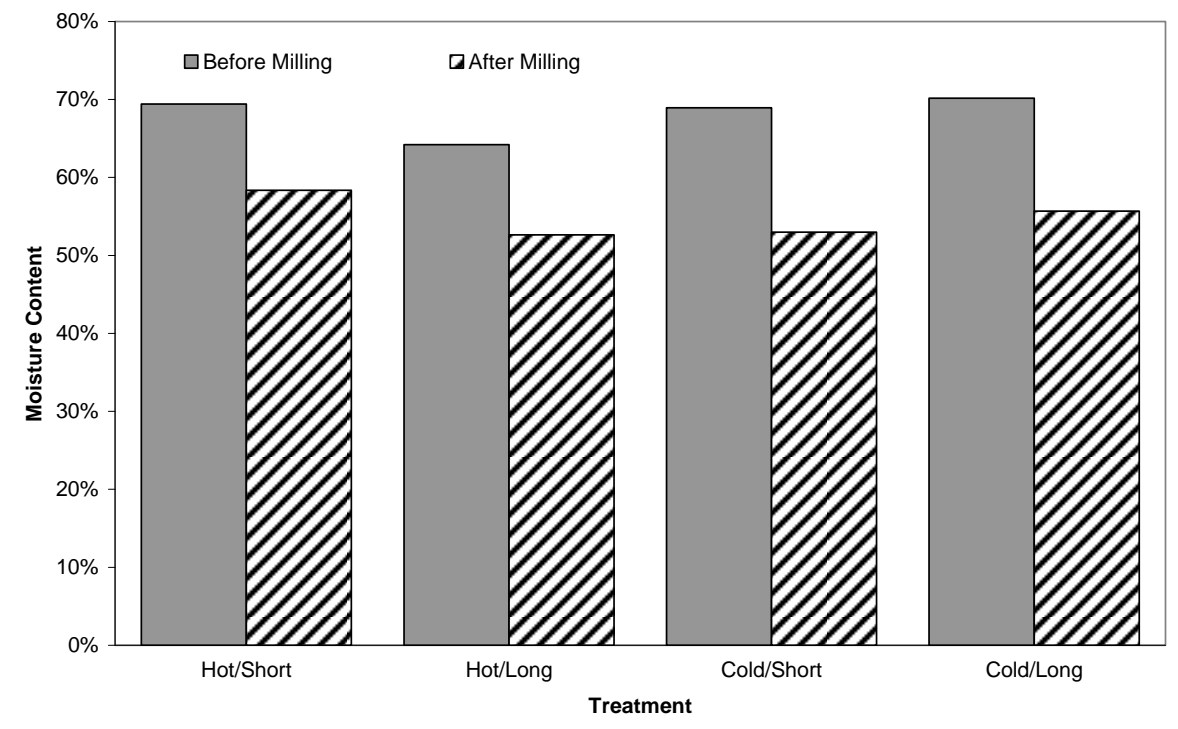

Figure 4.8.5: Average moisture content of cane trash samples before and after processing in the pilot scale experiment.

\subsubsection{Electrical Conductivity}

Figure 4.8.6 shows the increase in electrical conductivity of the liquid samples. The leaching step produces an increase in electrical conductivity ranging from 0.05 to $0.10 \mathrm{mS} / \mathrm{cm}$ in the excess leachate compared to the original clean water. The milling process, however, produced expressed liquids with much higher values of electrical conductivity ranging from 4.01 to $4.64 \mathrm{mS} / \mathrm{cm}$. The increase may also be the result of the short cane pieces mixed with the cane trash in the pilot scale test. Thus Figure 4.8.6 reflects high concentrations of the ions expressed during milling rather than an effect that resulting from treatment severity. 


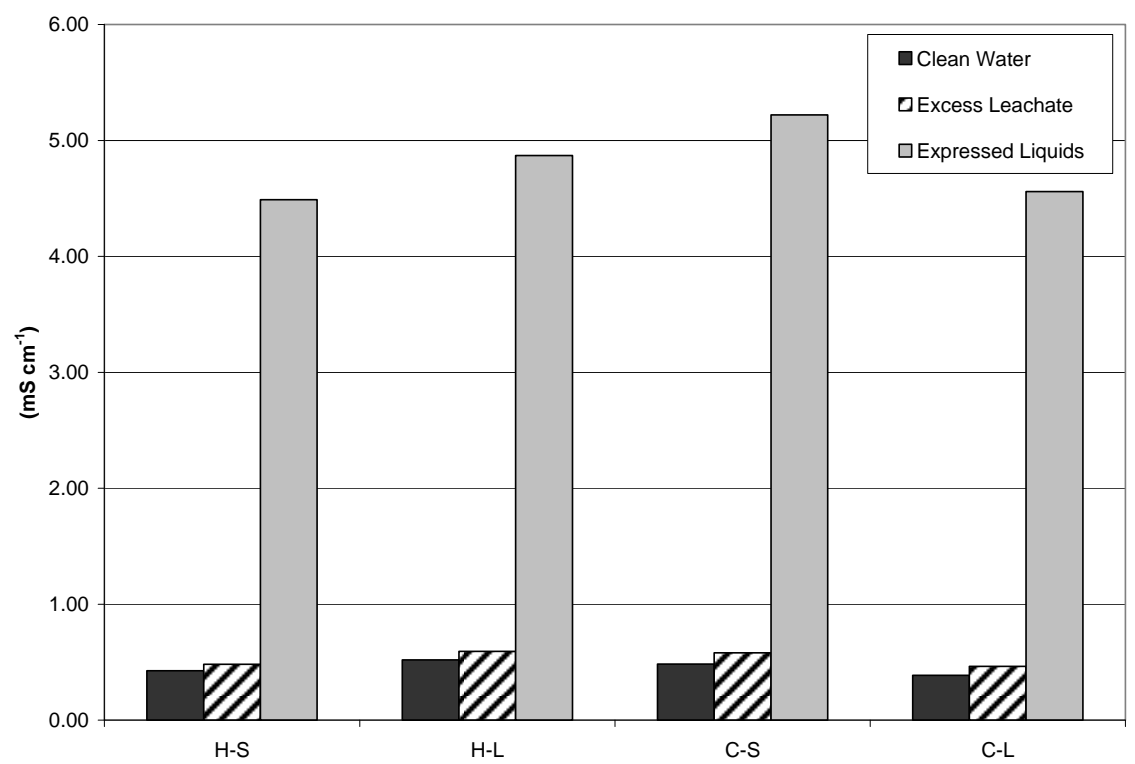

Figure 4.8.6: Electrical conductivity of liquids at three sampling points in cane trash treatment process during the pilot scale experiment.

\subsubsection{Total Suspended Solids in the Pilot Scale Experiment}

Both clean and leachate water samples were essentially free of dissolved solids. Table 4.8.3 shows the suspended solids in the soil/mud laden samples of liquids expressed by milling. The table provides an indication of the variability in samples. Despite the short sampling duration of 2-3 hours, the four samples contain a wide range of suspended solids from approximately 58,000 to $185,000 \mathrm{mg} / \mathrm{liter}$.

Table 4.8.3: Total suspended solids of expressed liquids from the treatments in the pilot scale experiment.

\begin{tabular}{c|c} 
Sample ID & $\begin{array}{c}\text { Suspended Solids } \\
(\mathbf{m g} / \mathbf{L})\end{array}$ \\
\hline H-S & 64,981 \\
H-L & 107,733 \\
C-S & 184,702 \\
C-L & 57,991
\end{tabular}

\subsubsection{Wastewater Analysis in the Pilot Scale Experiment}

Biological and chemical oxygen demands ( $\mathrm{BOD}_{5}$ and $\mathrm{COD}$, respectively) were measured to investigate the quality of the potential wastewater from the leaching process. Similar to the analysis of suspended solids, the $\mathrm{BOD}_{5}$ and $\mathrm{COD}$ of clean water is too low 
to be measured and was omitted from the analysis. Table 4.8 .4 shows the $\mathrm{BOD}_{5}$ and COD of the excess and expressed samples.

Table 4.8.4: Biological $\left(\mathrm{BOD}_{5}\right)$ and chemical (COD) oxygen demand of wastewater streams for cane trash processing in the pilot scale experiment.

\begin{tabular}{|c|c|c|c|c|}
\hline \multirow{3}{*}{ Sample ID } & \multicolumn{2}{|c|}{$\mathrm{BOD}_{5}$} & \multicolumn{2}{|c|}{ COD } \\
\hline & $\begin{array}{c}\text { Excess } \\
\text { Leachate }\end{array}$ & $\begin{array}{l}\text { Expressed } \\
\text { Liquids }\end{array}$ & $\begin{array}{l}\text { Excess } \\
\text { Leachate }\end{array}$ & $\begin{array}{l}\text { Expressed } \\
\text { Liquids }\end{array}$ \\
\hline & \multicolumn{2}{|c|}{ (mg/L) } & \multicolumn{2}{|c|}{ (mg/L) } \\
\hline $\mathrm{H}-\mathrm{S}$ & 103 & 24,470 & 229 & 34,267 \\
\hline H-L & 42 & 16,870 & 98 & 23,333 \\
\hline C-S & 82 & 21,930 & 186 & 34,000 \\
\hline C-L & 32 & 24,730 & 106 & 37,733 \\
\hline
\end{tabular}

For the purposes of comparison, the Hawaii State Department of Health requires that treated water have a $\mathrm{BOD}_{5}$ of no more than $30 \mathrm{mg} / \mathrm{L}$ based on composite sampling and $60 \mathrm{mg} / \mathrm{L}$ for a grab sample [15]. Process water from Puunene Mill is used in an irrigation system for the surrounding sugar cane fields and is thereby classified as recycled water, for which no limitations are prescribed. Clearly, the wastewater from the leaching and milling process contain high BOD and COD levels and would require treatment prior to usage for purposes other than irrigation. The high nutrient content may, however, be useful for replenishment of soil fertility.

\subsubsection{Fermentable Sugars Content of Leachate and Expressed Liquids from the Pilot Scale Experiment}

The leachate and expressed liquids from each of the treatments was analyzed for fermentable sugars, sucrose, glucose, and fructose, using high performance liquid chromatography and a refractive index detector. Results of the analysis are presented in Table 4.8.5. Fermentable sugars in the leachate streams from all treatments were below the limit of detection for the measurement, 0.0005\%. Expressed liquids contained total sugars at concentrations ranging from 2.25 to $3.73 \%$ by volume. Sucrose was present in greatest concentration for three of the four treatments with the remaining sugar content split roughly evenly between glucose and fructose. The Cold-Short treatment was the exception, containing very little sucrose but roughly equal amounts of glucose and 
fructose at $1 \%$ concentrations. Fermentable sugars concentrations of the liquid streams to assess their potential for use as a substrate for ethanol production however these sugar levels are deemed uneconomic for this purpose.

Table 4.8.5: Fermentable sugars concentrations in the leachate and expressed liquid streams from cane trash processing in the pilot scale experiment.

\begin{tabular}{|c|c|c|c|c|c|}
\hline Treatment & $\begin{array}{l}\text { Liquid } \\
\text { Stream }\end{array}$ & $\begin{array}{c}\text { Sucrose } \\
\text { content } \\
\text { (\%by vol.) }\end{array}$ & $\begin{array}{c}\text { Glucose } \\
\text { content } \\
\text { (\% by vol.) }\end{array}$ & $\begin{array}{l}\text { Fructose } \\
\text { content } \\
\text { (\% by vol.) }\end{array}$ & $\begin{array}{c}\text { Total Sugar } \\
\text { Content } \\
\text { (\%by vol.) }\end{array}$ \\
\hline Hot-Short & leachate & $<$ L.O.D. $^{1}$ & <L.O.D. ${ }^{1}$ & <L.O.D. ${ }^{1}$ & $<$ L.O.D. $^{1}$ \\
\hline Hot-Short & expressed liq. & 1.76 & 0.68 & 0.60 & 3.04 \\
\hline Hot-Long & leachate & $<$ L.O.D. $^{1}$ & <L.O.D. ${ }^{1}$ & <L.O.D. ${ }^{1}$ & <L.O.D. ${ }^{1}$ \\
\hline Hot-Long & expressed liq. & 1.74 & 0.65 & 0.52 & 2.91 \\
\hline Cold-Short & leachate & $<$ L.O.D. $^{1}$ & LL.O.D. $^{1}$ & $<$ L.O.D. $^{1}$ & $<$ L.O.D. $^{1}$ \\
\hline Cold-Short & expressed liq. & 0.14 & 1.09 & 1.02 & 2.25 \\
\hline Cold-Long & leachate & $<$ L.O.D. $^{1}$ & <L.O.D. ${ }^{1}$ & $<$ L.O.D. $^{1}$ & $<$ L.O.D. $^{1}$ \\
\hline Cold-Long & expressed liq. & 1.91 & 0.96 & 0.86 & 3.73 \\
\hline \multicolumn{6}{|c|}{${ }^{1}$ Limit of Detection $=0.0005 \%$} \\
\hline
\end{tabular}

\subsubsection{Characterization of Fuel Samples from the Pilot Scale Experiment}

The complete results from the fuel characterization are available in Table 4.8.1 as well as in Table C.6 in Subappendix C. Much of the data has been analyzed in section 4.8.1. Table 4.8.6 shows the ash fusion temperatures in the treated cane trash samples. The ash composition can greatly impact the melting temperatures [16]. Dayton et al. showed that in a pure $\mathrm{K}_{2} \mathrm{O}-\mathrm{SiO}_{2}-\mathrm{CaO}$ model system, melting temperatures dropped unexpectedly at intermediate concentrations of the three ash constituents. In other words, melting temperature did not follow a linear or exponential curve as ash concentrations were varied. Since the ash in the cane trash investigation consists primarily of soil oxides $\left(\mathrm{SiO}_{2}-\mathrm{Al}_{2} \mathrm{O} 3-\mathrm{Fe}_{2} \mathrm{O}_{3}\right)$, the pure $\mathrm{K}_{2} \mathrm{O}-\mathrm{SiO}_{2}-\mathrm{CaO}$ system is not applicable the data in Table 4.8.6 cannot be said to lie within a depression as described by Dayton et al. The melting temperatures, however, are considerably lower than those observed in the laboratory scale tests. In the laboratory scale tests, the ash consists primarily of $\mathrm{K}_{2} \mathrm{O}, \mathrm{SiO}_{2}$ and $\mathrm{CaO}$. Thus, it can be concluded that the inclusion of soil contaminants in treated sugar cane 
trash, as seen in the pilot scale tests, contributed to a critical reduction in ash fusion temperatures and subsequently an increased potential to produce slag in thermochemical conversion devices such as boilers or gasifiers.

Table 4.8.6: Ash fusion temperatures of the treated fuel samples.

\begin{tabular}{l|cccc} 
Treatment: & H-S & H-L & C-S & C-L \\
\hline Oxidizing Atmosphere $\left({ }^{\circ} \mathrm{C}\right)$ & & & \\
\hline Initial & 1217 & 1239 & 1251 & 1244 \\
Softening & 1249 & 1248 & 1266 & 1261 \\
Hemispherical & 1260 & 1272 & 1298 & 1277 \\
Fluid & 1277 & 1279 & 1312 & 1303 \\
Reducing Atmosphere ( $\left.{ }^{\circ} \mathrm{C}\right)$ & & & \\
\hline Initial & 1234 & 1239 & 1231 & 1257 \\
Softening & 1244 & 1247 & 1243 & 1265 \\
Hemispherical & 1251 & 1264 & 1249 & 1279 \\
Fluid & 1260 & 1272 & 1266 & 1308
\end{tabular}

Heating values reported in Table 4.8.1 are in the range of 11.12 to $14.23 \mathrm{MJ} / \mathrm{kg}$, considerably lower than the $18 \mathrm{MJ} / \mathrm{kg}$ that is normal for bagasse. Conversion of the current boilers to operate with such a low quality fuel would require a much higher feedrate to meet operational requirements of the system.

\subsubsection{Slagging and Fouling Probability}

In the pilot scale experiments, the treatments appear to reduce the probability for slagging and fouling when considering the total alkali concentrations. Increasing treatment severity has previously been found to progressively reduce the total alkali concentration per energy unit in other herbaceous fuels [10]. Figure 4.8.7 clearly shows no such correlation exists for these tests. All four treated cane trash samples lie outside of the normal range for boiler operation and are certain to result in excessive slagging and fouling of thermochemical energy conversion devices. The untreated slagging index was included in the figure for completeness, but as discussed above, it is not likely to be a true representation of the untreated cane trash material. 


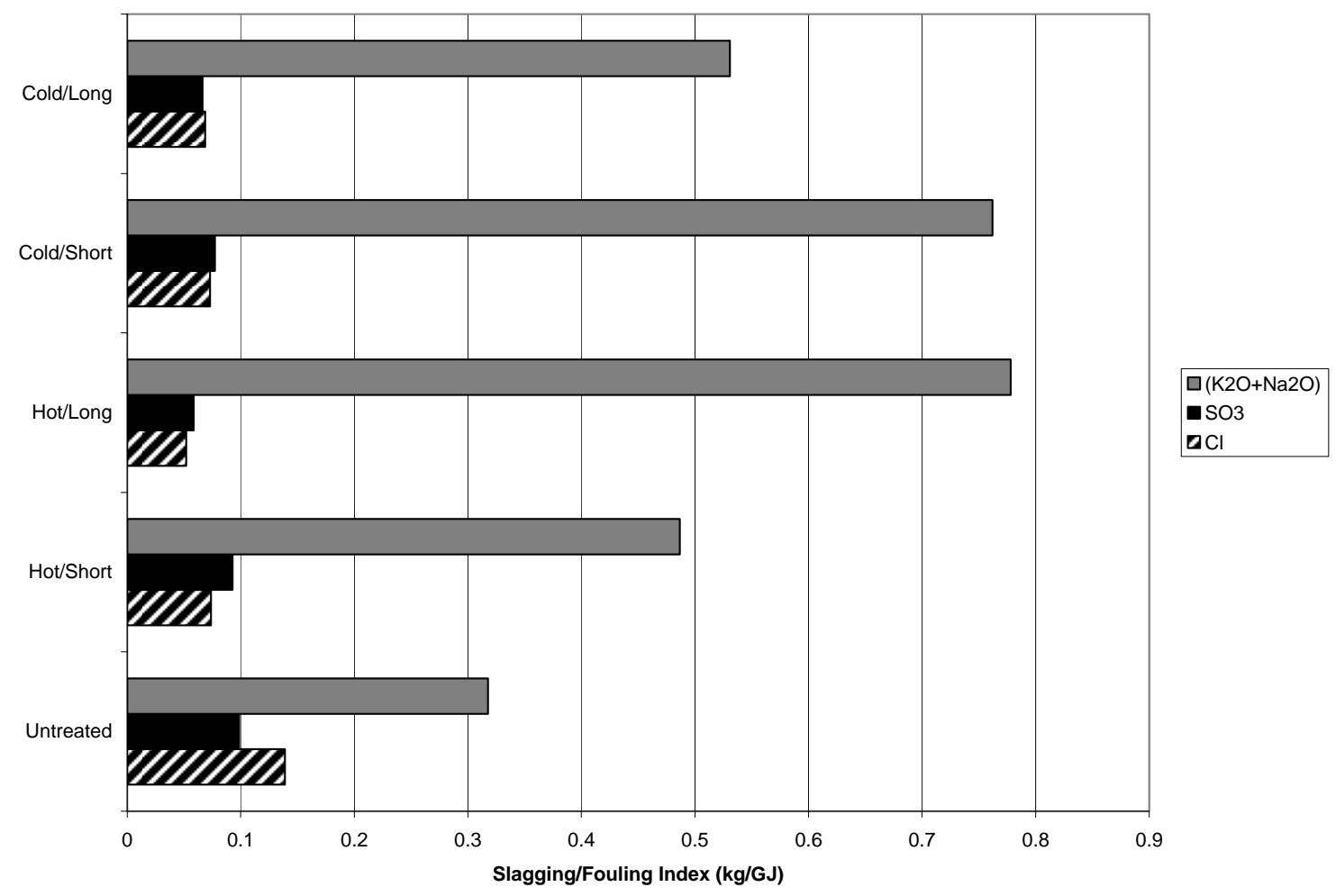

Figure 4.8.7: Concentrations of total alkali, $\mathrm{SO} 3$ and $\mathrm{Cl}$ on a unit energy basis for fuel samples from the pilot scale experiment.

\section{Summary and Conclusion}

\subsection{Summary}

Three experiments were designed, two at the laboratory scale and one at the pilot scale, using a $2^{3}$ factorial design to investigate the effects of water leaching as fuel preparation for the non-sugar bearing component of sugar cane called sugar cane trash.

Laboratory tests were carried out with hand-harvested cane trash from the island of Oahu. Trash components were separated during harvest, weighed and recombined in proportions relative to growth from a single seed piece. Before recombining the components, they were reduced in size using a Jeffco Cutter Grinder to $0.1 \mathrm{~cm}$ nominal length (pulverized) and using a paper cutter to $5 \mathrm{~cm}$ nominal length (chopped), representing approximately 50 times variation in particle size for the first test and $0.1 \mathrm{~cm}$ 
nominal length (pulverized) and $10 \mathrm{~cm}$ nominal length (chopped), representing approximately 100 times variation in particle size for the second test.

Roughly 400 g wet samples of each material were soaked in water, $25^{\circ} \mathrm{C}$ or $55^{\circ} \mathrm{C}$ for the first test, and $45^{\circ} \mathrm{C}$ or $75^{\circ} \mathrm{C}$ for the second test. Soak duration was 5 minutes or 60 minutes for the first test and 1 or 2.5 minutes for the second test. While soaking, samples were periodically agitated during the first test, and continuously agitated during the second test.

The leached cane trash samples were then dewatered using a hydraulic press. Material was transferred into a perforated cylinder and loaded to 9000 psi for approximately 30 seconds. Treatments were designated for temperature, particle size, and duration, for example, C-2"-5 reflects a treatment of cold water $\left(\sim 25^{\circ} \mathrm{C}\right), 2$ inch material, and 5 minute leaching duration..

Analysis included

1. on-site measurement of the electrical conductivity of the clean, tap water used for leaching, the excess post-leaching water, and the expressed liquids collected from the hydraulic press;

2. fuel characterization including moisture content, ultimate and proximate analysis, higher heating value, ash constituent analysis, water soluble alkali, total chlorine and ash fusion temperatures;

3. total suspended solids in the excess leachate and expressed liquids.

Material balances were determined and the balance of material across the experimental system was found to be within $3.1 \%$ on average with a standard deviation of $2 \%$ for the first set of experiments and within $2.1 \%$ on average with a standard deviation of $0.4 \%$ for the second set of treatments. Pulverized dry fiber closed to within $24.5 \%$ on average (4 tests) with a standard deviation of $3.1 \%$ for the first set of treatments and $14.2 \%$ on average ( 4 tests) with a standard deviation of $1.4 \%$ for the second set of treatments. The losses for the pulverised treatments were attributed to removal of water soluble alkalis and the loss of fiber adhered to processing equipment (mesh bags, hydraulic press, gloves, etc).

The mass balance on chopped dry fiber was closed to within $-2.4 \%$ on average with a standard deviation of $7.0 \%$ for the first set of treatments and $12.1 \%$ with a standard 
deviation of $10.8 \%$ for the second set of laboratory tests. The larger apparent losses for the chopped material seen in the second set of treatments is likely a function of variable moisture contents in the fiber samples. The larger particle size makes homogenization of the test lot difficult, the higher moisture content green leaves have a tendency to settle and bunch together producing variability even under careful sampling. All material balances were considered to be within experimental error.

Electrical conductivity (EC) results analyzed using the factorial design method show that particle size is the primary driver of EC changes. The 50 times reduction in particle size tested in the first set of experiments increased electrical conductivity in the leachwater by $2.17 \pm 0.030 \mathrm{mS} / \mathrm{cm}$. Electrical conductivity in the leachwater indicates a reduction in cane trash ion content. The effect of particle size reduction on electrical conductivity in the expressed liquids measured $-1.74 \pm 0.203 \mathrm{mS} / \mathrm{cm}$. The negative effect of particle size on EC value for expressed liquids is a reflection of the success of the initial leaching. If more ions are removed in the leaching step, fewer will remain to be removed in the milling step. This leads to lower EC values in express liquids for the small particle size and results in a negative value for particle size effect.

For the 100 times reduction in particle size tested in the second set of experiments the effect of particle size and duration can not be firmly delineated, although particle size is strongly indicated as the primary contributor. The 100 times reduction in particle size increased electrical conductivity in the leach water by $1.89 \pm 0.089 \mathrm{mS} / \mathrm{cm}$. The effect of particle size reduction on electrical conductivity in the expressed liquids measured $4.36 \pm 0.343 \mathrm{mS} / \mathrm{cm}$ The factorial design method shows that duration has an effect of $1.62 \pm 0.343 \mathrm{mS} / \mathrm{cm}$ and that there is an interaction effect between particle size and duration.

Fuel characterization showed the treated cane trash had a higher heating value consistent with bagasse at 17.07 to $18.32 \mathrm{MJ} / \mathrm{kg}$ for the first set of treatments and slightly less, 17.22 to $17.63 \mathrm{MJ} / \mathrm{kg}$ for the second set of treatments. No appreciable increase in heating value was noted as a result of the treatments in either set.

Ash composition showed a substantial reduction in concentration of soluble ions particularly $\mathrm{K}^{+}$and $\mathrm{Cl}^{-}$for both sets of treatments. While both the first and second set of treatments showed strong effects for particle size reduction, interaction between the 
variables tested make it impossible to isolate the effects of single variables other than particle size for potassium in the first test. A $55.66 \pm 3.18 \%$ reduction in potassium was attributed to the particle size reduction from $5 \mathrm{~cm}$ to $0.1 \mathrm{~cm}$.

Similar reduction in chlorine mass was also observed. However, reduction in chlorine was also found to be temperature sensitive at larger particle sizes. Further testing would be required to quantify $\mathrm{Cl}$ removal.

Ash fusion analysis showed all but two of the samples from the first set of treatments had melting points that exceeded the maximum measurable temperature of $1482^{\circ} \mathrm{C}$ and all ash samples were determined to be unlikely to cause slagging and fouling. For the second set of treatments all of the pulverized samples and the most severely treated chopped sample had melting points exceeding the maximum of $1482^{\circ} \mathrm{C}$.

Finally, a commonly used indicator of slagging and fouling involves calculating the concentration of total alkali and sulfur as oxides and chlorine on a unit energy basis. Values in the range of $0.17 \mathrm{~kg} / \mathrm{GJ}$ to $0.34 \mathrm{~kg} / \mathrm{GJ}$ are likely to cause slagging and fouling. Above $0.34 \mathrm{~kg} / \mathrm{GJ}$, the fuel is certain to cause slagging and fouling. All but one of the treated, chopped (2.5 or 4 inch) samples from both sets of treatments were found to lie above the $0.34 \mathrm{~kg} / \mathrm{GJ}$ threshold for total alkalis. The $+\mathrm{H}-4$ "-2.5 sample had a total alkali value of $0.328 \mathrm{~kg} / \mathrm{GJ}$, just under the $0.34 \mathrm{~kg} / \mathrm{GJ}$ limit.

Treated, pulverized samples for both sets of treatments were all below the 0.17 $\mathrm{kg} / \mathrm{GJ}$ limit for total alkalis, $\mathrm{SO}_{3}$ and $\mathrm{Cl}$. Comparing the alkali values per unit energy basis between the first and second sets of treatments, longer soak times appear to result in Therefore, it can be concluded that by reducing the particle size from $5 \mathrm{~cm}$ to $0.1 \mathrm{~cm}$ reduced the concentration of total alkali per energy unit by $0.388 \pm 0.002 \mathrm{~kg} / \mathrm{GJ}$, the concentration of $\mathrm{SO}_{3}$ per energy unit by $0.057 \pm 0.003 \mathrm{~kg} / \mathrm{GJ}$ and the concentration of $\mathrm{Cl}$ by $0.070 \pm 0.009 \mathrm{~kg} / \mathrm{GJ}$.

Pilot scale experiments were carried out at the HC\&S sugar mill site on Maui. Samples were machine harvested and separated during the cane cleaning process in the mill. Unburned sugar cane trash was extracted from a chain conveyor and included leaves, tops, and short cane pieces, too small for large scale milling. From the large samples, two cages were filled and weighed before being leached in a large tank of water. Particle size reduction could not be investigated due to equipment failure during the 
testing period. The original experimental design was thereby reduced to a $2^{2}$ factorial design in which water temperature and leaching duration were investigated as factors affecting cane trash treatments. Water temperatures of $25^{\circ} \mathrm{C}$ and $60^{\circ} \mathrm{C}$ were investigated as well as 1 and 10minute leaching durations. Treated cane trash was milled three times in a small Cuba mill to produce a moisture content consistent with current boiler operating experience.

In addition to the analysis carried out in the laboratory scale experiments, wastewater analysis, including biological and chemical oxygen demand $\left(\mathrm{BOD}_{5}\right.$ and COD), was added to quantify the quality of the wastewater exiting the treatment system for the pilot scale experiments. The overall mass balance on the experimental system was found to be closed to within $1.2 \%$ on average with a standard deviation of $0.8 \%$ for all four treatments. The dry fiber mass balance was closed to within $8.7 \%$ on average with a standard deviation of $18.6 \%$. The high standard deviation in the dry fiber balance was attributed to rocks and other debris that was removed from the material prior to milling.

Despite good mass balance closure for the complete system and the dry fiber, large and unexpected discrepancies were observed for ash input and output across the system. These discrepancies were attributed to collection of samples unrepresentative of the untreated cane trash material. Heavy rain resulted in substantial soil contamination which was not accurately portrayed in the sampling of the untreated material. Comparison of the untreated and treated samples was not possible due to the discrepancy and the treated samples were then considered independently.

Analysis of liquid samples taken during the experiments showed considerable leaching of water soluble alkalis had taken place, but also confirmed the level of soil contamination in the samples. $\mathrm{K}$ and $\mathrm{Cl}$ were found to be the elements most heavily leached from the samples. Fuel characterization showed the higher heating value of the treated samples to be well below that of bagasse ranging from 11.12 to $14.23 \mathrm{MJ} / \mathrm{kg}$. A reduced-scale Cuba mill was used to reduce the moisture in the samples to levels consistent with full scale milling in sugar factories. No variation in moisture removal was noted as a result of leaching treatments. 
Electrical conductivity measurements confirmed the effectiveness of leaching and showed the proportion of alkali removal was heavily weighted towards the milling process. Wastewater analysis showed the excess leachate and expressed liquids exceeded the Hawaii State Department of Health limits for treated water, but would be suitable for irrigation purposes and could be added to the irrigation system at HC\&S.

Reported ash fusion temperatures were much lower than those found in the laboratory scale experiments. The inclusion of excessive soil contaminants in the pilot scale tests resulted in a considerable decrease in ash fusion temperatures. Finally, the concentrations of total alkali per energy unit for the treated fuels were well above the $0.34 \mathrm{~kg} / \mathrm{GJ}$ threshold for slagging and fouling. Although $\mathrm{Cl}$ and $\mathrm{SO}_{3}$ are below the acceptable limits, the index does not account for interactions of those elements with the alkali in the system. The harvest conditions during the pilot scale tests were possibly the worst case that would be expected during the harvesting season. Further testing with a focus on particle size reduction would be required before definitive conclusions can be made regarding cane trash processing requirements at the pilot scale.

\subsection{Conclusions}

Particle size reduction of cane trash was found to improve the removal of potassium and chlorine by leaching compared to the other two variables, leaching duration and temperature. Hand harvested, leached cane trash with small particle size was found to have qualities very similar to bagasse and would likely make a suitable boiler fuel based on small scale testing.

The first set of laboratory scale tests conducted for leaching durations of 5 and 60 minutes showed no effect. Temperature was also shown to have little bearing on the successful leaching of alkali materials at the two test temperatures of 25 and $55^{\circ} \mathrm{C}$ with only chlorine concentration showing an effect. These results are not encouraging for the proposed commercial treatment procedures which have limited capacity to reduce particle size.

The parameters in the second set of experiments were selected, where possible, to mimic full scale conditions with short residence times and high temperature leach water. 
Proposed particle treatment for the commercial scale include no reduction (i.e. full size cane trash) to chopping to obtain 1 to 2 foot pieces. Lab scale equipment precluded handling material in these size classes.

Results from the second set of laboratory tests conducted for durations of 1 and 2.5 minutes show multiple interaction effects for almost all measures of successful fuel treatment. These results indicate that further work at the laboratory scale is needed to identify the ideal treatment conditions at the commercial scale.

Comparing the results of the two laboratory scale tests, particle size reduction is clearly the most important factor in successful leaching. However, at shorter time durations ( $<5 \mathrm{~min}$ ), interaction effects between temperature, duration and particle size arise. This would indicate that the commercial scale cleaning plant would need to operate with residence times greater than the preliminary 1 minute time period indicated by HC\&S personnel.

At the pilot scale, mechanical harvesting and poor field conditions can lead to soil contamination which will be a major issue surrounding cane trash processing. The simple leaching treatments at high temperature and long duration were not effective at removing soil contaminants and did not appreciably improve alkali leaching at the pilot scale. 


\section{Bibliography}

[1] Website for HC\&S: www.hcsugar.com/hcs.html, accessed on March 1, 2006

[2] Paes, L.A.D.; de Oliveira, M.A.; Potential Trash Biomass of the Sugar Cane Plant; Biomass Power Generation: Sugar Cane Bagasse and Trash, $1^{\text {st }}$ Edition, pg. 18-22; PNUD/CTC; 2005.

[3] Jenkins, B.M.; Turn, S.Q.; Williams, R.B.; Goronea, M.; Abd-el-Fattah, H.; Mehlschau, J.; Raubach, N.; Whalen, S.A; Chang, D.P.Y.; Kang, M.; Teague, S.V.; Raabe, O.G.; Campbell, D.E.; Cahill, T.A.; Pritchett, L.; Chow, J.; Jones, A.D.; Atmospheric pollutant emission factors from open burning of sugar cane by wind tunnel simulations; University California, Davis; 1995.

[4] Boyle, G.; Everett, B.; Ramage, J.; Energy Systems and Sustainability: Power for a Sustainable Future; Oxford University Press; 2003.

[5] Borman, Gary L.; Ragland Kenneth W., Combustion Engineering, McGraw-Hill International Editions, 1998

[6] Jenkins, B. M.; Bakker, R. R.; Wei, J. B. On the Properties of Washed Straw. Biomass and Bioenergy, 1996, 10(4), pg. 177-200.

[7] Miles, T.R.; Miles Jr. T.R.; Baxter, L.L.; Bryers, R.W.; Jenkins, B.M.; Oden, L.L.; Alkali Deposits Found in Biomass Power Plants, A Preliminary Investigation of Their Extent and Nature. Summary Report for the National Renewable Energy Laboratory. NREL Subcontract TZ-2-11226-1, 1995.

[8] Baxter, L.L.; Miles, T.R.; Miles Jr. T.R.; Jenkins, B.M.; Richards, G.H.; Oden, L.L; Transformation and Deposition of Inorganic Material in Biomass Boilers; In Second International Conference on Combustion Technologies for a Clean Environment, ed. M.G. Carvahlo. Pg. 9-15. Commission of the European Communities. Lisbon Portugal. 1993

[9] Kabata-Pendias, A; Trace Elements in Soils and Plants, Third Edition; CRC Press LLC, 2001 
[10] Turn, S.Q.; Kinoshita, C.M.; Jakeway, L.A.; Jenkins, B.M.; Baxter, L.L.; Wu, B.C.; Blevins, L.G.; Fuel Characteristics of Processed, High-fiber Sugarcane; Fuel Processing Technology, 81, pg. 35-55, 2003.

[11] Box, G.E.P.; Hunter, W.G.; Hunter, J.S.; Statistics for Experiments, An Introduction to Design, Data Analysis, and Model Building; John Wiley \& Sons, Inc., 1978

[12] Kinoshita, C.; Cogeneration in the Hawaiian Cane Sugar Industry; Hawaii Natural Energy Institute; HNEI 90-1002; 1990

[13] Turn, S.Q.; Kinoshita, C.M.; Ishimura, D.M.; Removal of Inorganic Constituents of Biomass Feedstocks By Mechanical Dewatering and Leaching; Biomass and Bioenergy, Vol. 12 No. 4, pg 241-252, Elsevier Science Ltd.; 1997

[14] Website for the Hawaii State Department of Health, http://www.hawaii.gov/health/environmental/about/rules/11-62.pdf , Accessed October 28, 2005.

[15] Dayton, D.C.; Jenkins, B.M.; Turn, S.Q.; Bakker, R.R.; Williams, R.B.; BelleOudry, D.; Hill, L.M.; Release of Inorganic Constituents from Leached Biomass during Thermal Conversion; Energy \& Fuels 13, 860-870, 1999. 
Subappendix A: Laboratory Scale Experiments I

Experimental Data and Calculations for Sugar Cane Trash Processing Investigation 
Table A.1: Details of the mass balance calculations for the laboratory scale experiments.

\begin{tabular}{|c|c|c|c|c|c|c|c|c|c|c|c|c|}
\hline \multirow{2}{*}{$\begin{array}{l}\text { Treatment } \\
\text { Description }\end{array}$} & \multicolumn{3}{|c|}{ H-JC-60 } & \multicolumn{3}{|c|}{ H-JC-5 } & \multicolumn{3}{|c|}{ H-2"-60 } & \multicolumn{3}{|c|}{ H-2"-5 } \\
\hline & 1-A & 1-B & 1-C & 2-A & 2-B & 2-C & 3-A & 3-B & 3-C & 4-A & 4-B & 4-C \\
\hline \multicolumn{13}{|l|}{ Overall System Mass Balance } \\
\hline Mass of Wet Cane Trash (g) & 418.7 & & 270.6 & 426.4 & & 253.3 & 403.5 & & 354.1 & 405.9 & & 368.2 \\
\hline Mass of Water (g) & 2940.7 & 2272.5 & 671.6 & 3024.8 & 2339.8 & 757.8 & 2961.3 & 2602.3 & 322.0 & 2857.2 & 2624.8 & 229.3 \\
\hline Overall Mass Balance $([B+C] / A)$ & & 0.957 & & & 0.971 & & & 0.974 & & & 0.987 & \\
\hline \multicolumn{13}{|l|}{ Dry Fiber Mass Balance } \\
\hline Mass of Dry Fiber (g) & 174.77 & & 130.73 & 177.98 & & 130.73 & 143.08 & & 150.94 & 143.93 & & 154.35 \\
\hline Suspended Solids (mg/L) & 0.00 & 5943.54 & 819.85 & 0.00 & 5239.43 & 1849.12 & 0.00 & 1116.31 & 4705.97 & 0.00 & 638.34 & 3707.91 \\
\hline Volume of Water (L) & 2.94 & 2.27 & 0.67 & 3.02 & 2.34 & 0.76 & 2.96 & 2.60 & 0.32 & 2.86 & 2.62 & 0.23 \\
\hline Mass of Sus. Solids in water (g) & 0.00 & 13.51 & 0.55 & 0.00 & 12.26 & 1.40 & 0.00 & 2.90 & 1.52 & 0.00 & 1.68 & 0.85 \\
\hline Dry Fiber Mass Balance (Out/In) & & 0.828 & & & 0.811 & & & 1.086 & & & 1.090 & \\
\hline \multicolumn{13}{|l|}{ Ash Mass Balance } \\
\hline Ash in Dry Fiber ( $g / g)$ & 0.11 & & 0.11 & 0.11 & & 0.10 & 0.12 & & 0.11 & 0.12 & & 0.11 \\
\hline Mass of Dry Fiber (g) & 174.77 & & 130.73 & 177.98 & & 130.73 & 143.08 & & 150.94 & 143.93 & & 154.35 \\
\hline Mass of Ash (g) & 18.65 & & 14.50 & 18.99 & & 12.48 & 17.06 & & 16.12 & 17.16 & & 16.48 \\
\hline Mass of Sus. Solids (Ash) (g) & 0.00 & 13.51 & 0.55 & 0.00 & 12.26 & 1.40 & 0.00 & 2.90 & 1.52 & 0.00 & 1.68 & 0.85 \\
\hline Mass of Ash in Sus. Solids (g) & & 1.50 & & & 1.17 & & & 0.31 & & & 0.18 & \\
\hline Ash Balance (Out/In) & & 0.887 & & & 0.793 & & & 1.052 & & & 1.021 & \\
\hline \multirow{2}{*}{$\begin{array}{l}\text { Treatment } \\
\text { Description }\end{array}$} & \multicolumn{3}{|c|}{ C-JC-60 } & \multicolumn{3}{|c|}{ C-JC-5 } & \multicolumn{3}{|c|}{ C-2"-60 } & \multicolumn{3}{|c|}{ C-2"-5 } \\
\hline & 5-AS & 5-B & $5-C$ & 6-AS & 6-B & 6-C & 7-AS & 7-B & 7-C & 8-AS & 8-B & 8-C \\
\hline \multicolumn{13}{|l|}{ Overall System Mass Balance } \\
\hline Mass of Wet Cane Trash (g) & 417.8 & & 252.4 & 396.8 & & 237.0 & 415.6 & & 351.1 & 413.2 & & 356.7 \\
\hline Mass of Water (g) & 3036.0 & 2343.5 & 754.6 & 3026.6 & 2457.7 & 483.8 & 3010.2 & 2764.4 & 272.8 & 2982.8 & 2765.9 & 223.5 \\
\hline Overall Mass Balance $([B+C] / A)$ & & 0.970 & & & 0.928 & & & 0.989 & & & 0.985 & \\
\hline \multicolumn{13}{|l|}{ Dry Fiber Mass Balance } \\
\hline Mass of Dry Fiber (g) & 174.39 & & 126.58 & 165.62 & & 117.94 & 147.37 & & 136.58 & 146.52 & & 143.87 \\
\hline Suspended Solids (mg/L) & 0.00 & 4573.72 & 1145.89 & 0.00 & 4573.72 & 1145.89 & 0.00 & 745.90 & 629.65 & 0.00 & 460.73 & 3190.29 \\
\hline Volume of Water (L) & 3.04 & 2.34 & 0.75 & 3.03 & 2.46 & 0.48 & 3.01 & 2.76 & 0.27 & 2.98 & 2.77 & 0.22 \\
\hline Mass of Sus. Solids in water (g) & 0.00 & 10.72 & 0.86 & 0.00 & 11.24 & 0.55 & 0.00 & 2.06 & 0.17 & 0.00 & 1.27 & 0.71 \\
\hline $\begin{array}{l}\text { Dry Fiber Mass Balance (Out/ln) } \\
\text { Ash Mass Balance }\end{array}$ & & 0.792 & & & 0.783 & & & 0.942 & & & 0.995 & \\
\hline Ash in Dry Fiber (g/g) & 0.11 & & 0.09 & 0.11 & & 0.10 & 0.12 & & 0.09 & 0.12 & & 0.09 \\
\hline Mass of Dry Fiber (g) & 174.39 & & 126.58 & 165.62 & & 117.94 & 147.37 & & 136.58 & 146.52 & & 143.87 \\
\hline Mass of Ash $(\mathrm{g})$ & 18.61 & & 11.63 & 17.67 & 0.00 & 12.35 & 17.57 & 0.00 & 12.44 & 17.47 & 0.00 & 12.85 \\
\hline Mass of Sus. Solids (Ash) (g) & 0.00 & 10.72 & 0.86 & 0.00 & 11.24 & 0.55 & 0.00 & 2.06 & 0.17 & 0.00 & 1.27 & 0.71 \\
\hline Mass of Ash in Sus. Solids (g) & & 0.99 & & & 1.18 & & & 0.19 & & & 0.11 & \\
\hline Ash Balance (Out/ln) & & 0.725 & & & 0.797 & & & 0.835 & & & 0.849 & \\
\hline
\end{tabular}




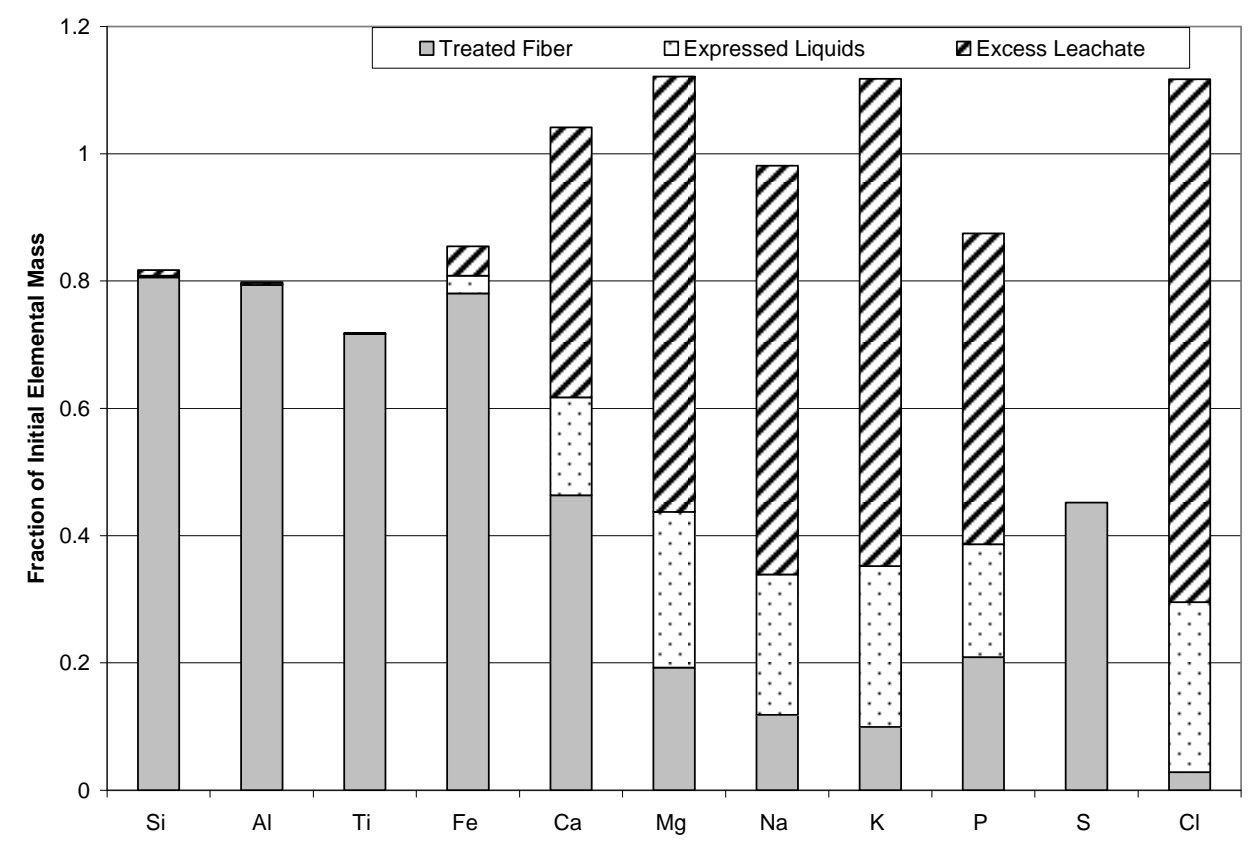

Figure A.1: Distribution of elements as a fraction of the initial mass for treatment H-JC-5 of the laboratory experiment.

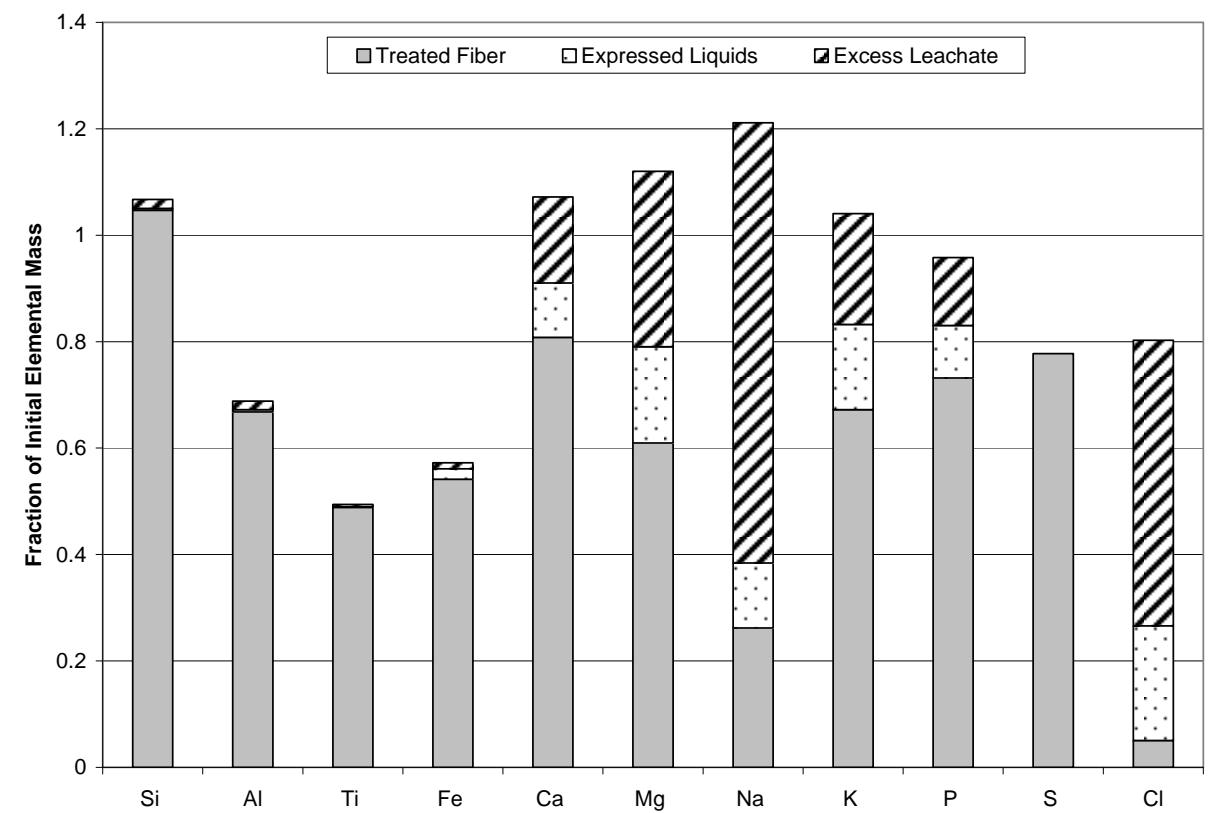

Figure A.2: Distribution of elements as a fraction of the initial mass for treatment $\mathrm{H}-2$ "-60 of the laboratory experiment. 


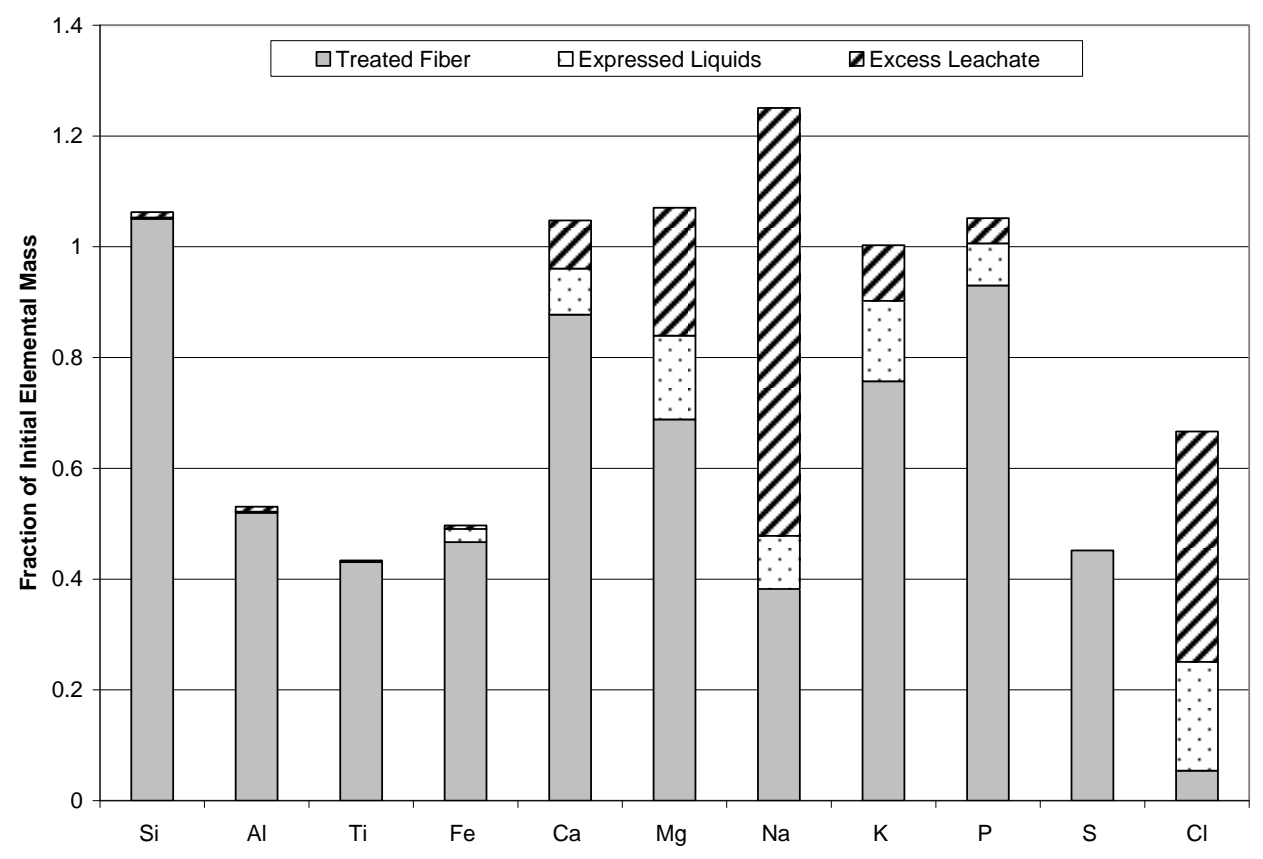

Figure A.3: Distribution of elements as a fraction of the initial mass for treatment H-2"-5 of the laboratory experiment.

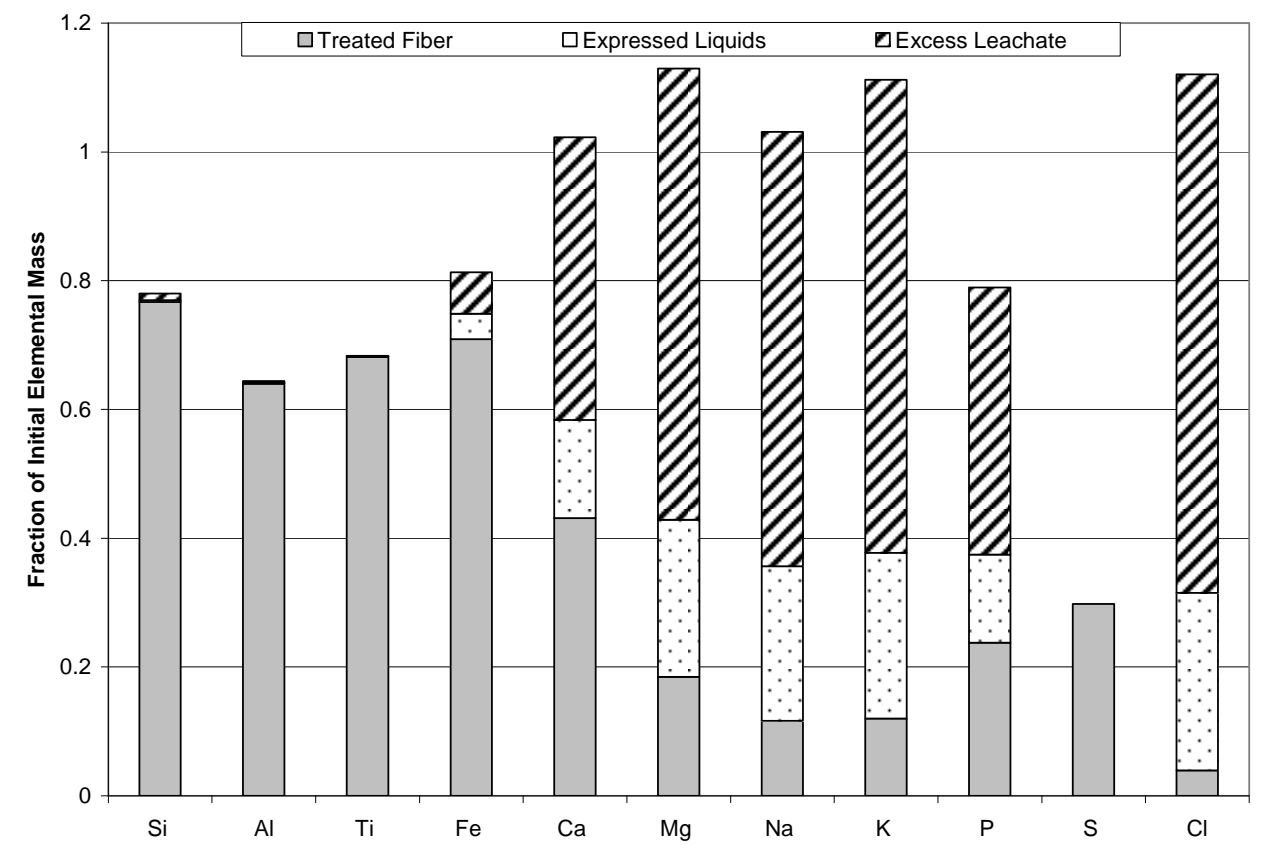

Figure A.4: Distribution of elements as a fraction of the initial mass for treatment C-JC-60 of the laboratory experiment. 


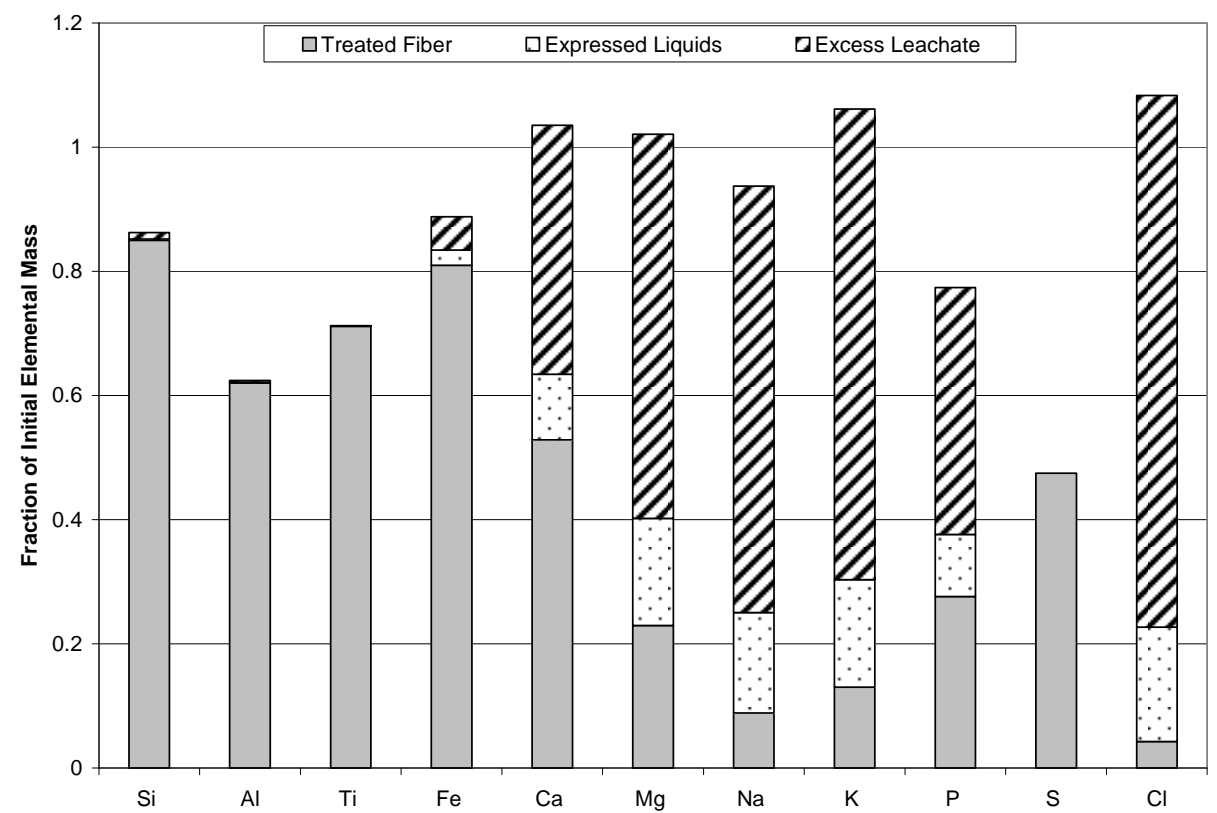

Figure A.5: Distribution of elements as a fraction of the initial mass for treatment C-JC-5 of the laboratory experiment.

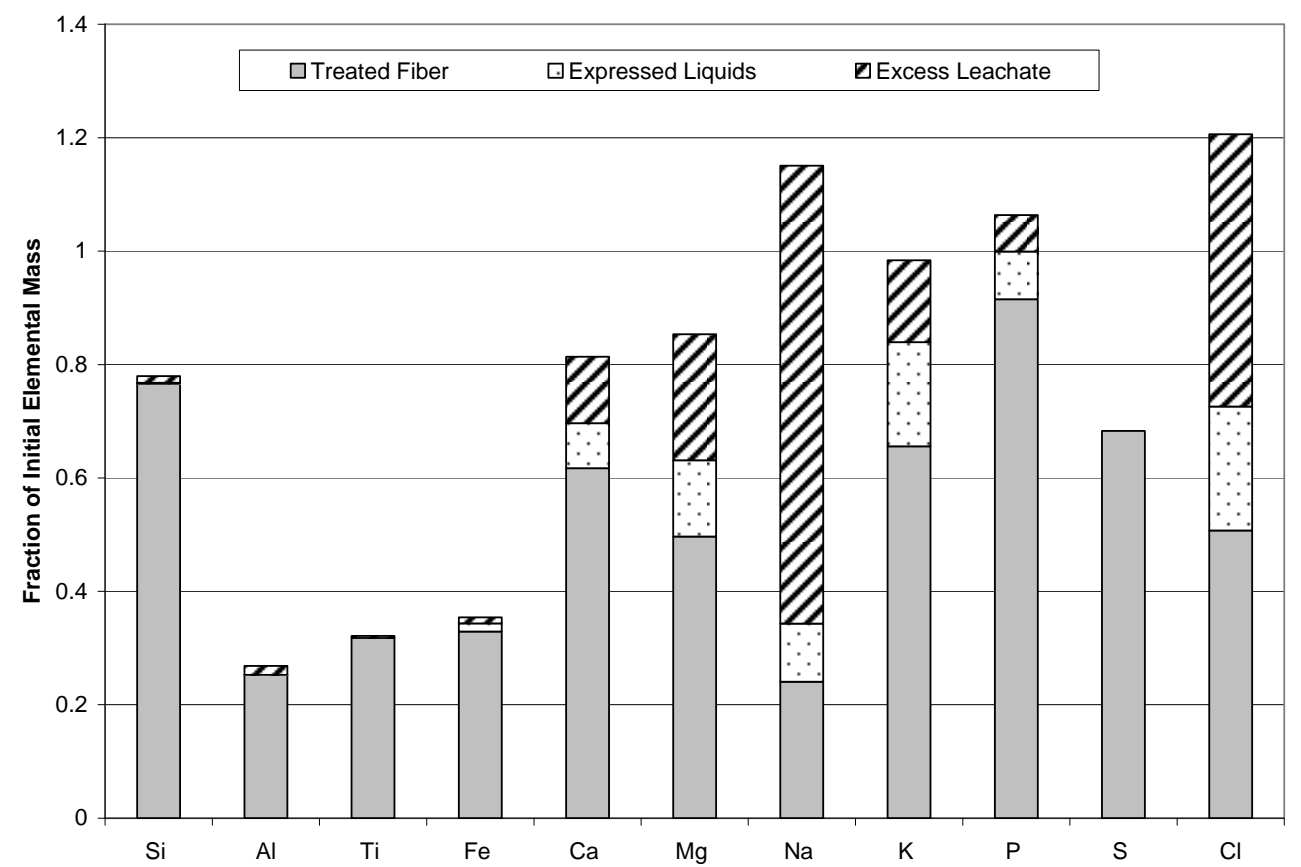

Figure A.6: Distribution of elements as a fraction of the initial mass for treatment C-2"-60 of the laboratory experiment. 
Table A.2: Element mass calculations from cane trash fiber treatments 1-4.

\begin{tabular}{|c|c|c|c|c|c|c|c|c|}
\hline \multirow{2}{*}{$\begin{array}{l}\text { Treatment } \\
\text { Description }\end{array}$} & \multicolumn{2}{|c|}{ H-JC-60 } & \multicolumn{2}{|c|}{ H-JC-5 } & \multicolumn{2}{|c|}{ H-2"-60 } & \multicolumn{2}{|c|}{ H-2"-5 } \\
\hline & 1-Before & 1-After & 2-Before & 2-After & 3-Before & 3-After & 4-Before & 4-After \\
\hline \multicolumn{9}{|c|}{ Elemental Mass Balance } \\
\hline Mass of Dry Fiber (g) & 174.77 & 130.73 & 177.98 & 130.73 & 143.08 & 150.94 & 143.93 & 154.35 \\
\hline Ash in Dry Fiber $(\mathrm{g} / \mathrm{g})$ & 0.1067 & 0.11 & 0.1067 & 0.10 & 0.12 & 0.11 & 0.12 & 0.11 \\
\hline \multicolumn{9}{|c|}{ Element Mass in Ash $(\mathrm{g} / \mathrm{g})$} \\
\hline $\mathrm{Si}$ & 0.306 & 0.3621 & 0.306 & 0.3786 & 0.3137 & 0.3502 & 0.3137 & 0.3456 \\
\hline $\mathrm{Al}$ & 0.013 & 0.0297 & 0.013 & 0.0160 & 0.0108 & 0.0077 & 0.0108 & 0.0059 \\
\hline $\mathrm{Ti}$ & 0.002 & 0.0026 & 0.002 & 0.0018 & 0.0017 & 0.0009 & 0.0017 & 0.0008 \\
\hline $\mathrm{Fe}$ & 0.014 & 0.0208 & 0.014 & 0.0170 & 0.0128 & 0.0073 & 0.0128 & 0.0062 \\
\hline $\mathrm{Ca}$ & 0.054 & 0.0399 & 0.054 & 0.0399 & 0.0465 & 0.0417 & 0.0465 & 0.0444 \\
\hline $\mathrm{Mg}$ & 0.020 & 0.0073 & 0.020 & 0.0069 & 0.0176 & 0.0145 & 0.0176 & 0.0162 \\
\hline $\mathrm{Na}$ & 0.005 & 0.0061 & 0.005 & 0.0020 & 0.0037 & 0.0030 & 0.0037 & 0.0042 \\
\hline $\mathrm{K}$ & 0.074 & 0.0135 & 0.074 & 0.0113 & 0.0787 & 0.0565 & 0.0787 & 0.0625 \\
\hline $\mathrm{P}$ & 0.008 & 0.0023 & 0.008 & 0.0027 & 0.0083 & 0.0065 & 0.0083 & 0.0081 \\
\hline $\mathrm{S}$ & 0.012 & 0.0028 & 0.012 & 0.0034 & 0.0085 & 0.0053 & 0.0085 & 0.0072 \\
\hline $\mathrm{Cl}$ & 0.004 & 0.0003 & 0.004 & 0.0002 & 0.0037 & 0.0003 & 0.0037 & 0.0003 \\
\hline \multicolumn{9}{|c|}{ Element Mass in Fiber (g) } \\
\hline $\mathrm{Si}$ & 5.712 & 5.2500 & 5.818 & 4.7264 & 5.3511 & 5.6449 & 5.3829 & 5.6969 \\
\hline $\mathrm{Al}$ & 0.247 & 0.4305 & 0.251 & 0.1995 & 0.1850 & 0.1237 & 0.1861 & 0.0968 \\
\hline $\mathrm{Ti}$ & 0.031 & 0.0374 & 0.031 & 0.0225 & 0.0297 & 0.0145 & 0.0298 & 0.0128 \\
\hline $\mathrm{Fe}$ & 0.267 & 0.3012 & 0.272 & 0.2122 & 0.2183 & 0.1184 & 0.2196 & 0.1026 \\
\hline $\mathrm{Ca}$ & 1.007 & 0.5782 & 1.025 & 0.4979 & 0.7923 & 0.6717 & 0.7970 & 0.7317 \\
\hline $\mathrm{Mg}$ & 0.375 & 0.1058 & 0.381 & 0.0858 & 0.2993 & 0.2333 & 0.3011 & 0.2665 \\
\hline $\mathrm{Na}$ & 0.084 & 0.0882 & 0.086 & 0.0250 & 0.0633 & 0.0478 & 0.0636 & 0.0685 \\
\hline $\mathrm{K}$ & 1.378 & 0.1962 & 1.403 & 0.1410 & 1.3422 & 0.9100 & 1.3502 & 1.0305 \\
\hline$P$ & 0.158 & 0.0329 & 0.161 & 0.0338 & 0.1422 & 0.1041 & 0.1430 & 0.1331 \\
\hline $\mathrm{S}$ & 0.341 & 0.0784 & 0.347 & 0.1569 & 0.2719 & 0.2113 & 0.2735 & 0.1235 \\
\hline $\mathrm{Cl}$ & 0.753 & 0.0327 & 0.767 & 0.0301 & 0.5280 & 0.0408 & 0.5311 & 0.0432 \\
\hline
\end{tabular}


Table A.3: Element mass calculations from cane trash fiber treatments 5-8.

\begin{tabular}{|c|c|c|c|c|c|c|c|c|}
\hline \multirow{2}{*}{$\begin{array}{l}\text { Treatment ID: } \\
\text { Sample } \\
\text { Point: }\end{array}$} & \multicolumn{2}{|c|}{ C-JC-60 } & \multicolumn{2}{|c|}{ C-JC-5 } & \multicolumn{2}{|c|}{ C-2"-60 } & \multicolumn{2}{|c|}{ C-2"-5 } \\
\hline & 5-Before & 5-After & 6-Before & 6-After & 7-Before & 7-After & 8-Before & 8-After \\
\hline $\begin{array}{l}\text { Elemental Mass Balance } \\
\text { Mass of Dry Fiber }(\mathrm{g}) \\
\text { Ash in Dry Fiber } \\
(\mathrm{g} / \mathrm{g}) \\
\text { Element Mass in Ash }(\mathbf{g} / \mathbf{g})\end{array}$ & $\begin{array}{l}174.39 \\
0.1067\end{array}$ & $\begin{array}{r}126.58 \\
0.09\end{array}$ & $\begin{array}{l}165.62 \\
0.1067\end{array}$ & $\begin{array}{r}117.94 \\
0.10\end{array}$ & 147.37 & $\begin{array}{r}136.58 \\
0.09\end{array}$ & $\begin{array}{r}146.52 \\
0.12\end{array}$ & $\begin{array}{r}143.87 \\
0.09\end{array}$ \\
\hline $\begin{array}{l}\mathrm{Si} \\
\mathrm{Al}\end{array}$ & $\begin{array}{l}0.306 \\
0.013\end{array}$ & $\begin{array}{l}0.380 \\
0.014\end{array}$ & $\begin{array}{l}0.306 \\
0.013\end{array}$ & $\begin{array}{l}0.377 \\
0.012\end{array}$ & $\begin{array}{l}0.314 \\
0.011\end{array}$ & $\begin{array}{l}0.343 \\
0.004\end{array}$ & $\begin{array}{l}0.314 \\
0.011\end{array}$ & $\begin{array}{l}0.337 \\
0.007\end{array}$ \\
\hline $\mathrm{Ti}$ & 0.002 & 0.002 & 0.002 & 0.002 & 0.002 & 0.001 & 0.002 & 0.001 \\
\hline $\mathrm{Fe}$ & 0.014 & 0.016 & 0.014 & 0.017 & 0.013 & 0.006 & 0.013 & 0.008 \\
\hline $\mathrm{Ca}$ & 0.054 & 0.039 & 0.054 & 0.043 & 0.046 & 0.043 & 0.046 & 0.044 \\
\hline $\mathrm{Mg}$ & 0.020 & 0.007 & 0.020 & 0.007 & 0.018 & 0.014 & 0.018 & 0.015 \\
\hline $\mathrm{Na}$ & 0.005 & 0.002 & 0.005 & 0.001 & 0.004 & 0.003 & 0.004 & 0.006 \\
\hline K & 0.074 & 0.014 & 0.074 & 0.014 & 0.079 & 0.073 & 0.079 & 0.072 \\
\hline$P$ & 0.008 & 0.003 & 0.008 & 0.003 & 0.008 & 0.011 & 0.008 & 0.009 \\
\hline $\mathrm{S}$ & 0.012 & 0.003 & 0.012 & 0.004 & 0.008 & 0.008 & 0.008 & 0.007 \\
\hline $\mathrm{Cl}$ & 0.004 & 0.000 & 0.004 & 0.000 & 0.004 & 0.003 & 0.004 & 0.003 \\
\hline \multicolumn{9}{|l|}{ Element Mass in Fiber (g) } \\
\hline $\mathrm{Si}$ & 5.700 & 4.415 & 5.414 & 4.651 & 5.512 & 4.267 & 5.480 & 4.326 \\
\hline $\mathrm{Al}$ & 0.246 & 0.158 & 0.234 & 0.145 & 0.191 & 0.048 & 0.189 & 0.094 \\
\hline $\mathrm{Ti}$ & 0.031 & 0.021 & 0.029 & 0.021 & 0.031 & 0.010 & 0.030 & 0.013 \\
\hline $\mathrm{Fe}$ & 0.266 & 0.189 & 0.253 & 0.205 & 0.225 & 0.074 & 0.224 & 0.097 \\
\hline $\mathrm{Ca}$ & 1.005 & 0.452 & 0.954 & 0.528 & 0.816 & 0.531 & 0.811 & 0.561 \\
\hline $\mathrm{Mg}$ & 0.374 & 0.077 & 0.355 & 0.092 & 0.308 & 0.175 & 0.307 & 0.190 \\
\hline $\mathrm{Na}$ & 0.084 & 0.023 & 0.080 & 0.017 & 0.065 & 0.043 & 0.065 & 0.071 \\
\hline K & 1.375 & 0.166 & 1.306 & 0.171 & 1.382 & 0.913 & 1.375 & 0.930 \\
\hline$P$ & 0.158 & 0.038 & 0.150 & 0.041 & 0.146 & 0.134 & 0.146 & 0.112 \\
\hline $\mathrm{S}$ & 0.340 & 0.101 & 0.323 & 0.153 & 0.280 & 0.191 & 0.278 & 0.345 \\
\hline $\mathrm{Cl}$ & 0.752 & 0.039 & 0.714 & 0.041 & 0.544 & 0.402 & 0.541 & 0.397 \\
\hline
\end{tabular}


Table A.4: Element mass calculations based on ICP-MS analysis for laboratory scale treatments 1-4.

\begin{tabular}{|c|c|c|c|c|c|c|c|c|c|c|c|c|}
\hline \multirow{2}{*}{$\begin{array}{l}\text { Treatment } \\
\text { ID: } \\
\text { Sample } \\
\text { Point: }\end{array}$} & \multicolumn{3}{|c|}{1 (Hot/Long/Pulverized) } & \multicolumn{3}{|c|}{2 (Hot/Short/Pulverized) } & \multicolumn{3}{|c|}{3 (Hot/Long/Chopped) } & \multicolumn{3}{|c|}{4 (Hot/Short/Chopped) } \\
\hline & A & B & C & A & B & C & A & B & C & A & B & C \\
\hline $\begin{array}{l}\text { Mass of } \\
\text { Water (g) }\end{array}$ & 2940.70 & 2272.50 & 671.60 & 3024.80 & 2339.80 & 757.80 & 2961.30 & 2602.30 & 322.00 & 2857.20 & 2624.80 & 229.30 \\
\hline $\begin{array}{l}\text { Density of } \\
\text { Liquid } \\
\text { (kg/L) }\end{array}$ & 1.000 & 1.000 & 1.008 & 1.000 & 1.001 & 1.008 & 1.000 & 1.000 & 0.999 & 1.000 & 1.000 & 0.994 \\
\hline $\begin{array}{l}\text { Volume of } \\
\text { Water (L) }\end{array}$ & 2.941 & 2.273 & 0.666 & 3.025 & 2.338 & 0.752 & 2.961 & 2.602 & 0.322 & 2.857 & 2.625 & 0.231 \\
\hline \multicolumn{13}{|c|}{ Element Concentrations (mg/L) } \\
\hline Si & 16.93 & 27.80 & 29.02 & 16.46 & 21.88 & 22.88 & 13.80 & 35.15 & 59.19 & 13.71 & 20.26 & 51.89 \\
\hline Al & 0.01 & 0.42 & 0.61 & 0.04 & 0.35 & 0.46 & 0.04 & 1.14 & 2.45 & 0.04 & 0.63 & 1.44 \\
\hline $\mathrm{Ti}$ & 0.00 & 0.01 & 0.01 & 0.00 & 0.01 & 0.01 & 0.00 & 0.05 & 0.09 & 0.00 & 0.03 & 0.08 \\
\hline $\mathrm{Fe}$ & 0.04 & 3.18 & 12.85 & 0.05 & 5.39 & 9.98 & 0.12 & 0.94 & 13.22 & 0.09 & 0.55 & 22.56 \\
\hline $\mathrm{Ca}$ & 14.97 & 222.60 & 220.20 & 16.04 & 194.80 & 219.80 & 13.22 & 51.67 & 264.20 & 12.80 & 27.66 & 299.30 \\
\hline $\mathrm{Mg}$ & 19.78 & 145.20 & 144.20 & 21.13 & 130.30 & 144.70 & 28.16 & 48.45 & 214.90 & 30.14 & 34.04 & 254.30 \\
\hline $\mathrm{Na}$ & 40.35 & 59.46 & 63.29 & 41.47 & 58.10 & 62.02 & 40.30 & 58.02 & 69.24 & 40.46 & 52.74 & 74.69 \\
\hline $\mathrm{K}$ & 3.70 & 505.20 & 492.00 & 4.49 & 463.80 & 476.40 & 3.97 & 108.20 & 673.80 & 3.78 & 52.14 & 856.00 \\
\hline $\mathbf{P}$ & 0.05 & 38.40 & 37.90 & 0.07 & 33.70 & 38.10 & 0.05 & 6.97 & 43.60 & 0.04 & 2.48 & 47.20 \\
\hline $\mathrm{S}$ & 0.00 & 0.00 & 0.00 & 0.00 & 0.00 & 0.00 & 0.00 & 0.00 & 0.00 & 0.00 & 0.00 & 0.00 \\
\hline $\mathrm{Cl}$ & 91.53 & 390.60 & 384.00 & 95.29 & 370.90 & 374.80 & 93.45 & 165.90 & 537.40 & 93.03 & 126.30 & 678.20 \\
\hline \multicolumn{13}{|c|}{ Element Mass in liquids (g) } \\
\hline Si & 0.050 & 0.063 & 0.019 & 0.050 & 0.051 & 0.017 & 0.041 & 0.091 & 0.019 & 0.039 & 0.053 & 0.012 \\
\hline Al & 0.000 & 0.001 & 0.000 & 0.000 & 0.001 & 0.000 & 0.000 & 0.003 & 0.001 & 0.000 & 0.002 & 0.000 \\
\hline $\mathrm{Ti}$ & 0.000 & 0.000 & 0.000 & 0.000 & 0.000 & 0.000 & 0.000 & 0.000 & 0.000 & 0.000 & 0.000 & 0.000 \\
\hline $\mathrm{Fe}$ & 0.000 & 0.007 & 0.009 & 0.000 & 0.013 & 0.008 & 0.000 & 0.002 & 0.004 & 0.000 & 0.001 & 0.005 \\
\hline $\mathrm{Ca}$ & 0.044 & 0.506 & 0.147 & 0.049 & 0.455 & 0.165 & 0.039 & 0.134 & 0.085 & 0.037 & 0.073 & 0.069 \\
\hline $\mathrm{Mg}$ & 0.058 & 0.330 & 0.096 & 0.064 & 0.305 & 0.109 & 0.083 & 0.126 & 0.069 & 0.086 & 0.089 & 0.059 \\
\hline $\mathrm{Na}$ & 0.119 & 0.135 & 0.042 & 0.125 & 0.136 & 0.047 & 0.119 & 0.151 & 0.022 & 0.116 & 0.138 & 0.017 \\
\hline $\mathrm{K}$ & 0.011 & 1.148 & 0.328 & 0.014 & 1.084 & 0.358 & 0.012 & 0.282 & 0.217 & 0.011 & 0.137 & 0.197 \\
\hline $\mathbf{P}$ & 0.000 & 0.087 & 0.025 & 0.000 & 0.079 & 0.029 & 0.000 & 0.018 & 0.014 & 0.000 & 0.007 & 0.011 \\
\hline $\mathrm{Cl}$ & 0.269 & 0.888 & 0.256 & 0.288 & 0.867 & 0.282 & 0.277 & 0.432 & 0.173 & 0.266 & 0.332 & 0.156 \\
\hline
\end{tabular}


Table A.5: Element mass calculations based on ICP-MS analysis for laboratory scale treatments 5-8.

\begin{tabular}{|c|c|c|c|c|c|c|c|c|c|c|c|c|}
\hline \multirow{2}{*}{$\begin{array}{l}\text { Treatment } \\
\text { ID: } \\
\text { Sample } \\
\text { Point: }\end{array}$} & \multicolumn{3}{|c|}{5 (Cold/Long/Pulverised) } & \multicolumn{3}{|c|}{6 (Cold/Short/Pulverised) } & \multicolumn{3}{|c|}{7 (Cold/Long/Chopped) } & \multicolumn{3}{|c|}{8 (Cold/Short/Chopped) } \\
\hline & A & B & C & A & B & C & A & B & C & A & B & C \\
\hline $\begin{array}{l}\text { Mass of } \\
\text { Water }(\mathrm{g})\end{array}$ & 3036.00 & 2343.50 & 754.60 & 3026.60 & 2457.70 & 483.80 & 3010.20 & 2764.40 & 272.80 & 2982.80 & 2765.90 & 223.50 \\
\hline $\begin{array}{l}\text { Density of } \\
\text { Liquid } \\
\text { (kg/L) }\end{array}$ & 1.000 & 1.000 & 0.971 & 1.000 & 0.996 & 0.979 & 1.000 & 1.000 & 0.984 & 1.000 & 1.000 & 1.000 \\
\hline $\begin{array}{l}\text { Volume of } \\
\text { Water (L) }\end{array}$ & 3.036 & 2.343 & 0.777 & 3.027 & 2.467 & 0.494 & 3.010 & 2.764 & 0.277 & 2.983 & 2.766 & 0.224 \\
\hline \multicolumn{13}{|c|}{ Element Concentrations (mg/L) } \\
\hline Si & 19.51 & 24.44 & 24.90 & 19.51 & 23.22 & 24.84 & 19.51 & 23.13 & 37.22 & 19.51 & 20.81 & 44.25 \\
\hline Al & 0.01 & 0.30 & 0.39 & 0.01 & 0.26 & 0.37 & 0.01 & 1.08 & 0.34 & 0.01 & 0.74 & 0.59 \\
\hline $\mathrm{Ti}$ & 0.00 & 0.01 & 0.01 & 0.00 & 0.01 & 0.01 & 0.00 & 0.04 & 0.01 & 0.00 & 0.03 & 0.02 \\
\hline $\mathrm{Fe}$ & 0.01 & 7.34 & 13.49 & 0.01 & 5.50 & 12.53 & 0.01 & 0.85 & 11.84 & 0.01 & 0.49 & 17.85 \\
\hline $\mathrm{Ca}$ & 14.66 & 196.70 & 205.90 & 14.66 & 162.30 & 213.70 & 14.66 & 36.42 & 246.20 & 14.66 & 25.99 & 293.80 \\
\hline $\mathrm{Mg}$ & 14.58 & 125.10 & 131.20 & 14.58 & 100.10 & 139.30 & 14.58 & 28.33 & 170.90 & 14.58 & 21.85 & 209.30 \\
\hline $\mathrm{Na}$ & 38.26 & 57.72 & 61.85 & 38.26 & 54.52 & 63.88 & 38.26 & 52.70 & 66.58 & 38.26 & 50.40 & 80.37 \\
\hline $\mathrm{K}$ & 3.38 & 434.30 & 458.70 & 3.38 & 404.30 & 462.20 & 3.38 & 72.70 & 923.60 & 3.38 & 39.05 & 1079.00 \\
\hline $\mathbf{P}$ & 0.04 & 28.00 & 27.80 & 0.04 & 24.20 & 30.30 & 0.04 & 3.41 & 44.50 & 0.04 & 1.97 & 57.00 \\
\hline$s$ & 0.00 & 0.00 & 0.00 & 0.00 & 0.00 & 0.00 & 0.00 & 0.00 & 0.00 & 0.00 & 0.00 & 0.00 \\
\hline $\mathrm{Cl}$ & 82.36 & 344.50 & 355.50 & 82.36 & 334.30 & 358.70 & 82.36 & 137.50 & 624.80 & 82.36 & 116.00 & 715.60 \\
\hline \multicolumn{13}{|c|}{ Element Mass in liquids (g) } \\
\hline Si & 0.059 & 0.057 & 0.019 & 0.059 & 0.057 & 0.012 & 0.059 & 0.064 & 0.010 & 0.058 & 0.058 & 0.010 \\
\hline $\mathrm{Al}$ & 0.000 & 0.001 & 0.000 & 0.000 & 0.001 & 0.000 & 0.000 & 0.003 & 0.000 & 0.000 & 0.002 & 0.000 \\
\hline $\mathrm{Ti}$ & 0.000 & 0.000 & 0.000 & 0.000 & 0.000 & 0.000 & 0.000 & 0.000 & 0.000 & 0.000 & 0.000 & 0.000 \\
\hline $\mathrm{Fe}$ & 0.000 & 0.017 & 0.010 & 0.000 & 0.014 & 0.006 & 0.000 & 0.002 & 0.003 & 0.000 & 0.001 & 0.004 \\
\hline $\mathrm{Ca}$ & 0.045 & 0.461 & 0.160 & 0.044 & 0.400 & 0.106 & 0.044 & 0.101 & 0.068 & 0.044 & 0.072 & 0.066 \\
\hline $\mathrm{Mg}$ & 0.044 & 0.293 & 0.102 & 0.044 & 0.247 & 0.069 & 0.044 & 0.078 & 0.047 & 0.043 & 0.060 & 0.047 \\
\hline $\mathrm{Na}$ & 0.116 & 0.135 & 0.048 & 0.116 & 0.135 & 0.032 & 0.115 & 0.146 & 0.018 & 0.114 & 0.139 & 0.018 \\
\hline $\mathrm{K}$ & 0.010 & 1.017 & 0.357 & 0.010 & 0.997 & 0.228 & 0.010 & 0.201 & 0.256 & 0.010 & 0.108 & 0.241 \\
\hline $\mathbf{P}$ & 0.000 & 0.066 & 0.022 & 0.000 & 0.060 & 0.015 & 0.000 & 0.009 & 0.012 & 0.000 & 0.005 & 0.013 \\
\hline $\mathrm{Cl}$ & 0.250 & 0.807 & 0.276 & 0.249 & 0.825 & 0.177 & 0.248 & 0.380 & 0.173 & 0.246 & 0.321 & 0.160 \\
\hline
\end{tabular}


Table A.6: Balance of element masses (out/in) for the laboratory scale treatments.

\begin{tabular}{c|r|r|r|r|r|r|r|r} 
ID & \multicolumn{1}{|c|}{$\mathbf{1}$} & \multicolumn{1}{|c|}{$\mathbf{2}$} & \multicolumn{1}{|c|}{$\mathbf{3}$} & \multicolumn{1}{|c|}{$\mathbf{4}$} & \multicolumn{1}{|c|}{$\mathbf{5}$} & \multicolumn{1}{|c|}{} & $\mathbf{7}$ & $\mathbf{8}$ \\
\hline Treatment & H-JC-60 & H-JC-5 & H-2"-60 & H-2"-5 & C-JC-60 & C-JC-5 & C-2"-60 & C-2"-5 \\
\hline Si & $92.54 \%$ & $81.72 \%$ & $106.74 \%$ & $106.27 \%$ & $77.98 \%$ & $86.26 \%$ & $77.93 \%$ & $79.33 \%$ \\
Al & $174.99 \%$ & $79.84 \%$ & $68.84 \%$ & $53.06 \%$ & $64.42 \%$ & $62.40 \%$ & $26.84 \%$ & $50.66 \%$ \\
Ti & $121.67 \%$ & $71.83 \%$ & $49.40 \%$ & $43.36 \%$ & $68.32 \%$ & $71.23 \%$ & $32.14 \%$ & $43.39 \%$ \\
Fe & $118.77 \%$ & $85.47 \%$ & $57.21 \%$ & $49.70 \%$ & $81.31 \%$ & $88.79 \%$ & $35.40 \%$ & $45.79 \%$ \\
Ca & $117.11 \%$ & $104.16 \%$ & $107.20 \%$ & $104.76 \%$ & $102.28 \%$ & $103.52 \%$ & $81.35 \%$ & $81.70 \%$ \\
Mg & $122.92 \%$ & $112.12 \%$ & $112.01 \%$ & $107.03 \%$ & $112.98 \%$ & $102.09 \%$ & $85.33 \%$ & $84.87 \%$ \\
Na & $130.76 \%$ & $98.15 \%$ & $121.10 \%$ & $125.05 \%$ & $103.11 \%$ & $93.72 \%$ & $115.08 \%$ & $127.92 \%$ \\
K & $120.41 \%$ & $111.78 \%$ & $104.05 \%$ & $100.28 \%$ & $111.19 \%$ & $106.16 \%$ & $98.38 \%$ & $92.39 \%$ \\
$\mathbf{P}$ & $91.79 \%$ & $87.50 \%$ & $95.78 \%$ & $105.14 \%$ & $78.94 \%$ & $77.38 \%$ & $106.36 \%$ & $89.45 \%$ \\
$\mathbf{C l}$ & $23.02 \%$ & $45.20 \%$ & $77.73 \%$ & $45.15 \%$ & $29.78 \%$ & $47.47 \%$ & $68.29 \%$ & $124.03 \%$
\end{tabular}


Subappendix B: Laboratory Scale Experiments II

Experimental Data and Calculations for Sugar Cane Trash Processing Investigation 
Table B.1: Details of the mass balance calculations for the second set of laboratory scale experiments.

\begin{tabular}{|c|c|c|c|c|c|c|c|c|c|c|c|c|}
\hline \multirow{2}{*}{$\begin{array}{l}\text { Treatment } \\
\text { Description }\end{array}$} & \multicolumn{3}{|c|}{ W-JC-2.5 } & \multicolumn{3}{|c|}{ W-JC-1.0 } & \multicolumn{3}{|c|}{$+\mathrm{H}-\mathrm{JC}-2.5$} & \multicolumn{3}{|c|}{$+\mathrm{H}-4 "-2.5$} \\
\hline & $\mathbf{P}^{*}$ & $\mathbf{L}^{*}$ & $E^{*}$ & $\mathbf{P}^{*}$ & $\mathbf{L}^{*}$ & $E^{*}$ & $\mathbf{P}^{*}$ & $\mathbf{L}^{*}$ & $E^{*}$ & $\mathbf{P}^{*}$ & $\mathbf{L}^{*}$ & $E^{*}$ \\
\hline \multicolumn{13}{|l|}{ Overall System Mass Balance } \\
\hline Mass of Wet Cane Trash (g) & 400 & & 392.8 & 400 & & 370.1 & 400 & & 355.3 & 400 & & 456.4 \\
\hline Mass of Water $(\mathrm{g})$ & 2918.2 & 2240.3 & 677.9 & 3120.4 & 2470.4 & 650 & 2874 & 2184.3 & 689.7 & 2910.6 & 2572.3 & 338.3 \\
\hline Overall Mass Balance $([B+C] / A)$ & \multicolumn{3}{|c|}{0.998} & \multicolumn{3}{|c|}{0.992} & \multicolumn{3}{|c|}{0.986} & \multicolumn{3}{|c|}{1.017} \\
\hline \multicolumn{13}{|l|}{ Dry Fiber Mass Balance } \\
\hline Mass of Dry Fiber (g) & 238.4 & & 194.9 & 238.4 & & 202.3 & 238.4 & & 195.4 & 233.64 & & 238 \\
\hline Suspended Solids g & 0.000 & 6.542 & 0.992 & 0.000 & 6.029 & 0.925 & 0.000 & 7.508 & 0.692 & 0.000 & 1.044 & 0.626 \\
\hline Dry Fiber Mass Balance (Out/In) & \multicolumn{3}{|c|}{0.849} & \multicolumn{3}{|c|}{0.878} & \multicolumn{3}{|c|}{0.854} & \multicolumn{3}{|c|}{1.026} \\
\hline \multicolumn{13}{|l|}{ Ash Mass Balance } \\
\hline Ash in Dry Fiber (g/g) & 0.094 & & 0.09 & 0.094 & & 0.09 & 0.094 & & 0.07 & 0.097 & & 0.10 \\
\hline Mass of Dry Fiber (g) & 238.4 & & 194.9 & 238.4 & & 202.3 & 238.4 & & 195.4 & 233.64 & & 238 \\
\hline Mass of Ash (g) & 22.42 & & 18.30 & 22.42 & & 17.38 & 22.42 & & 14.54 & 22.78 & & 24.51 \\
\hline Mass of Sus. Solids (Ash) (g) & 0 & 6.542 & 0.992 & 0.000 & 6.029 & 0.925 & 0.000 & 7.508 & 0.692 & 0.000 & 1.044 & 0.626 \\
\hline Mass of Ash in Sus. Solids (g) & & 0.707 & & & 0.597 & & & 0.610 & & & 0.171 & \\
\hline Ash Balance (Out/In) & \multicolumn{3}{|c|}{0.85} & \multicolumn{3}{|c|}{0.80} & \multicolumn{3}{|c|}{0.68} & \multicolumn{3}{|c|}{1.08} \\
\hline Treatment & \multicolumn{3}{|c|}{$+\mathrm{H}-4 "-1.0$} & \multicolumn{3}{|c|}{$+\mathrm{H}-\mathrm{JC}-1.0$} & \multicolumn{3}{|c|}{$W-4 "-2.5$} & \multicolumn{3}{|c|}{ W-4"-1.0 } \\
\hline Description & $\mathbf{P}$ & $\mathbf{L}$ & $\mathbf{E}$ & $\mathbf{P}$ & $\mathbf{L}$ & $\mathbf{E}$ & $\mathbf{P}$ & $\mathbf{L}$ & $\mathbf{E}$ & $\mathbf{P}$ & $\mathbf{L}$ & $\mathbf{E}$ \\
\hline \multicolumn{13}{|l|}{ Overall System Mass Balance } \\
\hline \multirow{4}{*}{$\begin{array}{l}\text { Mass of Wet Cane Trash }(\mathrm{g}) \\
\text { Mass of Water }(\mathrm{g}) \\
\text { Overall Mass Balance }([\mathrm{B}+\mathrm{C}] / \mathrm{A}) \\
\text { Dry Fiber Mass Balance }\end{array}$} & 400 & & 406.4 & 400 & & 358.4 & 400 & & 390 & 400 & & 381.3 \\
\hline & 3015 & 2747.7 & 267.3 & 3032.2 & 2381.9 & 650.3 & 3112.1 & 2907.3 & 204.8 & 3060.5 & 2877.4 & 183.1 \\
\hline & & 1.002 & & & 0.988 & & & 0.997 & & & 0.995 & \\
\hline & & & & & & & & & & & & \\
\hline Mass of Dry Fiber (g) & 233.64 & & 207.3 & 238.4 & & 198.5 & 233.64 & & 189.2 & 233.64 & & 183.2 \\
\hline Suspended Solids (g) & 0.000 & 0.183 & 0.622 & 0.000 & 5.675 & 0.699 & 0.000 & 0.000 & 0.487 & 0.000 & 0.000 & 0.543 \\
\hline Dry Fiber Mass Balance (Out/In) & & 0.891 & & & 0.859 & & & 0.812 & & & 0.786 & \\
\hline Ash Mass Balance & & & & & & & & & & & & \\
\hline Ash in Dry Fiber (g/g) & 0.097 & & 0.099 & 0.094 & & 0.079 & 0.097 & & 0.093 & 0.097 & & 0.0922 \\
\hline Mass of Dry Fiber (g) & 233.64 & & 207.3 & 238.4 & & 198.5 & 233.64 & & 189.2 & 233.64 & & 183.2 \\
\hline Mass of Ash (g) & 22.78 & & 20.71 & 22.42 & & 15.80 & 22.78 & & 17.77 & 22.78 & & 16.89 \\
\hline Mass of Sus. Solids (Ash) (g) & 0.000 & 0.183 & 0.622 & 0.000 & 5.675 & 0.699 & 0.000 & 0.000 & 0.487 & 0.000 & 0.000 & 0.543 \\
\hline Mass of Ash in Sus. Solids (g) & & 0.080 & & & 0.507 & & & 0.046 & & & 0.050 & \\
\hline Ash Balance (Out/In) & & 0.913 & & & 0.727 & & & 0.782 & & & 0.744 & \\
\hline
\end{tabular}




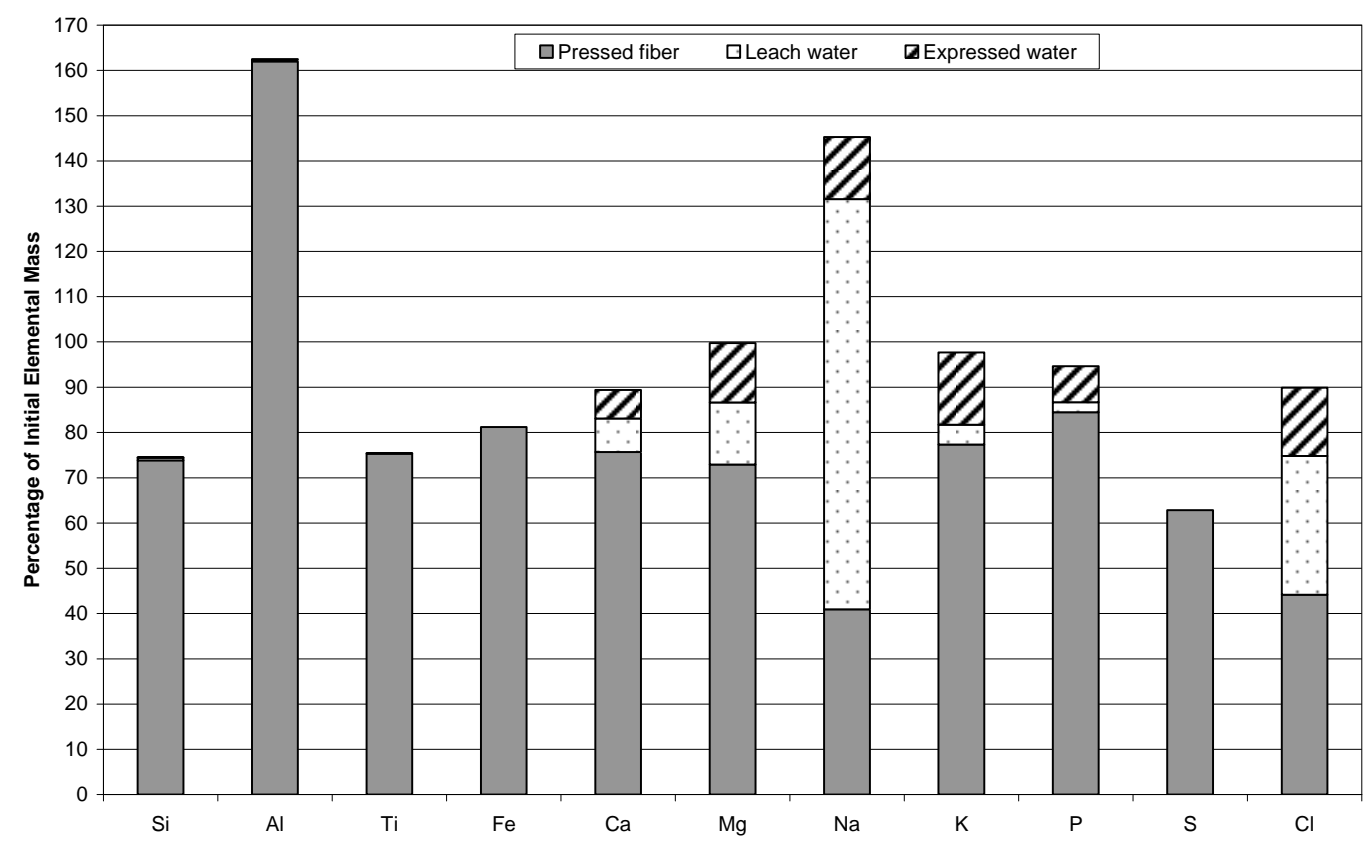

Figure B.1: Distribution of elements as a fraction of the initial mass for treatment W-4"-1.0 of the second set of laboratory scale experiments.

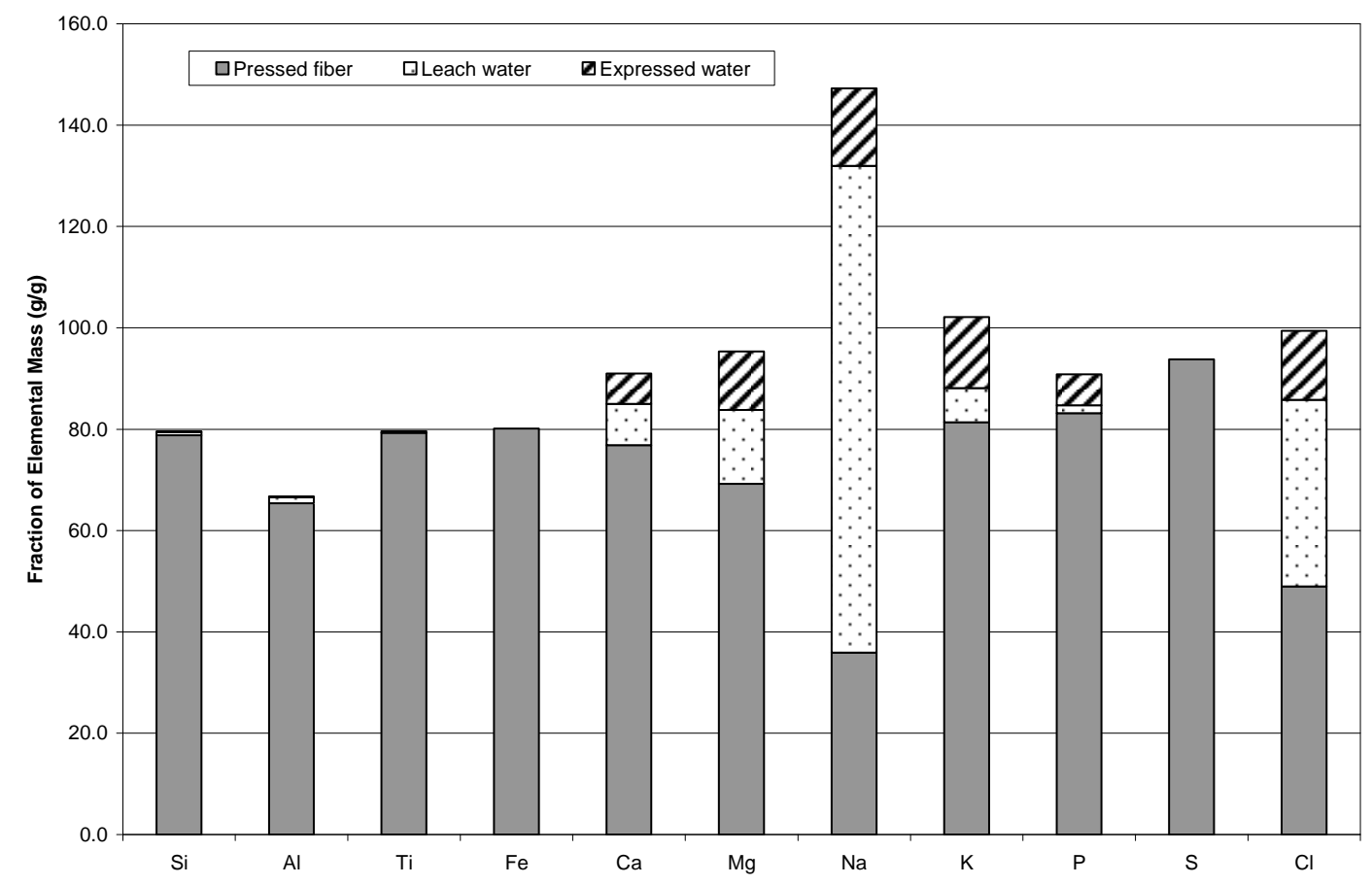

Figure B.2: Distribution of elements as a fraction of the initial mass for treatment W-4"-2.5 of the second set of laboratory experiments. 


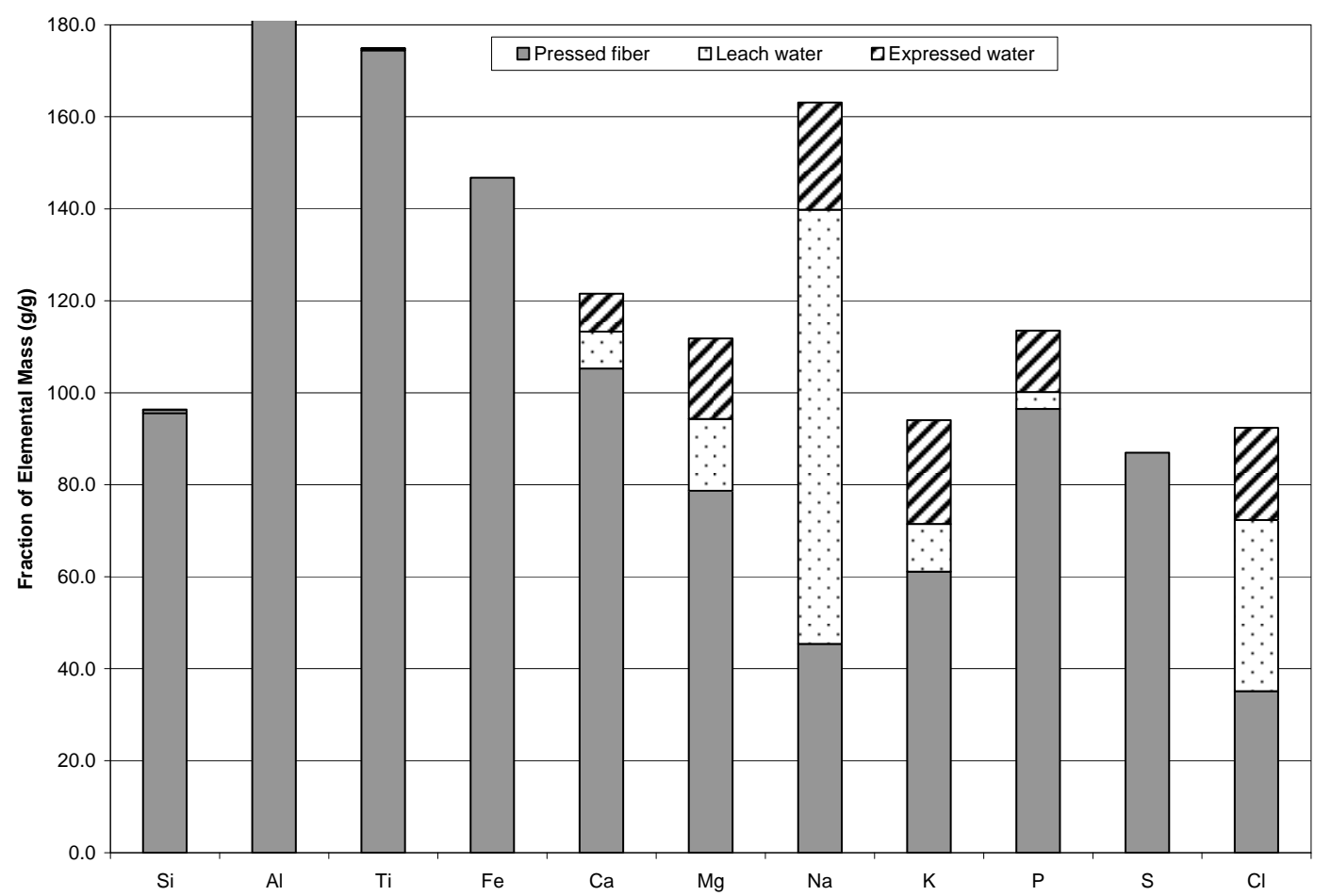

Figure B.3: Distribution of elements as a fraction of the initial mass for treatment $+\mathrm{H}-4 "-1.0$ of the second set of laboratory experiments.

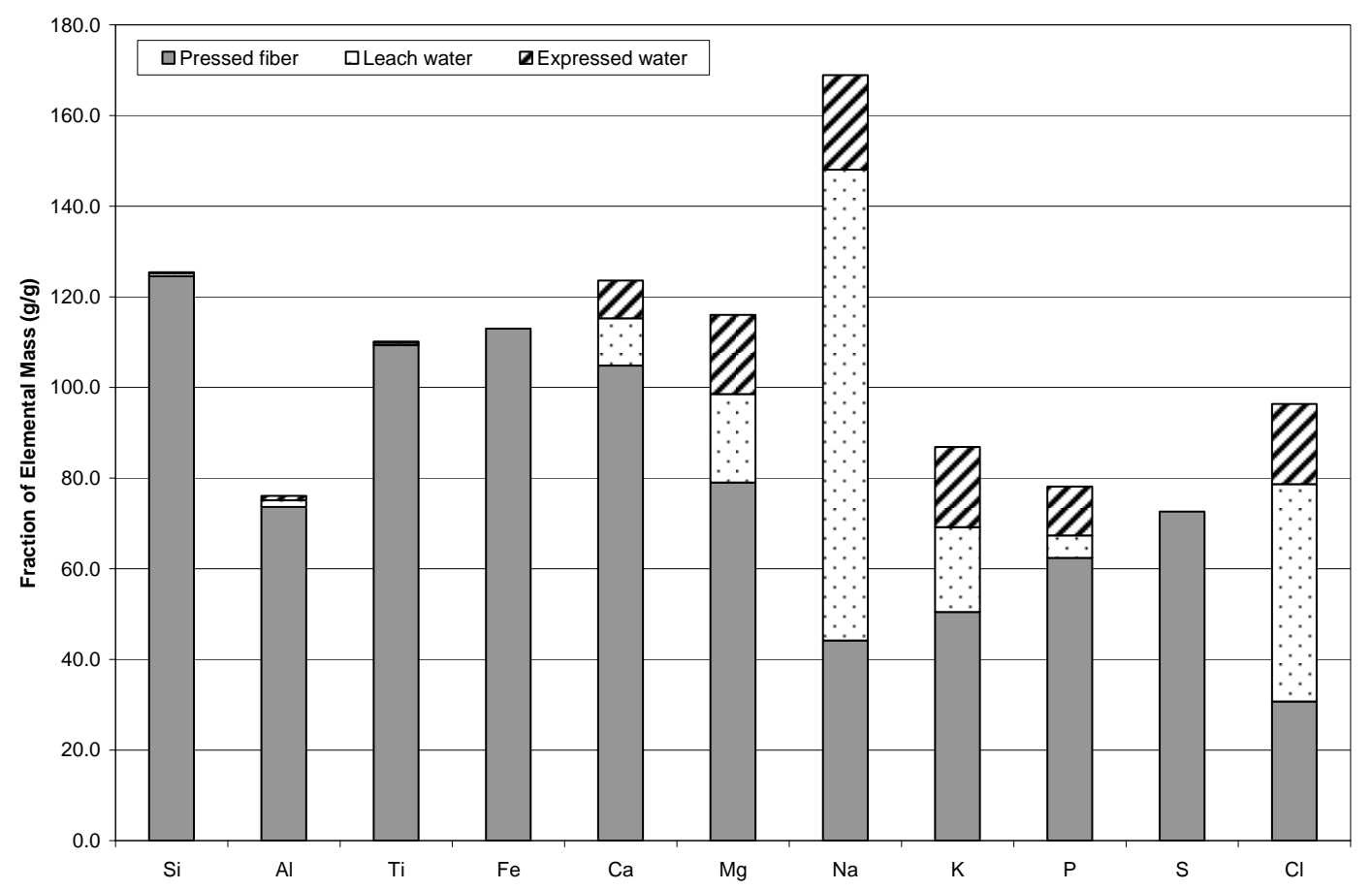

Figure B.4: Distribution of elements as a fraction of the initial mass for treatment $+\mathrm{H}-4 "-2.5$ of the second set of laboratory experiments. 


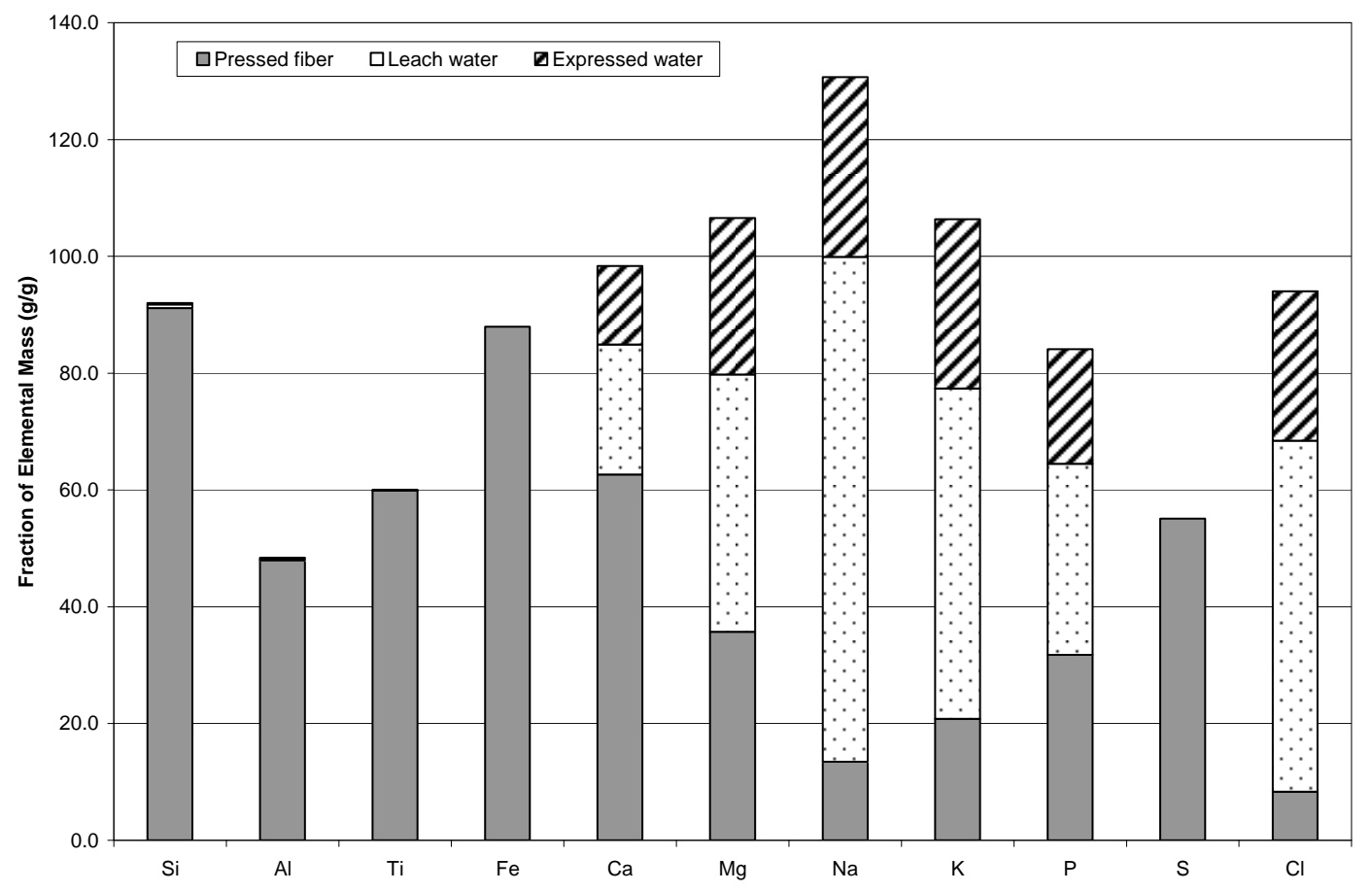

Figure B.5: Distribution of elements as a fraction of the initial mass for treatment W-JC-1.0 of the second set of laboratory experiments.

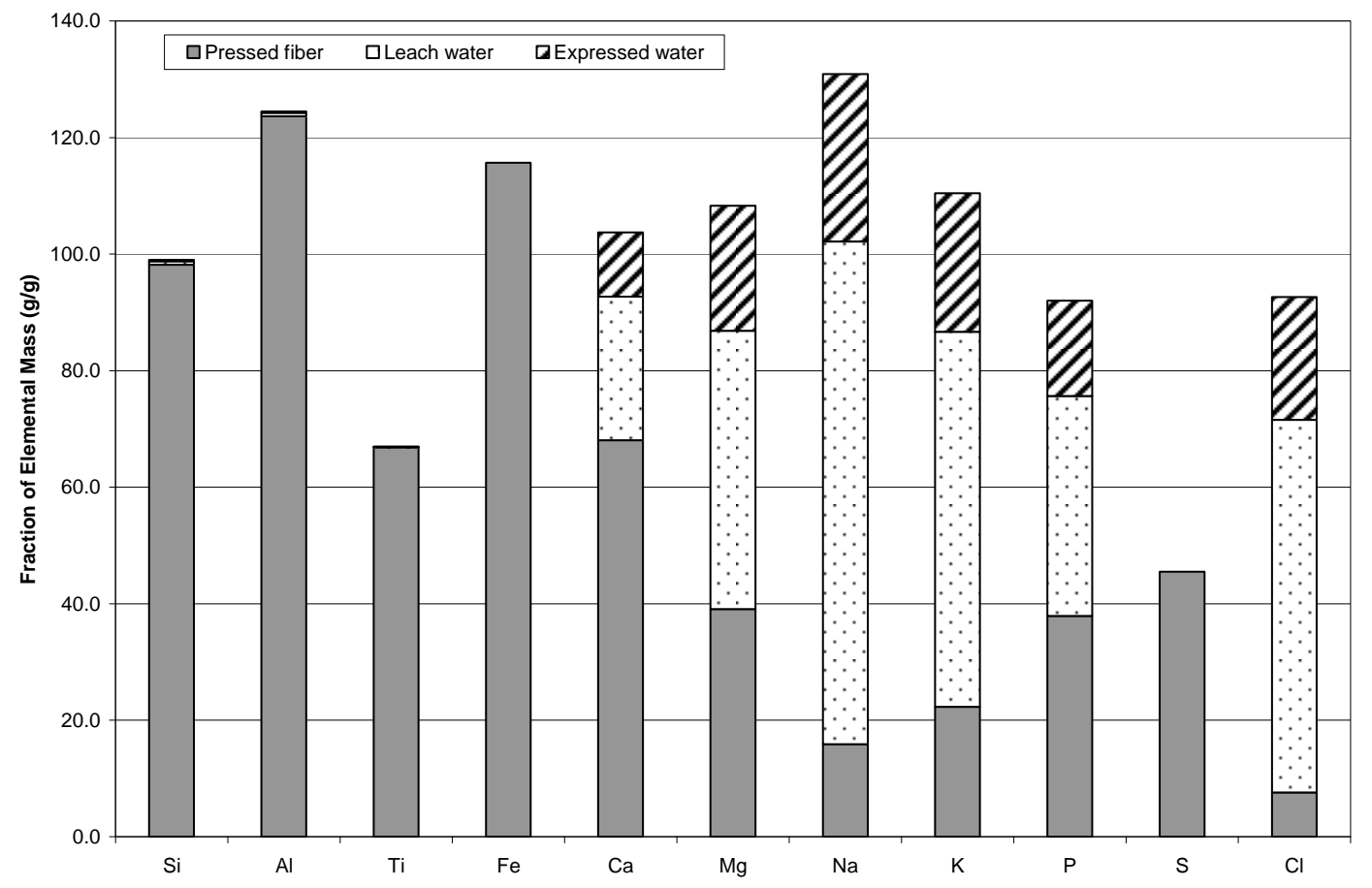

Figure B.6: Distribution of elements as a fraction of the initial mass for treatment W-JC-2.5 of the second set of laboratory experiments. 


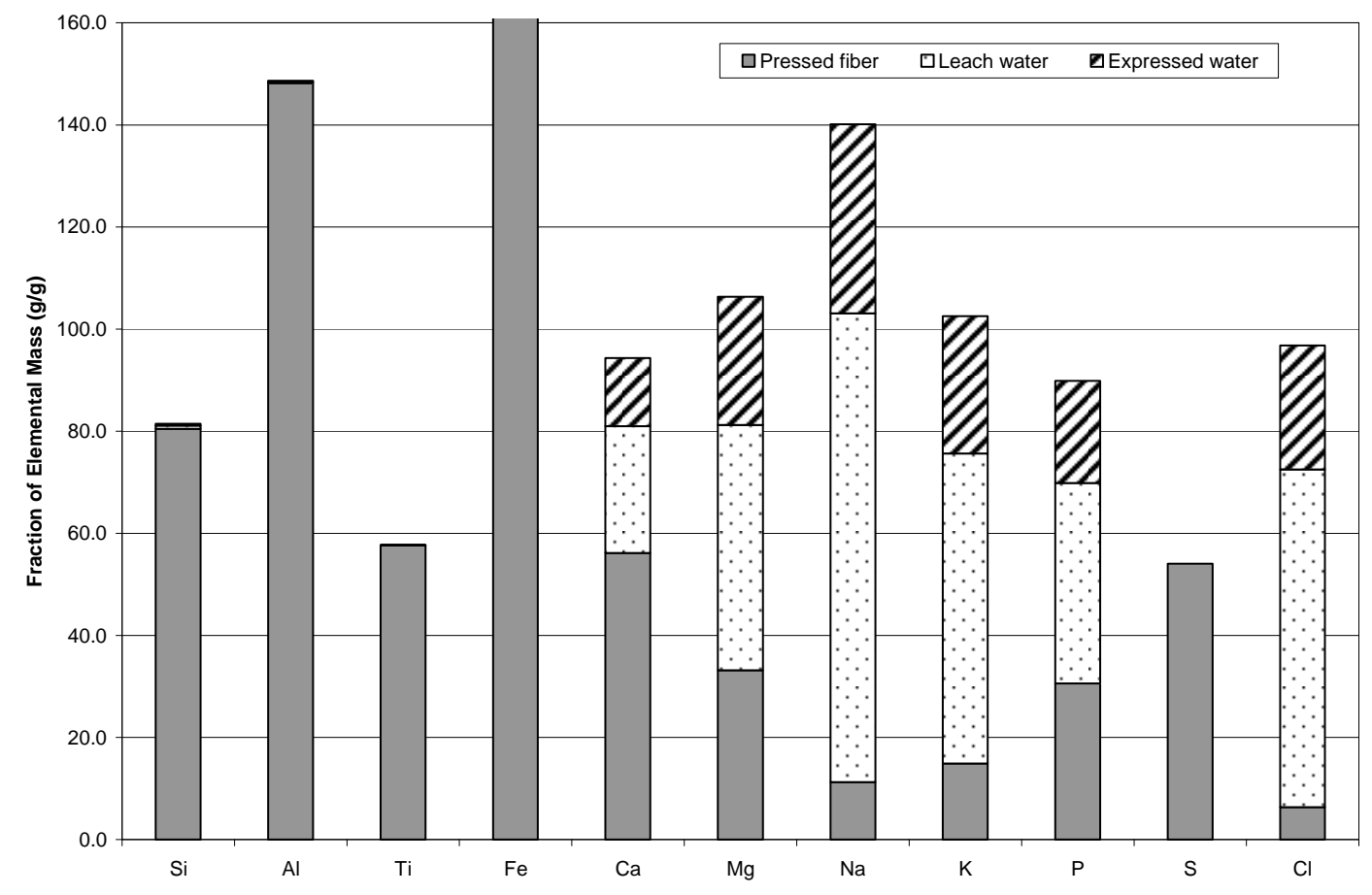

Figure B.7: Distribution of elements as a fraction of the initial mass for treatment $+\mathrm{H}-\mathrm{JC} 1.0$ of the second set of laboratory experiments.

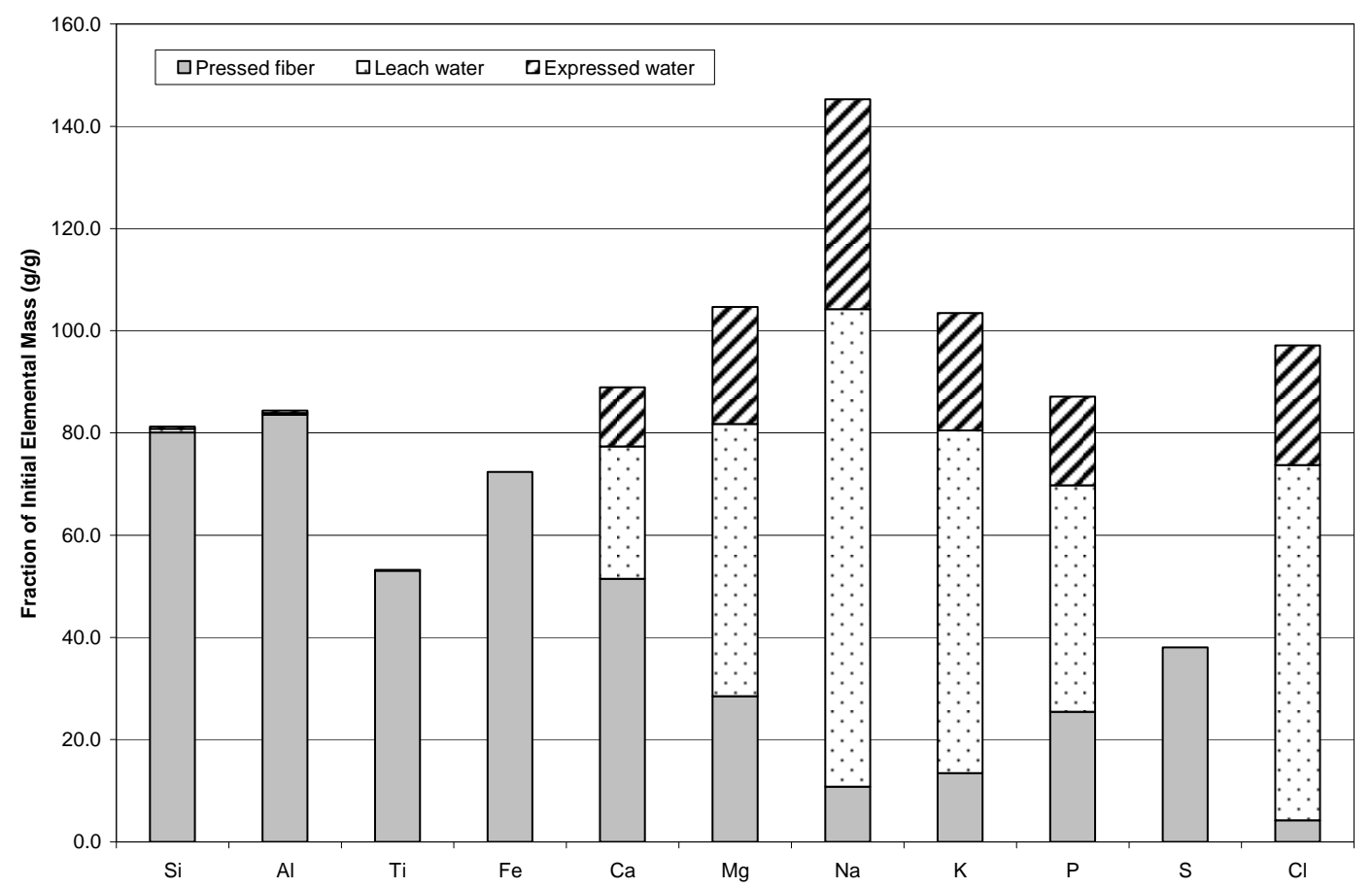

Figure B.8: Distribution of elements as a fraction of the initial mass for treatment $+\mathrm{H}-\mathrm{JC}-2.5$ of the second set of laboratory experiments. 
Table B.2: Element mass calculations for the second set of laboratory scale cane trash fiber treatments 9-12.

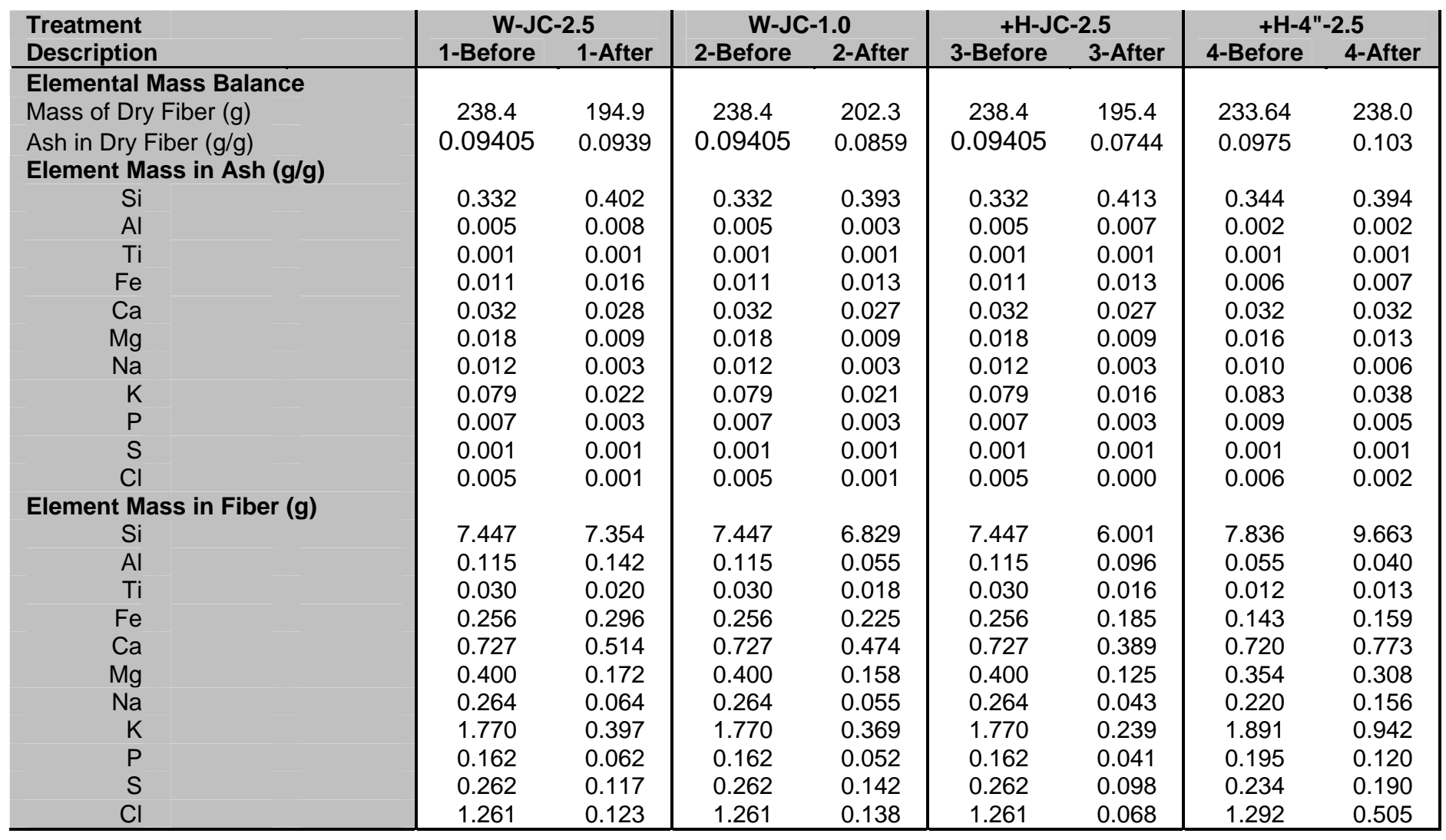


Table B.3: Element mass calculations for the second set of laboratory scale cane trash fiber treatments 13-16.

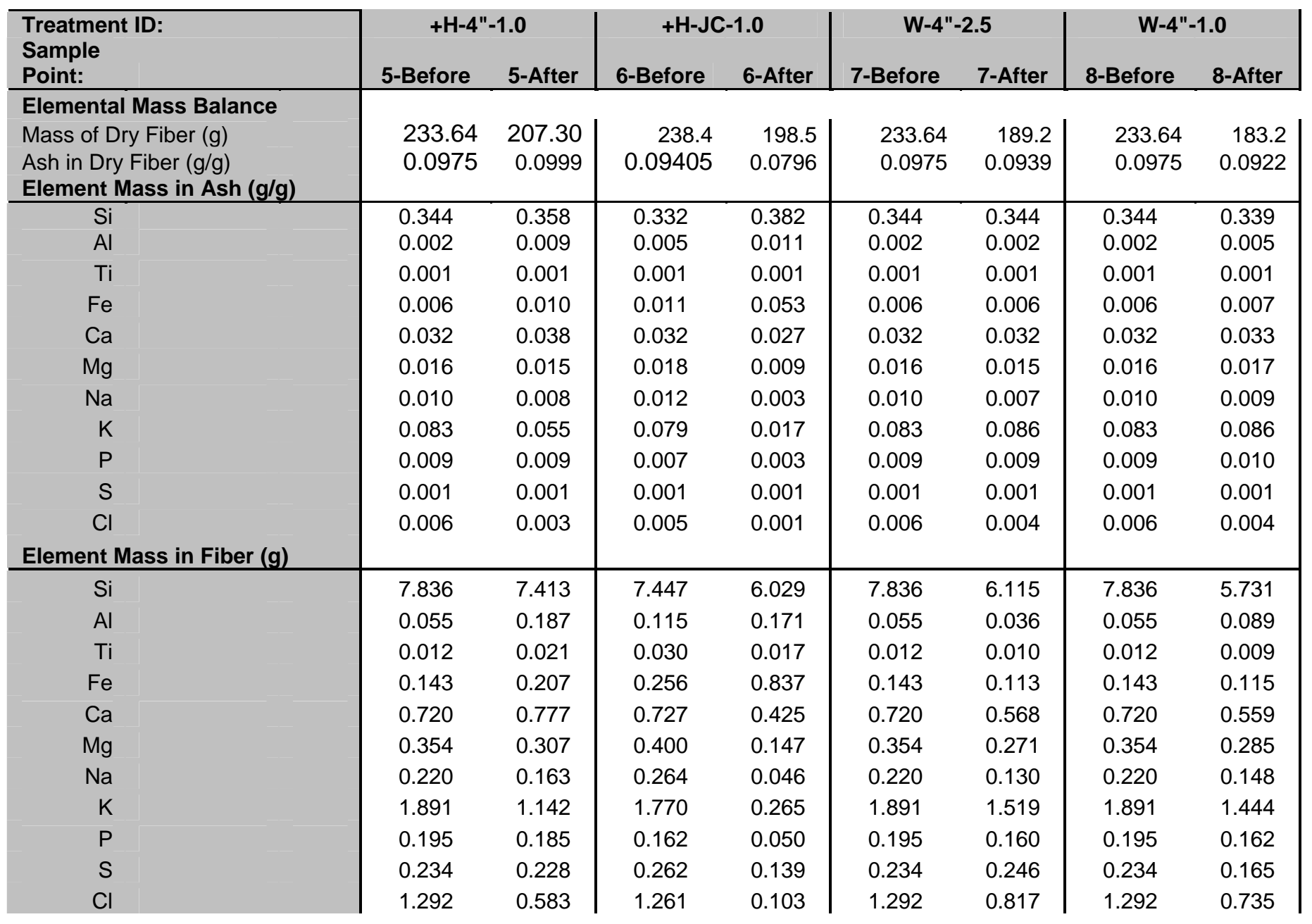


Table B.4: Element mass calculations based on ICP-MS analysis for second set of laboratory scale treatments 9-12.

\begin{tabular}{|c|c|c|c|c|c|c|c|c|c|c|c|c|}
\hline \multirow{2}{*}{$\begin{array}{l}\text { Treatment } \\
\text { ID: } \\
\text { Sample } \\
\text { Point: }\end{array}$} & \multicolumn{3}{|c|}{ W-JC-2.5 } & \multicolumn{3}{|c|}{ W-JC-1.0 } & \multicolumn{3}{|c|}{$+\mathrm{H}-\mathrm{JC}-2.5$} & \multicolumn{3}{|c|}{$+\mathrm{H}-4 "-2.5$} \\
\hline & A & B & C & A & B & C & A & B & $\mathbf{C}$ & A & B & C \\
\hline $\begin{array}{l}\text { Mass of } \\
\text { Water (g) }\end{array}$ & 2918.20 & 2233.76 & 619.81 & 3120.40 & 2464.37 & 616.97 & 2874.00 & 2176.79 & 644.01 & 2918.20 & 2233.76 & 619.81 \\
\hline $\begin{array}{l}\text { Density of } \\
\text { Liquid } \\
\text { (kg/L) }\end{array}$ & 1.000 & 1.000 & 1.000 & 1.000 & 1.000 & 1.000 & 1.000 & 1.000 & 1.000 & 1.000 & 1.000 & 0.994 \\
\hline $\begin{array}{l}\text { Volume of } \\
\text { Water (L) }\end{array}$ & 2.92 & 2.23 & 0.62 & 3.12 & 2.46 & 0.62 & 2.87 & 2.18 & 0.64 & 2.92 & 2.23 & 0.62 \\
\hline \multicolumn{13}{|c|}{ Element Concentrations (mg/L) } \\
\hline $\mathrm{Si}$ & 15.14 & 20.48 & 28.50 & 15.14 & 19.00 & 28.36 & 15.14 & 24.46 & 50.76 & 15.14 & 21.13 & 63.27 \\
\hline Al & 0.01 & 0.31 & 0.46 & 0.01 & 0.14 & 0.34 & 0.01 & 0.21 & 0.80 & 0.01 & 0.32 & 2.64 \\
\hline $\mathrm{Ti}$ & 0.00 & 0.02 & 0.04 & 0.00 & 0.01 & 0.02 & 0.00 & 0.01 & 0.05 & 0.00 & 0.03 & 0.14 \\
\hline $\mathrm{Ca}$ & 9.84 & 83.46 & 134.16 & 9.84 & 68.50 & 164.43 & 9.84 & 89.81 & 135.42 & 9.84 & 29.88 & 312.90 \\
\hline Mg & 13.79 & 94.14 & 152.75 & 13.79 & 79.30 & 192.47 & 13.79 & 107.59 & 156.25 & 13.79 & 29.48 & 348.18 \\
\hline $\mathrm{Na}$ & 47.31 & 155.15 & 186.31 & 47.31 & 144.29 & 205.19 & 47.31 & 171.53 & 254.73 & 47.31 & 142.99 & 378.00 \\
\hline $\mathbf{K}$ & 1.98 & 511.35 & 682.08 & 1.98 & 407.82 & 834.33 & 1.98 & 546.84 & 632.52 & 1.98 & 135.70 & 1692.39 \\
\hline $\mathbf{P}$ & 0.08 & 27.39 & 42.77 & 0.08 & 21.49 & 51.63 & 0.08 & 33.03 & 43.60 & 0.08 & 3.71 & 105.53 \\
\hline $\mathrm{Cl}$ & 131.40 & 463.80 & 549.90 & 131.40 & 401.30 & 682.40 & 131.40 & 515.10 & 585.80 & 131.40 & 306.50 & 1491.10 \\
\hline \multicolumn{13}{|c|}{ Element Mass in liquids (g) } \\
\hline $\mathrm{Si}$ & 0.044 & 0.046 & 0.018 & 0.047 & 0.047 & 0.017 & 0.044 & 0.053 & 0.033 & 0.044 & 0.054 & 0.012 \\
\hline Al & 0.000 & 0.001 & 0.000 & 0.000 & 0.000 & 0.000 & 0.000 & 0.000 & 0.001 & 0.000 & 0.001 & 0.001 \\
\hline $\mathrm{Ti}$ & 0.000 & 0.000 & 0.000 & 0.000 & 0.000 & 0.000 & 0.000 & 0.000 & 0.000 & 0.000 & 0.000 & 0.000 \\
\hline $\mathrm{Ca}$ & 0.029 & 0.186 & 0.083 & 0.031 & 0.169 & 0.101 & 0.028 & 0.195 & 0.087 & 0.029 & 0.077 & 0.061 \\
\hline $\mathrm{Mg}$ & 0.040 & 0.210 & 0.095 & 0.043 & 0.195 & 0.119 & 0.040 & 0.234 & 0.101 & 0.040 & 0.076 & 0.068 \\
\hline $\mathrm{Na}$ & 0.138 & 0.347 & 0.115 & 0.148 & 0.356 & 0.127 & 0.136 & 0.373 & 0.164 & 0.138 & 0.368 & 0.074 \\
\hline $\mathrm{K}$ & 0.006 & 1.142 & 0.423 & 0.006 & 1.005 & 0.515 & 0.006 & 1.190 & 0.407 & 0.006 & 0.349 & 0.331 \\
\hline $\mathbf{P}$ & 0.000 & 0.061 & 0.027 & 0.000 & 0.053 & 0.032 & 0.000 & 0.072 & 0.028 & 0.000 & 0.010 & 0.021 \\
\hline $\mathrm{Cl}$ & 0.383 & 1.036 & 0.341 & 0.410 & 0.989 & 0.421 & 0.378 & 1.121 & 0.377 & 0.382 & 0.788 & 0.291 \\
\hline
\end{tabular}


Table B.5: Element mass calculations based on ICP-MS analysis for second set of laboratory scale treatments 13-16.

\begin{tabular}{|c|c|c|c|c|c|c|c|c|c|c|c|c|}
\hline \multirow{2}{*}{$\begin{array}{l}\text { Treatment } \\
\text { ID: } \\
\text { Sample } \\
\text { Point: } \\
\end{array}$} & \multicolumn{3}{|c|}{$+\mathrm{H}-4 "-1.0$} & \multicolumn{3}{|c|}{$+\mathrm{H}-\mathrm{JC}-1.0$} & \multicolumn{3}{|c|}{$W-4 "-2.5$} & \multicolumn{3}{|c|}{ W-4"-1.0 } \\
\hline & A & B & C & A & B & C & A & B & C & A & B & C \\
\hline $\begin{array}{l}\text { Mass of } \\
\text { Water }(\mathrm{g})\end{array}$ & 3015.00 & 2747.52 & 169.08 & 3032.20 & 2376.22 & 587.30 & 3112.10 & 2907.30 & 152.31 & 3060.50 & 2877.40 & 118.76 \\
\hline $\begin{array}{l}\text { Density of } \\
\text { Liquid } \\
\text { (kg/L) }\end{array}$ & 1.000 & 1.000 & 1.000 & 1.000 & 1.000 & 1.000 & 1.000 & 1.000 & 1.000 & 1.000 & 1.000 & 1.000 \\
\hline $\begin{array}{l}\text { Volume of } \\
\text { Water (L) }\end{array}$ & 3.02 & 2.75 & 0.17 & 3.03 & 2.38 & 0.59 & 3.11 & 2.91 & 0.15 & 3.06 & 2.88 & 0.12 \\
\hline \multicolumn{13}{|c|}{ Element Concentrations (mg/L) } \\
\hline Si & 15.14 & 19.20 & 56.03 & 15.14 & 20.27 & 42.40 & 15.14 & 17.60 & 40.51 & 15.14 & 16.41 & 48.84 \\
\hline Al & 0.01 & 0.16 & 1.28 & 0.01 & 0.14 & 0.41 & 0.01 & 0.22 & 0.53 & 0.01 & 0.06 & 0.68 \\
\hline $\mathrm{Ti}$ & 0.00 & 0.02 & 0.05 & 0.00 & 0.00 & 0.02 & 0.00 & 0.02 & 0.00 & 0.00 & 0.00 & 0.00 \\
\hline $\mathrm{Ca}$ & 9.84 & 21.53 & 359.45 & 9.84 & 79.20 & 171.59 & 9.84 & 20.71 & 292.95 & 9.84 & 18.98 & 391.51 \\
\hline Mg & 13.79 & 22.18 & 404.36 & 13.79 & 89.31 & 189.03 & 13.79 & 19.69 & 296.63 & 13.79 & 18.61 & 431.87 \\
\hline $\mathrm{Na}$ & 47.31 & 123.33 & 494.55 & 47.31 & 157.37 & 256.62 & 47.31 & 120.10 & 365.82 & 47.31 & 113.69 & 416.43 \\
\hline $\mathrm{K}$ & 1.98 & 70.46 & 2488.50 & 1.98 & 454.02 & 811.86 & 1.98 & 43.62 & 1718.64 & 1.98 & 28.43 & 2507.40 \\
\hline $\mathbf{P}$ & 0.08 & 2.56 & 151.43 & 0.08 & 26.81 & 55.13 & 0.08 & 0.99 & 77.74 & 0.08 & 1.48 & 128.74 \\
\hline $\mathrm{Cl}$ & 131.40 & 224.30 & 1966.50 & 131.40 & 455.20 & 676.60 & 131.40 & 211.60 & 1496.40 & 131.40 & 177.10 & 2110.70 \\
\hline \multicolumn{13}{|c|}{ Element Mass in liquids (g) } \\
\hline Si & 0.046 & 0.053 & 0.009 & 0.046 & 0.048 & 0.025 & 0.047 & 0.051 & 0.006 & 0.046 & 0.047 & 0.006 \\
\hline Al & 0.000 & 0.000 & 0.000 & 0.000 & 0.000 & 0.000 & 0.000 & 0.001 & 0.000 & 0.000 & 0.000 & 0.000 \\
\hline $\mathrm{Ti}$ & 0.000 & 0.000 & 0.000 & 0.000 & 0.000 & 0.000 & 0.000 & 0.000 & 0.000 & 0.000 & 0.000 & 0.000 \\
\hline $\mathrm{Ca}$ & 0.030 & 0.059 & 0.061 & 0.030 & 0.188 & 0.101 & 0.031 & 0.060 & 0.045 & 0.030 & 0.055 & 0.046 \\
\hline Mg & 0.042 & 0.061 & 0.068 & 0.042 & 0.212 & 0.111 & 0.043 & 0.057 & 0.045 & 0.042 & 0.054 & 0.051 \\
\hline $\mathrm{Na}$ & 0.143 & 0.339 & 0.084 & 0.143 & 0.374 & 0.151 & 0.147 & 0.349 & 0.056 & 0.145 & 0.327 & 0.049 \\
\hline $\mathrm{K}$ & 0.006 & 0.194 & 0.421 & 0.006 & 1.079 & 0.477 & 0.006 & 0.127 & 0.262 & 0.006 & 0.082 & 0.298 \\
\hline $\mathbf{P}$ & 0.000 & 0.007 & 0.026 & 0.000 & 0.064 & 0.032 & 0.000 & 0.003 & 0.012 & 0.000 & 0.004 & 0.015 \\
\hline $\mathrm{Cl}$ & 0.396 & 0.616 & 0.332 & 0.398 & 1.082 & 0.397 & 0.409 & 0.615 & 0.228 & 0.402 & 0.510 & 0.251 \\
\hline
\end{tabular}


Table B.6: Balance of element masses (out/in) for the second set of laboratory scale treatments.

\begin{tabular}{|c|c|c|c|c|c|c|c|c|}
\hline ID & 1 & 2 & 3 & 4 & 5 & 6 & 7 & 8 \\
\hline Treatment & W-JC-2.5 & W-JC-1.0 & $+\mathrm{H}-\mathrm{JC}-2.5$ & $+\mathrm{H}-4 "-2.5$ & $+\mathrm{H}-4 "-1.0$ & $+\mathrm{H}-\mathrm{JC}-1.0$ & W-4"-2.5 & W-4"-1.0 \\
\hline Si & $99.01 \%$ & $91.98 \%$ & $81.25 \%$ & $123.47 \%$ & $94.85 \%$ & $81.44 \%$ & $78.29 \%$ & $73.37 \%$ \\
\hline Al & $124.49 \%$ & $48.41 \%$ & $84.37 \%$ & $74.89 \%$ & $338.90 \%$ & $148.66 \%$ & $65.67 \%$ & $159.93 \%$ \\
\hline $\mathrm{Ti}$ & $66.98 \%$ & $60.02 \%$ & $53.25 \%$ & $108.38 \%$ & $172.15 \%$ & $57.74 \%$ & $78.35 \%$ & $74.26 \%$ \\
\hline $\mathrm{Fe}$ & $115.67 \%$ & $87.96 \%$ & $72.40 \%$ & $111.20 \%$ & $144.45 \%$ & $327.28 \%$ & $78.86 \%$ & $79.92 \%$ \\
\hline $\mathrm{Ca}$ & $103.73 \%$ & $98.32 \%$ & $88.91 \%$ & $121.70 \%$ & $119.71 \%$ & $94.32 \%$ & $89.63 \%$ & $88.04 \%$ \\
\hline Mg & $108.32 \%$ & $106.57 \%$ & $104.62 \%$ & $114.38 \%$ & $110.23 \%$ & $106.31 \%$ & $93.99 \%$ & $98.34 \%$ \\
\hline $\mathrm{Na}$ & $130.90 \%$ & $130.72 \%$ & $145.28 \%$ & $167.29 \%$ & $161.54 \%$ & $140.11 \%$ & $145.90 \%$ & $143.89 \%$ \\
\hline $\mathrm{K}$ & $110.45 \%$ & $106.35 \%$ & $103.42 \%$ & $85.50 \%$ & $92.56 \%$ & $102.50 \%$ & $100.55 \%$ & $96.14 \%$ \\
\hline $\mathbf{P}$ & $92.00 \%$ & $84.10 \%$ & $87.08 \%$ & $76.88 \%$ & $111.70 \%$ & $89.85 \%$ & $89.41 \%$ & $93.14 \%$ \\
\hline $\mathrm{Cl}$ & $91.19 \%$ & $92.60 \%$ & $95.61 \%$ & $94.59 \%$ & $90.70 \%$ & $95.34 \%$ & $97.62 \%$ & $88.24 \%$ \\
\hline
\end{tabular}




\section{Subappendix C: Pilot Scale Experimental Data and}

Calculations for Sugar Cane Trash Processing Investigation 


\section{Leachate and Milling Water Balance}

In the Cane Trash Processing investigation, analytical methods were employed to determine concentrations of major and minor elements and thereby track them throughout the treatment process. Liquid components were analyzed using inductively-coupled plasma mass spectrometry (ICP-MS). The suite of elements that are included in the analysis are listed in Table C.1.

Table C.1: Suite of Major and Minor Elements Considered in Cane Trash Processing Investigation.

\begin{tabular}{|c|c|c|c|}
\hline \multicolumn{2}{|c|}{ Major Elements } & \multicolumn{2}{|c|}{ Minor (Trace) Elements } \\
\hline Symbol & Name & Symbol & Name \\
\hline Al & Aluminum & B & Boron \\
\hline $\mathrm{Ca}$ & Calcium & $\mathrm{Ba}$ & Barium \\
\hline $\mathrm{Fe}$ & Iron & $\mathrm{Be}$ & Beryllium \\
\hline $\mathbf{K}$ & Potassium & Cd & Cadmium \\
\hline Mg & Magnesium & Co & Cobalt \\
\hline $\mathbf{N a}$ & Sodium & $\mathrm{Cr}$ & Chromium \\
\hline $\mathbf{P}$ & Phosphorus & $\mathrm{Cu}$ & Copper \\
\hline Si & Silicon & Mn & Manganese \\
\hline Ti & Titanium & Mo & Molybdenum \\
\hline & & $\mathrm{Ni}$ & Nickel \\
\hline & & $\mathbf{P b}$ & Lead \\
\hline & & Sn & Tin \\
\hline & & $\mathrm{Sr}$ & Strontium \\
\hline & & $\mathbf{V}$ & Vanadium \\
\hline & & $\mathrm{Zn}$ & Zinc \\
\hline
\end{tabular}

The total mass of water used during leaching was calculated from the tank dimensions and depth of water read off of a measure submerged in the tank before and after the samples were treated. The tank dimensions are $3.66 \mathrm{~m}$ length by $1.22 \mathrm{~m}$ width. The first test of the pilot scale experiment $\left(60^{\circ} \mathrm{C}\right.$ leach water, 1 minute leach duration) will be used to present the calculation method. The tank depths for the first test were recorded as $1.08 \mathrm{~m}$ before leaching and $1.07 \mathrm{~m}$ after leaching for total clean $\left(\mathrm{V}_{\text {tank,before }}\right)$ and leach $\left(\mathrm{V}_{\text {tank,after }}\right)$ water volumes of $4.83 \mathrm{~m}^{3}$ and $4.77 \mathrm{~m}^{3}$ respectively. Thus, the volume of water absorbed by the cane trash during leaching ( $\left.\mathrm{V}_{\text {H2O,add }}\right)$ is:

$$
V_{H 2 O, a d d}=V_{\text {tan } k \text {,after }}-V_{\text {tan } k \text {,before }}=0.0566 \mathrm{~m}^{3}=56.6 \mathrm{~L}
$$

Knowing the concentration in $\mathrm{mg} / \mathrm{l}$ of the elements from the ICP-MS analysis, the mass of each element in the water tank before leaching can be found. The mass of Potassium entering the experimental system in the clean water is:

$$
M_{K, \text { cleanH 2O }}=C_{K, A} \times V_{\text {tan } k \text {,before }}=3.13 \mathrm{mg} / \mathrm{L} \times 48,280 \mathrm{~L}=15,112 \mathrm{mg} \mathrm{K}
$$

Where A describes the water sampled before leaching, B the water after leaching and C the water that was expressed during the milling process in the Cuba Mill. Continuing 
with potassium as an example, the concentration was determined from samples of the tank water after leaching the cane trash. Thus, the mass of potassium leaving the system as excess leachate is:

$$
M_{K, \text { leachH 2O }}=C_{K, B} \times V_{\tan k, \text { after }}=11.9 \mathrm{mg} / \mathrm{L} \times 4770 \mathrm{~L}=56763 \mathrm{mg} \mathrm{K}
$$

The Potassium removed during milling of the leached cane trash involves a similar analysis. The mass of water expressed from the cane trash using the Cuba mill was weighed on site. Samples were then taken and the excess was discarded. For the first test, $60^{\circ} \mathrm{C}$ leaching water and 1 minute soaking time, the total mass of expressed liquid was $97.18 \mathrm{~kg}$. The density of the sample was measured by weighing a known volume of the sample and found to be $911.39 \mathrm{~kg} / \mathrm{m}^{3}$. Thus the total volume of the expressed water is $106.6 \mathrm{~L}$. So the mass of Potassium contained in the expressed water can be determined.

$$
M_{K, C}=C_{K, C} \times V_{\text {exp ressed }}=646 \mathrm{mg} / \mathrm{L} \times 106.6 \mathrm{~L}=68864 \mathrm{mg} \mathrm{K}
$$

The three masses; $M_{k, A}, M_{K, B}, M_{K, C}$, represent the inputs (A) and outputs (B,C) to the system over the course of the treatments and, when compared with the Potassium in the untreated and treated cane trash fiber, can be used to determine the overall closure of the experimental system. A closed system would allow determination of the percentage of each element that was removed from the cane trash by the treatment to be determined.

The tables showing the entire suite of elements for each of the four tests can be found below as Tables C.2-C.3. 
Table C.2: Concentration of elements in liquid samples from the pilot scale tests in mg/L

\begin{tabular}{|c|c|c|c|c|c|c|c|c|c|c|c|c|}
\hline \multirow{2}{*}{ Major } & \multicolumn{3}{|c|}{1} & \multicolumn{3}{|c|}{2} & \multicolumn{3}{|c|}{3} & \multicolumn{3}{|c|}{4} \\
\hline & 1-A & 1-B & $1-C$ & 2-A & 2-B & $2-C$ & 3-A & 3-B & 3-C & 4-A & 4-B & 4-C \\
\hline $\mathrm{Al}$ & 0.38 & 6.95 & 59.27 & 0.10 & 13.09 & 63.35 & 0.07 & 6.87 & 83.39 & 0.10 & 2.02 & 61.81 \\
\hline $\mathrm{Ca}$ & 24.85 & 23.77 & 332.61 & 26.79 & 30.12 & 429.25 & 25.45 & 28.10 & 501.54 & 21.08 & 22.07 & 282.84 \\
\hline $\mathrm{Fe}$ & 0.79 & 6.89 & 328.22 & 0.48 & 12.35 & 284.95 & 0.22 & 6.29 & 401.90 & 0.38 & 2.04 & 273.79 \\
\hline $\mathrm{K}$ & 3.13 & 11.86 & 646.33 & 3.84 & 20.48 & 615.26 & 3.45 & 8.23 & 475.32 & 2.75 & 10.22 & 619.42 \\
\hline $\mathrm{Mg}$ & 15.21 & 16.69 & 311.07 & 18.81 & 20.87 & 320.64 & 18.67 & 19.09 & 390.68 & 14.59 & 15.63 & 253.87 \\
\hline $\mathrm{Na}$ & 41.64 & 44.51 & 185.97 & 51.35 & 55.49 & 192.12 & 53.16 & 53.17 & 227.96 & 36.95 & 40.62 & 147.59 \\
\hline $\mathbf{P}$ & 0.09 & 0.37 & 9.89 & 0.07 & 0.47 & 4.76 & 0.05 & 0.19 & 3.90 & 0.07 & 0.16 & 5.97 \\
\hline Si & 23.43 & 31.74 & 126.18 & 21.83 & 33.96 & 119.43 & 23.93 & 30.64 & 135.25 & 22.92 & 25.40 & 122.54 \\
\hline Ti & 0.06 & 0.94 & 18.06 & 0.01 & 1.58 & 11.12 & 0.01 & 0.91 & 25.82 & 0.02 & 0.25 & 12.53 \\
\hline \multicolumn{13}{|l|}{ Minor } \\
\hline B & 0.0182 & 0.0416 & 1.1067 & 0.0179 & 0.0739 & 0.9970 & 0.0187 & 0.0301 & 1.1151 & 0.0139 & 0.0267 & 0.7130 \\
\hline $\mathrm{Ba}$ & 0.0113 & 0.0451 & 2.5496 & 0.0110 & 0.0881 & 2.8432 & 0.0090 & 0.0394 & 2.4853 & 0.0073 & 0.0238 & 1.4365 \\
\hline $\mathrm{Be}$ & $<0.0005$ & $<0.0005$ & 0.0070 & $<0.0005$ & 0.0008 & 0.0063 & $<0.0005$ & $<0.0005$ & 0.0062 & $<0.0005$ & $<0.0005$ & 0.0062 \\
\hline Cd & $<0.0001$ & $<0.0001$ & 0.0073 & $<0.0001$ & $<0.0001$ & 0.0073 & 0.0002 & $<0.0001$ & 0.0110 & 0.0001 & 0.0001 & 0.0063 \\
\hline Co & $<0.001$ & 0.0062 & 1.5593 & 0.0018 & 0.0100 & 2.5600 & $<0.001$ & 0.0031 & 4.0073 & $<0.001$ & 0.0021 & 1.4962 \\
\hline $\mathrm{Cr}$ & 0.0017 & 0.0109 & 0.1324 & 0.0015 & 0.0158 & 0.1423 & 0.0025 & 0.0116 & 0.1507 & 0.0020 & 0.0058 & 0.1158 \\
\hline $\mathrm{Cu}$ & 0.0180 & 0.0274 & 0.4882 & 0.0110 & 0.0206 & 0.2924 & 0.0013 & 0.0034 & 0.1499 & 0.0015 & 0.0032 & 0.2481 \\
\hline Mn & 0.0345 & 0.1701 & 25.8826 & 0.0331 & 0.3506 & 30.8149 & 0.0080 & 0.1390 & 56.0068 & 0.0127 & 0.0963 & 18.4800 \\
\hline Mn & 0.0370 & 0.1722 & 25.7122 & 0.0353 & 0.3506 & 30.8610 & 0.0108 & 0.1419 & 56.3341 & 0.0154 & 0.0985 & 18.5982 \\
\hline Mo & 0.0069 & $<0.005$ & 0.1212 & 0.0076 & $<0.005$ & 0.1555 & 0.0061 & 0.0078 & 0.2198 & 0.0064 & $<0.005$ & 0.1032 \\
\hline $\mathrm{Ni}$ & 0.0043 & 0.0191 & 0.7775 & 0.0050 & 0.0339 & 1.2351 & 0.0037 & 0.0188 & 2.0586 & 0.0039 & 0.0086 & 0.7888 \\
\hline $\mathrm{Pb}$ & $<0.001$ & 0.0028 & 0.0158 & $<0.001$ & $<0.001$ & 0.0162 & 0.0051 & $<0.001$ & 0.0262 & $<0.001$ & $<0.001$ & 0.0143 \\
\hline Sn & 0.0134 & $<0.001$ & 0.0409 & $<0.001$ & $<0.001$ & 0.0112 & $<0.001$ & $<0.001$ & 0.0293 & 0.0014 & $<0.001$ & 0.0533 \\
\hline $\mathrm{Sr}$ & 0.1512 & 0.1669 & 3.8319 & 0.1670 & 0.2326 & 4.6343 & 0.1721 & 0.1918 & 5.3190 & 0.1318 & 0.1500 & 3.4359 \\
\hline V & 0.0233 & 0.0350 & 1.6013 & 0.0202 & 0.0409 & 1.6599 & 0.0254 & 0.0347 & 3.1516 & 0.0208 & 0.0234 & 1.2890 \\
\hline $\mathrm{Zn}$ & 0.1949 & 0.2418 & 8.1725 & 0.4035 & 0.3641 & 3.4936 & 0.0606 & 0.0754 & 2.1486 & 0.0678 & 0.1035 & 1.8429 \\
\hline
\end{tabular}


TableC.3: Calculated masses of elements in leaching tank before and after leaching and after milling of the cane trash. Trace elements were omitted since none are reported in the fuel characterization.

\begin{tabular}{|c|c|c|c|c|c|c|c|c|c|c|c|c|}
\hline \multirow{2}{*}{ Treatment ID: } & \multicolumn{3}{|c|}{1 (Hot/Short) } & \multicolumn{3}{|c|}{2 (Hot/Long) } & \multicolumn{3}{|c|}{3 (Cold/Short) } & \multicolumn{3}{|c|}{4 (Cold/Long) } \\
\hline & A & B & C & A & B & C & A & B & C & A & B & C \\
\hline $\begin{array}{l}\text { Mass of Water } \\
\text { (Tank/Expr.) (kg) }\end{array}$ & 4828.02 & 4771.39 & 97.18 & 4700.60 & 4643.96 & 108.55 & 4941.29 & 4898.81 & 117.36 & 4799.71 & 4757.23 & 110.91 \\
\hline $\begin{array}{l}\text { Density of Liquid (B or C) } \\
\text { (kg/L) }\end{array}$ & 1.000 & 1.000 & 0.911 & 1.000 & 1.000 & 1.000 & 1.000 & 1.000 & 1.008 & 1.000 & 1.000 & 1.000 \\
\hline $\begin{array}{l}\text { Volume of Water } \\
\text { (Tank/Expr.) (L) }\end{array}$ & 4828.02 & 4771.39 & 106.63 & 4700.60 & 4643.96 & 108.49 & 4941.29 & 4898.81 & 116.48 & 4799.71 & 4757.23 & 110.93 \\
\hline \multicolumn{13}{|l|}{ Concentrations (mg/L) } \\
\hline Si & 23.43 & 31.74 & 126.18 & 21.83 & 33.96 & 119.43 & 23.93 & 30.64 & 135.25 & 22.92 & 25.40 & 122.54 \\
\hline $\mathrm{Al}$ & 0.38 & 6.95 & 59.27 & 0.10 & 13.09 & 63.35 & 0.07 & 6.87 & 83.39 & 0.10 & 2.02 & 61.81 \\
\hline $\mathrm{Ti}$ & 0.06 & 0.94 & 18.06 & 0.01 & 1.58 & 11.12 & 0.01 & 0.91 & 25.82 & 0.02 & 0.25 & 12.53 \\
\hline $\mathrm{Fe}$ & 0.79 & 6.89 & 328.22 & 0.48 & 12.35 & 284.95 & 0.22 & 6.29 & 401.90 & 0.38 & 2.04 & 273.79 \\
\hline $\mathrm{Ca}$ & 24.85 & 23.77 & 332.61 & 26.79 & 30.12 & 429.25 & 25.45 & 28.10 & 501.54 & 21.08 & 22.07 & 282.84 \\
\hline $\mathrm{Mg}$ & 15.21 & 16.69 & 311.07 & 18.81 & 20.87 & 320.64 & 18.67 & 19.09 & 390.68 & 14.59 & 15.63 & 253.87 \\
\hline $\mathrm{Na}$ & 41.64 & 44.51 & 185.97 & 51.35 & 55.49 & 192.12 & 53.16 & 53.17 & 227.96 & 36.95 & 40.62 & 147.59 \\
\hline $\mathbf{K}$ & 3.13 & 11.86 & 646.33 & 3.84 & 20.48 & 615.26 & 3.45 & 8.23 & 475.32 & 2.75 & 10.22 & 619.42 \\
\hline $\mathbf{P}$ & 0.09 & 0.37 & 9.89 & 0.07 & 0.47 & 4.76 & 0.05 & 0.19 & 3.90 & 0.07 & 0.16 & 5.97 \\
\hline $\mathrm{Cl}$ & 84.26 & 93.00 & 568.89 & 112.02 & 118.20 & 670.85 & 105.58 & 110.29 & 536.22 & 78.02 & 84.29 & 539.47 \\
\hline \multicolumn{13}{|l|}{ Mass in liquids (kg) } \\
\hline $\mathrm{Si}$ & 0.1131 & 0.1514 & 0.0135 & 0.1026 & 0.1577 & 0.0130 & 0.1182 & 0.1501 & 0.0158 & 0.1100 & 0.1209 & 0.0136 \\
\hline $\mathrm{Al}$ & 0.0018 & 0.0332 & 0.0063 & 0.0005 & 0.0608 & 0.0069 & 0.0004 & 0.0337 & 0.0097 & 0.0005 & 0.0096 & 0.0069 \\
\hline $\mathrm{Ti}$ & 0.0003 & 0.0045 & 0.0019 & 0.0001 & 0.0073 & 0.0012 & 0.0001 & 0.0045 & 0.0030 & 0.0001 & 0.0012 & 0.0014 \\
\hline $\mathrm{Fe}$ & 0.0038 & 0.0329 & 0.0350 & 0.0023 & 0.0574 & 0.0309 & 0.0011 & 0.0308 & 0.0468 & 0.0018 & 0.0097 & 0.0304 \\
\hline $\mathrm{Ca}$ & 0.1200 & 0.1134 & 0.0355 & 0.1259 & 0.1399 & 0.0466 & 0.1258 & 0.1377 & 0.0584 & 0.1012 & 0.1050 & 0.0314 \\
\hline Mg & 0.0734 & 0.0796 & 0.0332 & 0.0884 & 0.0969 & 0.0348 & 0.0922 & 0.0935 & 0.0455 & 0.0700 & 0.0743 & 0.0282 \\
\hline $\mathrm{Na}$ & 0.2010 & 0.2124 & 0.0198 & 0.2414 & 0.2577 & 0.0208 & 0.2627 & 0.2605 & 0.0266 & 0.1773 & 0.1933 & 0.0164 \\
\hline $\mathbf{K}$ & 0.0151 & 0.0566 & 0.0689 & 0.0181 & 0.0951 & 0.0668 & 0.0171 & 0.0403 & 0.0554 & 0.0132 & 0.0486 & 0.0687 \\
\hline $\mathbf{P}$ & 0.0004 & 0.0018 & 0.0011 & 0.0003 & 0.0022 & 0.0005 & 0.0003 & 0.0009 & 0.0005 & 0.0003 & 0.0008 & 0.0007 \\
\hline $\mathrm{Cl}$ & 0.4068 & 0.4437 & 0.0607 & 0.5265 & 0.5489 & 0.0728 & 0.5217 & 0.5403 & 0.0625 & 0.3745 & 0.4010 & 0.0598 \\
\hline
\end{tabular}




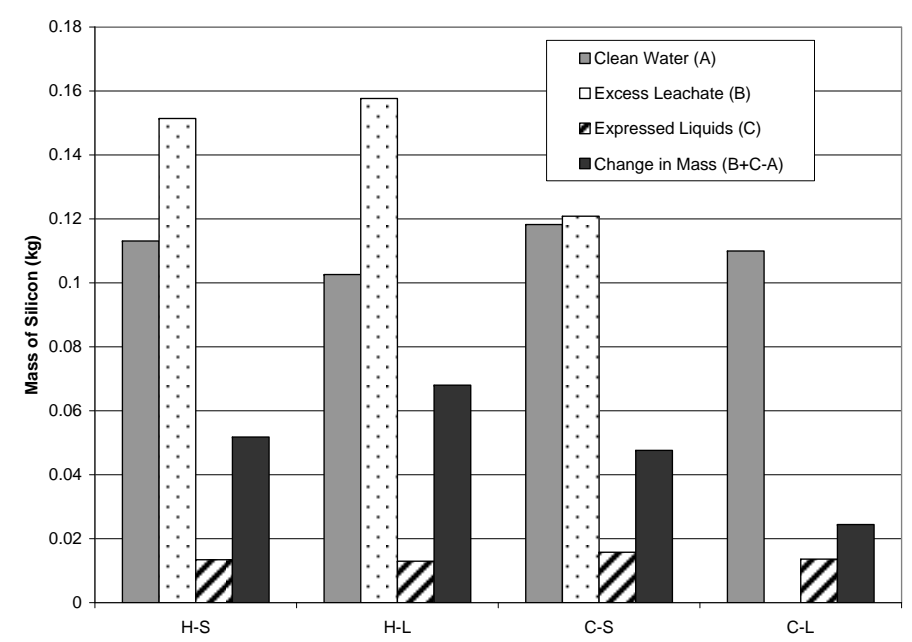

(a)

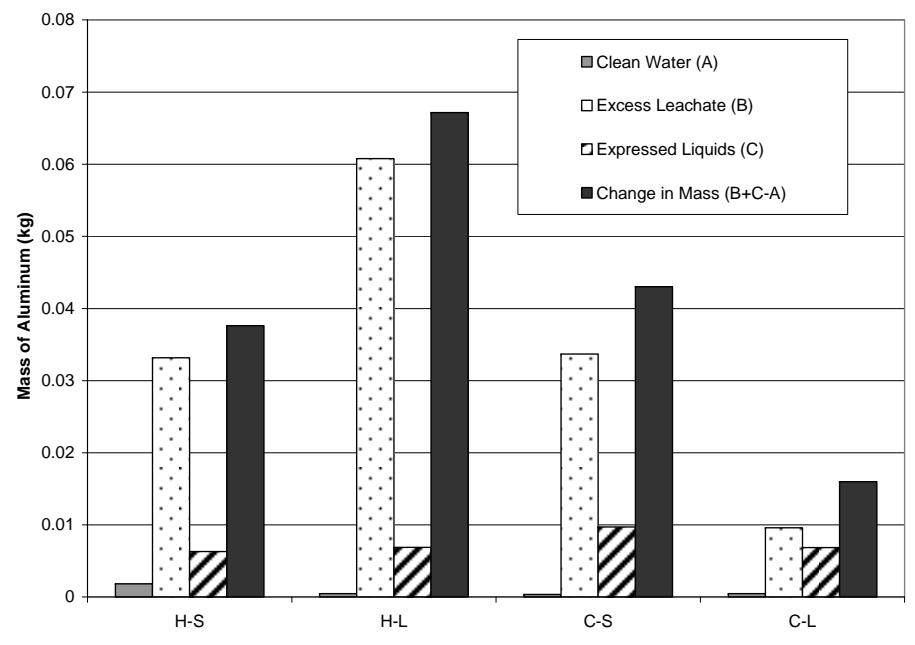

(b)

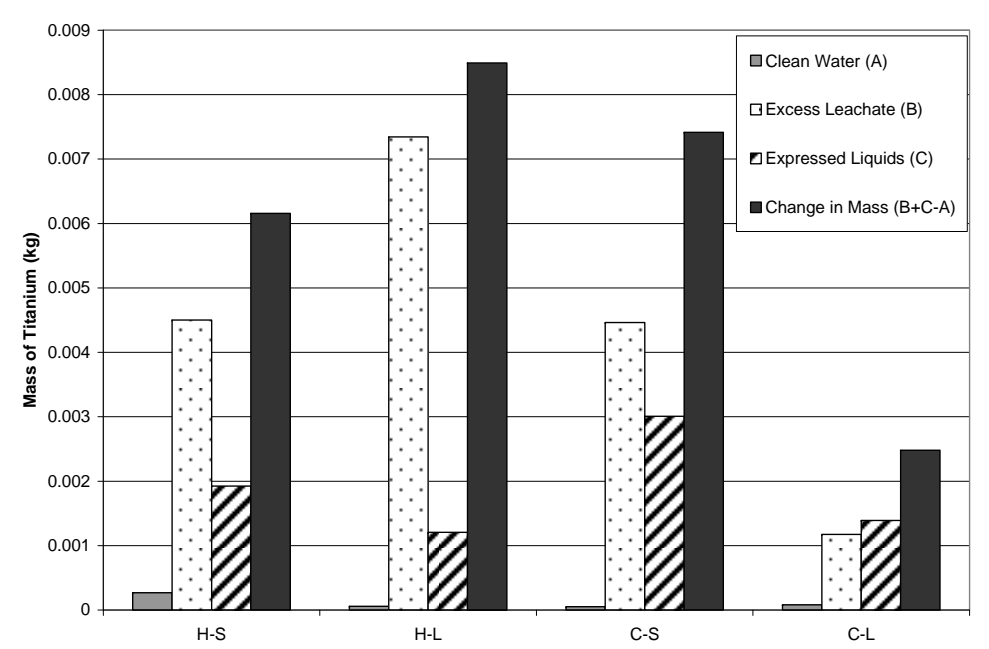

(c)

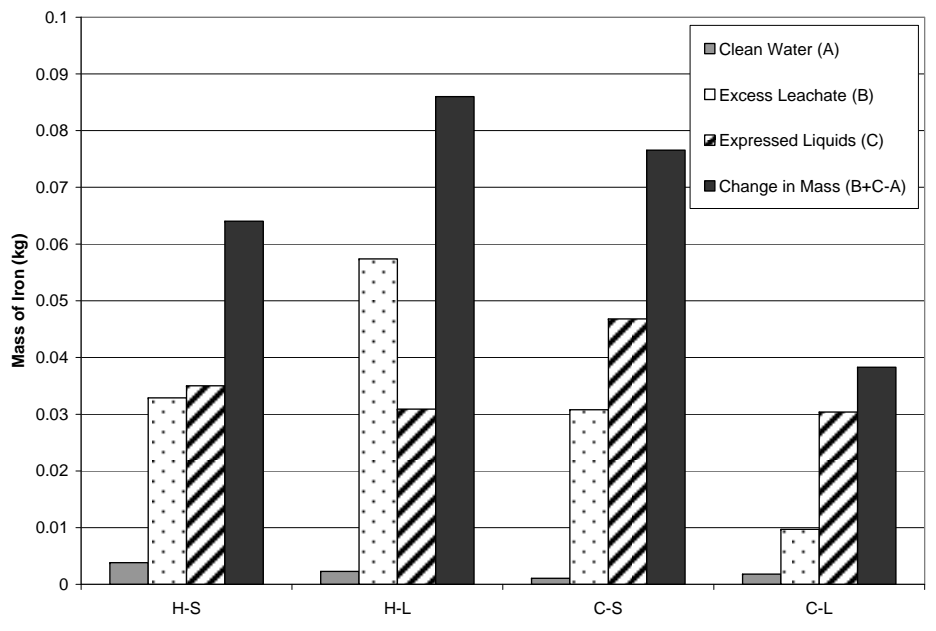

(d)

Figure C.1: Breakdown of liquids by elemental constituent. a) Silicon b) Aluminum c) Titanium d) Iron 


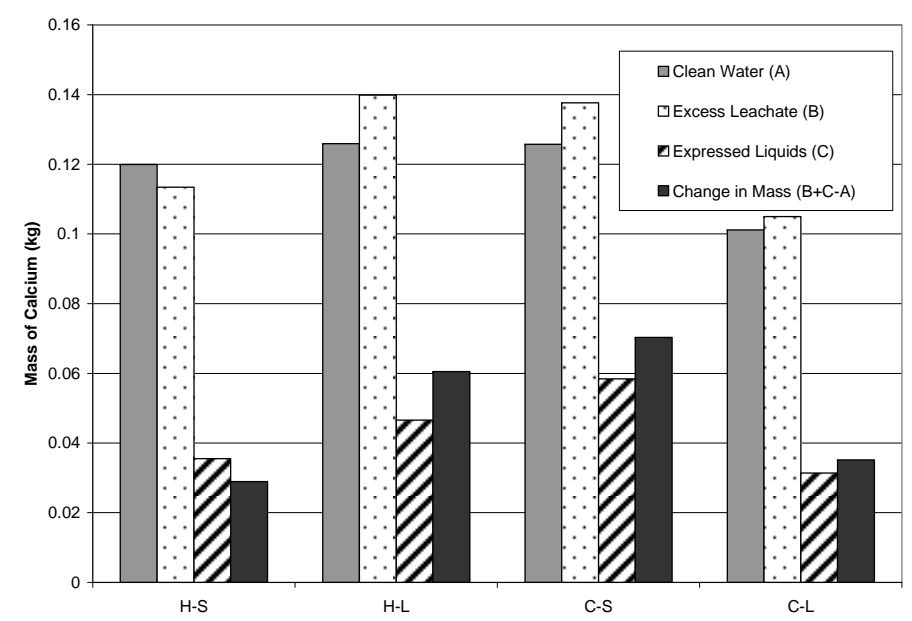

(a)

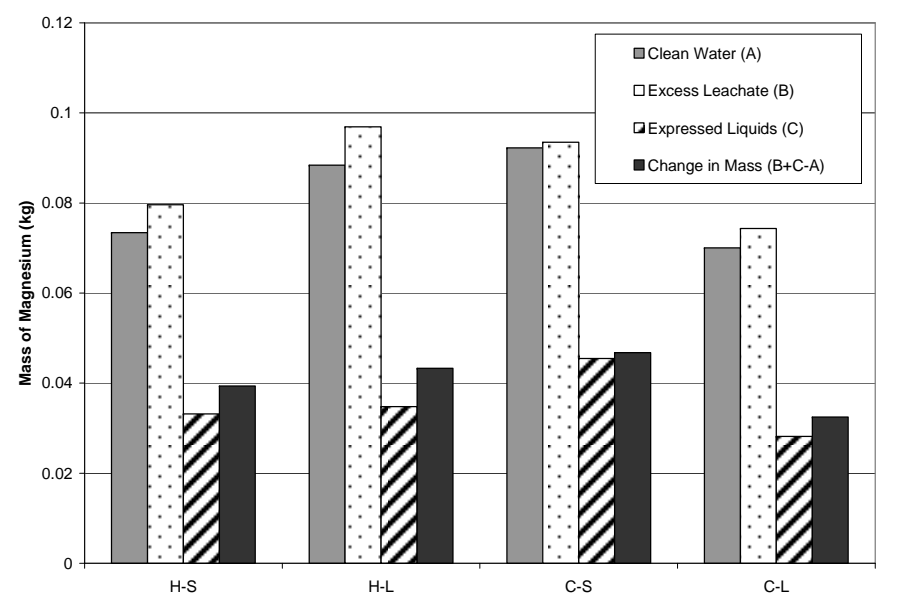

(b)

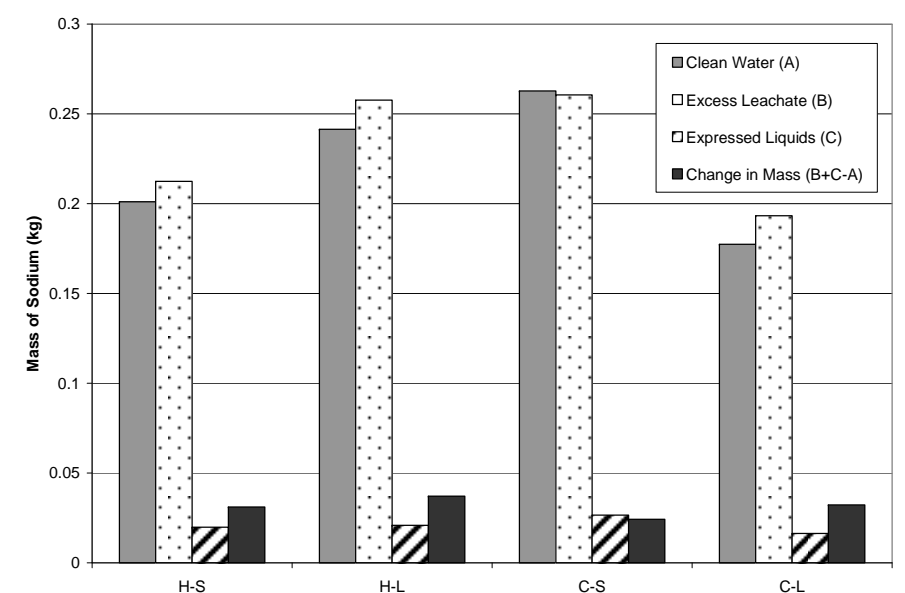

(c)

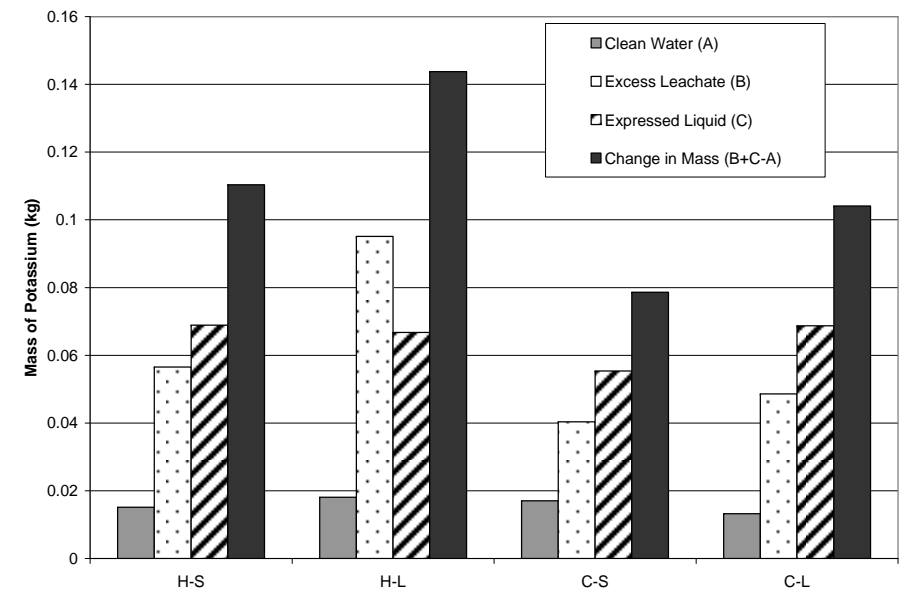

(d)

Figure C.2: Continuation of liquid sample breakdown. (a)Calcium (b) Magnesium (c) Sodium (d) Potassium 


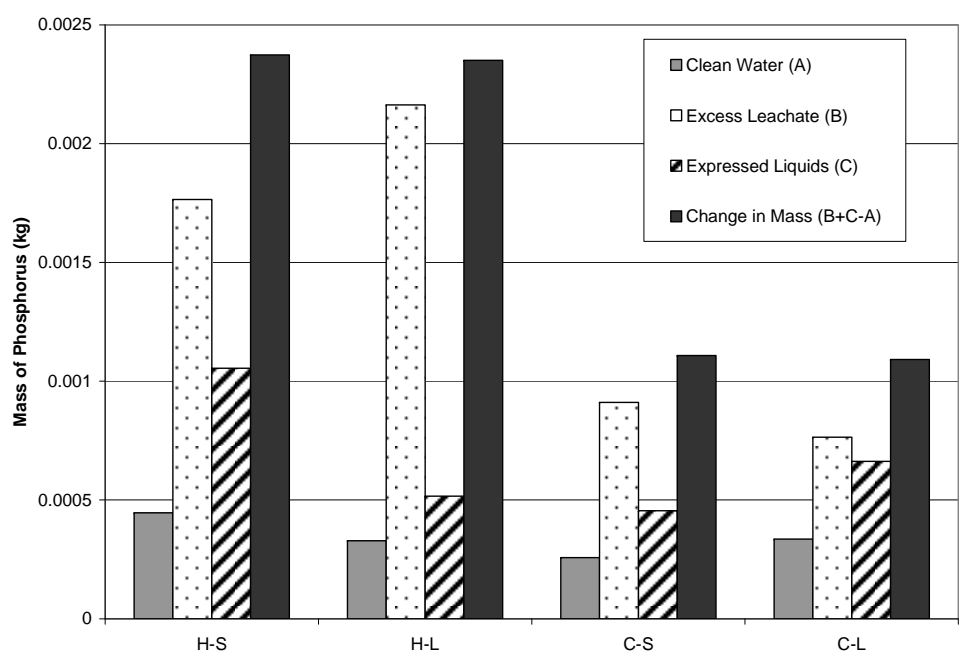

(a)

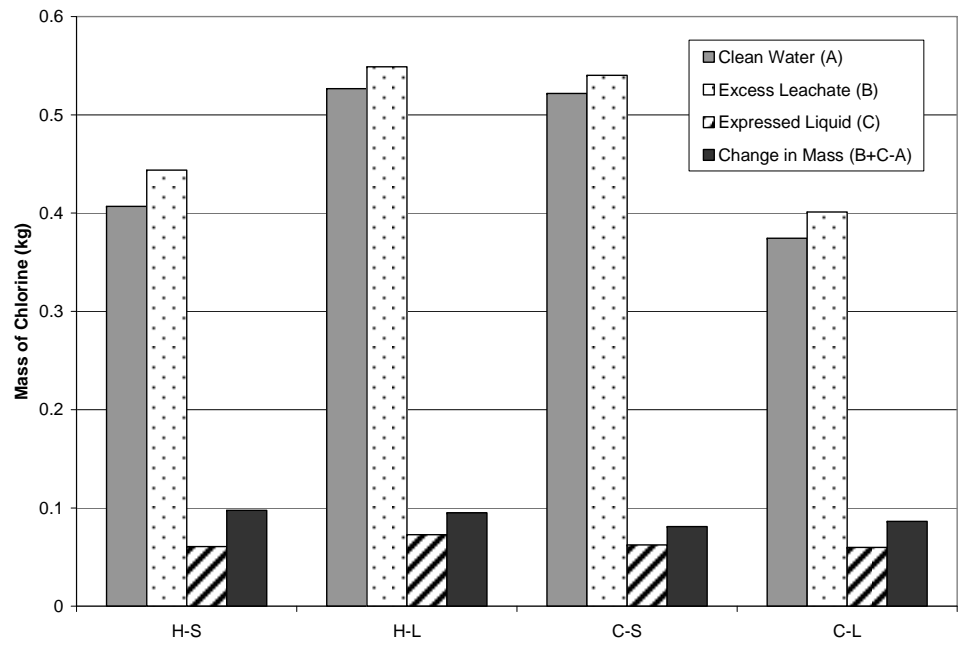

(b)

Figure C.3: Continuation of liquid sample breakdown. (a) phosphorus (b) chlorine 


\section{Fuel Ash Balance}

The cane trash was treated by first leaching the sample in water at two temperatures and two durations and then milling to obtain approximately 50\% moisture (the upper moisture limit of the HC\&S boiler). Masses of fiber and water were tracked and balanced during the course of the procedure. Once the treated cane trash had been processed through the Cuba Mill, samples were taken and sent to Hazen Research Inc. in Golden, Colorado for analysis. There, the samples were dried and analyzed to determine a variety of characteristics including ultimate and proximate make-up, elemental ash composition, higher heating value, water soluble alkalis and ash fusion temperatures. The complete results for the pilot scale tests are shown in Tables C.4 and C.5.

Table C.4: Fuel Characterization of Samples of Cane Trash Before and After Pilot Scale Treatments (Results from Hazen Research Inc. Laboratories in Golden, Colorado)

\begin{tabular}{|c|c|c|c|c|c|c|c|c|}
\hline \multirow{2}{*}{$\begin{array}{l}\text { Description: } \\
\text { ID \#: }\end{array}$} & \multicolumn{2}{|c|}{ Hot/Short } & \multicolumn{2}{|c|}{ Hot/Long } & \multicolumn{2}{|c|}{ Cold/Short } & \multicolumn{2}{|c|}{ Cold/Long } \\
\hline & $1-U$ & 1-HS & $2-U$ & 2-HL & $3-U$ & 3-CS & $4-U$ & 4-CL \\
\hline $\begin{array}{l}\text { Moisture } \\
\text { Content } \\
\text { (sampled) }\end{array}$ & 70.72 & 61.59 & 63.29 & 54.19 & 71.97 & 52.97 & 70.95 & 55.98 \\
\hline \multicolumn{9}{|c|}{ Proximate Analysis (\% dry basis) } \\
\hline Ash & 15.93 & 24.88 & 18.34 & 27.51 & 18.28 & 39 & 13.52 & 29.63 \\
\hline Volatile & 72.11 & 64.19 & 67.98 & 64.04 & 70.14 & 58.29 & 73.95 & 61.02 \\
\hline \multirow[t]{2}{*}{ Fixed C } & 11.96 & 10.93 & 13.68 & 8.45 & 11.58 & 2.71 & 12.53 & 9.35 \\
\hline & 100 & 100 & 100 & 100 & 100 & 100 & 100 & 100 \\
\hline HHV (BTU/lb) & 6880 & 6109 & 6678 & 5866 & 6719 & 4773 & 7169 & 5759 \\
\hline$(\mathrm{MJ} / \mathrm{kg})$ & 16.03 & 14.23 & 15.56 & 13.67 & 15.66 & 11.12 & 16.70 & 13.42 \\
\hline \multicolumn{9}{|c|}{ Ultimate Analysis (\% dry basis) } \\
\hline C & 46.34 & 40.42 & 43.79 & 39.85 & 44.69 & 33.17 & 45.75 & 38.29 \\
\hline $\mathrm{H}$ & 4.67 & 5.13 & 5.46 & 3.97 & 4.39 & 3.33 & 4.61 & 3.77 \\
\hline$N$ & 0.35 & 0.24 & 0.31 & 0.26 & 0.29 & 0.2 & 0.32 & 0.23 \\
\hline S & 0.1 & 0.09 & 0.1 & 0.08 & 0.09 & 0.06 & 0.09 & 0.07 \\
\hline Ash & 15.93 & 24.88 & 18.34 & 27.51 & 18.28 & 39 & 13.52 & 29.63 \\
\hline O (by diff) & 32.61 & 29.24 & 32 & 28.33 & 32.26 & 24.24 & 35.71 & 28.01 \\
\hline $\mathrm{Cl}$ & 0.176 & 0.105 & 0.192 & 0.071 & 0.285 & 0.081 & 0.233 & 0.092 \\
\hline \multicolumn{9}{|c|}{ Elemental Analysis of Ash (\% dry basis) } \\
\hline $\mathrm{SiO} 2$ & 61.22 & 49.69 & 56.78 & 45.2 & 46.26 & 43.39 & 56.16 & 45.43 \\
\hline $\mathrm{Al} 2 \mathrm{O} 3$ & 12.8 & 16.74 & 14.64 & 19.38 & 19.53 & 20.89 & 14.59 & 19.19 \\
\hline TiO2 & 2.52 & 3.8 & 3.14 & 4.45 & 4.07 & 4.18 & 2.78 & 4.79 \\
\hline $\mathrm{Fe} 2 \mathrm{O} 3$ & 9.69 & 15.07 & 11.82 & 16.61 & 16.62 & 17.64 & 11.19 & 17.92 \\
\hline $\mathrm{CaO}$ & 4.02 & 4.79 & 5.26 & 2.63 & 4.64 & 5.34 & 3.88 & 4.72 \\
\hline $\mathrm{MgO}$ & 1.55 & 2.62 & 2.62 & 1.68 & 2.95 & 3.51 & 1.7 & 2.87 \\
\hline $\mathrm{Na} 2 \mathrm{O}$ & 0.87 & 0.97 & 1.08 & 0.71 & 1.06 & 1.16 & 1.02 & 1.06 \\
\hline K2O & 2.38 & 1.81 & 1 & 3.15 & 1.04 & 1.01 & 4.61 & 1.34 \\
\hline P2O5 & 0.56 & 0.44 & 0.48 & 0.42 & 0.54 & 0.4 & 0.63 & 0.42 \\
\hline SO3 & 0.93 & 0.53 & 1.01 & 0.29 & 0.69 & 0.22 & 1.25 & 0.3 \\
\hline $\mathrm{Cl}$ & 0.05 & 0.02 & 0.1 & 0.31 & 0.31 & 0.02 & 0.3 & 0.03 \\
\hline $\mathrm{CO} 2$ & 0.18 & 0.09 & 0.12 & 0.71 & 0.09 & 0.09 & 0.16 & 0.08 \\
\hline \multirow{2}{*}{$\begin{array}{l}\text { Undetermined } \\
\text { Total }\end{array}$} & 3.23 & 3.43 & 1.95 & 4.46 & 2.2 & 2.15 & 1.73 & 1.85 \\
\hline & 96.77 & 96.57 & 98.05 & 95.54 & 97.8 & 97.85 & 98.27 & 98.15 \\
\hline
\end{tabular}


Table C.5: Ash fusion temperatures and concentration of water soluble alkalis as determined by Hazen Research Inc. (Boulder Colorado).

\begin{tabular}{|c|c|c|c|c|c|c|c|c|}
\hline \multicolumn{9}{|c|}{$\begin{array}{l}\text { Ash Fusion Temperature (C) } \\
\text { Oxidizing Atmosphere }\end{array}$} \\
\hline Initial & 1262.78 & 1216.67 & 1265.56 & 1239.44 & 1272.22 & 1251.11 & 1206.11 & 1466.11 \\
\hline Softening & 1277.78 & 1249.44 & 1288.89 & 1247.78 & 1312.78 & 1266.11 & 1273.89 & 1260.56 \\
\hline Hemispherical & 1295.00 & 1260.00 & 1306.67 & 1271.67 & 1327.78 & 1297.78 & 1281.11 & 1277.22 \\
\hline Fluid & 1328.33 & 1277.22 & 1326.11 & 1278.89 & 1340.56 & 1311.67 & 1287.22 & 1303.33 \\
\hline \multicolumn{9}{|c|}{ Reducing Atmosphere } \\
\hline Initial & 1260.00 & 1234.44 & 1260.00 & 1239.44 & 1275.56 & 1231.11 & 1221.11 & 1257.22 \\
\hline Softening & 1288.89 & 1243.89 & 1295.56 & 1247.22 & 1284.44 & 1243.33 & 1261.11 & 1265.00 \\
\hline Hemispherical & 1302.78 & 1250.56 & 1301.11 & 1263.89 & 1312.78 & 1249.44 & 1298.89 & 1278.89 \\
\hline Fluid & 1327.22 & 1260.00 & 1318.89 & 1272.22 & 1318.89 & 1266.11 & 1307.78 & 1307.78 \\
\hline \multicolumn{9}{|c|}{ Water Soluble Alkalis } \\
\hline $\mathrm{Na} 2 \mathrm{O}$ & 0.100 & 0.054 & 0.094 & 0.044 & 0.090 & 0.065 & 0.088 & 0.052 \\
\hline K2O & 0.320 & 0.248 & 0.349 & 0.150 & 0.581 & 0.187 & 0.450 & 0.206 \\
\hline
\end{tabular}

Using the elemental ash analysis of the fuels, a balance of elements was carried out on the solid samples for comparison to the liquid samples. Considering again the first test (ID\# 1), the mass of dry matter was found using the moisture content of a sample of the material.

$$
M_{\text {drymatter }}=M_{\text {total }} \times\left(1-\frac{\% \text { Moisture }}{100 \%}\right)=224.84 \mathrm{~kg} \times\left(1-\frac{68.38 \%}{100 \%}\right)=71.09 \mathrm{kgdry}
$$

After the treatment, the sample weight and moisture content showed the mass of dry matter to be $59.74 \mathrm{~kg}$. The loss of dry matter is primarily attributed to rocks and debris being removed during the milling process. The fraction of each element in its respective oxide form must also be known since the ash elements are reported as oxides. Potassium oxide $\left(\mathrm{K}_{2} \mathrm{O}\right)$, for example, contains approximately $83 \%$ potassium. So, the amount of potassium in the cane trash before and after the treatments can be calculated.

$$
\begin{aligned}
& M_{K, A}=\frac{\% K_{2} \text { OinAsh }}{100 \%} \times \frac{\% \text { AshinDryMatter }}{100 \%} \times \frac{\% \mathrm{KinK}_{2} \mathrm{O}}{100 \%} \times M_{\text {drymatter }} \\
& M_{K, A}=\frac{2.38 \%}{100 \%} \times \frac{15.93 \%}{100 \%} \times \frac{83 \%}{100 \%} \times 71.09 \mathrm{~kg}=0.2237 \mathrm{kgK}
\end{aligned}
$$

Similarly, the mass of Potassium in the cane trash sample after the treatment was calculated to be $\mathrm{M}_{\mathrm{K}, \mathrm{B}}=0.2234 \mathrm{kgK}$. Therefore, it can be concluded that by treating the fuel sample, the mass of Potassium that was removed from the cane trash was $320.75 \mathrm{mg}$. The remaining elements considered in the calculation are contained in the following table (Table C.5). Clearly, many of the elements appear to gain alkalis during the treatment. The reason for this and its implications are discussed in detail in the main report. Note also that Sulfur (S), Carbon (C) and Chlorine were calculated based on the breakdown of the fuel because their percentage in the dry ash is too small to be determined reliably. 
Table C.6: Comparison of Elemental Masses Before and After Pilot Scale Treatments of Cane Trash Samples.

\begin{tabular}{|c|c|c|c|c|c|c|c|c|}
\hline \multirow{2}{*}{$\begin{array}{l}\text { Treatment \#: } \\
\text { Description: }\end{array}$} & \multicolumn{2}{|c|}{1} & \multicolumn{2}{|c|}{2} & \multicolumn{2}{|c|}{3} & \multicolumn{2}{|c|}{4} \\
\hline & Untreated & Hot/Short & Untreated & Hot/Long & Untreated & Cold/Short & Untreated & Cold/Long \\
\hline Mass of Dry Fiber (kg) & 71.073 & 59.744 & 115.328 & 73.156 & 93.663 & 80.664 & 74.363 & 65.327 \\
\hline Ash in Dry Fiber (kg/kg) & 0.159 & 0.249 & 0.183 & 0.275 & 0.183 & 0.390 & 0.135 & 0.296 \\
\hline \multicolumn{9}{|l|}{ Element Mass in Ash (kg/kg) } \\
\hline Si & 0.2862 & 0.2323 & 0.2654 & 0.2113 & 0.2162 & 0.2028 & 0.2625 & 0.2124 \\
\hline $\mathrm{Al}$ & 0.0677 & 0.0886 & 0.0775 & 0.1026 & 0.1034 & 0.1106 & 0.0772 & 0.1016 \\
\hline $\mathrm{Ti}$ & 0.0151 & 0.0228 & 0.0188 & 0.0267 & 0.0244 & 0.0251 & 0.0167 & 0.0287 \\
\hline $\mathrm{Fe}$ & 0.0678 & 0.1054 & 0.0827 & 0.1162 & 0.1162 & 0.1234 & 0.0783 & 0.1253 \\
\hline $\mathrm{Ca}$ & 0.0287 & 0.0342 & 0.0376 & 0.0188 & 0.0332 & 0.0382 & 0.0277 & 0.0337 \\
\hline Mg & 0.0093 & 0.0158 & 0.0158 & 0.0101 & 0.0178 & 0.0212 & 0.0103 & 0.0173 \\
\hline $\mathrm{Na}$ & 0.0065 & 0.0072 & 0.0080 & 0.0053 & 0.0079 & 0.0086 & 0.0076 & 0.0079 \\
\hline $\mathbf{K}$ & 0.0198 & 0.0150 & 0.0083 & 0.0262 & 0.0086 & 0.0084 & 0.0383 & 0.0111 \\
\hline $\mathbf{P}$ & 0.0024 & 0.0019 & 0.0021 & 0.0018 & 0.0024 & 0.0017 & 0.0027 & 0.0018 \\
\hline$S$ & 0.001 & 0.0009 & 0.001 & 0.0008 & 0.0009 & 0.0006 & 0.0009 & 0.0007 \\
\hline $\mathrm{Cl}$ & 0.0018 & 0.0011 & 0.0019 & 0.0007 & 0.0029 & 0.0008 & 0.0023 & 0.0009 \\
\hline \multicolumn{9}{|l|}{ Element Mass in Fiber (kg) } \\
\hline $\begin{array}{rr}\text { Si } \\
\end{array}$ & 3.24 & 3.45 & 5.61 & 4.25 & 3.70 & 6.38 & 2.64 & 4.11 \\
\hline Al & 0.77 & 1.32 & 1.64 & 2.06 & 1.77 & 3.48 & 0.78 & 1.97 \\
\hline $\mathrm{Ti}$ & 0.17 & 0.34 & 0.40 & 0.54 & 0.42 & 0.79 & 0.17 & 0.56 \\
\hline $\mathrm{Fe}$ & 0.77 & 1.57 & 1.75 & 2.34 & 1.99 & 3.88 & 0.79 & 2.43 \\
\hline $\mathrm{Ca}$ & 0.33 & 0.51 & 0.80 & 0.38 & 0.57 & 1.20 & 0.28 & 0.65 \\
\hline $\mathrm{Mg}$ & 0.11 & 0.23 & 0.33 & 0.20 & 0.30 & 0.67 & 0.10 & 0.34 \\
\hline $\mathrm{Na}$ & 0.07 & 0.11 & 0.17 & 0.11 & 0.13 & 0.27 & 0.08 & 0.15 \\
\hline $\mathrm{K}$ & 0.22 & 0.22 & 0.18 & 0.53 & 0.15 & 0.26 & 0.38 & 0.22 \\
\hline $\mathbf{P}$ & 0.03 & 0.03 & 0.04 & 0.04 & 0.04 & 0.05 & 0.03 & 0.04 \\
\hline $\mathrm{S}$ & 0.07 & 0.05 & 0.12 & 0.06 & 0.08 & 0.05 & 0.07 & 0.05 \\
\hline $\mathrm{Cl}$ & 0.13 & 0.06 & 0.22 & 0.05 & 0.27 & 0.07 & 0.17 & 0.06 \\
\hline
\end{tabular}


